Nadine Viermann

Herakleios, der schwitzende Kaiser 


\section{Millennium-Studien}

zu Kultur und Geschichte

des ersten Jahrtausends $\mathbf{n}$. Chr.

\section{Millennium Studies}

in the culture and history

of the first millennium C.E.

Herausgegeben von / Edited by

Wolfram Brandes, Alexander Demandt,

Peter von Möllendorff, Dennis Pausch,

Rene Pfeilschifter, Karla Pollmann

\section{Volume 89}


Nadine Viermann

Herakleios,

der schwitzende

Kaiser

Die oströmische Monarchie in der ausgehenden Spätantike 
Diese Publikation wurde im Rahmen des Fördervorhabens 16TOA021 - Reihentransformation für die Altertumswissenschaften („Millennium-Studien“) mit Mitteln des Bundesministeriums für Bildung und Forschung im Open Access bereitgestellt. Das Fördervorhaben wird in Kooperation mit dem DFG-geförderten Fachinformationsdienst Altertumswissenschaften - Propylaeum an der Bayerischen Staatsbibliothek durchgeführt.

ISBN 978-3-11-071114-1

e-ISBN (PDF) 978-3-11-071135-6

e-ISBN (EPUB) 978-3-11-071137-0

ISSN 1862-1139

DOI https://doi.org/10.1515/9783110711356

\section{(cc) BY}

Dieses Werk ist lizenziert unter der Creative Commons Attribution 4.0 International Lizenz.

Weitere Informationen finden Sie unter http://creativecommons.org/licenses/by/4.0/

\section{Bibliografische Information der Deutschen Nationalbibliothek}

Die Deutsche Nationalbibliothek verzeichnet diese Publikation in der Deutschen Nationalbibliografie; detaillierte bibliografische Daten sind im Internet über http://dnb.dnb.de abrufbar.

(c) 2021 Nadine Viermann, publiziert von Walter de Gruyter GmbH, Berlin/Boston

Dieses Buch ist als Open-Access-Publikation verfügbar über www.degruyter.com.

Druck und Bindung: CPI books GmbH, Leck

www.degruyter.com 
Meinen Eltern 



\section{Vorwort}

Die vorliegende Arbeit ist eine überarbeitete Version meiner Dissertation in Alter Geschichte, welche ich im September 2019 eingereicht und im Juni 2020 an der Universität Konstanz verteidigt habe. Das Projekt wurde im Rahmen des ExC 16 „Kulturelle Grundlagen von Integration“ angefertigt, dessen großzügige finanzielle Unterstützung es mir ermöglicht hat, weit über die Grenzen der Universität Konstanz mit Kolleg:innen in Kontakt zu treten. Mein besonderer Dank gilt Steffen Diefenbach (Konstanz), der mein Projekt als Erstbetreuer von Beginn an begleitet hat, sowie meinem Zweitbetreuer Kai Trampedach (Heidelberg), der mir seit meinem Studium mit Rat, konstruktiver Kritik und Inspiration zur Seite stand. Ohne die inhaltlichen wie administrativen Orientierungshilfen meiner Betreuer hätte ich mich im Promotionsdschungel oft nur schwerlich zurechtfinden können; meinen Blick auf die Spätantike verdanke ich maßgeblich unserem regelmäßigen Austausch. Bei Daniel König (Konstanz) bedanke ich mich nicht nur für die interessanten Gespräche, sondern auch dafür, dass er schnell und unbürokratisch das Drittgutachten meiner Doktorarbeit verfasst hat. In der Überarbeitungsphase hat die Arbeit nicht nur dank des ausführlichen Feedbacks der drei Gutachter an Substanz gewonnen, sondern auch durch die großzügige Unterstützung von Rene Pfeilschifter (Würzburg), dem Herausgeber der Millennium-Studien; er hat sich bis ins kleinste Detail mit dem Manuskript beschäftigt und mir ein hohes Maß an Vertrauen entgegengebracht - selbst bzw. vor allem dann, wenn wir im Detail nicht immer einer Meinung waren. Die vier Jahre an der Universität Konstanz waren maßgeblich durch Gespräche mit Ulrich Gotter und Henning Börm geprägt, die mich immer wieder dazu gebracht haben, voreilig gezogene Schlüsse zu hinterfragen und einen Schritt weiter bzw. größer zu denken. Von ganz besonderer Bedeutung war außerdem meine Doktorand:innen-Schreibgruppe mit Nora Binder, Anne Diekjobst, Tilman Meyer und Livia Gertis: In den regelmäßigen Treffen habe ich nicht nur erfahren dürfen, wie wichtig die gegenseitige Unterstützung durch Peers ist, sondern auch endlich verstanden, was es mit Performanz auf sich hat. Hervorheben möchte ich außerdem Johannes Wienand (Braunschweig), der über ein unerschöpfliches Reservoir an Hilfsbereitschaft, Motivation und Begeisterung für das Fach zu verfügen scheint; die regelmäßigen Treffen sowie sein umfassendes Feedback haben mir immer wieder den Kopf zurechtgerückt, mich inspiriert und mir dabei geholfen, unvermeidliche Phasen des Selbstzweifels zu überwinden. Dass ich als Althistorikerin meine Faszination für die Spätantike entdeckt habe, verdanke ich maßgeblich Christine Strube (Heidelberg), deren Seminare zur byzantinischen Archäologie einen bleibenden Eindruck hinterlassen haben. Während meiner Auslandsaufenthalte konnte ich besonders von der Gastfreundschaft und Unterstützung durch Claudia Rapp (Wien), James Howard-Johnston (Oxford) und Mary Whitby (Oxford) profitieren. Ohne die Großzügigkeit und die regelmäßige Ermutigung durch Mary Whitby hätte ich es kaum geschafft, bei der Lektüre von Georg von Pisidien nicht den Mut zu verlieren. Dank gebührt außerdem Felix M. Klein, Christoph Begass, Christian Rollinger und 
Jeroen Wijnendaele, die ihre unpublizierten Manuskripte mit mir geteilt haben. Für ihre emotionale Unterstützung bedanke ich mich bei Eleonore Lehr-Rottmann. Dass es in meiner Zeit in Konstanz um so viel mehr ging als nur um die Doktorarbeit, lag schließlich an wunderbaren Menschen wie Nora, Sandro, Julia, Philipp, Gerhard und Maja sowie der unvergesslichen Zeit in der Schotten-WG mit Jana, Sascha und Steffen. Zuletzt bedanke ich mich bei Per für die gemeinsamen Jahre und bei Maike für ihre Freundschaft.

Istanbul, Dezember 2020 


\section{Inhalt}

Vorwort — VII

$1 \quad$ Einleitung - 1

1.1 Forschungsstand, Fragestellung und Vorgehen - 1

1.2 Quellenmaterial — 8

$2 \quad$ Hauptstädtische Monarchie und militärischer Sektor - 27

$2.1 \quad$ Vom Heerführer zum sesshaften Kaiser — 29

2.2 Der sesshafte Kaiser: Auswirkungen auf den militärischen

Sektor -33

2.2.1 Soldaten -34

2.2.2 Militärische Funktionsträger - 35

2.2.3 Kaiserliche Garden — 45

2.3 Mechanismen politischer Entscheidungsprozesse — 49

2.4 Ermächtigungsstrategien der Kaiser — 62

2.5 Die hauptstädtische Monarchie im späten 6. Jahrhundert — 66

3 Dynamiken gewaltsamer Machtwechsel - 78

3.1 Der Sturz des Maurikios - $\mathbf{8 0}$

3.2 Die Usurpation des Herakleios - 93

3.3 Krönungsrituale - 104

3.3.1 Funktion und Entwicklung von Krönungsritualen - 105

3.3.2 Die Krönungen des Phokas und des Herakleios - 110

3.4 Erinnerung an den gewaltsamen Machtwechsel 128

$4 \quad$ Remilitarisierung des Kaisertums - 138

4.1 Die Regierung des Phokas - eine Kontrastfolie - 139

4.2 Vom sesshaften Kaiser zum Heerführer — 150

4.3 Eine Dynastie im Entstehen - 160

4.3.1 Münzprägung - 165

4.3.2 Endogamie - 171

4.4 Abkehr von Konstantinopel $\mathbf{1 7 6}$

$5 \quad$ Der schwitzende Kaiser 186

5.1 Den Kaiser loben - Panegyrik im Kontext — 188

5.2 „Wie einer von uns“ - der kriegführende Kaiser — 191

5.2.1 Herakleios’ Kampagne in Kleinasien — 191

5.2.2 Die Expeditio Persica $\mathbf{1 9 2}$ 
5.3 „Obwohl er fort war, war er da“ - der abwesende Kaiser — 206

5.3.1 Herakleios' Gegenoffensive und die Belagerung

Konstantinopels - 206

5.3.2 In Bonum und Bellum Avaricum — 213

5.4 „Feldherr des kosmischen Geburtstages“ - der siegreiche Kaiser -229

5.4.1 Friedensschluss mit den Persern - 229

5.4.2 Die Heraclias - 232

5.5 Der Kaiser und die Eschatologie - 242

$6 \quad$ Zwischen Triumph und Katastrophe -252

6.1 Mit dem Sieg im Rücken — 253

6.1.1 Rückkehr nach Konstantinopel I 253

6.1.2 Herakleios in Jerusalem - die Restitutio Crucis - 261

6.1.3 Religionspolitik -283

6.2 Im Angesicht der Niederlage - $\mathbf{3 0 0}$

6.2.1 Das Vorrücken der Araber - $\mathbf{3 0 0}$

6.2.2 Rückkehr nach Konstantinopel II -304

7 Herakleios' Nachfolge — 317

7.1 Sollbruchstellen der herakleischen Politik - $\mathbf{3 1 8}$

7.2 Ausblick - 326

$8 \quad$ Fazit -333

$9 \quad$ English Summary $-\mathbf{3 4 0}$

10 Anhang - 347

10.1 Abkürzungen - 347

10.2 Quellenverzeichnis - 347

10.3 Literaturverzeichnis - $\mathbf{3 5 0}$

$10.4 \quad$ Register $-\mathbf{3 7 0}$

10.4.1 Personenregister - $\mathbf{3 7 0}$

10.4.2 Ortsregister - $\mathbf{3 7 3}$

10.4.3 Stellenregister $-\mathbf{3 7 4}$ 


\section{Einleitung}

„Ihre Könige dort sind keine Menschen von Dauer. Man wählt den Würdigsten aus und setzt ihn auf den Thron. Geschieht im Reich Unheil oder Ungewöhnliches oder treffen Wind und Regen nicht zur rechten Jahreszeit ein, so setzt man (den König) zugleich ab und bringt einen anderen auf den Thron.“"1

Dieses Zitat stammt aus einem chinesischen Reisebericht, erhalten in den Annalen der T’ang-Dynastie. Zu einem nicht genauer bestimmbaren Zeitpunkt im 7. oder 8. Jahrhundert erreichte eine chinesische Delegation die Hauptstadt des römischen Reiches, Konstantinopel, und hielt nicht nur Impressionen des Stadtbildes fest, sondern auch ihren Eindruck vom römischen Kaiser. ${ }^{2}$ Mit dem klaren Blick eines Außenseiters bringt der Bericht ein zentrales Charakteristikum (spät-)römischer Monarchie auf den Punkt: die Prekarität von Herrschaft. Während Monarchie als Institution in der Spätantike nicht mehr grundsätzlich zur Debatte stand - die Idee des einen Kaisers an der Spitze des Gemeinwesens hatte sich organisch mit derjenigen des einen, christlichen Gottes verbunden - musste der Mann auf dem Thron sich andauernd behaupten. Wer die Kaiserwürde innehatte, war angesichts des Mangels an einer institutionalisierten Nachfolgeregelung Verhandlungssache. Konnte der einstmals Gekrönte die an ihn gerichteten Erwartungen nicht erfüllen, so sah er sich mit dem Risiko konfrontiert, dass ein alternativer Kandidat ihn herausforderte; dies konnte ihn nicht nur die Kaiserwürde, sondern auch das Leben kosten. Wie der chinesische Bericht ganz treffend beschreibt, war die römische Monarchie also ein meritokratisches System, wobei die Art des Verdienstes, an dem ein Kaiser gemessen wurde, stets genauer zu bestimmen ist.

Ausgehend von dieser grundlegenden Beobachtung vollzieht die vorliegende Arbeit nach, mit welchen Herausforderungen sich oströmische Monarchen der ausgehenden Spätantike konfrontiert sahen, mit welchen Mitteln sie versuchten, ihre Herrschaft zu sichern, und im Rahmen welcher Diskurse dieses Ringen um Stabilität von den Zeitgenossen besprochen wurde. Der Fokus liegt dabei auf dem Kaiser Herakleios (610 - 641), dessen Regierungszeit sich - wie im Folgenden deutlich werden wird - durch eine besondere Entwicklungsdynamik auszeichnete.

\subsection{Forschungsstand, Fragestellung und Vorgehen}

Bei dem Verhandeln von Epochengrenzen, einer der Geschichtswissenschaft inhärenten Praxis, lässt sich in der Forschung der letzten Jahrzehnte ein Paradigmen-

1 Übersetzung aus Schreiner 1989, 494.

2 Zum Kontakt zwischen dem römischen Reich und der chinesischen T'ang-Dynastie siehe Schreiner 1989, 493 f.; auch Dagron 2003, 13 zitiert den Bericht.

Ә OpenAccess. () 2021 Nadine Viermann, publiziert von De Gruyter. (cc))BY Dieses Werk ist lizenziert unter der Creative Commons Attribution 4.0 International. https://doi.org/10.1515/9783110711356-002 
wechsel nachvollziehen. Während klare Abgrenzungen zwischen Antike und einem andersartigen Mittelalter - bzw. Byzanz im östlichen Mittelmeerraum - lange Zeit den Diskurs bestimmt haben, hat zuletzt ein Trend deutlichen Anklang gefunden, der entgegen der Definition eines ,Ende der Antike“ einen inklusiveren Ansatz vertritt: ${ }^{3}$ Eine erweiterte Spätantike, die grob das erste Millennium umfasst, wird dabei als eigenständige Epoche betrachtet; neben klar identifizierbaren Brüchen betont die Forschung gleichsam auch Kontinuitäten in der soziokulturellen wie politischen Entwicklung, welche sich noch weit über konventionelle Epochengrenzen hinaus nachvollziehen lassen. ${ }^{4}$ Doch selbst die Stimmen, die sich von dem heuristischen Wert klarer Grenzziehungen distanzieren, haben das 7. Jahrhundert im östlichen Mittelmeerraum als eine Phase der beschleunigten Transformation identifiziert. ${ }^{5}$

Im 7. Jahrhundert durchliefen der mediterrane Raum und der Nahe Osten angesichts der Expansion der muslimischen Araber einen grundlegenden Umbruch. Das römische Reich, das einstmals das gesamte Mittelmeer umfasst hatte, schrumpfte auf Kerngebiete in Anatolien und Thrakien sowie Enklaven in Griechenland und Italien; die externen Bedrohungen, welche im Süd-Osten zunächst von den sassanidischen Persern und dann von den Arabern, im Norden von den Avaren und Slaven und in Italien von den Langobarden ausgingen, stellten die römischen Kapazitäten auf eine Zerreißprobe. ${ }^{6}$ Doch der Wandel dieser politischen Entität vollzog sich nicht nur territorial; mit Blick auf die Sozialgeschichte, die Verwaltungs-, Wirtschafts- und Militärgeschichte hat die Forschung die Transformation eines genuin römischen Gemeinwesens hin zu einem anders gearteten, ,byzantinischen' nachvollzogen. ${ }^{7}$ Rezente

3 Einen Überblick über die Diskussion der Epochenfrage mit Blick auf den östlichen Mittelmeerraum bietet Meier 2012, 187-200.

4 Hier haben sich vor allem die Arbeiten von Garth Fowden (1993, 2014) als richtungsweisend herausgestellt. Der Erweiterung des zeitlichen Rahmens entspricht die Erweiterung des geographischen Rahmens, der neben dem Mediterraneum auch vermeintlich periphere Regionen vermehrt in den Fokus des Interesses rückt. Zur Spätantike als distinkte Epoche siehe etwa Av. Cameron 2002 mit Überblick über die englischsprachige Debatte; vgl. dies. 2012; siehe auch Meier 2012, 194-196 zur Spätantike als „Schwellenzeit“. Wickham 2005 dagegen betont eher die Brüche von der Antike hin zu einem sich herausbildenden Mittelalter.

5 Siehe Haldon 2002, der Herakleios' Regierung als „watershed“ (ebd., 16) beschreibt; ähnlich Meier 2012. Auch die Studie von Pfeilschifter 2013 zur hauptstädtischen Monarchie im 5. und 6. Jahrhundert endet mit der Erhebung des Herakleios.

6 Siehe Donner 1981; Kaegi 1992. Fowden 2014 qualifiziert das Aufkommen des Islams nicht so sehr als Zäsur denn als typisches Phänomen einer (zeitlich und geographisch) erweiterten Spätantike; vgl. den von Zuckerman 2013 herausgegebenen Sammelband. Meier 2019a (953-1088) untersucht die arabische Expansion als Teil der Völkerwanderung und gibt außerdem einen konzisen Überblick über die externen Bedrohungen, derer sich das oströmische Reich im 6. und 7. Jahrhundert erwehren musste. 7 Zum oströmischen Reich im 7. Jahrhundert siehe die weiterhin grundlegenden Publikationen von Stratos 1968-1980; Haldon 1990 und ders. 2016; Winkelmann u. a. 1978 zur Herausbildung eines byzantinischen Feudalismus; Brandes 1989 zur Stadtentwicklung und ders. 2002b zu Finanzen und Administration; Haldon 1984 zur Umgestaltung des Militärs - unter anderem der viel diskutierten Frage nach der Herausbildung der Themenverfassung; zur Themenverfassung siehe auch Karayann- 
Arbeiten haben dabei vor allem die Krisenhaftigkeit des 7. Jahrhunderts herausgestellt, im Zuge dessen nicht nur das Herrschaftsgebiet des römischen Reiches dezimiert wurde, sondern auch eine zunehmende Desintegration etablierter Bezugsrahmen zu verzeichnen ist. Während die umfassende Monographie von James Howard-Johnston mit „Witnesses of a World Crisis“ (2010) die äußerst vielfältigen Quellen dieser Epoche in den Blick nimmt, arbeitet Phil Booth in „Crisis of Empire“ (2014) heraus, wie das römische Imperium als praktischer und ideeller Bezugsrahmen für christliche Gemeinden im Nahen Osten an Anziehungskraft einbüßte; ein weiterhin richtungweisender Sammelband zur Regierungszeit des Kaisers Herakleios beschriebt diese unter den Schlagwörtern „Crisis and Confrontation“ und meint damit sowohl interne wie auf externe Konflikte. ${ }^{8}$ Die Diagnose einer Krise bringt indes auch die Frage nach Bewältigungsstrategien mit sich - die Frage, warum das oströmische Reich aller Widrigkeiten zum Trotz überlebte und nicht wie das sassanidische Reich an der arabischen Expansion zu Grunde ging; mit besonderer Prägnanz wird dies von John Haldon in „The Empire that Would not Die“ (2016) analysiert. Als einen zentralen Faktor identifiziert die Forschung in diesem Zusammenhang Religion, oder genauer gesagt die sukzessive Durchdringung der Gesellschaft mit christlichen Deutungsmustern in der deutschsprachigen Forschung als Liturgisierung bezeichnet -, die zwar klare Differenzen schuf (Christen vs. Nicht-Christen; ,Orthodoxe` vs. ,Häretiker`) aber gleichzeitig auch integrative Wirkung in Hinblick auf das römische Gemeinwesen zeitigte. ${ }^{9}$ Die vielfältigen Facetten, in denen sich diese Entwicklung spiegeln konnte, haben unter anderem Averil Cameron und Mary Whitby in einer Reihe von Publikationen herausgearbeitet. ${ }^{10}$

Basierend auf den gerade umrissenen Forschungsdiskursen richtet die vorliegende Arbeit den Blick auf die oströmische Monarchie mit Konstantinopel als Hauptstadt. Methodisch verorte ich mich in einer wissenschaftlichen Strömung, die die herrschaftssoziologischen, strukturgeschichtlichen und praxeologischen Voraussetzungen monarchischer Herrschaft in der Antike ins Zentrum der Untersuchung rückt. Dieser Zugriff ermöglicht es, neben dem konkreten Regierungshandeln eines römischen Kaisers auch die diskursiven, performativen und repräsentativen Aspekte monarchischer Herrschaft in die Analyse einzubeziehen, und leistet damit einen

opulos 1959; Lilie 1976 zur Umgestaltung des byzantinischen Staates in Reaktion auf die Ausbreitung der Araber. Ein recht rezenter Forschungsüberblick zum 7. Jahrhundert, insbesondere der Regierungszeit des Herakleios, findet sich bei Brandes 2002a.

8 Reinink/Stolte 2002.

9 Olster 1994; Stoyanov 2011; Haldon 2016; zur Liturgisierung siehe zuletzt Meier 2016; auch in Meier 2019a wird diesem Aspekt eine zentrale Bedeutung zugewiesen.

10 Die zahlreichen Studien von Averil Cameron sind in zwei Sammelbänden (Av. Cameron 1981, 1996b) zusammengefasst; in diesem Zusammenhang sind vor allem Mary Whitbys Arbeiten zu Georg von Pisidien relevant (1994, 1995, 1998, 2002, 2003, 2020). Zur Formierung des Christentums vom 6. bis ins 8. Jahrhundert siehe auch Herrin 1987 und Meyendorff 1989. 
wichtigen Beitrag zum Verständnis des jeweiligen politischen Systems. ${ }^{11}$ Besondere Erwähnung gebührt in diesem Zusammenhang Egon Flaig, dessen Beschreibung der römischen Monarchie als Akzeptanzsystem die Forschung nachhaltig geprägt hat. Flaig umreißt damit ein System, das keine institutionelle Zuschreibung von Legitimität an den Herrscher kannte, sondern darauf basierte, dass der Kaiser die Akzeptanz der herrschaftsrelevanten Gruppen initial kreieren und daraufhin verstetigen musste, um an der Macht zu bleiben - ein System, dem die Herausforderung des Herrschers durch alternative Kandidaten inhärent war. ${ }^{12}$

Die Entwicklung der oströmischen Monarchie in der Spätantike wurde vor allem auch in der deutschsprachigen Forschung mit einer Reihe richtungweisender Publikationen bedacht. Zuletzt hat Rene Pfeilschifter mit seiner Monographie zum „Kaiser und Konstantinopel“ (2013) die Strukturmerkmale und Funktionsmechanismen einer hauptstädtischen Konfiguration von Monarchie herausgearbeitet, welche sich vor allem dadurch auszeichnete, dass die Kaiser nicht wie früher die Provinzen bereisten und an der Spitze der römischen Truppen in den Krieg zogen, sondern dauerhaft in Konstantinopel residierten. Die fortschreitende Bindung der Kaiser an die Hauptstadt am Bosporus führte zu neuartigen Formen der Kommunikation und Interaktion zwischen dem Monarchen und der Konstantinopolitaner Bevölkerung und Elite, denen nun bei der Aushandlung kaiserlicher Herrschaft eine maßgebliche Funktion zukam; der Kern dieser Interaktion bestand, wie Steffen Diefenbach $(1996,2002)$ gezeigt hat, in der ostentativen Zuschaustellung kaiserlicher Frömmigkeit. Unter dem Kaiser Justinian (527-565) erreichten Trends wie die Sakralisierung des Kaisertums einen vorzeitigen Höhepunkt - so der weitgehende Konsens der Forschung. ${ }^{13}$ Während die althistorische Forschung Justinians Regierung gemeinhin als Grenze des Untersuchungszeitraumes ansetzt, lässt sich in rezenten Arbeiten die Tendenz erkennen, den zeitlichen Rahmen noch weiter zu spannen. Als ausgewiesener Kenner des 5. und 6. Jahrhunderts hat Mischa Meier zuletzt auch das frühe 7. Jahrhundert verstärkt in seine Untersuchungen einbezogen und dabei vor allem eine Transformation des Kaiserbildes akzentuiert. Mit Blick auf Herakleios hält er fest, dass die neuartigen Züge des Kaisertums sich „nur noch schwer mit den Instrumentarien zur Beschreibung und Analyse antiker Herrschaftsformen erfassen [lassen]“; stattdessen beobachte man „eine neue Form der Monarchie“. ${ }^{14}$

11 Beispielhaft seien hier die Arbeiten von Meier 2003a, Wienand 2012, Pfeilschifter 2013, Omissi 2018 und Maier 2019 genannt; konzeptionell auch Winterling 2011.

12 Die zentralen Thesen seiner Monographie (1992) fasst Flaig in einem Aufsatz (1997) zusammen, wo er seinen Zugriff auf die römische Monarchie bis in die Spätantike erweitert.

13 Siehe vor allem die Monographien von Meier 2003a und Leppin 2011; außerdem Meier 2016 explizit zur „Liturgisierung und Hypersakralisierung“.

14 Zitat Meier 2016, 100. Meier 2012 spannt einen Bogen vom 4. bis ins 7. Jahrhundert und betont schließlich den Zäsurcharakter des frühen 7. Jahrhunderts (ebd. 236-249); ähnlich Meier 2017. Arbeiten, die sich dezidiert mit dem 7. Jahrhundert beschäftigen sind Meier 2014b, 2015. Auch in seinem monumentalen Werk zur Völkerwanderung (2019) führt Meier die Untersuchung bis ins frühe 7. Jahrhundert. 
In der Tat lässt sich während Herakleios’ Herrschaft ein grundlegender Wandel in der kaiserlichen Herrschaftspraxis nachvollziehen. Nach über zwei Jahrhunderten der hauptstädtischen Monarchie war Herakleios der erste Kaiser, der Konstantinopel über Jahre hinweg verließ, um als oberster Feldherr die römischen Truppen gegen die Perser anzuführen, die zu diesem Zeitpunkt die Provinzen Syrien, Palästina und Ägypten besetzt hatten. ${ }^{15}$ Rene Pfeilschifter betont zurecht die enorme Bedeutung und Tragweite dieser Entscheidung: Er liest den Umstand, dass die Bindung des Kaisers an seine Hauptstadt sich unter Herakleios offenbar lockerte, als Ende einer hauptstädtischen Konfiguration von Monarchie und lässt damit seine Untersuchung zum „Kaiser und Konstantinopel“ enden. ${ }^{16}$ Dass Herakleios’ Entscheidung, Konstantinopel zu verlassen, kein kurzweiliges Phänomen war, sondern vielmehr die Weichen für die Regierungspraxis seiner Nachfolger stellte, zeigt sich in dem Umstand, dass sein Enkel Konstans II. über mehrere Jahre hinweg seine Residenz im sizilischen Syrakus einrichtete, wo er im Jahr 668 ermordet wurde. ${ }^{17}$

Während der Regierung des Herakleios erlebte das römische Reich Triumphe ebenso wie Katastrophen. Im Jahr 610 durch Usurpation an die Macht gekommen, konnte Herakleios das Vorrücken der Perser, die seit dem Sturz des Maurikios und der Erhebung des Phokas im Jahr 602 gegen die römischen Grenzen anrannten, zunächst nicht aufhalten. Erst nach Jahren der persönlichen Kriegführung gelang dem Kaiser 628 die grandiose Rückgewinnung der Ostprovinzen; an dem Sieg konnte er sich jedoch nur kurz erfreuen: Wenige Jahre später sahen sich Palästina, Syrien und Ägypten mit den ersten Ausläufern der arabischen Expansion konfrontiert, die Herakleios' Restitutionswerk sukzessive zunichte machte. Die Forschung zu Herakleios wird maßgeblich von der einzigen rezenteren Monographie geprägt, die sich diesem Kaiser umfassend widmet, nämlich Walter E. Kaegis biographischer Betrachtung „Heraclius: Emperor of Byzantium“ (2003). ${ }^{18}$ David. M. Olsters Monographie „Politics of Usurpation“ (1993), die die Dynamiken der gewaltsamen Machtwechsel von 602 und 610 eingehend analysiert und kontextualisiert, geht kaum über Herakleios' Krönung zum Kaiser im Oktober 610 hinaus. Entgegen einer stark individualistisch geprägten Biographie wie der Kaegis, die gerne auch die Tragik der Geschehnisse in den Vordergrund rückt, hat die vorliegende Arbeit den Anspruch, Herakleios' Herrschaft einer strukturgeschichtlichen Analyse zu unterziehen.

Die Fragen, die diese Untersuchung leiten, sind folgende: Warum verließ Herakleios als erster Kaiser seit über zweihundert Jahren wieder längerfristig die Hauptstadt? Wie wurde der Umstand, dass Herakleios mit etablierten monarchischen Verhaltensweisen brach, von seinen Zeitgenossen wahrgenommen? Welche Auswirkungen zeitigte dieser Paradigmenwechsel, die neuerliche Abwesenheit des Kaisers

$15 \mathrm{Zu}$ diesem grundlegenden Umbruch siehe Raum 2019, bes. $134 \mathrm{f}$.

16 Pfeilschifter 2013, 25-28.

17 Einen konzisen Überblick über die Ereignisgeschichte des 7. Jahrhunderts bietet Haldon 1990, 41-91.

18 Vgl. auch die Biographie von Pernice 2005. 
von Konstantinopel, auf das hauptstädtische Umfeld einerseits und auf monarchische Herrschaftspraxis im oströmischen Reich andererseits? Die Remilitarisierung des Kaisertums unter Herakleios - der Wandel von einem sesshaften Monarchen hin zu einem kriegführenden - wird also nicht nur ereignishistorisch nachvollzogen, sondern in ihrer Entwicklungslogik aufgearbeitet. Ziel dieser Arbeit ist es, zu den kausalen Zusammenhängen vorzustoßen, die der Entwicklung oströmischer Monarchie im frühen 7. Jahrhundert zugrunde liegen, und die Voraussetzungen, die Modi und die Folgen dieses Prozesses offenzulegen. Es geht darum, politische Entscheidungsprozesse zu entschlüsseln und gleichzeitig die Ebene der politischen Kommunikation, also die Verarbeitung von getroffenen Entscheidungen, in die Analyse einzubeziehen. Dabei habe ich nicht den Anspruch, die Entwicklung des oströmischen Reiches im turbulenten frühen 7. Jahrhundert allumfassend aufzuarbeiten. Während ich sowohl innen- wie außenpolitische Faktoren in die Analyse der oströmischen Monarchie einbeziehe, richtet sich der Blick ganz dezidiert auf das Verhältnis des Kaisers zu Konstantinopel; denn wie sich zeigen wird, blieb das hauptstädtische Umfeld auch unter Herakleios der zentraler Faktor in der Aushandlung und Sicherung kaiserlicher Herrschaft - obwohl der Monarch nicht mehr dauerhaft am Bosporus residierte. Die Zustände in den römischen Provinzen werden nicht um ihrer selbst willen besprochen, sondern nur dann in die Analyse einbezogen, wenn sie dazu beitragen, das Verständnisse der Prozesse zu schärfen, die sich in Konstantinopel abspielten.

Der Untersuchung liegt die Überzeugung zugrunde, dass sich die Entwicklung der oströmischen Monarchie im frühen 7. Jahrhundert nur vor dem Hintergrund eines über Jahrhunderte geformten politischen Systems in ihren Kausalzusammenhängen erfassen lässt. ${ }^{19}$ Das Kapitel 2 verfolgt dementsprechend das Ziel, die Strukturmerkmale der hauptstädtischen Monarchie im 5. und 6. Jahrhundert einer Revision zu unterziehen. Unter Strukturen begreife ich dabei Regelmäßigkeiten, Muster und Bedingungen menschlichen Handelns, die durch Sets kollektiv geteilter Normvorstellungen und Erwartungshaltungen konstituiert werden. Ein solches Verständnis von Strukturen bietet auch der Kategorie des Akteurs einen Platz, der sich - bewusst oder unbewusst, explizit oder implizit - in seinem Handeln auf Strukturen bezieht, diese reproduziert bzw. modifiziert. ${ }^{20}$ Basierend darauf vollziehen die darauffolgenden Kapitel nach, wie politische Akteure bzw. Gruppen sich innerhalb des etablierten

19 Anachronistische Ansätze, die das 7. Jahrhundert rückblickend etwa vor der Warte mittelbyzantinischer Standards beurteilen, können die Eigenarten dieser Phase nur schwerlich angemessen herausarbeiten.

20 Dabei ist wichtig zu betonen, dass ich Strukturen nicht als dem menschlichem Handlungswillen und Wirkungsraum äußerliche Entitäten verstehe. Gemäß dem von Anthony Giddens etablierten Paradigma einer „Dualität von Struktur“ sind Strukturen einerseits Voraussetzung menschlichen Handelns, andererseits werden Strukturen allein durch menschliches Handeln zu gesellschaftlicher Wirklichkeit und können derart von Historikern beobachtet werden; zu dem soziologischen Ansatz von Giddens siehe die konzise Übertragung auf die Geschichtswissenschaft durch Welskopp 2001. Zum Struktur-Begriff in der (historischen) Sozialwissenschaft siehe außerdem Reckwitz 1997; zum Verhältnis von Struktur und Ereignis siehe Koselleck 1973 und Suter/Hettling 2001. 
Strukturrahmens bewegten und welche Auswirkungen konkrete politische Entscheidungen im Zusammenspiel mit externen Prozessen auf diesen Strukturrahmen zeitigten. Kapitel 3 analysiert die beiden gewaltsamen Machtwechsel von 602 und 610 und arbeitet heraus, wie die Verkettungen kontingenter Faktoren eine Erweiterung des politischen Handlungsspielraumes bedingen konnte, welcher dann wiederum von Akteuren aktiv ausgenutzt wurde. Kapitel 4 beschäftigt sich mit der Frage, mit welchen Mitteln Herakleios nach seiner Erhebung 610 versuchte, die eigene Herrschaft zu sichern und potentiellen Risiken vorzubeugen, die sich aus dem erweiterten Handlungsspielraum ergaben. In diesem Zusammenhang wird auch die Frage nach den Gründen für die Remilitarisierung des Kaisertums adressiert. Kapitel 5 begibt sich auf die Ebene des zeitgenössischen Diskurses: Ausgehend von der Beobachtung, dass Herakleios' plötzliche Abwesenheit von Konstantinopel und sein Engagement als Feldherr in der Hauptstadt durchaus kritisch gesehen wurden, arbeite ich heraus, mit welchen Kommunikationsangeboten die kaiserliche Transgression nicht nur bewältigt, sondern explizit positiv konnotiert werden konnte. Kapitel 6 vollzieht nach, welche Auswirkungen herausragender militärischer Sieg einerseits und katastrophale Niederlage andererseits auf Herakleios' Herrschaft im Verhältnis zum hauptstädtischen Umfeld zeitigten - sowohl diskursiv wie auch praktisch. Kapitel 7 blickt schließlich auf Herakleios' Nachfolge und verdeutlicht, dass die Maßnahmen, die der Kaiser im Sinne der Herrschaftssicherung getroffen hatte, sich zwar für seine Person als erfolgreich erwiesen aber nicht zu einer dauerhaften Stabilisierung monarchischer Herrschaft führten. Ein kursorischer Überblick über politische Prozesse im weiteren Verlauf des 7. Jahrhunderts zeigt, inwiefern die von Herakleios verfolgte Politik neue Standards monarchischer Herrschaftsausübung gesetzt hatte.

Die vorliegende Arbeit richtet den Fokus auf Wandel ebenso wie auf Kontinuität im politischen System Ostroms und leistet damit auch einen Beitrag zur Diskussion von Epochen und Epochengrenzen; sie verdeutlicht, was sich im frühen 7. Jahrhundert im Hinblick auf monarchische Herrschaft änderte und was blieb, und arbeitet die praktischen und diskursiven Instrumentarien heraus, mit dem die relevanten Akteure internen wie externen Herausforderungen begegneten. Dass sich die Menschen, die das oströmische bzw. byzantinische Reich bewohnten, über das gesamte Fortbestehen dieser politischen Entität als Römer - oder genauer gesagt: als Rhomaioi - verstanden, wurde in der Forschung wiederholt betont. ${ }^{21}$ In Synthese geht die Arbeit der Frage nach, ob die monarchische Herrschaft des 7. Jahrhunderts auch aus der analytischen Perspektive der Wissenschaft weiterhin als römisch zu qualifizieren und als solche zu untersuchen ist, oder ob die Zäsuren unter Herakleios eine neue Form der Monarchie einleiteten.

21 Siehe zuletzt Kaldellis 2019. 


\subsection{Quellenmaterial}

Widmet man sich der Untersuchung der oströmischen Monarchie im frühen 7. Jahrhundert, ist eine ganze Vielzahl von Quellen in Betracht zu ziehen. Auf den folgenden Seiten geht es darum, das äußerst weit gefächerte Material vorzustellen, damit die teilweise komplexen Diskussionen zum Entstehungskontext nicht den Argumentationsfluss der analytischen Kapitel stören. Allein wenn der kommunikative Kontext der Quellen meine Analyse direkt bedingt, werden die entsprechenden Fragestellungen an späterer Stelle noch einmal aufgegriffen und im Detail diskutiert.

Die vorliegende Arbeit basiert vor allem auf literarischen Quellen, deren Auswertung einen besonders facettenreichen Zugriff auf die oben dargelegte Fragestellung verspricht. Die Dichte der materiellen Quellen dagegen nimmt gegenüber den vorigen Jahrhunderten stark ab. Nur wenige bildliche Artefakte können für die Untersuchung oströmischer Monarchie im frühen 7. Jahrhundert nutzbar gemacht werden. ${ }^{22}$ Ähnlich dürftig ist der Bestand an epigraphischem Material; ein Sachverhalt, der den allgemeinen Rückgang von Inschriften vor allem im östlichen Mittelmeerraum in dieser Zeit wiederspiegelt. ${ }^{23}$ Auch architektonische Evidenz, die sich mit kaiserlicher Initiative in Verbindung bringen lässt, ist nur in geringem Maße vorhanden. ${ }^{24}$ Während das frühe 7. Jahrhundert in Konstantinopel archäologisch kaum nachvoll-

22 Besonders prominent sind dabei die während der Regierung des Herakleios geprägten Silberteller mit der Darstellung von Szenen aus dem Alten Testament um den König David (siehe etwa Spain Alexander 1977). Darüber hinaus wurde die berühmte Josua-Rolle, ein prächtig illustrierter Rotulus aus dem 10. Jh., als Kopie eines Originals aus dem frühen 7. Jahrhundert interpretiert; siehe HowardJohnston (im Druck). Eine Darstellung des alttestamentarischen Hiob und seiner Familie, welche auf einem Folio einer koptischen Bibelhandschrift beigefügt wurde, sehen manche Forscher wiederum als dem Bildnis des Herakleios nachempfunden; zu beiden Handschriften siehe Tsamakda 2010, 32.

23 Aus der geringen Anzahl griechischer Inschriften des frühen 7. Jahrhunderts ist vor allem ein Stein hervorzuheben, der die (literarisch nicht überlieferte) Instandsetzung der Langen Mauern durch Herakleios markiert. Die Inschrift, die sich inzwischen im Archäologischen Museum Istanbul befindet, wurde allerdings bisher nur unzureichend publiziert; siehe Bayliss/Crow 2002; vgl. Crow 2006 zu der Mauer. Ich bedanke mich bei James Crow, der mir das Manuskript eines noch nicht veröffentlichten Aufsatzes zur Verfügung gestellt hat, das die Lesung der Inschrift enthält.

24 Der Ausbau der Magnaura, eines Empfangssaales im kaiserlichen Palast von Konstantinopel, ist zwar durch ein Epigramm in der Anthologia Graeca (9.655) überliefert, archäologisch allerdings nicht mehr nachvollziehbar; siehe Kaegi 2003, 199. Nach der Doppelbelagerung Konstantinopels von 626 wurde das Areal der Blachernenkirche durch eine Erweiterung der theodosianischen Stadtmauer geschützt; siehe Chron. Pasch. AD 627. Das sog. Goldene Tor an der Ostseite des Jerusalemer Tempelberges wurde wiederholt auf Herakleios und dessen Aufenthalt in Jerusalem im Zusammenhang mit der Restitutio Crucis bezogen - eine Hypothese, die nicht durch schriftliche Quellen unterfüttert werden kann und eingehender Diskussion bedarf; siehe Peters 1983; Mango 1992. Angesichts dieses eher dürftigen Zustandes ist ein Befund aus Armenien besonders beachtenswert: Die Kathedrale im armenischen Mren wurde - so bezeugt die in situ erhaltene Bauinschrift - nach dem Sieg des Herakleios über die Perser von lokalen Magnaten erreichtet. Ein Relief dieser Kathedrale könnte die Rückerstattung des Heiligen Kreuzes nach Jerusalem durch Herakleios abbilden; siehe Thierry/Thierry 1971; Thierry 1997; Maranci 2008/2009; vgl. die ausführliche Diskussion unten Kap. 6.1.2. 
ziehbar ist, stießen Wissenschaftler in den letzten Jahrzehnten bei Ausgrabungen in und um Jerusalem wiederholt auf Befunde, die Aufschluss über die Belagerung und Eroberung der Stadt durch die Perser im Jahr 614 geben. ${ }^{25}$ Zumindest numismatisches Material enttäuscht nicht: Die Entwicklung der Münzprägung ist über die gesamte Regierungszeit des Herakleios nahezu lückenlos nachvollziehbar. ${ }^{26}$

Das Bedürfnis nach einem Überblick über die literarischen Quellen erwächst nicht nur aus deren schierer Menge, sondern vor allem auch aus deren Heterogenität: Griechische Texte stehen lateinischen, syrischen, armenischen, koptischen und arabischen gegenüber. Ebenso vielfältig wie die Sprachen der Quellen sind auch die Kontexte ihrer Entstehung. Das Spektrum der vorhandenen Genres reicht von Geschichtsschreibung, die sich an klassischer Tradition orientiert, über Chroniken bis hin zu Predigten, Hagiographien und apokalyptischem Schrifttum, wobei sich manche Texte nur schwerlich einer derartigen Kategorisierung unterwerfen lassen. In dem Überblick wird unter anderem deutlich, welch enormen Wandel Verschriftlichungspraktiken bzw. literarische Produktion in der Spätantike durchliefen; mit den griechischen und lateinischen Traditionen einer als ,klassisch verstandenen Antike haben die hier präsentierten Texte oft nur noch wenig gemein.

Bei der Untersuchung des 7. Jahrhunderts lässt sich auf eine ganze Reihe an zeitgenössischen Texten zurückgreifen, die bisweilen gar als Gelegenheitsschriften recht unvermittelt auf Geschehenes reagierten. Will man die Abläufe so detailliert wie möglich nachvollziehen, muss diese Basis allerdings durch wesentlich später entstandenes bzw. kompiliertes Material ergänzt werden. Die Überlieferung ist dabei nicht selten durch nachträgliche Übersetzungen und Überarbeitungen der ursprünglichen Texte beeinträchtigt, sodass sich eine angemessene Beurteilung bisweilen schwierig gestaltet. Obwohl die Anzahl an modernen Bearbeitungen stetig wächst und beinahe alle Quellen zumindest in einer modernen Übersetzung vorliegen, gibt es doch weiterhin Texte, die angesichts des Mangels an ausreichend kommentierten Editionen nur mit Mühe zu nutzen sind. ${ }^{27}$

Zeitgenössische Quellen, hauptstädtisch: Ich beginne meinen Überblick mit den Quellen, die während bzw. kurz nach dem Untersuchungszeitraum entstanden sind, daher als zeitgenössisch gewertet werden können und mit dem hauptstädtischen Milieu in Verbindung stehen. Das Geschichtswerk des Theophylakt Simokattes wird in der Regel als das letzte seiner Art in der Tradition klassischer Geschichtsschreibung verstanden. Im Gegensatz zu seinen direkten Vorgängern Prokop, Agathias und

25 Reich 1993 zu einem Massengrab; Bijovski 2010 zu einem Münzhort; außerdem Avni 2010.

26 Die Münzen sind dokumentiert in DOC (Catalogue of the Byzantine Coins in the Dumbarton Oaks Collection and in the Whittemore Collection) und MIB (Moneta Imperii Byzantini); zu papyrologischem Material aus Ägypten, welches in meiner Diskussion allerdings nicht herangezogen wird, siehe Howard-Johnston 2010, 179 und Zuckerman 2010.

27 Einen wertvollen Beitrag zur Erschließung der Quellen zum 7. Jahrhundert hat zuletzt James Howard-Johnston mit seiner Monographie „Witnesses of a World Crisis” (2010) geleistet, auf die ich mich im Folgenden wiederholt beziehen werde. 
Menander Protektor tritt bei Theophylakt allerdings erstmals auch im Genre der säkularen Geschichtsschreibung ein christlicher Deutungshorizont in den Vordergrund. ${ }^{28}$ Aus Ägypten stammend gelangte Theophylakt, der über eine fundierte rhetorische Ausbildung verfügte, zu einem nicht näher bestimmbaren Zeitpunkt nach Konstantinopel, wo er bis in hohe zivile Ämter aufstieg. Über ein Nahverhältnis zum Kaiser Herakleios - und damit einhergehend über die Frage, ob es sich bei den Historien um ein Auftragswerk handelte - lässt sich nur spekulieren. ${ }^{29}$ Die Abfassungszeit des Historien kann in die mittlere bis späte Regierungszeit des Herakleios angesetzt werden: Das Jahr 628 steht als Terminus post quem fest, da der Autor vom Tod des Perserkönigs Chosroes II. weiß. ${ }^{30}$ Explizite Spuren von der Bedrohung und Eroberung der römischen Ostprovinzen durch die Araber, die 634 ihren Anfang nahm und 636 mit der Niederlage der Römer am Yarmouk einen vorläufigen Höhepunkt fand, lassen sich im Text keine erkennen. ${ }^{31}$ Die Spanne der erzählten Zeit reicht dabei jedoch kaum in die Gegenwart des Autors hinein; sie umfasst vielmehr - bis auf einige Rück- und Vorausblicke - die Regierungszeit des Maurikios mit den Kriegen gegen Avaren und Perser und kulminiert in der Erhebung des Phokas, dessen Regierung den recht knappen narrativen Endpunkt der Historien bildet. ${ }^{32}$ Angesichts der spezifischen Fragestellung dieser Arbeit dient Theophylakts Geschichte vor allem als Quelle für den Sturz des Maurikios, den der Autor möglicherweise als Augenzeuge miterlebt hatte. Dabei muss allerdings stets die rückblickende Deutung des Autors bedacht werden, der - vor dem Hintergrund der bereits mehrere Jahrzehnte andauernden Regierung des Herakleios - Maurikios als tragischen Helden und Phokas als Tyrannen stilisiert. Explizite Stellungnahmen zu Herakleios finden sich in dem Geschichtswerk

$28 \mathrm{Zu}$ den Historien siehe die Einleitungen in den Übersetzungen von Schneider 1985 und Whitby/ Whitby 1986, außerdem Mi. Whitby 1988. Eine Einordnung in die literarische Tradition findet sich bei Hunger 1978, 313-319; vgl. außerdem Brodka 2004; Treadgold 2007, 329-340; Howard-Johnston 2010, 142-146 und Efthymiadis 2010.

29 Dem Geschichtswerk sind kaum biographische Angaben zum Autor zu entnehmen. Die ihm zugeschriebenen Ämter lassen sich vor allem späteren Handschriften, der Suda sowie der Sammlung des Photios entnehmen; siehe Schneider 1985, 4f., Mi. Whitby 1988, 30 - 32.

30 Hist. 8.12.13.

31 Siehe Schneider 1985, 13; Mi. Whitby 1988, 39f. Vgl. auch Efthymiadis 2010, 171f., 180, der die düstere Grundstimmung des Geschichtswerkes als Indikator für die bereits einsetzenden Angriffe der Araber versteht; dagegen Meier 2014a, 165 Anm. 90.

32 Zum Aufbau des Geschichtswerkes siehe Schneider 1985, 11f. und Whitby/Whitby 1986, xvii-xx; zu den Quellen des Theophylakt siehe Howard-Johnston 2010, 143f. Angesichts eines recht abrupten Endes wurde wiederholt gemutmaßt, dass Theophylakt eine Erweiterung seines Geschichtswerkes auf die Regierungszeit des Herakleios plante, siehe Schneider 1985, 12 und Mi. Whitby 1988, 46-51, dagegen Speck 1993. Dass Historiographen ihr Werk nicht bis in die eigene Gegenwart fortführten bzw. nicht bis in die Zeit des gerade regierenden Kaisers vordrangen, ist mit Blick auf die Tradition des Genres allerdings nicht überraschend. 
kaum; die wenigen Ausnahmen, etwa der einleitende Dialog zwischen Geschichte und Philosophie, bedürfen eingehender Untersuchung. ${ }^{33}$

Neben den Historien des Theophylakt lässt sich ein weiteres Geschichtswerk für die Untersuchung des frühen 7. Jahrhunderts heranziehen. Diese Weltgeschichte beginnend mit der Erschaffung Adams ist allerdings nur fragmentarisch in mittel- und spätbyzantinischen Manuskripten erhalten (etwa den Exzerptsammlungen des Konstantin Porphyrogennetos oder der Suda, einem mittelbyzantinischen Lexikon aus dem 10. Jahrhundert), wo sie einem nicht näher bestimmbaren Johannes von Antiochia zugeschrieben wird. ${ }^{34}$ Formal ist das Werk der syrisch-historiographischen Tradition zuzuordnen - unter anderem repräsentiert durch Johannes Malalas; Details des Textes indes lassen darauf schließen, dass der Autor in Konstantinopel lebte und wirkte. ${ }^{35}$ Während das 6. Jahrhundert in den erhaltenen Fragmenten nur sporadisch abgedeckt ist, zeichnen sich die Schilderungen des Machtwechsels von 602, der Herrschaft des Phokas sowie der Usurpation des Herakleios 610, die in der Edition von Umberto Roberto als letzte der johanneischen Fragmente identifiziert werden, durch bemerkenswerte Detailgenauigkeit aus. Aus diesem Sachverhalt wird geschlossen, dass der Autor besagte Ereignisse als Augenzeuge miterlebte und sein Werk in nicht allzu großem zeitlichem Abstand verschriftlichte. ${ }^{36}$

Als besonders aufschlussreich für den hauptstädtischen Kontext erweist sich das Chronicon Paschale, eine Weltchronik, die mit der Erschaffung Adams beginnt und bis in die Lebenszeit des Autors, die späten 620er Jahre, hineinreicht. ${ }^{37}$ Über den anonymen Autor lassen sich kaum stichhaltige Aussagen treffen; zumindest eine Verortung als Kleriker im Umfeld des konstantinopolitaner Patriarchen Sergios ist plausibel. ${ }^{38}$ In seinem Schaffen lässt der Autor sich durch ein primär chronologisches Interesse leiten; manche der annalistisch geordneten Jahreseinträge bleiben bis auf die offizielle Datierungsformel schlichtweg leer. Außerdem fügt der Autor wiederholt Exkurse bei, die sich um die Berechnung christlicher Feiertage wie den Ostertermin drehen - daher der Name, mit dem das Werk in der Manuskripttradition versehen

33 Zu der Diffamierung des Phokas siehe Meier 2014b und Kap. 3.4; zu dem einleitenden Dialog siehe ebd. und S. 296-299.

34 Siehe die Einleitungen in Mariev 2008 und Roberto 2005; außerdem Treadgold 2007, 311-329 (mit weiterer Literatur) und Howard-Johnston 2010, 140 - 142.

35 Siehe Roberto 2010, 55.

36 Während Roberto 2005, xf., xxvii-xxx und Treadgold 2007, 311-315 davon ausgehen, dass alle erhaltenen Fragmente einem Autor zuzuschreiben sind, plädiert Howard-Johnston 2010, 141f. aufgrund eines stilistischen Bruches dafür, dass das Material ab der Regierung des Justin I. aus einer anderen Feder stammt; so auch Mango 1990, 13f. Zu der ,Johanneischen Frage، (d. h. der Frage danach, welche Fragmente dem Johannes zuzuschreiben sind) siehe Mariev 2008, 4-8 mit Kritik an der Ausgabe von Roberto 2005.

37 Zur Osterchronik siehe vor allem die Einleitung in der Übersetzung von Whitby/Whitby 1989 und Howard-Johnston 2010, 37-59.

38 Whitby/Whitby 1989, xxviif. und Howard-Johnston 2010, 54-59. 
wurde. ${ }^{39}$ Die historischen Informationen, welche die Chronik liefert, konzentrieren sich auf das öffentliche Leben der Hauptstadt: Angelegenheiten des Kaiserhauses und der Kirche, Bauprojekte, Aufstände und sonstige Bedrohungen; was außerhalb Konstantinopels passiert bzw. das dortige Geschehen nicht direkt tangiert, findet in der Regel wenig Beachtung. Der schriftstellerische Wert der Osterchronik ist recht gering, da der Autor sich vor allem auf das Abschreiben bzw. Exzerpieren von vorhandenen Quellen beschränkt. ${ }^{40}$ Doch gerade darin liegt bisweilen der enorme Quellenwert: Für das frühe 7. Jahrhundert etwa liefert die Osterchronik nicht nur genuine Informationen und absolute Daten, die für eine Rekonstruktion der Geschehnisabläufe in Konstantinopel unerlässlich ist, sondern reproduziert auch wiederholt offizielle Dokumente wörtlich im Text - so etwa eine Depesche, mit welcher der in Persien weilende Herakleios die Hauptstadt über den Tod des Perserkönigs Chosroes II. und den Friedensschluss mit dessen Nachfolger Seiroe informierte. ${ }^{41}$ Erschwert wird die Auswertung der Osterchronik allerdings dadurch, dass die letzten Folia des einzigen erhaltenen Manuskriptes fehlen bzw. beschädigt sind, sodass der Text im Eintrag zum Jahr 628 recht abrupt abbricht..$^{42}$ Die Frage nach dem eigentlichen Ende der Chronik, die auch die Interpretation des Gesamtwerkes - etwa die Frage nach dem Anlass für dessen Verschriftlichung - tangiert, steht demnach weiterhin zur Debatte. Plausibel ist in jedem Fall, dass die Osterchronik unter dem Eindruck der erfolgreichen Beendigung des jahrzehntelangen Krieges gegen die Perser verfasst bzw. zumindest abgeschlossen wurde. ${ }^{43}$

Die weiteren zeitgenössischen Quellen unterscheiden sich grundlegend von den bisher präsentierten historio- bzw. chronographischen Schriften. Einen zentralen Platz in den analytischen Kapiteln dieser Arbeit nehmen die Gedichte des Georg von Pisidien ein. ${ }^{44}$ Aus Antiochia in Pisidien stammend durchlief Georg im frühen 7. Jahrhundert als Kleriker eine Karriere im Umfeld des Patriarchen Sergios. Über die von ihm besetzten hochrangigen Ämter informieren uns eine Reihe von Handschrif-

39 Bereits in der Einleitung der Chronik werden verschiedene Methoden aufgezeigt, das Osterdatum zu berechnen, siehe Whitby/Whitby 1989, xi, außerdem Beaucamp 1979.

$40 \mathrm{Zu}$ den Quellen siehe Whitby/Whitby 1989, xv-xxii und Howard-Johnston 2010, 43-55.

41 Chron. Pasch. AD 628.

42 Ein Versuch, den beschädigten Text zu rekonstruieren, wurde von Oikonomides 1971 unternommen; vgl. auch Ericsson 1968 zu den Konsequenzen, welche die Beschädigung des Manuskriptes für die Interpretation nach sich zieht.

43 Obwohl der Titel der Osterchronik das Jahr 630 als Endpunkt des Werkes angibt, wurde dies wiederholt in Frage gestellt, siehe dazu die Diskussion und alternative Vorschläge bei Whitby/Whitby 1989, xi-xiii und 190 f.; die These, dass die Chronik mit Herakleios’ Restitutio Crucis im Jahr 630 abschloss (so etwa Howard-Johnston 2010, 41) ist durchaus verlockend, allerdings nicht zu belegen. $44 \mathrm{Zu}$ Georg von Pisidien siehe die Einleitungen in den Übersetzungen von Pertusi 1959 und Tartaglia 1998, außerdem Olster 1994, 51-71; Howard-Johnston 2010, 16-35; Meier 2015, 170 - 174; vgl. auch die Detailstudien von Ma. Whitby 1994, 1995, 1998, 2002, 2003. Seine Gedichte, zu denen moderne Leser bisweilen nur schwerlich Zugang finden (vgl. Frendo 1984, 159-162), genossen in byzantinischer Zeit höchstes Ansehen: Michael Psellos hielt Georgs Iamben für denen des Euripides überlegen (siehe Howard-Johnston 2010, 17 Anm. 3). Zu der Überlieferungssituation siehe Lauxtermann 2003, $57 \mathrm{f}$. 
ten: Er diente als Skeuophylax, zuständig für die Besitztümer der Hagia Sophia, als Chartophylax, als Archivar, und als Referendarios, als welcher er für die Kommunikation zwischen Patriarchat und Kaiserpalast verantwortlich zeichnete. ${ }^{45}$ Zwölf im Umfang stark variierende Gedichte sind unter Georgs Namen erhalten, darüber hinaus eine Reihe von ihm zugeschriebenen Fragmenten und Epigrammen, mit denen er die Regierungszeit des Herakleios begleitete. Sein frühestes Werk, In Heraclium ex Africa redeuntem, entstand kurz nach Herakleios' Erhebung im Oktober 610; eine Phase der gesteigerten Produktivität ist in den 620er Jahren zu verzeichnen, bevor der Dichter in den frühen 630ern verstummte. ${ }^{46}$ Georg behandelt seine Themen durchgehend vor einem christlichen Deutungshorizont, zeigt allerdings auch eine umfassende Kenntnis paganer Traditionen. Während einige seiner Werke sich vorrangig mit umfassenderen, religiösen Themen beschäftigen (etwa dem Osterfest oder der göttlichen Schöpfung), eignet anderen ein direkter tagespolitischer Bezug, da sie recht unvermittelt auf Zustände in der Hauptstadt reagieren; ${ }^{47}$ die Trennlinie zwischen diesen beiden Typen verläuft allerdings nicht scharf. ${ }^{48}$ Ein Großteil der Gedichte zeichnet sich durch einen enkomiastischen Charakter aus; das Lob bezieht sich dabei auf verschiedene Akteure in der Hauptstadt, allen voran der Kaiser Herakleios und der Patriarch Sergios. Von einer bestehenden Tradition der panegyrischen Epik hebt Georg sich dabei insofern ab, als seine Gedichte vollständig im iambischen Trimeter verfasst sind, anstatt in dem für epische und enkomiastische Dichtung typischen Hexameter. ${ }^{49}$ Aus der Perspektive dieser Arbeit liegt der Wert von Georgs Oeuvre nicht so sehr in dem Umstand, dass sich aus seinen Texten vereinzelt Informationen zur Rekonstruktion von Geschehnisabläufen herausdestillieren lassen; als fruchtvoll erweisen sich die Gedichte vielmehr deswegen, da in ihnen eine spezifische Deutung der Ereigniszusammenhänge vorgebracht wird, die die hauptstädtische Gesellschaft des

45 Siehe Pertusi 1959, 12f. mit Anm. 1 (S. 13); außerdem Ma. Whitby 1998, 247 und Howard-Johnston 2010, $17 \mathrm{f}$.

46 Siehe den Überblick bei Howard-Johnston 2010, 17-25. Die Datierungen mancher Gedichte sind umstritten; eine genauere Diskussion erfolgt in den folgenden Kapiteln nur dann, wenn die Datierungsfrage Auswirkungen auf meine Argumentation hat. $\mathrm{Zu}$ den Epigrammen siehe Lauxtermann 2003, $65 \mathrm{f}$.

$47 \mathrm{Zu}$ solchen „occasional poems“ siehe Lauxtermann 2003, 58.

48 Eine strikte Einteilung in panegyrische Gedichte einerseits („Panegirici epici“) und religiöse andererseits, wie sie Pertusi 1959 für seine Edition und Übersetzung zumindest anberaumt hatte (der Band zu den religiösen Gedichten ist nie erschienen), wurde zuletzt - etwa in der Übersetzung von Tartaglia 1998 - nicht mehr beibehalten. Ein einziges Prosa-Werk Georgs ist erhalten, eine Adaption (metaphrasis) der Acta des zeitgenössischen persischen Märtyrers Anastasios aus dem Jahr 630; Georgs Text muss kurz darauf entstanden sein, siehe Pertusi 1958; Flusin 1992 I, 191-197 (Übers. ebd. 202259); Ma. Whitby 2003, 177-181; Howard-Johnston 2010, 26.

49 Zum Genre der panegyrischen Epik und der Kontextualisierung von Georgs Werk siehe Nissen 1940, Pertusi 1959, 32-37; Frendo 1984, bes. 162-166: im 6. Jahrhundert wurde es gängig, Hexameter-Gedichten einen iambischen Prolog vorzuschalten, so geschehen etwa bei der Ekphrasis des Paulos Silentiarios. Vgl. auch Ma. Whitby 2003, 176f.: Allein Georgs De vita humana ist in Hexametern verfasst; iambische Dichtung scheint für ein Publikum einfacher zugänglich gewesen zu sein. 
frühen 7. Jahrhunderts bewegten. Sie gewähren ein einmaliges Schlaglicht auf Aushandlungsprozesse im Umfeld des kaiserlichen Palastes, der hauptstädtischen Funktionselite und des Patriarchats - etwa hinsichtlich der Rolle und Positionierung des Kaisers. ${ }^{50}$

Ebenso wie die Gedichte des Georg von Pisidien lassen sich auch die Predigten seines Zeitgenossen Theodor Synkellos als ursprünglich orale Medien qualifizieren. Der Beiname Synkellos verweist auf ein hohes kirchliches Amt, welches seinen Träger zu einem der wichtigsten Berater des Patriarchen sowie zum Mittelsmann zwischen kirchlicher und weltlicher Autorität macht. ${ }^{51}$ Theodor trat etwa als Teilnehmer einer hochrangigen Gesandtschaft auf, die während der Doppelbelagerung Konstantinopels im Jahr 626 zum Khagan der Avaren geschickt wurde, um über einen Friedensschluss zu verhandeln. ${ }^{52}$ Diese Belagerung sowie den unverhofften Sieg der römischen Verteidigung thematisiert Theodors Predigt De obsidione Constantinopolis, die kurz nach dem Ereignis vor einem hauptstädtischen Publikum gehalten wurde. ${ }^{53}$ Manche Manuskripte nennen Theodor außerdem auch als Autor einer weiteren, etwas früher zu datierenden Predigt, der Narratio in depositionem pretiosae vestis Deiparae in Blachernis. Der Text kommemoriert die Rückführung der Marienreliquie durch den Patriarchen Sergios in die Blachernenkirche außerhalb der Stadtmauern, nachdem diese angesichts avarischer Plünderungen zeitweilig hatte in Sicherheit gebracht werden müssen. ${ }^{54}$ Das verbindende Thema beider Predigten ist die Wirkmächtigkeit der Theotokos, der Muttergottes, als übernatürliche Schutzherrin einer von auswärtigen Feinden bedrohten Hauptstadt. ${ }^{55}$ Theodors Predigten sind wie einige der Gedichte des Georg von Pisidien ursprünglich als Gelegenheitsschriften zu qualifizieren; sie richten sich allerdings an eine breitere Öffentlichkeit - an die hauptstädtische Gemeinde,

50 Siehe Meier 2015, 173; zum Kaiserbild siehe vor allem die Studien von Ma. Whitby 1994, 1998, 2002. Olster 1994, 63 hat außerdem zu Recht betont, dass man Georgs Oeuvre nicht als homogenes Ganzes, sondern entlang von seinem Entstehungsprozess über zwanzig Jahre hinweg interpretieren sollte. Eine eingehende Diskussion des kommunikativen Kontextes der Gedichte findet sich unten Kap. 5.1.

$51 \mathrm{Zu}$ Theodor Synkellos siehe Howard-Johnston 2010, 146-148.

52 Siehe Chron. Pasch. AD 626 (721).

53 Howard-Johnston 2010, 147; Hurbanic 2016, bes. 272.

54 Siehe Wenger 1955, 116-123 und Av. Cameron 1979a, die einen Teil der Predigt übersetzt. Die Datierung der Predigt ist allerdings umstritten, da sie unter anderem von der Datierung der Plünderungen des Konstantinopolitaner Hinterlandes infolge eines missglückten Treffens zwischen Herakleios und dem Khagan abhängt (dazu siehe S. 206 mit Anm. 93). Während Av. Cameron 1979a, 43f. die Predigt auf 619/20 datiert, geht Mango 2000, 20 davon aus, das der Text 624/5 verfasst und vorgetragen wurde, was auch mir am plausibelsten erscheint; Wenger 1955, 123 plädiert für einen Vortrag der Predigt zwischen 620 und 625. Howard-Johnston 2010, 147 f. datiert die Predigt aus mir nicht verständlichen Gründen auf die Zeit nach der Beendigung des Perserkrieges 628; Van Dieten 1972, $20 \mathrm{f}$. setzt sie 627 an. Die Rückerstattung der Reliquie wurde am 2. Juli kommemoriert (siehe Mateos 1962, 328-321; das Typikon bildet allerdings den Zustand des späten 9. Jahrhunderts ab).

$55 \mathrm{Zu}$ der Marienverehrung siehe Baynes 1949; Av. Cameron 1978, 1979a, 1979b. 
welche darum rang, die traumatischen Erfahrungen feindlicher Belagerung anhand einer sinnstiftende Deutung zu bewältigen. ${ }^{56}$

Den Überblick über das zeitgenössische Quellencorpus aus dem hauptstädtischen Umfeld beschließen von Herakleios herausgegebene Gesetzesnovellen. Vier in griechischer Sprache verfasste Novellen sind erhaltenen, erlassen zwischen 612 und 629, die allesamt kirchliche Angelegenheiten regeln - etwa eine Begrenzung der Anzahl von Klerikern in der Hagia Sophia und der Blachernenkirche (Nov. 1 Konidaris). ${ }^{57}$ Abgesehen von dem Inhalt dieser Novellen ist auch die Entwicklung der offiziellen kaiserlichen Titulatur von Interesse, wie sie in den Protokollen nachzuvollziehen ist. ${ }^{58}$ Ein im Namen des Kaisers herausgegebenes Edikt, die Ekthesis aus dem Jahr 638, steht schließlich im Zusammenhang mit Herakleios' Bemühungen, die dogmatischen Streitigkeiten, die das Christentum spalteten, beizulegen. ${ }^{59}$

Zeitgenössische Quellen, nicht hauptstädtisch: Den kleinasiatischen Raum repräsentiert die Vita des Hl. Theodor von Sykeon, dessen eponyme Klostergründung nahe der Überlandstraße lag, die Konstantinopel mit der Provinz Syria verband..$^{60}$ Theodors Schüler Georg begann noch vor dem Tod des Heiligen im Jahr 613, an dessen Vita zu arbeiten; die Vollendung des Textes erfolgte allerdings frühestens $641 .{ }^{61}$ Die Vita liefert nicht nur wichtige Informationen zum ländlichen Leben in Galatien; angesichts der zentralen Lage des Klosters und der großen Bekanntheit des Heiligen fanden wiederholt auch Informationen von überregionaler Bedeutung Eingang in die Erzählung: So sah sich das Kloster mit feindlicher Bedrohung, meuternden Soldaten und römischen Truppenbewegungen konfrontiert. Theodor selbst stand in regem Austausch mit der weltlichen wie geistlichen Elite der Hauptstadt; in seinem Kloster in Sykeon empfing er hochrangige Besucher bis hin zu Herakleios persönlich und reiste selbst mehrfach nach Konstantinopel. ${ }^{62}$

56 Auch die Ergänzung des Akathistos-Hymnos durch ein zweites Proömium wird in der Forschung in der Regel mit der Belagerung von 626 in Verbindung gebracht: Van Dienten 1972, 19; Av. Cameron 1979b, 6, 22; Peltomaa 2001, 21f.; Peltomaa 2009, 284f., 295-297; vgl. Wellesz 1956, 152 zu einer alternativen Datierungsoption. Darüber hinaus lässt sich auch ein Hymnos auf die Kreuzerhöhung (Trypanis 1968, 149-158) im frühen 7. Jahrhundert verorten.

57 Siehe Einleitung und Übersetzung in Konidaris 1982; zur Datierung ebd. 53-60, zur Praxis der Gesetzgebung unter Herakleios siehe auch Stolte 2002.

58 Dazu siehe S. $234 \mathrm{f}$.

59 Übersetzung bei Allen 2009, 208-217; siehe dazu Kap. 6.1.3 und S. 312f.

60 Siehe Festugière 1970; Übersetzung in Dawes/Baynes 1948, 87-192, außerdem Howard-Johnston 2010, 149-151. Bei der Betrachtung des hagiographischen Genres sei außerdem auf die Wunder des Hl. Demetrios von Thessaloniki verwiesen, die das Eingreifen des Heiligen in die Geschicke der von Attacken durch Slaven und Avaren geplagten Stadt imaginieren. Die Wundererzählungen decken die Zeit von den 580er Jahren bis ca. 650 ab und bieten einen Einblick in die Geschicke des Balkans; Übersetzung und Kommentar bei Lemerle 1979/1981; Howard-Johnston 2010, 152-154.

61 Dem Autor ist der Tod des Herakleios im Jahr 641 bekannt, siehe Vit. Theod. Syk. 166.

62 Siehe vor allem Kaegi 1973. Herakleios ließ Theodors Körper kurz nach dessen Tod nach Konstantinopel überführen (Kaegi 2003, 76). 
Während die kleinasiatische Evidenz hiermit bereits ausgeschöpft ist, zeichnet sich der Nahe und Mittlere Osten durch eine höhere Dichte an überliefertem Material aus. Aus Palästina stammt eine Quelle, welche die Eroberung Jerusalems durch die Perser 614 thematisiert. Der ursprünglich griechische Text ist verloren; allein eine georgische und mehrere arabische Übersetzungen sind erhalten. ${ }^{63}$ Der Text gibt sich als Abhandlung eines Antiochos Strategos, Mönch aus der Lavra des St. Sabas nahe Jerusalem, aus. Bei genauerem Hinsehen zeigt sich allerdings, dass es sich um eine Kompilation mehrerer Komponenten handelt: Auf eine Sammlung von Informationen zur Eroberung Jerusalems, welche sich durch anti-persische und anti-jüdische Ressentiments auszeichnet und als direkte Reaktion auf das Ereignis zu verstehen ist, folgt ein Abschnitt, der sich als Augenzeugenbericht der Deportation der christlichen Gemeinde um den Patriarchen Zacharias ins persische Ctesiphon gibt. Die Quelle endet mit zwei Appendizes, die dem Text zu einem nicht näher bestimmbaren Zeitpunkt angehängt wurden: eine Aufstellung der Anzahl von Christen, die der Eroberung 614 zum Opfer gefallen waren, und ein Bericht über die Rückerstattung der Kreuzreliquie durch Herakleios im Jahr $630 .^{64}$

Aus dem näheren Umfeld von Jerusalem stammen außerdem zwei Texte, die sich um den Heiligen Anastasios den Perser drehen: eine Vita des Heiligen sowie ein Bericht über die Rückführung von dessen Reliquien aus Persien nach Palästina. ${ }^{65}$ Als Soldat im persischen Heer hatte er die Besetzung Palästinas miterlebt, desertierte allerdings kurz nach 615, konvertierte unter dem Namen Anastasios zum Christentum und ließ sich in einem Kloster außerhalb der Stadtmauern Jerusalems nieder. In Nachahmung christlicher Märtyrer früherer Jahrhunderte begab er sich zu der in Caesarea stationierten persischen Besatzung, um dort das Martyrium zu suchen. Anastasios provozierte seine Festnahme, wurde schließlich nach Persien überführt und am 22. Dezember 627 in Dastagert hingerichtet. Ein anonymer Mönch des Anastasios-Klosters verfasste während des kurzen Patriarchates des Modestos (März bis Dezember 630) die Vita des Märtyrers. ${ }^{66}$ Der zweite Text, die Translatio, kommemoriert die Rückführung von Anastasios' Leichnam aus Persien ins Anastasios-Kloster im Jahr

63 Siehe Howard-Johnston 2010, 164-167. Die einzige Übersetzung in eine moderne Sprache ist die englische von Conybeare 1910, der allerdings Passagen auslässt, die ihm als „pious ejaculations“ unwichtig erscheinen (siehe die kurze Einleitung S. 502). Eine Neubearbeitung der arabischen wie georgischen Versionen sowie eine Neuübersetzung scheint in Arbeit (Sean W. Anthony und Stephen Shoemaker), war mir allerdings noch nicht zugänglich.

64 Siehe dazu Howard-Johnston 2010, 165, 167; der Autor firmiert bisweilen auch unter dem Namen Strategios. Der Bericht von der Rückerstattung des Kreuzes scheint unter dem Eindruck des römischen Sieges über die Perser verfasst worden zu sein; von der kurz darauf folgenden Bedrohung Palästinas durch die Araber zeigt er keine Spuren. Vgl. auch Antiochus Monachus, der in der Epistula ad Eustathium (PG 89, cols. 1421-1428) berichtet, wie die Lavra des St. Sabas eine Woche vor der Einnahme Jerusalems durch Beduinen geplündert wurde, siehe die Übersetzung bei Flusin 1992 II, 177-179.

65 Siehe die Publikation von Flusin 1992 I- II, mit Einleitung, Übersetzung und ausführlicher Kontextualisierung, außerdem Howard-Johnston 2010, 169-171.

66 Siehe Flusin 1992 II, 185-193 und Text ebd. I, 40 - 91. 
631 und wurde in direkter Reaktion auf das Ereignis niedergeschrieben. ${ }^{67}$ Der Text bietet nicht nur Informationen zum Anastasios-Kult, der sich in kurzer Zeit über den gesamten Mittelmeerraum verbreiten sollte, sondern gibt auch einen umfassenden Einblick in das politisch-religiöse Klima im Palästina des frühen 7. Jahrhunderts. ${ }^{68}$

Dem Umfeld des palästinensischen Mönchtums entstammte auch Sophronios, der seit dem Beginn des 7. Jahrhunderts im gesamten Mittelmeerraum tätig war und von 634 bis zu seinem Tod 639 als Patriarch von Jerusalem amtierte. Ein ganzes Corpus an recht heterogenen Texten stammt aus seiner Feder. ${ }^{69}$ Sophronios komponierte anakreontische Gedichte - unter anderem zur Eroberung Jerusalems durch die Perser (n. 14) und der Rückkehr der Kreuzreliquie nach dem Tod des Chosroes (n. 18) - und weicht mit seiner Deutung der Geschehnisse bisweilen signifikant von der hauptstädtischen Linie ab. ${ }^{70}$ Aus seiner Zeit als Patriarch sind eine Reihe von Predigten erhalten, in denen er unter anderem das Vorrücken der Araber thematisiert, die Palästina seit 633/4 bedrohten. ${ }^{71}$ Als Vorkämpfer des chalkedonensischen Christentums stellte Sophronios sich ab den frühen 630er Jahren entschieden gegen die monoenergetisch/monotheletische Kompromissformel, mit der Herakleios die zerstrittenen christlichen Denominationen zu einigen versuchte. Aus diesem Kontext heraus entstand kurz nach seiner Erhebung zum Oberhaupt der Jerusalemer Kirche ein Synodalbrief an die anderen ökumenischen Patriarchen, mit dem er sich deutlich für das strikte Festhalten am Dogma des Konzils von Chalkedon aussprach. ${ }^{72}$

Eine letzte aus Palästina stammende Quelle, das Sefer Zerubbabel, repräsentiert schließlich die jüdische Perspektive und ist dem apokalyptischen Schrifttum zuzurechnen. ${ }^{73}$ Der enigmatische Text gibt sich als Offenbarung des post-exilischen jüdischen Führers Zerubabbel und verweist als solche auf die Ereignisse, die auf die endzeitliche Wiedererrichtung Israels und den dritten Tempel hindeuten. Der Text genoss im mittelalterlichen Judentum hohe Beliebtheit und ist in zahlreichen Manuskripten und Bearbeitungen erhalten. Die Rekonstruktion seines Ursprunges gestaltet

67 Siehe Flusin 1992 I, 95f. und Text 98-107.

68 Eine weitere Heiligenvita aus Palästina ist die des Johannes von Choziba, verfasst von dessen Schüler Antonios in den 620er Jahren. Die Vita konzentriert sich auf die Angelegenheiten um das Kloster in Choziba; siehe Einleitung und Übersetzung in Vivian/Athanassakis 1994 sowie HowardJohnston 2010, 167-169.

69 Siehe zusammenfassend Howard-Johnston 2010, 171-174; zu Sophronios außerdem Schönborn 1972; Booth 2013a.

70 Anakreontika bei Gigante 1957. Sophronios verfasste auch eine Vita des Johannes des Almosengebers, des Patriarchen von Alexandria, die allerdings nur in Form späterer Bearbeitungen erhalten ist. 71 Predigten bei Gallico 1991 und Ferrière 1999.

72 Zum Synodalbrief (mit Übersetzung) Allen 2009.

73 Siehe Einleitung und Übersetzung in Reeves 2006, 40 - 66. Zu apokalyptischem Schrifttum in der Spätantike Mango 1980, 201-217; Alexander 1985; Brandes 1990; Magdalino 2007; vgl. auch Stoyanov 2011a, 45-75 und Greisiger 2014 mit einer eingehenden Analyse der Evidenz (sowohl jüdisch als auch christlich) zum 7. Jahrhundert; zur jüdischen Perspektive Van Bekkum 2002; zu der Bedeutung von eschatologischem/apokalyptischem Gedankengut im Zusammenhang mit der Ausbreitung des Islams siehe zuletzt Shoemaker 2018. 
sich daher schwierig. In der rezenten Forschung herrscht allerdings der Konsens, dass das Sefer Zerubbabel vor dem Hintergrund der Auseinandersetzungen zwischen Römern und Persern im ersten Viertel des 7. Jahrhunderts entstand: einer Zeit, geprägt von eschatologischen Naherwartungen, als die Juden Palästinas sich kurzzeitig Hoffnung auf eine Wiedereinrichtung des Tempelkultes in Jerusalem machen konnten. ${ }^{74}$

Ähnlich wie das Sefer Zerubabbel kommentiert auch die syrische Alexanderlegende rezente politische Entwicklungen, indem sie deren Deutung in Form von Prophezeiungen in eine als autoritativ verstandene Vergangenheit projiziert. ${ }^{75}$ Bei dem Text handelt es sich um eine Bearbeitung des Stoffes des sog. Alexanderromanes, dessen Variationen in Antike und Mittelalter im gesamten Mittelmeerraum große Popularität genossen. Textimmanente Indizien lassen darauf schließen, dass die Legende in direkter Reaktion auf die erfolgreiche Beendigung von Herakleios' Feldzug gegen die Perser im syrischen Raum entstand - in einem Umfeld, das, im Gegensatz zu den miaphysitischen Gemeinden dieser Region, der hauptstädtischen Position wohlgesonnen war. $^{76}$

Dem monastischen Milieu um die Stadt Mardin ist ein syrischer, anonym überlieferter Text zuzuordnen, der nur in einem Manuskript erhalten ist und unter der Bezeichnung Chronicon ad annum 724 firmiert. Mit der Erschaffung der Welt beginnend, endet er mit der Angabe des Todes des Kaliphen Yazid II. im Jahr 724. Bei dem Manuskript handelt es sich um eine Sammlung heterogener Texte mit nur geringer Gesamtkohärenz. Einer der Textbausteine betrifft die römisch-persischen Kriege des 6 . und 7. Jahrhunderts und liefert neben wertvollen Informationen (etwa zum Treffen zwischen Herakleios und dem persischen General Shahrbaraz 629) auch absolute Datierungen; der letzte zugehörige Eintrag beschreibt die Plünderungen der Klöster bei Mardin durch arabische Truppen 635/6. Darauf folgt nur noch eine knappe Zusammenstellung kirchengeschichtlicher Eckdaten sowie schließlich eine Liste der Kaliphen bis zum oben genannten Yazid II. ${ }^{77}$ Aus dieser Konstellation wird in der Regel geschlossen, dass der Kompilator des Gesamtwerkes sich unter anderem einer Chronik bediente (bzw. diese schlichtweg kopierte), die kurz nach 636 verfasst wurde. ${ }^{78}$

74 Reeves 2006, 40 -51; siehe auch Wheeler 1991; Van Bekkum 2002 und zuletzt vor allem Greisiger 2013, bes. 361-363; Greisiger 2014, 46-62.

75 Übersetzung in Budge 1889, 144-161; zu sog. Vaticinia ex eventu siehe S. 243.

76 Siehe Reinink 1985, 2002, 2005; Greisiger 2014, 231-242. Mit der syrischen Alexanderlegende ist eine Versvariante des Materials, das sog. syrische Alexanderlied, eng verbunden (Text und Übers. in Reinink 1983). Reinink 1983, 1-15 (bes. 12) geht davon aus, dass das Alexanderlied von der Legende abhängt und kurz nach ihr entstanden ist.

77 Siehe die Teil-Übersetzung bei Palmer 1993, 13-23.

78 Vgl. die Diskussionen bei Palmer 1993, 5-12; Hoyland 1994, 118-120 und Howard-Johnston 2010, 59-66; als Autor des Materials zum 7. Jahrhundert wird ein gewisser Thomas, Presbyter in einem der Klöster bei Mardin, angenommen, der selbst im Text auftaucht (siehe etwa Howard-Johnston 2010, 64); zu Herakleios in syrischen Quellen siehe Watt 2002. 
Einen zeitgenössischen Einblick in die Geschicke Ägyptens bietet die Vita des Hl. Johannes des Almosengebers, verfasst von Leontios, dem Bischof von Neapolis auf Zypern. ${ }^{79}$ Leontios konzipierte sein Werk als Supplement einer bereits existierenden Vita, in welcher Sophronios, der spätere Patriarch von Jerusalem, die jungen Jahre des Johannes abgedeckt hatte. Während Sophronios' Vita allerdings nur noch in Form von mittelbyzantinischen Bearbeitungen erhalten ist, existiert das Supplement unabhängig davon in drei Variationen. ${ }^{80}$ Leontios konzentriert sich auf Johannes' Wirken als Patriarch von Alexandria (610-619), beschreibt dessen enge Verflechtungen mit der Familie des Herakleios und vermittelt einen Eindruck vom Vorrücken der Perser, die 619 Alexandria eroberten und Johannes zur Flucht in seine Heimat Zypern zwangen.

Aus Afrika, genauer gesagt Karthago, stammt die Doctrina Jacobi nuper baptizati, eine antijüdische Schrift, die kurz nach 634 entstand. ${ }^{81}$ Der Text gibt sich als Aufzeichnung von Debatten einer Gruppe von Juden, an deren Ende der kürzlich zwangsgetaufte Jakob seine Gesprächspartner von der Richtigkeit und Überlegenheit des christlichen Glaubens überzeugen kann. Abgesehen von Einblicken in jüdisches Leben liegt der Wert dieser Quelle in den zahlreichen konkreten Verweisen auf politische und religiöse Spannungen - sowohl zwischen Juden und Christen als auch innerchristlich -, die das gesellschaftliche Klima im Mittelmeerraum des frühen 7. Jahrhunderts prägten.

Zur Frage, wie zentrale Ereignisse der Regierungszeit des Herakleios gedeutet und tradiert wurden, geben schließlich auch zwei lateinische liturgische Texte Aufschluss, der Sermo de Exaltatione S. Crucis und die Reversio S. Crucis, deren Ursprung in den 630/40er-Jahren verortet wird. ${ }^{82}$ Als Predigt bzw. liturgische Legende begleiteten die beiden Texte den Feiertag der Kreuzerhöhung am 14. September; in ihrem Zentrum steht die Erzählung des Raubes der Kreuzreliquie durch den Perserkönig Chosroes II. und ihre Rückführung nach Jerusalem durch Herakleios. Zuletzt kam wiederholt die These auf, dass die lateinischen Texte auf ein verlorenes griechisches Original aus dem nahöstlichen Raum zurückgehen. ${ }^{83}$

Späteres 7. Jahrhundert: Für die Rekonstruktion der Geschicke Ägyptens in der ersten Hälfte des 7. Jahrhunderts ist die Chronik des Johannes, des miaphysitischen Bischofes von Nikiu im Nildelta, von großem Wert, obwohl die komplizierte Überlieferungslage - allein eine äthiopische Übersetzung ist vorhanden, die von einer arabischen Übersetzung des wahrscheinlich koptischen Originales angefertigt wurde -

79 Einleitung und Übersetzung in Festugière 1974 und Übersetzung in Dawes/Baynes 1948, 207-270. 80 Siehe Dawes/Baynes 1948, 195-198; Rapp 2004, 121 f. und Howard-Johnston 2010, 172; zu Leontios außerdem Mango 1984.

81 Siehe Übersetzung und Einleitung bei Dagron/Déroche 2010; außerdem Howard-Johnston 2010, $155-157$.

82 Siehe Borgehammar 2009; ebd. 148-160 zur umstrittenen Frage der Datierung.

83 Brandes 2002a, 35f. geht bereits von einer „totally unknown Eastern source“ aus; Borgehammar 2009, 157-160; Greisiger 2014, 132f.; siehe dazu $266 f$. 
die Arbeit mit der Quelle erschwert. ${ }^{84}$ Die Chronik beginnt mit der Erschaffung Adams und reicht bis ins Jahr 643, die Lebenszeit des Autors. Wann genau Johannes, der noch bis in die 690er Jahre aktiv war, sein Werk niederschrieb, kann nur gemutmaßt werden. ${ }^{85}$ Nachdem die Chronik sich detailliert dem Bürgerkrieg in Ägypten widmet, der durch die Revolte des Herakleios, Exarch von Karthago, ausgelöst wurde, bricht der Text im Jahr 610 ab - ein Hiat, der aller Wahrscheinlichkeit nach der Überlieferungslage geschuldet ist. Erst 640 setzt die Erzählung mit der Bedrohung und sukzessiven Eroberung Ägyptens durch die Araber wieder ein, die Johannes selbst miterlebte. Trotz des Fokus auf die Geschehnisse in Ägypten verliert der Autor überregionale politische Verflechtungen nicht aus dem Auge; den Sturz des Phokas durch Herakleios thematisiert er ebenso wie die Nachfolgestreitigkeiten nach dessen Tod im Jahr 641 und ergänzt damit entscheidend die verfügbare Informationsdichte. ${ }^{86}$

Einen weiteren Einblick in die Entwicklung von östlichem Mittelmeerraum und Nahem Osten bietet eine Geschichte Armeniens, deren Erzählung im späten 5. Jahrhundert einsetzt und sich bis in der 650er Jahre erstreckt, ergänzt durch kurze Nachrichten vom Ende des arabischen Bürgerkrieges 661. Der anonym überlieferte Text wurde mit einer „Geschichte des Herakleios“ identifiziert, die nach Angaben mehrerer mittelalterlicher Handschriften ein armenischer Bischof namens Sebeos, ein Teilnehmer des Konzils von Dvin 645, verfasst hatte. Obwohl die Forschung diese Zuschreibung wiederholt in Zweifel gezogen hat, wird die Quelle in der Regel weiterhin als Sebeos bzw. Ps.-Sebeos zitiert. Unabhängig von der Autoren-Frage kann von einer Verschriftlichung im Laufe der 660er Jahre ausgegangen werden. ${ }^{87}$ Aus der Perspektive Armeniens, der umkämpften Pufferzone zwischen den Großmächten Rom, Persien und später dem arabischen Kaliphat, entfaltet der Text ein eindrückliches Bild der politischen und religiösen Verflechtungen des 7. Jahrhunderts. Der Autor hatte offenbar Zugang zu vielfältigem Material, eventuell aufbewahrt in den Archiven von Dvin, und nutzte sowohl römische als auch persische Zeugnisse, um seine Geschichte zusammenzustellen. Bisweilen integriert er gar Originaldokumente in seinen Text, so etwa die Briefkommunikation zwischen Modestos, dem locum tenens im

84 Übersetzung des äthiopischen Textes bei Charles 1916; vgl. Hoyland 1997, 152-156 und HowardJohnston 2010, 181-189. Eine Übersetzung und Einleitung durch Phil Booth soll demnächst in der Reihe Translated Texts for Historians erscheinen.

85 Siehe Hoyland 1997, 153 und Howard-Johnston 2010, 182, die beide für eine Verschriftlichung nicht allzu lang nach 643 plädieren.

86 Neben lokalen Quellen nutzt Johannes für das 7. Jahrhundert offenbar auch hauptstädtisches Material, laut Howard-Johnston 2010, 183 wohl die Chronik von Johannes von Antiochia bzw. deren Erweiterung(en), die nicht mehr im Original erhalten ist.

87 Siehe die Einleitung in der Übersetzung von Thomson/Howard-Johnston 1999 und HowardJohnston 2010, 71-102, der die Quelle unter dem Titel „History of Khosrov“ behandelt, da er meint, in Chosroes II. die zentrale Figur der Geschichte zu erkennen. Besondere Beachtung ist der armenischen Geschichte auch zugekommen, da sie den ausführlichsten quasi zeitgenössischen und nicht-muslimischen Bericht vom Aufstieg des Islams beinhaltet; zu den armenischen und albanischen Quellen zu Herakleios siehe außerdem Howard-Johnston 2002. 
Patriarchat des von den Persern besetzten Jerusalem, und dem armenischen Katholikos Komitas. ${ }^{88}$ Während die armenische Geschichte in der Regel als verlässliche Quelle gewertet wird, erschweren allein chronologische Verwirrungen bisweilen deren Nutzung. ${ }^{89}$

Ebenfalls in armenischer Sprache verfasst ist die Geschichte Albaniens, die, anonym überliefert, von späteren Kommentatoren einem Movses Dasxuranci zugewiesen wurde, unter dessen Namen man sie in der Regel zitiert. ${ }^{90}$ Die überlieferte Form der Geschichte stammt aus dem späten 10. Jahrhundert. Untersuchungen haben allerdings deutlich gemacht, dass es sich dabei um eine Kompilation mehrerer älterer Texte handelt. ${ }^{91}$ Ein Block, der sich vor allem auch stilistisch vom Rest abhebt, behandelt die Jahre 624-682; die Entstehung dieses Textes, der seinerseits auf mehr oder weniger gut identifizierbares älteres Material zurückgreift, wurde überzeugend in das späte 7. Jahrhundert datiert. ${ }^{92}$ Ähnlich wie die Geschichte Armeniens beschreibt auch diese Quelle die Auswirkungen der Machtkämpfe zwischen Rom und Persien auf einen regionalen Zusammenhang, das kaukasische Albanien. Anhand des Textes lässt sich das Endstadium des römisch-persischen Krieges wesentlich detaillierter rekonstruieren - etwa die Allianz des Herakleios mit den Türken sowie deren Plünderung Albaniens.

Ins persische Reich führt die Chronik von Khuzistan (nach dem Herausgeber auch als Anonymus Guidi bezeichnet), die den Zeitraum vom späten 6. bis ins mittlere 7. Jahrhundert abdeckt. ${ }^{93}$ Der syrische Text entstand in Mesopotamien kurz nach dem Tod des letzten sassanidischen Großkönigs Yazdegerd III. 652 und richtet den Fokus auf die Angelegenheiten der nestorianischen Kirche, liefert darüber hinaus aber auch vereinzelte Informationen zum römisch-persischen Krieg sowie der Eroberung Persiens durch die Araber. Den bisweilen gar dokumentarischen Charakter der Armenischen und Albanischen Geschichte erreicht diese Chronik nicht; sie weist stattdessen eine Reihe anekdotenhafter Einschübe auf, etwa zum Wirken einer christlichen Elite im persischen Reich.

88 Zu den Quellen siehe Thomson/Howard-Johnston 1999 I, lxv-lxx. Howard-Johnston 2010, 80 - 86 geht davon aus, dass der Autor unter anderem das verlorene persische Kwadaynamag, das Buch der Könige, nutzte, eine Art persisches Nationalepos, das in mehreren Versionen zirkulierte und unter anderem auch in die arabische Tradition eingeflossen ist (siehe dazu auch ebd. 341-348). Von römischer Seite habe Sebeos, so Howard-Johnston, einen offiziellen Bericht von den letzten Jahren des Krieges gegen die Perser genutzt, dessen sich unter anderem auch Theophanes Confessor bediente. 89 So wird etwa das zweimalige Vorrücken der Perser bis nach Chalkedon in den Jahren 615 und 626 in Sebeos $38 \mathrm{zu}$ einem einzigen Ereignis zusammengelegt, sodass die Abläufe eines ganzen Jahrzehntes durcheinandergeraten; siehe dazu Thomson/Howard-Johnston 1999 II, $210 \mathrm{f.}$

90 Siehe die Einleitung in der Übersetzung von Dowsett 1961; Howard-Johnston 2002 und ders. 2010, $105-128$.

91 Sofern seine Quellen unabhängig überliefert sind, zeigt sich, dass der Kompilator nur minimal in das ihm zugängliche Material eingriff, siehe Howard-Johnston 2010, $107 \mathrm{f}$.

92 Siehe Howard-Johnston 2010, 108-113 mit Bezug auf Akopjan 1978 (non vidi).

93 Übersetzung in Nöldeke 1893; siehe Hoyland 1997, 182-189 und Howard-Johnston 2010, 128-135. 
Aus dem westlichen Teil des Mittelmeerraumes, genauer gesagt dem fränkischen Gallien, stammt die Chronik des Fredegar, die in den 650er Jahren auf Latein verfasst wurde. Auf die Zusammenstellung von älterem Material, beginnend mit der Erschaffung Adams, folgt ein Bericht, der sich vom späten 6. Jahrhundert bis in die 640er Jahre erstreckt und primär die Angelegenheiten des fränkischen Reiches und dessen Beziehungen zu seinen Nachbarn thematisiert. ${ }^{94}$ Vereinzelt liefert der Text auch Notizen zu den Entwicklungen im Osten, etwa Herakleios' Sieg über die Perser und dem Verlust der Ostprovinzen an die muslimischen Araber, aufgrund derer sich erahnen lässt, in welcher Form Informationen in einem inzwischen stark fragmentierten Mittelmeerraum zirkulierten. ${ }^{95}$

Die westsyrische Tradition: Die Quellen, deren Autoren bzw. Kompilatoren zumindest das mittlere 7. Jahrhundert noch selbst miterlebt haben, sind hiermit ausgeschöpft. Allerdings existiert eine ganze Reihe späterer Texte, die entscheidend zur Rekonstruktion des Untersuchungsgegenstandes beitragen, sowohl aus dem hauptstädtischen Umfeld als auch aus Gegenden, die nach den arabischen Eroberungen nicht mehr zum römischen Reich gehörten. Eine Schlüsselrolle in der späteren Überlieferung kommt der sog. westsyrischen Tradition zu. Deren Hauptvertreter sind die Universalgeschichte des Michael Syrus, des jakobitischen Patriarchen von Antiochia (1166 - 1199), und die anonyme Chronik, die bis ins Jahr 1234 reicht. Beide Werke nutzen erwiesenermaßen für das 7. und 8. Jahrhundert eine gemeinsame Quelle: die verlorene Geschichte des Dionysios von Tel-Mare, der von 818 bis 845 als jakobitischer Patriarch von Antiochia amtierte. ${ }^{96}$ Die Überlieferungskette lässt sich allerdings noch weiter zurückverfolgen: Dionysios seinerseits hatte - wie er in seiner Einleitung, die bei Michael Syrus erhalten ist, selbst festhält - die Geschichte des Theophilos von Edessa vorliegen, eines maronitischen (also monotheletischen) Christen, der bis zu seinem Tod 785 als Gelehrter am abbasidischen Hof in Bagdad tätig war. Theophilos' Schrift fand allerdings nicht nur in der syrischsprachigen Tradition Anwendung: Sowohl der hauptstädtische Chronograph Theophanes Confessor nutzte sie (offenbar in griechischer Übersetzung) im frühen 9. Jahrhundert als auch Agapios, der arabisch schreibende, melkitische Bischof von Manbij (syr. Hierapolis), im mittleren 10. Jahrhundert. Ein Vergleich der oben aufgeführten Derivate macht es möglich, Theophilos' Geschichte zumindest zu einem gewissen Grad zu rekonstruieren. ${ }^{97}$ Hinsichtlich des frühen und mittleren 7. Jahrhunderts lag Theophilos' Fokus auf den kriegerischen Auseinandersetzungen zwischen den Großmächten Rom und Persien sowie dem

94 Siehe die Einleitung in der Übersetzung von Wallace-Hadrill 1960 und Hoyland 1997, 216-219; zuletzt Esders 2009, 241-244.

95 Siehe Esders 2009, 2018. Ähnliche Informationen finden sich auch in einer spanischen Chronik, die das Werk des Johannes von Biclaro von 602 bis 741 weiterführt, siehe Howard-Johnston 2010, 432f.; zu Fredegar außerdem Collins 2007.

96 Siehe Palmer 1993, 84-104; rekonstruierter Text ebd. 105-221.

97 So geschehen durch Hoyland 2011; siehe dessen Einleitung, außerdem ders. 1997, 631-671 und Howard-Johnston 2010, 192-236. 
Vorrücken der Araber, wobei er sich auf die Gegenden konzentrierte, die ihm am besten bekannt waren: Syrien, das römische Mesopotamien sowie besonders seine Heimatstadt Edessa. Weitere Kriegsschauplätze wie etwa Armenien oder Ägypten behandelte er dagegen nur kursorisch. Die von Theophilos transportierten Informationen werden in der Regel als verlässlich gewertet. Problematisch ist seine eher sparsame Angabe von absoluten Daten, was bei seinen Benutzern, die, wie etwa Theophanes Confessor, eine striktere annalistische Struktur $\mathrm{zu}$ bedienen hatten, bisweilen zu Verwirrung führte. ${ }^{98}$

Mittelbyzantinisch, hauptstädtisch: In der Forschung zum frühen 7. Jahrhundert erweisen sich zwei hauptstädtische Geschichtswerke der mittelbyzantinischen Zeit als zentral. Nikephoros, der Autor des Breviarium, durchlief eine zivile Karriere in der kaiserlichen Verwaltung, bevor er im Jahr 806 unerwartet zum Patriarchen von Konstantinopel aufstieg. Aufgrund seines Engagements für die ikonophile Partei wurde er von Kaiser Leon V. abgesetzt und ins Exil geschickt, wo er 828 verstarb. ${ }^{99} \mathrm{Zu}$ welchem Zeitpunkt Nikephoros, aus dessen Feder auch eine Reihe an theologischen Traktaten stammt, sein Geschichtswerk verfasste, ist nicht mit Sicherheit zu rekonstruieren; in der Regel wird aber angenommen, dass er sich diesem Unterfangen vor seiner Erhebung zum Patriarchen widmete. ${ }^{100}$ Das Breviarium, das stilistisch an antike Geschichtsschreibung anknüpft, beginnt im Jahr 602 mit dem Sturz des Maurikios, widmet sich ausführlich der Regierung des Herakleios und führt, nachdem es die Regierung von dessen Enkel Konstans II. beinahe komplett übergangen hat, die Erzählung von 668 bis ins Jahr 769 weiter. ${ }^{101}$ Der Hiat von über zwanzig Jahren lässt darauf schließen, dass Nikephoros' Quelle nach Herakleios Tod im Jahr 641 abbrach und dass erst ab der Regierung von Konstans' Sohn Konstantin IV. wieder Material zur Verfügung stand. ${ }^{102}$ Nikephoros bediente sich für das frühe 7. Jahrhundert also offenbar einer Quelle mit Fokus auf die politischen Zusammenhänge der Hauptstadt, die kurz nach Herakleios’ Tod entstanden war. ${ }^{103}$ Über das Breviarium eröffnet sich somit der Zugang zu zeitgenössischem Material, das eine ganze Reihe an einzigartigen In-

98 Siehe Howard-Johnston 2010, $202 \mathrm{f}$.

99 Zum Breviarium siehe die Einleitung der Übersetzung von Mango 1990; außerdem Speck 1988, 195-497, Hoyland 1997, 432- 434 und Howard-Johnston 2010, 237-267

100 Mango 1990, bes. 12 und Howard-Johnston 2010, $242 \mathrm{f}$.

101 Damit könnte das Breviarium als Fortsetzung der Geschichte des Theophylakt Simokattes konzipiert worden sein, deren Erzählung mit dem Sturz des Maurikios abbricht; siehe Howard-Johnston 2010, 242.

102 Bisweilen wurde angenommen, dass der abrupte Bruch dem Umstand geschuldet ist, dass an dieser Stelle ein Folio verloren gegangen ist, auf dem die Erzählung der Nachfolgestreitigkeiten mit dem Sturz von Heraklonas und Martina und der Alleinherrschaft des Konstans II. zu Ende gebracht wurde, siehe Mango 1990, $14 \mathrm{f}$., der sich allerdings dagegen ausspricht.

103 Siehe Mango 1990, 12-14; Howard-Johnson 2010, 248 ist der Meinung, dass es sich bei der hauptstädtischen Quelle um die zweite Fortsetzung des Johannes von Antiochia handelt; Zuckerman 2013, 206-209 geht davon aus, dass Nikephoros für seinen Bericht der Nachfolgestreitigkeiten nach Herakleios’ Tod eine im Exil verfasste Schrift des Patriarchen Pyrrhos nutzte. 
formationen transportiert. Nutzt man Nikephoros zur Rekonstruktion von Ereigniszusammenhängen, ist dennoch Vorsicht geboten, da er seine Quellen offenbar nicht schlichtweg kopierte, sondern an sein Bedürfnis nach stilistischer Feinheit anpasste. Der relativen Chronologie - absolute Daten liefert der Text so gut wie keine - ist dabei nur unter Vorbehalt zu vertrauen, da Nikephoros zeitliche Abfolgen erwiesenermaßen zugunsten einer thematischen Ordnung vernachlässigte. ${ }^{104}$

Die Chronographie des Theophanes Confessor, eines Zeitgenossen des Nikephoros, entstand einige Jahrzehnte nach dem Breviarium. ${ }^{105}$ Aus einer hochrangigen und wohlhabenden Familie stammend entschied sich Theophanes früh für eine monastische Laufbahn und gründete schließlich selbst das Kloster von Megas Agros in Bithynien. Wie Nikephoros hielt auch er am ikonophilen Dogma fest, fiel den Verfolgungen des Kaisers Leon V. zum Opfer und verstarb 818 in Haft. Während das Breviarium die Form einer diskursiven Erzählung einnimmt, wählte Theophanes die annalistische Struktur, die Jahr für Jahr mit absoluter Datierung abarbeitet. Sein Werk, das mit der Erhebung Diokletians im Jahr 284 beginnt und bis 813 reicht, gibt sich als Fortsetzung einer Welt-Chronik des Georg Synkellos. Im Vergleich zu anderen hauptstädtischen Quellen geht Theophanes’ Blick, sofern ihm Material zur Verfügung stand, verhältnismäßig weit über das Umfeld Konstantinopels hinaus. Weite Teile des Textes lassen sich mit hier bereits behandeltem Material abgleichen: Theophanes nutzte für das frühe 7. Jahrhundert erwiesenermaßen Theophylakt Simokattes, Johannes von Antiochia, Theophilos von Edessa, die hauptstädtische Quelle, welche auch die Grundlage für Nikephoros’ Breviarium bildete, und die Gedichte des Georg von Pisidien. ${ }^{106}$ Eine Reihe an Informationen - etwa zu Herakleios' Kampagnen gegen die Perser ab 624 - sind jedoch allein in der Chronographie überliefert. Theophanes stand also offenbar einschlägiges Material zur Verfügung; die Vermutung, dass es sich dabei um offizielle Felddepeschen handelte, die in regelmäßigen Abständen vom Kriegsschauplatz zur Berichterstattung nach Konstantinopel geschickt wurden, ist durchaus plausibel. ${ }^{107}$ Trotz Theophanes’ enormem Quellenwert dürfen gewisse Probleme, vor allem die Chronologie betreffend, nicht übergangen werden:

104 Vgl. Howard-Johnston 2010, 250 - 256.

105 Zur Chronographie siehe die Einleitung der Übersetzung von Mango/Scott 1997, außerdem Speck 1988, 51-193, Hoyland 1997, 428 - 432 und Howard-Johnston 2010, 268-312.

106 Vgl. Howard-Johnston 2010, 274-279, 295-299. Der Vergleich mit erhaltenen Quellen zeigt, dass Theophanes zumindest inhaltlich meist nur in geringem Maße in sein Material eingriff. Zur HerakleiosRezeption bei Theophanes siehe Sirotenko 2018.

107 Howard-Johnston geht noch weiter und stellt die These auf (zuletzt 2010, 284-295; ähnlich 1992), dass es sich bei Theophanes’ Quelle um eine offizielle Geschichte von Herakleios’ Feldzügen gegen die Perser handelte, verfasst von Georg von Pisidien, in der Prosa-Passagen durch Vers-Material angereichert wurden. So verlockend diese Hypothese auch sein mag, überzeigt sie doch im Detail nicht; vgl. Ma. Whitby 2002, 168-172. 
Das annalistische Schema gab einen strengen Rahmen vor, in den der Autor eine Vielzahl von Quellen, die oft keine absolute Datierung lieferten, einpassen musste. ${ }^{108}$ Aus dem mittleren 10. Jahrhundert stammt schließlich das Zeremonienbuch, das vom Kaiser Konstantin Porphyrogennetos angefertigt bzw. in Auftrag gegeben wurde. ${ }^{109}$ Neben entindividualisierten Schilderungen zeremonieller Gepflogenheiten rund um den oströmischen Kaiser und das hauptstädtische Palastumfeld schließt die Kompilation auch Berichte konkreter Ereignisse mit ein, von denen sich vier in der Regierungszeit des Herakleios verorten lassen. ${ }^{110}$ Dem Kompilator scheinen zeitgenössische Aufzeichnungen aus dem frühen 7. Jahrhundert vorgelegen zu haben, die ohne nennenswerte Überarbeitungen in dem mittelbyzantinischen Text erhalten geblieben sind.

Arabisch-sprachig: Zuletzt sei eine Reihe von arabischsprachigen Quellen erwähnt, die in der Analyse allerdings nur geringen Platz einnehmen werden. Die um die Wende vom 9. zum 10. Jahrhundert verfasste Chronik von Seert befasst sich mit der Geschichte der nestorianischen Kirche bzw. des nestorianisch-monastischen Milieus, ordnet diese aber in den Rahmen großflächiger politischer Entwicklungen ein. ${ }^{111}$ So wird nicht nur das Verhältnis der nestorianischen Christen zu den persischen Großkönigen, in deren Hoheitsgebiet die Gemeinden ansässig waren, thematisiert, sondern auch deren Verwicklungen in die weitgreifenden Machtverschiebungen des frühen 7. Jahrhunderts.

Sa'id ibn Batriq stammte aus dem ägyptischen Fustat und wurde 935 unter dem Namen Eutychios zum melkitischen (chalkedonensischen) Bischof von Alexandria ernannt. Seine Annalen - in weiten Teilen eine Kompilation älterer Quellen - geben sich als Universalgeschichte, widmen sich aber besonders ausführlich den politischen Umbrüchen im östlichen Mittelmeerraum des späten 6. und 7. Jahrhunderts; die Erzählung endet bald nach der Eroberung Ägyptens durch die Araber. ${ }^{112}$ Auf die Annalen des arabisch schreibenden Christen Agapios, der ausgiebig von der verlorenen Geschichte des Theophilos von Edessa Gebrauch machte, wurde bereits an früherer Stelle verwiesen. ${ }^{113}$

Die Annalen des in Bagdad wirkenden Gelehrten Al-Tabari, verfasst ebenfalls im frühen 10. Jahrhundert, sind eines der bedeutendsten arabisch-islamischen Geschichtswerke. Sein Bericht von Aufstieg und rasantem Fall des sassanidischen Rei-

108 Theophanes' relative wie absolute Chronologie muss also stets mit Vorsicht behandelt werden. Vgl. die Auflistung von Fehlern bei Howard-Johnston 2010, 279-284; zur generellen Problematik der Datierungsangaben ab der Regierung des Phokas siehe Mango/Scott 1997, lxvif.

109 Siehe die Einleitung in der Übersetzung von Moffat/Tall 2012.

110 De cerim. 2.27-30.

111 Siehe die Übersetzung von Scher 1908-1919, Howard-Johnston 2010, 324-331 und ausführlich Wood 2013. Teile des Manuskriptes sind verloren; erhalten sind die Jahre 250-423 und 483-650.

112 Siehe die Einleitung in der Übersetzung von Bredy 1985, außerdem Howard-Johnston 2010, 331341.

113 Siehe Howard-Johnston 2010, 196. 
ches - entsprechend auch vom römisch-persischen Krieg im frühen 7. Jahrhundert ist von besonderem Wert, da er ausgiebig Gebrauch von älteren Quellen macht, die im Original verloren sind. ${ }^{114}$

Im späten 11. Jahrhundert entstand schließlich die Geschichte der Patriarchen von Alexandria des koptischen Christen Mawhub ibn Mansur ibn Mufarrij, der für sein Vorhaben Material aus Klosterbibliotheken zusammentrug und ins Arabische übersetzte. ${ }^{115}$ Ihm lag unter anderem eine Sammlung von Viten koptischer Patriarchen vor, verfasst im frühen 8. Jahrhundert durch einen Mönch Georg. Die Vita des Patriarchen Benjamin (623-662) vermittelt ein Bild der arabischen Eroberung Ägyptens aus der Perspektive der miaphysitisch/koptischen Bevölkerung, für die der Rückzug der römischen Zentralmacht zumindest zeitweise eine Verbesserung ihrer Situation darstellte. ${ }^{116}$

114 Siehe Howard-Johnston 2006, VI und ders. 2010, 366-369 ausführlich zu Al-Tabaris Quellen. 115 Siehe die Einleitung der Übersetzung von Evetts 1907-1910 und Howard-Johnston 2010, 315 - 323. $116 \mathrm{Zu}$ den Patriarchenviten des Georg siehe Howard-Johnston 2010, 316-323. 


\section{Hauptstädtische Monarchie und militärischer Sektor}

Um die Dynamiken des frühen 7. Jahrhunderts in ihrer Entwicklungslogik nachvollziehen zu können, beginnt diese Untersuchung mit einem eingehenden Blick auf die Strukturmerkmale und Funktionsmechanismen der oströmischen Monarchie in der Spätantike; der Fokus liegt dabei auf zwei Faktoren, die sich in der Analyse als zentral erweisen werden, nämlich auf der Hauptstadt und dem Militär. Die Entwicklung der oströmischen Monarchie des 5. und 6. Jahrhunderts wird von der historischen Forschung in der Regel als Erfolgsgeschichte erzählt. Vor allem im Vergleich zum weströmischen Reich, dessen letzter Kaiser, Romulus Augustulus, im Jahr 476 vom Heermeister Odoaker abgesetzt wurde, erscheint das ungebrochene Fortbestehen römischer Monarchie in Konstantinopel so bemerkenswert wie erklärungsbedürftig. Neben der Betonung kontingenter Faktoren, etwa dem Umstand, dass die militärischen Bedrohungen sich im Osten als weniger gravierend und ressourcenzehrend erwiesen als im Westen, wurden zuletzt auch verstärkt strukturbezogene Erklärungsmuster für die divergierende Entwicklung von ost- und weströmischem Reich angebracht. ${ }^{1}$

Seit Arkadios (395-408) etablierte sich Konstantinopel mit seinen sesshaften und unkriegerischen Kaisern als Zentrum und Fokuspunkt machtpolitischen Geschehens. In der Stadt am Bosporus befand sich nicht nur der kaiserliche Palast; sie beherbergte auch den oströmischen Senat und eines der fünf ökumenischen Patriarchate. Mit der fortschreitenden räumlichen wie ideellen Bindung der oströmischen Kaiser an ihre Hauptstadt ging eine Erweiterung monarchischer Handlungsspielräume und Positionierungsoptionen einher. Während im Westen des Reiches weitgehend unabhängige Feldherren die Hoheit über die Truppen monopolisierten und die Kaiser bisweilen zu bloßen Platzhaltern herabstuften, konnten sich die oströmischen Monarchen von ihrem Sitz in Konstantinopel aus weitestgehend gegenüber dem Militär behaupten. In einem zunehmend christlich geprägten Deutungsrahmen etablierten sich Formen und Verfahren symbolischer Kommunikation, welche die Interaktion zwischen den Kaisern und ihren Untertanen strukturierten. Die Sakralisierung der kaiserlichen Persona und die Liturgisierung von Interaktionsformen ermöglichte es selbst vordergründig schwachen Kandidaten auf dem Thron, ihre monarchische Autorität zu wahren, sich $\mathrm{zu}$ einem gewissen Grad gegen destruktive Einflüsse $\mathrm{zu}$ immunisieren und ihre

\footnotetext{
1 Die Forschung zur oströmischen Monarchie der letzten Jahrzehnte ist enorm vielfältig; die verschiedenen Aspekte werden im Folgenden genauer beleuchtet. Als zentral in der deutschsprachigen Forschung haben sich die Arbeiten von Diefenbach (1996, 2002), Meier (bes. 2012) und Pfeilschifter (2013) erwiesen. Zu den Gründen für das Scheitern der weströmischen Monarchie siehe zusammenfassend Flaig 1997, 23-26; zum weströmischen Reich im Allgemeinen siehe McEvoy 2013 und Börm 2018. Diefenbach 2019, 78-92 hat zuletzt das Verhältnis der Kaiser des 4. und 5. Jahrhunderts zu Rom einer Revision unterzogen.
}

Ә OpenAccess. ( 2021 Nadine Viermann, publiziert von De Gruyter. (c) BY Dieses Werk ist lizenziert unter der Creative Commons Attribution 4.0 International. https://doi.org/10.1515/9783110711356-003 
Herrschaft zu sichern. Ein Kaiser, der eine direkte Verbindung zu Gott beanspruchte und dessen Herrschaft als Mimesis der göttlichen verstanden wurde, konnte nicht zuletzt gegenüber kirchlichen Instanzen eine verhältnismäßig souveräne Position behaupten. Die Position als Vorkämpfer des orthodoxen Glaubens wurde sowohl von den Kaisern betont als auch von der Hauptstadt eingefordert. ${ }^{2}$ Selbst krisenhafte Zustände, wie etwa in der zweiten Hälfte des 5. Jahrhunderts, als auch in Konstantinopel mächtige Heermeister die Kaiser zu überwältigen drohten, konnten anhand des praktischen wie diskursiven Instrumentariums, welches diese hauptstädtische Konfiguration von Monarchie bereitstellte, überwunden und wieder in stabilere Bahnen gelenkt werden. ${ }^{3}$

Der Bedeutungszuwachs Konstantinopels nicht nur als Residenz-, sondern als Hauptstadt zeitigte Auswirkungen darauf, welche Gruppen sich an machtpolitischen Entscheidungsfindungen aktiv beteiligten bzw. sich in derartigen Zusammenhängen als relevant erwiesen: Die Akzeptanz der oströmischen Senatsaristokratie, soweit sie als Funktionselite in Konstantinopel ansässig war, und des hauptstädtischen Volkes kristallisierten sich als maßgeblich heraus; um seine Position zu sichern, musste der Kaiser diese Gruppen mit kommunikativen Mitteln an sich binden. ${ }^{4}$ Das in den Provinzen stationierte Heer dagegen, das noch im 3. und 4. Jahrhundert die Aushandlung monarchischer Herrschaft maßgeblich bestimmt hatte, verlor angesichts der Zentralisierung politischer Entscheidungsprozesse - im Gegensatz zum Westen - zunehmend an Relevanz..$^{5}$ Gemäß Rene Pfeilschifter zeichnete sich das oströmische Reich des 5. und 6. Jahrhunderts durch eine „strukturelle Trennung“ zwischen „drinnen und draußen“ aus. ${ }^{6}$ Monarchische Herrschaft sei während dieser Phase allein im Mikrokosmos Konstantinopel ausgehandelt worden; was außerhalb der Stadtmauern lag, die unter Theodosios II. zu einem kaum bezwingbaren Verteidigungswall ausgebaut worden waren, verlor an Bedeutung: „Das übrige Riesenreich, der ,Rest“, wenn man so will, er gehörte zum politischen System nicht dazu. ${ }^{\text {“7 }}$ Dem Heer erkennt Pfeilschifter folgerichtig die Stellung als Akzeptanzgruppe ab. Während im Westen die Institution des römischen Kaisertums dem Druck einer nichtrömischen Militärelite erlag, ermöglichte die Bindung an Konstantinopel die „Rettung des Kaisertums vor der Dominanz des eigenen Militärs“. ${ }^{8}$

2 Zur Sakralisierung des christlichen Kaisers siehe Martin 1984; Diefenbach 1996, bes. 39; Meier 2003c; Pfeilschifter 2013, 76-85; Leppin 2013; zur Liturgisierung der Interaktionsformen siehe Diefenbach 2002; Meier 2016; ders. 2017, $534 \mathrm{f}$.

3 Zum 5. Jahrhundert siehe Meier 2012, 206-222.

4 Zum Begriff der Akzeptanz und der Akzeptanzgruppe siehe Flaig 1992, bes. 174-207; in Übertragung auf die Spätantike siehe ebd. 1997; Diefenbach 1996, 35; Pfeilschifter 2013, 1-38.

5 Zum Kaiser und der Armee im 3. und 4. Jahrhundert siehe Hebblewhite 2017.

6 Pfeilschifter 2013 und ders. 2014 (Zitat S. 130 und im Titel des Aufsatzes).

7 Zitat Pfeilschifter 2014, 119; zur Stadtmauer als Faktor bei der Abschottung Konstantinopels ebd. 119-130.

8 Zitat Pfeilschifter 2013, 22. Vgl. Martin 1997, 53: „Zwar blieb auch im Osten das Heer eine wichtige Grundlage kaiserlicher Gewalt und spielte die Selbstdarstellung des Kaisers als Sieger weiterhin eine 
Obwohl ich nicht in Frage stelle, dass die Bindung des Kaisers an Konstantinopel entscheidend dazu beitrug, das Überleben der Institution Kaisertum im Osten des Reiches zu sichern, soll im Folgenden die These von der Marginalisierung des militärischen Sektors einer Revision unterzogen werden. Dabei wähle ich eine Perspektive, welche die Zuschreibung von politischer Wirkmächtigkeit nicht allein auf die Unterscheidung zwischen ,Innen“ und ,Außen` zurückführt. Um das Phänomen ,hauptstädtische Monarchie‘ zu ergründen, betont diese Arbeit die konstante Interdependenz von interner und externer Sphäre. Das fortifikatorische Bollwerk im Westen der Stadt mochte zwar zuverlässig vor bewaffneten Eindringlingen schützen, stellte allerdings nicht zwangsläufig ein Hindernis für machtpolitische Impulse dar. Während der hier untersuchten Zeitspanne konnte monarchische Herrschaft allein in Konstantinopel wirksam gemacht werden, wie Pfeilschifter eindrücklich gezeigt hat: Kaiser war derjenige, der die Hauptstadt kontrollierte bzw. von den dort ansässigen Gruppen akzeptiert wurde. Die Faktoren, die machtpolitische Prozesse und damit Möglichkeiten und Grenzen monarchischer Herrschaft bedingten, schlossen allerdings einen wesentlich breiteren Radius bzw. Referenzrahmen ein - nicht nur ideell, sondern auch praktisch. Obwohl die Befestigungsanlagen der Stadt dem Kaiser einen weitreichenden Schutz vor militärischen Übergriffen boten, heißt das nicht, dass es keine Wechselwirkungen zwischen Hauptstadt und Reich, zwischen Kaiser und dem Militär mehr gab.

Die im folgenden dargelegte Perspektive dient dazu, den Blick auf die Remilitarisierung des Kaisertums durch Herakleios im frühen 7. Jahrhundert zu schärfen und in ihrer Entwicklungslogik aufzuarbeiten. Angesichts der Funktion dieses Kapitels für die Arbeit im Ganzen beschränke ich mich darauf, die grundlegenden Charakteristika der Interdependenz zwischen hauptstädtischer Monarchie und militärischem Sektor herauszuarbeiten; eine kleinteilige und quellenbasierte Analyse konkreter Konstellationen kann nur in Ausnahmefällen geleistet werden. ${ }^{9}$

\subsection{Vom Heerführer zum sesshaften Kaiser}

Anders als ihre Vorgänger zogen die oströmischen Kaiser seit Arkadios nicht mehr persönlich in den Krieg. Die Herausbildung einer hauptstädtischen Konfiguration von Monarchie wurzelte also in einem Bruch mit etablierten monarchischen Verhaltensformen. Untersucht man die Interdependenz zwischen hauptstädtischer Monarchie

große Rolle, aber das Kaisertum wurde, vor allem wegen der dauernden Residenz in Konstantinopel, in einen umfassenderen Beziehungszusammenhang eingeordnet.“

9 Außerdem sei darauf hingewiesen, dass im Folgenden auf eine eingehende Untersuchung bzw. Berücksichtigung der Prozesse im Westen des Reiches verzichtet wird. Die Eigenheit der politischen Konfiguration in Konstantinopel, deren Charakteristika oben bereits kurz vorgestellt wurden, erlaubt eine derart einseitige Herangehensweise; einzelne Querverweise auf den Westen werden höchstens genutzt, um die im Osten beobachtbaren Phänomene noch präziser zu charakterisieren. 
und militärischem Sektor, so kommt man kaum umhin zu fragen, warum die oströmischen Kaiser über zwei Jahrhunderte hinweg nicht mehr als Feldherren agierten.

Die Funktion des Kaisers als Imperator, als Oberbefehlshaber der Truppen, war römischer Monarchie von Beginn an inhärent. Bei der Einrichtung des Prinzipats durch Augustus basierte die Autorität des Oberhauptes der römischen Res publica unter anderem in seiner Weisungsgewalt über das Heer. Indem Augustus die republikanische Amts- bzw. Ehrentitulatur, Imperator, als festen Namensbestandteil annahm, monopolisierte er die Möglichkeit militärischen Triumphes für sich und seine Nachfolger. Die Position des Imperator stand dabei in Bezug zu dem Ideal der Propagatio imperii - der Erweiterung der Grenzen des römischen Reiches mit kriegerischen Mitteln. ${ }^{10}$ Nachdem im 1. und 2. Jahrhundert die Intensität der persönlichen Präsenz des Imperators auf den Schlachtfeldern variiert hatte, verschob sich der Fokus kaiserlicher Aktivität ab dem 3. Jahrhundert auf die Sicherung der Reichsgrenzen, die vermehrt externen Bedrohungen ausgesetzt waren. Die Kaiser, die sich nun fast ausnahmslos aus dem Heer rekrutierten, verbrachten einen Großteil ihrer oft kurzen Regierungszeit bei den in den Provinzen stationierten Truppen; das Heer gewann damit als maßgeblicher Faktor für kaiserliche Herrschaft und Herrschaftssicherung gegenüber den vorigen Jahrhunderten noch an Relevanz. Auch das Tetrarchische System und das Residenzkaisertum des 4. Jahrhunderts richteten sich in weiten Teilen nach den Erfordernissen der Grenzsicherung und ermöglichten die Präsenz zumindest eines Augustus bzw. Caesars an den jeweiligen militärstrategischen Brennpunkten. Mit der Regierung des Theodosios I. begann sich das Blatt allerdings zu wenden: Sein Ausbau Konstantinopels als Hauptstadt, die Rom gleichwertig war, stellte die Weichen für die darauffolgenden Jahrhunderte, in denen die Kaiser des oströmischen Reiches persönliche militärische Aktivität einstellten. ${ }^{11}$ Den Titel des Imperators indes behielten auch die sesshaften Kaiser; Sieghaftigkeit blieb integraler Bestandteil kaiserlicher Selbstdarstellung, wurde jedoch von persönlicher kriegerischer Aktivität abgekoppelt und vielmehr als dem Herrscher inhärente Qualität konzipiert. Der unkriegerische Kaiser avancierte zum ewigen Sieger. ${ }^{12}$ Die Soldaten wurden weiterhin auf den Augustus als obersten Dienstherrn eingeschworen - mit dem Unterschied, dass dieser nicht mehr mit ihnen auf dem Schlachtfeld stand, sondern als gotterwählter Herrscher in Konstantinopel für das Wohl seiner Untergebenen betete. ${ }^{13}$

10 Zur militärischen Persona des Augustus siehe Havener 2016.

11 Siehe den Überblick zu „Imperial Involvement in Warfare“ bei Lee 2007, 21-37; zur wachsenden Bedeutung Konstantinopels seit Theodosios I. siehe Maier 2019, 435-441 (architektonischer Ausbau der Stadt), 442-449 (Stabilisierung von Macht); zu der Entwicklung christlich-römischer Monarchie im 4. Jahrhundert siehe auch Leppin 2017.

12 Maier 2019, 451-462 zur Entwicklung vom basileus polemikos zum basileus niketes; Diefenbach 1996, 58; Meier 2009, 260; Pfeilschifter 2016, 4 zur Sieghaftigkeit des sesshaften Kaisers; zur Siegesideologie der hauptstädtischen Monarchie siehe Lee 2007, 37-50.

13 Zum betenden Kaiser siehe Pfeilschifter 2013, 223 und ders. 2014, 140 f. (Beispiel: in Bezug auf den frommen Theodosios II. siehe etwa Sokr. 7.18.15-18). 
Johannes Lydos vermerkte in seiner Schrift De magistratibus, verfasst um die Mitte des 6. Jahrhunderts, dass Theodosios I. seinen Söhnen aufgrund von deren ungeeigneter Kondition per Gesetz verboten habe, persönlich in den Krieg zu ziehen; ${ }^{14}$ auch Arkadios habe in Hinblick auf seinen minderjährigen Sohn Theodosios II. an dieser Regelung festgehalten. Daraus sei ein generelles Gesetz hervorgegangen, welches den römischen Kaisern verbot, in den Krieg zu ziehen, und die Kriegsführung stattdessen den Generälen, den $\sigma \tau \rho \alpha \tau \eta$ oú, übertrug. ${ }^{15}$ In der Forschung herrscht weitgehender Konsens darüber, dass es ein derartiges Gesetz nicht gegeben hat. Bei der Notiz des Johannes handelt es sich wohl vielmehr um den Versuch, eine retrospektiv plausible Erklärung für den Paradigmenwechsel im frühen 5. Jahrhundert zu etablieren - eine Erklärung dafür, dass die römischen Kaiser aufhörten, persönlich in den Krieg zu ziehen, und dass auch diejenigen Kaiser, die - im Gegensatz zu Arkadios und Theodosios II. - angesichts militärischer Erfahrung durchaus als Befehlshaber qualifiziert gewesen wären, nach ihrer Krönung in Konstantinopel blieben. ${ }^{16}$ Die hier umrissene Entwicklung scheint also nicht nur aus Sicht der modernen Geschichtswissenschaft bemerkenswert und erklärungsbedürftig.

Felix K. Maier hat in seiner Habilitationsschrift herausgearbeitet, dass die Konzentration auf Konstantinopel als Haupt- und Residenzstadt bereits mit Theodosios I. eingeleitet wurde, dass der Rückzug seiner Nachfolger also nicht allein mit dem Umstand zu erklären ist, dass anstelle von kriegserfahrenen Männern deren minderjährige Söhne auf dem Thron saßen. ${ }^{17}$ Als Grund für das Sesshaftwerden der ost-

14 Joh. Lyd. De mag. 2.11.

15 Joh. Lyd. De mag. 3.41. Die Passage schildert zunächst, wie Konstantin I. die Prätorianergarden auflöste; die Heereseinheiten wurden unter das Kommando der Comites bzw. Generäle (strategoi) gestellt und die Palastgarden unter die Aufsicht des Magister officiorum: „Und solange es der Fall war, dass die Kaiser persönlich in die Kriege auszogen, hatte das Amt einige Kraft und Macht, und wenn auch nicht so große, dann doch zumindest mehr als die anderen. Von dem Zeitpunkt aber, als es geschah, dass der letzte Theodosius gerade als Kind die Kaiserwürde annahm und er gemäß der Gesetzgebung seines Vaters den Kriegen nicht beiwohnen durfte, und als es durch ein allgemeines Gesetz verhindert wurde, welches dem Kaiser der Römer verbot, in den Krieg zu ziehen, da wurden die Angelegenheiten des Krieges natürlich zum Betätigungsfeld für die Generäle, die Angelegenheiten des

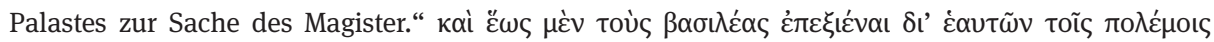

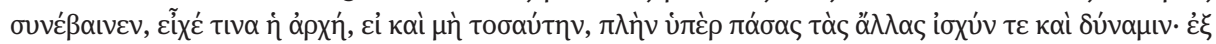

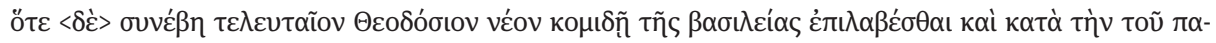
тро̀

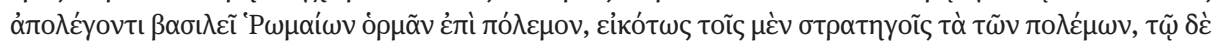

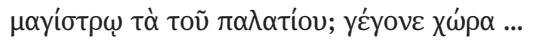

16 Zu Joh. Lyd.vgl. Diefenbach 1996, 41; Szidat 2010, 185; Pfeilschifter 2013, 45 Anm. 11; Maier 2019, 459. Lee 2007, 35 weist darauf hin, dass mit Markian und Leon I. zwar Männer mit militärischer Erfahrung auf den Thron kamen, dass Aspar allerdings ganz bewusst Männer in fortgeschrittenem Alter ausgewählt habe, die ihm in der Truppenführung keine Konkurrenz mehr machen konnten. Erst Zenon brachte dann tatsächlich Potential mit sich, entschied sich aber auch gegen die persönliche Kriegsführung, was gemäß Lee daran gelegen haben könnte, dass die Erinnerung an katastrophale Enden kriegführender Kaiser (Julian, Valens) noch sehr präsent war.

17 Maier 2019, 339-449. 
römischen Kaiser hat Maier eine Konstellation ins Spiel gebracht, die er mit dem Begriff des ,Imperator-Dilemma“ beschreibt: Dem Anspruch an den römischen Kaiser, persönlich als Feldherr und im besten Fall gar als Propagator imperii an den Grenzen des römischen Reiches tätig zu werden, konnten die Monarchen des 3. und 4. Jahrhunderts angesichts der Auswirkungen der Völkerwanderung und eines erstarkenden sassanidischen Reiches nicht mehr gerecht werden. Stattdessen hielt man die Grenzen nur mit Müh und Not; barbarische Stammeseinheiten wurden auf römischen Gebieten angesiedelt und mit Geldzahlungen ruhig gehalten. Usurpationen, die aus dem militärischen Umfeld hervorgingen, brachten den regierenden Kaiser regelmäßig in massive Bedrängnis. Mit dem Rückzug nach Konstantinopel hätten sich die Kaiser, so Maier, dieser Diskrepanz zwischen Erwartung und Wirklichkeit entziehen können; durch die Bindung an die Hauptstadt konnte die monarchische Position unabhängig von kriegerischen Erfolgen eingerichtet werden. ${ }^{18}$ Die Kaiser entzogen sich nicht nur den Risiken der persönlichen Kriegsführung und einer mit Niederlagen einhergehenden Destabilisierung ihrer Herrschaft, sondern erschlossen im hauptstädtischen Umfeld auch alternative monarchische Betätigungsfelder. Während monarchisches Charisma zuvor in hohem Maße von militärischer Performance abhängig gewesen war, verlegten sich die sesshaften Monarchen auf die ostentative Zurschaustellung christlicher Tugenden wie Frömmigkeit und Demut; ihre Person und Position wurde in Konstantinopel sukzessive in einen genuin christlichen Deutungshorizont einschrieben. Mit der Bindung des Kaisers an Konstantinopel ging also eine fortschreitende Sakralisierung des Kaisertums einher, welche die monarchische Position stabilisierte. ${ }^{19}$

Die Herausbildung einer hauptstädtischen Konfiguration von Monarchie brachte neue Handlungsoptionen, aber ebenso Zwänge mit sich. Wie bereits betont, ging mit der Konzentration auf Konstantinopel eine Bedeutungssteigerung des hauptstädtischen Volkes und des Palastumfeldes einher: Um Akzeptanz zu erzeugen und zu verstetigen, musste kaiserliches Verhalten den Bedürfnissen und Erwartungen dieser Gruppen zumindest zu einem gewissen Grad entsprechen. Während in den Jahrhunderten zuvor vor allem das Heer Kaisernähe eingefordert hatte, ${ }^{20}$ war es nun die hauptstädtische Bevölkerung, die auf diese Form der Zuwendung bestehen konnte. Eine neuerliche Abwesenheit und damit einhergehende Vernachlässigung Konstantinopels hätte das Risiko eines Akzeptanzverlustes der maßgeblichen Gruppen mit sich gebracht und die Chancen eines alternativen Kandidaten, die Stimmung der

18 Maier 2019, 1-15 zum Begriff des Imperator-Dilemmas; ebd. 451-462; siehe auch Börm 2016, 625f. 19 Zu diesen neuen Betätigungsfeldern siehe Diefenbach 1996, 2002; ders. 2019, 63-78; Meier 2007; Kelly 2013. Es bleibt zu betonen, dass sich auch diese Akzeptanzbasis und die (christliche) Deutungshoheit der Kaiser mitunter als fragil und kritikanfällig erweisen konnten. Zur Sakralisierung des Kaisertums siehe auch unten S. 198-200.

20 Zum Nahverhältnis zwischen Kaiser und Soldaten im 1. und 2. Jahrhundert siehe Stäcker 2003. 
Hauptstadt auf seine Seite zu ziehen, erhöht. ${ }^{21}$ Die Sicherung Konstantinopels als Dreh- und Angelpunkt monarchischer Herrschaft avancierte zur höchsten Priorität, sodass selbst Männer mit umfassender militärischer Erfahrung nach ihrer Erhebung zum Kaiser die Stadt nicht mehr verließen. Eine Usurpation in der Hauptstadt stellte ein wesentlich größeres Risiko dar als die Rebellion eines Feldherrn in den Provinzen; ${ }^{22}$ die Einnahme Konstantinopels mit militärischen Mitteln war angesichts der enormen Befestigungsanlagen im Westen der Stadt geradezu unmöglich, solange - und darin lag der ausschlaggebende Punkt - die Stadt sich und ihren Kaiser geschlossen verteidigte. Die hauptstädtische Konfiguration von Herrschaft trug zur Sicherung des Kaisertums im Osten des Reiches bei; die Männer auf dem Thron entzogen sich dem - mit Felix K. Maier gesprochen - Imperator-Dilemma, begaben sich damit aber in ein neues Korsett an Verhaltenserwartungen, das ihren Handlungsspielraum in anderer Weise beschränkte.

\subsection{Der sesshafte Kaiser: Auswirkungen auf den militärischen Sektor}

Nachdem die Entwicklungslogik hinter dem Sesshaftwerden der oströmischen Kaiser in ihren Grundzügen beleuchtet wurde, stellt sich nun die Frage, welche Auswirkungen dieser Prozess auf das Verhältnis der Kaiser zum militärischen Sektor zeitigte. ${ }^{23}$ Unter dem ,militärischen Sektor verstehe ich dabei keine eindeutig und unverrückbar definierbare Gruppierung, sondern Bereiche der oströmischen Gesellschaft, die verhältnismäßig klar durch ihre militärische Aktivität geprägt waren. Der militärische Sektor ist sowohl extra als auch intra muros anzusiedeln. Während sich die großen Heeresverbände meist in den Provinzen aufhielten, ist davon auszugehen, dass auch in der näheren Umgebung Konstantinopels Einheiten stationiert waren. ${ }^{24}$

21 Siehe Börm 2013, 81 und ders. 2016, 626f.; Diefenbach 2019, 76 beschreibt die Bindung des Kaisers an Konstantinopel als eine ,janusköpfige Angelegenheit“.

22 Daraus erklärt sich, um ein paar Beispiele zu nennen, dass Zenon nach seiner Rückkehr aus dem isaurischen Exil erst lauthals die persönliche Führung der Kampagne gegen die Goten auf dem Balkan ankündigte (was bei den Soldaten auf Begeisterung stieß), nur um die Entscheidung im letzten Moment zu revidieren und lieber in Konstantinopel seine prekäre Position zu sichern (Malch. fragm. 18.3; vgl. Pfeilschifter 2013, 63), und dass Maurikios’ Entschluss, das römische Heer persönlich gegen die Avaren anzuführen, auf entschiedene Gegenwehr aus Palastkreisen stieß (Theoph. Sim. Hist. 5.16.2-4); dazu unten $74 \mathrm{f}$.

$23 \mathrm{Zu}$ den Auswirkungen des hauptstädtischen Kaisertums auf den militärischen Sektor siehe Lee 2007, 30 -37; Börm 2013, 75-84; ders. 2016, 622, 624-627; Parnell 2017, 98f. Es sei außerdem auf die bisher noch nicht veröffentlichte Dissertation von Anne Poguntke verwiesen, eine Untersuchung zum Amt des Magister militum in der Spätantike (non vidi); siehe vorerst Poguntke 2014 und 2016.

24 Zu den in/bei Konstantinopel stationierten Truppen siehe Pfeilschifter 2013, 225-231; Dagron 1974 , 108 vermutet, dass am Hebdomon einige der vom Magister militum praesentalis befehligten Truppen stationiert waren. 
Innerhalb der Stadt schließlich befanden sich die kaiserlichen Gardesoldaten, die insgesamt mehrere Tausend Mann umfassten. Doch den militärischen Sektor allein mit Verweis auf die Masse der Soldaten zu umreißen, wäre zu kurz gegriffen. Als ebenfalls diesem Sektor zugehörig begreift diese Arbeit Funktionsträger bzw. Befehlshaber, auf höchster Ebene die Magistri militum, die als Mitglieder des Senates das politische Klima der Hauptstadt entscheidend prägten.

\subsubsection{Soldaten}

Bis ins 4. Jahrhundert hatten die römischen Kaiser die direkte Kommunikation mit den Soldaten stets forciert; damit wurden sie der Bedeutung dieser Gruppe für die Stabilität monachischer Herrschaft gerecht: Das Heer - bzw. bestimmte Heereseinheiten rief den Kaiser aus, konnte ihm die Akzeptanz allerdings ebenso wieder entziehen und einen alternativen Kandidaten durch Akklamation zum Kaiser machen; das Heer - bzw. loyale Heereseinheiten - war schließlich auch das einzige Instrument, mithilfe dessen sich ein Kaiser eines potentiellen Konkurrenten erwehren konnte. ${ }^{25}$ Mit dem Rückzug der Kaiser nach Konstantinopel erfuhr das Verhältnis zwischen Kaisern und Soldaten eine maßgebliche Modifizierung. Obwohl auch die hauptstädtischen Kaiser weiterhin durchaus mit Heereseinheiten in Berührung kamen, etwa mit den nahe Konstantinopel stationierten oder regelmäßig durchziehenden Truppen, ${ }^{26}$ zeichnete sich diese Interaktion doch durch eine andere Qualität aus: Der Kaiser führte die Soldaten nicht mehr persönlich in den Krieg; die an den Grenzen stationierten Einheiten bekamen ihn in der Regel gar nicht zu Gesicht. Indirekte Kommunikation fand freilich über Soldzahlungen und Donative statt, die anlässlich spezieller Anlässe ausgezahlt wurden. Das Bildnis und der Name des Kaisers waren weiterhin in den Feldlagern präsent, die Truppen wurden weiterhin auf den Throninhaber eingeschworen. ${ }^{27}$ Zumindest im 5. Jahrhundert zeichneten sich auch Kaisererhebungen noch durch einen militärischen Charakter aus (die Kaiser wurden von anwesenden Truppen auf dem Hebdomon außerhalb der Stadtmauern erhoben); im späten 5. Jahrhundert jedoch wurde das Ritual in den zivilen Raum innerhalb der Stadtmauern verlegt. ${ }^{28}$ Anders als in den Jahrhunderten davor hatte die Erhebung eines

25 Siehe Flaig 1997, $17 \mathrm{f}$.

26 In Folge des Sieges über den Usurpator Eugenios wurde ein Teil der Truppen unter der Führung des Goten Gainas nach Osten zurückgeschickt und von Arkadios vor den Mauern Konstantinopels empfangen. Dass dieses Zusammentreffen überhaupt in den Quellen erwähnt wird, ist dadurch bedingt, dass die Soldaten, die gerade noch Arkadios akklamiert hatten, kurz darauf an gleicher Stelle dessen Praefectus praetorio per Orientem Rufinus ermordeten; zum Rufinus-Attentat und der Quellenlage siehe Poguntke 2016, $253 \mathrm{f}$.

27 Siehe Lee 2007, 51-66.

$28 \mathrm{Zu}$ Erhebungs- bzw. Krönungsritualen siehe vor allem Trampedach 2005; eine ausführliche Diskussion von Krönungsritualen findet sich in Kapitel 3.3.1. 
alternativen Kandidaten durch die Truppen in den Provinzen nun keine direkten Auswirkungen mehr auf die politische Ordnung. ${ }^{29}$ Nur wer Konstantinopel kontrollierte, war römischer Kaiser.

Wie reagierten nun die Soldaten auf diese Entwicklung - die Soldaten, die zuvor stets Kaisernähe eingefordert hatten? Ein schematischer Überblick erweckt den Eindruck, dass im oströmischen Reich die Loyalität der Soldaten auch gegenüber den sesshaften Kaisern aufrechterhalten werden konnte. Während im Westen die Bindung zwischen Heer und Kaiser seit dem späten 4. Jahrhundert zunehmend erodierte und sich mit dem höchsten Heermeisteramt eine Institution etablierte, welche die Hoheit über die Armee dauerhaft sichern konnte, blieben die Soldaten im Osten des Reiches weiterhin direkt auf den Kaiser bezogen. ${ }^{30}$ Meutereien, bei denen ganze Heereseinheiten der Zentrale ihren Gehorsam aufkündigten, sind zwar durchaus zu verzeichnen, entzündeten sich allerdings primär dann, wenn die Soldaten sich in ihrer Versorgung, ihrer Besoldung und ihrem generellen Wohlergehen bedroht sahen. Solange der oströmische Kaiser also die Versorgung der Truppen im Griff hatte und sich ostentativ um das Wohl der Soldaten sorgte, akzeptierten diese das Arrangement eines sesshaften Kaisers und stellten keine genuine Bedrohung für die Stabilität von dessen Herrschaft dar. ${ }^{31}$

\subsubsection{Militärische Funktionsträger}

Komplexer gestaltet sich der Blick auf die zweite Gruppe, auf hohe militärische Funktionsträger. Die Position des Oberbefehlshabers an kriegerischen Brennpunkten, die im 3. und 4. Jahrhundert zumeist von dem regierenden Kaiser bzw. einem Repräsentanten des Kaiserkollegiums ausgefüllt worden war, musste im Zusammenhang mit der Herausbildung der hauptstädtischen Monarchie Kommandoträgern überlassen werden - ein Arrangement, das nicht ohne Konsequenzen bleiben konnte.

29 Mit Blick auf das 5. Jahrhundert wird dies vor allem durch die Erhebung des Leontios in Kilikien deutlich: Obwohl Leontios wichtige Truppeneinheiten hinter sich hatte - unter anderem den isaurischen General Illous - und seine Krönung durch die Witwe des verstorbenen Kaisers Leon I., Verina, unterstützt wurde, zeitigte seine Erhebung keine direkten Auswirkungen auf das politische Klima in Konstantinopel. Zur Usurpation des Leontios siehe Kiel-Freytag 2010 und Pfeilschifter 2013, 557-560. 30 Siehe Flaig 1997, $23 \mathrm{f}$.

31 Siehe Martin 1997, 61; Szidat 2010, 195; Börm 2013, 77. Auch Poguntke 2014, 419-422 betont die Bedeutung einer angemessenen Versorgung für die Loyalität der Soldaten; sei die Versorgung nicht gewährleistet gewesen, habe dies die Position der Feldherren gestärkt (so etwa unter Zenon); ähnlich in Bezug auf das 4. Jahrhundert auch Lee 2015, 103. Lee 2007, 67 weist allerdings darauf hin, dass sich Unruhen von Seiten der Soldaten im 6. Jahrhundert häufen (gegenüber dem 5. Jahrhundert, in dem Unruhen meist von prominenten Individuen ausgingen); zu den Meutereien unter Maurikios siehe unten S. 80 - 82. Zu „military unrest“ ab 471 siehe die Studie von Kaegi 1981; vgl. auch Jones 1964 I, 395 : „The army, somewhat surprisingly, seems very rarely to have made its influence felt.“ 
Potentielle Spannungen zwischen Kaisern und Heermeistern sind ein genuines Charakteristikum römischer Monarchie: In einem politischen System, das nicht auf institutionellen Kriterien beruhte, sondern auf der Generierung und Aufrechterhaltung von Akzeptanz der relevanten Gruppen, stellten erfolgreiche Militärs stets ein Risiko für die Autorität des regierenden Kaisers dar. ${ }^{32}$ Die Entwicklungen des 5. Jahrhunderts indes modifizierten die Parameter, innerhalb derer sich diese Spannungen Bahn brechen konnten. Indem im Kontext der Hauptstadt neue monarchische Betätigungsfelder erschlossen wurden, gelang es den Kaisern, sich zu einem gewissen Grad von den militärischen Funktionsträgern abzuheben, da sie nicht mehr auf dem gleichen Feld (der Kriegsführung) mit diesen konkurrierten. Aus diesem Rückzug in die Hauptstadt erwuchs allerdings ein anderes Dilemma: Um die Sicherung der weiterhin umkämpften Reichsgrenzen zu gewährleisten, waren die sesshaften Kaiser noch stärker von der Leistung und Loyalität ihrer Generäle abhängig und mussten ihnen gleichzeitig relativ große Autonomie in den Provinzen gewähren. Mit der Festigung eines hauptstädtischen Kaisertums gewann der militärische Sektor an Eigenständigkeit. ${ }^{33}$

Das römische Reich fußte, ebenso wie andere vormoderne Imperien, in hohem Maße auf militärischer Schlagkraft. Eine effiziente Verwaltung, welche die steuerliche Ausbeutung der Provinzen zugunsten der politischen Zentrale und somit einen dauerhaften Einkommensfluss ermöglichte, trug ebenfalls zum Prosperieren der Res publica bei; die Machtressourcen und der Grad an Unabhängigkeit, über die hohe militärische Funktionsträger in der Spätantike verfügten, waren allerdings ungleich größer als die ihrer Kollegen aus dem zivilen Sektor. Angesichts des Umstandes, dass die Kaiser sich nicht mehr persönlich als Feldherren betätigten, stellten sie die „Schicht [, auf die der Kaiser] wie auf keine andere angewiesen war.“" ${ }^{34}$ In den Händen der Generäle lag die Sicherung der konstant instabilen Reichsgrenzen und die Beilegung interner Konflikte bis hin zum konkreten Schutz des Kaisers; an ihren Fähigkeiten hing der Erfolg in militärischen Auseinandersetzungen, die weiterhin zu einem gewissen Grad auf den Machthaber in Konstantinopel rückwirkten. Die Stabilisierung oströmischer Herrschaft, welche durch die Bindung an Konstantinopel hatte herbeigeführt werden können, ging also mit dem Umstand einher, dass militärische Funktionsträger in den Provinzen - ungestört von kaiserlicher Präsenz und mit dem

32 Während der ersten Jahrhunderte der Kaiserzeit wurden die hohen Befehlsposten vor allem durch Männer aus dem Ritterstand besetzt, während die Kaiser senatorischen Hintergrund hatten; diese Konstellation ermöglichte einen gewissen Grad an Abgrenzung. Ab dem 3. Jahrhundert wurden dann allerdings vermehrt auch Männer aus dem Ritterstand zum Kaiser erhoben; siehe Lee 2007, 24. 268 wurden Senatoren von den Posten der Legionskommandanten ausgeschlossen, was die Ausbildung einer rein zivilen Karrieresparte bedingte, siehe Szidat 2010, 184.

33 Siehe Demandt 1980, bes. 629 („Die dynastische Legitimation des Kaiserhauses machte principes pueri und principes clausi möglich, doch nur um den Preis, dass jemand anderes die Führung der Truppe in die Hand nahm.“).

34 Demandt 1970, 628. Jones 1964, 174-178 betont dagegen, dass auch die zivilen Funktionsträger im Osten machtpolitisch äußerst bedeutend waren, ähnlich Martin 1997, 53. 
Rückhalt durch die Truppen - entscheidende Machtressourcen akkumulieren konnten. Diese Machtressourcen im provinzialen Rahmen auszuspielen, war angesichts der Fokussierung des politischen Systems auf die Hauptstadt nur in begrenztem Maße möglich: Es erwies sich wiederholt, dass selbst Individuen, die sich bei den Truppen enormen Rückhalt erarbeitet hatten, dem Kaiser in Konstantinopel von der Provinz aus nicht gefährlich werden konnten, solange dieser die Hauptstadt hinter sich hatte. ${ }^{35}$ Doch konnte in den Provinzen gewonnenes militärisches Prestige durchaus auf die machtpolitische Zentrale übertragen werden. Dies musste nicht zwangsläufig durch Usurpation geschehen; ${ }^{36}$ hohen militärischen Funktionsträgern standen neben der direkten und möglicherweise gewaltsamen Herausforderung des regierenden Kaisers subtilere Mittel und Wege zu Verfügung, um den Kaiser in Konstantinopel unter Druck zu setzen und politische Entscheidungsprozesse zu beeinflussen.

Will man die Mechanismen verstehen, die die Interdependenz zwischen dem Kaiser und militärischen Funktionsträgern bedingten, muss zunächst die Zusammensetzung dieser Gruppe genauer bestimmt werden. Dabei geht es nicht darum, die Kommandostruktur des römischen Heeres im Allgemeinen einer Untersuchung zu unterziehen; ${ }^{37}$ der Fokus liegt stattdessen auf der hochrangigen Führungsgruppe, die als Bindeglied zwischen intra und extra muros, zwischen dem militärischen Sektor in den Provinzen und dem politischen Establishment Konstantinopels bis hin zum engeren Palast-Umfeld und dem Kaiser selbst verstanden werden kann.

Um den Blick auf die hohen militärischen Funktionsträger zu schärfen, bedarf es eines Exkurses zu der Zusammensetzung bzw. Formierung der oströmischen Elite in den Jahrhunderten nach der Etablierung des Konstantinopolitaner Senates unter Constantius II. Die politische Elite bestand, kurz gesagt, aus zivilen und militärischen Amtsträgern bzw. ehemaligen Amtsträgern einer gewissen Rangstufe. ${ }^{38}$ Im 4. Jahr-

35 Das beste Beispiel ist Vitalian, der über Jahre hinweg Thrakien kontrollierte, was aber nicht zum Sturz des Kaisers Anastasios führte; zur Revolte des Vitalian siehe Kaegi 1981, 92f.; Meier 2007a, 203209.

$36 \mathrm{Zu}$ Einflussnahmen jenseits der Usurpation siehe Szidat 2010, 213f. („Alternativen zur Usurpation").

37 Zur Kommandostruktur siehe etwa Jones 1964 II, 654-656 und Mi. Whitby 2000b, 288-290.

38 Der Begriff der ,Elite‘, ebenso wie ,Adel` und ,Aristokratie‘, wird in der Forschung zur Spätantike nicht unbedingt einheitlich angewandt. Börm 2010, 146 weist darauf hin, dass es sich dabei trotz der Existenz zeitgenössischer Termini um moderne Konstrukte handelt. Die Kriterien hinsichtlich der Zugehörigkeit zu einer bzw. der Elite schwanken in der Literatur: „Abstammung, eine Position in einer offiziellen - herrscherlichen oder religiösen - Hierarchie, Grundbesitz, Nähe zum Herrscher, die Anerkennung durch die peers (wohl der wichtigste Punkt) sowie ein entsprechender Lebensstil“ (Börm 2010, 164). Pfeilschifter 2013, 452 dagegen zählt zur Elite diejenigen, „die mit dem Kaiser wenigstens gelegentlich als Individuen in Kontakt treten konnten“; einen umfassenden Überblick über die Forschung zu und Definition der oströmischen Elite findet sich bei Begass 2018, 6-14; vgl. auch Whately 2013, 50 und Meier 2008 mit einem Überblick über „Aristokratie(n) in Byzanz“. Die von Begass gewählte Herangehensweise (explizit ebd. 12f.), als Elite erst einmal diejenigen zu fassen, die durch die Belegung bestimmter Ämter der Rangklasse der Illustres zuzuordnen sind, halte ich für sinnvoll. Dass dadurch kirchliche Würdenträger ausgeschlossen werden, lässt sich bei der hier vorzunehmenden 
hundert war im Osten gemäß dem Cursus honorum die Bekleidung einer Praetur Voraussetzung für den Übergang vom provinzialen Curialen- in den Senatorenstand. Unter Theodosios I. kam es zu einer Erweiterung der Zugangsmöglichkeiten, was einen geradezu inflationären Zuwachs derjenigen Männer zur Folge hatte, die zumindest nominell dem Konstantinopolitaner Senat angehörten. Mit Markian setzte eine Gegenbewegung ein, welche die höchste senatorische Rangklasse der Illustres gegenüber denen der Spectabiles und Clarissimi bevorzugte: Allein die Illustres stellten nun den aktiven Senat in Konstantinopel, während die Spectabiles und Clarissimi verstärkt an ihre Heimatstädte in den Provinzen gebunden wurden. Unter Justinian erfolgte schließlich eine weitere Binnendifferenzierung der Illustres, die eine noch deutlicher begrenzte Führungsschicht eng mit dem Kaiser verknüpfte. Die Zugehörigkeit zur Rangstufe der Illustres war nicht erblich (Söhne von Illustres hielten als solche nur den Rang des Clarissimus), sondern an die Bekleidung bestimmter ziviler und militärischer Ämter gebunden. Der Kaiser konnte Ämter auch ehrenhalber verleihen und bestimmte Individuen durch die Verleihung des Patrikiats als höchste Würde, die sich mit keinerlei Aufgaben verband und auf Lebenszeit verliehen wurde, innerhalb der Riege der Illustres privilegieren. ${ }^{39}$ Diese Konskriptionspraxis brachte eine vergleichsweise hohe vertikale Mobilität mit sich: Durch die Besetzung illustrer Ämter als Alternative zum traditionellen Cursus honorum stiegen im 5. und 6. Jahrhundert vermehrt Männer nicht-distinguierter Herkunft in illustren Rang auf und bildeten in Konstantinopel ein Gegengewicht zu den Erben aristokratischer Familien. ${ }^{40}$

Die oströmische Elite, wie sie sich im Laufe des 5. Jahrhunderts herauszubilden begann, unterschied sich demnach stark von der stadtrömischen. Bereits A. H. M. Jones formulierte prägnant: „The new hierarchy effectively transformed the aristocracy from one of birth into one of office." 41 Der Senat in seiner ursprünglichen Funktion als Beratungs- und Entscheidungsgremium verlor zunehmend an institutioneller Bedeutung; die Konzentration auf illustre Amtsträger führte allerdings zu einem Erstarken des Einflusses seiner Mitglieder, die sich als politische Führungsschicht, als Amts- bzw. Funktionselite, in Konstantinopel um den Kaiser sammelten

Untersuchung verkraften; vgl. Av. Cameron 2004 mit dem Versuch einer Typologisierung der Elite: neben der politischen, d.h. der Senatsaristokratie, identifiziert sie auch eine kirchliche und intellektuelle Elite.

$39 \mathrm{Zu}$ den Illustres siehe die prosopographische Studie von Begass 2018, die alle Männer dieses Ranges zwischen 457 und 518 n.Chr. auflistet; zum Rang des Illustris ebd. 42-45 und zu den Spectabiles und Clarissimi ebd. 52-54. Zu ehrenhalber verliehenen Ämtern siehe ebd., 54f.; zum Patrikiat ebd., 45f., 419f. Im Westen trug nur der Magister utiusque militiae den Titel des Patricius, was die umfassenden Vollmachten dieser Position verdeutlicht. Im Osten dagegen wurde das Patrikiat stets mehreren Männern verliehen, die eine Gruppe enger kaiserlicher Amicii bzw. Berater konstituierten. 40 Zu der Entwicklung des Senates siehe zuletzt im Überblick Begass 2021 und ders. 2018, bes. 35- 41 und 480 - 485; Olster 1993, 26 -35; Jones 1964 II, 528f.; außerdem mehr mit Blick auf die Entwicklung im 6. - 8. Jahrhundert Haldon 1990, 166 -172, 389-399; ders. 2004.

41 Jones 1964 II, 529; siehe auch Begass 2018, 44. 
und als Comitatus, als dessen engster Beraterkreis, fungierte. ${ }^{42}$ Während eine ganze Reihe ziviler Ämter einen illustren Rang mit sich brachte (der Comes domesticorum, der Magister officiorum, die Praefecti praetorio, der Praefectus urbi, der Praepositus sacri cubiculi, um nur einige zu nennen), wurde auf dem militärische Karrierepfad nur den Magistri militum diese Auszeichnung gewährt. ${ }^{43}$ Fragt man nach dem Einfluss des militärischen Sektors auf machtpolitische Prozesse in Konstantinopel, erweist sich also die Untersuchung der aktiven und ehemaligen Magistri militum als vielversprechend, die sich - nicht selten von verhältnismäßig niedriger Herkunft - bis in eines dieser Oberkommandos hochgearbeitet hatten und damit zu Mitgliedern der hauptstädtischen Polit-Elite avancierten.

Die Gruppe illustrer Militärs lässt sich für die Spätantike verhältnismäßig gut umreißen. In der Kaiserzeit waren zivile und militärische Kompetenzen in den Händen der Statthalter, der senatorischen Legati Augusti pro praetore, vereint gewesen. Mit dem Ausschluss der Senatoren vom Militärdienst durch Gallienus wurde allerdings der Grundstein für die Herausbildung zweier eigenständiger Karrierewege gelegt, die unter Diocletian und Konstantin noch klarere Form annahmen: Die Notitia dignitatum unterscheidet schließlich klar zwischen einer zivilen und einer militärischen Verwaltungsebene. ${ }^{44}$ Wie klar diese beiden Ebenen im 5. und 6. Jahrhundert im praktischen Vollzug voneinander getrennt waren, bleibt in der Forschung umstritten. Während Alexander Demandt gar die Herausbildung eines „Militäradels“ postuliert, der sich sowohl im west- als auch im oströmischen Reich über mehrere Generationen hinweg gefestigt habe, ${ }^{45}$ wird von anderer Seite betont, dass bisweilen durchaus personelle Überschneidungen zwischen ziviler und militärischer Verwaltung bestanden; ${ }^{46}$ zum Ende des 6 . Jahrhunderts begannen sich beide Bereiche dann tatsächlich wieder stärker miteinander zu verschränken, nicht zuletzt in Form der neu eingerichteten Exarchate in Karthago und Ravenna. ${ }^{47}$ Doch selbst wenn nicht von einer kategorischen Trennung zwischen militärischer und ziviler Administration auszuge-

42 Börm 2010, 169f. (mit weiteren Literaturverweisen): „Als Institution besaß der spätantike Senat kaum noch Einfluss, sehr wohl aber als Versammlung der Reichsaristokratie. Er bündelte gewissermaßen die auctoritas seiner Mitglieder.“

43 Eine Übersicht über Ämter und Titel mit illustrem Rang findet sich bei Begass 2018, 60 f.; vgl. auch ebd. 420, wo darauf verwiesen wird, dass Zugang zum Senat über militärische Ämter gegenüber den zivilen stark beschränkt war - als Grund dafür nimmt Begass an, dass die oströmischen Kaiser aus den Entwicklungen im Westen, d.h. der dortigen Dominanz hoher Militärs, gelernt hätten. Laut Demandt 2007, 307 hatte auch der Comes domesticorum illustren Rang.

44 Demandt 2007, 292; Szidat 2010, 184. Dabei bleibt zu betonen, dass sowohl die militärischen als auch die zivilen Funktionsträger als Militia bezeichnet wurden, die Militia armata bzw. Militia officialis; vgl. Kelly 2004, 20.

45 Demandt 1980: Militäradel als distinkte Gruppe an militärischen Funktionsträgern, die sich nicht/ kaum mit der etablierten Aristokratie verband; vgl. bereits Demandt 1970, 785. In Reaktion auf Demandt siehe Gluschanin 1991; vgl. Begass 2018, 8. Zur Herausbildung und Bedeutung einer Militär-Elite im 4. Jahrhundert siehe auch Frank 1969, 167-199.

46 So etwa Olster 1993, $34 \mathrm{f}$.

$47 \mathrm{Zu}$ den Exarchaten siehe Meier 1998. 
hen ist, lässt es sich rechtfertigen, Männer, die als Magister militum dienten bzw. gedient hatten, als eine distinkte Gruppe innerhalb der hauptstädtischen Elite zu behandeln. ${ }^{48}$

Wie lässt sich nun diese Gruppe illustrer Militärs genauer charakterisieren? Die militärische Kommandostruktur des oströmischen Reiches unterschied sich wesentlich von der im Westen: Während im Westen der Magister utriusque militiae als Befehlshaber des gesamten Feldheeres über eine umfassende Machtvollkommenheit verfügte - auf Kosten der oft unmündigen Kaiser -, wurde das Amt des Magister militum im Osten auf mehrere Kommandos aufgeteilt. Nach der Rückkehr des Heeres, das im Westen den Usurpator Eugenius bekämpft hatte, schuf Theodosius I. fünf gleichrangige Kommandos mit eigenen Truppenkontingenten - neben zwei Magistri militum praesentales jeweils einen per Orientem, Illyricum und Thraciam. ${ }^{49}$ Unter Justinian kamen noch weitere Kommandos dazu, per Italiam et Africam, per Armeniam und Spaniae..$^{50}$ Gezielte Maßnahmen der oströmischen Kaiser bzw. hoher Palastkreise, zivile Ämter zu begünstigen und die Verfügungsgewalt militärischer Funktionsträger in Schranken zu halten, zeigten - so die gängige Forschungsmeinung - die erhoffte Wirkung. ${ }^{51}$ Limitierte Reichweite, interne Konkurrenz, eine zeitliche Befristung, ständige Rotation und häufige Wechsel der Kommandos - oft wurden sie nur für ein Jahr besetzt - führten dazu, dass die Heermeister des Ostens zu keinem Zeitpunkt die Machtressourcen akkumulieren konnten, über die ihr Counterpart im Westen verfügte. ${ }^{52}$ Das Schicksal der weströmischen Kaiser, die sich seit dem Aufstieg des Stilicho der dauerhaften Bevormundung und gar Überwältigung durch ihre Magistri utriusque militiae ausgesetzt sahen, konnte im Osten abgewandt wer-

48 Siehe Börm 2013, 75 Anm. 59: „Die militia armata war von der militia officialis (und der militia palatina) klar unterschieden. Es gab nun kaum noch Männer, die durch ihre Laufbahn mit beiden Sektoren verbunden waren, und die Machtbalance zwischen den beiden Bereichen war empfindlich.“ Vgl. auch Meier 2008, 294, der in seiner Übersicht zur byzantinischen Aristokratie auf die „partiell zutreffende und in ihren Konsequenzen viel zu wenig untersuchte Differenzierung zwischen dem ,Zivil-“ und dem ,Militäradel“" hinweist.

49 Jones 1964 I, 343 f. Zum Magister utriusque militiae im Westen siehe Enßlin 1931; O’Flynn 1983; Castritius 1984; McEvoy 2013 zu den Dynamiken zwischen minderjährigen Kaisers und mächtigen Heerführern.

50 Jones 1964 II, 655 f. Zum Amt des Magister militum und seiner Entwicklung in Ost und West sei auf die nach wie vor einschlägige Untersuchung von Demandt 1970 verwiesen; außerdem zusammenfassend ders. 2007, 311-313.

51 Begass 2018, 420; Demandt 1970, 784.

52 Lee 2007, 33f. und ders. 2015, 104, 112; zur Vergabepraxis von Ämtern im Allgemeinen siehe Begass 2018, 415-429; zu befristeter Besetzung von Ämtern ebd., 417-419; zur Befristung militärischer Kommandos unter Justinian siehe Parnell 2017, 83f. und ders. 2012, 7-9. Siehe auch Börm 2016, 622 Anm. 82, der darauf hinweist, dass die Aufteilung des Kommandos der Perseroffensive des Jahres 503 auf fünf Generäle militärstrategisch kontraproduktiv war, allerdings dadurch zu erklären ist, dass Anastasios einen potentiellen Persersieg nicht einem einzigen Mann überlassen wollte. 
den. ${ }^{53}$ Spätestens nachdem die Krise überwunden worden war, die das politische Klima Konstantinopels in der zweiten Hälfte des 5. Jahrhunderts destabilisierte, ${ }^{54}$ hätten die oströmische Kaiser - so gemeinhin die Ansicht der Forschung - relativ frei sowohl über die zivilen als auch über die militärischen Amtsträger, versammelt in der hauptstädtischen Senatsaristokratie, verfügen können. ${ }^{55}$

Eine derartige Lesart basiert allerdings auf der Grundannahme eines recht einseitigen Verhältnisses zwischen Kaiser und Angehörigen der Eliten, die in der Literatur bisweilen anklingt. Der Kaiser als alleiniger Fokus eines fest etablierten Patronagesystems wird dabei - überspitzt gesagt - einer abhängigen Funktionselite ohne eigenständige Gruppenidentität gegenübergestellt: Ämtervergabe und Besetzungsentscheidungen lagen - so offenbar die Einschätzung - im Ermessen des Kaisers; er war es, der über den Aufstieg in die höchsten gesellschaftlichen Schichten entschied. In der Macht des Monarchen habe es gestanden, „die Hierarchie der höfischen Gesellschaft beständig umzuformen und diese ihre Abhängigkeit deutlich fühlen zu lassen“. ${ }^{56}$ Die Senatoren werden als eine ohnmächtige Elite, als loyales Gefolge gezeichnet, die sich um Kaisernähe als das höchst-gehandelte Gut bemühten. ${ }^{57}$ Anstatt sich als Mitglieder einer homogenen und distinguierten Führungsgruppe zu begreifen, hätten sich die höchsten Würdenträger allein in ihrer Stellung und Beziehung zum Kaiser definiert und profiliert. ${ }^{58}$,Je loyaler sie [i.e. die Angehörigen der Elite] ihm [i.e. dem Kaiser] dienten, desto mehr Verantwortung, Macht und Prestige konnten sie erwarten. " ${ }^{\circ 9}$ Wettstreit bzw. Konkurrenz habe primär auf der Ebene der Peers stattgefunden; dem übermächtigen Kaiser habe man kaum etwas entgegenzusetzen gehabt. $^{60}$

53 Der Gothe Gainas scheint versucht zu haben, in Konstantinopel eine dem Stilicho ähnliche Stellung zu okkupieren, scheiterte allerdings unter anderem an dem Widerstand der hauptstädtischen Bevölkerung; siehe Börm 2013, 76 und ausführlicher Faber 2011.

$54 \mathrm{Zu}$ dieser Krise siehe Meier 2012, 206-222.

55 Dazu Börm 2013, 79: Das „Primat des kaiserlichen Hofes und des ,zivilen“ Sektors“ habe sich erneut durchgesetzt.

56 Zitat Pfeilschifter 2012, 141; zur Ernennungspraxis von militärischen Funktionsträgern verschiedener Rangstufen siehe Parnell 2017, 79-83.

57 Betonung der Loyalität zum Kaiser als ausschlaggebendes Kriterium für eine lange und erfolgreiche Karriere auch bei Begass 2018, 421, ähnlich Begass 2021; vgl. auch Parnell 2017, $100 \mathrm{f}$.

58 Zur „Ohnmacht der spätantiken Hofeliten“ siehe Pfeilschifter 2012, passim (bes. 145), zur „Vereinzelung der Eliten“ ebd. 140; ebenfalls zu den oströmischen Eliten ders. 2013, 452-465. Siehe auch Begass 2018, 424: „die politische Architektur mit dem Kaiser als Zentrum und den Senatoren als Trabanten [führte] zu einem permanenten Kampf um Aufmerksamkeit, Privilegien - kurz: um Kaisernähe (...).“ Vgl. zum späten 6. Jahrhundert Olster 1993, 35: „The Constantinopolitan aristocracy by the end of the sixth century was far from a politically, socially or culturally cohesive elite. Rather, it was a dependent client of imperial patronage, whose weakness stemmed from its dependence on civil or military offices to maintain itself.“

59 Zitat Pfeilschifter 2012, 140.

$60 \mathrm{Zu}$ innersenatorischer Konkurrenz und wie sie vom Kaiser ausgenutzt wurde siehe Begass 2018, $424-429$. 
Diese Lesart hat in Grundzügen durchaus ihre Berechtigung: Die oströmischen Kaiser konnten sich - im Gegensatz zu den Augusti im Westen - als unumstrittener Bezugspunkt des politischen Systems halten. Den Schlüssel zum Aufstieg in der hauptstädtischen Funktionselite primär in der Loyalität zum Kaiser zu vermuten, wird jedoch meiner Ansicht nach den komplexen Prozessen und Dynamiken der hauptstädtischen Monarchie des 5. und 6. Jahrhunderts nicht ganz gerecht. Die Position des Kaisers als Gravitationspunkt des Konstantinopolitaner Beziehungsgeflechts war zweifelsohne gesetzt; seine Souveränität in Hinblick auf politische Entscheidungsprozesse - wie etwa die Besetzung hochrangiger Ämter - war allerdings eingeschränkt. Obwohl sich Loyalität gegenüber dem Kaiser durchaus auszahlen konnte und dieser offensichtlich darum bemüht war, ein abhängiges Gefolge um sich zu scharen, gehen Angehörige der Eliten keineswegs in einer Charakterisierung als loyale Untertanen auf; vielmehr standen ihnen - zumindest manchen von ihnen - Mittel und Wege zur Verfügung, den Kaiser unter Druck zu setzen und Entscheidungsfindungen zu ihren Gunsten zu beeinflussen. Der Kaiser war mit einer Gruppe hochrangiger Individuen konfrontiert, die versuchten, anhand ihrer jeweiligen Ressourcen machtpolitische Interessen durchzusetzen.

Ihr Engagement an den Kriegsschauplätzen und die Verfügungsgewalt über ihre Truppen ermöglichte es militärischen Funktionsträgern, sich eine eigenständige Auctoritas aufzubauen, die sich als soziales Prestige auch in die Hauptstadt übertragen ließ. Hatten sie die Stellung des Magister militum erreicht, wurden selbst Männer von niedriger Herkunft in die Konstantinopolitaner Elite aufgenommen und drangen damit von der Provinz in die Sphären vor, innerhalb derer monarchische Herrschaft ausgehandelt wurde. Die Kaiser ihrerseits bewegten sich auf dem schmalen Grat zwischen der Notwendigkeit einerseits, von Generälen erfochtene Erfolge anzuerkennen, und der Wahrung kaiserlicher Autorität und Überlegenheit andererseits: Leistung auf dem Schlachtfeld musste zu einem gewissen Grad gewürdigt werden, um die fähigen Männer angemessen zu entlohnen und ihre Loyalität zu sichern; ${ }^{61}$ je deutlicher erfolgreiche Militärs allerdings in Konstantinopel exponiert wurden, als desto bedrohlicher erwiesen sie sich im Ringen um die Aufrechterhaltung der hauptstädtischen Hierarchie.

Ein Triumph im engeren Sinne stand erfolgreichen Feldherren freilich nicht mehr zu; seit Augustus blieb diese Ehre dem Princeps vorbehalten. Auch der Vandalentriumph des Jahres 534, welcher in der Literatur entlang der Terminologie Prokops lange Zeit als „Triumph des Belisar“ bezeichnet wurde, muss - wie zuletzt in der Forschung wiederholt betont - vielmehr als Machtdemonstration Justinians verstanden werden. ${ }^{62}$ In dem wechselvollen Verhältnis zwischen Justinian und Belisar offenbart

61 Siehe Lee 2007, 68f. und ders. 2015, $109 \mathrm{f}$.

62 MacCormack 1986, 125-129; Meier 2002, 287f.; ders. 2003a, 150-165; ders. 2019b. Börm 2013 plädiert für eine explizite Demütigung des Belisar durch Justinian während der Feierlichkeiten; vgl. dazu Pfeilschifter 2017, 459-461, der in Anm. 9 die Thesen Börms relativiert. Zum Triumph von 534 siehe auch Diefenbach 2019, 92-100, der betont (96f.), dass siegreiche Feldherren im 5. und 6. Jahr- 
sich exemplarisch das Dilemma, in dem sich die Kaiser bezüglich hoher militärischer Funktionsträger befanden: Trotz wiederholter Verdachtsmomente hinsichtlich der Loyalität des Generals war Justinian auf die offenbar außergewöhnlichen Fähigkeiten Belisars angewiesen; auf öffentliche Erniedrigungen und unehrenhafte Entlassungen folgte stets die Rehabilitation. ${ }^{63}$

Ein häufig eingeräumtes Zugeständnis an verdiente Generäle bestand in der Verleihung des Konsulates, des höchsten säkularen Amtes, welches in der Spätantike seine ursprüngliche politische Funktion eingebüßt hatte und primär repräsentativ ausgerichtet war. Der Konsulat ging mit einer verstärkten Präsenz im öffentlichen Raum Konstantinopels einher: Die jeweiligen Inhaber waren zur Ausrichtung prächtiger Pompae aus eigenem Vermögen verpflichtet und konnten durch die Euergesia, die sie dabei zur Schau stellten, wiederum bei der hauptstädtischen Bevölkerung als wichtiger Akzeptanzgruppe Prestige aufbauen. Auch dem Belisar wurde im Jahr nach seinem Vandalensieg der Konsulat verliehen, anlässlich dessen er prunkvolle Spiele ausrichtete. ${ }^{64}$ Dabei ist $\mathrm{zu}$ betonen, dass der Konsulat keinesfalls militärischen Funktionsträgern vorbehalten war; auch zivile Beamte und verstärkt Verwandte des regierenden Kaisers bekleideten das Amt. ${ }^{65}$ Dass Justinian die Besetzung des Konsulates 541/2 einstellte, ist vor dem Hintergrund zu verstehen, dass der jeweilige Kandidat dem Kaiser durch seine öffentliche Exposition gefährlich in die Quere kommen konnte; als Justinians Neffe und Nachfolger Justin II. den Konsulat wiederbelebte, war und blieb dieses Amt ein Privileg des Kaisers bzw. der kaiserlichen Familie. ${ }^{66}$

Die Rivalität zwischen Kaisern und militärischen Funktionsträgern im hauptstädtischen Raum wurde durch den Umstand verschärft, dass letztere seit der Wende vom 4. zum 5. Jahrhundert wieder verstärkt private bewaffnete Einheiten um sich zu scharen begannen, die in der Forschung in der Regel unter dem Begriff ,Bukellarier“

hundert den Siegesfeierlichkeiten in der Hauptstadt in der Regel fernblieben; zu kaiserlicher Triumphalpraxis siehe unten 197f., 254-256.

63 Zu der von Belisar ausgehenden Bedrohung siehe Börm 2010, 177 f.; ders. 2013, 86 Anm. 127; ähnlich Meier 2002, 284f. Nach der Eroberung Karthagos 533 soll sich Belisar auf dem Thron des Gelimer

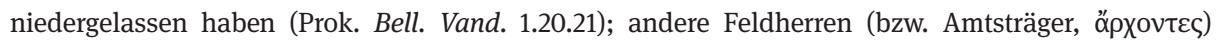
schwärzten den noch in Africa weilenden Belisar bei Justinian an, indem sie ihm vorwarfen, eine Usurpation anzustreben (Prok. Bell. Vand. 2.8.1-5). Im Zusammenhang mit der Belagerung Ravennas wurde Belisar von den Goten das weströmische Kaisertum angetragen; Belisar nahm das Angebot allerdings nur zum Schein an, um Ravenna einzunehmen; siehe Prok. Bell. Goth. 6.29.17-41; dazu Jones 1964 I, 278; Börm 2008, 152.

64 Diefenbach 2019, 95.

65 Jones 1964 II, $532 \mathrm{f}$.

66 Zum Konsulat siehe Begass 2018, 47-49, der auch festhält: „Die Kaiser mussten in den Consuln eine permanente mögliche Bedrohung ihrer eigenen Macht sehen.“ Zum Ende des Konsulates siehe Meier 2002, der zwar auch die potentielle Rivalität zwischen Kaiser und Konsuln betont (bes. 282), allerdings zu dem Schluss kommt, dass es angesichts der massiven reichsweiten Umbrüche um 540 für die altrömische Institution des Konsulates keinen Raum mehr gegeben habe (298). Zum spätantiken Konsulat im Allgemeinen siehe Sguaitamatti 2012, bes. 108-125 zur Ernennungspraxis. 
zusammengefasst werden. ${ }^{67}$ Während des Prinzipats war eine derartige Praxis streng reglementiert gewesen, um die Hoheit des Kaisers über militärische Einheiten nicht zu gefährden. Doch als die Kaiser sich ab dem späten 4. Jahrhundert von den Kriegsschauplätzen in ihre Residenzen zurückzogen und der direkte Bezug zwischen Monarch und Herr vor allem im Westen zu erodieren begann, begegnen uns wiederholt bewaffnete Hausmächte, die sowohl west- wie auch oströmischen Amtsträgern unabhängig von dem jeweils besetzten Kommando direkt unterstellt waren; Demandt spricht gar von einer „Privatisierung des Heeres“. ${ }^{68}$ Belisar soll laut Prokop aus eigener Tasche 7000 Reiter beschäftigt haben. ${ }^{69}$ Die Quellen legen nahe, dass Generäle ihre bewaffneten Gefolgschaften, die vor allem als Leibwache gedient zu haben scheinen, keineswegs vor den Mauern Konstantinopels entließen; vielmehr standen diese ihnen auch innerhalb der Stadt zur Verfügung und konnten im Konfliktfall die Interessen des Dienstherren auch gegenüber dem Kaiser verteidigen, bzw. dies zumindest versuchen: Nachdem der Kaiser Leon I. den Magister militum praesentalis Aspar im den kaiserlichen Gemächern hatte ermorden lassen, rannten dessen $\mathrm{Bu}$ kellarier gegen den Palast an und konnten nur durch die kaiserlichen Gardesoldaten zurückgehalten werden. ${ }^{70}$ Unter Justinian scheint es zu einer graduellen Einhegung dieses Phänomens gekommen zu sein - zumindest insofern, als dass derartige Gefolgschaften in kriegerischen Konflikten regelmäßig auch zugunsten des Kaisers eingesetzt wurden: Laut Prokop führte Belisar zusätzlich zu den römischen Truppen Einheiten seiner Bukellarier in den Krieg gegen die Vandalen. ${ }^{71}$ Die grundlegende Problematik war damit jedoch keinesfalls gebannt. Dass die Bukellarier auch im frühen 7. Jahrhundert noch innerhalb Konstantinopels machtpolitisch relevant waren, zeigt das Beispiel des Magister militum und Comes excubitorum Priskos, der seine Bukellarier 610 in seinem Anwesen zusammenzog, als sich in der Stadt Widerstand gegen den noch regierenden Kaiser Phokas regte. ${ }^{72}$ Als es Herakleios nach seiner Erhebung zum Kaiser gelang, den widerspenstigen Priskos zu entmachten, gliederte er dessen Bukellarier umgehend in seine eigenen Einheiten ein. ${ }^{73}$ Dass Amtsträger über bewaffnete Einheiten verfügten, die primär an sie anstatt an den Kaiser gebunden waren, kann als Epiphänomen der Entwicklung betrachtet werden, dass die Hoheit der Monarchen über den militärischen Sektor in der Spätantike zunehmend brüchig

$67 \mathrm{Zu}$ den Bukellariern siehe zuletzt Wijnendaele (im Druck).

68 Demandt 1980, 632.

69 Prok. Bell. Goth. 3.1.20. Unabhängig davon, ob man der konkreten Zahl Glauben schenkt oder nicht, zeigt der Abschnitt, über welche Mittel hohe militärische Funktionsträger mitunter verfügten.

$70 \mathrm{Zu}$ Aspar Malalas 14.40; auch Markian scharte bei seinem Usurpationsversuch gegen Zenon eine Riege von ihm untergebenen Soldaten um sich; siehe Joh. Ant. fragm. 303; Theoph Conf. AM 5971 (De Boor 126).

71 Prok. Bell. Vand.1.11.1-21; siehe Jones 1964 I, 273; Koehn 2018, 174 zu der Expeditionsarmee. Zu der Entwicklung der Bukellarier im 6. Jahrhundert siehe Wijnendaele (im Druck).

72 Joh. Ant. fragm. 321.

73 Nik. Brev. 2; die Dynamiken zwischen Priskos und Phokas bzw. Priskos und Herakleios werden unten 99f., 153-156 ausführlich diskutiert. 
wurde; diese Konstellation konnte wiederum zu einer Zuspitzung der Konflikte zwischen Kaiser und hohen militärischen Funktionsträgern führen. Die Versuche der Kaiser, die Privattruppen ihrer Amtsträger mit gesetzlichen Mitteln einzuschränken, erwiesen sich langfristig als erfolglos. ${ }^{74}$

\subsubsection{Kaiserliche Garden}

Wie bereits ihre Vorgänger verfügten auch die sesshaften Kaiser in Konstantinopel über ein Corps an Elitesoldaten, das ihnen als Leibwache diente. Gegenüber dem Feldheer waren die Gardesoldaten angesichts ihres engen Verhältnisses zum Kaiser privilegiert. In den Quellen finden sie zahlreiche Erwähnung: Sie treten sowohl in zeremoniellen Zusammenhängen auf (etwa bei der Erhebung von Kaisern) als auch bei städtischen Unruhen, wo sie in der Regel ihrer eigentlichen Funktion nachkommen, nämlich dem Schutz des Palastes und des Kaisers. Bisweilen wurden die Gardesoldaten auch zur Verteidigung der Stadt eingesetzt. ${ }^{75}$

Die Entwicklung der kaiserlichen Garden lässt sich folgendermaßen zusammenfassen: ${ }^{76}$ Im Nachklang seines Sieges über Maxentius löste Konstantin die Prätorianergarde auf und entkleidete den Prätorianerpräfekt, dessen Machtvollkommenheit ein dauerhaftes Risiko für den Kaiser darstellte, seiner militärischen Kompetenzen. Anstelle der Prätorianer übernahmen die Scholae palatinae den Schutz des Kaisers. Mit der Niederlassung der Kaiser in Konstantinopel ging der Wandel der Scholae von einer mobilen Einsatztruppe, die mit dem Kaiser durch das Reich reiste, zu einer dauerhaft in der Hauptstadt ansässigen Institution einher. Die Notitia dignitatum nennt sieben Einheiten der Scholae, die in und um Konstantinopel stationiert waren. ${ }^{77}$ Als Leibwache im engeren Sinne zeichnete sich die Gruppe der Candidati durch besondere Nähe zum Kaiser aus. ${ }^{78}$ Der Dienst in einer der Gardeeinheiten war höchst

$74 \mathrm{Zu}$ den Bukellariern siehe Schmitt 1994; Demandt 2007, 312f., Szidat 2010, 202f. und zu dem Versuch, Bukellarier gesetzlich zu verbieten, siehe Börm 2010, 168; Wijnendaele (im Druck) zu „legal and social status“ der Bukellarier.

75 Siehe Pfeilschifter 2013, 239-245; vgl. Croke 2005b, 146.

76 Die in Konstantinopel stationierten Gardesoldaten waren keine homogene Gruppe, sondern einer Reihe verschiedener Einheiten zugeordnet, deren Zusammensetzung, Organisation, spezifische Funktion und Verhältnis zueinander der Forschung nach wie vor Rätsel aufgibt.

77 Not. dign. or. 11. Mit einer Stärke von ca. 400 Mann pro Einheit ist von einer Gesamtzahl um 2800 Männer im 5. Jahrhunderte auszugehen. Unter Justinian wurde ihre Zahl auf 3500 aufgestockt (Prok. Hist. arc. 24.15).

78 Die Protectores bzw. Protectores domestici stellten eine weitere Gruppe von Gardesoldaten mit spezifischem Zuständigkeitsbereich dar, aus der zumindest im 4. Jahrhundert noch hohe Offiziere rekrutiert wurden. Umfassend zu den Scholae palatinae Frank 1969; außerdem Jones 1964 II, 613 f; Dagron 1984, 113-115; zu den Protectores siehe Jones 1964 II, 636-640; Frank 1969, 179-168 und Haldon 1984, 130 - 136. 
begehrt und brachte soziale wie finanzielle Privilegien mit sich. ${ }^{79}$ In dem Zusammenhang dieser Arbeit ist entscheidend zu betonen, dass die Scholae nicht zum Zuständigkeitsbereich der Heermeister gehörten - selbst die beiden Magistri militum praesentales hatte keinen Zugriff auf sie; stattdessen waren sie administrativ einem Zivilbeamten, dem Magister officiorum, untergeordnet. ${ }^{80}$ Unter Leon I. trat neben die Scholae eine weitere, 300 Mann starke Einheit, die Exkubitoren, mit einem Comes an der Spitze, welche als besonders schlagkräftiges Elitecorps für den Schutz der Ein- und Ausgänge des kaiserlichen Palastes zuständig waren. ${ }^{81}$ Mit der Schaffung der Exkubitoren, die übers 6. und 7. Jahrhundert hinweg ihre Stellung als wichtigste Gardeeinheit sicherten, ging ein Bedeutungsschwund der Scholarier einher, zumindest in Bezug auf ihre militärische Schlagkraft. Sie blieben als Einheit bestehen, fungierten allerdings primär in zeremoniellen Kontexten als Schautruppe, deren prestigereiche Mitgliedschaft als Ehrerweisung verliehen bzw. mit Geld erkauft werden konnte. ${ }^{82}$ Die Befehlshaber der Garden können wiederum als distinkte Gruppe innerhalb der militärischen Funktionsträger ausgemacht werden. Obwohl die Einheiten, über welche die verschiedenen Gardekommandeure im 5. und 6. Jahrhundert verfügten, zahlenmäßig kleiner waren als die, die früher etwa ein Prätorianerpräfekt befehligt hatte, darf ihre Stellung nicht unterschätzt werden: Je enger die Bindung des Kaisers an Konstantinopel, desto größer die Bedeutung der Garden bzw. die Vollmacht ihrer Kommandeure im Verhältnis zum Kaiser. ${ }^{83}$

79 Frank 1969, 174-179.

80 Die effektive Befehlsgewalt unterlag allerdings - so Haldon 1984, 142-150 - offenbar dem Comes domesticorum. Die sieben Einheiten der Scholae wurden jeweils von einem Tribun befehligt. Vgl. Croke 2005a, 163-175 zu Zenon als Comes domesticorum und seinem Verfügungsbereich.

81 Zu den Exkubitoren siehe Jones 1964 II, 658 - 659; Frank 1969, 206 - 213; Haldon 1984, 136 - 141; Ma. Whitby 1987, 483-488; Pfeilschifter 2013, 241f. In der Forschung herrschte lange die Ansicht, dass Leon I. die isaurisch dominierten Exkubitoren als Gegengewicht zu den Scholae geschaffen habe, deren größtenteils germanische Mitglieder zu diesem Zeitpunkt unter dem Einfluss des alanischen Heermeisters Aspar gestanden hätten; siehe Frank 1969, 203-205. Diese Ansicht wurde zuletzt zwar mit dem Verweis darauf relativiert, dass es bereits vor Leon I. eine gleichnamige Einheit gegeben habe; so Croke 2005b und 2005a, 169-171, der sich auch gegen die klare Dichotomie Scholae = germanische Garden und Exkubitoren = isaurische Garden ausspricht. Es ist jedoch kaum zu leugnen, dass die Exkubitoren, ob zuvor bereits als Einheit in Konstantinopel existent oder nicht, durch Leon I. eine klare Bedeutungssteigerung erfuhren. Ich halte es weiterhin für gerechtfertigt, hinter dieser Maßnahme den Versuch Leons zu sehen, seine Position in der Hauptstadt durch eine an ihn persönlich gebundene und schlagkräftige Truppe zu sichern und potentieller Fremdbestimmung vorzubeugen; siehe Börm 2013, 78. Börm 2010, 168 weist darauf hin, dass es kaum ein Zufall gewesen sein wird, dass ausgerechnet Leon I. als „Gründer der neuen Garde“ Privatleuten gesetzlich verbot, sich mit Bewaffneten zu umgeben (Cod. Iust. 9.12.10).

82 Zu den Scholae im 6. Jahrhundert siehe Jones 1964 II, 657 f.; Frank 1969, 213 - 217; Haldon 1984, 119 128, bes. 125-128; zu den Candidati, die im kaiserlichen Zeremoniell auch im 6. Jahrhundert weiterhin eine Rolle spielten, siehe Ma. Whitby 1987, 464-466.

83 Sowohl der Magister officiorum als auch der Comes domesticorum und Comes excubitorum gehörten als Illustres der politischen Elite der Hauptstadt an. 
Die Palastgarden waren nie strikt von den außerstädtischen Militäreinheiten getrennt; es gab sowohl Überschneidungen als auch wechselseitigen Einfluss. Gardesoldaten wurden aus dem Heer rekrutiert, ehemalige Gardesoldaten fungierten als Magistri militum, Gardisten bzw. deren Befehlshaber konnten vom Kaiser für militärische bzw. diplomatische Missionen in die Provinzen gesandt werden und ab dem Ende des 6. Jahrhunderts wurden Comites excubitorum auch verstärkt als Heermeister eingesetzt. Die direkte Interaktion mit und Befehlsgewalt über die Garden, die gegenüber den einfachen Soldaten eindeutig privilegiert wurden, bot den Kaisern nicht nur die Möglichkeit, eine derart schlagkräftige Truppe stärker an die eigene Person zu binden, als es bei den Provinzheeren der Fall war; indem sie vertraute Gardisten in die Provinz zum Heer abordneten, konnten auch die sesshaften Kaiser eine gewisse, wenn auch nicht persönliche Kontrolle über den militärischen Sektor in den Provinzen erreichen und ein Gegengewicht zu der Machtposition der Generäle etablieren. ${ }^{84}$

Innerhalb des hier behandelten Zeitraumes scheint die Loyalität der Garden gegenüber ihrem Kaiser grundsätzlich gefestigt gewesen zu sein. In prekären Situationen standen sie ihm entschieden zur Seite. ${ }^{85}$ Eine Revolte gegen den regierenden Kaiser, die von den Reihen der Garden ausging, ist im 5. und 6. Jahrhundert nicht zu verzeichnen. Erst wenn ein Kaiser massiv an Gunst eingebüßt hatte und das Fortbestehen seiner Herrschaft geradezu aussichtslos erschien, kam es zu Abfällen. Als der Anastasius-Neffe Hypatios während des Nika-Aufstand gegen Justinian im Hippodrom zum Kaiser akklamiert wurde, weigerten die kaiserlichen Garden sich, zugunsten des Justinian in das Geschehen einzugreifen; die gewaltsame Niederschlagung des Aufstandes konnte nur durch Feldeinheiten gelingen, kommandiert von den Befehlshabern Belisar und Mundos. ${ }^{86}$ 610, als die Flotte des Usurpators Herakleios vor Konstantinopels ankerte und Phokas in der Stadt zunehmend an Rückhalt verlor, stellten sich die Exkubitoren unter ihrem Kommandanten Priskos geschlossen gegen den noch regierenden Kaiser. ${ }^{87}$

Zwischenfazit: In der Forschung wurde wiederholt betont, die Bindung der oströmischen Monarchen an ihre Hauptstadt habe einerseits die individuelle Herrschaft gesichert und andererseits das Überleben der Institution Kaisertum ermöglicht, während ihre westlichen Kollegen am Druck einer übermächtigen Militärelite zu Grunde gingen. Allerdings darf dabei nicht übersehen werden, dass sich auch die oströmischen Kaiser hoher militärischer Funktionsträger erwehren mussten. Wie oben

84 Siehe Dagron 1974, 113-115; zu Entsendungen von Gardesoldaten (bzw. gar Comites excubitorum) in die Provinz siehe Jones 1964 II, 658 f. und Pfeilschifter 2013, 243 Anm. 78; zur Rekrutierungspraxis im oströmischen Reich ab 400 (römisch- vs. barbarisch-stämmige Mitglieder) siehe den Überblick bei Frank 1969, 201-219, außerdem Pfeilschifter 2013, 245.

85 Nach der Ermordung Aspars durch Leon I. schützten die Exkubitoren den Palast vor dessen Bukellariern (Malalas 14.40).

86 Prok. Bell. Pers. 1.24.39-51.

87 Joh. Ant. fragm. 321; Chron. Pasch. AD 610; zum Sturz des Phokas siehe ausführlich unten Kap. 3.2; zur Frage der Loyalität der Garden vgl. Pfeilschifter 2013, 245 f. 
nachvollzogen, verlor die Masse des Heeres für die Aushandlung monarchischer Herrschaft tatsächlich an Relevanz, nachdem die Kaiser sich in Konstantinopel niedergelassen hatten; auch die städtischen Garden scheinen keine genuine Bedrohung für die sesshaften Monarchen dargestellt zu haben. Hohe militärische Funktionsträger indes konnten trotz der administrativen Strukturen, die ihren Einfluss beschränkten, erhebliche Machtmittel akkumulieren. Zunehmend selbstbewusste und unabhängige Militärs, teilweise mit nichtrömischem Hintergrund, die entweder offiziell in Amt und Würden und somit als Teil der hauptstädtischen Eliten agierten oder als Warlords vom Balkan aus die Hauptstadt bedrohten, schränkten die Handlungsmöglichkeiten der oströmischen Kaiser ein. ${ }^{88}$ Diese Entwicklung bündelte sich in der Person des alanischen Heermeisters Aspar, der als Magister militum praesentalis maßgeblichen Einfluss auf die Erhebung der Kaiser Markian und Leon I. nahm und von Letzterem nur unter Mühen aus dem Weg geräumt werden konnte. Leons Emanzipation gegenüber seinem ehemaligen Gönner war allerdings teuer erkauft: Sie gelang, indem er mit dem Isaurier Zenon einen konkurrierenden Heermeister und dessen Clique aufbaute; 474 trat Zenon dann als Leons Schwiegersohn auch dessen Nachfolge an. ${ }^{89}$ Strukturelle Unsicherheiten hinsichtlich der Besetzung des Kaiserthrones - etwa die Frage, welche sozialen, ethnischen bzw. religiösen Gruppen überhaupt dafür in Frage kamen führten in der zweiten Hälfte des 5. Jahrhunderts zu andauernden Machtkämpfen und machten das Kaisertum in den Worten Mischa Meiers „disponibel“. Die Entwicklung im Westen, wo sich gezeigt hatte, dass Herrschaft über die Römer auch ohne römischen Kaiser funktionieren konnte, mag als Exempel gedient und die Prozesse im Osten beeinflusst haben. ${ }^{90}$

Eine entscheidende Wende sieht die Forschung in der Regel in der Erhebung des Anastasios 491, der im Gegensatz zu seinen Vorgängern vor seiner Krönung als Palastbeamter, als Silentiarios, gedient hatte. Anastasios' Sieg über die aufständischen Isaurier unter Zenons Bruder Longinos, der als General selbst Ambitionen auf den Thron gezeigt hatte, gilt als Emanzipation einer zivil-urbanen Sphäre gegenüber der Bevormundung durch hohe Militärs. Darüber hinaus zeitigte unter Anastasios ein Sakralisierungsschub nicht nur stabilisierende Wirkung auf dessen Position im hauptstädtischen Kontext, sondern auch auf die Institution des Kaisertums im Ganzen. Spätestens hinsichtlich der Herrschaft Justinians kann Henning Börm konstatieren, dass sich „der Vorrang von Herrscher und Hof gegenüber der militia armata wieder fest etabliert [hatte]““.91

88 Meier 2012, 215.

89 Bei Croke 2005a wird diese Konstellation ausgiebig untersucht. Dass Zenon es als erster Magister militum selbst bis auf den Thon geschafft habe, habe laut Meier $(2012,217)$ einen Präzedenzfall geschaffen und Nachahmer angespornt - das erkläre die verhältnismäßig häufigen Usurpationsversuche während Zenons Regierungszeit.

90 Siehe Meier 2012, 206 -222, Zitat 218. Zu den Auswirkungen des Endes weströmischer Monarchie auf die oströmische Herrschaftskonfiguration vgl. ders. 2014c.

91 Zu Anastasios Meier 2009; Meier 2012, 119-222; Börm 2013, 79, 86 (Zitat). 
Ohne eine Stabilisierung der oströmischen Monarchie in der ersten Hälfte des 6. Jahrhunderts leugnen zu wollen, meine ich doch, dass eine derartige Sichtweise zu einem gewissen Grad den Kern des hier behandelten Problems verdeckt: Die Rivalität zwischen einem sesshaften Kaiser und hohen militärischen Funktionsträgern war kein individuelles Phänomen, welches sich auf bestimmte Personenkonstellationen reduzieren lässt, sondern ein strukturelles, wie im folgenden Unterkapitel genauer erläutern werden soll. ${ }^{92}$ Weder der Sieg des Anastasios über die Isaurier noch die unter Justinian auf neue Ebenen gehobene Sakralisierung konnten die Bedrohung des sesshaften Kaisers durch den militärischen Sektor grundsätzlich aus dem Weg räumen; zumindest in latenter Form musste der Machthaber in Konstantinopel sich mit dieser stets auseinandersetzen.

\subsection{Mechanismen politischer Entscheidungsprozesse}

Im Folgenden soll die These von der Bedrohung der sesshaften Kaiser in Konstantinopel durch den militärischen Sektor untermauert werden. Ein Überblick über die Mechanismen politischer Entscheidungsprozesse und die dabei tonangebenden Akteure wird zeigen, in welchem Maße hohe militärische Funktionsträger die Autorität der sesshaften Kaiser des 5. und 6. Jahrhunderts beeinträchtigen konnten. Geht man davon aus, dass das Ziel militärischer Funktionsträger ein Zuwachs an Macht, Status, Einfluss und damit auch Vermögen war, konnte dieses Ziel - zumindest im oströmischen Reich - nachhaltig nur in Bezug zum Kaiser erreicht werden, der die politischen Prozesse zumindest nominell steuerte und sanktionierte. Das heißt, militärische Funktionsträger konnten entweder versuchen, den regierenden Kaiser unter Druck zu setzen, um bestehende Kommandos zu verstetigen bzw. neue Kommandos zu erwirken und damit ihre Machtbasis zu erweitern, oder sie konnten ihre Reichweite und ihr Prestige nutzen, um die Besetzung des Thrones direkt $\mathrm{zu}$ beeinflussen. Letzterer Punkt - die Besetzung des Thrones - dient als roter Faden des nun folgenden Überblickes.

Die Frage nach den Mechanismen monarchischer Sukzession in der Spätantike ist eine oft gestellte; zuletzt hat Henning Börm die maßgeblichen Tendenzen zusammengefasst. Im Zuge der Reichskrise des 3. Jahrhunderts entschied vorrangig militärische Schlagkraft über die Besetzung des Thrones. Das Prinzip, nach welchem dem bzw. den (militärisch) fähigsten Kandidaten die Lenkung der Res publica übertragen wurde, prägte auch die Ausgestaltung der diokletianischen Tetrarchie. Nicht Blutsverwandtschaft, die während des Prinzipats eine zunehmend wichtige, wenn auch nicht alleinig ausschlaggebende Rolle gespielt hatte, sondern individuelle Eignung und Verdienst bestimmten über die Zusammenstellung des Herrscherkollegiums: je zwei Augusti und Caesares, die durch Heiratsallianzen miteinander verbunden waren.

92 Darauf, dass es sich um ein strukturelles Problem handelt, verweist auch Börm 2010, $166 \mathrm{f}$. 
Mit Konstantin, der sich entgegen der Konzeption des tetrarchischen Systems als leiblicher Sohn des verstorbenen Augustus Constantius Chlorus erst als Caesar und schließlich als Augustus durchsetzen konnte, erfolgte ein erneuter Aufschwung des dynastischen Prinzips. Seinen Bruch mit dem tetrarchischen System versuchte Konstantin - letztendlich erfolgreich - durch die Betonung von consanguinitas als maßgeblichem Kriterium für monarchische Sukzession zu kompensieren. Die von Konstantin gesetzten Maßstäbe stellten die Weichen für die weitere Entwicklung: Bis in die Mitte des 5. Jahrhunderts entstammten alle reichsweit anerkannten Kaiser (mit Ausnahme Jovians) erst der konstantinischen und später der valentinianisch-theodosianischen Dynastie. Dabei bleibt mit Henning Börm zu betonen, dass die spätantike Monarchie zu keinem Zeitpunkt die Form einer institutionalisierten Erbmonarchie annahm: Monarchische Sukzession war und blieb weiterhin grundsätzlich verhandelbar. Dynastische Verbindungen wogen schwer, wurden allerdings durch eine Reihe weiterer, potentiell ausschlaggebender Faktoren ausbalanciert. ${ }^{93}$

Das Ziel dieses Kapitels ist es herauszuarbeiten, welche Rolle der militärische Sektor bei der Nachfolgeregelung im oströmischen Reich des 5. und 6. Jahrhunderts spielte bzw. welche Impulse von diesem ausgingen. Dabei geht es hier weder um die eigentlichen Kaisererhebungen, welche die zuvor gefällte Entscheidung für einen bestimmten Kandidaten performativ umsetzten und wirksam machten, ${ }^{94}$ noch um die zeitgenössischen Deutungen von Selektionsprozessen bzw. getroffenen Wahlen, wie sie uns in den Quellen entgegentreten. Stattdessen sollen die Mechanismen hinter der Entscheidungsfindung aufgedeckt werden; konkret gesagt steht die Frage im Vordergrund, welche Personen als Thronfolger aufgebaut wurden, wer nach dem Tod eines Kaisers tatsächlich zum Zuge kam $^{95}$ und wer den Kaiser durch bisweilen offene Usurpation herauszufordern versuchte. Ich werde dafür argumentieren, dass monarchische Sukzession, solange sie nicht strikt entlang des dynastischen Prinzips verlief und Herrschaft vom Vater an den Sohn übertragen werden konnte, primär von den Interessen hoher militärischer Funktionsträger bestimmt wurde, bisweilen gehemmt durch das Bemühen einer zivilen/urbanen Sphäre, sich im Ringen um Macht und Einfluss zu behaupten.

Die Praxis, leibliche Söhne noch zu Lebzeiten zum Nachfolger zu designieren, die sich bereits während des Prinzipats etabliert und mit Konstantin erneut verfestigt hatte, fand auch im oströmischen Reich des Spätantike Anwendung. Theodosios I. übertrug die Herrschaft an seine Söhne Arkadios und Honorius. Der in Konstantinopel residierende Arkadios krönte 402 seinen Sohn Theodosios II. im Alter von nur einem

93 Siehe Börm 2015a; außerdem Szidat 2010, 165-182 und Lee 2007, 27 f.; zum oströmischen Reich im Speziellen siehe auch Diefenbach 1996, 37f.; zu monarchischer Sukzession außerdem Dagron 2003, 13-53 und Omissi 2018, 3-12.

$94 \mathrm{Zu}$ Krönungsritualen siehe Trampedach 2005; die Funktion derartiger Inszenierungen wird unten Kap. 3.3.1 im Detail besprochen.

$95 \mathrm{Zu}$ den Voraussetzungen für eine Erhebung zum Kaiser in der Spätantike (Untersuchungszeitraum 337-467) siehe Szidat 2010, 182-187. 
Jahr zum Augustus. ${ }^{96}$ Nach Arkadios konnte eine derartige Form der dynastischen Sukzession indes nicht weitergeführt werden: Bis ins späte 6. Jahrhundert bekamen die oströmischen Kaiser keine Söhne mehr. ${ }^{97}$ Allein bei Basiliskos, der den Kaiser Zenon 475 kurzzeitig vom Thron verdrängen konnte, lag die Herrschaftsübergabe vom Vater an den Sohn zumindest in der Luft: Er erhob seinen Sohn Markos erst zum Caesar und kurz darauf zum Augustus. Bei der Rückkehr Zenons im Jahr 476 wurden allerdings beide Männer abgesetzt. ${ }^{98}$ Angesichts des Nichtvorhandenseins leiblicher Söhne erfolgte bisweilen die Designation männlicher Blutsverwandter zweiten Grades: Leon I. (457-474) erhob seinen Enkel Leon II., den Sohn seiner Tochter Ariadne, zum Augustus; dieser verstarb jedoch bereits kurz nach dem Tod seines Großvaters. ${ }^{99}$ Justin I. (518-527) krönte seinen Neffen Justinian kurz vor seinem Tod zum Augustus. ${ }^{100}$ Männliche Blutsverwandte des Kaisers konnten aber durchaus auch übergangen werden; sowohl Anastasios als auch Justinian, die beide mehrere Neffen hatten, verstarben, ohne einen Nachfolger designiert zu haben. Erst Maurikios (581-602) hatte gleich mehrere Söhne; seinen Ältesten, Theodosios, erhob er im Alter von sieben Jahren zum Augustus. ${ }^{101}$ Maurikios' Bemühungen, eine neue Dynastie zu etablieren, fanden allerdings beim Staatsstreich des Jahres 602, bei dem der Kaiser mitsamt seiner männlichen Nachkommen ermordet wurde, ein abruptes Ende.

Als beim überraschenden Tod des Theodosios II. 450 kein männlicher, dynastisch legitimierter Nachfolger zur Verfügung stand, erwies sich die Initiative des alanischen Magister militum praesentalis Aspar als ausschlaggebend. ${ }^{102}$ Als Sohn des Ardabur, der sich bereits in die höchste militärische Riege des Reiches hochgearbeitet hatte, begann Aspar seine Karriere unter Theodosios II., bekleidete als Magister militum mehrere Kommandos und im Jahr 434 gar den Konsulat. Seine Stellung in der politischen Elite Konstantinopels war derart gefestigt, dass er mit Markian, seinem ehemaligen Domestikos, und Leon I., dem Tribun der in Selymbria stationierten Truppen, 450 bzw. 457 zwei Männer aus seinem Umfeld auf den Thron bringen konnte, während er selbst weiterhin das Amt des Magister militum praesentalis besetzte. ${ }^{103}$ Um die

96 Chron. Pasch. AD 402; siehe Diefenbach 1996, 38 auch zur Bedeutung der weiblichen Mitglieder des Kaiserhauses bei der Sukzession.

97 Verina, die Frau des Leon I., brachte einen Sohn zur Welt, der allerdings früh starb; siehe Croke $2005 a, 158$.

98 Zur Usurpation des Basiliskos und Zenons Rückkehr siehe Pfeilschifter 2013, 536 - 544; zu Markus siehe PLRE II, Marcus 4 (720).

99 PLRE II, Leo 7 (664f.).

100 Siehe Croke 2007, 43-55.

101 Die Umstände der Erhebung des Theodosios werden unten 72f. diskutiert.

$102 \mathrm{Zu}$ Aspar und seiner Einflussnahme siehe Trampedach 2005, 285; Pfeilschifter 2013, 512-535; zu den Entscheidungsträgern nach Theodosios' Tod siehe auch Szidat 2010, 397-400. Einen Überblick über die ereignisgeschichtlichen Zusammenhänge von der Erhebung des Marcian bis zur Regierung des Anastasios bietet Jones 1964 I, 217-237.

103 PLRE II, Fl. Ardabur Aspar (164-169); siehe auch Jones 1964 I, 181 f. und zum Hintergrund und Aufstieg des Aspar siehe Croke 2005a, 149-163. 
Erhebung des Markian, der über keine eigenständige Reputation verfügte, mit der nötigen Legitimität $\mathrm{zu}$ versehen, wurde dieser mit Pulcheria, der jungfräulichen Schwester des verstorbenen Theodosios II., in einer Jakobs-Ehe verheiratet. ${ }^{104}$ Ohne selbst je nach dem Purpur zu greifen, ${ }^{105}$ baute Aspar seine Machtfülle bzw. die seiner Familie stetig aus: Sein Sohn Patrikios heiratete 470 Leons Tochter Leontia und wurde zum Caesar erhoben, was einer Designation gleichkam. ${ }^{106}$ Doch Leon ließ sich die Bevormundung durch seinen ehemaligen Gönner auf die Dauer nicht gefallen: In der Person des isaurischen Militärs Zenon baute er einen alternativen Kandidaten auf. Bereits 466/67 hatte Leon diesen mit seiner älteren Tochter Ariadne verheiratet und sukzessive zum Comes domesticorum und Magister militum erhoben. Als Aspar auf Befehl Leons hin 471 im Palast ermordet wurde, deckte Zenon seinem Schwiegervater den Rücken. ${ }^{107}$ Den Rang des Augustus erreichte Zenon allerdings erst 474 nach dem Tod des Leon I., als ihn dessen kurzzeitiger Nachfolger, Zenons Sohn Leon II., im Hippodrom krönte. ${ }^{108}$

Zenons Regierung (474-491) war durch anhaltende Unruhen geprägt. ${ }^{109}$ Kurz nach dem Tod seines Sohnes Leon, der ihn als alleinigen Augustus zurückließ, gelang dem Basiliskos die einzig zumindest zeitweilig erfolgreiche Usurpation im oströmischen Reich des 5. und 6. Jahrhunderts. Diesen Coup als „Palastverschwörung“ zu bezeichnen, wie es etwa Henning Börm tut, ${ }^{110}$ ist meiner Ansicht nach zu einseitig. Zwar nahm Basiliskos, der Bruder der Augusta Verina und somit Schwager des verstorbenen Leon I., als ehemaliger Konsul, Patrikios und Caput senatus durchaus eine herausgehobene Stellung innerhalb der hauptstädtischen Elite und des kaiserlichen Palastes ein; seine Position hatte er sich allerdings auf einer militärischen Laufbahn erarbeitet: Nach verschiedenen Kommandos in den Provinzen besetzte er zuletzt das Amt des Magister militum praesentalis. Auch die Männer, die Basiliskos’ Vorhaben unterstützten, zeichneten sich durch militärischen Hintergrund aus. ${ }^{111}$ Nach Zenons Flucht aus der Hauptstadt übernahm die Augusta Verina die Krönung ihres Bruders

104 PLRE II, Marcianus 8 (714f.).

105 Siehe Meier 2012, $206 \mathrm{f}$.

106 PLRE II, Iulius Patricius 15 (842f.); ein weiteres Indiz, dass es bei Patrikios tatsächlich um die Nachfolge ging, war, dass er vom arianischen Glauben zum orthodoxen, d.h. zum Chalkedonense konvertierte; vgl. Demandt 1970, 757.

107 Die Dynamiken des Machtkampfes zwischen Leon I. und Aspar werden detailliert bei Croke 2005a aufgeschlüsselt; zum Aufbau Zenos ebd. 163-175.

108 PLRE II, Fl. Zenon 7 (1200).

109 Zu Zenon siehe die Monographie von Kosinski 2010; außerdem Meier 2012, 215-222; Pfeilschifter 2013, 536-561.

110 Börm 2013, 78 Anm. 82.

$111 \mathrm{Zu}$ nennen wären prominent Armatos (Magister militum per Thrakias - PLRE II, Armatus [148f.]), Markian (Magister militum praesentalis mit erstrangigen dynastischen Verbindungen - siehe PLRE II, Fl. Marcianus 17 [717f.]) und der isaurische General Illous (PLRE II, Illus 1 [586-590]); auch ein gewisser Zuzos (PLRE II, Zuzus [1207]), ein Schwager der Augusta Verina, war an der Verschwörung beteiligt; zu seiner Karriere lassen sich allerdings keine näheren Aussagen treffen. 
auf dem Hebdomon. ${ }^{112}$ Basiliskos konnte sich allerdings nur ein Jahr in Konstantinopel halten. ${ }^{113}$ Zenons Rückkehr aus dem isaurischen Exil im darauffolgenden Jahr gelang unter anderem aufgrund des Seitenwechsels des Heermeisters Armatos, der von Basiliskos mit Truppen losgeschickt worden war, um den Konkurrenten aufzuhalten: Zenon sicherte sich Armatos' Unterstützung, indem er versprach, dessen Sohn zum Caesar zu erheben. Kurz nachdem ihm die Übernahme der Hauptstadt geglückt war, entledigte Zenon sich allerdings des unliebsamen Nachfolgers. ${ }^{114}$

479, nur wenige Jahre nach Zenons Rückkehr, rebellierte dessen Schwager, der General Markian, der bereits an der Usurpation des Basiliskos beteiligt gewesen war; Markian hatte nicht nur eine erfolgreiche militärische Karriere hinter sich, sondern auch dynastische Verbindungen: Er war der Enkel des gleichnamigen Ostkaisers Markian und Sohn des Westkaisers Anthemios. Außerdem war er mit Leontia, der jüngeren Tochter des Leon I., in deren zweiten Ehe verheiratet und somit Zenons Schwager. ${ }^{115}$ Unterstützung fand Markian bei dem Goten Theoderich Strabo, der mit seinen Einheiten von Thrakien aus Konstantinopel unter Druck setzte. ${ }^{116}$ Mit einer Gruppe aus Römern und Goten bestürmte Markian den Palast in Konstantinopel, konnte allerdings nach anfänglichen Erfolgen durch den Magister officiorum Illous, der die Palastgarden befehligte, zurückgeschlagen werden. ${ }^{117}$

Das Verhältnis zwischen den Landsleuten Zenon und Illous - bereits durch die Beteiligung des Letzteren an der Usurpation des Basiliskos angekratzt - erwies sich nur wenige Jahre später erneut als brüchig: Zenon schickte Illous 481 als Magister militum in den Osten, enthob ihn allerdings kurz darauf seiner Ämter, da er offenbar ein zu großes Risiko darstellte. Diese Herabsetzung beantwortete Illous mit offener Rebellion und begann, im Osten Truppen um sich zu scharen; Zenon schickte ihm den General Leontios entgegen. ${ }^{118}$ Doch Leontios lief zu Illous über und wurde mit dessen Unterstützung 484 im kilikischen Tarsos von der Augusta Verina gekrönt, die man

112 Theod. Lect. epit. 401; Vita Dan. 69; Mal. 15.2f.; Theoph. Conf. AM 5967 (De Boor 120f.); Vict. Tun. s.a. 475; Anon. Vales. 41; Marc. Com. Chron. ad a. 475; Prok. Bell. Vand. 1.7.18; Evagr. Hist. eccl. 3.3. Siehe dazu Pfeilschifter 2013, 536-544; Kosinski 2010, 79-82; Brandes 1993.

113 Sein Scheitern scheint vor allem seiner Religionspolitik zuzuschreiben zu sein, die in der Hauptstadt auf Ablehnung stieß, dazu siehe Pfeilschifter 2013, 564-584; vgl. Redies 1997.

114 Armatos handelte außerdem aus, dass ihm lebenslänglich das Amt des Magister militum übertragen wurde (Mal. 15.5; Theoph. Conf. AM 5969 [De Boor 124]). Zenon adoptierte darüber hinaus auch den Sohn des Theoderich des Amalers, um dessen Unterstützung gegen Theoderich Strabo sicherzustellen; auch diese Verbindung wurde bald wieder aufgelöst; siehe Jones 1964 I, 225.

115 PLRE II, Fl. Marcianus 17 (717f.). Gemäß den Quellen bediente er sich des Arguments, gegenüber Zenon im Vorrang zu sein, da seine Frau Leontia im Gegensatz zu Zenons Frau Ariadne im Purpur geboren worden war; siehe Joh. Ant. fragm. 303; Theoph Conf. AM 5971 (De Boor 126).

116 Leon I., Basiliskos und Zenon hatten Theoderich bereits wiederholt als Zugeständnis das Amt des Magister militum praesentalis verliehen; siehe PLRE II, Theodericus Strabo 5 (1073-1076); zu den wechselvollen Beziehungen der Römer zu den beiden Theoderichen (Theoderich Strabo und Theoderich der Amaler) siehe Jones 1964 I, 224-227.

117 Zum Usurpationsversuch des Markian siehe Pfeilschifter 2013, 551-554.

118 PLRE II, Leontius 17 (670f.). 
zuvor aus ihrem Exil herbeigeholt hatte. Die Krönung in der Provinz entfaltete allerdings in Konstantinopel keine Wirkmächtigkeit, wo Zenon weiterhin die Zügel in der Hand hatte. Leontios und Illous erlitten kurz darauf eine schwere Niederlage; nach mehrjähriger Belagerung in einer isaurischen Bergfestung wurden die beiden Männer schließlich hingerichtet. ${ }^{119}$

Als Zenon 491 verstarb, ohne einen Nachfolger designiert zu haben, sah eine Parteiung der hauptstädtischen Elite um den Praepositus sacri cubiculi Urbikios die Gelegenheit gekommen, sich der jahrzehntelangen Bevormundung durch alanische bzw. isaurische Heermeister zu entledigen. Die ,Wahl' eines Nachfolgers wurde formal der Augusta Ariadne, Zenons Witwe, übertragen, die sich für einen bereits in die Jahre gekommenen Palastbeamten, den Silentiarios Anastasios, entschied. Um wiederum einem Mann ohne eigenständige Autorität die nötige Legitimität zu verleihen, wurde er mit Ariadne verheiratet. ${ }^{120}$ Zenons Bruder Longinos, der das Amt des Magister militum praesentalis innegehabt, mehrmals den Konsulat bekleidet und sich Hoffnungen auf die Nachfolge seines Bruders gemacht hatte, ging angesichts dieser Entwicklung mit seinem gleichnamigen Landsmann, dem Magister officiorum Longinos, in den Widerstand. ${ }^{121}$ Isaurische Truppen wurden in Kleinasien zusammengezogen; bei der Schlacht von Cotyaeum 492 unterlagen sie allerdings den kaiserlichen Einheiten - der isaurische Einfluss auf Konstantinopel war damit gebrochen. ${ }^{122}$

Unter Anastasios lässt sich eine gewisse Stabilisierung des politischen Klimas beobachten; erst nach zwanzig Jahren an der Macht sah auch er sich mit Usurpationsgefahr konfrontiert: Im Zuge des Staurotheis-Aufstandes 512, bei dem die chalkedonensische Bevölkerung Konstantinopels sich gegen die kaiserliche Religionspolitik auflehnte, wurden Rufe nach einer Krönung des Areobindos laut. ${ }^{123}$ Areobindos entstammte der Familie des Aspar, war mit Anicia Juliana verheiratet, ihrerseits Nachfahrin der valentinianisch-theodosianischen Dynastie und Tochter des ehemaligen Westkaisers Anicius Olybrius; er hatte Kommandos als Magister militum und 506 den Konsulat belegt - in seiner Person verband sich also eine weiterhin mächtige Militärdynastie mit altem römischem Adel. Doch Areobindos entzog sich den Avancen der hauptstädtischen Bevölkerung; Anastasios’ Regierung war vorerst gesichert. ${ }^{124}$

Anastasios' späte Jahre auf dem Thron indes waren geprägt von weiteren Unruhen aus dem militärischen Sektor: Anlässlich mangelhafter Versorgung seiner Truppen

119 Zur Usurpation des Leontios siehe Kiel-Freytag 2010 und Pfeilschifter 2013, 557-560.

$120 \mathrm{Zu}$ Ariadne siehe Meier 2010.

121 Siehe PLRE II, Fl. Longinus 6 (689f.) und PLRE II, Longinus 3 (688). Zu den Mechanismen hinter der Erhebung des Anastasios siehe Meier 2009b, 63-75; Pfeilschifter 2013, 154-159.

122 Meier 2009b, 75-84.

123 Zum Staurotheis-Aufstand siehe Meier 2007a.

124 Siehe PLRE II, Fl. Areobindus Dagalaiphus Areobindus 1 (143f.); Begass 2018, 86; zu der Familie ebd., 29, 351-378. Über die Gründe für Areobindos' Zurückhaltung lässt sich nur spekulieren; Meier 2007a, 200 sieht einen Grund in dem Umstand, dass Anastasios Areobindos' Familie durch zahlreiche Gunsterweisungen an sich gebunden habe. 
erhob sich 513 der Comes foederatorum Vitalian, der in kurzer Zeit Thrakien, Moesia Secunda und Scythia unter seine Kontrolle brachte. In Opposition zu der von Anastasios betriebenen Kirchenpolitik, die auf einen Ausgleich mit den Miaphysiten abzielte, gab er sich als Verfechter des chalkedonensischen Glaubensbekenntnisses. Mit einem großen Heer rückte Vitalian bis zum Hebdomon vor, machte allerdings zu keinem Zeitpunkt Anstalten, sich selbst zum Kaiser erheben zu lassen. ${ }^{125}$ Nachdem die kaiserlichen Truppen mehrere Niederlagen erlitten hatten und Vitalian erneut auf Konstantinopel vorgerückt war, bahnte sich eine Einigung an: Anastasios verlieh Vitalian das Amt des Magister militum per Thrakias. Kurz darauf, im Jahr 515, eskalierte der Konflikt allerdings erneut. Nun wandte sich das Blatt: In Folge einer vernichtenden Niederlage zog Vitalian sich nach Thrakien zurück. Anastasios' Nachfolger Justin I. rehabilitierte Vitalian und ernannte ihn zum Magister militum praesentalis; als solcher setzte er sich weiter für das chalkedonensische Dogma ein und war an der Schlichtung des akakianischen Schismas beteiligt. Doch schien der Militär, der als Champion der Orthodoxie hohes Ansehen genoss, weiterhin als Bedrohung für den regierenden Kaiser wahrgenommen worden zu sein; 520 erlag Vitalian einem Mordkomplott, für den angeblich Justins Neffe Justinian verantwortlich war. ${ }^{126}$

Auch Anastasios ernannte zu Lebzeiten keinen Nachfolger, obwohl mit seinen Neffen Hypatios, Pompeios und Probos, die allesamt im Militär Karriere gemacht hatten, durchaus potentielle Kandidaten zur Verfügung standen. ${ }^{127}$ Anastasios' Bemühungen, seine Herrschaft gegenüber hohen Militärs zu stärken, hatte Erfolge gezeitigt: Zum Zeitpunkt seines Todes 518 gab es in Konstantinopel niemanden, der die politischen Prozesse nach individuellem Gutdünken lenken konnte, wie es Jahrzehnte zuvor Aspar getan hatte. Die Dynamiken, die sich nach dem Bekanntwerden von Anastasios' Tod entfalteten, lassen allerdings darauf schließen, dass mit der fortschreitenden Konzentration auf Konstantinopel als Dreh- und Angelpunkt kaiserlicher Herrschaft eine Bedeutungssteigerung der städtischen Garden einher gegangen war. Gemäß dem Zeremonienbuch wurde die Nachricht von Anastasios’ nächtlichem Tod zuerst an den Magister officiorum Keler (den Befehlshaber der Scholai) und den Comes excubitorum Justin weitergegeben, die ihre Einheiten formieren konnten, bevor sich am nächsten Morgen die restlichen Würdenträger im Palast zusammenfanden. ${ }^{128}$ Anders als 491, als die Verantwortung für die Wahl eines Nachfolgers formal an die Augusta Ariadne als Vertreterin der kaiserlichen Familie weitergegeben werden konnte, stand 518 keine Person mit vergleichbarer Autorität zur Verfügung. Die

125 Zu diesem Zeitpunkt muss klar gewesen sein, dass eine Krönung außerhalb Konstantinopels nicht die erhoffte politische Wirkmächtigkeit entfalten würde - zumindest dann, wenn der regierende Kaiser in Konstantinopel noch fest im Sattel saß. Laut einiger Quellen war Vitalian zuvor während des Staurotheis-Aufstandes in Konstantinopel 512 zum Kaiser akklamiert worden, siehe Meier 2007a, 167 f.; dies zog allerdings offenbar keine Folgen nach sich.

126 Zur Revolte des Vitalian siehe Kaegi 1981, 92f. und Meier 2007a, 203-209.

127 PLRE II, Fl. Hypatius 6 (577-581); Pompeius 2 (898f.); Fl. Probos 8 (912f.).

128 De cerim. 1.93. 
maßgeblichen Impulse der Entscheidungsfindung kamen von Seiten der bewaffneten Garden, während sich die versammelten Senatoren angesichts der Vereinzelung von Interessen als nicht handlungs- bzw. entscheidungsfähig erwiesen. In Palast und Hippodrom entfaltete sich eine chaotische Dynamik, die von den konfligierenden Initiativen der Garde-Einheiten bestimmt wurde. Nachdem verschiedene potentielle Kandidaten aus deren Reihen ins Spiel gebracht worden waren, machte schließlich der Comes excubitorum Justin selbst das Rennen. ${ }^{129}$

Unter Justin I. kam es wieder zu einer Designation: Ab wann genau Justins Neffe Justinian, der 518 bereits als Candidatus in den kaiserlichen Garden gedient hatte, ${ }^{130}$ zum Nachfolger seines Onkels Justin aufgebaut wurde, ist in der Forschung umstritten. ${ }^{131}$ Festzuhalten sei zumindest, dass Justinian kurz nach 518 in das einflussreiche Amt des Magister militum praesentalis befördert wurde. Ob er als solcher tatsächlich Truppen ins Feld führte, ist unklar; die Vollmachten, die aus einer derartigen Stellung erwuchsen, sind allerdings nicht zu unterschätzen. ${ }^{132}$ Bei Justins Tod 527 folgte Justinian, der kurz davor zum Augustus erhoben worden war, seinem Onkel jedenfalls reibungslos nach. ${ }^{133}$

In der Forschung herrscht in der Regel Konsens dahingehend, dass Justinian den militärischen Sektor weitestgehend im Griff hatte. ${ }^{134}$ Dennoch war auch Justinians Herrschaft einigen Bewährungsproben ausgesetzt, besonders während des sog. NikaAufstandes: Im Jahr 532 eskalierten Auseinandersetzungen mit der hauptstädtischen Bevölkerung in tagelangen Aufständen und der Zerstörung des Stadtzentrums. Justinians Rückhalt in Konstantinopel bröckelte; im Hippodrom, wo sich die Bevölkerung sowie einige Senatoren versammelt hatten, kam es gar zur Krönung eines alternativen Kandidaten. Dieser Kandidat, Hypatios, war nicht nur der Neffe des verstorbenen Kaisers Anastasios, sondern konnte auch auf eine erfolgreiche militärische Karriere

$129 \mathrm{Zu}$ Justin und seiner Karriere vor seiner Ernennung zum Comes excubitorum siehe Croke 2005b, 145f. und PLRE II, Iustinus 4 (648-651): In der Auseinandersetzung des Anastasios mit den Isauriern hatte Justin als Befehlshaber des Feldheeres gedient, außerdem wurde er gegen die Perser eingesetzt und war an der Niederschlagung der Revolte des Vitalian beteiligt. Börm 2013, 80 dagegen sieht Justin als „Kandidat des Hofes, nicht der Armee“; siehe zur Erhebung Jones 1964 I, 267 f.; Trampedach 2005, 281, 286; Pfeilschifter 2013, 165-175.

130 De cerim. 1.93.

131 Die These, Justinian habe seit der Krönung Justins die Zügel in der Hand gehabt, bleibt dahingestellt; siehe dazu ausführlich Croke 2007.

132 Börm 2013, 80 sieht Justinian eher als Zivilisten denn als Vertreter des militärischen Sektors; vgl. allerdings Koehn 2018, der 56-67, der Justinians militärischen Hintergrund betont; Lee 2007, 71.

133 PLRE II, Fl. Petrus Sabbatius Iustinianus 7 (645-648); als einzige zeitgenössische Quelle gibt Victor von Tununna (ad. a. 525) an, Justin habe Justinian bereits im Jahr 525 zum Caesar erhoben, bevor dann 527 die Krönung zum Augustus erfolgte; siehe dazu Croke 2007, 43-55.

134 Siehe dazu oben 48f. Unter Justinian wurden mindestens zwei der amtierenden Comites excubitorum gewaltsam aus dem Weg geschafft (siehe Croke 2005b, 146), was zeigt, dass er darum bemüht war, Kontrolle über die Garden zu halten. 
zurückblicken. ${ }^{135}$ Allein mit Hilfe der aus dem Osten zurückgekehrten Truppen unter der Führung des Generals Belisar, die im Hippodrom ein Massaker anrichtete, konnte Justinian die Lage in der Stadt wieder unter Kontrolle bringen; Hypatios wurde gemeinsam mit seinem Bruder Pompeios hingerichtet. ${ }^{136}$

Im Nachklang des Nika-Aufstandes konnte Justinian seine Stellung zwar wieder sichern, sah sich allerdings weiterhin den Ambitionen hoher Militärs ausgesetzt. Im Jahr 549 kam es zu einer Verschwörung um den armenischen General Artabanes. ${ }^{137}$ Von den Persern zu den Römern übergelaufen, war Artabanes bis zum Magister militum per Africam, Magister militum praesentalis und Comes foederatorum aufgestiegen. Nachdem er in Afrika entscheidende militärische Erfolge hatte erringen können, kehrte er nach Konstantinopel zurück und versuchte, durch die Verbindung mit Justinians Nichte Praeiecta die Einheirat in die kaiserliche Familie zu erwirken. Justinian und Theodora taten allerdings alles, um die Hochzeit zu verhindern. ${ }^{138}$ Aus Groll über die Zurückweisung schloss sich Artabanes einer Verschwörung an, die vom armenischen Adligen Arsakes ${ }^{139}$ angestoßen worden war. Ziel soll es gewesen sein, Germanos, einen weiteren Neffen Justins und somit Cousin Justinians, an dessen Stelle zum Kaiser zu erheben. ${ }^{140}$ Germanos, der zu diesem Zeitpunkt bereits auf eine illustre militärische Karriere zurückblicken konnte, erwies sich allerdings als loyal gegenüber Justinian; die Verschwörung wurde aufgedeckt. ${ }^{141}$

135 Hypatios hatte auf mehreren Kommandos als Magister Militum gedient, siehe PLRE II, Fl. Hypatius 6 (577-581) und Begass 2018, 146-153; ausführlich zu Hypatios Meier $2014 a$.

136 Justinian nutzte den Nachklang des Aufstandes, um unliebsame Männer kaltzustellen und die hauptstädtische Elite nach seinem Gutdünken umzustrukturieren. Zum Nika-Aufstand Meier 2003b, der die These aufstellt, Justinian habe die Eskalation inszeniert, um die Opposition innerhalb der hauptstädtischen Elite erst bloßzustellen und dann zu beseitigen; vgl. Greatrex 1997; Leppin 2011, 142 148; Pfeilschifter 2013, 178-210; Brandes 2014.

137 PLRE III, Artabanes 2 (125-130). Auch hier ist die Terminologie wieder irreführend; etwa Börm 2013, 80 f.: „coup d'état, der 549 aus einer Verschwörung am Hof hervorging“. Die Verschwörung spielte sich zwar am Hof ab, aber die wichtigsten Protagonisten gehörten dem militärischen Sektor an. 138 Praeicta (PLRE III, Praeiecta 1 [1048f.]) war zuvor mit Areobindus verheiratet gewesen (PLRE III, Areobindus 2 [107-109]), dem Magister militum per Africam, der der Revolte des Guntarith zum Opfer fiel. Artabanes gelang es, Guntarith zu beseitigen und die Ordnung im römischen Afrika wiederherzustellen; daraufhin forderte er Areobindus' Witwe zur Frau. Anstatt mit Artabanes wurde Justinians Nichte allerdings schnell mit einem gewissen Johannes (PLRE III, Ioannes 63 [665]) verheiratet, einem Verwandten des Anastasios, der abgesehen von seinem familiären Hintergrund nicht besonders herausstach und keine wichtigen Ämter (weder militärische noch zivile) bekleidet hatte - und demnach dem Kaiser kaum gefährlich werden konnte.

139 PLRE III, Arsaces (123f.); aus dem Haus der Arsakiden.

140 PLRE II, Germanus 4 (505-507).

141 Zu der Verschwörung siehe Meier 2003a, 261-264; Leppin 2011, 281f.; Pfeilschifter 2013, 467. Artabanes wurde von Justinian seiner Ämter enthoben, kurz darauf allerdings wieder als Magister militum per Thracias nach Sizilien geschickt. Ein weiteres erfolgloses Mordkomplott gegen Justinian im Jahr 562 (siehe Meier 2003a, 264- 269 und Pfeilschifter 2013, 467) scheint auf den ersten Blick anders gelagert, da nun Männer aus dem zivilen Bereich als Protagonisten in den Vordergrund treten, genauer gesagt geradezu dubiose Gestalten, die sich nicht einmal durch besondere Nähe zum Kaiser aus- 
Als Justinian im Jahr 565 verstarb, ohne einen Nachfolger designiert zu haben, kam mit dessen Neffen Justin II. nach Anastasios der einzige Kaiser des 5. und 6. Jahrhunderts an die Macht, der vor seiner Erhebung keine militärische Funktion ausgefüllt hatte; stattdessen hatte er das zivile Amt des Curopalates, des Vorstehers des kaiserlichen Palastes, bekleidet. ${ }^{142}$ Angesichts Justinians Tod brachte eine Delegation aus Senatoren und Palastbeamten, angeführt von dem Praepositus sacri cubiculi Kallinikos, Justin und seine Ehefrau Sophia, eine Nichte der verstorbenen Kaiserin Theodora, des Nachts unter großer Eile in den Palast, wo am nächsten Tag die Krönung vollzogen wurde. Die Exkubitoren und ihr Comes Tiberios, stationiert an den Eingängen des Palastes, deckten die nächtliche Initiative. ${ }^{143}$ Am nächsten Tag sah sich die städtische Öffentlichkeit mit vollendeten Tatsachen konfrontiert, erhob allerdings keinen Einspruch, sondern stimmte in den Jubel ein. ${ }^{144}$ Doch die Vormacht des städtischen Palastumfeldes war fragil: Die Zielstrebigkeit, mit der die Krönung des Justin II. am Tag nach Justinians nächtlichem Tod im Palast vollzogen wurde, ist vor dem Hintergrund zu verstehen, dass mit dem gleichnamigen Justin, einem erfahrenen General und Sohn des Germanos, Justinians Cousin, ein weiterer vielversprechender Kandidat für den Thron zur Verfügung stand. Im entscheidenden Moment 565 befand sich dieser jedoch nicht in der Hauptstadt, sondern kommandierte die römischen Truppen an der Donau. Nach seiner Krönung beorderte Justin II. seinen Namensvetter nach Konstantinopel zurück, stellte ihn erst unter Hausarrest und exilierte ihn schließlich nach Ägypten, wo er verstarb. Welches Risiko der General für die Stabilität von Justins Herrschaft darstellte, ist damit offenkundig. ${ }^{145}$

Dass die Bedeutung der städtischen Garden und ihrer Kommandeure zum Ende des 6. Jahrhunderts weiter anstieg, machte sich unter Justin II. erneut bemerkbar. 574 adoptierte dieser den Comes excubitorum Tiberios und erhob ihn zum Caesar; die Quellen bringen diesen Schritt mit Justins fragiler psychischer Verfassung in Verbindung: Die Nachricht von der Eroberung der Grenzfestung Dara durch die Perser habe den Kaiser in eine Nervenkrise gestürzt, aufgrund derer er den Regierungsgeschäften nicht mehr gerecht werden konnte. Gemeinsam mit Justins Ehefrau Sophia übernahm

zeichneten - der Bankier Markellos, der Musiker Ablabios und Sergios, Neffe des Senators Aitherios (im Amt des Curator divinae domus Antiochi; PLRE III, Aetherius 2 [21f.]). Die Aufklärung des Komplotts führte dazu, dass Belisar unter der Begründung, Mitglieder seines Stabes seien an der Verschwörung beteiligt gewesen, unter Hausarrest gestellt, ein halbes Jahr später aber wieder rehabilitiert wurde. Dieser Umstand wirft den Verdacht auf, dass es bei der ganzen Angelegenheit nicht so sehr um die dubiosen Verschwörer ging, sondern darum, Justinians erfolgreichsten General wieder einmal für eine gewisse Zeit kaltzustellen.

142 Zum Amt des Curopalates siehe Ma. Whitby 1987, 469-476. Nach der Justins Krönung wurde sein Schwiegersohn Baduarius in das Amt des Curopalates erhoben (PLRE III, Baduarius 2 [164f.]).

143 Goripp, der mit seinem In laudem Iustini minoris einen ausführlichen Bericht der Krönung liefert, widmet Tiberios in diesem Zusammenhang ganze 13 Verse (1.212-1.225); zur Bedeutung der Exkubitoren siehe Av. Cameron 1976a, 138; Croke 2005b, $147 \mathrm{f}$.

144 Siehe Mi. Whitby 2000a, 86f.; zur Krönung des Justin II. siehe Trampedach 2005, $282 \mathrm{f}$.

145 PLRE III, Iustinus 4 (750 - 754); Börm 2013, 81. 
Tiberios die Regierung. Kurz vor Justins Tod 578 erfolgte Tiberios’ Proklamation zum Augustus. ${ }^{146}$

Tiberios' Herrschaftsantritt verlief vergleichsweise reibungslos; allerdings sah auch er sich mit einer über Generationen gewachsenen Militärelite konfrontiert, genauer gesagt der Familie des Germanos, die - im Gegensatz zu ihm - mit der justinianischen Dynastie blutsverwandt war. Nach der Ermordung von Germanos' älterem Sohn Justin ging aus dieser Familie mit dem jüngeren Sohn Justinian ein weiterer Störfaktor für den regierenden Kaiser hervor. Unter Justin II. und Tiberios bekleidete Justinian - wie sein Bruder und Vater zuvor - höchste militärische Kommandos und wurde schließlich in dem erneut entflammten Perserkrieg eingesetzt. Als seine Kampagnen nicht den erhofften Erfolg zeitigten, rief Tiberios ihn ab und setzte stattdessen den Comes excubitorum Maurikios - seinen späteren Nachfolger auf dem kaiserlichen Thron - als Oberbefehlshaber gegen die Perser ein. Gemäß einer nur in westlichen Quellen erhaltenen Tradition wurde zweimal der Versuch unternommen, Justinian an Stelle des Tiberios auf den Thron zu bringen, gar mit Unterstützung der Augusta Sophia. ${ }^{147}$

Auch Tiberios sorgte bereits zu Lebzeiten für seine Nachfolge. Am 5. August 582 erhob er zwei Männer in den Rang des Caesar: einen Germanos, der zu dieser Gelegenheit Tiberios' ältere Tochter Charito heiratete, und Maurikios, der die jüngere Tochter Konstantina ehelichte. Maurikios bekleidete seit 574 das Amt des Comes excubitorum und hatte sich als Oberbefehlshaber im Perserkrieg ausgezeichnet. Germanos' Hintergrund ist undeutlich; allerdings scheint auch er ein Kommando als Magister militum bekleidet zu haben. ${ }^{148}$ Die Vermutung liegt nahe, dass er der Familie des bereits genannten Germanos, des Neffen des Justin I., entstammte - genauer gesagt, dass es sich bei ihm entweder um Germanos' Sohn oder Enkel handelte. ${ }^{149}$ Folgt

146 Zu Tiberios siehe PLRE III, Tiberius Constantinus 1 (1323-1326); außerdem Jones 1964 I, 304-306; zur Sukzession siehe Mi. Whitby 2000a, 94 f. Das Verhältnis zwischen Justin und Tiberios war offenbar bereits vor 565 ein enges gewesen. Justin förderte den jungen Tiberios, dem dank seines einflussreichen Gönners eine steile Karriere beschieden war. Nach Justins Krönung blieb Tiberios im Amt des Comes excubitorum und wurde darüber hinaus als Oberbefehlshaber in den Krieg gegen die Avaren geschickt; $\mathrm{zu}$ Justin II. und Tiberios siehe unten S. $69 \mathrm{f}$.

147 PLRE III, Iustinianus 3 (744-747). Obwohl die genauen Abläufe im Dunkeln bleiben, spricht doch meiner Meinung nach nichts dagegen, dahinter authentische Hinweise auf einen weiterhin schwelenden Machtkampf zu sehen; dazu siehe unten $69 \mathrm{f}$.

148 Theophanes (AM 6074 [252]) bezeichnet ihn als strategos, also mit dem griechischen Begriff für Magister militum.

149 Zwei Kandidaten stehen hier zur Debatte: Nach dem Tod seiner ersten Frau heiratete der ältere Germanos die ostgotische Prinzessin Matasuentha, mit der er einen Sohn, Germanos, zeugte (PLRE III, Germanos 3 [528]). Den Namen Germanos trug allerdings auch ein Enkel des älteren Germanos, nämlich der Sohn von dessen Sohn aus erster Ehe, Justinian, dessen Unstimmigkeiten mit Tiberios oben bereits erwähnt wurden (PLRE IIIB, Germanos 5 [529].) Greg. Tour. Hist. Frank. 5.30 schreibt, dass es nach der Beilegung des Zwistes zischen Tiberios und Justinian Pläne gegeben habe, Justinians Sohn mit Tiberios' Tochter zu verheiraten; der Plan sei dann allerdings laut Gregor nicht zur Umsetzung gekommen. 
man dieser Identifikation, offenbart sich der anhaltende Einfluss von Germanos’ Familie in Konstantinopel: Tiberios kam nicht umhin, ihren Spross, der selbst in höchste militärische Ränge aufgestiegen war, in der Sukzession zumindest in Betracht zu ziehen. Von den beiden Männern wurde schließlich allein Maurikios am 13. August zum Augustus befördert; als Tiberios am folgenden Tag verstarb, folgte ihm Maurikios scheinbar ohne Komplikationen nach. Über das Schicksal des Germanos schweigen die Quellen weitestgehend. ${ }^{150}$

Zwischenfazit: Mit dem kursorischen Überblick über die politischen Dynamiken des 5. und 6. Jahrhunderts hoffe ich gezeigt zu haben, dass hohe militärische Funktionsträger sowie die städtischen Garden maßgeblichen Einfluss auf die monarchische Sukzession ausübten. ${ }^{151}$ Der militärische Sektor sollte somit als ein integraler Teil des politischen Systems Konstantinopel verstanden und untersucht werden. Die Mechanismen monarchischer Sukzession lassen sich folgendermaßen zusammenfassen: Nachdem die theodosianische Dynastie mit dem Tod des Theodosios II. ein Ende genommen hatte, bestimmten im 5. Jahrhundert Magistri militum wie Aspar und Zenon, deren Familien oft von einem nichtrömischen bzw. provinzialen Hintergrund über den Dienst im römischen Heer in höchste politische Sphären aufgestiegen waren, über die Besetzung des Thrones. Diese Entwicklung spiegelt zu einem gewissen Grad die Situation im Westen wider, wo den militärischen Funktionsträgern allerdings ungleich größere Handlungsspielräume zur Verfügung standen. ${ }^{152}$ Nach Zenons Tod konnte sich zwischenzeitig eine zivile Palastgruppierung mit ihrem Kandidaten Anastasios durchsetzen. Mit der Konzentration auf den hauptstädtischen Interaktionsraum ging im 6. Jahrhundert eine Bedeutungssteigerung der Palastgarden einher; die Comites excubitorum, die Befehlshaber des von Leon I. neu gegründeten Elitecorps, kristallisierten sich als prominenteste Akteure heraus - Justin I., Tiberios und Maurikios hatten vor ihrer Krönung dieses Amt bekleidet.

Das dynastische Prinzip erwies sich hinsichtlich monarchischer Sukzession weiterhin als relevant, war allerdings flexibel anwendbar. Angesichts der Ermangelung leiblicher Söhne wurden strategische Heiratsallianzen zwischen der Kaiserfa-

150 Nur Joh. Nik. 94.26 gibt an, „owing to his huminilty of heart he refused to be emperor”. Ein Germanos trat im Jahr 602 noch einmal ins Rampenlicht, siehe unten S. 84-92. Die Gründe dafür, dass Maurikios letztendlich das Rennen machte, sind schwer $\mathrm{zu}$ bestimmen; seine Reputation als erfolgreicher Persien-General mag ihm zuträglich gewesen sein. Mango/Scott 1997, 374 Anm. 4 geben an, Germanos sei zu diesem Zeitpunkt „governor of Africa” gewesen und habe daher einen geographischen Nachteil gegenüber Maurikios gehabt; diese Verbindung überzeugt allerdings nicht, siehe Pfeilschifter 2013, 140 mit Anm. 43.

151 Vgl. Trampedach 2005, 288: „Wie gelangte ein Kandidat in den Palast, wenn er beim Tod des Kaisers nicht schon darin saß (also designiert worden war)? Von größter Bedeutung war das militärische Kapital, über das er verfügen konnte.“ Allerdings betont Trampedach ebd. 288f. auch die Bedeutung der Palastbeamten und des Senates.

152 Die Überwältigung der weströmischen Kaiser durch barbarische Heermeister; siehe zusammenfassend Börm 2013, 76; außerdem McEvoy 2013. Zu den weströmischen Heermeistern siehe O’Flynn 1983; Henning 1999; Kuhoff 2012; Poguntke 2016. 
milie und prominenten Individuen geschlossen, um Kandidaten gezielt aufzubauen (Zenon, Maurikios) bzw. diese nach einer Thronvakanz ex post mit der nötigen Legitimität zu versehen (Leon I., Anastasios); dabei wird die Bedeutung weiblicher Mitglieder des Kaiserhauses, wie der Augusta Ariadne, deutlich. ${ }^{153}$ Wollten hohe Militärs die Sukzession nach ihren Interessen beeinflussen, so geschah dies bevorzugt, indem sie versuchten, die Einheirat in die kaiserliche Familie zu erzwingen und dadurch eine Designation (z. B. die Erhebung zum Caesar) zu erwirken - entweder ihre eigene oder die ihres Sohnes. ${ }^{154}$ Aspar konnte seine Ansprüche zumindest zeitweise gegenüber Leon I. geltend machen; die Ambitionen des Artabanes beinahe ein Jahrhundert später scheiterten an dem entschiedenen Widerstand Justinians. Tiberios sah sich gezwungen, gleich zwei Kandidaten mit seinen Töchtern zu verheiraten und in diesem Zuge zum Caesar zu erheben. Dass relativ viele Kaiser (Theodosios II., Markian, Zenon, Anastasios, Justinian) verstarben, ohne einen Nachfolger aufgebaut zu haben, lässt sich damit erklären, dass eine vorzeitige Designation die Gefahr einer Marginalisierung des Senior Augustus mit sich brachte. ${ }^{155}$

In der Forschung wurde wiederholt angemerkt, dass alle Usurpationen bzw. Usurpationsversuche im oströmischen Reich von Mitgliedern der Senatsaristokratie bzw. ehemaligen Konsularen ausgingen. ${ }^{156}$ Diese Beobachtung ist durchaus korrekt; der Sachverhalt kann allerdings noch präziser gefasst werden: Männer, die dem Kaiser ernsthaft gefährlich werden bzw. ihn gar stürzen konnten, waren allesamt auf dem militärischen Karrierepfad in die hauptstädtische Elite aufgestiegen; es handelte sich um ehemalige Magistri militum, die als Illustres zum politischen Establishment Konstantinopels gehörten und oft gar mit den höchsten Ehren eines Patrikios bzw. Konsuls ausgezeichnet worden waren. Die Initiative musste gar nicht einmal unbedingt von ihnen direkt ausgehen; in den seltenen Fällen, in denen die hauptstädtische Bevölkerung einen konkreten Kandidaten forderte, handelte es sich immer um Männer mit militärischem Hintergrund (Areobindos, Hypatios). Obwohl auch zivile Funktionsträger wie die Praefecti praetorio ihren Einfluss geltend machen konnten, obwohl sich vor allem die Palastbeamten durch einen außerordentlichen Grad an

$153 \mathrm{Zu}$ Ariadne siehe Meier 2010.

$154 \mathrm{Zu}$ den familiären Netzwerken, die durch derartige Verbindungen entstanden, siehe Demandt 1980 und Schwarcz 2003. Im Westen passierte es wesentlich öfter, dass hohe Militärs ihre Machtposition durch die Einheirat in die Kaiserfamilie zementierten, so geschehen etwa im Falle des Stilicho, der Flavia Serena, die Nichte des Theodosios I. heiratete. Dass die kaiserliche Familie das Risiko, das von derartigen Verbindungen ausging, wahrnahm und versuchte es einzuhegen, zeigt das Beispiel der Pulcheria, der Schwester des Theodosios, die sich zur Jungfräulichkeit entschied; siehe Soz. 9.1.3: „Zuerst widmete sie Gott ihre eigene Jungfrauenschaft und erzog ihre Schwestern zur gleichen Lebensweise, um keinen anderen Mann in den Palast zu bringen und um jeden Anlass zu Eifersucht und

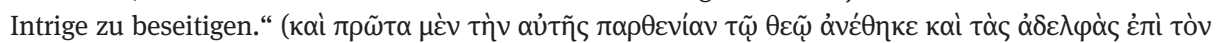

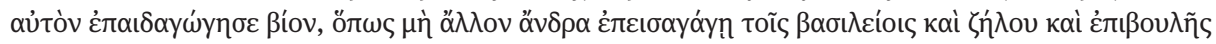

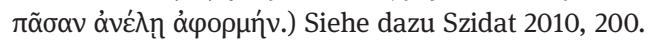

155 Siehe Trampedach 2005, 287 Anm. 35.

156 Meier 2002, 282; Pfeilschifter 2013, 452; Begass 2018, 4, 421; etwas differenzierter Szidat 2010, $257 \mathrm{f}$. 
Kaisernähe auszeichneten, ging von der zivilen Administration keine strukturelle Bedrohung für den Monarchen aus. Allein bei Thronvakanzen, wenn der regierende Kaiser verstorben war, ohne einen Nachfolger zu bestimmen, konnten bisweilen Männer aus dem direkten Palastumfeld ihren konkret räumlichen Vorteil, d.h. die Kontrolle über die Abläufe im Palast, nutzen, um durch zielstrebiges Handeln ihre Kandidaten durchzubringen; so geschehen bei den Erhebungen des Anastasios und des Justin II. ${ }^{157}$

Neben der Überwältigung des regierenden Kaisers und der offenen Usurpation sind noch weitere Formen der Einflussnahme aus dem militärischen Sektor zu beobachten: Mit Gehorsamsverweigerung in der Provinz konnten Feldherren den Kaiser unter Druck setzen und die Umsetzung der eigenen Interessen erzwingen. Vitalian etwa gelang es, seine Stellung durch die Revolte in der Provinz derart festigen, dass er wiederholt in höchste offizielle Kommandos gesetzt wurde. Angesichts der Zentralität Konstantinopels zeitigten Kaiserkrönungen in der Provinz allerdings keine nachhaltige Wirkung. ${ }^{158}$

\subsection{Ermächtigungsstrategien der Kaiser}

Die zentrale Herausforderung der sesshaften Kaiser des 5. und 6. Jahrhunderts bestand darin, den militärischen Sektor zu kontrollieren, anstatt von ihm kontrolliert zu werden. Konnte der Kaiser seine Hoheit über den militärischen Sektor nicht wahren, so lief er Gefahr, dass ihm die politischen Geschicke der Hauptstadt - bis hin zu Sukzessionsfragen - entglitten. Die Kaiser in Konstantinopel erwiesen sich als vergleichsweise resilient: Trotz einer strukturellen Abhängigkeit vom militärischen Sektor verkümmerte die oströmische Monarchie nie zu einer leeren Institution ohne Eigengewicht in politischen Entscheidungsprozessen. Auf den folgenden Seiten werde ich der Frage nachgehen, mit welchen Mitteln es den Kaisern gelang, sich gegenüber militärischen Funktionsträgern zu emanzipieren.

$157 \mathrm{Zu}$ Kaisern (bzw. Usurpatoren) mit zivilem Hintergrund - allerdings auch für den westlichen Reichsteil - vgl. Szidat 2010, 182-187 und 261-268; ebd. 267 wird betont, dass die „Interessen ziviler Amtsträger bei Thronvakanzen stärker bedroht [waren] als die der militärischen Kommandanten“, da sie Macht nur durch ihre institutionelle Stellung und nicht durch militärische Deckung ausüben konnten (vgl. ebd. 194); um sich abzusichern, galt es, einen Kandidaten auf den Thron zu bringen, der der bestehenden zivilen Führungsriege wohlgesonnen war.

158 Angesichts der Konzentration dieses Kapitels auf den militärischen Sektor wurde die Frage nach der Bedeutung der hauptstädtischen Bevölkerung für die Aushandlung und Festigung monarchischer Herrschaft bisher bewusst weitgehend ausgeklammert. In welchem Maße die Kaiser von der Akzeptanz dieser Gruppe abhängig waren, wurde in der Forschung oft betont, siehe etwa Pfeilschifter 2013, 294 354. In den Kapiteln 3.1 und 3.2 werde ich die Wechselwirkungen, die sich zwischen Impulsen des militärischen Sektors und der öffentlichen Stimmung in Konstantinopel entfalten konnten, eingehend besprechen. 
Die extremste Option der Gegenwehr von Seiten des Kaisers bestand darin, einen General, von dem ein akutes Risiko ausging, aus dem Weg zu räumen. Abgesehen von den prominentesten ,Opfern` kaiserlicher Ermächtigung, dem Alanen Aspar und dessen Söhnen, lassen sich eine Reihe weiterer Beispiele anführen: Vitalian, der Anastasios massiv in Bedrängnis gebracht hatte und erst unter Justin I. beseitigt wurde, und schließlich Justin, dessen Prestige als General seinem Verwandten und Namensvetter Justin II. gefährlich zu werden drohte. ${ }^{159}$ Einem derartigen Verfahren waren allerdings klare Schranken gesetzt; solange Funktionsträger sich nicht offen gegen den Kaiser stellten oder ihnen illoyales Verhalten bzw. Usurpationsabsichten zumindest plausibel unterstellt werden konnten, hatten die Kaiser kaum etwas gegen sie in der Hand. Vor dem Hintergrund des Ideals monarchischer Civilitas konnte willkürliches Verhalten gegenüber der hauptstädtischen Elite für den Kaiser zum Problem werden; trotz der Vereinzelung der oströmischen Aristokratie regte sich mitunter eine gewisse Standessolidarität, welche die einzelnen Vertreter zu einem gewissen Grad vor der Willkür des Kaisers schützte. Die Möglichkeit der Diffamierung des Kaisers als Tyrann und eines damit einhergehenden Akzeptanzverlustes lag allzu nahe. ${ }^{160}$ Henning Börm hat darauf aufmerksam gemacht, dass die oströmischen Kaiser zumindest in der ersten Hälfte des 5. Jahrhundert bisweilen einen subtileren Weg gingen, um ambitionierte Generäle aus ihrem näheren Umfeld zu entfernen: Sie schickten diese als Augusti in den Westen des Reiches - so geschehen bei Anthemios, dem Schwiegersohn des Kaisers Markian, und Anicius Olybrius, die angesichts ihrer herausgehobenen Stellung für Leon I. eine latente Bedrohung darstellten. ${ }^{161}$

Komplementär zu der Einhegung prominenter Individuen muss es den Kaisern darum gegangen sein, die Kontrolle über die Besetzung der höchsten Kommandos nicht nur nominell, sondern auch praktisch aufrecht $\mathrm{zu}$ erhalten, anstatt sich von einflussreichen Militärs die Personalentscheidungen diktieren $\mathrm{zu}$ lassen. Bemühungen des Kaisers, ein auf Patronagebeziehungen basierendes, loyales Umfeld zu schaffen, sind als Phänomen nicht per se bemerkenswert; für die sesshaften Monarchen bestand allerdings besondere Dringlichkeit, den militärischen Sektor an sich zu binden und die Autonomie hoher Funktionsträger so weit wie möglich zu beschränken. Indem sie die entscheidenden Kommandos mit engen Vertrauten besetzten, anstatt diese für ambitionierte Militärs zur Disposition zu stellen, konnten sie ihre Reichweite über die Mauern Konstantinopels hinaus sichern. So verwundert es

159 Siehe Lee 2007, 69f. und fürs 4. Jahrhundert ders. 2015, 116f. Im Westen des Reiches versuchte Valentinian III. sich eben dieser Methode zu bedienen: Er brachte - angeblich eigenhändig - den Heermeister Aetius um, wurde dann allerdings selbst von dessen Gefolgsleuten ermordet; dazu siehe Börm 2018, 99-104.

160 Zu dieser Problematik siehe Börm 2010, bes. 168-172; ähnlich Börm 2013, 72f.; zur hauptstädtischen Elite siehe auch Pfeilschifter 2012 und ders. 2013, 452-474. Vgl. den Fall des Phokas: Sein unsensibles Vorgehen gegenüber der hauptstädtischen Elite und der daraus resultierende Akzeptanzverlust trugen letztendlich zu seinem Sturz bei; dazu siehe unten Kap. 4.1.

161 Börm 2010, 165 f. 
kaum, dass im 5. wie im 6. Jahrhundert oft Verwandte des regierenden Kaisers in den wichtigen Heermeisterämtern installiert wurden - bisweilen trotz mangelnder militärischer Qualifikation. ${ }^{162}$ Ein loyales Umfeld erwirkten die Kaiser außerdem dadurch, dass sie Männer niedrigerer Herkunft in Ämter und Würden erhoben und damit ein Gegengewicht zu etablierten Kreisen und gewachsenen Machtstrukturen schufen. ${ }^{163}$ Alternativ konnten sie auf Personen zurückgreifen, die ihnen aufgrund ihrer sozialen Stellung nicht gefährlich werden konnten: Dass unter Justinian ausgerechnet ein Eunuch, Narses, zum bedeutenden Feldherren aufstieg, ist kaum ein Zufall, nachdem sich der General Belisar nicht zuletzt aufgrund seiner außerordentlichen Erfolge als Risikofaktor erwiesen hatte. ${ }^{164}$

Der sicherste Weg, sich gegenüber militärischen Funktionsträgern zu behaupten, lag allerdings in der Stärkung der monarchischen Position. Dass die Bindung an Konstantinopel den Kaisern, die nicht mehr persönlich in den Krieg zogen, alternative Betätigungsfelder eröffnete, wurde bereits erwähnt; die fortschreitende Sakralisierung der kaiserlichen Persona und die Liturgisierung der Interaktion mit der hauptstädtischen Bevölkerung bildeten im 5. und 6. Jahrhunderts ein Gegengewicht zu dem Druck, der von hohen militärischen Funktionsträgern ausging. ${ }^{165}$ Überblickt man das 5. und 6. Jahrhundert, so fällt indes auf, dass auch die sesshaften Kaiser an militärischer Repräsentation festhielten: Auf Münzen erschienen sie im Gewand des Feldherrn, des Imperators, die Namen besiegter Völker bildeten Teil ihrer Titulatur und sowohl materielle (z.B. Reiterstatuen im öffentlichen Raum) als auch ephemere Zeugnisse (Panegyrik) feierten sie als Sieger. ${ }^{166}$ Was auf den ersten Blick als Paradox anmutet, löst sich auf, wenn man die hier adressierten Dynamiken in die Überlegung einbezieht: In noch höherem Maße als ihre Vorgänger im Prinzipat bewegten sich die sesshaften Kaiser der Spätantike auf dem schmalen Grat zwischen der Anerkennung militärischer Erfolge, welche mit einer Statuserhöhung des jeweiligen Befehlshabers einherging, und der Wahrung kaiserlicher Autorität und Überlegenheit. Nicht allein die fortschreitende Sakralisierung führte zu einer Stabilisierung oströmischer Herr-

162 Siehe Lee 2007, 71; Olster 1993, 34f. fürs 6. Jahrhundert.

163 Diese Strategie verfolgte allen voran Justinian, selbst von bescheidener Herkunft; siehe Börm 2010, 182.

164 Börm 2010, 177 f.; ders. 2013, 86 Anm. 127. In diesem Zusammenhang mag auch die, vor allem im 5. Jahrhundert nachvollziehbare, Förderung nichtrömischer Feldherren gestanden haben, deren Griff nach dem Thron aufgrund ihrer Herkunft ausgeschlossen war. Die Sollbruchstelle dieser Strategie, nämlich der Umstand, dass es für die Kontrolle des Imperiums nicht unbedingt einer Krone bedurfte, zeigte sich in geringerem Maße im oströmischen, wesentlich deutlicher im weströmischen Reich, wo unmündige Kaiser sich barbarisch-stämmigen Feldherren ausgeliefert sahen, die schließlich die römische Monarchie abschafften; siehe etwa McEvoy 2013.

165 Diese Entwicklung wurde von Diefenbach 1996, 2002 herausgearbeitet; zuletzt zusammenfassend ders. 2109, 75f.; siehe außerdem Meier 2012 mit einem noch breiteren Überblick; fürs 6. Jahrhundert ders. 2016. Was genau die Forschung unter Sakralisierung des Kaisertums versteht, wird unten S. 198200 genauer diskutiert.

166 Lee 2007, 37-50; Aspekte kaiserlicher Repräsentation werden unten S. 197 f. genauer beleuchtet. 
schaft, sondern auch der Umstand, dass es den Kaisern in der Regel gelang, die von Generälen erfochtenen Erfolge vor einem hauptstädtischen Publikum auf die eigene Person zu übertragen. 498 zelebrierte Konstantinopel den Sieg der kaiserlichen Truppen über die isaurische Partei in Kleinasien: Longinos und Indes, die prominenten Anführer der Aufständischen, wurden in Ketten durch die Stadt bis in den Hippodrom geführt, wo der Kaiser Anastasios den unbestrittenen Mittelpunkt des Spektakels bildete. In ihren Panegyriken zeichnen Priscian und Prokop Anastasios, der weder vor noch nach seiner Krönung als Befehlshaber tätig gewesen war, mit Verweis auf glorreiche Feldherren der römischen Vergangenheit, wie etwa Pompeius Magnus, als Triumphator; den Generälen, die den Sieg gegen die Isaurier errungen hatten, bleibt in diesem Narrativ nur die Position der loyalen Untertanen. ${ }^{167}$ Im Zuge der Siegesfeierlichkeiten, welche sich nach Belisars Sieg über die Vandalen vor den Augen der hauptstädtischen Bevölkerung entfalteten, nahm nicht Belisar die Rolle des Triumphators ein, sondern Justinian, der als gottgleicher Herrscher im Kathisma des Hippodroms über dem Geschehen thronte und die eigentlichen Ehrungen empfing. Justinian als unumstrittener Mittelpunkt des Geschehens verflocht den Sieg über die Vandalen mit einer konsequenten, religiös konnotierten Überhöhung der eigenen Person; Belisar zeigte sich als ergebener Untertan. ${ }^{168}$

Triumphalismus bildete also weiterhin das Fundament monarchischer Herrschaft, auch wenn die Repräsentation des sieghaften Kaisers an die Parameter der hauptstädtischen Monarchie angepasst wurde: An die Stelle des charismatischen Kriegers trat spätestens mit der Niederlassung in Konstantinopel der ewige Sieger. Monarchische Sieghaftigkeit war nicht mehr an konkrete militärische Erfolge geknüpft - konnte demnach durch Niederlagen nicht geschmälert werden -, sondern entwickelte sich zu einer dem Kaiser von dem Moment seiner Krönung an inhärenten Qualität; konkrete Siege des römischen Heeres konnten diese Qualität noch akzentuieren. Solange die sesshaften Kaiser vor der Kulisse Konstantinopels ihre Vormachtstellung gegenüber den Generälen glaubhaft vermitteln konnten, solange die Idee von der Sieghaftigkeit des Imperiums an den regierenden Kaiser gebunden blieb,

167 Börm 2013, 69 f., 79 (zu den Generälen); zum Triumph des Anastasios außerdem Croke 2008 und McCormick 1986, 61. Vgl. allgemein zu spätantiken Siegesfeierlichkeiten McCormick 1986, 35-79; Pfeilschifter 2016; Diefenbach 2019.

168 Siehe zuletzt Diefenbach 2019, 92-100 mit Diskussion der These von Börm 2013, dass die Inszenierung primär dem Zweck gedient habe, Belisar vor der versammelten Bevölkerung Konstantinopels zu erniedrigen (siehe bes. ebd. 65); vgl. Pfeilschifter 2017, 459-461, bes. Anm. 9. Ähnlich wie Diefenbach und Pfeilschifter bin ich der Meinung, dass Börm den Aspekt der Demütigung Belisars überstrapaziert.Vgl. auch Meier 2019b; ders. 2002, $287 \mathrm{f}$. zum Triumph und 284f. zu der Bedrohung, die für Justinian von Belisar ausging (und zu dessen wechselvoller Karriere); es sei darauf hingewiesen, dass dem Belisar ein Jahr nach dem Vandalensieg der Konsulat verliehen wurde und er prunkvolle Spiele ausrichtete. Zu Triumphen römischer Feldherren in der Provinz siehe Pfeilschifter 2016, 455 457: Belisar in Antiochia, Johannes Troglita in Karthago. 
ließ sich die Bedrohung, welche vom militärischen Sektor ausging, zu einem gewissen Grad einhegen. ${ }^{169}$

\subsection{Die hauptstädtische Monarchie im späten 6. Jahrhundert}

In der Entwicklung der oströmischen Monarchie wird die Regierung Justinians von der Forschung in der Regel als Schlüsselphase gesehen. ${ }^{170}$ Mit der Rückeroberung des Westens konnte der Anspruch auf ein Imperium Romanum, welches das gesamte Mediterraneum umfasste, vorübergehend wiederbelebt werden. Justinians Herrschaft erwies sich zwar nicht als unumstritten, aber insgesamt doch als stabil. Zentrale Charakteristika der hauptstädtischen Monarchie, wie die fortschreitende Sakralisierung der kaiserlichen Persona und die Liturgisierung von Interaktionsformen, erreichten zwischen 527 und 565 einen vorläufigen Höhepunkt. Die spezifische Ausformung kaiserlicher Autorität, die Justinian über Jahrzehnte etablierte, hielt den vielfältigen Bedrohungen stand, mit denen er sich im Laufe seiner 38 Jahre währenden Regierung konfrontiert sah; dazu zählen kontingente Faktoren wie das Ausbrechen der Pest in Konstantinopel und dem gesamten Mittelmeerraum, aber auch innenpolitische Schwierigkeiten wie das andauernde Ringen um Einigung der verschiedenen christlichen Denominationen und eine kaiserliche Religionspolitik, die vor allem in den späten Jahren Justinians auf verstärkte Ablehnung stieß. Die Standards, die Justinian auf verschiedenen Feldern etablierte - auf dem sakralen Feld spricht Meier gar von einer folgenschweren Übersteigerung ${ }^{171}$-, spannten den Rahmen, innerhalb dessen seine Nachfolger ihre Regierung gestalten konnten. Das Erbe war kein leichtes: Einerseits mussten Justinians Nachfolger den über Jahrzehnte geformten Erwartungshaltungen gerecht werden; andererseits war jeder Kaiser - bedingt durch den meritokratischen Charakter römischer Monarchie - darauf bedacht, seiner Herrschaft ein eigenes Profil zu geben und sich gegenüber dem Vorgänger abzuheben.

Als Justin II. dem verstorbenen Justinian 565 auf den Thron folgte, stand er vor einer besonderen Herausforderung: Sein Onkel hatte ihn nicht persönlich als Nachfolger designiert; stattdessen war er, der vormalige Curopalates, von einer Parteiung im kaiserlichen Palast auf den Thron gehievt worden. ${ }^{172}$ Der Charakter von Justins Politik wird bereits in der Panegyrik des Goripp, die kurz nach der Krönung entstand, auf den Punkt gebracht: Beim Versuch, die junge Herrschaft mit der nötigen Legitimität zu versehen, diente der verstorbene Justinian sowohl im positiven wie auch im

169 Diefenbach 2019, bes. 70 weist außerdem darauf hin, dass in den Inszenierungen von Siegesfeierlichkeiten im 5. und 6. Jahrhundert Gott als Urheber von militärischem Erfolg herausgestellt wurde; mit einer derartigen Deutung wurde das charismatische Potential von Sieg nicht den Generälen überlassen.

170 Siehe etwa die Monographien von Meier 2003a und Leppin 2011.

171 Meier 2016.

172 Siehe oben S. 58. 
negativen Sinne als Referenzpunkt. Die Betonung eines besonderen Nahverhältnisses zu Justinian und der Verweis auf dynastische Kontinuität einerseits sowie explizite Kritik an dessen politischen Entscheidungen andererseits halten sich im Lob auf Justin II. die Waage. ${ }^{173}$ Parallel zu der literarischen Stilisierung Goripps lassen sich auch Justins praktische Maßnahmen entlang der Dichotomie von Anknüpfung und Abgrenzung beschreiben. Mit Blick auf den militärischen Sektor fällt dabei vor allem auf, dass Justin von der Politik seines Onkels abwich, die Feinde an den Reichsgrenzen durch umfangreiche Geldzahlungen in Schach $\mathrm{zu}$ halten, und stattdessen einen wesentlich konfrontativeren Kurs einschlug. Eine avarische Delegation, die sich in Konstantinopel einfand, um die von Justinian zugesicherten Zahlungen in Empfang zu nehmen, wurde von Justin harsch zurückgewiesen. Goripp wiederum nutzt die Schilderung dieses Aufeinandertreffens vor der beeindruckenden Kulisse des hauptstädtischen Palastes, um Justin - mit Verweisen auf typische Kategorien imperialer Sieghaftigkeit - als von Gott erwählten Garanten römischer Souveränität zu zeichnen. $^{174}$

Auf dem Balkan zeitigte Justins konfrontative Politik vorübergehend Erfolg: Die Expansionsbemühungen der Avaren richteten sich nach Westen, anstatt weiterhin Thrakien zu beeinträchtigen; an der Ostgrenze dagegen hatte das kühne römische Vorgehen katastrophale Folgen. Vor dem Hintergrund des 50-jährigen Friedens, der 561/2 noch unter Justinian geschlossen worden war, entspann sich zwischen Justin und dem persischen Großkönig Chosroes I. ein Ringen um Einfluss und Oberhoheit in den gemeinsamen Grenzregionen. Die Aussicht auf eine Allianz mit den Türken, die von ihrem zentralasiatischen Standpunkt aus Interesse an der Machtkonstellation im kaukasischen Raum zeigten, mag römische Hoffnungen auf Machtzuwachs begünstigt haben. Schließlich bot der Appell armenischer Adliger an Konstantinopel, das

173 Vor allem die durch Justinians Politik geleerten Staatskassen werden von Goripp wiederholt thematisiert (Laud. Iust. 2.249-274). Kritik an Justinians Politik findet sich auch in Justins Gesetzgebung - Just. Nov. 148 pr.: „Denn als wir herausfanden, dass die Staatskasse mit vielen Schulden belastet und zum extremen Mangel getrieben war, haben wir sie von Last und Schwierigkeit befreit, indem wir die Schulden aus eigenen Mitteln zurückgezahlt haben. Außerdem haben wir auch die militärischen Angelegenheiten, bereits ruiniert durch den Mangel am Notwendigen, sodass das Gemeinwesen erschüttert wurde von Invasionen und unzähligen Einbrüchen der Barbaren, mit entsprechenden Korrekturen versehen, soweit es uns möglich war.“ (Fiscum enim cum multis debitis oneratum et ad extremam inopiam adactum inveniremus, in nos ipsos aere alieno recepto onere atque difficultate magna liberavimus. Deinde rem militarem rerum necessariarum penuria iam dilapsam, ita ut res publica barbarorum invasionibus irruptionibusque infinitis labefactaretur, quoad eius facere potuimus, idonea emendatione dignamur.) Dass Justin die von Justinian aufgenommenen Schulden nach seiner Krönung aus eigenen Mitteln zurückzahlte, wird auch in Gor. Laud Iust. 2.399-406 erwähnt. Außerdem belebte Justin wenige Monate nach seiner Krönung den Konsulat wieder, der unter Justinian zuletzt 541 besetzt worden war (siehe Gor. Laud. Iust. 4); zum Ende des Konsulates unter Justinian siehe Meier 2002.

174 Empfang der avarischen Delegation: Gor. Laud. Iust. 3.151-407, außerdem Menand. Prot. fragm. 14 und Joh. Eph. Hist. eccl. 6.24; siehe Kommentar bei Av. Cameron 1976a, 185f. Vgl. außerdem Av. Cameron 1980, bes. $71 \mathrm{zu}$ Justins Versuch, seine Herrschaft in der Stadt sichtbar zu machen. 
christliche Armenien bei seiner Behauptung gegen die Ausbreitung des zoroastrischen Feuerkultes zu unterstützen, ein willkommenes Argument, um entschieden gegen das sassanidische Reich vorzugehen. Vermeintliche persische Schwäche gab Justin 572 das Selbstbewusstsein, erneut Tributzahlungen einzubehalten; kurz darauf unternahmen römische Truppen erste Vorstöße in die Arzanene. Doch bevor nennenswerte Erfolge erzielt werden konnten, überquerte eine persische Armee unter persönlicher Führung des Großkönigs Chosroes I. den Euphrat, plünderte Syrien und nahm schließlich nach sechsmonatiger Belagerung die römische Grenzfestung Dara ein. Allein mithilfe erneuter hoher Geldzahlungen an Persien konnte ein Friedensschluss erwirkt werden. ${ }^{175}$

Dass sich ausgerechnet der Zivilist Justin II. als Kriegstreiber betätigte, Friedensschlüsse brach und ostentativ darum bemüht war, trotz hoher Risiken die römische Autorität gegenüber äußeren Feinden zu behaupten, ist bemerkenswert. Eine derartige Politik wird in der Regel als pragmatischer Versuch Justins plausibilisiert, die von Justinian stark in Mitleidenschaft gezogenen Staatsfinanzen nicht noch weiter durch Tributzahlungen zu strapazieren. ${ }^{176}$ Die hier gewählte Perspektive legt allerdings eine alternative bzw. ergänzende Interpretation nahe: Justin, der vor seiner Krönung keinerlei militärischen Erfahrung hatte sammeln können, versuchte vom Palast aus, mit einer konfrontativen Politik sein kaiserliches Profil zu schärfen und dem militärischen Sektor den eigenen Stempel aufzudrücken. Nachdem er bereits die Avaren bei der Audienz vor der versammelten hauptstädtischen Elite abgekanzelt hatte, setzte Justin nun ein weiteres klares Zeichen in der Beziehung zum römischen Erzfeind an der östlichen Reichsgrenze. ${ }^{177}$

Mit den Persern hatte Justin einen besonderen Gegner gewählt. Das Verhältnis zwischen dem sassanidischen Persien und Rom lässt sich grob in drei Phasen einteilen: Nach der Etablierung der sassanidischen Dynastie im frühen dritten Jahrhundert standen die beiden Nachbarn über mehr als ein Jahrhundert in beinahe konstantem Konflikt; erst nach dem Perserfeldzug Julians beruhigte sich das Verhältnis. Im späten vierten und fünften Jahrhundert sind kaum bewaffnete Aufeinandertreffen zu verzeichnen; stattdessen formalisierten sich die diplomatischen Kontakte, geprägt von gegenseitiger Anerkennung und Wertschätzung zwischen den beiden Reichen, die jeweils mit der Sicherung anderer Grenzzonen beschäftigt waren. Ab dem frühen sechsten Jahrhundert eskalierten die Konflikte allerdings erneut: 540 brach Chosroes I. den mit Justinian ausgehandelten Ewigen Frieden und verheerte die römischen Ostprovinzen. Seitdem trat kaum mehr dauerhafte Ruhe ein. Der 50-jährige Friede von 561/2 musste auf römischer Seite durch hohe Tributzahlungen erkauft

175 Zu Justins Außenpolitik siehe Mi. Whitby 2000a, 90 -94; Jones 1964 I, 304-306; zum erneuten Ausbruch des Perserkrieges siehe Mi. Whitby 1988, 250 - 258 und Turtledove 1983.

176 Mi. Whitby 1988, 251.

177 Justin schickte erst einmal seinen Neffen Markian als Magister Militum gegen die Perser; PLRE IIIB, Marcianus 7 (821-823). 
werden. ${ }^{178}$ Während im dritten und vierten Jahrhundert Konflikte regelmäßig von römischer Seite provoziert worden waren - ein Sieg über die Perser versprach dem regierenden Kaiser enormen Prestigegewinn -, büßte militärische Konfrontation mit den Sassaniden, wie Henning Börm zuletzt argumentiert hat, für die sesshaften Kaiser an Attraktivität ein: $\mathrm{Zu}$ hoch waren die damit einhergehenden Risiken, nicht zuletzt die mögliche Exponierung eines siegreichen Generals, welcher die Autorität des Kaisers hätte beeinträchtigen können. ${ }^{179}$

Mit seiner riskanten Aggression gegen Persien hatte Justin II. in der Tat zu hoch gepokert; die Folgen der römischen Niederlage waren umso schwerwiegender: Die Nachricht vom Verlust Daras stürzte den Kaiser gemäß den Quellen in eine Nervenkrise; angesichts seiner eigenen Regierungsunfähigkeit habe er den loyalen Tiberios, seinen Comes excubitorum, 574 zum Caesar erhoben. ${ }^{180}$ Während die Forschung dieser Erzählung in der Regel recht unkritisch folgt, ${ }^{181}$ eröffnet sich vor dem Hintergrund dieses Kapitels eine alternative Deutungsmöglichkeit; dabei ist allerdings zu betonen, dass es sich beim Folgenden um eine Hypothese handelt, die nicht im Detail verifiziert werden kann. Wenige Jahre nach seiner Krönung scheint Justins Rückhalt in Konstantinopel zu bröckeln begonnen zu haben. Innenpolitisch sorgte seine rigide Sparpolitik für Missbilligung; seine religionspolitischen Vorstöße zeitigten nicht den gewünschten Erfolg. ${ }^{182}$ Nachdem das Scheitern seiner kühnen Maßnahmen im militärischen Bereich mit dem Debakel am Euphrat besiegelt worden war, konnte Justin II. sich - so die Hypothese - nicht mehr länger souverän an der Spitze der politischen Hierarchie halten und musste Tiberios das Feld räumen. Tiberios’ Machtbasis lag in der militärischen Kontrolle des Palastes; seine Entsendung als Befehlshaber in die Provinz hatte seinen Einfluss noch ausgebaut. Als er den Rückhalt des hauptstädtischen Umfeldes verspielt hatte, scheint Justin II. keine andere Wahl mehr geblieben zu sein, als dem aufstrebenden Tiberios das Feld zu räumen und seine letzten Jahre als lame duck ohne Entscheidungshoheit im Palast zu fristen. ${ }^{183}$ Anstatt offener Usur-

178 Zur Entwicklung der Beziehungen zwischen den Sassaniden und Rom siehe Mi. Whitby 1988, 202-209; Blockley 1985 und Börm 2016; zu den römisch-persischen Kriegen der Spätantike siehe auch Greatrex/Lieu 2002 und zuletzt zum 6. und frühen 7. Jahrhundert Meier 2019a, 1020 - 1035.

179 Börm 2016, 624-633. Als Belisar im Jahr 530 bei Dara einen Sieg über die Perser errang, gelang es Justinian, den Triumph seines Generals im öffentlichen Raum Konstantinopels gänzlich auf sich zu übertragen: Auf dem Augusteion würdigte ein Reiterstandbild Justinian als Triumphator omnium gentium und auch im Hippodrom wurde er mit Widmungen als Sieger über Perser und Protobulgaren geehrt; siehe Börm 2013, 67. Allerdings muss hinzugefügt werden, dass 532 - also nur kurz nach dem Persertriumph - der Nika-Aufstand ausbrach, der Justinian beinahe zu Fall gebracht hätte; der Prestigegewinn durch den Persertriumph erwies sich also offenbar nicht als sonderlich nachhaltig.

180 Am ausführlichsten Joh. Eph. Hist. eccl. 3.2-5, der die Krankheit Justins als Strafe Gottes für dessen (miaphysitenfeindliche) Kirchenpolitik deutet. Zur Krönung des Tiberios zum Caesar durch Justin außerdem Evagr. Hist. eccl. 5.13, Theoph. Sim. Hist. 3.11.5-3.12.1.

181 Siehe etwa Av. Cameron 1976b.

$182 \mathrm{Zu}$ Justins Innenpolitik siehe Mi. Whitby 2000a, 87-90; zur Religionspolitik Av. Cameron 1976c. 183 Ähnlich bereits bei Börm 2013, 81f. Man könnte in diesem Zusammenhang gar noch weiter gehen und die These aufstellen, dass Tiberios die Erhebung des Justin 565 nicht nur mithilfe der ihm un- 
pation wählte Tiberios - folgt man dieser Deutung - einen wesentlich subtileren Weg der Ermächtigung. Mit dem ostentativen Einverständnis Justins übernahm er die Regierung, konnte sich als Caesar für die kaiserliche Nachfolge in Stellung bringen und nach seiner Krönung zum Augustus im palastinternen Machtkampf schließlich auch die Augusta Sophia und deren Parteiung ausstechen. ${ }^{184}$

Nach seiner Erhebung zum Caesar legte Tiberios den Fokus darauf, den östlichen Kriegsschauplatz wieder in den Griff zu bekommen, was ihm mit einer Mischung aus diplomatischer Annäherung und entschiedenem militärischem Vorgehen auch gelang. Im Jahr 575 oder 576 konnte er gar einen Triumph feiern: Nachdem einer persischen Armee die Überquerung des Euphrats missglückt war, fielen dem römischen Heer Kriegselefanten und weitere Beute in die Hände; die Feldherren schickten diese zum Caesar Tiberios nach Konstantinopel, wo die Spolien des römischen Erfolges der Bevölkerung präsentiert wurden. Der verantwortliche General Justinian - der jüngere Sohn des Germanos, Spross einer bedeutenden Militärdynastie ${ }^{185}$ - blieb im Osten, wo die Kämpfe andauerten. Tiberios musste sich in der öffentlichen Wahrnehmung also keines direkten Konkurrenten erwehren, sondern konnte den Sieg auf die eigene Person beziehen. ${ }^{186}$

Wenige Jahre später, 582, kehrte allerdings doch ein siegreicher General von der Perserfront nach Konstantinopel zurück: Maurikios, Tiberios' ehemaliger Comes excubitorum, der Justinian als Magister militum per Orientem ersetzt hatte. Theophanes berichtet, der Heimkehrer sei mit großen Ehren vom Kaiser empfangen worden; daraufhin habe „Tiberius einen Triumph für Maurikios’ Siege gefeiert“ und den General mit seiner Tochter Konstantina vermählt. ${ }^{187}$ Die Position des Triumphators und das Zentrum der Feierlichkeiten nahm also erneut, zumindest formal, der Kaiser ein; doch kam er offenbar nicht umhin, dem erfolgreichen General Zugeständnisse zu machen:

tergebenen Exkubitoren gedeckt hatte, sondern dass er maßgeblich für dessen Wahl verantwortlich gewesen war. Sich selbst bereits nach Justinians Tod für die Nachfolge in Stellung zu bringen, mag für Tiberios zu riskant gewesen sein, zumal mehrere hochrangige Verwandte Justinians zur Verfügung standen (neben Justin dem Curopalates auch Justin der General, Sohn des Germanos). Somit hätte Tiberios mit dem Zivilisten Justin den Kandidaten unterstützt, auf den er den größten Einfluss ausüben konnte. Diesen Gedanken verdanke ich Gesprächen mit Kai Trampedach.

184 Sophia (PLRE III, Aelia Sophia 1 [1179f.]) hatte offenbar eigene Ambitionen; sie soll es darauf abgesehen haben, Tiberios zu heiraten und damit ihre Position zu sichern; Tiberios war allerdings bereits mit Ino verheiratet und weigerte sich, sich scheiden $\mathrm{zu}$ lassen. Im Palast entbrannte ein Machtkampf, bis es Tiberios nach Justins Tod gelang, Sophia aus dem Palast zu entfernen, indem ihr vorgeworfen wurde, gemeinsam mit dem General Justinian, einem Cousin des Justin, gegen ihn intrigiert zu haben; zu Sophia und Tiberios siehe Garland 1999, 49-57 und Av. Cameron 1975.

185 PLRE IIIB, Iustinianus 3 (744-747); zu Justinian siehe oben S. 59.

186 Die genaue Ausgestaltung des Persertriumphes lässt sich nicht mehr rekonstruieren; welche Rolle Justin II. dabei einnahm, bleibt unklar; siehe McCormick 1986, 68f. (mit Angaben der Quellen), 129f.; Börm 2013, 83f.; Pfeilschifter 2016, 473.

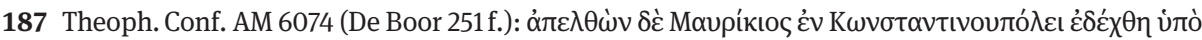

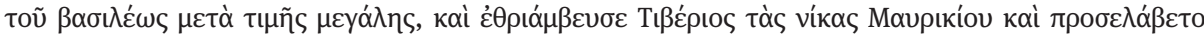

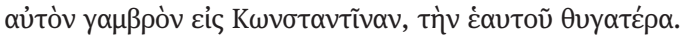


Der Vermählung mit Konstantina folgte Maurikios’ Erhebung in den Rang des Caesars. ${ }^{188}$ Zusammen mit Maurikios wurde allerdings noch ein weiterer Mann, nämlich Germanos, ${ }^{189}$ zum Caesar erhoben - eine Maßnahme, welche die Sukzessionsfrage zumindest zu einem gewissen Grade offen hielt und die interne Konkurrenz zwischen den beiden Anwärtern auf den Thron schürte. Der Persersieg und die ehrenvolle Rückkehr in die Hauptstadt, die nur kurze Zeit zurücklag, mögen schließlich dazu beigetragen haben, dass Maurikios sich wenige Tage später, angesichts Tiberius' kritischen Gesundheitszustandes, gegenüber dem Konkurrenten Germanos durchsetzen konnte: Er allein wurde zum Augustus gekrönt.

Die von Tiberius initiierten Vorstöße an der Perserfront gingen auf Kosten des Balkans, wo Avaren sowie slawische Stammesverbände die römischen Stellungen erneut unter Druck setzten. Als Tiberios 582 nach nur kurzer Regierung starb, waren die Fronten weder im Osten noch im Westen geklärt. ${ }^{190}$ Nachdem er die Alleinherrschaft angetreten hatte, führte Maurikios den Krieg über ein Jahrzehnt weiter. Als 589 oder 590 die Nachricht in Konstantinopel eintraf, dass die römische Armee unter der Führung des Herakleios (des Vaters des späteren Kaisers Herakleios) einen Sieg über die Perser errungen habe, veranlasste Maurikios Siegesfeierlichkeiten, die mit Pferderennen im Hippodrom begangen wurden. ${ }^{191}$ Auch diesmal verblieben die Generäle im Osten.

Eine entscheidende Wendung nahm der Konflikt zwischen Römern und Persern im darauffolgenden Jahr, als interne Machtkämpfe das persische Reich zu schwächen begannen. ${ }^{192}$ Der Großkönig Hormizdas, der nach dem Tod seines Vaters Chosroes I. im Jahr 579 an die Macht gekommen war, erwies sich innerhalb der persischen Elite als höchst umstritten; als Hormizdas' führender General Baram Chobin sich gegen ihn erhob und mit den Truppen auf Ctesiphon vorrückte, ${ }^{193}$ entluden sich die Spannungen: Hormizdas wurde abgesetzt und ermordet; an seiner Stelle rückte sein Sohn Chosroes II. als Großkönig nach. Baram Chobin gab sich mit diesem Arrangement allerdings nicht zufrieden und setzte Ctesiphon weiter militärisch unter Druck; Chosroes sah den einzigen Ausweg in der Flucht. Auf römischem Territorium angelangt bat er Maurikios mittels eines Sendschreibens um Hilfe gegen den Usurpator, der

188 Siehe dazu McCormick 1986, 69; Pfeilschifter 2016, 473.

$189 \mathrm{Zu}$ der Identität des Germanos siehe oben S. $59 \mathrm{f}$.

$190 \mathrm{Zu}$ der Außenpolitik des Tiberios siehe Jones 1964 I, 307-309; Mi. Whitby 1988, 258-275; Mi. Whitby 2000a, 95-98.

191 Theoph. Conf. AM 6080 (De Boor 262); Theoph. Sim. Hist. 3.6.5; McCormick 1986, 69 f.; Pfeilschifter 2016, 473.

192 Ein Überblick über die Ereignisse bieten Jones 1964 I, 310 f. und Mi. Whitby 2000, 103f., ausführlicher ders. 1988, 276-292.

193 Im Gegensatz zu seinem Vater führte Hormizdas seine Truppen nicht persönlich in den Krieg. Zwischen ihm und Baram Chobin, der gegen die Türken entscheidende Siege hatte einfahren können, entspann sich ein Wettstreit. Nachdem Hormizdas Baram Chobin öffentlich gedemütigt hatte, kam es zur Rebellion; zu Baram Chobin und den unterschiedlichen Überlieferungssträngen hinsichtlich des Ausbruchs der Revolte siehe Bonner 2020, 247-251. 
sich inzwischen zum Großkönig hatte krönen lassen. ${ }^{194}$ Maurikios willigte ein, den Erben der sassanidischen Dynastie zu unterstützen.

Die letzten Jahrzehnte hatten deutlich gezeigt, dass aggressives Vorgehen gegenüber dem persischen Reich hohe Risiken barg und Konstantinopel in der Regel geschwächt aus der Konfrontation hervorging. Warum fällte Maurikios dennoch die Entscheidung, aktiv in die persischen Thronwirren einzugreifen und sich damit noch weiter in den seit Jahrzehnten schwelenden Konflikt zu verstricken? Michael Whitby sieht Maurikios' Entscheidung von der Hoffnung getrieben, durch die Unterstützung des dynastisch legitimierten Herrschers die Ostgrenze endgültig zu befrieden und erneut ein stabiles Verhältnis zum Nachbarn zu erwirken. ${ }^{195}$ Darüber hinaus scheint allerdings noch ein weiterer Faktor das römische Engagement bedingt zu haben: nämlich das spezielle Verhältnis der beiden Großmächte zueinander mit dem Potential, Parallelen in ihren jeweiligen Herrschaftsstrukturen auszumachen. ${ }^{196}$ Maurikios konnte den Sturz des persischen Großkönigs durch seinen höchsten General nicht hinnehmen, da der persische Coup als Präzedenzfall für mögliche Entwicklungen im römischen Reich hätte dienen können; denn in der Überwältigung des Souveräns durch hohe Militärs lag eben die Gefahr, der sich auch die römischen Kaiser stets erwehren mussten.

Maurikios war sich offenbar des Risikos bewusst, das eine Eskalation des Perserkrieges nicht nur für den Zustand des römischen Heeres, sondern auch hinsichtlich der innenpolitischen Stabilität mit sich bringen konnte. Die Logik seines Handelns erschließt sich beim Blick auf die Chronologie. Nachdem das persische Heer zum Usurpator Baram Chobin übergelaufen waren, floh Chosroes am 1. März 590 auf römisches Territorium. Vom Statthalter Probos in Circensium in Empfang genommen, veranlasste er das oben erwähnte Schreiben an Maurikios. Über Hierapolis gelangte die Depesche nach Konstantinopel. ${ }^{197}$ Maurikios seinerseits erhob am 26. März, an

194 Zum persischen Bürgerkrieg vgl. Mi. Whitby 1988, 292-297 und Bonner 2020, 253-263; außerdem Rubin 2004.

195 Mi. Whitby 1988, 299. Ob Chosroes nach seiner Flucht gegenüber den Römern tatsächlich den Eindruck erweckte, zum Christentum konvertieren $\mathrm{zu}$ wollen, wie es manche Quellen suggerieren (Theoph. Sim. Hist. 4.6.1-3 und Evagr. Hist. eccl. 6.17), und damit die Hoffnung schürte, nach einer Wiedereinsetzung ganz Persien für den christlichen Glauben zu gewinnen, ist fraglich.

196 Gemeinsamkeiten und Unterschiede auf herrschaftsstruktureller Ebene trägt Börm 2010 zusammen. In dem bei Theophylakt Simokattes überlieferten Brief (Hist. 4.11.1-11), mit dem Chosroes II. sich nach seiner Flucht an Maurikios wandte, wird nicht nur die Erhabenheit, sondern auch die Gleichrangigkeit der beiden Nachbarn als „zwei Augen der Erde“ betont (dieses Bild findet sich bereits in Petr. Patric. fragm. 13). Whitby/Whitby 1986, 113, 25 halten den Brief für eine authentische Übersetzung

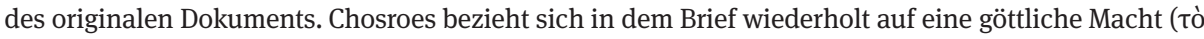
$\theta \varepsilon \tilde{o v}$ ); man könnte sich vorstellen, dass die Formulierung auch im Original bewusst offengehalten wurde, um auch einen christlichen Gott einzuschließen.

197 Theoph. Sim. Hist. 4.9.10.-4.10.10 mit den Kommentaren zu den Daten von Whitby/Whitby 1986, 115-117; zu Chosroes’ Flucht außerdem Bonner 2020, 259-261. 
Ostern, seinen ältesten Sohn, den siebenjährigen Theodosios, zum Augustus. ${ }^{198}$ Dass der Kaiser sich ausgerechnet in diesem Moment - also kurz nachdem die Depesche in der Hauptstadt eingetroffen sein muss ${ }^{199}$ - zur Designation eines Nachfolgers entschloss, kann kaum ein Zufall sein. Von dem Coup in Persien und dem Hilfegesuch Chosroes', welches er schwerlich abschlagen konnte, in Kenntnis gesetzt, sah sich Maurikios zu schnellem Handeln gedrängt. ${ }^{200}$ Er selbst war ein knappes Jahrzehnt zuvor als Persersieger von Tiberius zum Caesar erhoben worden; der Wiederholung eines derartigen Szenarios galt es nun, da der Konflikt eine entscheidende Wendung zu nehmen versprach, vorzubeugen. Mit der Krönung seines Sohnes zum Augustus gedachte Maurikios offenbar, die Nachfolgefrage zu klären, bevor weitere Schritte in Bezug auf die Situation in Persien eingeleitet wurden. ${ }^{201}$

Unter massiven militärischen Anstrengungen konnte der Usurpator Baram Chobin besiegt und Chosroes wiedereingesetzt werden. Maurikios' Risikobereitschaft zahlte sich aus: Der römische Einsatz brachte die Rückgabe von Dara und Martyropolis sowie die Übernahme von Iberien und eines großen Teiles Persarmeniens. Der von Justin II. überstürzt vom Zaun gebrochene Krieg, der über zwei Jahrzehnte an den römischen Ressourcen gezehrt hatte, konnte 591 gar mit einem Gebietsgewinn zu Ende gebracht werden. ${ }^{202}$ Über den prestigeträchtigen Persersieg hinaus hatte Maurikios' Engagement zu einer Propagatio imperii geführt, wie sie seit Langem keinem römischen Kaiser mehr beschert gewesen war: Ein Erfolg, so sollte man meinen, von enormer Öffentlichkeitswirkung. Spuren von triumphalen Feierlichkeiten in der Hauptstadt, die den Erfolg gegen Baram Chobin und den Zugewinn an römischem Territorium zelebrierten, sucht man in den Quellen allerdings vergeblich; dieser Befund verwundert. ${ }^{203}$ Warum machte der Kaiser den bemerkenswerten Erfolg über die Perser nicht im hauptstädtischen Kontext für sich nutzbar, wie es seine Vorgänger Tiberios oder Justinian, teilweise bei wesentlich weniger substanziellen Anlässen, getan hatten? Angesichts der sporadischen Quellenlage können als Antwort auf diese

198 Chron. Pasch. AD 590; Theoph. Conf. AM 6082 (De Boor 267); zu Theodosios siehe PLRE IIIB, Theodosius 13 (1293f.).

199 Angesichts der höchsten Priorität, die der Angelegenheit sicherlich von allen Beteiligten zuerkannt wurde, ist davon auszugehen, dass die Depesche die Hauptstadt verhältnismäßig rasch erreichte.

200 Die Korrelation von Chosroes Hilfegesuch und Theodosios' Krönung, mehr noch die kausale Bedingtheit, wird weder in den Quellen angezeigt, noch wurde sie bisher von der Forschung gesehen. Dass Kaiser ihre Söhne gerade in politisch prekären Zeiten zu Caesaren oder Augusti erhoben, ist allerdings naheliegend; so geschehen auch im Falle des Honorius, den sein Vater Theodosios I. im Jahr 393 in Reaktion auf die Usurpation des Eugenius zum Augustus erhob.

201 Chron. Pasch. AD 590 hält fest, dass Theodosios zwar von Maurikios gekrönt, aber nicht von der Öffentlichkeit akklamiert oder in die offiziellen Register aufgenommen wurde.

202 Vgl. Mi. Whitby 1988, 297-304.

203 Die ausführlichste Quelle zur Regierung des Maurikios sind die Historien des Theophylakt Simokattes, die - verschriftlicht unter der Herakleios - darum bemüht waren, Maurikios' Andenken zu rehabilitieren. Dass ausgerechnet diese Quelle einen von Maurikios gefeierten Perser-Triumph, hätte er denn stattgefunden, überging, ist äußerst unwahrscheinlich; siehe dazu Börm 2013, $84 \mathrm{f}$. 
Frage nur Spekulationen angeführt werden. Wollte Maurikios vor dem hauptstädtischen Publikum eine für ihn potentiell kritische Hervorhebung des Generals Narses vermeiden, der als Magister militum den Sieg über Barams Truppen verantwortet hatte?204

An dieser Stelle bietet es sich an, Maurikios’ Verhältnis zum militärischen Sektor sowie seine Initiativen im militärischen Bereich genauer in den Blick zu nehmen. Dabei fällt zunächst auf, dass Maurikios in noch höherem Maße als seine Vorgänger versucht zu haben scheint, persönlich in die Dynamiken des militärischen Sektors in den Provinzen einzugreifen. Formen der Ermächtigung gegenüber hohen militärischen Funktionsträgern, derer sich bereits seine Vorgänger bedient hatten, fanden gehäuft Anwendung: Als Kaiser, der darauf bedacht war, eine neue Dynastie zu etablieren, fokussierte sich Maurikios auf die Förderung der eigene Familie, deren Mitglieder durch verschiedene Formen der Zuwendung, unter anderem auch finanzieller Art, konsequent aufgebaut und in bedeutenden Ämtern installiert wurden. ${ }^{205}$ Innerhalb dieses Kreises kam es nicht nur zu einer Vermischung ziviler und militärischer Kompetenzen; ${ }^{206}$ auch die Praxis, Befehlshabern der Palastgarden gleichsam Kommandos über Provinzheere zu übertragen und damit das kaiserliche Kontrollspektrum auszuweiten, wurde von Maurikios weitergeführt. ${ }^{207}$

Im Gegensatz zu seinen Vorgängern ging Maurikios allerdings über die Entsendung enger Vertrauter in die Provinzen hinaus. Nachdem sich die Kaiser über beinahe zwei Jahrhunderte im städtischen Palastumfeld eingerichtet hatten, machte Maurikios erstmals seit Theodosios I. wieder konkrete Anstalten, persönlich als Heerführer aktiv zu werden. Angesichts von Vorstößen der Avaren leitete Maurikios mehrmals die Befestigung der Langen Mauern, des ca. 64 km westlich vor Konstantinopel gelegenen Verteidigungswalls, der die gesamte thrakische Halbinsel durchspannte. ${ }^{208}$ Maurikios’

204 Da der Krieg im Osten mit dem römischen Sieg vorerst beendet war, konnte Maurikios den Feldherren nicht schlichtweg in der Provinz ausharren lassen. Es bleibt jedoch unklar, warum Maurikios nicht eine Lösung hätte wählen können, die dem Vandalentriumph von 534 entsprach, bei dem der siegreiche Feldherr Belisar zum Zuge kam, sich aber gleichzeitig unter Justinian als eigentlichen Triumphator unterordnete.

205 Mi. Whitby 1988, 14-17 und ders., 2000a, 100: Maurikios’ Vater Paulos stieg zum Caput senatus auf; sein Cousin bzw. Neffe Domitian wurde als Bischof von Melitene installiert, reiste allerdings auch als Gesandter zum persischen Großkönig Hormizdas.

206 Maurikios' Bruder Petros (PLRE IIIB, Petrus 55 [1009-1011]) wurde zum Curopalates ernannt und außerdem als General auf dem Balkan eingesetzt.

207 Philippikos (PLRE IIIB, Philippicus 3 [1022-1026]), der Ehemann seiner Schwester Gordia, besetzte sowohl das Amt des Comes excubitorum als auch des Magister militum per Orientem.

208 Bereits 584 unternahm Maurikios nach einem Einfall der Avaren eine Expedition zu den Langen Mauern, begleitet von seiner Garde und laut Theophanes auch von den Demen (Theoph. Sim. Hist. 1.7.2 und Theoph. Conf. AM 6076 [De Boor 254]); 598 befestigte Maurikios gemeinsam mit Heer, den Exkubitoren und Vertretern der Zirkusparteien erneut die Langen Mauern (Theoph. Sim. Hist. 7.15.7 und dazu Mi. Whitby 1988, 163). Eine Begehung der Langen Mauern - anlässlich von Reparaturarbeiten nach Erdbebenschäden - hatte bereits Justinian einige Jahrzehnte zuvor unternommen; seine Rückkehr in die Stadt war damals von groß angelegten, vor allem religiös konnotierten Feierlichkeiten 
Engagement beschränkte sich jedoch nicht allein auf die akute Sicherung der Hauptstadt: Eine mehrwöchige Expedition durch Thrakien führte ihn an der Spitze der römischen Truppen bis nach Anchialos an der Schwarzmeerküste, wo er die Schäden der avarischen Plünderungen begutachtete. Aufgrund von Unstimmigkeiten in den Quellen bleibt die genaue Datierung dieser Expedition, von der Theophylakt Simokattes am ausführlichsten berichtet, umstritten. ${ }^{209}$ Dass Maurikios sich persönlich in Thrakien betätigte, während die Situation in Persien noch unentschieden war, ist indes eher unwahrscheinlich; es erscheint plausibler, dass der Kaiser die Expedition nach der erfolgreichen Beilegung des Perserkrieges 591 mit den aus dem Osten abgezogenen Truppen durchführte - nicht zuletzt, um die schlagkräftigsten Einheiten des römischen Heeres wieder stärker an seine Person zu binden. ${ }^{210}$ Bemerkenswert ist in diesem Zusammenhang, dass Maurikios' Vorhaben - unabhängig von der Datierungsfrage - einen Einblick in die Stimmungslage des hauptstädtischen Palastumfeldes gibt, dessen Protagonisten mit deutlicher Ablehnung auf das kaiserliche Engagement am Kriegsschauplatz reagierten. Indem der Kaiser an der Spitze der römischen Truppen gen Westen aufbrach, setzte er sich über den Appell der Senatoren, des Patriarchen sowie seiner Familie hinweg, einen General zu bestellen, anstatt selbst ins Feld zu ziehen. ${ }^{211}$

Maurikios versuchte offenbar, im Umgang mit dem militärischen Sektor eigene Impulse zu setzen. Der Umstand, dass er vor seiner Designation durch Tiberios umfassende Erfahrung als Feldherr hatte sammeln können, mag der umstrittenen Entscheidung, persönlich nach Thrakien aufzubrechen, zuträglich gewesen sein; dabei bleibt allerdings erneut zu betonen, dass auch diejenigen seiner Vorgänger, die einen militärischen Karrierepfad begangen hatten, nach ihrer Krönung stets in Konstantinopel geblieben waren. Die hier gewählte Perspektive legt die Interpretation nahe, dass hinter Maurikios' Bruch mit kaiserlicher Verhaltenspraxis der Versuch stand, die Autonomie der in den Provinzen operierenden Generäle durch persönliche Präsenz einzuschränken und den militärischen Sektor enger an die Autorität des Monarchen zu binden. Doch Maurikios' Versuche, seinen Handlungsspielraum zu erweitern, wurden im Keim erstickt: Ohne einem einzigen Feind begegnet zu sein, brach er die

begleitet worden (Theoph. Conf. AM 6051 [De Boor 234] und De cerim. 1 App. [Reiske 497f.]); siehe McCormick 1986, 67; Leppin 2011, $321 \mathrm{f}$.

209 Theoph. Sim. Hist. 5.16-6.3.8; Theoph. Conf. AM 6083 (De Boor 268f.): Theophylakt setzt seinen Bericht über die Expedition nach Anchilaos nach der Beilegung des Perserkrieges 591 an, scheint dabei allerdings Elemente von unterschiedlichen Aufenthalten des Maurikios in Thrakien zusammenzuwerfen: einen Aufenthalt, der mit Verweis auf eine Sonnenfinsternis auf den Oktober 590 datiert werden kann, und einen, der mit der Ankunft einer Gesandtschaft des fränkischen Königs Theoderich in Verbindung steht - Theoderich wurde erst Weihnachten 595 gekrönt; zu den Problemen mit der Chronologie siehe die Kommentare bei Whitby/Whitby 1986, 155 Anm. 86, 200 Anm. 73 und Mango/ Scott 1997, 392 Anm. 1, 405 Anm. 12; außerdem Mi. Whitby 1988, 156-158.

210 Theoph. Sim. Hist. 5.16.1 legt den Zusammenhang zwischen der Verlagerung des Heeres und der kaiserlichen Expedition nahe.

211 Theoph. Sim. Hist. 5.16.2-4. 
Thrakien-Expedition nach wenigen Wochen ab und kehrte in die Hauptstadt zurück. Der konkrete Anlass für seine Rückkehr war laut Theophylakt Simokattes die Ankunft mehrerer Gesandtschaften in Konstantinopel - einer persischen Delegation sowie einer Gesandtschaft des frisch gekrönten fränkischen Königs Theoderich -, derer sich der Kaiser persönlich annahm. ${ }^{212}$

Maurikios' Thrakien-Expedition wirft ein Schlaglicht auf das Dilemma des regierenden Kaisers. Die Strukturen, die sich über zwei Jahrhunderte hauptstädtischer Monarchie herausgebildet hatten, fesselten den Kaiser geradezu an Konstantinopel als zentraler Aushandlungsort monarchischer Herrschaft und schränkten seine Bewegungsfreiheit massiv ein; wie aus dem Bericht des Theophylakt hervorgeht, drängten die hauptstädtischen Interessensgruppen auf Kaisernähe. Die zentrale Herausforderung für den Kaiser war es, einerseits den Verhaltenserwartungen der hauptstädtischen Gruppen gerecht zu werden und deren Akzeptanz zu sichern, und andererseits seine Autorität über den militärischen Sektor soweit es ging zu wahren vor allem in Zeiten erhöhter militärische Aktivität. Es war äußerst riskant, die unmittelbare Kontrolle über Konstantinopel durch längere Abwesenheit zu gefährden; ein derartiges Machtvakuum hätte allzu leicht durch einen potentiellen Herausforderer ausgenutzt werden können. Um seine Rolle als Gravitationspunkt palatialer Machtstrukturen auszufüllen, begab sich Maurikios zurück nach Konstantinopel, als die Ankunft der Gesandtschaften repräsentative Anlässe erforderten.

Der kursorische Blick auf die Regierung des Maurikios legt nahe, dass der Kaiser sich wiederholt Interaktionsmöglichkeiten mit den herrschaftsrelevanten Gruppen Konstantinopels entgehen ließ, die seine Herrschaft hätten stabilisieren können. Er war offenbar nicht in der Lage, den römischen Triumph über die Perser im hauptstädtischen Umfeld durch typische Formen der triumphalen Repräsentation nutzbar zu machen. Wenn auch nicht direkt schädlich fürs kaiserliche Prestige, so kann dies zumindest als verpasste Chance gewertet werden. Seinen ältesten Sohn Theodosios erhob er 590 zwar zum Augustus, ließ ihn allerdings nicht - wie die Osterchronik explizit festhält - in der Öffentlichkeit akklamieren; ${ }^{213}$ ein derartiger Akt hätte die Bevölkerung noch enger an die Kaiserfamilie binden können. Maurikios war sich offenbar durchaus der Risiken bewusst, die vom militärischen Sektor ausgehen konnten; seine halbherzige Thrakien-Expedition scheint allerdings nicht die erhofften Effekte gezeitigt zu haben. Es sticht ins Auge, dass der Kaiser im Zusammenhang mit militärischen Angelegenheiten trotz seiner Erfahrung als Feldherr wiederholt Entscheidungen traf, die letztendlich seine Position negativ beeinträchtigen. Dies äußert sich besonders deutlich darin, dass sich unter Maurikios' Regierung wiederholt Widerstand aus den Reihen des Heeres regte. Die Konflikte zwischen dem Kaiser und den

212 Theoph. Sim. Hist. 6.3.5-8.

213 Chron. Pasch. AD 590. Einen gänzlich anderen Weg ging Herakleios ca. zwanzig Jahre später, als er die Krönung seines Sohnes Herakleios Konstantin im Jahr 613 auf verschiedenen Kanälen gegenüber der Öffentlichkeit kundtat; dazu gehört auch, dass Herakleios Konstantin auf allen Münznominalen neben seinem Vater erschien; siehe unten Kap. 4.3; 4.3.1. 
Soldaten, welche bisweilen in längerfristigen Befehlsverweigerungen eskalierten, entzündeten sich allesamt in Situationen, in denen Provinzheere ihre Interessen nicht angemessen vertreten sahen, etwa angesichts der Bestellung unbeliebter Befehlshaber oder Soldkürzungen. Maurikios verscherzte es sich konsequent mit der Gruppe, die in der Regel - wie oben besprochen - auf den sesshaften Kaiser bezogen blieb, solange ihre Bedürfnisse gedeckt blieben. Das Gros der Forschung sieht hinter diesen Maßnahmen nicht etwa Maurikios’ Fahrlässigkeit bei der Administration, sondern vielmehr sein Bemühen darum, die angeschlagenen Staatskassen zu schonen; schon zu Lebzeiten haftete dem Kaiser der Ruf des Geizhalses an. Doch wie sich im nächsten Kapitel zeigen wird, sollte seine Beharrlichkeit und Kompromisslosigkeit gegenüber den Belangen der Soldaten eine Dynamik in Gang setzen, die letztendlich in seinem Sturz kulminierte. 


\title{
3 Dynamiken gewaltsamer Machtwechsel
}

In Buch 3.41 seiner Kirchengeschichte nimmt Evagrios Scholastikos eine Anekdote zur Steuer-Politik des Kaisers Anastasius zum Anlass, die Überlegenheit des Christentums gegenüber dem alten paganen Glauben herauszustellen. Was als eine Erwiderung auf die Polemik seines paganen Vorgängers im Historiker-Metier, Zosimos, gegen das Christentum beginnt - dieser hatte den Niedergang des römischen Reiches aufgrund der Vernachlässigung der traditionellen Götter verkündet -, kulminiert in der eindrücklichen Offenlegung von Evagios' Geschichtsbild. ${ }^{1}$ Die römische Vergangenheit dient ihm trotz der Anerkennung von Leistungen herausragender Figuren wie Caesar oder Augustus allein als Wegbereiter für die Entfaltung des Christentums. Als Evidenz für die Wirkmächtigkeit des christlichen Glaubens kontrastiert Evagrios schließlich die - in seiner lückenhaften Darstellung - durchweg unnatürlichen und grausamen Tode der paganen Kaiser mit denen ihrer christlichen Nachfolger und kommt zu folgendem Schluss:

\begin{abstract}
„Nun schau, ob von der Zeit an, da der hochberühmte Konstantin die Herrschaft übernahm und die Stadt, die seinen Namen trägt, gründete und Christus weihte, auch nur einer ihrer Kaiser (außer natürlich Julian der Hierophant und Kaiser), von den Seinen oder von den Feinden umgebracht wurde oder ob überhaupt ein Usurpator einen Kaiser überwältigt hat, abgesehen von Basiliscus, der Zeno vertrieb, von dem er auch gestürzt und getötet wurde. Ich glaube dir, was du über Valens sagst, der den Christen so viel Schlimmes angetan hat. Denn über einen anderen kannst nicht einmal Du etwas Schlechtes sagen.“2
\end{abstract}

Im späten 6. Jahrhundert, der Abfassungszeit der Kirchengeschichte, meinte Evagrios auf eine beinahe ungestörte Reihung christlicher Herrscher zurückblicken zu können, die allein durch vorübergehende Irrwege unter Julian, häretische Umtriebe wie die des Valens oder vorübergehende Störungen unter Zenon und Basiliskos getrübt worden war. Die in Mailand und Ravenna residierenden Kaiser des weströmischen Reiches und deren weniger friedvolle Enden blendet er in seinem Überblick freilich konsequent aus. Evagrios geht es beinahe drei Jahrhunderte nach der Hinwendung Konstantins zum Christentum wohl kaum mehr darum, auf eine ernsthaft empfundene pagane Konkurrenz zu reagieren; auch die Wahl des fast ein Jahrhundert früher schreibenden Zosimos als Widerpart zeigt, dass es sich bei seinem Exkurs eher um

1 Zu Evagr. Hist. eccl. 3.41 siehe Kaegi 1968, 217-223 sowie die Anmerkungen in Mi. Whitby 2000c, 187-192; allgemein siehe Allen 1981.

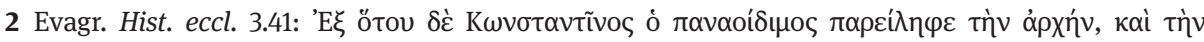

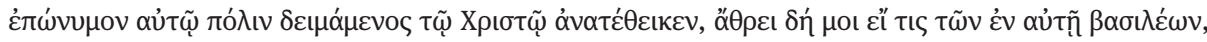

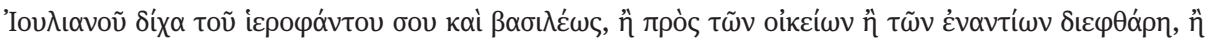

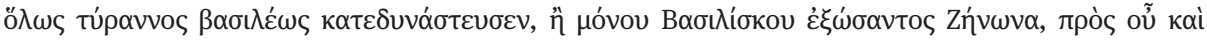

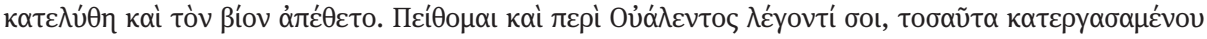

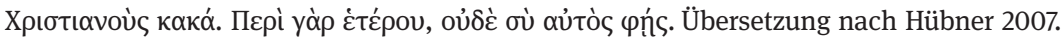


eine rhetorische Anstrengung handelt. ${ }^{3}$ Den eigentlichen Akzent setzt Evagrios auf die Stabilität, Dauer und Größe der von Konstantin in seiner neuen Hauptstadt begründeten Monarchie, die als Festung des (rechten) christlichen Glaubens eine heilsgeschichtlich relevante Stellung einnimmt. Dem regierenden Kaiser Maurikios positiv gesinnt, entwirft Evagrios ein optimistisches Bild des späten 6. Jahrhunderts. ${ }^{4}$

$\mathrm{Zu}$ einem gewissen Grad deckt sich Evagrios’ Einschätzung mit dem Bild des oströmischen Reiches im 5. und 6. Jahrhundert, wie ich es im vorigen Kapitel entworfen habe. Vor allem im Vergleich zur weströmischen Monarchie, die dem Druck nichtrömischer Militäreliten erlag, erwies sich die hauptstädtische Konfiguration von Monarchie, wie sie sich in Konstantinopel etablierte, als widerstandsfähig. Die verhältnismäßig seltenen Usurpationsversuche verliefen in der Regel im Sand; einen regierenden Kaiser zu stürzen gelang nur ein einziges Mal: Im Jahr 475 ergriff Zenon angesichts einer Verschwörung aus den Reihen hoher Militärs die Flucht aus Konstantinopel; an seiner Stelle wurde Basiliskos gekrönt. Es dauerte allerdings nur etwa eineinhalb Jahre, bis es Zenon gelang, aus dem isaurischen Exil zurückzukehren und Basiliskos, dessen Rückhalt in Konstantinopel stetig schwand, zu beseitigen. ${ }^{5}$

Etwa ein Jahrzehnt, nachdem Evagrios seine optimistische Sicht auf das oströmische Reich niedergeschrieben hatte, wendete sich jedoch das Blatt. Im November 602 eskalierte eine Rebellion der Balkan-Truppen. Die Unruhen im Heer griffen auf Konstantinopel über; der Kaiser Maurikios wurde nach zwanzigjähriger Herrschaft gestürzt und brutal ermordet. An seiner Stelle zog der ehemalige Zenturio Phokas im kaiserlichen Palast ein. Doch die Geschehnisse des Novembers 602 waren erst der Beginn einer turbulenten Phase für die Stadt am Bosporus. Acht Jahre später, im Oktober 610, erlag Phokas seinerseits einer Revolte, die sich um Herakleios, den Exarchen von Karthago, zusammengebraut hatte. Nach Jahrhunderten der relativen Stabilität ereigneten sich innerhalb kurzer Zeit zwei Machtwechsel, die jeweils in der öffentlichen Hinrichtung des gestürzten Kaisers gipfelten. Ziel dieses Kapitels ist es, die Dynamiken dieser beiden Ereignisse in ihren Kausalzusammenhängen nachzuvollziehen. Dabei wird sich herausstellen, dass die Machtwechsel zwar oberflächlich Gemeinsamkeiten aufweisen, sich in ihren Voraussetzungen und Abläufen jedoch bei genauerer Analyse deutlich unterscheiden: Während man im Fall des Herakleios tatsächlich von einer Usurpation sprechen kann, ist dieser Begriff, der im Folgenden noch genauer definiert wird, auf den Machtwechsel von 602 nicht sachgerecht anwendbar.

3 Vgl. dazu Mi. Whitby 2000c, 192 Anm. 166; Allen 1981, 62f., 161; dagegen Kaegi 1968, 221-223.

4 Zur Stellung des Evagrios siehe Mi. Whitby 2000c, xiii-xv. Es kursierten auch gegensätzliche Deutungsmuster: Der miaphysitische Kirchenhistoriker Johannes von Ephesos etwa (Joh. Eph. Hist. eccl. 6.1), der dem chalkedonensischen Regime in Konstantinopel feindlich gegenüber stand, erklärte die Kriege und Unruhen seiner Zeit als Vorboten des kurz bevorstehenden Endes.

$5 \mathrm{Zu}$ Zenon und Basiliskos siehe S. 52f. 


\subsection{Der Sturz des Maurikios}

Im späten November des Jahres 602 versank Konstantinopel im Chaos. Ein aufständisches Heer, das sich Wochen zuvor nahe der Donaugrenze der Befehlsgewalt der kaiserlichen Heermeister entzogen hatte, rückte von Westen auf die Hauptstadt vor. Innerhalb der Mauern zog die Bevölkerung marodierend durch die Straßen und skandierte gegen den Kaiser Maurikios. Ganz außergewöhnlich war eine derartige Situation nicht: Städtische Unruhen, die in Zerstörungen ganzer Stadtteile eskalierten und im Zuge derer sich kollektiver Unmut gegen den gerade regierenden Kaiser Bahn brach, stellten in der Metropole am Bosporus keine Seltenheit dar; ${ }^{6}$ die Balkantruppen waren bei weitem nicht das erste Kontingent, das sich gegen die Direktiven Konstantinopels auflehnte. Doch die Geschehnisse des Novembers 602 entwickelten sollten eine ganz eigene, überraschende Dynamik. ${ }^{7}$

Der Prozess, der letztendlich in Maurikios' Sturz mündete, nahm im Herbst 602 seinen Beginn in dem Befehl des Kaisers, die Balkantruppen sollten jenseits der Donau überwintern und sich dort auf eigene Faust versorgen, anstatt wie gewohnt über die kalten Monate in die römischen Provinzen zurückzukehren. ${ }^{8}$ Neben militärstrategischen Gründen ${ }^{9}$ lagen einer derartigen Anordnung auch finanzielle Überlegungen zugrunde: Ein Zweifrontenkrieg hatte über Jahrzehnte hinweg an den römischen Ressourcen gezehrt und auch nach der Beilegung des Perserkrieges 591 konnte die Bilanz offenbar nicht signifikant verbessert werden.

Seit seinem Herrschaftsantritt 582 versuchte Maurikios, der angespannten Finanzlage durch konkrete Sparmaßnahmen Herr zu werden. Eine derartige Politik schädigte nicht nur den Ruf des Kaisers - sowohl im Heer als auch in der Hauptstadt wurde er als Geizhals geschmäht,$-{ }^{10}$ sondern hatte bereits vor 602 wiederholt zu

6 Zu den regelmäßig stattfindenden Aufständen bzw. Randalen der Demen vgl. Al. Cameron 1976, 271298.

7 Den ausführlichsten Bericht zu den Ereignissen des Novembers 602 gibt Theoph. Sim. Hist. 8.6-8.13; außerdem Chron. Pasch. AD 602 (wichtig für die absolute Chronologie); Joh. Nik. 102.9-12, 103.4-8; Theoph. Conf. AM 6094 (De Boor 283-290); Joh. Ant. fragm. 318. Weitere Quellen, die allerdings keine darüber hinaus gehenden Erkenntnisse versprechen, sind aufgelistet bei Pfeilschifter 2013, 261 Anm. 20. Vgl. zur Ereignisrekonstruktion Stratos 1968, 40 -56; Mi. Whitby 1988, 24-27, 165 169; Olster 1993, 53-57; Pfeilschifter 2013, 261-269.

8 Theoph. Sim. Hist. 8.6; Theoph. Conf. AM 6094 (De Boor 286).

9 Siehe Whitby/Whitby 1986, 173 Anm. 54, 219 Anm. 30 mit Verweis auf Maurikios' Strategikon (11.4.82 ff.); ebenso Mi. Whitby 1988, 165-167. Kaegi 1981, 111-113 weist darauf hin, dass das Überwintern von Truppen jenseits der Donau auch als Strafmaßnahme gedeutet werden kann; vgl. De Vleeschouwer 2019, $444 \mathrm{f}$.

10 Joh. Eph. Hist. eccl. 5.20 erklärt die Sparpolitik mit der Notwendigkeit, die finanziellen Lücken zu schließen, die aufgrund der Freigiebigkeit des Tiberios entstanden seien. In den posthum entstandenen Quellen überwiegt die geradezu topische Betonung von Maurikios' Geiz und Habgier: Joh. Nik. 95.1, 21f. etwa stellt die unbegründete Habgier des Maurikios als Quelle des Übels in den Vordergrund; dazu Whitby/Whitby 1986, 75 Anm. 7 in Zusammenhang mit Theoph. Sim. Hist. 3.2.8.; 
aktivem Widerstand geführt. Im Jahr 588 revoltierten inmitten des Perserkrieges die in Syrien stationierten Truppen für beinahe ein gesamtes Jahr gegen eine kaiserliche Order, die eine Reduzierung des Soldes und die Ersetzung des erfolgreichen Feldherren Philippikos durch den unbeliebten Priskos vorsah. Beigelegt werden konnte die sogenannte Monokarton-Revolte, in die der Patriarch Georg von Antiochia vermittelnd eingriff, allein durch die Zahlung des regulären Soldes und den Abzug des Priskos. ${ }^{11}$ Auch an der von awarischen Stammesverbänden bedrängten Balkanfront reagierten Truppenkontingente in den 590er Jahren wiederholt ablehnend auf Direktiven der Hauptstadt. ${ }^{12} 593$ sträubten sich die Soldaten, als der Magister militum Priskos anordnete, einen Großteil der von den Avaren erbeuteten Güter nach Konstantinopel zu übersenden, um sie an den Kaiser und dessen Söhne zu verteilen. ${ }^{13} \mathrm{Im}$ Winter des selben Jahres ordnete Maurikios erstmals an, dass die Soldaten jenseits der Donau überwintern sollten, was als unzumutbar empfunden wurde; Priskos gelang es schließlich, die Lage zu entschärfen, indem er dem Heer eigenmächtig den Abzug gewährte. ${ }^{14} 594$ kam es angesichts des Versuchs, die Soldaten anstatt mit Geld anteilig mit Kleidern und Waffen zu entlohnen, erneut zu kollektivem Ungehorsam; allein das versöhnliche Auftreten des Feldherren Petros, Maurikios' Bruder, und Versprechen kaiserlicher Vergünstigungen konnte die Situation eingehen. ${ }^{15}$

Konflikte zwischen Maurikios bzw. dessen Generälen und den römischen Truppen wurden indes nicht allein durch kaiserliche Sparbemühungen ausgelöst. 598 erhob sich im Balkan-Heer massiver Widerstand gegen den Feldherrn Komentiolos, dem taktische Fahrlässigkeit zu Ungunsten der Soldaten vorgeworfen wurde; man schickte gar eine Gesandtschaft nach Konstantinopel, um sich bei Maurikios über die Zustände zu beschweren. Der Kaiser indes stärkte Komentiolos den Rücken und stieß damit die Bittsteller vor den Kopf. In Zusammenhang mit einem weiteren Fauxpas - Maurikios weigerte sich, Geiseln vom Avaren-Khagan freizukaufen, und besiegelte damit deren Todesurteil - kam gar das Gerücht auf, der Kaiser selbst habe sein Heer ins Verderben führen wollen. ${ }^{16}$

Vorwurf der Habgier außerdem in Theoph. Sim. Hist. 8.7.2f.; vgl. dazu Gräbner 1982 und allgemein zu der Unbeliebtheit und dem schlechten Ruf des Maurikios siehe Olster 1993, 49-51.

11 Evagr. Hist. eccl. 6. 4-6, 9-13; Theoph. Sim. Hist. 3.1-4; Theoph. Conf. AM 6079 (De Boor 260); siehe Kaegi, 1981, 68-72; Mi. Whitby 1988, 286-289; Olster 1993, 52f.; Pfeilschifter 2013, 253 f.; vgl. Börm 2013, 82 und Leppin 2015, $212 \mathrm{f}$.

12 Zu den Aufständen der Balkanarmee siehe Kaegi 1981, 104-110; Mi. Whitby 1988, 156-165; Olster 1993, 51; Pfeilschifter 2013, 254-256.

13 Theoph. Sim. Hist. 6.7.6-16.; siehe dazu Kaegi 1981, 104f. und Pfeilschifter 2013, 254.

14 Theoph. Sim. Hist. 6.10.1-3; Theoph. Conf. AM 6086 (De Boor 272); den Priskos kostete die Missachtung des kaiserlichen Befehls seinen Posten.

15 Theoph. Sim. Hist. 7.1; Theoph. Conf. AM 6088 (De Boor 274).

16 Theoph. Sim. Hist. 7.13.8-14.12 zu Komentiolos Versagen als Feldherr; 8.1.9-11 zu der Gesandtschaft; Theoph. Conf. AM 6092 (De Boor 278-280); ibid. 280 zu der Weigerung, Geiseln frei zu kaufen; vgl. Joh. Ant. fragm. 316. Gemäß Theophanes gab das Zurückweisen dieser Delegation, an der auch der spätere Kaiser Phokas teilnahm, den Anlass für eine Verschwörung gegen Maurikios, die schließlich 
„No other sixth century reign witnessed as much military unrest and deep-seated sedition" - so Walter Kaegis Fazit zur Herrschaft des Maurikios in seiner umfassenden Studie zu militärischen Unruhen. ${ }^{17}$ Dabei ist zu betonen, dass die zahlreichen Konflikte zwischen Kaiser und Heer unter Maurikios allesamt aus Konstellationen resultierten, in denen Truppeneinheiten ihre Existenzgrundlage durch kaiserliche Direktiven beeinträchtigt sahen. Im vorigen Kapitel wurde festgestellt, dass die Bindung der in den Provinzen stationierten Truppen an die sesshaften und unkriegerischen Kaiser im 5. und 6. Jahrhunderts nicht prinzipiell ein Problem darstellte - solange die Versorgung der Soldaten garantiert war und die Kaiser sich ostentativ um deren Wohlergehen bemühten. ${ }^{18}$ Der oben ausgeführte Befund legt nahe, dass es sich auch im späten 6. Jahrhundert weiterhin derart verhielt; das Feldheer blieb prinzipiell auf den Kaiser in Konstantinopel bezogen. Die zahlreichen Unruhen aus den Reihen des Heeres - Unruhen der Soldaten, wohlgemerkt, nicht der Befehlshaber - resultierten nicht aus einem generellen Akzeptanzschwund, sondern daraus, dass die Soldaten sich durch konkrete Entscheidungen des Maurikios missachtet und benachteiligt sahen.

Dass sich auch im Jahr 602 schnell Widerstand unter den Truppen regte, als erneut der Befehl einging, jenseits der Donau zu überwintern, ist vor diesem Hintergrund kaum verwunderlich. Vergleichbare Konfliktsituationen im zurückliegenden Jahrzehnt hatten gezeigt, dass die Soldaten die diensthabenden Feldherren und indirekt auch den Kaiser in Konstantinopel durch Befehlsverweigerung unter Druck setzen konnten; wiederholt hatten sie auf diesem Wege ihren Willen durchgesetzt. Doch während die Konfrontationen auf dem Balkan im vergangenen Jahrzehnt letztendlich hatten beigelegt werden können, kam es nun zur Eskalation. Der Magister militum, Maurikios' Bruder Petros, trat in Verhandlungen mit den meuternden Soldaten, die eigenmächtig die Donau überquert hatten und auf thrakischem Gebiet standen. Gleichzeitig bemühte er sich, Maurikios angesichts der angespannten Lage zum Einlenken zu bewegen; dieser jedoch beharrte auf der Umsetzung seines Befehls. ${ }^{19}$ Anders als Priskos knapp zehn Jahre zuvor setzte Petros sich nicht über kaiserlichen Vorgaben hinweg; ein Kompromiss war demnach nicht in Sicht.

Als sich für die Soldaten herauskristallisierte, dass die kaiserliche Seite auf ihrer Position beharrte, ergriffen sie erneut die Initiative. „Auch am folgenden Tag machten

602 in dessen Ermordung gipfelte. Dabei scheint es sich jedoch eher um eine post 602 verbreitete Deutung zu handeln, da nicht der Eindruck entsteht, dass Maurikios' Sturz von langer Hand geplant war. Laut Joh. Ant. war die Weigerung des Maurikios, die Geiseln des Khagans auszulösen, Grund für den Plan der Armee, diesen zu beseitigen. Zu dieser Konstellation siehe ausführlich Pfeilschifter 2013, 255f. mit Anm. 9.

17 Kaegi 1981, 116; siehe auch Lee 2007, 67, der festhält, dass sich im 6. Jahrhundert Unruhen von Seiten der Soldaten häuften, während Revolten im 5. Jahrhundert vor allem von prominenten Individuen ausgegangen waren.

18 Siehe Kap. 2.2.1.

19 Die Verhandlungen werden ausführlich beschrieben bei Theoph. Sim. Hist. 8.6.2-8.7.6. 
die Truppen eine weitere Versammlung, nahmen sich Phokas, den Befehlshaber einer Hundertschaft, zum Anführer, hoben ihn hoch auf den Schild und feierten seine Ausrufung in außergewöhnlicher Weise mit Hochrufen“ - so Theophylakt Simokattes. ${ }^{20}$ Für das Verständnis der Geschehnisse des Novembers 602 ist die Deutung dieser Handlung entscheidend. Aus Theophylakts Bericht wird in der Forschung wiederholt geschlossen, Phokas sei bereits nahe der Donaugrenze zum Kaiser erhoben worden. ${ }^{21}$ Untersucht man die Konstellation allerdings entlang ihrer praxeologischen Voraussetzungen, so wird deutlich, dass eine Kaiser-Erhebung in der Provinz extrem unwahrscheinlich ist. Mit der Festigung einer hauptstädtischen Konfiguration von Monarchie seit dem frühen 5. Jahrhundert fanden Kaisererhebungen bzw. -krönungen nur noch in (bzw. in der direkten Umgebung von) Konstantinopel statt. ${ }^{22}$ Die Ausnahme bestätigt die Regel: Die einzige Krönung, die in der Provinz vollzogen wurde, nämlich die des Leontios im Jahr 484 in Tarsos, zeitigte keine Auswirkungen auf die politische Konstellation in Konstantinopel und verlief schnell im Sande. ${ }^{23}$ Damit der Akt der Erhebung seine Performanz entfalten und einen Mann effektiv zum römischen Kaiser machen konnte, musste er im hauptstädtischen Raum und unter Beteiligung der hauptstädtischen Gruppen stattfinden.

Die Balkantruppen erhoben Phokas nicht zum Kaiser. ${ }^{24}$ Nachdem die Verhandlungen gescheitert waren und sie sich vom Magister militum Petros losgesagt hatten,

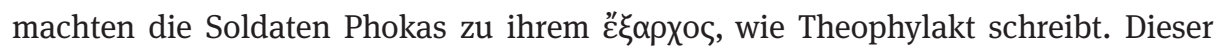
Begriff bezeichnete ursprünglich einen Offizier im spätrömischen Heer, im späten 6. Jahrhundert dann das neu eingerichtete Amt eines Statthalters mit umfassenden militärischen und zivilen Kompetenzen. ${ }^{25}$ Als Bezeichnung für einen Befehlshaber verstehe ich den Begriff auch bei Theophylakt. Phokas' Erhebung zum Befehlshaber als Ersatz für den abgesetzten Petros geschah غ̇ктó um eine eigenmächtige Handlung der meuternden Soldaten handelte. Eine ganz ähnliche Konstellation ist im Jahr 588 in Syrien bei der bereits erwähnten MonokartonRevolte zu beobachten. Anstatt den neuen Magister militum Priskos anzunehmen, erhoben die Soldaten einen gewissen Germanos, einen in Edessa stationierten Kom-

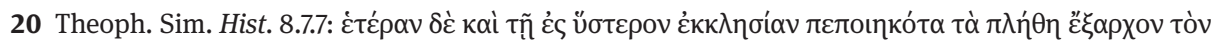

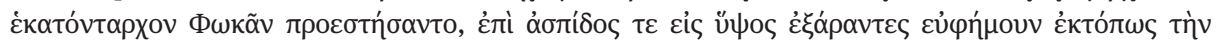

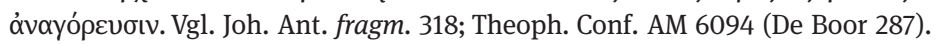

21 So Whitby/Whitby 1986, 220 Anm. 32 und Mango/Scott 1997, 416 Anm. 30.

22 Ausführlich zu Krönungen siehe unten 3.3.

23 Zur Usurpation des Leontios siehe Kiel-Freytag 2010 und Pfeilschifter 2013, 557-560.

24 So auch Stratos 1968, 45; Schreiner 1985, 357 Anm. 1099; Olster 1993, 53; Pfeilschifter 2013, 271. In Joh. Ant. fragm. 318 bestimmen die Truppen bereits zu Beginn der Erhebung, dass Phokas Kaiser werden solle, allerdings wird er erst auf dem Hebdomon auf einen Schild erhoben und zum Kaiser ausgerufen. Joh. Nik. 102.9-11, vermerkt, dass es zuerst vier Kommandeure gegeben habe, aus denen dann Phokas per Los ausgewählt worden sei.

25 Siehe Meier 1998. 
mandanten, zum Feldherrn. ${ }^{26}$ Sowohl die syrische Revolte 588 als auch die der Balkantruppen 602 entstand primär aus dem Bedürfnis der Soldaten, ihren Lebens- bzw. Dienststandard zu sichern: Mit Befehlsverweigerung gedachten sie, ihren Forderungen Nachdruck zu verleihen. Zur Krönung eines Gegenkaisers kam es in keinem der beiden Fälle. Dass die Balkantruppen - im Gegensatz zu denen in Syrien - kurz nach Phokas' Erhebung zum Befehlshaber begannen, in Richtung Konstantinopel vorzurücken, ist vor allem der geographischen Lage, der relativen Nähe zur Hauptstadt, geschuldet.

Die Meutereien aus den Reihen des Heeres, die während der Regierung des Maurikios ausbrachen, konnten durch Zugeständnisse von Seiten der Befehlsgewalt beigelegt werden; zu keinem Zeitpunkt gab es - zumindest soweit die Abläufe aus den Quellen zu rekonstruieren sind - von Seiten der Soldaten Anstalten, das Regime in Konstantinopel zu stürzen bzw. einen alternativen Kandidaten auf den Thron zu bringen. Im Falle der Revolte der Balkantruppen im Jahr 602 verhielt es sich erstmals anders: Gemäß dem ausführlichen Bericht des Theophylakt Simokattes schickte Maurikios, inzwischen über die Geschehnisse in Kenntnis gesetzt, Gesandte zum meuternden Heer, das sich weiter der Hauptstadt näherte. Doch der Zeitpunkt für Gespräche war aus der Sicht der Soldaten bereits verstrichen; anstatt auf die kaiserlichen Beschwichtigungsversuche einzugehen, schickten sie Boten zu einer kaiserlichen Jagdgesellschaft, die sich vor den Toren Konstantinopels aufhielt: An Maurikios' Stelle - so die Forderung des Heeres - sollte entweder dessen ältester Sohn Theodosios oder Germanos, Theodosios' Schwiegervater, treten. ${ }^{27}$ Warum sich das aufgebrachte Heer im November 602 erstmals nicht beschwichtigen ließ, ist nicht mit Sicherheit zu sagen. Offenbar empfanden die Balkantruppen die Spannungen, die sich über ein Jahrzehnt hinweg zwischen Kaiser und Heer aufgebaut hatten, angesichts eines erneuten unpopulären Befehls schlichtweg als unüberbrückbar. Auch der Umstand, dass Maurikios dem Balkanheer seine Aufmerksamkeit gewidmet hatte, indem er die Truppen über mehrere Wochen hinweg persönlich angeführt hatte, konnte deren Loyalität nun nicht mehr uneingeschränkt garantieren. ${ }^{28}$

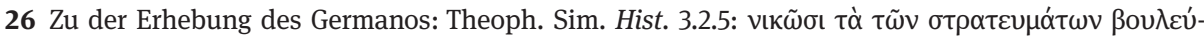

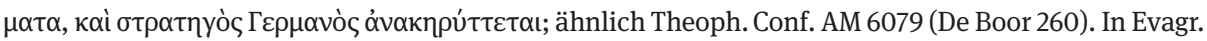

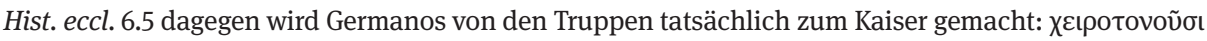

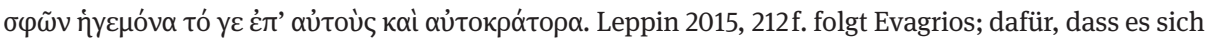
nicht um eine Kaisererhebung handelte, plädieren auch Kaegi 1981, 71 und Börm 2013, 82. Zu Germanos siehe PLRE IIIA, Germanus 6 (529f.). Missbilligung der Soldaten gegenüber Maurikios äußerte sich in Syrien darin, dass sie Kaiserbilder und -statuen zerstörten; siehe Theoph. Sim. Hist. 3.2.8.

27 Theoph. Sim. Hist. 8.8.3-5; Theoph. Conf. AM 6094 (De Boor 287). Gemäß den Derivaten des Theophilos von Edessa trug das meuternde Heer zuerst dem Feldherrn Petros, dem Bruder des Maurikios, die Krone an; dieser weigerte sich allerdings und floh nach Konstantinopel, siehe Hoyland 2011, $53-55$.

$28 \mathrm{Zu}$ Maurikios' Interaktion mit dem Heer siehe oben S. 74-77. 
Die Forderung der Soldaten nach einem Herrscherwechsel ist darüber hinaus in zweierlei Hinsicht bemerkenswert: ${ }^{29}$ Erstens dient sie als weiteres Indiz dafür, dass Phokas zu diesem Zeitpunkt noch nicht zum Kaiser gekrönt worden war; zweitens zeigt sie, welche Kriterien sich bei der Suche nach einem Ersatz für Maurikios zunächst als handlungsleitend erwiesen. Für das Heer war Maurikios' ältester Sohn, der bereits 590 zum Augustus gekrönte Theodosios, der naheliegende Nachfolger. ${ }^{30}$ Es ging also zu Beginn der Revolte keineswegs um einen Sturz der gesamten Familie, sondern allein um die Beseitigung des unbeliebten Maurikios; dynastische Legitimation wog schwer. Etwas komplizierter verhält es sich mit Germanos, Theodosios' Schwiegervater, über den die Quellen kaum genauere Angaben machen, außer dass er - so Theophylakt - eines der führenden Senatsmitglieder war. ${ }^{31}$ In der Forschung wurde wiederholt die Vermutung getätigt, Theodosios' Schwiegervater sei identisch mit dem Germanos, der 582 gemeinsam mit Maurikios zum Caesar erhoben worden war. ${ }^{32}$ Damit wäre der Alternativ-Kandidat des Heeres aller Wahrscheinlichkeit nach ein Nachkomme der justinianischen Dynastie, der - als Spross einer Familie von erfolgreichen Heermeistern - selbst eine militärische Karriere durchlaufen hatte, dadurch in den hauptstädtischen Senat aufgenommen und schon einmal bei der Thronfolge in Betracht gezogen worden war. Akzeptiert man diese Identifizierung, zeigt sich an dem Umstand, dass Maurikios seinen Sohn und designierten Thronfolger Theodosios mit Germanos' Tochter verheiratete, ${ }^{33}$ die anhaltende Bedeutung dieser Familie. Mit Blick auf die Geschehnisse des Novembers 602 bestätigt sich schließlich das Muster, welches im vorigen Kapitel hinsichtlich monarchischer Sukzession im 5. und 6. Jahrhundert beobachtet wurde: Stand ein leiblicher Sohn zur Verfügung, wurde dieser früh designiert und übernahm nach dem Tod des Vater unumstritten die Herrschaft; war dies nicht der Fall, kamen in der Regel militärische Funktionsträger zum Zuge. Die ,Wahl' des Heeres war wohlüberlegt; auch wenn es letztendlich ganz anders kommen sollte, hatten die von ihnen favorisierten Kandidaten Theodosios und Germanos auch innerhalb der Entscheidungsstrukturen der Hauptstadt strategisch gesehen die besten Karten.

Rene Pfeilschifter suggeriert, Phokas sei nach seiner Erhebung zum Befehlshaber nur noch die Flucht nach vorne geblieben: Er habe die eigene Krönung anstreben müssen, um am Leben zu bleiben. ${ }^{34}$ Dagegen hat der Überblick über das 5 . und

29 Dass die Soldaten sich an Theodosios und Germanos wandten, ist allein in Theophylakt und dem von ihm anhängigen Theophanes überliefert. Ich sehe allerdings keinen Grund, diese Episode als nicht authentisch zu verwerfen.

30 Zur Krönung des Theodosios siehe oben S. $72 \mathrm{f}$.

31 Theoph. Sim. Hist. 8.4.10.

32 So Whitby/Whitby 1986, 215 Anm. 18; Mi. Whitby 1988, 15; Olster 1993, 54; Börm 2010, 167; ausführlich Pfeilschifter 2013, 277-280; siehe auch PLRE IIIA, Germanus 5 (529) und Germanus 11 (531f.). Zu dem Germanos, der 582 mit Maurikios zum Caesar erhoben wurde siehe oben S. $59 \mathrm{f}$.

33 Zur Hochzeit zwischen Theodosios und Germanos' Tochter siehe Chron. Pasch. AD 602; Theoph. Sim. Hist. 8.4.10 f.

34 Pfeilschifter 2013, 272f. 
6. Jahrhundert gezeigt, dass selbst meuternde Feldherren in die offizielle Amtshierarchie reintegriert werden konnten, bzw. dass den Kaisern aufgrund von deren Machtfülle und Einfluss bisweilen schlicht nichts anderes übrigblieb. Das beste Beispiel ist Vitalian, dem selbst nach Jahren der Befehlsverweigerung wiederholt höchste militärische Ämter übertragen wurden. Dem Balkanheer und seinem Befehlshaber stand demnach stets noch die Option des Einlenkens offen; ein gewaltsamer Machtwechsel war aus ihrer Sicht nicht unvermeidbar. Selbst nachdem sie eigenmächtig einen Befehlshaber bestimmt und sich in Richtung Konstantinopel aufgemacht hatten, stand nicht zur Debatte, die Hauptstadt mit Militärgewalt einzunehmen; stattdessen projizierten die Soldaten ihre Hoffnungen auf zwei Kandidaten, die als Teil des politischen Establishments bereits eine herausragende Position in der hauptstädtischen Hierarchie besetzten. Die beiden Kandidaten indes entzogen sich den Avancen der Truppen und kamen Maurikios' Befehl nach, in die Stadt zurückzukehren. ${ }^{35}$

Dass Maurikios die römischen Truppen wiederholt mit derart harschen Maßnahmen vor den Kopf stieß, ist schwer zu erklären. Entweder handelte es sich um geradezu verzweifelte Versuche, die angespannte militärische und finanzielle Lage in den Griff zu bekommen, oder man muss Maurikios - trotz seiner persönlichen Erfahrung als Militär, die er vor seiner Krönung hatte sammeln können - einen gravierenden Mangel an strategischem Fingerspitzengefühl attestieren. ${ }^{36}$ Zuletzt ließe sich mutmaßen, dass Maurikios die Bedrohung, die von einem aufständischen Heer ausgehen konnte, schlichtweg unterschätzte. Bisher hatten die Mauern der Hauptstadt den Kaisern, solange diese sich des Rückhaltes der hauptstädtischen Bevölkerung und Eliten versichern konnten, stets einen verlässlichen Schutz vor militärischem Druck aus der Provinz geboten. So konzentrierte sich auch Maurikios, als er im November 602 vom Vorrücken der Soldaten in Richtung Konstantinopel in Kenntnis gesetzt wurde, primär auf die Sicherung der Stadt. Die kaiserlichen Maßnahmen zeitigten vorerst die erhoffte Wirkung: Bei Pferderennen im Hippodrom akklamierten ihm die Zirkusparteien und signalisierten damit ihre Akzeptanz. ${ }^{37}$ Kurz darauf, als sich Maurikios’ Beschwichtigungsbemühungen gegenüber den Truppen als erfolglos erwiesen hatten und das Balkanheer weiter auf Konstantinopel vorrückte, bemannten die Demenmitglieder auf kaiserlichen Befehl hin die Theodosianischen Stadtmauern. ${ }^{38}$

35 Theoph. Sim. Hist. 8.8.6.

36 Vgl. Olster 1993, 64: „The true causes of the usurpation of Phocas lay in the political dynamics that had developed in Byzantium during the course of the sixth century. Maurice's inept handling of the army was not due solely to his own malfeasance, but was the outcome of a nearly century of gradual disenfranchisement of the field army."

37 Akklamationen im Hippodrom: Laut Theoph. Sim. Hist. (8.7.8f.) akklamierten nur die Blauen; laut Theoph. Conf. AM 6094 (De Boor 287) auch die Grünen, die allerdings Kritik an dem ehemaligen Prätorianerpräfekten Konstantin Lardys und dem Senator Domentiolos, zwei Vertrauten des Kaisers, übten; dazu siehe Al. Cameron 1976, 332; Mango/Scott 1997, 416 Anm. 32; Pfeilschifter 2013, $262 \mathrm{f}$.

38 Theoph. Simok. Hist. 8.8.1f.; Theoph. Conf. AM 6094 (De Boor 287). Dass die Demen zur Verteidigung der Stadt eingesetzt wurden, ist im späten 6. Jahrhundert nicht unüblich; siehe Al. Cameron 
Beim Bekanntwerden der Revolte regte sich in Konstantinopel also noch kein öffentlicher Widerstand gegen Maurikios. Erst als die Nachricht von den Offerten des Heeres an Theodosios bzw. Germanos Konstantinopel erreichte, geriet die Konstellation langsam in Bewegung; allerdings ging auch hier die Initiative vorerst nicht von der hauptstädtischen Bevölkerung aus. Während Theodosios nicht weiter in Erscheinung trat, sondern sich angesichts der Entwicklung in Thrakien unverzüglich in den Palast an die Seite seines Vaters begab und dort auch verharrte, konnte sein Schwiegervater nicht ohne Weiteres unter Kontrolle gebracht werden. Obwohl Germanos sich - zumindest zu diesem Zeitpunkt - nicht dezidiert gegen Maurikios stellte, schien er sich seiner prekären Position bewusst: vom Kaiser des Hochverrats bezichtigt sah den einzigen Ausweg im Kirchenasyl. ${ }^{39}$ Zunächst begab er sich in die Theotokos-Kirche im Kyrosviertel; des Nachts rettete er sich dann in die Hauptkirche der Stadt, die Hagia Sophia. Während die Balkantruppen weiterhin auf Konstantinopel vorrückten, ließ Maurikios nicht von Germanos ab. Vor den Augen einer versammelten Menschenmenge machten kaiserliche Gardesoldaten sich daran, den Schutzsuchenden aus der Kirche zu führen. Angesichts dieses versuchten Verstoßes gegen das Kirchenasyl eskalierte die bereits angespannte Situation. ${ }^{40}$

Während Maurikios' Regierung ist nicht nur eine vergleichsweise hohe Zahl an Revolten von Truppeneinheiten zu verzeichnen, sondern auch Unruhen innerhalb der Stadtmauern. Als der Kaiser gemeinsam mit seinem ältesten Sohn Theodosios beim Fest der Hypapante am 2. Februar 601 barfuß an einer nächtlichen Prozession durch die Stadt teilnahm, schlug ihm die Unzufriedenheit der hauptstädtischen Bevölkerung entgegen, die angesichts einer Getreideknappheit unter Hunger litt. In der versammelten Menge brach Unruhe aus; Steine flogen gegen die beiden Augusti, die sich nur mit Hilfe der kaiserlichen Leibgarde in Sicherheit bringen konnten. ${ }^{41}$ Dabei bleibt jedoch zu betonen, dass derartige Zusammenstöße zwischen Kaiser und Bevölkerung im Konstantinopel des 5. und 6. Jahrhunderts keine Seltenheit waren und nicht zwangsläufig zum endgültigen Akzeptanzverlust bzw. gar einem Machtwechsel führen mussten. Auch im November 602 konnte zunächst kaum absehbar gewesen sein, wie sich die Dinge entwickeln würden.

Was die Stimmung in der hauptstädtischen Bevölkerung, die zunächst noch Unterstützung für Maurikios signalisiert hatte, zum Kippen brachte, war die Ahnung eines bevorstehenden Sakrilegs auf kaiserlichen Befehl. Maurikios' Verhalten - die Vehemenz, geradezu Hektik, mit der er versucht hatte, Germanos habhaft zu werden -

1976, 105-125, 258-261; Olster 1993, 37 f.: „demes [...] as a supplemental military force”; Pfeilschifter 2013, $230 \mathrm{f}$.

39 Theoph. Sim. Hist. 8.8.7-10; Theoph. Conf. AM 6094 (De Boor 287f.).

40 Theoph. Sim. Hist. 8.8.11-8.9.6; Theoph. Conf. AM 6094 (De Boor 288).

41 Während Maurikios in die Marienkirche von Blachernae nahe der Stadtmauer weiterzog, bemächtigten sich die Aufrührer eines Mannes, der dem Kaiser ähnlich sah, und trieben ihn unter Spott durch die Straßen (Joh. Ant. fragm. 317; Theoph. Conf. AM 6093 [De Boor 283]); zu diesem Vorfall auch Theoph. Sim. Hist. 8.4.11-5.4. 
legt nahe, dass er diesen als empfindlichen Risikofaktor empfand. Sein unsensibles Vorgehen jedoch, mit dem er offenkundig gegen christliche Prinzipien verstieß, wurde von der Bevölkerung nicht toleriert; einen derartigen Affront konnte der Kaiser sich nicht leisten. Nachdem der Funke im Stadtzentrum gezündet hatte, griffen die Unruhen bald auf die gesamte Stadt aus; nun verließen auch die auf der Stadtmauer stationierten Demen ihre Posten und mischten sich unter die marodierende Menge. ${ }^{42}$ Die Ausschreitungen, die sich daraufhin entfalteten, folgten bekannten Mustern städtischer Aufstände: ${ }^{43}$ Der Unmut der Bevölkerung entlud sich in Schmähungen des Kaisers und des Patriarchen Kyriakos sowie in Zerstörungen; das Anwesen von Maurikios' engem Vertrauten Konstantin Lardys ging in Flammen auf. ${ }^{44}$ Soweit es sich aus den Quellen rekonstruieren lässt, gingen die Aufständischen allerdings weiterhin nicht explizit auf die vom Heer vorgebrachte Option des Kaiserwechsels ein; Akklamationen zugunsten des Theodosios oder Germanos sind nirgendwo verzeichnet.

Der entscheidende Wendepunkt der Abläufe ereignete sich in der darauffolgenden Nacht vom 22. auf den 23. November. Als die Lage in den Straßen der Hauptstadt zusehend außer Kontrolle geriet, entschied Maurikios sich $\mathrm{zu}$ einer drastischen Maßnahme: Anstatt weiter im kaiserlichen Palast auszuharren, legte er seine kaiserlichen Insignien ab und ergriff über einen der palasteigenen Meerzugänge die Flucht. In einfachem Gewand und mit Gold im Gepäck bestieg er gemeinsam mit Frau und Kindern ein Boot, um auf die asiatische Seite des Marmarameeres zu gelangen. ${ }^{45}$ Sowohl die Beweggründe der kaiserlichen Flucht als auch deren Konsequenzen sind genauer ins Auge zu fassen. Städtische Unruhen, bei denen der regierende Kaiser sich mit Missbilligung breiter Teile der Bevölkerung konfrontiert sah, sind, wie bereits gesagt, als ein typisches Phänomen der hauptstädtischen Monarchie zu identifizieren; die sesshaften Kaiser ihrerseits entwickelten Strategien bzw. Handlungsmuster, mit solchen Situationen umzugehen. Bei den zwei in der Forschung meistdiskutierten Aufständen, dem Staurotheis-Aufstand des Jahres 512 und dem Nika-Aufstand des Jahres 532, begaben sich die regierenden Kaiser Anastasios bzw. Justinian in den Hippodrom, um sich dort der aufgebrachten Bevölkerung zu stellen. Während Anastasios die Lage tatsächlich mit einer Demutsgeste in den Griff bekommen konnte - er nahm seine Krone ab und signalisierte damit, seine Herrschaft liege in den Händen der versammelten Bevölkerung -, ${ }^{46}$ ging Justinians Plan, die Aufständischen mit dem

42 Theoph. Sim. Hist. 8.8.7-8.9.6; Theoph. Conf. AM 6094 (De Boor 287f.).

43 Vgl. Al. Cameron 1976, 271-298 zu Aufständen der Zirkusparteien.

44 Theoph. Sim. Hist. 8.9.3-5; Theoph. Conf. AM 6094 (De Boor 288): gemäß beider Quellen wird Maurikios als Anhänger der Häresie des Markian verschmäht, siehe Schreiner 1985, 358 Anm. 1112; Whitby/Whitby 1986, 223 Anm. 45 und Mango/Scott 1997, 417 Anm. 41 schreiben dieser spezifischen Beleidigung keine weitere Bedeutung zu; als „stock vocabulary of abuse” sei sie aufgrund des Gleichklangs mit Maurikios’ Namen gewählt worden; siehe dazu auch Gräbner 1982.

45 Theoph. Sim. Hist. 8.9.7; Theoph. Conf. AM 6094 (De Boor 288).

46 Zum Staurotheis-Aufstand siehe Meier 2007a. 
Evangelium in der Hand zu beschwichtigen, nicht auf. ${ }^{47}$ Der Nika-Aufstand konnte schlussendlich nur durch massive Gewaltanwendung des Feldheeres unter der Führung des General Belisar, das gerade vom Persienfeldzug zurückgekehrt war, niedergeschlagen werden. Bemerkenswert in Hinblick auf die Konstellation im November 602 ist der Umstand, dass Maurikios noch nicht einmal versuchte, die Bevölkerung durch ein Kommunikationsangebot zu beschwichtigen. Über die Gründe dafür kann nur spekuliert werden: Schätzte Maurikios die Lage in Konstantinopel derart ausweglos ein oder war er schlichtweg nicht allzu geschickt im Umgang mit seinen Untertanen? Dass er wiederholt Interaktionsmöglichkeiten mir der hauptstädtischen Bevölkerung ungenutzt ließ, wurde bereits im vorigen Kapitel angemerkt. ${ }^{48}$ Militärische Mittel, den Aufstand niederzuschlagen, derer sich etwa Justinian hatte bedienen können, standen Maurikios jedenfalls nicht zur Verfügung, sodass er offenbar seinen letzten Ausweg in der Flucht sah.

Doch Maurikios mag mit seinem Handeln auf ein anderes Vorbild rekurriert haben: Es war nämlich bereits einem oströmischen Kaiser gelungen, nach einer Flucht aus Konstantinopel wieder auf den Thron zurückzukehren. Von einer Verschwörung hoher Militärs in Kenntnis gesetzt, zog sich Zenon 475 in seine Heimat Isaurien zurück, wo er über eine breite Unterstützerbasis verfügte; an seiner Stelle wurde Basilikos zum Kaiser gekrönt. Eineinhalb Jahre später rückte Zenon mit einem isaurischen Heer auf die Hauptstadt vor. Die Entscheidung fiel allerdings nicht auf dem Schlachtfeld und erst recht nicht beim Kampf um die Stadtmauern. Dass Zenon kampflos in Konstantinopel einziehen konnte, lag in dem Umstand begründet, dass Basiliskos die Akzeptanz der Hauptstadt durch seine unpopuläre Religionspolitik innerhalb kürzester Zeit verspielt hatte. Dazu kam, dass sich der Feldherr Armatos, den Basiliskos dem Zenon mit Truppen entgegengeschickt hatte, bestechen ließ: Angesichts der Hoffnung auf Ämter und Würden für sich und seine Familie schlug er sich auf Zenons Seite. ${ }^{49}$ Auch Maurikios scheint darauf gesetzt zu haben, außerhalb Konstantinopels seine Kräfte zu sammeln: Theophylakt Simokattes bemerkt, er habe bei seiner Flucht ausgerechnet auf Unterstützung durch den römischen Erzfeind, den persischen Großkönig Chosroes II., gehofft. ${ }^{50}$ Chosroes stand tatsächlich in Maurikios’ Schuld: Nachdem der persische General Baram Chobin im Jahr 590 Ctesiphon in seine Gewalt gebracht hatte, ersuchte Chosroes den römischen Kaiser um militärische Unterstüt-

47 Zu dem Zeitpunkt, als Justinian sich der Bevölkerung im Hippodrom stellte, war die Situation offenbar bereits zu verhärtet, als dass noch eine Schlichtung hätte erreicht werden können; Justinian war zuvor wiederholt nicht auf die Forderungen der Bevölkerung eingegangen. Zum Nika-Aufstand siehe Greatrex 1997; Meier 2003b; Leppin 2011, 142-148; Pfeilschifter 2013, 178-210; Brandes 2014; Ayaita 2015. Laut Prokop (Bell. Pers. 1.24.32-38) wollte auch Justinian aus der Stadt fliehen, wurde allerdings durch das Eingreifen seiner Ehefrau Theodora überzeugt zu bleiben.

48 Siehe S. $76 \mathrm{f}$.

49 Zu den Abläufen siehe Pfeilschifter 2013, 536 - 544, außerdem Kosinski 2010, 79 - 82; vgl. auch S. 53

zu Zenons Bündnisschluss mit dem General Armatos.

50 Theoph. Sim. Hist. 8.9.11; Theoph. Conf. AM 6094 (De Boor 288f.). 
zung. Mit römischer Hilfe wurde der Usurpator gestürzt und der Erbe der sassanidischen Dynastie kehrte auf den persischen Thron zurück. ${ }^{51}$ Doch während Chosroes sich angesichts des Coups in seiner Hauptstadt rasch auf römisches Territorium hatte begeben können, stagnierte Maurikios’ Flucht am südlichen Ufer des Marmarameeres: Von Krankheit geplagt ${ }^{52}$ zog er sich in die Kirche des Heiligen Autonomos zurück, wo er wenige Tage später von Phokas' Truppen aufgegriffen wurde..$^{53}$

In Konstantinopel wiederum verbreitete sich die Nachricht von Maurikios' Flucht wie ein Lauffeuer und brachte neue Dynamiken in Gang. Während zuvor in der Stadt noch keine Forderungen nach einem Kaiserwechsel laut geworden waren, ergriffen nun verschiedene Akteure bzw. Akteursgruppen die Initiative. Auch dieser Ablauf erstaunt nicht. ${ }^{54}$ Im 5. und 6. Jahrhundert wurde nur zwei Mal ein Gegenkaiser erhoben: der bereits erwähnte Basiliskos im Jahr 475 und Hypathios im Jahr 532 während des Nika-Aufstandes. Basiliskos’ Krönung auf dem Hebdomon fand statt, nachdem Zenon Konstantinopel verlassen hatte; ${ }^{55}$ Hypatios wurde im Hippodrom zum Kaiser erhoben bzw. gerierte sich tatsächlich auch als solcher, nachdem sich das fälschliche Gerücht verbreitet hatte, Justinian sei aus der Hauptstadt geflohen. ${ }^{56}$ Die Hemmschwelle, in Konstantinopel einen alternativen Kandidaten zum Kaiser zu machen, war hoch. $\mathrm{Zu}$ einem gewissen Grad lag dies sicherlich in dem Umstand begründet, dass es kaum möglich war, den regierenden Kaiser aus dem gut befestigten Palast, dem Kristallisationspunkt monarchischer Macht, zu beseitigen, solange dessen Garden $\mathrm{zu}$ ihm hielten. ${ }^{57}$ Erst wenn ein bedrängter Kaiser eigenmächtig den Palast verlassen und damit gewissermaßen seinen Herrschaftsanspruch aufgegeben hatte

51 Dazu siehe oben S. 71-74.

52 Gemäß Theoh. Sim. Hist. 8.9.10 litt Maurikios an Arthritis; auch Joh. Ant. fragm. 318 erwähnt die schlechte Gesundheit des Kaisers.

53 Maurikios soll seinen Sohn Theodosios zu Chosroes schickt haben (Theoph. Sim. Hist. 8.9.11f.); bei der Frage, ob Theodosios die Flucht gelang, oder ob er - wie Theoph. Sim. Hist. 8.11.1f. beschreibt umkehrte und kurz darauf ebenfalls ermordet wurde, sind sich die Quellen uneinig. Die Gerüchte um Theodosios' Überleben diskutiere ich unten S. 140, 147.

54 Während laut Theoph. Sim. Hist. 8.9.7 Maurikios in der Nacht vom 22. auf den 23. November floh, gibt Joh. Ant. fragm. 318 an, Maurikios habe zwar geplant zu fliehen, sei allerdings aufgrund seiner schlechten Gesundheit doch im Palast geblieben; erst nachdem er von der Erhebung des Phokas auf dem Hebdomon gehört habe, sei er tatsächlich auf die asiatische Seite übergesetzt. Dieser Ablauf ist allerdings meiner Ansicht nach nicht plausibel; zu den Diskrepanzen zwischen Theoph. Sim. und Joh. Ant. siehe Olster 2003, 59-62. Vgl. Zon. 3.299, laut dem die Unruhen in der Stadt erst nach Maurikios' Flucht eskalierten.

55 In den Quellen folgt die Krönung des Basiliskos auf die Flucht des Zenon: Theod. Lect. epit. 401; Vita Dan. 69; Malal. 15.2f.; Theoph. Conf. AM 5967 (De Boor 120 f.); Vict. Tun. s.a. 475; Anon. Vales. 41; Marc. Com. Chron. ad a. 475; Prok. Bell. Vand. 1.7.18; Evagr. Hist. eccl. 3.3.

56 Malal. 18.71 (p. 475 Dindorf); Chron. Pasch. AD 532 (625); siehe dazu Meier 2003b, 274f., 294-296; Greatrex 1997, 79.

57 Wiederholt war eine Erstürmung des Palastes gescheitert: Aspars Truppen wurden nach dessen Ermordung von Leons Exkubitoren zurückgehalten; ebenso Markian, der unter Zenon versuchte, den Palast einzunehmen; siehe oben S. 44, 53. 
- bzw. wenn die Öffentlichkeit davon ausging, dass es sich so verhielt -, kam es zur Erhebung eines alternativen Kandidaten.

Nachdem Maurikios' nächtliche Flucht bekannt geworden war, ging es am Tag darauf ganz konkret darum, das von ihm hinterlassene Vakuum zu füllen; Konstantinopel brauchte einen Kaiser. Nun zeigte sich, wer in einer derart chaotischen und offenen Situation die entscheidenden Impulse geben konnten. Laut Theophylakt Simokattes rückte Germanos von seiner vorherigen Zurückhaltung ab und bekundete nun sein Interesse am Kaiserthron, trat mit Repräsentanten der Demen in Verbindung und warb um deren Unterstützung. Die grüne Zirkuspartei indes wies Germanos' Avance harsch zurück, da sie in ihm einen unverbesserlichen Anhänger der Blauen sahen. Vertreter der Grünen begaben sich ihrerseits zum aufständischen Heer, welches inzwischen einen Tagesmarsch vor Konstantinopel stand, nahe der Stadt Rhegion am Marmarameer; sie priesen deren Anführer Phokas, den sie als Maurikios' Nachfolger auserkoren hatten, und ermutigten ihn, zum Hebdomon vorzurücken, dem traditionellen Truppen-Sammelplatz außerhalb der Theodosianischen Stadtmauer. Phokas ging auf die Offerte ein und begab sich zum Hebdomon, wo - wie im folgenden Unterkapitel detailliert analysiert wird - die Krönungszeremonie eingeleitet wurde. ${ }^{58}$

Folgt man Theophylakts Erzählung, so kristallisierten sich die Repräsentanten der Zirkusparteien als maßgebliche Entscheidungsträger heraus. Obwohl einer derartigen Einschätzung in der Forschung zuletzt von David M. Olster widersprochen wurde, ${ }^{59}$ halte ich die aus Theophylakt rekonstruierte Ereignislogik für plausibel. ${ }^{60}$ Mit der Herausbildung einer hauptstädtischen Monarchie stieg die Bevölkerung Konstantinopels zu einem maßgeblichen Faktor für die Stabilität monarchischer Herrschaft auf. Der Beitrag dieser Gruppe zu politischen Entscheidungsprozessen war oft reaktiv: Mit Zustimmung oder Ablehnung reagierten sie auf Impulse prominenter Individuen. Das eigentliche politische Gewicht der hauptstädtischen Bevölkerung offenbarte sich vor allem dann, wenn sie sich kollektiv gegen als unzumutbar empfundene Zustände erhob. Im Jahr 400 wurde der Versuch des gothischen Heermeisters Gainas, in Konstantinopel eine den westlichen Heermeistern vergleichbare Machtposition zu erreichen, durch einen Aufstand der hauptstädtischen Bevölkerung vereitelt. ${ }^{61}$ Ebenso konnte es geschehen, dass die hauptstädtische Bevölkerung sich gegen den regierenden Kaiser stellte und ihn durch kollektiven Akzeptanzentzug massiv unter Druck setzte. ${ }^{62}$ Wenn Konstantinopel im Chaos versank, entsprach das einer Ermächtigung

58 Joh. Ant. fragm. 318; Theoph. Sim. Hist. 8.9.13-8.10.1; Theoph. Conf. AM 6094 (De Boor 289).

59 Olster 1993, 59-62, bes. 62: „Exciting reading though it is, Theophylact's highly colored tale of mass frenzy and deme power obscures the actual political dynamics at work in the fall of Maurice. It not only exaggerates the demes' roles, but minimizes the army's role and especially, the role of Germanus and his supporters." Olster geht davon aus, dass die kaiserlichen Garden desertierten; dafür fehlt in den Quellen aber jeglicher Hinweis.

60 Zu einer ähnlichen Einschätzung kommt Pfeilschifter 2013, 269-291; zusammenfassend 291-293.

61 Zu Gainas siehe Faber 2011; Börm 2013, 76; Pfeilschifter 2013, 497-507.

$62 \mathrm{Zu}$ den prominentesten Beispielen, dem Staurotheis- und Nika-Aufstand, siehe oben S. 54, 56f. 
der hauptstädtischen Bevölkerung; in derart prekären Situationen spielte diese Gruppe, zu einem gewissen Grad repräsentiert durch die Zirkusparteien, eine nicht nur reaktive, sondern aktive Rolle in politischen Entscheidungsprozessen. ${ }^{63}$ So verhielt es sich in dem hier analysierten Fall: Nach der Flucht des Maurikios konnte selbst ein gestandenes Mitglied der hauptstädtischen Elite wie Germanos nicht einfach an der weiterhin tobenden Bevölkerung Konstantinopels vorbei agieren; mit ihrer Ablehnung scheiterte sein Versuch, die von Maurikios hinterlassene Leerstelle zu füllen. Dabei ist zu betonen, dass es sich bei der hauptstädtischen Bevölkerung keineswegs um eine homogene Masse handelte, sondern dass innerhalb dieser Gruppe verschiedene Interessen, gebündelt durch die Demen, im Konflikt zueinander stehen konnten. Im November 602 erwiesen sich die Impulse der grünen Zirkuspartei als entscheidend.

Der Prozess, der letztendlich in Maurikios’ Flucht und Phokas’ Krönung endete, nahm seinen Anfang in der Rebellion der an der Donau stationierten Soldaten. Dass die Truppen unter Phokas' Führung auf Konstantinopel vorrückten und mit ihrer Offerte an Theodosios und Germanos die Option eines Machtwechsels in den Raum stellten, bedingte die Stimmung in Konstantinopel. Dass sich die Spannungen in der Hauptstadt derart entluden und Maurikios in der Flucht den letzten Ausweg sah, ist allerdings nicht allein auf die Geschehnisse in Thrakien zurückzuführen. ${ }^{64}$ Ein knappes Jahrhundert zuvor meuterten die Balkantruppen unter Vitalian über mehrere Jahre hinweg und rückten wiederholt bis in die Nähe der Hauptstadt vor; obwohl der damals regierende Kaiser Anastasios sich keinesfalls uneingeschränkter Beliebtheit erfreute - der Staurotheis-Aufstand lag nur kurz zurück -, zeitigte die Revolte des Heeres keine konkreten Auswirkungen auf die politische Lage in Konstantinopel; die hauptstädtische Bevölkerung hielt zum Kaiser. ${ }^{65}$ Im frühen 7. Jahrhundert jedoch verhielt es sich anders.

Maurikios zeigte sich der Situation, die sich im Herbst 602 entfaltete, als nicht gewachsen. Nachdem er das Heer wiederholt durch strenge Maßnahmen und Kompromisslosigkeit vor den Kopf gestoßen hatte, bewies er auch im Umgang mit der hauptstädtischen Bevölkerung im entscheidenden Moment nicht das nötige Fingerspitzengefühl; sein Affront gegen Germanos und der Verstoß gegen christliche Prinzipien löste die Eskalation innerhalb der Stadtmauern aus. Man kommt kaum umhin, den Machtwechsel von $602 \mathrm{zu}$ einem gewissen Grad individuellen Fehlentscheidungen des Maurikios zuzuschreiben. Es lässt sich die Überlegung anstellen, was passiert

$63 \mathrm{Zu}$ der hauptstädtischen Bevölkerung als Akzeptanzgruppe siehe die ausführliche Diskussion bei Pfeilschifter 2013, 294-354; vgl. Al. Cameron 1976, 280 - 285 zu der Rolle der Demen bei Aufständen in Konstantinopel; zum Kaiser und den Demen siehe auch Olster 1993, 35-38.

64 Den Machtwechsel des Jahres 602 als Militärputsch zu qualifizieren, ist demnach nicht treffend; siehe auch Pfeilschifter 2013, 269 f., der sich gegen eine derartige Einschätzung ausspricht. Vgl. Meier 2014b, 149 Anm. 27, für den der zentrale Faktor bei den Machtwechseln der Umstand ist, dass „der Angriff auf die Herrschaft sowohl des Maurikios als auch später des Phokas von außen erfolgte“.

$65 \mathrm{Zu}$ Vitalian siehe oben S. $54 \mathrm{f}$. 
wäre, wenn der Kaiser im Palast ausgeharrt hätte, anstatt nach Kleinasien zu fliehen, oder wenn er zugunsten seines Sohnes abgedankt hätte, um die Lage zu entschärfen. ${ }^{66}$ Hätte er damit sein Leben und das Fortbestehen seiner Dynastie retten können?

Ich verstehe den Machtwechsel des Jahres 602 als Ergebnis einer Verkettung kontingenter Faktoren. Dass ein ehemaliger Zenturio des meuternden Balkanheeres an Maurikios' Stelle in Konstantinopel zum Kaiser gekrönt werden würde, war zu Beginn des Prozesses keinesfalls absehbar - geschweige denn geplant. Phokas kam erst als Kaiser in Frage, als Maurikios sich nach Kleinasien abgesetzt hatte und die konfligierenden Interessensgruppen innerhalb der Stadtmauern sich nicht auf einen internen Kandidaten einigen konnten. Phokas war der Joker der grünen Zirkuspartei. Laut Egon Flaig ist „die Kategorie ,Usurpation“ (...) zu bestimmen als die Herausforderung des amtierenden Herrschers durch einen Rivalen. ${ }^{“ 67}$ Folgt man dieser Definition, trifft der Begriff ,Usurpation` auf die Geschehnisse des Novembers 602 nicht zu. Phokas forderte Maurikios nicht als Kaiser heraus; erst als Maurikios seine kaiserlichen Insignien abgelegt und nach Kleinasien geflohen war, wurde Phokas die Kaiserwürde angetragen.

Was in dem oben umrissenen Ereigniszusammenhang jedoch letztendlich zählt, ist das Ergebnis. Der Prozess, der in der Krönung des Phokas kulminierte, machte deutlich, dass Druck von außen, militärischer Druck, die politische Konstellation der Hauptstadt maßgeblich beeinflussen konnte. Wie im vorigen Kapitel betont, waren die sesshaften Kaiser selbst während verhältnismäßig stabiler Phasen nicht gänzlich unabhängig vom militärischen Sektor. Die Möglichkeiten der Einflussnahme durch hohe militärische Funktionsträger waren allerdings beschränkt; Druck auf den regierenden Kaiser wurde im 5. und 6. Jahrhundert in der Regel nur verhältnismäßig subtil ausgeübt wurde, etwa durch strategische Heiratsallianzen. Maurikios' Sturz und Phokas' Krönung eröffneten hingegen eine neue Perspektive: Die Ereignisdynamik des Novembers 602 hatte verdeutlicht, dass direkte militärische Aggression die Stimmung in Konstantinopel zum Kippen bringen konnte. Aus dem Ergebnis der Verkettung kontingenter Faktoren - der Krönung des ehemaligen Zenturio Phokas erschlossen sich neue Handlungsoptionen. Allein vor diesem Hintergrund wird der Prozess verständlich, der einige Jahre später in Karthago seinen Ursprung nahm.

\subsection{Die Usurpation des Herakleios}

Der Machtwechsel von 602 hatte mit der Rebellion der Balkantruppen begonnen, die sich kollektiv gegen die als unzumutbar empfundenen Direktiven der Hauptstadt

66 Für beide Szenarien gab es Referenzpunkte: Justinian war während des Nika-Aufstandes eben nicht geflohen; Justin II. hatte die Herrschaft Jahre vor seinem Tod faktisch an seinen Adoptivsohn Tiberios übergeben.

67 Flaig 1997, 19; eine alternative Definition von Usurpation bringt Pfeilschifter 2013, 273 Anm. 37 ins Spiel. 
auflehnten. Im Gegensatz dazu wurde der Aufstand, der etwa acht Jahre später in Karthago ausbrach, nicht von Soldaten initiiert bzw. getragen, sondern von einem mächtigen Individuum und dessen Umfeld, dem Exarchen Herakleios. ${ }^{68}$ Die Exarchate von Nordafrika und Italien mit Sitz in Karthago und Ravenna waren unter Maurikios eingerichtet worden. Diese Maßnahme zielte darauf ab, die unter Justinian zurückeroberten Gebiete effektiver zu verwalten und mit lokalen Ressourcen zu verteidigen, während die oströmischen Streitkräfte aufgrund der andauernden Auseinandersetzungen mit Avaren und Sassaniden auf dem Balkan bzw. im Osten gebunden waren. Als direkte Vertreter der Kaiser waren die Exarchen mit umfassenden militärischen und zivilen Kompetenzen ausgestattet. ${ }^{69}$ Herakleios, der Vater des späteren Kaisers, trat das Amt des Exarchen von Karthago zu einem nicht näher bestimmbaren Zeitpunkt an, nachdem er sich unter Maurikios als Magister militum im Krieg gegen die Perser hervorgetan hatte und in den Rang des Patrikios aufgestiegen war. ${ }^{70} \mathrm{Ab}$ der zweiten Hälfte des Jahres 607 erhob Herakleios sich gegen Phokas; ${ }^{71}$ dezidierte Ziel seines Unterfangens war es - wie im Folgenden deutlich wird - das Regime in Konstantinopel zu stürzen.

Die Revolte des Balkanheeres ist als spontane Reaktion auf kaiserliche Befehle zu verstehen; ihr Ergebnis - der Sturz des Maurikios und die Krönung des ehemaligen Zenturios Phokas - war zu Beginn weder intendiert noch absehbar. Angesichts des auf Konstantinopel vorrückenden Heeres überschlugen sich innerhalb von zwei Wochen die Geschehnisse. Die afrikanische Revolte unterscheidet sich davon allein aufgrund ihrer geographischen Spannweite und ihrer zeitlichen Ausdehnung; im Gegensatz zur Balkanrevolte zeichnet sie sich außerdem durch ein hohes Maß an strategischem Kalkül und Weitblick aus. Herakleios gelang es, die fragile Gesamtlage im Mittelmeerraum und die Schwäche von Phokas' Truppen auszunutzen, die mehrere Krisenherde gleichzeitig bespielen mussten: Neben Auseinandersetzungen mit den Persern, die durch den Sturz des Maurikios erneut entfacht worden waren, ${ }^{72}$ brachen im Nahen Osten immer wieder lokale Unruheherde auf. ${ }^{73}$ Dank der militärischen

68 Zur Usurpation des Herakleios siehe Stratos 1968, 80 - 91; Olster 1993, 117-138; Kaegi 2003, 37-52; Roberto 2010 (Fokus auf Konstantinopel) und Pfeilschifter 2013, 584-605; zu der Problematik der teilweise widersprüchlichen Quellen siehe Olster 1993, 117. Kaegi 1981, 124 äußert die Vermutung, dass der Grund für die Revolte in Missbilligung von Befehlshabern und Truppenkontingenten über die plötzliche Bedeutung und den Erfolg der Balkantruppen gelegen habe, die einen der Ihrigen auf den Thron hatten bringen können.

$69 \mathrm{Zu}$ den Exarchaten siehe Meier 1998.

70 PLRE IIIA, Heraclius 3 (584-586).

71 Der Beginn der Revolte kann anhand von Münzprägungen festgesetzt werden, siehe Grierson 1950b, 89; außerdem MIB II, 84.

72 Dazu siehe S. 141, 176-179.

73 Joh. Nik. verzeichnet Zerwürfnisse zwischen Bevölkerung und Heer in Antiochia (Joh. Nik. 104) und eine Rebellion von Offizieren im ägyptischen Merada (Joh. Nik. 105); vgl. außerdem Sebeos 31 (Thomson/Howard-Johnston I, 57f.), der besonders die Leiden der Bevölkerung hervorhebt; laut Theoph. Conf. AM 6101 (De Boor 296) revoltierten die Juden in Antiochia; vgl. auch Chron. Pasch. AD 
Ressourcen, die ihm als Exarch zur Verfügung standen, gelang es Herakleios von Karthago aus, den südlichen Mittelmeerraum zu sichern. Mit Hilfe maurischer Stammesverbände brachte sein Neffen Niketas im Laufe des Jahres 608 weite Teile Ägyptens inklusive Alexandria unter seine Kontrolle. Auch die Truppen des Phokas-treuen Comes Orientis Bonosos, der von Palästina nach Ägypten gekommen war, um den Aufstand einzuhegen, konnten sich nicht gegen Niketas durchsetzen. ${ }^{74}$ Neben Ägypten besetzten Herakleios’ Truppen schließlich auch Zypern; Bonosos zog sich nach Konstantinopel zurück. ${ }^{75}$ Das Ausmaß der Unruhen im südlichen Mittelmeerraum blieb in der Hauptstadt nicht unbemerkt, zumal mit der Aussetzung der Getreidelieferungen aus Ägypten Druck ausgeübt wurde. ${ }^{76}$

Bei der afrikanischen Revolte handelte es sich nicht etwa nur um eine lokale Abspaltungsbewegung. Die Sicherung Afrikas und Ägyptens war ein erster Schritt, der die Machtbasis für Herakleios' eigentliches Vorhaben etablierte. Der Schlüssel zum Verständnis der zugrundeliegenden Intention findet sich in einer außergewöhnlichen Serie von Münzen, die im Gegensatz zu den schriftlichen Quellen, die allesamt nach dem erfolgreichen Machtwechsel entstanden, einen ungebrochenen Blick auf die Entfaltung der Revolte in eventu bietet. Für die Indiktionen 11, 12, 13, 14 - entsprechend den Jahren 607/8, 608/9, 609/10, 610/11 - wurden in Karthago, Alexandria, Zypern und eventuell auch Alexandretta Münzen geprägt, die Herakleios und seinen gleichnamigen Sohn als Konsuln abbilden. ${ }^{77}$ Die Averse der Solidi zeigen zwei frontale Büsten in Konsular-Tracht (ohne Kopfbedeckung; besonders prominent ist der Loros zu erkennen $)^{78}$ mit der Beischrift DN (oder DMN) ERACLIO CONSULI; auf den Reversen ist ein Stufenkreuz mit der Beischrift VICTORIA CONSULI (oder CONSLB) versehen. ${ }^{79}$

610 (699f.). Die Quellen verzeichnen ein Ansteigen von Unruhen der Zirkusparteien im gesamten östlichen Mittelmeerraum, siehe Al. Cameron 1976, 82- 84 und Olster 1993, 108-115.

$74 \mathrm{Zu}$ den Kämpfen in Ägypten siehe Joh. Nik. 107.1- 8, 16; 107.19-109.17; dazu Olster 1993, 124-127;

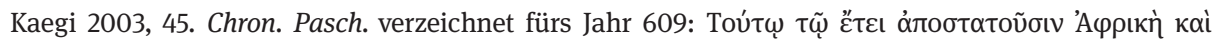
’A $\lambda \varepsilon \xi \xi^{\prime} v \delta \rho \varepsilon \iota \alpha$ („In diesem Jahr rebellierten Afrika und Alexandria.“). Die Alexandrinische Münzstätte begann in der 11. Indiktion, herakleische Münzen zu prägen, war also spätestens 608 in der Hand der Rebellen. Zu Bonosos siehe PLRE IIIA, Bonosos 2 (239-240).

75 Die Einnahme von Zypern ist numismatisch belegt, siehe Grierson 1950b, 82f. mit Appendix Nr. 5 und 6; Olster 1993, 127 f. Zu einem potentiellen Aufenthalt des Herakleios auf Zypern siehe Rapp 2004, 130.

76 Chron. Pasch. AD 609 (699); Theoph. Conf. AM 6100 (De Boor 296).

77 Zu den Münzen siehe Grierson 1950a, 1950b; DOC II.1, 207-215, Taf. 7; MIB II, 84-87, Taf. 37; zuletzt Penna/Morrisson 2013, 25-27.

$78 \mathrm{Zu}$ Konsulartracht bzw. konsularen Insignien auf frühbyzantinischen Münzen siehe DOC II.1, 78-80. Vgl. auch Olster 1993, 176-179 zu der Feier eines kaiserlichen Konsulats durch entsprechende Münzprägung im späten 6. und frühen 7. Jahrhundert.

79 Mit dem Stufenkreuz wird auf Prägetypen von Münzen des Tiberios zurückgegriffen; Maurikios und Phokas ließen Engel auf dem Revers abbilden, siehe MIB II, 84. Mit dem Rückgriff auf Stempel des Tiberios erklärt Grierson 1950b, 81 auch das seltene Vorkommen der Beischrift VICTORIA AUG auf herakleischen Münzen aus Alexandria, die per Indiktion auf 607/08 zu datieren sind: Um schnell auf die neuen Machtverhältnisse reagieren zu können, griff man nach der Eroberung Alexandrias durch 
Durch die Haartracht lässt sich die vom Betrachter aus links abgebildete, bartlose Figur als Herakleios Junior und die rechte, bärtige als Herakleios Senior identifizieren. Durch seine Positionierung auf dem linken Ehrenplatz steht Herakleios Junior in der Rangordnung vor seinem Vater. ${ }^{80}$

Die Aufständischen rissen also das kaiserliche Monopol der Münzprägung an sich und signalisierten dadurch ihren Bruch mit Phokas. Doch wie ist der Titel des Konsuls $\mathrm{zu}$ interpretieren? In der Forschung wurde wiederholt versucht, dem Vorgehen der Herakleioi ,verfassungsrechtlich' auf den Grund zu gehen. ${ }^{81}$ Derartige Deutungen erweisen sich allerdings als anachronistisch. Römische Monarchie hatte keine ,verfassungsrechtliche' Basis; Sukzession bzw. Usurpation verliefen nicht entlang rechtlicher Kategorien. Über den Erfolg oder Misserfolg eines Kaisers ebenso wie seines Herausforderers entschied die situative Akzeptanz durch die relevanten Gruppen: Seit dem frühen 5. Jahrhundert waren dies im oströmischen Reich die hauptstädtische Bevölkerung und die im Palastumfeld versammelte Funktionselite. ${ }^{82}$ Die Erhebung eines Kaisers musste seitdem in Konstantinopel vollzogen werden, um die erwünschte Wirkung zu entfalten. In der Provinz mit Unterstützung des Heeres einen alternativen Kaiser zu erheben und diesen auch auf Münzen als Kaiser abzubilden, wie es Usurpatoren bis ins 4. Jahrhundert getan hatten, war nicht mehr zielführend. ${ }^{83}$ Die Herakleioi wählten eine alternative Lösung: den Konsulat. ${ }^{84}$

Die Besetzung des Konsulats war unter Justinian eingestellt worden; seitdem Justin II. das Amt - oder besser gesagt: die Würde - wiederbelebt hatte, wurde der

Niketas auf ältere Stempel zurück. Diese AUG-Beischrift wurde dann schnell durch die KonsularBeischrift ersetzt.

80 Siehe MIB II, 84. Auf manchen Silber- und Kupfernominalen aus Karthago findet sich die Abbildung nur einer statt zwei Büsten (etwa MIB II, Taf. 37, 11-15 und DOC II.1 210-212, Nr. 4-9 mit Taf. 7), teilwiese mit Bart, teilweise - wenn man es bei dem Abrieb überhaupt richtig erkennen kann - ohne Bart, mit einem Adlerkopf-Zepter als Indikator konsularischer Autorität in der Hand, ebenfalls mit der Beischrift ERACLIO CONSULI; da sie keine Datierung tragen, ist nicht klar zu sagen, wie diese sich chronologisch zu den Münzen mit Doppelbüste verhalten; dazu siehe Grierson 1950b, 73, 84 f. mit einem Deutungsversuch. $\mathrm{Zu}$ einem Bleisiegel, das ebenfalls die Herakleioi als Konsuln abbildet, siehe Morrison 2001.

81 Etwa Grierson 1950b und Rösch 1979, der (ebd. 50) fragt, „welche Möglichkeiten und rechtlich einwandfreien Vorgehensweisen es gab, um im frühen 7. Jahrhundert Kaiser zu werden." Grierson in DOC II.1, 207 bezeichnet die Annahme des Konsulates als „convenient constitutional fiction”; Olster 1993 dagegen übergeht schlichtweg die Problematik, die dieses Set von Münzen aufwirft.

82 Siehe dazu unten Kap. 3.3.1.

83 Zu Usurpationen im 4. Jahrhundert siehe Omissi 2018.

84 Pfeilschifter 2013, 597 f. meint, dass der Titel des Konsuls auf den Münzen nur auf den älteren der beiden Herakleioi bezogen sei; dies leuchtet allerdings nicht ein, da sowohl Vater als auch Sohn in der Tracht eines Konsuls dargestellt sind. Für Hahn in MIB II, 84 erklärt sich der Konsulat aus der Stellung des älteren Herakleios als Exarch, die ihm den Titel des Exconsul eingebracht habe; vgl. Grierson 1950b, 79 Anm. 22; dagegen etwa Rösch 1979, 54, der allerdings dafür argumentiert (ebd. 61), Herakleios habe sich mit der Annahme des Konsul-Titels „sichtbar zum Führer der unzufriedenen Senats von Konstantinopel [gemacht]“; vgl. auch Kaegi 2003, 40-42. 
Konsulat nur noch vom Kaiser selbst bzw. dessen Familie besetzt, trug also eindeutig imperiale Implikationen; seinen ursprünglichen politischen Gehalt hatte der Konsulat längst verloren. ${ }^{85}$ Dass die Herakleioi in dem von ihnen kontrollierten Gebieten den Konsulat annahmen, ist als eine symbolische und nicht etwa rechtlich begründete Geste zu verstehen: Sie distanzierten sich damit von Phokas und artikulierten ihren Anspruch auf den kaiserlichen Thron, ohne die Unternehmung durch eine inakzeptable Kaiserkrönung in der Provinz von vorneherein ihrer Erfolgschancen zu berauben. ${ }^{86}$ Nachdem Herakleios Junior Jahre später tatsächlich in Konstantinopel gekrönt worden war, fand der in Afrika angetretene Konsulat keine Erwähnung mehr. ${ }^{87}$

Im Jahr 602 war die Erhebung des ehemaligen Zenturios Phokas erst ins Spektrum des Möglichen gerückt, als die Geschehnisse in der Hauptstadt mit Maurikios' Flucht eine unvorhergesehene Wende genommen hatten. Im Gegensatz dazu war es, wie die Münzen belegen, von Beginn an das erklärte Ziel der afrikanischen Revolte, das Regime in Konstantinopel zu stürzen und Herakleios' gleichnamigen Sohn an Phokas' Stelle auf den Thron zu bringen; anders sind die Konsulats-Prägungen nicht zu erklären. Entlang der oben angebrachten Definition Egon Flaigs handelt es sich also bei der afrikanischen Revolte tatsächlich um eine Usurpation, um die Herausforderung des regierenden Kaisers. Flaig fügt seiner Definition Folgendes hinzu: „In einem Akzeptanz-System tritt der Herausforderer immer schon als Herrscher auf." 88 Dies trifft wiederum auf die Revolte der Herakleioi nicht ganz zu: Aus den oben genannten Gründen konnten sie in Afrika noch nicht als Kaiser auftreten bzw. sich explizit kaiserliche Attribute aneignen; mit dem imperial konnotierten Konsulat machten sie ihren Herrschaftsanspruch dennoch unmissverständlich klar. ${ }^{89}$

Die Aneignung des Konsulates durch die Herakleioi war ein einmaliger Akt; weder davor noch danach ist ein vergleichbares Vorgehen belegt. ${ }^{90}$ Darin offenbart sich der liminale Charakter des frühen 7. Jahrhunderts. Über Jahrhunderte hatte Konstantinopel den sesshaften Kaisern eine sichere Bastion geboten. Die Intention der afrikanischen Revolte, nämlich einen Machtwechsel in Konstantinopel durch militärischen

85 Zum Konsulat im 5. und 6. Jahrhundert siehe Rösch 1978, 32; Meier 2002; Sguaitamatti 2012; Begass 2018, 47-49.

86 Es stellt sich die Frage, an welche Adressaten sich die Konsul-Prägungen richteten. In erster Linie wurden die Münzen wohl von der Bevölkerung der Gebiete, welche die Herakleioi besetzt hatten, rezipiert. Ob die Kunde von der Aneignung des Konsulats bis nach Konstantinopel vordrang, ist unklar. In den literarischen Quellen findet dieser Schritt keine Erwähnung.

87 Nach seiner Krönung in Konstantinopel am 15. Januar 611 trat Herakleios den ersten offiziellen Konsulat an; vgl. Rösch 1979, 62. Es bleibt etwas rätselhaft, warum Herakleios zu diesem Anlass nicht

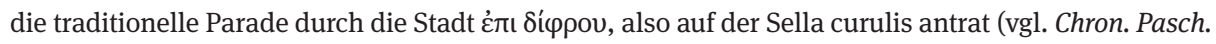
AD 611); Whitby/Whitby 1989, 151 Anm. 428 schlagen Geldmangel als Grund vor.

88 Flaig 1997, 20.

89 An den Grenzen der Flaig'schen Definition zeigt sich erneut die Eigenheit der hauptstädtischen Konfiguration von Monarchie und in welchem Maße diese sich strukturell von der hohen Kaiserzeit bzw. dem 4. Jahrhundert unterschied.

90 Siehe Kaegi 2003, $40-42$. 
Druck aus den Provinzen zu erwirken, war erst nach den Ereignissen von 602 ins Spektrum des Möglichen gerückt. Wie genau diese Option praktisch wahrgenommen bzw. umgesetzt werden konnte, musste allerdings noch ausgelotet werden; ich verstehe die Aneignung des Konsulates in diesem Sinne als Experiment innerhalb eines plötzlich erweiterten Handlungsspielraumes. Als sich in der zweiten Hälfte des 7. Jahrhunderts Usurpationen in den Provinzen häuften, hatte sich dieser Spielraum bereits derart verfestigt, dass die Prätendenten nicht mehr auf den Konsulat als Hilfskonstrukt zurückgriffen. ${ }^{91}$

Nach mehrjährigen Kämpfen hatten die Aufständischen das südliche Mittelmeer weitestgehend unter ihre Kontrolle gebracht. Nachdem die militärische Sicherung Ägyptens maßgeblich durch Herakleios' Neffen Niketas geleistet worden war, trat nun auch Herakleios' gleichnamiger Sohn, der auf den Münzen bereits in prominenter Position abgebildet war, persönlich in Erscheinung. Mit einer Flotte, bemannt mit maurischen Kontingenten, machte Herakleios Junior sich, aller Wahrscheinlichkeit nach im Sommer 610, auf den Weg nach Konstantinopel. ${ }^{92}$ Laut Johannes von Nikiu traf er, wann immer er auf seinem Weg durch das Mittelmeer an Land ging, auf Unterstützung der lokalen Bevölkerung, vor allem von Seiten der grünen Zirkuspartei. ${ }^{93}$ Phokas' Machtbasis begann offensichtlich zu bröckeln.

In den Quellen finden sich wiederholt Vermerke, welche suggerieren, dass die Herakleioi bereits über einen längeren Zeitraum mit dem hauptstädtischen Senat bzw. mit dem Comes excubitorum Priskos als einem prominenten Vertreter der Konstantinopolitaner Elite in Kontakt standen. ${ }^{94}$ Theophanes Confessor bringt Herakleios' Aufbruch nach Konstantinopel gar direkt mit einer Aufforderung des Senates, der sich von Phokas losgesagt hatte, in Verbindung. ${ }^{95}$ Die Forschung indes debattiert, ob diese Vermerke als authentisch zu werten sind, oder ob es sich dabei um eine retrospektive Beugung der Abläufe handelt, die alle Seiten nach dem erfolgten Machtwechsel besser dastehen lassen sollte. ${ }^{96}$ Ein Zitat aus Prokops Bella trägt zur Klärung bei. Der Autor

91 Einen Überblick über Usurpationen im späteren 7. Jahrhundert findet sich in Haldon 1990, 41-91; siehe dazu unten Kap. 7.2.

92 Joh. Nik. 109.25. Olster 1993, 127 f. vermutet, Herakleios sei aufgebrochen, während in Ägypten noch gekämpft wurde. Das scheint mir allerdings wenig plausibel, da unnötig riskant. Ich sehe keine Evidenz, dass Herakleios vor dem Frühjahr 610 von Karthago aufbrach. Vgl. Theoph. Conf. AM 6101 (De Boor 297) und Nik. Brev. 1 mit der Erzählung, es habe ein Wettrennen zwischen Herakleios Junior per Schiff und seinem Cousin Niketas auf dem Landweg gegeben, dessen Sieger zum Kaiser gekrönt werden würde. Dabei handelt es sich allerdings um eine Legende (siehe Howard-Johnston 2010, 203). Wie oben gezeigt, stand Herakleios von vorneherein als alleiniger Kandidat der afrikanischen Revolte fest; siehe dazu Rösch 1979, 57 f. und Olster 1993, 117 f.; ebd. Anm. 3 mit weiteren Quellen, in denen die Wettrennen-Legende zu finden ist.

93 Joh. Nik. 109.25; dazu siehe Olster 1993, $127 \mathrm{f}$.

94 Joh. Ant. fragm. 319; Theoph. Conf. AM 6100 (De Boor 295f.); Nik. Brev. 1.

95 Theoph. Conf. AM 6101 (De Boor 297).

96 Olster 1993, 130f. geht von einer ,Rückdatierung‘ der Komplizenschaft von Herakleios und hauptstädtischen Akteuren aus; zu der Frage nach Initiative und Voraussetzungen für die Revolte vgl. 
legt Antonina, der Frau von Justinians wichtigstem Feldherren Belisar, folgenden Satz in den Mund: „Wir können nicht im Feldlager einen Umsturz herbeiführen, wenn nicht einige drinnen mithelfen. ${ }^{\text {“97 }}$ Ohne genauer auf den Kontext dieses Zitates einzugehen, lässt sich festhalten, dass es eines der zentralen strukturellen Charakteristika oströmischer Monarchie des 5. und 6. Jahrhunderts auf den Punkt bringt. Wie durch die Geschehnisse des Novembers 602 erneut gezeigt, konnte militärische Aggression wenn überhaupt nur bedingt Einfluss auf die politische Hierarchie der Hauptstadt ausüben; der ausschlaggebende Faktor für die Stabilität monarchischer Herrschaft war die Stimmung in Konstantinopel. Dass Herakleios Junior erst dann nach Konstantinopel aufbrach, als er sich der Unterstützung prominenter Individuen innerhalb der Hauptstadt sicher sein konnte, minderte zu einem gewissen Grad das Risiko, das mit einer derartigen Unternehmung einherging. Dass der Senat als Gremium in Erscheinung trat, um Herakleios zu dem Coup zu bewegen, wie es die Quellen suggerieren, ist aufgrund der Vereinzelung und internen Konkurrenz seiner Mitglieder dagegen eher unwahrscheinlich. ${ }^{98}$

Mit der Frage, was die hauptstädtischen Akteure sich von der Unterstützung der Herakleioi erhoffen konnten, richtet sich nun der Blick auf Konstantinopel. Während der achtjährigen Regierung des Phokas waren in der Hauptstadt wiederholt Unruhen ausgebrochen; nicht nur die hauptstädtische Bevölkerung begehrte mehrmals gegen Phokas auf, auch Vertreter der Elite, gruppiert um Germanos und die weiblichen Überlebenden von Maurikios’ Familie, intrigierten gegen den Kaiser. Die Aufdeckung der Verschwörungen bot Phokas die Möglichkeit, sich unangenehmer Individuen durch Hinrichtungen und Verbannungen zu entledigen. ${ }^{99}$ Andere wiederum hatten zumindest zeitweilig von dem Machtwechsel profitiert: Priskos etwa, der bereits unter Maurikios als Magister militum gedient hatte, behielt unter Phokas seinen Rang, wurde zum Comes excubitorum befördert und heiratete im Jahr 607 Phokas’ Tochter Domentzia. ${ }^{100}$ Bei seiner Krönung hatte Phokas als ehemaliger Zenturio keine Verbindungen zur hauptstädtischen Elite. Um in Konstantinopel die nötige Loyalitätsbasis zu sichern, musste er etablierten Männern wie Priskos Zugeständnisse machen. Als Priskos jedoch im Zuge der Hochzeitsfeierlichkeiten im Hippodrom auf Gemälden der Zirkusparteien in der Position des Thronfolgers dargestellt wurde, wies Phokas

ebd., 117-119; Pfeilschifter 2013, 587 f., 596f. dagegen hält die Verbindung für plausibel: „Herakleios unternahm die Fahrt nur, weil er auf Helfer in der Stadt bauen (...) konnte“ (Zitat S. 588).

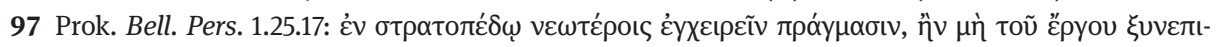

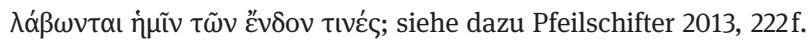

98 Zum Senat und der hauptstädtischen Elite im 5. und 6. Jahrhundert siehe oben S. 37-39.

99 Die Unruhen und Verschwörungen werden ausführlich unten S. 145-150 behandelt.

100 PLRE IIIB, Priscus 6 (1052-1057). Hierin offenbart sich erneut das Schema, das ich im vorigen Kapitel als typisch für das 5. und 6. Jahrhundert herausgearbeitet habe: Mächtige Militärs verbanden sich mit der Kaiserfamilie, um sich - sofern der Kaiser keinen leiblichen Sohn hatte - für die Nachfolge in Stellung zu bringen. 
dies harsch zurück. ${ }^{101}$ Eine weitere Auszeichnung des Priskos, die Erhebung zum Caesar etwa (also zum designierten Nachfolger), war damit vorerst nicht in Sicht. Aus dieser Zurückweisung heraus begann Priskos, sich für einen erneuten Machtwechsel zu positionieren. ${ }^{102}$ Es bleibt allein die Frage, warum der gekränkte Schwiegersohn sich - geht man davon aus, dass er tatsächlich die afrikanische Revolte unterstützte an einen externen Kandidaten wandte, anstatt selbst zu usurpieren. Offenbar war er als einzelner Vertreter der hauptstädtischen Elite nicht in der Lage, einen Machtwechsel herbeiführen und bedurfte externer Impulse.

Die afrikanische Flotte ihrerseits rückte durchs Mittelmeer vor. In Abydos an der Südküste des Hellesponts gelandet wurde Herakleios von dem dortigen Comes Theodor empfangen. Die Kunde seiner Ankunft verbreitete sich schnell; Herakleios' Unterstützerkreis wuchs: Nicht nur lokale Funktionsträger schlossen sich der Revolte an, sondern auch Senatoren, die von Phokas exiliert worden waren. ${ }^{103}$ Bereits Herakleios' Einfahrt ins Marmarameer, begleitet von einem Tross an Unterstützern, gestaltete sich geradezu triumphal. ${ }^{104}$ Auf der Konstantinopel vorgelagerten Insel Kalonimon traf Herakleios auf Stephan, den Metropoliten von Kyzikos, der ihm seine Hochachtung erwies, indem er ihm eine Krone aus der Kirche der Theotokos von Artake übergab. ${ }^{105}$ In der Forschung liest man wiederholt, Herakleios sei bereits durch diesen Akt gekrönt worden. ${ }^{106}$ Dies ist allerdings wenig überzeugend; wie bereits betont, konnten Krönungen nur in Konstantinopel bzw. unter Teilhabe der städtischen Gruppen stattfinden. ${ }^{107}$ Das symbolträchtige Zusammentreffen zwischen Herakleios und dem Metropoliten auf der Insel ist vielmehr als ein weiteres Zeichen der Unterstützung für den Prätendenten zu verstehen. Durch das Überreichen der Krone wurde die Revolte religiös sanktioniert; auch Herakleios’ Zwischenstopp in Herakleia und sein Gebet im dortigen Heiligtum der Glykeria dienten diesem Ziel. ${ }^{108}$

Theophanes Confessor berichtet mit Verweis auf Georg von Pisidien, die herakleische Flotte habe an ihren Masten Reliquien und Ikonen der Theotokos getragen, ${ }^{109}$

101 Zum Eklat bei der Hochzeit siehe Joh. Ant. fragm. 319; Theoph. Conf. AM 6099 (De Boor 294 ); vgl. Nik. Brev. 1.; vgl. Al. Cameron 1976, 253 und Pfeilschifter 2013, 593-596.

102 Joh. Ant. fragm. 319 und Nik. Brev. 1 bringen seine Kontaktaufnahme mit den Herakleioi explizit mit der Zurückweisung bei der Hochzeit in Verbindung.

103 Joh. Ant. fragm. 321; Theoph. Conf. AM 6102 [De Boor 298f.] gibt den Namen des Comes von Abydos an. Bei diesem Theodor könnte es sich wiederum um den Illustris Theodor handeln, der sich nach Joh. Nik. 109.26 ,together with a large number of wise senators” sowie seinem zivilen und militärischen Anhang dem Herakleios unterwarf.

104 Joh. Ant. fragm. 321; Theoph. Conf. AM 6103 (De Boor 299f.).

105 Fahrt durchs Marmarameer: Joh. Ant. fragm. 321; Theoph. Conf. AM 6103 (De Boor 299f.); laut Joh. Ant. (ebd.) befreiten Mitglieder der Zirkusparteien angesichts von Herakleios' Vorrückens dessen Mutter und Verlobte, die von Phokas als Geiseln gehalten worden waren.

106 So etwa Olster 1993, 131; Kaegi 2003, 48.

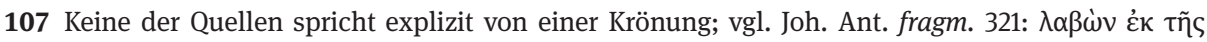

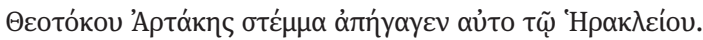

108 Joh. Ant. fragm. 321.

109 Theoph. Conf. AM 6102 (De Boor 298). 
und die Forschung folgt diesem Bilde nur allzu gerne. Tatsächlich findet sich auch in Georg von Pisidiens Heraclias, einem nach 628 entstandenen panegyrischen Epos, der Verweis, dass Herakleios dem Phokas „das verehrungswürdige Bild der unbefleckten

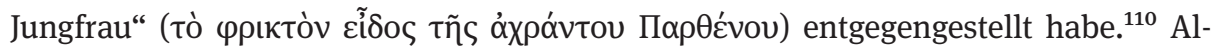
lerdings muss offenbleiben, ob es sich dabei um einen authentischen Hinweis auf die Verhältnisse des Jahres 610 oder doch eher um eine retrospektive Projektion handelt, die zu zirkulieren begann, als Herakleios' Verbindung zur Theotokos sich in den späten 620er Jahren weiter festigte. ${ }^{111}$ In Georg von Pisidiens erstem überlieferten Gedicht - In Heraclium ex Africa redeuntem, das kurz nach Herakleios' Ankunft in Konstantinopel entstand - ist jedenfalls trotz eines dezidiert religiösen Deutungsrahmens von Theotokos-Reliquien bzw. Ikonen nicht die Rede. ${ }^{112}$

Als Herakleios' Flotte ins Marmarameer einfuhr, geriet auch die Lage in Konstantinopel zunehmend in Bewegung. ${ }^{113}$ Die Sicherung der Langen Mauern in Thrakien, zu denen Phokas seinen Bruder Domentziolos abgeordnet hatte, erwies sich schnell als sinnlos, da Herakleios sich der Hauptstadt weiter per Schiff näherte. ${ }^{114}$ Eine Flotte, die er Herakleios hätte entgegenschicken können, stand dem Kaiser offenbar nicht zu Verfügung. Phokas hielt sich anfangs noch in den Außenbezirken der Stadt auf; eventuell versuchte er, eine direkte Konfrontation mit der hauptstädtischen Bevölkerung zu vermeiden, mit der er zuletzt wiederholt aneinandergeraten war. Erst als sich am 3. Oktober 610 die feindlichen Schiffe der Stadt bis auf die Höhe des Hebdomon genähert hatten, zog Phokas sich in den kaiserlichen Palast im Stadtzentrum zurück, ${ }^{115}$ der sich militärisch besser sichern ließ. Wie bereits sein Vorgänger Maurikios sah sich auch Phokas gezwungen, auf die Mitglieder der Zirkusparteien zurückzugreifen, um die Stadt zu befestigen: Auf Befehl des Kaisers sammelten die Grünen sich im Kaisarios- und Sophia-Hafen, die Blauen in dem des Hormisdas. ${ }^{116}$ Priskos indes desertierte nun offen: Anstatt den Befehlen seines Schwiegervaters nachzukommen, sammelte er die ihm unterstellten Exkubitoren sowie seine Bukellarier in seinem Anwesen. ${ }^{117}$ Mit den Exkubitoren hatte sich nun also die militärisch schlagkräftigste Einheit der Hauptstadt von Phokas abgewandt. Die Demen scheinen

110 Georg. Pis. Heracl. 2.13-16; Zitat ebd. 2.14.

$111 \mathrm{Zu}$ der Bedeutung der Theotokos und der Art und Weise, wie die Idee ihrer Wirkmächtigkeit für Konstantinopel mit Herakleios' Herrschaft verflochten wurde, siehe Kap. 5.3.2. Georg von Pisidiens Heraclias entstand nach dem Sieg über die Perser, also post 628, beinahe zwei Jahrzehnte nach Herakleios' Krönung.

$112 \mathrm{Zu}$ In Heraclium ex Africa redeuntem siehe ausführlich unten S. 130 - 133.

113 Die Aussagen der verschiedenen Quellen zu vereinbaren, ist im Detail schwierig, siehe dazu Roberto 2010; die groben Linien der Abläufe lassen sich aber durchaus herausarbeiten.

114 Joh. Ant. fragm. 321; Theoph. Conf. AM 6102 (De Boor 298f.).

115 Laut Chron. Pasch. AD 610 hielt er sich im kaiserlichen Palast am Hebdomon auf, laut Joh. Ant. fragm. 321 befand er sich im Blachernae-Viertel und begab sich dann nach Buridai, wo er die Schiffe des Herakleios sah, bevor er in den Palast floh; absolute Datierung gemäß Chron. Pasch. AD 610.

116 Joh. Ant. fragm. 321; vgl. Roberto 2010, $58 \mathrm{f}$.

117 Joh. Ant. fragm. 321; zu Priskos’ Rolle siehe Olster 1993, 72-75, 128-130 und Roberto 2010, 62f. 
sich vorerst gemäß dem kaiserlichen Befehl in den Häfen formiert zu haben. Doch die Ruhe währte nur kurz: Am Morgen des 4. Oktobers kochte die angespannte Stimmung in Konstantinopel über. Angesichts des Drucks, der von der im Hafen ankernden, hoch bewaffneten Flotte ausging, brach Phokas' Rückhalt in sich zusammen. Zwischen der grünen Zirkuspartei und Phokas’ Vertrautem Bonosos kam es zu Scharmützeln: Teile des Kaisarios-Hafens gingen in Flammen auf; Priskos griff mit seinen Exkubitoren in die Kämpfe ein. ${ }^{118} \mathrm{Im}$ Gegensatz zu 602 kam es nun tatsächlich zu militärischen Auseinandersetzungen.

Auf wessen Initiative hin die Situation eskalierte, ist angesichts der unterschiedlichen Perspektivierungen der Quellen schwer nachzuvollziehen. ${ }^{119}$ Folgendes kristallisiert sich heraus: Bei Ankunft der herakleischen Flotte erhob sich die grüne Zirkuspartei gegen Phokas und erscheint in den Auseinandersetzungen im Hafen als die treibende Kraft; ${ }^{120}$ anstatt ihrer Schutzfunktion nachzukommen, stellten sich auch Priskos' Exkubitoren gegen den Kaiser. Bonosos, der Phokas zuvor als Comes Orientis in der Levante und Ägypten gedient hatte, blieb dem Kaiser loyal, kam jedoch ums Leben; ${ }^{121}$ auch die blaue Zirkuspartei distanzierte sich nicht von Phokas. ${ }^{122}$ Ob und inwiefern Herakleios' Truppen in die Kämpfe im Hafen eingriffen, bleibt unklar. ${ }^{123}$ Es mag sein, dass eher ihre schiere Präsenz als ihr militärischer Beitrag ausschlaggebend dafür war, dass Teile der hauptstädtischen Bevölkerung sich gegen Phokas erhoben und sich gemeinsam mit den Exkubitoren gegen die kaisertreuen Truppen durchsetzen konnten. Herakleios' Aspiration auf den Thron muss inzwischen auch in Konstantinopel bekannt und offensichtlich gewesen sein. Verschiedene städtische Akteure (Priskos) und Gruppierungen (die grüne Zirkuspartei, die Exkubitoren) sahen angesichts der herakleischen Flotte die Möglichkeit, den unbeliebten Phokas zu beseitigen und sich in Bezug auf den neuen Kaiser von vorneherein gewinnbringend zu

118 Datierung in Chron. Pasch. AD 610.

119 Chron. Pasch. AD 610; Joh. Ant. fragm. 321; Joh. Nik. 109.27-110.3; Theoph. Conf. AM 6102 (De Boor 299); Nik. Brev. 1; siehe dazu Whitby/Whitby 1989, 149 Anm. 423; Olster 1993, 132-136; Roberto 2010; Pfeilschifter 2013, $600-604$.

120 Joh. Ant. fragm. 321 gibt an, die Kämpfe seinen auf Signal des berühmten Wagenlenkers Kalliopas ausgebrochen; siehe Roberto 2010, 59 und Pfeilschifter 2013, 601f. Al. Cameron 1976, 284 f. schätzt die Rolle der Zirkusparteien nicht allzu wichtig ein; dagegen Whitby/Whitby 1989, 149 Anm. 423. Laut Joh. Ant. fragm. 321 hatten Mitglieder der grünen Zirkuspartei zuvor bereits Herakleios' Ehefrau (Eudokia diese heiratete Herakleios allerdings erst nach seiner Krönung) und seine Mutter Fabia befreit, als die Flotte sich der Hauptstadt näherte.

121 Laut Joh. Ant. fragm. 321 wurde er von den Grünen ermordet, laut Chron. Pasch. AD 610 von einem Exkubitor, laut Joh. Nik. 110.2 von einem kaiserlichen Wagenlenker; siehe PLRE IIIA, Bonosus 2 (239f.). 122 Laut Joh. Nik. 110.3 verfolgten die Mitglieder der grünen Zirkuspartei die Blauen zu Schiff, die daraufhin Schutz in der Hagia Sophia suchten; dass die Blauen sich nicht von Phokas distanziert hatten, zeigt auch der Umstand, dass bei den ersten von Herakleios veranstalteten Wagenrennen deren Flagge verbrannt wurde (Chron. Pasch. AD 610).

123 Joh. Nik. 110.2, Theoph. Conf. AM 6102 (De Boor 299) und Nik. Brev. 1 suggerieren eine aktive Beteiligung der afrikanischen Truppen. 
positionieren. ${ }^{124}$ Als deutlich wurde, dass die kaisertreuen Einheiten auf verlorenem Posten standen, akklamierte die Besatzung der Schiffe Herakleios bereits als neuen Augustus; die Städter stimmten in die Rufe ein. ${ }^{125}$

Phokas, im Palast verschanzt und jeglicher Fluchtmöglichkeit beraubt, stand in Konstantinopel auf verlorenem Posten. Die Hauptstadt hatte ein klares Zeichen für Herakleios gesetzt. Im Morgengrauen des nächsten Tages ${ }^{126}$ verschafften sich einige Senatoren ohne Schwierigkeiten Zugang zum Palast - die Verteidigung durch die kaiserlichen Garden war längst zusammengebrochen. Sie ergriffen Phokas, entledigten ihn seiner kaiserlichen Insignien und führten ihn vor Augen der versammelten Bevölkerung durch die Stadt zum Hafen. Gefesselt und mit nichts als einem schwarzen Gewand bekleidet wurde der gestürzte Kaiser auf Herakleios' Schiff gebracht und nach weiteren Demütigungen hingerichtet. Acht Jahre nachdem die hauptstädtische Bevölkerung Phokas auf seinem Weg vom Goldenen Tor in den Palast frenetisch zugejubelt hatte, trug sie seinen abgeschlagenen Kopf auf einem Speer über die Mese und verbrannte ihn auf dem Theodosiosforum. Auch dessen engste Vertraute fielen der Raserei zum Opfer. ${ }^{127}$ Erneut hatte sich Konstantinopel seines Kaisers entledigt; eindrücklicher hätte das Ende einer Regierung kaum inszeniert werden können.

Sowohl der Machtwechsel von 602 als auch der von 610 wurde durch eine Kombination aus externem militärischem Druck und Instabilität des politischen Klimas in Konstantinopel erwirkt. Das Ergebnis der afrikanischen Revolte entsprach in Grundzügen dem Ergebnis der Revolte der Balkantruppen: In beiden Fällen kulminierten die Geschehnisse in der Ermordung des Kaisers und der Erhebung eines alternativen Kandidaten. Eine Analyse der jeweiligen Ereigniszusammenhänge hat allerdings die Unterschiede in den Abläufen, die zu eben diesem Ergebnis führten, deutlich hervortreten lassen. ${ }^{128}$ Im November 602 war es in Konstantinopel erst zu einer mehrheitsfähigen Entscheidung für einen alternativen Kandidaten gekommen, nachdem Maurikios aus der Hauptstadt geflüchtet war. 610 dagegen war Phokas noch im Palast verschanzt, als Herakleios im Hafen zum Augustus akklamiert wurde. Die Erfahrung

124 Bewertung des Machtwechsels: Rösch 1979, 61 sieht in der Unterstützung durch den Senat und die Grünen den maßgeblichen Grund für den Erfolg der Revolte; Olster 1993, 132 den Betrug der Exkubitoren; Sarris 2011, 243-245 beschreibt ihn als „senatorial coup” (ebd. 245) und Pfeilschifter 2013, $603 \mathrm{f}$. betont die Initiative der Grünen und einzelner Mitglieder der städtischen Elite.

125 Joh. Nik. 110.1; Nik. Brev. 1.

126 Zur Chronologie wieder Chron. Pasch. AD 610 (700).

127 Zur Ermordung des Phokas siehe Joh. Ant. fragm. 321; Chron. Pasch AD 610 (700f.); Joh. Nik. 110.5-7; Theoph. Conf. AM 6102 (De Boor 299); Nik. Brev. 1. Zu dem Umgang mit Phokas siehe unten S. $125 \mathrm{f}$.

128 Meier 2014b, 149-154 betont vor allem die strukturelle Ähnlichkeit der beiden Coups: Ein von außen kommender Aggressor stieß den etablierten Kaiser in Konstantinopel vom Thron und ließ sich selbst krönen. Kaegi 1981, 125f. dagegen zieht einen Vergleich zwischen den für das 6. Jahrhundert typischen Aufständen, zu denen er auch den der Balkantruppen 602 zählt, und denen des 7. Jahrhunderts mit der Revolte des Herakleios als Prototyp. Siehe auch Olster 1993, 136f. zu Gemeinsamkeiten und Unterschieden der beiden Machtwechsel. 
des acht Jahre zurückliegenden Machtwechsels hatte in mehrfacher Hinsicht den Handlungsspielraum erweitert: Sie hatte die Herakleioi animiert, von Afrika aus eine Usurpation zu planen; sie hatte jedoch auch in Konstantinopel die Hemmschwelle gesenkt, einen alternativen Kandidaten auszurufen, selbst wenn der regierende Kaiser sich noch im Palast befand. ${ }^{129}$ Die praktische Herausforderung lag sowohl 602 als auch 610 darin, den externen Kandidaten in die Hauptstadt zu überführen. Wie dies jeweils vonstattenging, wird das folgende Kapitel im Detail zu analysieren.

\subsection{Krönungsrituale}

Die antiken Quellen diskreditieren Phokas durchweg als Tyrannen, der den rechtmäßigen Kaiser Maurikios brutal vom Thron gestoßen habe. Diesem Urteil folgt auch die moderne Forschung allzu leichtfertig, wenn sie dessen achtjährige Regierung als illegitime Schreckensherrschaft charakterisiert. ${ }^{130}$ Die retrospektive Wertung sowohl der Quellen als auch der Forschungsliteratur täuscht allerdings über einen zentralen Sachverhalt hinweg: Die Wirksamkeit und Legitimität von Phokas’ Herrschaft stand nach seiner Krönung im November 602 nicht zur Debatte; in der Realität Konstantinopels war er - bis zu seinem Sturz durch Herakleios acht Jahre später - Kaiser und nicht etwa Tyrann. ${ }^{131}$

Dieser Sachverhalt verweist auf ein strukturelles Charakteristikum römischer Monarchie: Nicht die Art, wie ein Kaiser zur Macht kam, bzw. das Verhältnis zum Vorgänger, sondern die situative Akzeptanz durch die relevanten soziopolitischen Gruppen erwies sich als ausschlaggebend für die Wirksamkeit monarchischer Herrschaft. Wem diese Akzeptanz zukam, der war Kaiser, ungeachtet seines spezifischen Weges an die Macht - ob über Verwandtschaftsverhältnisse, durch politisches Kalkül, militärische Übermacht oder rohe Gewalt. ${ }^{132}$ Um kaiserliche Autorität für einen neuen

129 Vgl. Olster 1993, 184: „The revolt of Heraclius was an almost necessary consequence of Phocas’ usurpation. His success was a spur to others' ambitions, for without a legitimate ruler, there was no holding back ambitious generals with sufficient military forces to attempt revolt." Ich stimme Olster zu, dass es einen kausalen Zusammenhang zwischen 602 und 610 gibt, allerdings ist seine Einschätzung, bei Phokas habe es sich um einen illegitimen Herrscher gehandelt, falsch; Phokas war so lange ,legitim', bis ihm angesichts von Herakleios Vorrücken die Akzeptanz entzogen wurde.

130 Beispiele für derartige Wertungen in der Sekundärliteratur zusammengetragen bei Meier 2014b, $141-143$.

131 Siehe dazu Meier 2014a. Im folgenden Unterkapitel wird genauer ausgeführt, inwiefern die Diffamierung des Phokas als Ergebnis einer geschickten Erinnerungspolitik des Herakleios zu verstehen ist.

132 Siehe Flaig 1997, 19; Diefenbach 1996, 37 (mit Verweis auf Flaig 1992, 174-207): eine Usurpation „sei somit keine ,illegitime‘ Aneignung von Herrschaft, sondern ein Akzeptanzentzug als eine dem politischen System immanente (und damit legitime) Erscheinungsform, die ein gestörtes Kommunikationsverhältnis zwischen dem regierenden Kaiser und den Akzeptanzgruppen, deren an ihn gerichtete Verhaltenserwartungen der Kaiser nicht erfüllt habe, voraussetze.“ Vgl. auch Szidat 2010, $25-42$. 
Kandidaten überhaupt verfügbar zu machen, bedurfte es allerdings eines Moments der gesellschaftlichen Vergewisserung, der performativen Anerkennung und symbolischen Übertragung von Macht. Die Krönungen des Phokas und des Herakleios sind als ein solcher Moment des gesellschaftlichen Konsens zu untersuchen, durch welchen ein thrakischer Zenturio bzw. ein aufständischer Condottiere zum römischen Kaiser aufstiegen - durch welchen also ein auswärtiger Kandidat in das gesellschaftliche Geflecht der Hauptstadt integriert wurde. Mit Blick auf Räumlichkeit, Zeitlichkeit, die beteiligten Akteure bzw. Öffentlichkeiten sowie den Umgang mit dem gestürzten Vorgänger wird im Folgenden herausgearbeitet, inwiefern die jeweilige Ausgestaltung der Krönungsrituale zwischen Konvention und Innovation auf die Eigenheit der politischen Lage der Jahre 602 und 610 reagierte.

\subsubsection{Funktion und Entwicklung von Krönungsritualen}

Die römische Monarchie - auch in der Spätantike weiterhin geprägt durch ihre ursprüngliche Einrichtung als Ausnahmeregelung unter Augustus - verfügte weder über ein Nachfolgerecht im Sinne einer verschriftlichten Verfassung, noch hatte sich hinsichtlich der eigentlichen Kaisererhebung eine eindeutige Verfahrensregel im legalen Sinne etabliert; es gab keine Institution, die die Erhebung eines Kaisers vorbehaltlos durchführen konnte. Herrscherwechsel markierten demnach ein potentiell kritisches Moment. Vor allem bei unklarer Sachlage, etwa wenn beim Tod des Kaisers noch kein Nachfolger designiert worden war, entspann sich zwischen den jeweils maßgeblichen Einflussträgern ein Aushandlungsprozess mit teilweise überraschendem Ergebnis. Die Dynamiken derartiger Aushandlungsprozesse habe ich im vorigen Kapitel untersucht; im Vollzug des Erhebungs- bzw. Krönungsrituals fand das Ergebnis eines solchen Prozesses schließlich seinen Höhepunkt und gleichzeitig seine „dramatische Repräsentation“. ${ }^{133}$

Wenn ich im Folgenden von Krönungsritualen spreche, ist damit nicht nur der Akt des Aufsetzens einer Krone bzw. eines Diadems gemeint, sondern eine komplexe, aus vielerlei Versatzstücken bestehende Handlungssequenz, eine symbolträchtige Inszenierung, die „durch eine je spezifische Auswahl, Organisation und Strukturierung von Personen und Materialien etwas zur Erscheinung [bringt]“. ${ }^{134}$ Derartige Inszenierungen haben gleichermaßen repräsentative wie auch kreative Funktion. Sie reagieren auf das soziopolitische Setting, aus dem heraus sie entstehen, beziehen sich auf die

133 Vgl. zu Krönungsritualen und ihrer Funktion Trampedach 2005, 276f. (Zitat 277). Zu monarchischer Sukzession siehe auch oben Kap. 2.3. Im Folgenden kann und soll kein umfassender Überblick über das Forschungsfeld der Ritualtheorie(n) gegeben werden, sondern nur das herausgegriffen werden, was meiner Analyse zuträglich ist; einen guten Überblick mit Bezug zur althistorischen Forschung liefert Hölkeskamp 2015; außerdem der bereits etwas ältere, aber dennoch einschlägige Umriss bei Martschukat/Patzold 2003 und speziell zu Investitur- und Krönungsritualen Steinicke 2005.

134 Zum Begriff der Inszenierung vgl. Fischer-Lichte 2003, Zitat 46. 
vorherrschenden Machtstrukturen und repräsentieren getroffene Entscheidungen. ${ }^{135}$ Im Falle der Krönung eines Kaisers offenbart sich die kreative Funktion der Inszenierung darin, dass sie eine Statusveränderung performativ umsetzt. Kaiserkrönungen sind somit als Ritual im engeren Sinn zu bezeichnen: ${ }^{136}$ Ein Mitglied der römischen Res publica wird durch diesen konstitutiven Akt zum Kaiser gemacht, d.h. in einen anderen, sakral konnotierten Seins-Zustand erhoben. Damit die Inszenierung ihre Funktion erfüllt, muss ihre Syntax, d.h. die Auswahl und Sequenzierung der einzelnen Versatzstücke, sich auf „institutionell formierte[n] Verhaltenserwartungen“ beziehen: Die Syntax muss für diejenigen, die als Akteure bzw. Publikum beteiligt sind, lesbar bzw. zumindest (wieder)erkennbar und auch wiederholbar sein. ${ }^{137}$

Das Krönungsritual wird hier als soziale Integrationsleistung behandelt, als Moment gesellschaftlicher Selbstvergewisserung. Es bot den relevanten Akteuren bzw. Akteursgruppen die Gelegenheit, sich ihres Konsenses in Bezug auf die Besetzung des Kaiserthrones zu versichern, den potentiell chaotischen Schwebezustand des Interregnums hinter sich zu lassen und Machtstrukturen zu festigen. ${ }^{138}$ Eine Erhebung zum Kaiser galt dann als erfolgreich und dementsprechend auch legitim, wenn die rituelle Syntax den Erwartungshaltungen der maßgeblichen Gruppen entsprach. Im Falle der römischen Monarchie stand jedoch kein kodifizierter bzw. rechtlich bindender Ablaufplan zur Verfügung, auf den sich Erwartungshaltungen beziehen konnten; stattdessen spannten weichere Faktoren wie gesellschaftlich gefestigte Norm- und Regelvorstellungen den Rahmen für die Ausgestaltung des Rituals. Spätantike Krönungsrituale zeichnen sich dementsprechend durch eine verhältnismäßig hohe „Abweichungstoleranz“ aus; ${ }^{139}$ mit Variationen und Modifikationen der rituellen Syntax konnte auf die jeweils spezifischen Umstände des Herrscherwechsels reagiert werden. Auf eben diesen Aspekt der Anpassung und die Frage, wie weit sie gehen konnte, lege ich im Folgenden meinen Fokus.

135 Vgl. Martschukat/Patzold 2003, 8; Steinicke 2005, 4.

136 Ich beziehe mich hier auf die Definition von Ritual (in Abgrenzung zur Zeremonie) bei Hölkeskamp 2015, 27 f.: „Das gilt insbesondere für Rituale und Zeremonien, die sich theoretisch und konzeptuell dadurch unterscheiden (sollen), dass dem Ritual eine ,performative Wirkmächtigkeit‘ zugeschrieben wird, die in einer dauernden oder ephemeren Statusveränderung, einem Übergang oder einer sonstigen Transformation des oder der Beteiligten bestehe - anders und konkreter gesagt: ,Rituale sagen nicht nur etwas, sie tun auch etwas: Sie machen jemanden zum König, (...)`. Die Zeremonie habe dagegen ,eher darstellenden, abbildenden Charakter ' und diene etwa dazu, ,eine immer schon gegebene politisch-soziale Ordnung“ bloß zu ,bekräftigen“" "Siehe außerdem Tambiah 2008, bes. $227 \mathrm{f}$. 137 Zum Begriff der Syntax Hölkeskamp 2015, 28 - 30 (Zitat 29); als maßgebliche Charakteristika von Ritualen nennt Hölkeskamp „Stereotypie und Wiedererkennbarkeit, Wiederholbarkeit und praktische Wiederholung“ (ebd. 28); vgl. auch Tambiah 2008, 231-237.

138 Zur Funktion und Bedeutung der Krone bzw. der Krönung vgl. sehr pointiert Wienand 2015a, 3 - 5; die Krönung kann als der Moment verstanden werden, an dem Macht (im Weber'schen Sinne) in Herrschaft übergeht.

139 Vgl. dazu Hölkeskamp 2015, 29; zur Dialektik von Tradition und Anpassung siehe auch Steinicke 2005, 4. 
Um die Krönungen von Phokas und Herakleios zu analysieren, gilt es, die strukturellen und normativen Parameter zu bestimmen, innerhalb derer sich die Rituale von 602 und 610 entfalten konnten. In diesem Sinne beginne ich mit einem Überblick über die Entwicklung der Krönungsrituale im Konstantinopel des 5. und 6. Jahrhunderts. Eine Krönung im engeren Sinne war keineswegs integraler Teil des Investiturrituals des römischen Kaisers, widersprach das Diadem als Symbol verpönter königlicher (i.e. tyrannischer) Macht doch der wirkmächtigen Idee, die römische Res publica werde durch einen Primus inter pares geleitet. ${ }^{140}$ Die schrittweise Emanzipation des Monarchen von den Verhaltenserwartungen und -zwängen der konservativen Hauptstadt Rom im 3. und 4. Jahrhundert allerdings brachte erweiterte Handlungsspielräume mit sich; das Diadem verlor seine negative Konnotation und avancierte stattdessen zum Symbol einer zunehmenden Sakralisierung des Kaisers. ${ }^{141}$ Das Ritual der Kaisererhebung zeichnete sich dabei weiterhin durch einen dezidiert militärischen Charakter aus, lag die Machtbasis des Imperators doch nach wie vor in der Kontrolle über das Heer. ${ }^{142}$ Erst mit der fortschreitenden Bindung des oströmischen Monarchen an die neue Hauptstadt Konstantinopel ab dem frühen 5. Jahrhundert lässt sich eine schrittweise Ausdifferenzierung der rituellen Syntax von Kaisererhebungen erkennen, in der die Diademkrönung zu einem von mehreren zentralen Bestandteilen avancierte. Die Forschung zu Krönungsritualen des 5. und 6. Jahrhunderts schwankt in ihrer Einschätzung zwischen zwei Polen: Je nach Blickwinkel legen die Analysen den Fokus entweder auf graduelle Modifikationen und Entwicklungsdynamiken oder betonen den zunehmend statischen Charakter des Rituals, welcher dann im mittelbyzantinischen Zeremoniell seine Vollendung gefunden habe. ${ }^{143}$ Wie bereits angedeutet sind in dem Zusammenhang dieser Arbeit die diachronen Anpassungen besonders interessant, da in ihnen die gesellschaftliche Funktion und Wirkmächtigkeit des Krönungsrituales besonders deutlich zu Tage tritt.

Besonders ins Auge stechen die Anpassungen des räumlichen Settings. Die Krönungen bzw. Erhebungen des frühen 5. Jahrhunderts trugen noch deutliche Spuren vom ursprünglich militärischen Charakter des Rituals: Leon I. wurde 475 wie seine Vorgänger auf dem Hebdomon, dem Truppensammelplatz vor den Toren Konstanti-

140 Vgl. Trampedach 2005, 275f. und Alföldi 1970, 263-266.

141 Siehe Martin 1984, bes. 129 -131; das bereits in hellenistischen Monarchien gängige Diadem löste unter Konstantin I. (genauer gesagt im Zuge seiner Vicennalienfeierlichkeiten) den Lorbeerkranz als zentrale Herrschaftsinsignie ab, siehe Wienand 2012, 315, 393-396; zum Diadem vgl. auch Alföldi 1970, $266-268$.

142 Die erste explizit überlieferte Krönung ist die des Caesars Julian (Amm. 20.4.17f.), der im Jahr 360 in Paris von seinen Truppen nach der Schilderhebung allerdings nicht mit einem Diadem, sondern mit dem Torques, einem metallenen Halsreifen, gekrönt wurde, siehe Trampedach 2005, 276, 278; zum militärischen Charakter von Kaisererhebungen im 3. und 4. Jahrhundert siehe Lee 2007, 53-57.

143 Ersteren Standpunkt (Dynamik) vertritt vor allem Trampedach 2005, letzteren (Statik) Dagron 2003, 59-69, 78f.; vgl. auch Martin 1984, 129f. und Pfeilschifter 2013, 160 -165. Einen Überblick der Kaisererhebungen von Markian bis Justin II. bietet Szidat 2010, 113-125 (der Versuch einer schematischen Ordnung ebd. 70 -84), außerdem veraltet Boak 1919. 
nopels, durch die versammelten Soldaten zum Kaiser erhoben; erst nachdem ihm dort das Diadem auf den Kopf gesetzt worden war, empfingen ihn die Senatoren und geleiteten ihn in die Stadt. ${ }^{144}$ Mit der Kooptation seines Enkels Leon II. 473 kam es zu einer Verlagerung in die zivile Sphäre: Im Beisein der hauptstädtischen Bevölkerung, des Senates und der kaiserlichen Gardesoldaten wurde das Ritual im Kathisma, der kaiserlichen Loge im Hippodrom, vollzogen. ${ }^{145}$ Seit der Erhebung Justinians 527 fand der eigentliche Akt der Krönung schließlich im exklusiveren Umfeld des Palastes vor ausgewähltem Publikum statt; eine Präsentation und Akklamation des Gekrönten im Hippodrom war von nun an - wenn überhaupt Bestandteil des Rituals - nur nachgeordnet. ${ }^{146}$ Trotz der erhöhten Exklusivität wurde an der Inszenierung eines gesamtgesellschaftlichen Konsenses festgehalten: Vertreter bzw. Repräsentanten von Heer und Volk waren auch im Palast anwesend. ${ }^{147}$

Die Auswahl und Gewichtung der rituellen Versatzstücke offenbaren ein ähnliches Bild. Bei der Erhebung des Leon I. erfolgte die Einkleidung in die kaiserlichen Gewänder sowie die Diademkrönung erst nach seiner Akklamation zum Augustus durch die Soldaten. Der eigentlich konstitutive Moment war der ganz zu Beginn erfolgte Akt der Schilderhebung und Torqueskrönung mit stark militärischer Konnotation. Bereits bei seinem Nachfolger Leon II. war die Diademkrönung im Kathisma des Hippodroms allerdings der Akklamation zum Augustus vorgeschaltet. Die sakral konnotierte Diademkrönung avancierte demnach mit der Verlagerung in die Stadt zum entscheidenden Element, während das militärische Erbe der Schilderhebung gewissermaßen als Vorspann beibehalten wurde. ${ }^{148}$

Fragt man nach den Mechanismen hinter der schrittweisen Anpassung des Rituals, so offenbart sich, in welch hohem Maße sich die jeweiligen Modalitäten des Herrscherwechsels auf die Inszenierung auswirkten. Hier lässt sich primär zwischen zwei Szenarien unterscheiden: Entweder erhob ein noch lebender Kaiser einen Kandidaten zum Augustus und legte damit seine Nachfolge fest ${ }^{149}$ oder der Kaiser hatte bis zu seinem Tod keinen derartigen Schritt unternommen, sodass die Nachfolgefrage

144 Zur Erhebung des Leon I. (De cerim. 1.91) siehe Lilie 1989; Siebigs 2010 I, 201-214 und zu den Umständen ausführlich auch ebd. II, 657-727. Auch die Erhebungen des Valens, Arkadios, Honorios und Theodosios II. hatten sich auf dem Hebdomon abgespielt; siehe Lee 2007, 54; Pfeilschifter 2013, 161 Anm. 78.

145 Zur Erhebung des Leon II. (De cerim. 1.94) siehe Croke 2003.

146 Krönung Justinians in De cerim. 1.95: nach einer Zusammenkunft im großen Triklinos des Palastes fand die Krönung im Delphax, einem offenen Hof, statt; vgl. Meier 2003a, 120 - 123.

147 Siehe etwa die Erhebung des Maurikios durch Tiberios, bei der sich Klerus, Senat, Garden und Vertreter des Volkes im Palast versammeln (Theoph. Sim. Hist. 1.1.2). Auch die teilweise erhaltenen Antrittsreden der frisch gekrönten Kaiser zeugen von der Wichtigkeit dieses (inszenierten) Konsenses, vgl. etwa die des Anastasios in De cerim. 1.92.

148 Vgl. Trampedach 2005, $280 \mathrm{f}$.

149 So geschehen bei Leon I./Leon II., Leon II./Zenon, Justin I./Justinian, Justin II./Tiberios, Tiberios/ Maurikios; zum kontrollierten Herrschaftsübergang vgl. Pfeilschifter 2013, 137-147. 
als offen und verhandelbar im Raum stand. ${ }^{150}$ Im Falle einer Kooptation eines Junior Augustus bestand für den Senior ein verhältnismäßig hoher Grad an Handlungsfreiheit; trotz gewisser Traditionsbindungen und Verhaltenserwartungen hatte er die Möglichkeit, das Ritual nach den jeweiligen Bedürfnissen auszurichten. Mit der Verlagerung vom militärischen in den städtischen Raum versuchte Leon I., sich von den militärischen Eliten zu emanzipieren, die - besonders in Person des Alanen Aspar kaiserliches Regierungshandeln beeinträchtigten; die Steigerung der Exklusivität bei Justinians Krönung wiederum zielte darauf ab, sich zu einem gewissen Grad gegen den Einfluss der unberechenbaren städtischen Bevölkerung zu immunisieren. ${ }^{151}$ Bei Kooptationen fungierte der Senior Augustus in der Regel auch als Koronator: Er war es, der seinem Nachfolger das Diadem aufsetzte. War beim Tode des regierenden Kaisers die Nachfolgefrage dagegen noch ungeklärt, setzte sich ein Prozess in Gang, der deutlicher als eine Kooptation die vorherrschende Machtkonstellation offenlegte. ${ }^{152}$ Als Koronator trat in Ermangelung eines Senior Augustus seit der Proklamation des Anastasios 491 der jeweilige Patriarch von Konstantinopel in Erscheinung. ${ }^{153}$ Die beiden Machtwechsel des frühen 7. Jahrhunderts sind streng genommen keinem dieser beiden Szenarien zuzuordnen; im Folgenden zeigt die Analyse der jeweils spezifischen Abläufe, wie sich die außergewöhnliche Situation auf die Ausgestaltung des Krönungsrituals auswirkte.

150 So geschehen beim Ableben des Theodosios II., Markian, Zenon, Anastasios und Justinian; zum „ungeregelten Herrschaftsübergang“ vgl. Pfeilschifter 2013, 147-159.

$151 \mathrm{Zu}$ den Kooptationen und den zugrundeliegenden Intentionen siehe Trampedach 2005, 286-290; Lee 2007, 56 dagegen vermutet mit Verweis auf Candidus fragm. 1, dass Leon I. mit der Verlagerung der Krönung des Leon II. in den Hippodrom spontan auf die Forderung der dort versammelten Bevölkerung reagiert habe.

152 Nach dem plötzlichen Tod des Theodosios II. im Jahr 450 zog der übermächtige Heermeister Aspar die Strippen und ließ den ehemaligen Offizier Markian erheben (ähnlich wie 7 Jahre später Leon I.; zur Erhebung des Markian siehe Burgess 1993/94, zu Leon I. De cerim. 1.91). Nach Zenons Tod 491 stand in der Person Ariadnes eine Kaiser-Witwe zur Verfügung, der die Wahl übertragen werden konnte, doch tatsächlichen Wert hatte ihre Entscheidung für den Silentiarios Anastasios nur dadurch, dass hohe Funktionsträger diese mittrugen (De cerim. 1.92, siehe Szidat 2010, 118 f.). 518 gaben die kaiserlichen Garden den Ton in einem chaotischen Wahlprozess an, an dessen Ende der Comes excubitorum Justin auf den Thron gelangte (De cerim. 1.93, siehe Sode 2009 und Pfeilschifter 2013, 165-175). 565 schließlich waren es einflussreiche Palastbeamte, die - gestärkt durch den Rückhalt der Palastgarden - nach dem nächtlichen Tod des Justinian zügig die Krönung des Curopalates Justin II., Justinians Neffen, einleiteten (Gorip. Laud. Iust. 2.84-360; siehe Szidat 2010, 124f.).

153 Der Einsatz des Patriarchen ist als Epiphänomen einer fortschreitenden Sakralisierung zu verstehen; tatsächlichen Einfluss bei der Kaiserwahl hatte der Patriarch allerdings kaum; zur Rolle des Patriarchen bei Krönungen siehe Pfeilschifter 2013, 378 - 383; Dagron 2003, 80 - 82; Winkelmann 1978; Ensslin 1943/49. Leon I. hatte sich selbst gekrönt und die Insignien angelegt, siehe De cerim. 1.91. 


\subsubsection{Die Krönungen des Phokas und des Herakleios}

Die Flucht des Maurikios hatte in Konstantinopel ein Machtvakuum hinterlassen und eine spezielle Dynamik in Gang gesetzt, im Zuge derer verschiedene Akteure sich möglichst günstig zu positionieren suchten. Angesichts einer grundsätzlich ergebnisoffenen Lage gaben Mitglieder der grünen Zirkuspartei bei der Entscheidungsfindung den stärksten Impuls. Nachdem sie die Ambitionen des Germanos im Keim erstickt hatten, traten sie mit dem bereits nahe der Stadt stehenden rebellischen Heer in Verbindung und forderten dessen Anführer Phokas auf, die von Maurikios hinterlassene Leerstelle zu füllen. ${ }^{154}$ Dieser starke Impuls reichte allerdings noch nicht aus, um die Situation endgültig zu klären; das eigentliche Ritual sollte sich erst in den darauffolgenden Tagen entfalten.

Die Synthese der Quellen ergibt folgenden Ablauf der Krönung sowie der zugehörigen Feierlichkeiten: Nachdem Phokas auf die Offerte der Grünen eingegangen und zum Hebdomon aufgebrochen war, bestand seine erste Maßnahme darin, einen Boten in die Stadt zu schicken, „damit die Bevölkerung von Byzanz mit dem Patriarchen und dem Senat sich bei ihm einfinde“. ${ }^{155}$ Die Städter kamen der Aufforderung nach und versammelten sich auf dem Hebdomon. Vor dieser Kulisse machte Phokas Anstalten, dem ebenfalls anwesenden Germanos die Krone anzutragen, doch die versammelte Öffentlichkeit, angeheizt durch die grüne Zirkuspartei, setzte ein klares Zeichen, indem sie einmütig den Rebellenführer als neuen Kaiser akklamierte. ${ }^{156}$ Auf dem Tribunal, einer auf dem Truppensammelplatz installierten Tribüne, wurde Phokas auf einen Schild erhoben und zum Kaiser ausgerufen. ${ }^{157}$ Daraufhin fand die Krönung mit dem Diadem in der nahegelegenen Kirche des Johannes Prodromos statt, durchgeführt vom Patriarchen Kyriakos. ${ }^{158}$ Laut der Osterchronik, die als einzige Quelle eine absolute Chronologie liefert, spielten sich diese Vorgänge am 23. November $602 \mathrm{ab}$. Der bereits gekrönte Phokas campierte noch zwei Tage auf dem Hebdomon, bevor er laut der Osterchronik am 25. November - in einem von vier weißen Pferden gezogenen

154 Siehe oben Kap. 3.1.

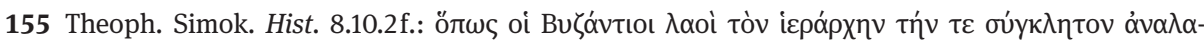

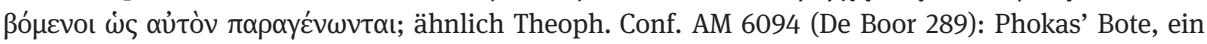
gewisser Tachygraph Theodoros, teilte die Aufforderung vom Ambo der Hagia Sophia aus mit. Die Funktion als zentralen Kommunikationsraum sollte die Kirche beibehalten; Herakleios etwa ließ seine Felddepeschen dort vor versammelter Gemeinde verlesen (Chron. Pasch. AD 628); vgl. auch Joh. Ant. fragm. 318 und Joh. Nik. 103.4, deren Berichte auch auf eine breite gesellschaftliche Beteiligung hindeuten.

156 Theoph. Sim. Hist. 8.10.4.

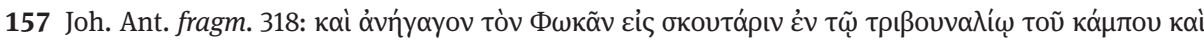

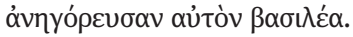

158 Theoph. Sim. Hist. 8.10.6; Chron. Pasch. AD 602; Theoph. Conf. AM 6094 (De Boor 289) fügt außerdem hinzu, Kyriakos habe von Phokas vor der Krönung ein Bekenntnis zur Orthodoxie gefordert. 
Wagen sitzend durch das Goldene Tor in die Stadt einzog. ${ }^{159}$ Über die Mese, die Hauptstraße Konstantinopels, begab Phokas sich zum kaiserlichen Palast im Stadtzentrum, wobei er die begeisterten Jubelrufe der Bevölkerung empfing und freigiebig Geschenke verteilte; anschließend ließ er im Hippodrom Pferderennen veranstalten. $\mathrm{Ab}$ dem 25. November rechnete Phokas seine Regierung. Am Tag darauf bedachte er das Heer mit einem Donativ. ${ }^{160}$ Wenig später erhob Phokas seine Frau Leontia zur Augusta und nutzte den Anlass für weitere Feierlichkeiten. ${ }^{161}$ Doch diesmal schlug die Hochstimmung um; es kam erneut zu Unruhen zwischen der grünen und blauen Zirkuspartei. Der Schlichtungsversuch von Phokas’ Männern verschärfte den Konflikt; drohende Stimmen wurden laut, die auf den noch lebenden Maurikios verwiesen. Der frisch gekrönte Kaiser verstand den Wink und machte sich daran, ein deutliches Zeichen zu setzen. ${ }^{162}$ Phokas' Handlanger griffen Maurikios auf, der sich aufgrund seiner schwachen Gesundheit weiterhin an der asiatischen Küste des Marmarameeres nahe der Kirche des Heiligen Autonomos befand. Gemeinsam mit seinen Söhnen wurde der ehemalige Kaiser vor versammeltem Publikum im Eutropios-Hafen von Chalkedon hingerichtet: Die nackten Körper warf man ins Meer; Maurikios' Kopf wurden dem weiterhin vor den Stadtmauern lagernden Heer vorgeführt. Neben der kaiserlichen Familie fielen in den folgenden Tagen auch enge Vertraute des Maurikios, etwa sein Bruder Petros, dem neuen Regime zum Opfer. ${ }^{163}$

159 Laut Theoph. Sim. Hist. 8.10.6 fand der Einzug am Tag nach der Krönung statt; aus verschiedenen Gründen ist allerdings der zeitlichen Abfolge in Chron. Pasch. AD 602 Glauben zu schenken, die auch von Theoph. Conf. AM 6094 (De Boor 289) unterstützt wird.

160 Chron. Pasch. AD 602.

161 Theoph. Sim. Hist. 8.10.8f. scheint zu implizieren, dass Leontia am Tag nach dem Einzug in die Stadt gekrönt wurde; laut Theoph. Conf. AM 6094 (De Boor 289) fand die Krönung der Leontia am 5. Tag nach der Krönung des Phokas statt; Chron. Pasch. sagt nichts dazu.

162 Nachdem ein Abgesandter des Phokas sich an dem Demarchen der Blauen, Kosmas, vergangen

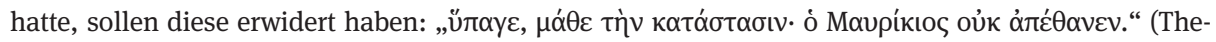
oph. Sim. Hist. 8.10.13; vgl. auch Theoph. Conf. AM 6094 [De Boor 289] und in leichter Abwandlung Joh. Ant. fragm. 318). Die Übersetzung und Interpretation dieser Stelle ist umstritten, besonders aufgrund

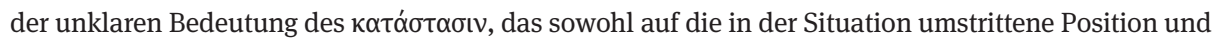
Rolle der Demen im Zeremoniell bezogen werden kann als auch auf die allgemein verwirrende politische Lage und unsichere Position des Phokas angesichts des noch lebenden Vorgängers; vgl. dazu Al. Cameron 1976, 251-253; Whitby/Whitby 1986, 226 Anm. 60; Olster 1993, 56, 62, 64; Pfeilschifter 2013, 268 Anm. 29; Meier 2016, $80 \mathrm{f}$.

163 Datum im Chron. Pasch. AD 602; außerdem Theoph. Sim. Hist. 8.11.1-6, 8.12.1-9; Theoph. Conf. AM 6094 (De Boor 289 f.), AM 6095 (290 f.). Olster 1993, 63 f. zweifelt diese Sequenzierung der Ereignisse bei Theophylakt und Theophanes an und beruft sich stattdessen auf Joh. Ant. fragm. 318; dessen stark verstümmelter Bericht lässt allerdings nur schwerlich Rückschlüsse auf eine relative Chronologie, geschweige denn auf kausale Zusammenhänge zu. Offenbar blieb unklar, ob auch Maurikios’ ältester Sohn Theodosios unter den Ermordeten war oder ob ihm die Flucht gelungen war; siehe Theoph. Sim. Hist. 8.13.3-6, 15.8-9; Sebeos 31, 33 (Thomson/Howard-Johnston I, 57, 63); Theoph. Conf. AM 6095 (De Boor 291); vgl. Olster 1993, 89, $91 \mathrm{f}$. mit weiteren Quellen. Welches Risiko (der vermeintliche) Theodosios auch noch für Herakleios darstellte, wird unten S. 164 besprochen. 
Wie im vorigen Kapitel dargelegt, unterschied sich der Machtwechsel des Jahres 610 grundsätzlich von dem des Jahres 602. Phokas' Erhebung hatte sowohl für die hauptstädtische Bevölkerung als auch für potentielle Prätendenten neue Handlungsoptionen eröffnet: Während Maurikios' Sturz als Verkettung kontingenter Faktoren $\mathrm{zu}$ lesen ist, entledigte sich 610 eine emanzipierte Stadtbevölkerung ihres ungeliebten Kaisers. Die Wahl war 602 angesichts der sich überstürzenden Ereignisse in der Hauptstadt spontan auf Phokas gefallen; Herakleios dagegen hatte seine Ambitionen auf den Thron bereits unmissverständlich zur Geltung gebracht, bevor er die Hauptstadt überhaupt erreichte. Angesichts der Präsenz seiner Schiffe im Hafen entzündeten sich Kämpfe, bei denen die kaisertreuen Truppen unterlagen. Bereits vor dieser Kulisse wurde Herakleios als neuer Kaiser akklamiert, sowohl von Seiten der Truppen auf den Schiffen als auch von Seiten der Städter, allen voran der grünen Zirkuspartei. ${ }^{164}$ Führende Aristokraten stürmten den Palast und ergriffen Phokas. Er wurde vor Herakleios hingerichtet; seinen Körper schleifte man durch die Stadt und verbrannte ihn auf dem Theodosius-Forum. ${ }^{165}$ Nachdem zumindest Teile der städtischen Bevölkerung dem Herakleios bereits ihre Anerkennung durch Akklamation signalisiert hatten, bestand die Herausforderung nun darin, den nach wie vor auf dem Schiff befindlichen Kandidaten in die Stadt zu überführen.

Der genaue Ablauf dieser Überführung lässt sich aufgrund der schwierigen Quellenlage nur rudimentär rekonstruieren; räumliche Faktoren sind oft nur ungenau bestimmbar und auch der zeitliche Rahmen gibt bisweilen Rätsel auf. Da Herakleios' Schiff zuvor im Sophia-Hafen vor Anker gelegen hatte, ${ }^{166}$ wird er Konstantinopel wohl von südlicher Seeseite her betreten haben. Obwohl die Quellen dazu keine Angaben machen, lässt sich mutmaßen, dass er über den nord-südlich verlaufenden Arm der Mese deren Hauptstrang erreichte, dann nach Osten abbiegend das Konstantins-Forum passierte und zum Palastareal vorstieß. ${ }^{167}$ Der Patriarch Sergios und das versammelte Volk empfingen Herakleios wohlwollend in der Stadt. Wie bereits Phokas acht Jahre zuvor gab auch Herakleios sich bescheiden: Als er auf seinen Verbündeten Priskos traf, machte er den Anschein, ihm die Krone antragen zu wollen. Priskos allerdings lehnte ab und Herakleios wurde von Senat und Volk erneut zum Kaiser akklamiert und schließlich mit dem Diadem gekrönt. ${ }^{168}$ Während die Quellen als Koronator einheitlich den Patriarchen Sergios angeben, herrscht hinsichtlich des genauen Ortes der Krönung Unstimmigkeit: Laut der Osterchronik fand sie in der Hagia Sophia statt, laut Johannes von Nikiu in der Kirche des Apostels Thomas, laut

164 Joh. Nik. 110.1; Nik. Brev. 1.

165 Chron. Pasch. AD 610; Joh. Ant. fragm. 321 und darauf basierend Nik. Brev. 1; Joh. Nik. 110.5-7.

166 Theoph. Conf. AM 6102 (De Boor 298f.).

167 Zur Topographie Konstantinopels siehe Müller-Wiener 1994 mit Karte auf S. 21; zum Sophia-Hafen, den Justin II. im Zuge eines Ausbaus nach seiner Frau benannte, siehe Müller-Wiener 1994, 8; ders. 1977 (unter dem Lemma Kontoskalion) und Av. Cameron 1967, 11- 20.

168 Zum Aufeinandertreffen mit Priskos siehe Nik. Brev. 2; Herakleios’ Unwillen, zum Kaiser gekrönt zu werden, erwähnt auch Joh. Nik. 110.9. 
Theophanes in der Stephans-Kirche im Palast. ${ }^{169}$ Am selben Tag vollzog Sergios auch die Hochzeit von Herakleios und dessen Verlobter Eudokia, die in diesem Zuge zur Augusta erhoben wurde. Am Tag darauf fanden im Hippodrom Pferderennen statt. ${ }^{170}$

Während die relative Chronologie in ihren groben Zügen recht stimmig scheint, sorgt die absolute Chronologie für Verwirrung, da in der Osterchronik, die dahingehend als einzige Quelle konkrete Informationen liefert, eine Störung bei Wochentagen und Daten vorliegt. ${ }^{171}$ Die Forschung ist sich vor allem hinsichtlich des genauen Datums von Herakleios' Krönung uneinig. ${ }^{172}$ Der folgende Vorschlag zum Ablauf dient als Grundlage meiner weiteren Analyse: Am Sonntag (4.10.) überwältigte das aufständische Volk die Phokas-treuen Truppen und akklamierte Herakleios; am Montag (5.10.) wurde Phokas im Palast ergriffen und im Hafen ermordet. Dass Herakleios noch am selben Tag in die Stadt einzog, ist angesichts der Eskalation von Gewalt gegen Phokas auf der Mese und dem Theodosius-Forum unwahrscheinlich; stattdessen gehe ich davon aus, dass dies, ebenso wie seine Krönung durch den Patriarchen, am Dienstag (6.10.) erfolgte, als sich die Lage etwas beruhigt hatte. ${ }^{173} \mathrm{Am}$ Tag darauf (Mittwoch, 7.10.) ließ Herakleios Pferderennen im Hippodrom veranstalten; dieser Tag galt als offizieller Beginn seiner Regierung. ${ }^{174}$

Obwohl Räumlichkeit, Zeitlichkeit und Öffentlichkeit im Ritualvollzug nicht strikt voneinander getrennt werden können, sondern sich vielmehr gegenseitig bedingen und ergänzen, werde ich diese Aspekte in meiner Analyse zunächst separat behandeln. Bezüglich der Räumlichkeit fallen besonders zwei Umstände auf: Anstatt im

169 Chron. Pasch. AD 610; Joh. Nik. 110.9; Theoph. Conf. AM 6103 (De Boor 299).

170 Hochzeit: Theoph. Conf. AM 6103 (De Boor 299); Pferderennen: Chron. Pasch. AD 610.

171 Die Osterchronik gibt für den Ausbruch der Unruhen im Hafen Sonntag, den 4.10., an. Für die Ermordung des Phokas allerdings wird Montag, der 6.10. genannt; am selben Montag habe die Krönung stattgefunden und am Tag darauf, einem Dienstag, die Pferderennen im Hippodrom. Das Problem liegt in dem Umstand, dass Datum und Wochentag nicht übereinstimmen: Zwischen Sonntag und Montag ist ein Tag verloren gegangen. Der 6.10. war in diesem Jahr kein Montag, sondern ein Dienstag; entweder Wochentag oder Datum der Krönung sind demnach falsch. Mir scheint allerdings plausibel, dass sich die um chronologische Genauigkeit bemühte Chronik nicht in den absoluten Datumsangaben, sondern eher in den Wochentagen geirrt hat.

172 In der Literatur wird das genaue Datum der Krönung meist ohne eingehendere Diskussion an einem Tag zwischen dem 5. und dem 7. Oktober angesetzt (siehe etwa Whitby/Whitby 1989, 152f.; DOC II.1, 216; PLRE IIIA, Heraclius 3 (584-586); Kaegi 2003, 50). Dabei wird stets davon ausgegangen, dass die Ermordung des Phokas und die Krönung des Herakleios am selben Tag stattfanden, wobei primär auf die Evidenz der Osterchronik verwiesen wird, der allerdings - wie gezeigt - an dieser Stelle nicht vorbehaltlos vertraut werden sollte. Am ausführlichsten diskutiert noch Zuckerman (1995, 124), der zu dem Schluss kommt, dass die Krönung am 6.10. stattfand.

173 Dafür, dass Herakleios am 6.10. in Konstantinopel einzog, spricht auch folgender Zusammenhang: Am Tag seines Einzuges besuchte Herakleios die nahe des Hafens gelegene Thomaskirche; warum er ausgerechnet diese Kirche auswählt, die ansonsten für kaiserliches Zeremoniell keine besonders bedeutende Rolle spielte, wird ersichtlich, wenn man bedenkt, dass der 6.10. im orthodoxen Kalender der Festtag des Heiligen Thomas war. Dazu siehe unten S. 116f. mit Anm. 185.

174 Chron. Pasch. AD 610. 
Hippodrom bzw. im Palast wurde Phokas auf dem Hebdomon erhoben und knüpfte damit an die Tradition des 5. Jahrhunderts an. Außerdem wurde Phokas als erster römischer Kaiser in einer Kirche gekrönt; Herakleios tat es ihm gleich, wenn auch in einer anderen Kirche. Der Sakralraum als Ort der Krönung sollte auch in den folgenden Jahrhunderten beibehalten werden.

Dass das Ritual im Falle des Phokas erneut auf dem Hebdomon durchgeführt wurde, verwundert nur auf den ersten Blick. Auch Basiliskos - der einzige erfolgreiche Usurpator des 5. und 6. Jahrhunderts - hatte sich 475 dort erheben lassen, nachdem für seine beiden Vorgänger Leon II. und Zenon bereits der Hippodrom als Rahmen gedient hatte. Die Quellenlage zu den Geschehnisabläufen des Jahres 475 ist äußerst spärlich, doch lässt sich zumindest verlässlich rekonstruieren, dass die Augusta Verina, die Witwe des verstorbenen Kaisers Leon I., Basiliskos nach der Flucht ihres Schwiegersohnes Zenon auf dem Hebdomon krönte. ${ }^{175}$ Die Wahl des Hebdomon als Durchführungsort lässt sich sowohl bei Basiliskos als auch bei Phokas primär mit der räumlichen Situierung des jeweiligen Prätendenten erklären: Beide kamen von außerhalb der Stadt. Basiliskos, der nach einer langen Karriere als Feldherr nun das einflussreiche Amt des Magister militum praesentalis innehatte, stand zwar bereits an der Spitze der hauptstädtischen Hierarchie, befand sich allerdings zu dem Zeitpunkt, als sich die Verschwörung gegen Zenon zusammenbraute, im thrakischen Herakleia, also ca. $100 \mathrm{~km}$ westlich von Konstantinopel am Marmarameer. Phokas rückte als Anführer des aufständischen Heeres ebenfalls von Westen auf die Hauptstadt vor. ${ }^{176}$

Der Truppensammelplatz lag außerhalb der theodosianischen Stadtmauer an der siebten Meile der Via Egnatia, der wichtigsten Zugangsstraße nach Konstantinopel. ${ }^{177}$ Sowohl für Basiliskos als auch für Phokas bot er in mehrerlei Hinsicht ein Setting, das den Erfolg des zu vollziehenden Krönungsrituals wenn nicht gewährleisten, dann doch zumindest wahrscheinlich machen konnte. Während der jeweilige Vorgänger (Zenon bzw. Maurikios) die Hauptstadt bereits auf dem Seeweg verlassen hatte, konnte der Prätendent Konstantinopel nicht einfach betreten. Stattdessen galt es, den externen, also von außerhalb des urbanen Raumes kommenden Kandidaten erst einer Status-Änderung zu unterziehen: Durch das Krönungsritual wurde er vom Magister militum bzw. vom Anführer eines rebellierenden Heeres zum Kaiser gemacht. Erst als solcher konnte er im Triumph in die Stadt einziehen, von dieser aufgenommen und mit seiner neu gewonnenen Position in deren Hierarchie integriert werden. Die Wahl des Hebdomon entsprach also nicht nur der Richtung, aus welcher sich der Kandidat der Stadt näherte, nämlich von Westen; als Schwelle zwischen der thrakischen Provinz,

175 Eine ausführliche Deutung der Usurpation des Basiliskos bei Pfeilschifter 2013, 536-544, außerdem Kosinski 2010, 79-82.

$176 \mathrm{Zu}$ Basiliskos in Herakleia siehe Theod. Lect. epit. 401.

177 Genauer gesagt handelte es sich um den Truppensammelplatz im Viertel Hebdomon; in diesem Viertel befanden sich außerdem mehrere Kirchen, ein kaiserlicher Palast und eine Hafenanlage; siehe Simeonov 2016, der sich zwar auf die Hafenanlage am Hebdomon konzentriert, aber gleichzeitig einen guten Forschungsüberblick über das gesamte Areal bietet. 
also dem militärisch dominierten und konnotierten Außen, und dem zivilen, städtischen Innen eignete er sich als Austragungsort des Rituals, anhand dessen ein Militär zum Kaiser erhoben wurde. Das Hebdomon fungierte demnach sowohl handlungspragmatisch als auch symbolisch als liminaler Raum. Von dort aus erfolgte die Inbesitznahme der Stadt: Der frisch gekrönte Kaiser überschritt die Grenze, markiert durch die Stadtmauern, durch das monumentale Goldene Tor und zog unter Akklamation der hauptstädtischen Bevölkerung über die Mese ins Stadtzentrum. Dieser Einzug bediente sich traditioneller Triumphal-Symbolik und reihte sich damit in eine lange Reihe kaiserlicher Adventus ein. ${ }^{178}$

Dass der Ort der Erhebung von der räumlichen Positionierung und statusmäßigen Verortung des Prätendenten abhing, zeigen schließlich auch die Umstände des Jahres 610. Über den Seeweg mit dem Schiff ankommend und im Sophia-Hafen ankernd, kam für Herakleios eine Krönung auf dem Hebdomon nicht in Frage. Während Phokas' Akklamation zum Augustus auf dem Hebdomon und seine Krönung in der Johanneskirche in direkter zeitlicher Abfolge vonstattengingen, wurden diese beiden rituellen Versatzstücke 610 räumlich wie zeitlich entzerrt: Herakleios wurde bereits akklamiert, als er sich noch auf dem Schiff befand; die eigentliche Krönung ereignete sich zwei Tage später in der Stadt. Ich erkläre diesen Sachverhalt folgendermaßen: Da das Schiffsdeck kein adäquater Ort für eine Krönung war, reichte die Akklamation durch bestimmte repräsentative Vertreter der Bevölkerung aus, um einen vorläufigen, wenn auch noch nicht abgeschlossenen Statuswechsel zu indizieren. Mit dieser ostentativen Zustimmung im Rücken, konnte Herakleios zwei Tage darauf in die Stadt einziehen, um dort die weiteren Stationen seiner Transformation zu durchlaufen. ${ }^{179}$

Sakralräume und explizit religiös konnotierte Handlungen spielten bereits im 5. und 6. Jahrhundert eine zunehmend wichtige Rolle bei Kaiserkrönungen. ${ }^{180}$ Die Verlegung der Diademkrönung in eine Kirche könnte somit als weiterer Schritt einer fortschreitenden Sakralisierung des Kaisertums interpretiert werden. Dass gerade Phokas den Präzedenzfall für diese Tradition bildete, ist dennoch erklärungsbedürftig. Die Neuerung erschließt sich aus einem gesteigerten Legitimationsdruck. Während

178 Das auf Vollständigkeit bedachte Zeremonienbuch vermittelt für den Einzug des Leon I. nach seiner Krönung auf dem Hebdomon einen recht guten Eindruck von dem weiteren Transformationsprozess, dem sich der Kaiser während seines Einzuges in die Stadt unterzog, etwa durch wiederholte Wechsel der Gewänder (De cerim. 1.91). Zu derartigen ,Requisiten` oder Insignien etc. geben die Quellen für den Einzug des Phokas keine Hinweise, bis auf den kaiserlichen, von vier Schimmeln gezogenen Wagen. Zum triumphalen Einzug in die Stadt bzw. dem kaiserlichen Adventus vgl. MacCormack 1972; McCormick 1986; Brubaker 2001; Pfeilschifter 2016, 334-340: während des 5. und 6. Jahrhunderts boten vor allem liturgische Prozessionen die Möglichkeit für den sesshaften Kaiser, sich durch das Stadtgebiet zu bewegen und so mit dem Volk in Interaktion zu treten (vgl. dazu Diefenbach 1996, 2002, 2019).

179 Dass Herakleios die eigentliche Krönung innerhalb der Stadt vollziehen konnte, mag auch daran gelegen haben, dass mit der Usurpation des Phokas ein Präzedenzfall geschaffen war; die Erhebung eines externen Kandidaten stand damit als Handlungsoption zur Verfügung.

180 Siehe dazu Trampedach 2005. 
seine Vorgänger Maurikios und Tiberios vom jeweils regierenden Augustus zum Kaiser erhoben worden waren, gab es bei Phokas formal keinen Auctor imperii. Eine derartige Situation hatte sich zwar auch bereits dann ergeben, wenn ein Kaiser verstorben war, ohne einen Nachfolger zu bestimmen; als die Wahl 602 überraschenderweise auf einen auswärtigen Kandidaten fiel, bedurfte es allerdings eines noch stärkeren Legitimations-Fundamentes. Die religiöse Konnotation des Krönungsrituals, die sich seit Anastasios wiederholt in der Wahl des Patriarchen als Koronator offenbart hatte, wurde durch die Verlegung in den Sakralraum noch verstärkt: Für Phokas fungierte Gott symbolisch als Auctor imperii. ${ }^{181}$ Die Entscheidung für die am Hebdomon gelegene Johanneskirche entsprach der bereits geschilderten Ereignislogik: Der ehemalige Zenturio Phokas konnte somit als Gekrönter in die Stadt überführt werden. ${ }^{182}$

Dass Herakleios dem Beispiel seines Vorgängers folgte und sich auch in einer Kirche krönen ließ, ist per se nicht verwunderlich. Erklärungsbedürftig ist vielmehr die Verwirrung der Quellen bei der Identifikation derjenigen Kirche, in welcher die Diademkrönung stattfand. Bisher wurde allerdings in der Forschung übersehen, dass die drei oberflächlich konfligierenden Krönungsorte - die Hagia Sophia, die Stephanskirche im Palast und die Thomaskirche - Etappen von Herakleios' Einzug in die Stadt nachvollziehen. Keine der Quellen liegt, so mein Eindruck, mit ihrer Lokalisierung vollkommen falsch, sie geben schlichtweg unterschiedliche Stationen wieder. Die Thomaskirche ist nahe dem Sophia-Hafen zu verorten, ${ }^{183}$ wo Herakleios an Land ging, die Stephanskirche war die Hauptkirche des Palastes und die Hagia Sophia, die megale ekklesia Konstantinopels, bildete das Herz des Stadtzentrums. Der an eine Stationsliturgie gemahnende, sukzessive Besuch mehrerer städtischer Kirchen entlang des Prozessionsweges ist bereits im Zusammenhang mit Kaiserkrönungen des 5. Jahrhunderts zu beobachten: Leon I. betrat nach seiner Erhebung auf dem Hebdomon zuerst eine dortige Zeltkirche, dann unter Gebeten und Darbringung von Spenden die nahegelegene Johanneskirche und zuletzt - vor seinem Einzug in den Palast - die Hagia Sophia. Als ostentative Demutsbekundung vor Gott legte er beim Hereinkommen jeweils im Mutatorium das Diadem ab und setzte es beim Verlassen wieder auf bzw. bekam es in der Hagia Sophia vom dort befindlichen Patriarchen wieder aufgesetzt. ${ }^{184}$ Dass Herakleios bei seinem Einzug in die Stadt vom Hafen aus

181 Siehe dazu Olster 1993, 168f. Zur christlichen Herrschaftsrepräsentation und zum Bezug des Kaisers zu Gott vgl. Martin 1984; Meier 2003c. Dass in Phokas' wie in Herakleios' Fall der Patriarch als Koronator fungierte, ist nicht weiter verwunderlich. Seit Anastasios wurde der neue Kandidat vom Patriarchen gekrönt, wenn kein regierender Augustus zur Stelle war.

182 Bereits im 5. Jahrhundert hatte die unter Theodosios I. erbaute und unter Justinian erneuerte Kirche des Johannes Prodromos als Station des erweiterten Krönungsrituals gedient (siehe De cerim. 1.91); zur Kirche siehe Janin 1969, 413-415. Die Prodromos-Kirche ist nicht zu verwechseln mit der des Evangelisten Johannes, auch nahe dem Hebdomon gelegen (Janin 1969, 267-269).

183 Siehe Janin 1969, 248-250.

184 Zu städtischen Prozessionen und der Konstantinopolitaner Stationsliturgie siehe Baldovin 1989; zu der Geste des Absetzens und Wiederaufsetzens des kaiserlichen Diadems bei Kirchenbesuchen auch in mittelbyzantinischer Zeit siehe Dagron 2003, 92-94. 
ausgerechnet zuerst in der Thomaskirche Halt machte, ist dabei nicht nur durch räumliche Faktoren zu erklären. Beim 6. Oktober - also dem Tag von Herakleios' Einzug in Konstantinopel - handelt es sich um den Festtag des Heiligen Thomas im orthodoxen Kirchenkalender; auf seinem Weg in die Stadt erwies Herakleios dem Heiligen also an dessen Festtag die Ehre. ${ }^{185}$ Dass in der weniger bedeutsamen Thomaskirche bereits die Krönung durch den Patriarchen stattfand, ist allerdings zu bezweifeln.

Die Stephanskirche und die Hagia Sophia sind insofern komplementär zu denken, als sie verschiedene Öffentlichkeiten beinhalteten bzw. ansprachen: In der Hagia Sophia war ein Querschnitt der städtischen Bevölkerung präsent, während die Stephanskirche als Teil des Palastes nur einem wesentlich exklusiveren Publikum zugänglich war; dort versammelten sich hohe Würden- und Funktionsträger (also die Senatoren), Palastbeamte und eventuell kaiserliche Gardesoldaten. ${ }^{186}$ Auch bei der Krönung von Herakleios' ältestem Sohn, die nur etwas mehr als zwei Jahre später stattfand, ${ }^{187}$ bildeten diese beiden Kirchen den räumlichen Rahmen des Rituals: Herakleios Konstantin wurde in der Stephanskirche gekrönt, daraufhin brachte man ihn in die kaiserliche Loge des Hippodrom, wo er von Senatoren und Demen akklamiert wurde, und schließlich zog er gemeinsam mit seinem Vater zur Hagia Sophia. ${ }^{188} \mathrm{Ob}$ Herakleios sich nun im Jahr 610 nach seinem Weg vom Hafen ins Stadtzentrum zuerst in die Hagia Sophia oder die Stephanskirche im Palast begab und in welcher dieser

185 Ich verdanke diese Beobachtung meinem Zweitgutachter Kai Trampedach. Dass der Festtag des Heiligen Thomas am 6. Oktober begangen wurde, ist im Synaxarion von Konstantinopel vermerkt; siehe Delehaye 1902, Sp. 113-116. Dieser Zusammenhang untermauert auch die oben aufgestellte Annahme, dass Herakleios am 6. Oktober in Konstantinopel einzog.

186 Zur in der Stephanbasilika stattfindenden Krönung von Herakleios' Sohn Heraklonas heißt es in

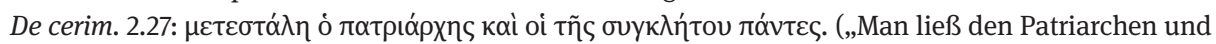
alle Angehörigen des Senats kommen.")

187 Während das Chron. Pasch. AD 613 als Datum den 22. Januar nennt, gibt Theoph. Conf. AM 6104 (De Boor 300) den 25. Dezember 612 an. Die Regierung des Herakleios Konstantin wurde ab dem 22. Januar gezählt, wodurch das Datum des Chron. Pasch. an Plausibilität gewinnt; siehe Whitby/ Whitby 1989, 156 Anm. 436; Olster 1982, 399.

188 Zur Krönung des Herakleios Konstantin siehe Chron. Pasch. AD 613; Theoph. Conf AM 6104 (300); Nik. Brev. 5. In keiner der Quellen wird explizit erwähnt, dass sich die Krönung in der Stephansbasilika abspielte; laut der Osterchronik schlichtweg „im Palast“ und laut Nikephoros im Anschluss an die Taufe, was die Verortung in einer Kirche nahelegt. Da Herakleios’ Tochter Epiphania bereits 612 erst in der Stephanskirche gekrönt und dann in die Hagia Sophia gebracht worden war (hier explizit Chron. Pasch. AD 612 und Theoph. Conf AM 6104 [300]), ist allerdings davon auszugehen, dass auch Herakleios Konstantins Krönung in der Stephanskirche stattfand. Eben diese Etappen sind schließlich auch bei der Krönung von Herakleios’ zweitem Sohn Heraklonas zum Augustus im Jahr 638 nachzuvollziehen (De cerim. 2.27). Theoph. Conf AM 6104 (300) gibt allerdings an, Herakleios Konstantin sei vom Patriarchen gekrönt worden; diese Information ist als unglaubwürdig zu disqualifizieren: Alle anderen Quellen - sowohl die für Herakleios Konstantin als auch für Herakleios' andere Kinder - geben an, dass der Vater die Krönung eigenhändig vornahm und damit der Tradition entsprach, dass der regierende Augustus seinem Nachfolger (im Beisein des Patriarchen selbstverständlich) das Diadem aufsetzte. 
beiden Kirchen die eigentliche Krönung durch den Patriarchen stattfand, ist nicht mit Sicherheit zu bestimmen. Allerdings lassen sich Plausibilitäten abwägen, die den Aspekt der Räumlichkeit wiederum mit dem des Publikums verbinden; hierfür ist eine ausführlichere Herleitung nötig.

Mit der Kooptation Justinians durch Justin 527 wurden Kaiserkrönungen vom Kathisma des Hippodroms ins exklusivere Umfeld des Palastes verlegt. Blickt man auf die Krönung des Phokas, fällt eine gegenläufige, nämlich inklusive Tendenz auf. Die offene, zugängliche Topographie des Truppensammelplatz am Hebdomon unterschied sich fundamental vom streng reglementierten und primär den Eliten vorbehaltenen Palast. Aus räumlicher Perspektive wurde die Logik hinter dieser Ortswahl bereits beleuchtet; darüber hinaus sind allerdings noch weitere Faktoren dafür anzubringen, dass der Truppensammelplatz eine angemessene und relativ verlässliche Kulisse für Phokas' Krönung bot. Das Hebdomon war qua seiner Funktion militärisch konnotiert; es diente der Sammlung und Verteilung durchziehender Soldaten und es ist $\mathrm{zu}$ vermuten, dass dort auch längerfristig Truppen stationiert waren. ${ }^{189}$ Basiliskos, der zuvor das Amt des Magister militum praesentalis bekleidet hatte, konnte sich vor dieser Kulisse der Zustimmung sicher sein. Auch der ehemalige Zenturio und Anführer des rebellischen Balkanheeres, Phokas, bewegte sich auf dem Hebdomon in einem ihm vertrauten und gleichzeitig wohlgesinnten Milieu. Rückhalt von Seiten der Soldaten reichte allerdings nicht aus, um die Wirksamkeit des Rituals zu gewährleisten; um einen Zenturio zum Kaiser zu machen, bedurfte es der Präsenz der städtischen Interessengruppen: Volk, Senat und Klerus (bzw. Patriarch). Für die Erhebung des Phokas indiziert der Bericht des Theophylakt eine breite und direkte öffentliche Teilhabe. ${ }^{190}$ Diese Teilhabe war kein kontingentes Nebenprodukt; der Umstand, dass Phokas die Städter explizit aufs Hebdomon bat, zeigt, dass er sich der Notwendigkeit von deren Präsenz bewusst war.

Als sich die Krönungsrituale im Laufe des 6. Jahrhunderts in den exklusiven Raum des Palastes verlagerten, ging damit eine graduelle Marginalisierung der hauptstädtischen Bevölkerung einher. Im November 602 zeigte sich allerdings erneut das politische Gewicht dieser Gruppe: Großflächige Unruhen und ostentativer Akzeptanzentzug bedingten die Flucht des Maurikios. Phokas' Krönung bezog also eben die Gruppe explizit ein, die den Sturz seines Vorgängers herbeigeführt hatte. Der hauptstädtischen Bevölkerung wurde im Ritual symbolisch die Entscheidungshoheit übertragen; ihrer Anwesenheit bedurfte es, um den ehemaligen Zenturio zum Kaiser zu machen. Dem entspricht auch die Anpassung der rituellen Syntax: Während die Akklamation zum Augustus im Laufe des 5. und 6. Jahrhunderts hinter die Diademkrönung gerückt war, den Akt also gewissermaßen nur nachträglich kommentierte, wurde die Abfolge nun erneut umgekehrt: Erst nach der Akklamation der versammelten Öffentlichkeit konnte - sowohl bei Phokas als auch Herakleios - die Dia-

189 Siehe Dagron 1974, 108.

190 Theoph. Simok. Hist. 8.10.2f. 
demkrönung mit ihrer auf transzendente Sphären verweisenden Semantik erfolgen. Je prekärer bzw. instabiler die Situation, je störanfälliger der Prozess der Entscheidungsfindung, umso mehr bedurfte es einer breiten öffentlichen Teilhabe. ${ }^{191}$

Vor diesem Hintergrund erscheint hinsichtlich der Krönung des Herakleios der im folgenden ausgebreitete Ablauf am plausibelsten: Nach dem Abstecher in die Thomaskirche zog Herakleios weiter in die Hagia Sophia, um sich dort vor der versammelten Gemeinde vom Patriarchen krönen zu lassen. Daraufhin begab er sich in den Palast und stattete unter Beisein von Senatoren und Palastbeamten der dortigen Stephanskirche einen Besuch ab, wo die Hochzeit zwischen ihm und seiner Verlobten Eudokia vollzogen wurde. Die irreführende Angabe bei Theophanes, Herakleios sei in der Stephanskirche gekrönt worden, könnte daher rühren - wie Christian Rollinger überzeugend argumentiert hat -, dass in der Palastkirche sowohl die Krönung der Eudokia zur Augusta stattfand als auch das Aufsetzen der Hochzeitskronen durch den Patriarchen. ${ }^{192}$

Nachdem er im Hafen bereits akklamiert worden war, vollzog Herakleios mit seinem Besuch verschiedener Kirchen als neuralgische Punkte der urbanen Topographie also nicht nur eine symbolische Aneignung der Stadt, sondern sprach bei jeder Station auch eine spezifische Öffentlichkeit an. Ich halte es für plausibel, dass sich die maßgeblichen Versatzstücke des Krönungsrituals (Akklamation und Diademkrönung) im inklusiven urbanen Raum abspielten und der Grad der Exklusivität kulminierend in dem Treffen mit den Senatoren im Palast - dann sukzessive gesteigert wurde. Bei der Kooptation seines Sohnes zwei Jahre später, als die Lage sich entscheidend stabilisiert hatte, konnte Herakleios es sich leisten, die rituelle Syntax wieder umzukehren: Erst nachdem die Diademkrönung im Palast vollzogen worden war, wurde Herakleios Konstantin der städtischen Öffentlichkeit präsentiert.

Hinsichtlich der rituellen Versatzstücke weisen beide Krönungen schließlich eine weitere Parallele auf, die sie von den Abläufen des 6. Jahrhunderts abhebt, nämlich die Spielart einer sog. Recusatio imperii. Diese Geste, im Zuge derer ein Kandidat die ihm angetragenen Ehren zuerst zurückwies, um sie schließlich - nach entsprechender Beharrlichkeit seiner Gegenüber - doch anzunehmen, ist der römischen Monarchie inhärent, brachte sie doch die Natur des augusteischen Herrschaftskonstrukts eines Primus inter pares prägnant auf den Punkt. ${ }^{193}$ In der Spätantike verlor die Recusatio

191 Vgl. Dagron 2003, 70. Ganz ähnlich verhält es sich auch acht Jahre später bei der Krönung des Herakleios.

192 Ich beziehe mich hier auf das noch unveröffentlichte Habilitations-Manuskript von Christian Rollinger. Darüber hinaus ist es denkbar, dass Herakleios nach gängigem Brauch sein Diadem vor dem Betreten des Gotteshauses absetzte und dieses vom Patriarchen später wieder aufgesetzt bekam. All diese Elemente wurden offenbar von Theophanes fälschlicherweise zur ,Krönung des Herakleios in der Stephanskirche‘ amalgamiert.

193 Zur Recusatio imperii ausführlich Huttner 2004, außerdem Szidat 2010, 75f. Unter diesem analytischen Begriff verstehe ich hier die Situationen, in denen ein Prätendent, der eigentlich die Macht anstrebte, kurzzeitig Zurückhaltung und Verzicht inszenierte (vgl. Hutter 2004, 415-418: „Die Recusatio imperii als Ritual“). Der Bericht des Theoph. Sim. (Hist. 8.10.4) betont die inszenierte Natur dieses 
angesichts der Festigung monarchischer Herrschaftsstrukturen an Dringlichkeit; sie war kein fester Bestandteil des Krönungsrituals mehr. Reflexe der Recusatio lassen sich dennoch weiterhin als Merkmal prekärer Herrscherwechsel beobachten, in Situationen also, in denen Kandidaten unter besonderem Legitimationsdruck standen. ${ }^{194}$ Bei den Erhebungen des Phokas und des Herakleios kam schließlich ein ganz spezieller Akzent zum Tragen, der sich qualitativ von einer ,klassischen' Recusatio abhob: Mit Germanos bzw. Priskos wurde dem jeweiligen Prätendenten nun gar ein vielversprechender Gegenkandidat gegenübergestellt, was die Dramatik dieser Geste noch deutlich erhöhte.

Ich verstehe die Recusatio als ein ephemeres Durchgangsstadium im Ritualvollzug, als ein retardierendes Moment, welches die Akklamation zum Augustus (bzw. eine weitere Akklamation innerhalb der Stadt im Fall des Herakleios) einleitete. Die Funktion dieses Spiels mit einer vermeintlichen Ergebnisoffenheit, welche die Aufmerksamkeit kurzzeitig auf eine alternative Person lenkte, lässt sich klar bestimmen: ${ }^{195}$ Aus der inszenierten Konfrontation mit dem Gegenüber konnten Phokas bzw. Herakleios gestärkt hervorgehen. Einerseits bot der Moment den beiden Prätendenten die Möglichkeit, sich durch inszenierte Demut, indem sie dem Anschein nach einem anderen Mann den Vortritt ließen, vom Stigma des machthungrigen Tyrannen zu distanzieren - glaubt man Nikephoros, tat Herakleios dies gar mit dem Verweis, seinen Zug auf Konstantinopel nur unternommen zu haben, um den Mord an Maurikios zu rächen. ${ }^{196}$ Andererseits erweckte die Verzögerung des Ritualvollzuges für das jeweils anwesende Publikum die Illusion situativer Entscheidungshoheit, sprach ihm Autorität zu und ermutigte es zu einer direkten Willensäußerung. Die Wirkung dieses Versatzstückes bestand darin, dass das Publikum aus der Ermächtigung heraus umso emphatischer seine Zustimmung für Phokas bzw. Herakleios kundtat und die im Vollzug begriffene Erhebung mit der notwendigen Legitimität versah.

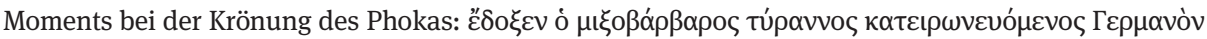

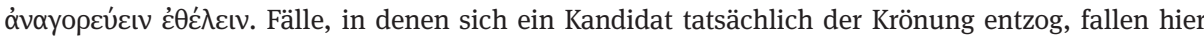
nicht ins Gewicht (zu diesen siehe Hutter 2004, 296-353).

194 Vgl. Kolb 2001, 99; Anastasios betont (allerdings erst nach der erfolgten Krönung) in seiner Ansprache an die versammelte Öffentlichkeit im Hippodrom, dass er gegen seinen eigenen Willen auserwählt worden sei (De cerim. 1.92). Justin muss laut De cerim. 1.93 zum kaiserlichen Ornat genötigt werden; auch in seinem Antrittsbrief an den Papst stellt Justin seinen Widerwillen heraus (Coll. Avell. 141: licet nolentes ac recusantes). Amm. 20.4.15-17 legt besonderen Wert auf die Recusatio des Caesars Julian, als dieser 361 ohne Zustimmung des Augustus Constantius II. vom gallischen Heer zum Augustus erhoben wurde. Zur Recusatio als panegyrischem Topos, der genutzt wurde, um retrospektiv legitime Herrschaft von Tyrannis zu unterscheiden, siehe Szidat 2010, $75 \mathrm{f}$.

195 Zur Funktion der Recusatio imperii siehe Huttner 2004, 415-460, allerdings nicht in Bezug auf Herakleios und Phokas.

196 Nik. Brev. 2; vgl. auch den in Chron. Pasch. AD 615 erhaltenen Brief des Senates an den Perserkönig Chosroes II., in welchem die Idee aufgegriffen wird, Herakleios sei nur gekommen, um Phokas zu bestrafen und dann wieder nach Afrika zurückzukehren; mit Schwierigkeiten habe man ihn schließlich überzeugen können, die Herrschaft anzutreten. Dass Herakleios allerdings bereits seit dem Ausbruch der afrikanischen Revolte 608 den Thron in Konstantinopel anstrebt hatte, habe ich in Kap. 3.2 gezeigt. 
Dieser Schritt barg allerdings durch die (wenn auch nur ephemere) Exposition eines alternativen Kandidaten auch ein gewisses Risiko, zumal sowohl Germanos als auch Priskos als herausragende Vertreter der hauptstädtischen Elite zuvor bereits eigene Ambitionen auf den Thron angedeutet hatten. Obwohl Germanos und Priskos im Ritualvollzug die von ihnen erwartete Rolle spielten (ob erzwungen oder freiwillig), obwohl der gewünschte Effekt eintrat, erwiesen beide Männer sich dem regierenden Kaiser in den Jahren nach der Krönung zunehmend als Dorn im Auge. Sowohl Germanos als auch Priskos wurden schließlich aufgrund vermeintlicher oder tatsächlicher Intrigen gegen den Monarchen unschädlich gemacht. ${ }^{197}$ Daraus lassen sich zwei Schlüsse ziehen: Um die Erhebung nicht über die Maßen zu gefährden, durfte die Recusatio erst zu einem Zeitpunkt in den Ritualvollzug zwischengeschaltet werden, als die Situation bereits weitgehend unter Kontrolle gebracht worden war. ${ }^{198}$ Gleichzeitig zeigt der schiere Umstand, dass es in beiden Fällen - trotz eines gewissen Restrisikos und trotz vorhersehbaren Konfliktes mit dem vermeintlichen Gegenkandidaten - offenbar dieser dramatischen Geste bedurfte, das Gewicht der Recusatio. Angesichts der Prekarität des Machtwechsels sah man sich offenbar gezwungen, die versammelte städtische Öffentlichkeit als maßgebliche Interessengruppe durch dieses retardierende Moment noch vor der eigentlichen Krönung zu würdigen und den städtischen Konsens zu betonen. ${ }^{199}$ Die Recusatio beeinflusste nicht das Ergebnis des Rituals, die Krönung von Phokas bzw. Herakleios zum Kaiser; sie diente vielmehr dazu, die öffentliche Wahrnehmung des Ritualvollzuges zu lenken und die Legitimität des Ergebnisses zu betonen.

Diese gezielte Verzögerung leitet über zum Aspekt der Temporalität der Krönungsrituale. Obwohl die mit einer Kaiserkrönung verbundenen Feierlichkeiten, welche als integraler Teil des Rituals zu identifizieren sind, traditionell mehrere Tage umfassen konnten, sticht sowohl für Phokas als auch Herakleios doch eine vergleichsmäßig deutliche zeitliche Entzerrung ins Auge. In beiden Fällen spannte sich der Prozess, der die Statusänderung erwirkte und einen Mann zum Kaiser erhob, über mindestens drei Tage: bei Phokas von der Akklamation und Krönung auf dem Hebdomon am 23. November bis zum Einzug in die Stadt am 25. November; bei Herakleios von der Akklamation in den Häfen am 4. Oktober über den Einzug in die Stadt und die Krönung am 6. bis zum Veranstalten von Pferderennen am 7. Oktober. Auch die zeitliche Entzerrung verstehe ich, vor allem im Fall des Phokas, als Reaktion auf die

197 Zum Schicksal des Germanos siehe unten S. 146; zu Priskos zu siehe unten S. 155.

198 Im Fall des Phokas hatten sich die Städter auf dessen Einladung hin bereits vor der Stadt versammelt, was als ausreichendes Indiz für den erwartbaren Erfolg der Erhebung gegolten haben muss. Die Avancen des Germanos waren zuvor explizit von der grünen Zirkuspartei, die in diesem Moment die Geschicke innerhalb der Stadt in der Hand gehabt zu haben scheint, zunichte gemacht worden. Herakleios war zuvor, noch auf seinem Schiff befindlich, von seinen eigenen Truppen sowie der städtischen Bevölkerung akklamiert worden.

199 Dass dieses Versatzstück in Zusammenhang mit der Kooptation durch einen Senior Augustus (einem wesentlich weniger fragilen Vorgang) nicht vorkam, ist demnach kaum verwunderlich. 
prekäre Konstellation des unvorhergesehenen Herrscherwechsels, zu dessen situativer Bewältigung zumindest in näherer Vergangenheit kein Präzedenzfall als Orientierungshilfe zur Verfügung stand. Nachdem die eigentliche Erhebung und Krönung relativ schnell vonstattengegangen war, um in der ergebnisoffenen Lage ein klares Zeichen zu setzen und keinen Raum für Alternativlösungen zu lassen, bot der zweitägige Aufenthalt des Frischgekrönten auf dem Hebdomon die Möglichkeit, den hauptstädtischen Raum gemäß den situativen Anforderungen einzurichten. Die Bevölkerung Konstantinopels musste sich nach den Ausschreitungen gegen Maurikios, die nur einen Tag zurücklagen, beruhigen und kognitiv wie praktisch auf den Empfang des neuen Kaisers einstimmen. Bei Herakleios ist die Entzerrung primär mit der Notwendigkeit zu erklären, den noch im Palast befindlichen Phokas zu beseitigen. Auch hier musste, bleibt man bei der Terminologie, der hauptstädtische Raum für den Empfang des neuen Kandidaten eingerichtet werden: Die Existenz zweier Augusti in Konstantinopel, die nicht im Kondominat miteinander verbunden waren, war schlichtweg keine praktikable Option.

Die Osterchronik, auf chronologische Genauigkeit bedacht, gibt schließlich einen letzten Hinweis, der den Aspekt der zeitlichen Organisation der Krönungsrituale mit denen der Räumlichkeit und der Öffentlichkeit verbindet, nämlich den Tag, ab welchem die Regierung der beiden Kaiser offiziell gezählt wurde: ab dem 25. November bei Phokas und ab dem 7. Oktober bei Herakleios. Diese Angabe führt auf den ersten Blick zu Irritation, stimmt dieses Datum doch bei keinem der beiden mit dem Tag der Akklamation zum Augustus bzw. der Diademkrönung überein. Im Fall des Phokas leuchtet diese Zählung eher ein, war der 25. November doch der Tag seines Einzuges in Konstantinopel. In der Besitznahme der Stadt lag demnach der eigentliche rite de passage. Die Überlegung lässt sich allerdings noch weiterführen. Vergleicht man beide Krönungen, tritt eine entscheidende Gemeinsamkeit zu Tage: Beide Kaiser zählten ihre Herrschaft ab dem Tag, an dem sie Pferderennen im Hippodrom veranstalteten. ${ }^{200}$ Aus dieser Beobachtung lassen sich folgende Schlüsse ziehen: Nach der Akklamation zum Augustus durch die versammelte Öffentlichkeit, nach dem Einzug in die Stadt und der Diademkrönung durch den Patriarchen in der Kirche scheint gerade das Pferderennen und die damit einhergehende Präsenz des neuen Kaisers im Hippodrom als konstitutiver Schritt der Kaisererhebung begriffen worden zu sein; mit diesem Schritt wurde Herrschaft wirksam und konnte demnach offiziell gezählt werden.

Dem Hippodrom eignete eine ganz spezielle Konnotation: Er war nicht nur der Ort der Kaisererhebungen des späten 5. und frühen 6. Jahrhunderts, sondern hatte sich mit der Festigung einer hauptstädtischen Monarchie als Rahmen etabliert, innerhalb dessen sich politische Kommunikation zwischen dem Kaiser und der hauptstädtischen Bevölkerung in geradezu institutionalisierter und regelmäßiger Manier entfalten konnte. Im Hippodrom wurde kaiserliche Sieghaftigkeit, nach wie vor die Essenz

200 Zu Phokas’ Krönung siehe Olster 1993, 176, 178; ihm entgeht jedoch, dass es sich bei Herakleios ebenso verhält. 
monarchischer Selbstdarstellung, in ihrer reinsten Form vor dem dort anwesenden Querschnitt der Gesellschaft präsentiert. Doch die Ansprache war nicht monodirektional: Im Hippodrom wandte sich auch die hauptstädtische Bevölkerung, deren Erwartungshaltung sich in den Agitationen der Zirkusparteien verdichten konnte, an den Kaiser, der wiederum darauf reagieren und in einen Aushandlungsprozess eintreten musste. Scheiterte die Kommunikation, wurden ebendort die Konflikte ausgetragen, die teilweise in mehrtägigen Gewaltexzessen wie etwa dem Nika-Aufstand gipfelten. ${ }^{201}$ Nachdem der Hippodrom bei Kaisererhebungen im mittleren bis späten 6. Jahrhundert an Bedeutung verloren hatte, wurde die dort stattfindende Konfrontation bzw. Kommunikation zwischen Kaiser und Volk im Zuge der Machtwechsel des frühen 7. Jahrhunderts wieder aufgewertet. Dass die Herrschaft vom Tag der Pferderennen an gezählt wurde, würdigte nicht zuletzt die grüne Zirkuspartei, die den Lauf der Dinge sowohl 602 als auch 610 maßgeblich beeinflusst hatte. So wichtig der Rückhalt bei den eigenen Truppen für beide Kandidaten auch war, den Ausschlag gab bei beiden Machtwechseln das hauptstädtische Umfeld. Obwohl im Vollzug der Krönungsrituale andere Akteure die Regie übernahmen, entschied die Beteiligung und Zustimmung der breiten Masse über deren Erfolg. Die jeweils spezifische rituelle Syntax trug diesem Umstand Rechnung.

Herakleios nutzte die Pferderennen am Tag nach seiner Krönung allerdings auch, um einen weiteren Kommentar zu Phokas abzugeben, womit die Analyse sich dem Umgang mit dem Vorgänger zuwendet. Die ältere Forschung hat vor allem die außergewöhnliche Grausamkeit des Umgangs mit Maurikios und Phokas betont - ihre öffentliche Ermordung und Schändung der Leichen - und dies als Evidenz für eine allgemeine Brutalisierung bzw. fortschreitende Verrohung der Sitten innerhalb der byzantinischen Gesellschaft angeführt. ${ }^{202}$ Mischa Meier schrieb zuletzt von den „erratisch wirkenden Ermordungen der Kaiser“. ${ }^{203}$ Um der Bedeutung dieser Handlungen offenzulegen, rekurriert Meier auf seine These, dass die Sakralisierung des Kaisers, welche unter Justinian zu einem Höhepunkt getrieben worden war, im späten 6. Jahrhundert als Immunisierungsstrategie ihre Funktionalität eingebüßt hatte: Die Schändung der kaiserlichen Körper durch die aufgebrachte Bevölkerung sei als ablehnende Reaktion auf die übersteigerten Sakralisierungstendenzen zu verstehen. Meier geht noch weiter, indem er die grausamen Morde als Indiz dafür versteht, dass

201 Zum Hippodrom als Austragungsort politischer Kommunikation siehe Al. Cameron 1976, 157-192; Canepa 2009, 167-174; zur Kommunikation zwischen Kaiser und Volk allgemein Pfeilschifter 2013, $294-354$.

202 Siehe den von Meier 2016, 78 zusammengetragenen Überblick; vgl. unter anderem Köpstein 1978, 293: „Der Sturz und die brutale Ermordung des Maurikios und seiner Söhne ist die erste Usurpation, die den Kaiser und seine Familie auch physisch angreift und damit die Institution des Kaisers prinzipiell antastet.“

203 Meier 2019a, 973. 
das Kaisertum als Institution im frühen 7. Jahrhundert an Plausibilität verloren habe. ${ }^{204}$

Die hier durchgeführte Analyse des erweiterten Krönungsrituals eröffnet eine alternative Perspektive auf die Hinrichtungen, aus der diese weder erratisch noch außerordentlich brutal - wohlgemerkt aus dem Kontext der Zeit - erscheinen. Weder Maurikios noch Phokas wurden als Kaiser ermordet. Die Quellen erwähnen explizit, dass beide ihrer Insignien entkleidet waren - ein symbolischer und gleichzeitig wirksamer Akt der Entmachtung: Maurikios hatte die Insignien vor der Flucht selbst abgelegt, dem Phokas nahm man sie bei der Erstürmung des Palastes ab. ${ }^{205}$ Der zugegebenermaßen äußerst brutale Umgang galt nicht dem Kaiser, sondern einem gestürzten Kaiser - einer Person, die nicht mehr Kaiser war und demnach ihre sakrale Aura bereits eingebüßt hatte. ${ }^{206}$ Beide Hinrichtungen ereigneten sich zu einem Zeitpunkt, als der neue Kandidat bereits gekrönt (Phokas) bzw. zumindest akklamiert (Herakleios) worden war. Obwohl die Schändung der gestürzten Kaiser in beiden Fällen zu einem gewissen Grad auf Impulse der hauptstädtischen Bevölkerung reagierte, waren doch sowohl Phokas als auch Herakleios an dem Vorgang beteiligt, indem sie entweder Befehle gaben oder gar selbst eingriffen. Angesichts ihrer Bemühungen, den eigenen Herrschaftsantritt möglichst erfolgversprechend zu gestalten, wäre eine gezielte Desakralisierung des Kaisers bzw. des Kaisertums als Institution für ihre eigene Positionierung vollkommen kontraproduktiv gewesen. ${ }^{207}$ Liest man die Gewaltexzesse dagegen als Komponenten des erweiterten Krönungsrituals, so offenbart sich nicht nur deren Funktion im rituellen Prozess, sondern auch ihr spezifischer symbolischer Gehalt.

Bei beiden Machtwechseln war der Umgang mit dem gestürzten Vorgänger von dessen räumlicher Verortung bedingt - Maurikios befand sich bereits außerhalb der Hauptstadt, Phokas noch im Palast. Dem Umgang mit Maurikios kam 602 keine oberste Dringlichkeit zu. Phokas konnte am 25. November 602 nach seiner Krönung auf dem Hebdomon in das Vakuum der kaiserlosen Hauptstadt vorstoßen, ohne sich direkt um Maurikios, der zuvor nach Kleinasien geflohen war, kümmern zu müssen. Erst als unter den Zirkusparteien erneut Unruhe ausbrach, sah Phokas sich genötigt, durch eine eindeutige und unwiderrufliche Maßnahme (die Auslöschung der männlichen Repräsentanten der gestürzten Kaiserfamilie) Klarheit hinsichtlich der Beset-

204 Meier 2016, bes. 99.

205 Insignien werden abgelegt/abgenommen: Theoph. Sim. Hist. 8.9.7; Joh. Ant. fragm. 321. Die Gewalt entlud sich nicht nur gegen den gestürzten Kaiser bzw. dessen Familie, sondern auch gegen ehemals hohe Funktionsträger, deren Schändung nicht vor dem Hintergrund von Sakralisierung und Desakralisierung verstanden werden kann; es bedarf also eines anderen Erklärungsmodells.

206 Sehr pointiert Wienand 2015a, 3: „A naked king, though, is not a king at all! A king cannot be undressed; he can only be undone.” Dagegen Meier 2016, 79: „Die spektakuläre, grausame und demütigende Hinrichtung eines Kaisers (...) stellte damit ein neuartiges Phänomen dar (...)“ [Hervorhebung durch Meier].

207 Oben wurde gezeigt, wie die Verlegung der Diademkrönung in Kirchen eben das sakrale Element kaiserlicher Herrschaft bzw. des Herrschaftsantrittes betonte. 
zung des Thrones zu schaffen. ${ }^{208}$ Die Hinrichtung erscheint eher als Nachspiel des Rituals denn als integraler Bestandteil und lief relativ geordnet ab: Im EutropiusHafen von Chalkedon wurden erst Maurikios' Söhne, dann er selbst enthauptet und ins Meer geworfen; die Köpfe der Ermordeten brachte man zunächst zu Phokas und führte sie schließlich dem am Hebdomon lagernden Heer vor - der Gruppe also, in deren Unzufriedenheit mit Maurikios der Machtwechsel seinen Ursprung genommen hatte. ${ }^{209}$

Im Oktober 610 war die Konfrontation dagegen eine wesentlich direktere, musste Phokas doch gewaltsam aus dem Palast entfernt werden, bevor Herakleios der Weg in die Stadt offenstand. Aus der komplexen Handlungssequenz lassen sich mehrere symbolträchtige Elemente extrahieren. ${ }^{210}$ Vertreter der hauptstädtischen Elite drangen in den Palast ein, ergriffen Phokas und entledigten ihn seiner kaiserlicher Insignien die Palastgarden hatten längst desertiert; gefesselt und mit nichts als einem schwarzen Gewand bekleidet wurde der gestürzte Kaiser im Beisein der hauptstädtischen Bevölkerung durch den Hafen geführt. Auf dem Schiffsdeck angekommen versetzte Herakleios ihm von einem Sitz bzw. dem Sattel eines Pferdes aus einen Fußtritt. ${ }^{211}$ Vor den Augen der Soldaten und hohen Militärs, die Herakleios aus Afrika begleitet hatten, wurde hier, so meine Interpretation, eine sog. Calcatio colli vollzogen, das symbolische Niedertrampeln eines besiegten Gegners. Diese im mediterranen Kulturraum weit verbreitete Demütigungs- bzw. Überlegenheitsgeste hatte in der römischen Kaiserzeit vor allem als ikonographische Chiffre Konjunktur, fand in der Spätantike allerdings auch Eingang in das praktische Repertoire triumphaler Inszenierungen. ${ }^{212}$ Siegreiche Kaiser vollzogen sie sowohl an auswärtigen Feinden als auch an internen Rivalen, also gescheiterten Usurpatoren. ${ }^{213}$ Mit der Calcatio colli als ri-

208 Die Bedeutung und Wertschätzung dynastischer Verbindungen, auch im Falle der Familie des unbeliebten Maurikios, hatte sich noch kurz davor offenbart, als das aufständische Heer zuallererst Maurikios' Sohn Theodosios, der 591 bereits zum Augustus gekrönt worden war, aufforderte, an Stelle seines Vaters die Herrschaft zu übernehmen; siehe oben S. 84. Das Gerücht, Theodosios habe das Massaker überlebt und sich zum Perserkönig Chosroes II. aufgemacht, der in Maurikios' Schuld stand, hielt sich hartnäckig und wurde wiederholt und von verschiedenen Akteuren politisch instrumentalisiert; siehe dazu unten S. 140, 147.

209 Theoph. Sim. Hist. 8.10.6-8.11.6, 8.12.8; Theoph. Conf. AM 6094 (De Boor 289f.). Maurikios' Körper wurde im Gegensatz zu Phokas' nicht verbrannt, sondern später beerdigt; siehe Olster 1993, 137. 210 Vgl. dazu Kaegi 2003, 50f. und Roberto 2010, $61 \mathrm{f}$.

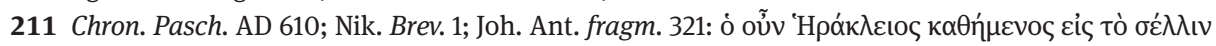

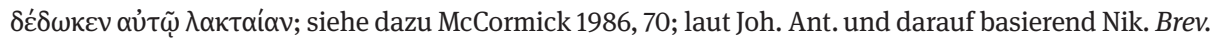
entfaltete sich auf dem Schiffsdeck ein Dialog zwischen Herakleios und Phokas.

212 Vgl. McCormick 1986, 57 f. mit Anm. 76; Malone 2009, bes. 61; Börm 2013, 69.

213 So geschehen unter Honorius, Valentinian III. und Anastasios, siehe Börm 2013, 69 und Croke 2008, 450 - 452; vgl. auch Wienand 2015b, 169-171 zur Demütigung und Verstümmelung des Usurpators Priscus Attalus im Zuge von Siegesfeierlichkeiten in Rom. Ich halte es zwar mit Börm 2013 (bes. 74) für plausibel, dass Justinian an dem Vandalenkönig Gelimer bei den Siegesfeiern 534 im Hippodrom eine Calcatio colli vollzog; allerdings nicht, dass sich auch der General Belisar, wie Börm meint, einer solchen Demütigung unterziehen musste. Die Calcati colli, die Justinian an Gelimer 
tuelle Unterwerfung setzte Herakleios ein deutliches Zeichen: Er, der Kaiser, degradierte Phokas als besiegten Usurpator.

Man richtete Phokas noch im Hafen hin, verstümmelte seinen toten Körper und überließ ihn der aufgewühlten Menschenmenge: Acht Jahre nachdem die hauptstädtische Bevölkerung Phokas auf seinem Weg vom Goldenen Tor in den Palast frenetisch zugejubelt hatte, trug sie seinen abgeschlagenen Kopf auf einem Speer über die Mese und verbrannte ihn auf dem Theodosiosforum. Auch dessen engste Vertraute fielen der Raserei zum Opfer. ${ }^{214}$ So grausam dieser Umgang auch anmuten mag, so typisch war er doch: Sowohl für die römische Kaiserzeit als auch die Spätantike gibt es zahlreichen Bild- und Textzeugnisse von abgetrennten Köpfen auf Speeren. Analog zur Calcatio colli handelte es sich auch dabei um die rituelle Demütigung und Degradierung besiegter Feinde im Zusammenhang mit Siegesfeierlichkeiten. In der Spätantike widerfuhr eine derartige Behandlung nicht nur auswärtigen Feinden, sondern auch gescheiterten Usurpatoren bzw. gestürzten Kaisern, wie etwa dem Maxentius, dessen abgetrennter Kopf nach der Schlacht an der Milvischen Brücke von Konstantin und dessen siegreichem Heer im Triumph durch Rom geführt wurde. ${ }^{215}$ Was auf den ersten Blick als außer Kontrolle geratene Aggression und Eskalation von Gewalt anmutet, war vielmehr Teil einer Inszenierung und gängiges Element kaiserlicher Triumphalpraxis. Martialischer Gewalt kam in diesem Zusammenhang eine geradezu integrative Funktion zu: Sie bot der hauptstädtischen Bevölkerung die Möglichkeit, sich von Phokas, den man acht Jahre zuvor noch auf den Thron gehievt hatte, zu distanzieren, sich Herakleios als neuem Kaiser anzuschließen und den neu gewonnenen gesellschaftlichen Konsens zu betonen.

Die letzte Episode der Degradierung des Vorgängers spielte sich schließlich im Hippodrom ab. Gemeinsam mit dem Kopf des Sakellarios Leontios wurde während der Pferderennen auch die Flagge der blauen Zirkuspartei sowie ein Bildnis des Phokas verbrannt; ein Bildnis, welches zu dessen Lebzeiten offenbar zu liturgischen Zwecken genutzt worden war. ${ }^{216}$ Der Tag nach Herakleios’ Krönung bot Anlass für ein Resümee

vollzieht, beschreibt auch Goripp (Laud. Iust. 1.275-287); die Szene ist auf kaiserliche Gewänder gestickt. Auch Justinian II. vollführte 706 die Calcatio colli im Hippodrom an seinem gestürzten Rivalen Leontios, siehe McCormick 1986, 73.

214 Zur Ermordung des Phokas siehe besonders ausführlich Chron. Pasch AD 610 (700f.); außerdem Joh. Ant. fragm. 321; Joh. Nik. 110.5-7; Theoph. Conf. AM 6102 (De Boor 299); Nik. Brev. 1.

215 Dazu siehe Wienand 2015b, 176-182 (Maxentius) und weitere Beispiele des 4. und frühen 5. Jahrhunderts ebd. 195 und passim zu Bürgerkriegstriumphen; vgl. McCormick 1986, 56f. mit Abb. 6; außerdem Wienand 2016a zum Beispiel des gestürzten Maximinus Thrax, dem eine ähnliche Behandlung wiederfuhr; sein Kopf wurde allerdings nicht im Triumph durch Rom geführt. Auch das Verbrennen von Teilen des Körpers eines gestürzten Kaisers ist nichts per se Neues; siehe Wienand 2016a, 462. Vgl. auch den Umgang mit den beiden Usurpatoren des Nika-Aufstandes (Börm 2013, 70 Anm. 43).

216 Die Stelle im Chron. Pasch. AD 610 ist enigmatisch: „(...) zusammen mit einem Bildnis des Phokas, das die Gottlosen unter den Menschen, weiße Gewänder tragend, zu dessen Lebzeiten in den Hip-

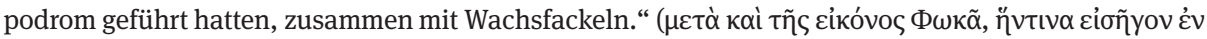


der vergangenen Ereignisse und diente gleichsam ihrer Bewältigung: Die blaue Zirkuspartei, die sich bis zum Ende nicht von Phokas distanziert hatte, ${ }^{217}$ wurde durch das Verbrennen ihrer Flagge einer symbolischen Bestrafung unterzogen und Phokas, nun durch sein Bildnis repräsentiert, einer letzten Demütigung ausgesetzt.

Ich hoffe gezeigt zu haben, dass die Brutalität im Zusammenhang mit den Herrscherwechseln 602 und 610 sich aus Praktiken speist bzw. auf diese referiert, die über Jahrhunderte als Teil römischer und eben auch christlicher Siegesfeierlichkeiten etabliert worden waren. Die Verbrennung von Phokas' Bildnis als ikonoklastischer Akt verdeutlicht, dass all die aufgeführten Demütigungsgesten Teil einer umfassenderen Damnatio memoriae waren - einer Kampagne, die gerade nicht der strikten Auslöschung von Erinnerung diente, sondern vielmehr der Neubewertung der Vergangenheit. ${ }^{218}$ Dem gestürzten Phokas widerfuhr im Oktober 610 die Behandlung eines Feindes des römischen Politeia; in der Realität Konstantinopels wurde seine achtjährige Kaiserherrschaft zur Tyrannis umgedeutet. Mit einer derartigen Inszenierung stieg Herakleios folgerichtig nicht nur zum Kaiser auf, sondern gleichsam zum Tyrannentöter; indem Phokas' Herrschaft ex post als illegitim gebrandmarkt wurde, gewann Herakleios' Erhebung entsprechend an Legitimität.

Die oben analysierten Handlungsabläufe machten zwei von außerhalb des hauptstädtischen Mikrokosmos kommende Kandidaten zum Kaiser: den Zenturio Phokas und den Exarchensohn Herakleios. Unabhängig vom weiteren Verlauf ihrer jeweiligen Herrschaft waren ihre Erhebungen - gemäß den strukturellen Voraussetzungen des politischen Systems - legitim. Durch eine spezifische und umsichtige Komposition des Krönungsrituals konnte der situative Erfolg des Thronprätendenten gewährleistet werden. Das war keineswegs selbstverständlich; im Falle des Usurpators Leontios etwa, den die Augusta Verina im Jahr 484 zum Kaiser krönte, wurde die Abweichungstoleranz des Rituals überstrapaziert. ${ }^{219}$ Die Erhebung fand nicht in Konstantinopel, sondern im kilikischen Tarsos statt; trotz der Autorität der Kaiserwitwe entfaltete die Erhebung in der Provinz keine Wirkmächtigkeit in Konstantinopel, dem machtpolitischen wie ideellen Zentrum des Reiches. Dieses zugegebenermaßen extreme Beispiel zeigt, dass gewisse Faktoren berücksichtigt werden mussten, damit sich die Performanz des Krönungsrituals tatsächlich entfalten konnte. ${ }^{220}$ So-

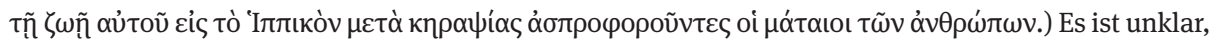
um was für eine Zeremonie es sich dabei handelte (vgl. Whitby/Whitby 1989, 153 Anm. 427), es scheint allerdings, dass Phokas eine gewisse Form der kultischen Verehrung seiner Person angestrebt hatte. 217 Nachdem sie bei den Auseinandersetzungen in den Häfen gegenüber den Grünen unterlegen waren, flüchteten sich Mitglieder der blauen Zirkuspartei ins Kirchenasyl der Hagia Sophia (Joh. Nik. 110.3).

218 Zur Damnatio memoriae siehe Elm 2012; vgl. Wienand 2016a, 427 Anm. 56.

$219 \mathrm{Zu}$ Leontios siehe Kiel-Freytag 2010.

220 Vgl. auch den Bericht zu den chaotischen Ereignissen nach dem Tod des Anastasios in De cerim. 1.93: Bevor Iustin I. letztendlich das Rennen machte, scheiterten mehrere Versuche, andere Kandidaten zu erheben, zum Beispiel an dem Umstand, dass die Palastbeamten die kaiserlichen Gewänder nicht herausgaben.
} 
wohl Phokas als auch Herakleios - bzw. den hinter ihnen stehenden Einflussnehmern - gelang es, angemessen auf die Erfordernisse der prekären Situation zu reagieren, die sich ihnen in Konstantinopel bot. Durch den sensiblen Umgang mit räumlichen Faktoren, die Einbeziehung einer breiten Öffentlichkeit, Momente der zeitlichen Kompression und Entzerrung und nicht zuletzt durch einen spezifischen Umgang mit dem gestürzten Vorgänger richteten sie das Setting auf eine Art und Weise ein, die es den hauptstädtischen Gruppen ermöglichte, mit Akzeptanz auf ihre Initiative zu reagieren. Besonders im Falle des Herakleios wurde das Krönungsritual mit etablierten Versatzstücken eines Bürgerkriegstriumphes angereichert. Indem einerseits der normative Rahmen berücksichtigt und andererseits spezifische, den Umständen angemessene Akzente gesetzt wurden, gelangen zwei Machtwechsel, wie sie Konstantinopel so noch nicht gesehen hatte. Der spezifische Ablauf sowohl der Machtwechsel im Allgemeinen als auch der Krönungsrituale im Speziellen bestätigt, dass Konstantinopel auch im frühen 7. Jahrhundert Dreh- und Angelpunkt politischer Aushandlungsprozesse blieb. Obwohl militärische Impulse aus den Provinzen die Abläufe der Hauptstadt nun wieder verstärkt beeinflussen konnten, hing monarchische Herrschaft weiterhin entscheidend von der Akzeptanz der hauptstädtischen Gruppen ab. Basierend auf seiner intensiven Beschäftigung mit dem frühen 7. Jahrhundert postuliert Mischa Meier eine Erosion des hauptstädtischen Akzeptanzsystems. ${ }^{221}$ Der hier ausgearbeitete Befund legt dagegen nahe, dass nicht das System als solches erodierte; wie Meier auch selbst feststellt, waren die Kaiser weiterhin „auf die Gunst der Konstantinopolitaner angewiesen“. ${ }^{222}$ Der entscheidende Unterschied besteht meiner Ansicht nach darin, dass Maurikios und Phokas - nicht zuletzt aufgrund von individuellen Fehlentscheidungen und unangemessenem Verhalten - im Gegensatz zu den meisten ihrer Vorgänger im 5. und 6. Jahrhundert nicht in der Lage waren, die Akzeptanz der herrschaftsrelevanten Gruppen dauerhaft aufrechtzuerhalten und deswegen gestürzt wurden. ${ }^{223}$

\subsection{Erinnerung an den gewaltsamen Machtwechsel}

Wenige Jahrzehnte nach Evagrios' optimistischer Perspektive auf die Stabilität römischer Herrschaft, die dieses Kapitel eingeleitet hat, erschütterten zwei gewaltsame Machtwechsel das politische Gefüge der Hauptstadt. Um diese Entwicklung als außerordentlich wahrzunehmen, bedurfte es nicht unbedingt des spezifischen Geschichtsbildes, wie es uns in Evagrios' Text entgegentritt; nachdem monarchische Sukzession seit dem späten 5. Jahrhundert zumindest oberflächlich friedlich verlaufen

221 Meier 2016, bes. 81; ders. 2014b, 149 Anm. 27, 152 Anm. 34, 160.

222 Meier 2016, 81.

223 Der Unterschied in der Formulierung ist ein feiner, aber meiner Ansicht nach doch ein entscheidender. Wie Phokas die Gunst der Hauptstadt systematisch verspielte, wird unten Kap.4.1 genauer beleuchtet. 
war, stellten die Machtwechsel von 602 und 610 einen harschen Einschnitt für die hauptstädtische Gesellschaft dar. ${ }^{224}$ Zum Abschluss dieses Kapitels frage ich, wie dieser Bruch von Zeitgenossen gedeutet und bewältigt wurde.

Die Analyse der Krönungen hat gezeigt, dass bereits die jeweiligen Rituale mit ihrer spezifischen Inszenierung dem Zweck dienten, die chaotische Phase des Machtwechsels zu überwinden, neue Hierarchien $\mathrm{zu}$ etablieren und den gesellschaftlichen Zusammenhalt zu festigen; die Bewältigung der Machtwechsel fand sich demnach bereits im Krönungsritual angelegt. Über ihr eigentliches Geschehen hinaus wurden die Machtwechsel schließlich im Zuge eines kollektiven Erinnerungsprozesses mit einer bestimmten Deutung versehen. Dieser Prozess lässt sich allerdings in seiner authentischen Form nur in Bezug auf den Machtwechsel von 610, also die Usurpation und Krönung des Herakleios, nachvollziehen. Wie sich bereits bei der Analyse des erweiterten Krönungsrituals angedeutet hat, wurde Herakleios’ Erhebung primär in Opposition zu seinem Vorgänger Phokas inszeniert. Die Damnatio memoriae am Vorgänger - ein Prozess, entlang dessen die Erinnerung nicht ausgelöscht, sondern in eine spezifische Richtung gesteuert wurde - nahm bereits bei der Erhebung im Oktober 610 ihren Anfang und zog sich ab dann wie ein roter Faden durch Herakleios' Herrschaft. ${ }^{225}$ Eine derartige Erinnerungspolitik fand ihren Ausdruck etwa im öffentlichen Raum der Hauptstadt: Bildnisse des Phokas wurden zerstört und architektonische Hinterlassenschaften umgewidmet; ${ }^{226}$ sie äußerte sich allerdings auch darin, dass Zeugnisse, die Phokas in gutem Licht dastehen ließen, konsequent getilgt bzw. überschrieben wurden. Dies hat zur Folge, dass kaum zeitgenössische Quellen überlebt haben, die einen direkten (d.h. durch die herakleische Erinnerungspolitik ungetrübten) Einblick darin bieten, wie die Erhebung und Herrschaft des Phokas während seiner acht Jahre währenden Regierung offiziell gedeutet wurde. ${ }^{227}$ Anders verhält es sich in Bezug auf Herakleios: Obwohl er als Kaiser keinesfalls unumstritten war - weder bei seinen Zeitgenossen noch in der Nachwelt -, garantierten seine überdurchschnittlich lange Regierungszeit sowie der Umstand, dass er die Herrschaft innerhalb der Familie weitergeben konnte, das Überleben einer ganzen Reihe an äußerst facettenreichen zeitgenössischen Zeugnissen. Die folgenden Kapitel werden diese Zeugnisse wiederholt in den Fokus der Untersuchung stellen; an dieser Stelle befrage ich sie dahingehend, wie das Verhältnis des Herakleios zum gestürzten Vorgänger im hauptstädtischen Kommunikationsraum konzipiert wurde.

224 Siehe dazu Meier 2014b, bes. 152-154.

225 Zur Damnatio memoriae an Phokas siehe Meier 2014b, 160 - 165.

226 Chron. Pasch. AD 610 berichtet, wie ein Bildnis des Phokas im Hippodrom verbrannt wurde. Herakleios ließ eine von Phokas errichtete Säule (Chron. Pasch. AD 609) durch ein Kreuz bekrönen (ebd. AD 612); siehe Whitby/Whitby 1989, 155 Anm. 435; laut Nikephoros Kallistos (Hist. eccl. 8.32) trug

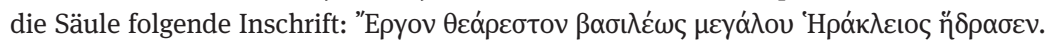

$227 \mathrm{Zu}$ den wenigen Ausnahmen, die größtenteils aus dem westlichen Mittelmeerraum stammen, wo die Damnatio memoriae nach Phokas' Sturz offenbar nicht derart strikt griff wie in Konstantinopel, siehe Meier 2014b, 140f. Anm. 5. 
Mischa Meier hat zuletzt bereits eindrücklich den Prozess herausgearbeitet, im Zuge dessen Phokas ab 610 systematisch als Tyrann verunglimpft wurde - eine Erinnerungspolitik, die sich als derart erfolgreich herausstellen sollte, dass die darin transportierte Wertung auch in der rezenten Forschung oft noch unreflektiert übernommen wird. ${ }^{228}$ Die verzerrte Vorstellung von Phokas’ Herrschaft als unrechtmäßiges Gewaltregime hat sich als derartig resistent erwiesen, dass es sich lohnt, Ursprung, Entwicklung und Funktion dieser Topik auch in dieser Arbeit einer genaueren Untersuchung zu unterziehen.

Wie bereits bei der Analyse des Krönungsrituals herausgearbeitet, war die Abgrenzung zum Vorgänger entlang der Tyrannen-Topik bereits in der Erhebung des Herakleios angelegt (öffentliche Demütigung, Verstümmelung und Hinrichtung des Phokas); eine explizite Ausformulierung fand diese Konfiguration erstmals - soweit es sich anhand der erhaltenen Quellen nachvollziehen lässt - in einem Gedicht des Georg von Pisidien (In Heraclium ex Africa redeuntem). ${ }^{229}$ Obwohl der Text keinen expliziten Datierungshinweis liefert, geht die Forschung in der Regel davon aus, dass er recht früh in der Regierungszeit des Herakleios entstand: ${ }^{230}$ Eine derart eingehende Thematisierung des Machtwechsels, die gerade nicht durch weitere Aspekte der herakleischen Herrschaftspraxis, wie sie sich im Laufe der Jahre herauskristallisieren sollten, angereichert wurde, ${ }^{231}$ erscheint in der Tat vor allem in relativ direkter Reaktion auf das Ereignis plausibel.

In dem 89 Verse umfassenden Gedicht entwirft Georg von Pisidien ein Bild monarchischer Herrschaft, das vor allem durch die Gegenüberstellung von gottgegebenem Kaisertum einerseits und Tyrannis andererseits an Kontur gewinnt. Herakleios sei - so beginnt das Gedicht, das den Kaiser konsequent in der 2. Person anspricht - vom Wort

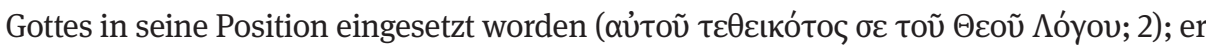

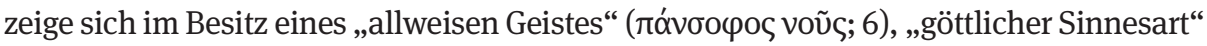

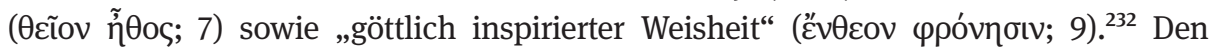
Kontrast zu dieser sakralen Sphäre, welcher er den Kaiser zurechnet, entwickelt der

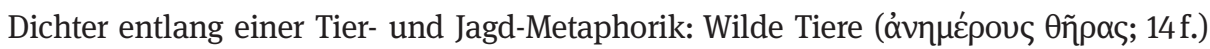

228 Meier 2014b; zur Diffamierung des Phokas siehe auch Olster 1993, 1-21.

$229 \mathrm{Zu}$ Georg von Pisidien siehe oben S. 12-14; der kommunikative Kontext der Gedichte wird unten Kap. 5.1 genauer besprochen.

230 Sternbach 1891, 35; Pertusi 1959, 18 f., 83 Anm. 64; Frendo 1984, 167; Ma. Whitby 1994, 200; Ma. Whitby 1998, 271; Tartaglia 1998, 14; Lauxtermann 2003, 38; Howard-Johnston 2010, 17; Meier 2014b, 154; bis auf Pertusi datieren alle hier Gelisteten das Gedicht in die Jahre 610/11.

231 Die Existenz eines designierten Nachfolgers etwa, des Augustus Herakleios Konstantin, die sich nicht nur als ein zentraler Aspekt der kaiserlichen Selbstdarstellung etablierte (siehe dazu Kap. 4.3; 4.3.1), sondern auch in den späteren Gedichten des Georg von Pisidien thematisiert wird, findet in In Heraclium ex Africa redeuntem keine Erwähnung. Daher gehe ich davon aus, dass das Gedicht vor der Geburt bzw. Krönung des Jungen im Januar 613 komponiert wurde.

232 Siehe Frendo 1984, 171f.; Ludwig 1991, 83f.; Ma. Whitby 2003, 181. Eine weitere Verbindung zwischen Gott und Herakleios wird in Heracl. ex Afr. 10-14 durch dessen intensive Kenntnis der Heiligen Schriften hergestellt. 


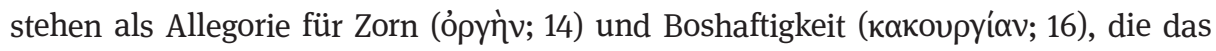

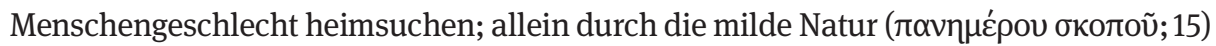

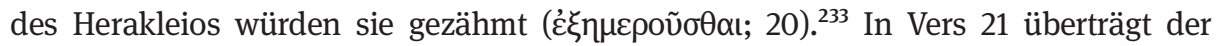
Dichter die Tier-Metaphorik schließlich auf einen konkreten Zusammenhang, wenn er

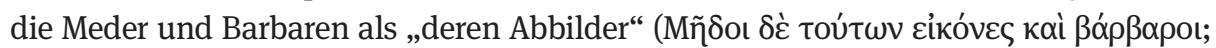
21) beschreibt: die sassanidischen Perser und Avaren, ${ }^{234}$ die außenpolitischen Feinde

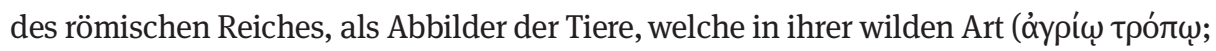
22) durch das zahme Wort des Herakleios bezwungen würden ( $\tau \tilde{\omega}$

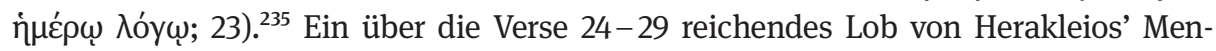
schenliebe ( $\left.\varphi \iota \lambda \alpha v \theta \rho \omega \pi^{\prime} \alpha\right)$ leitet über zum eigentlichen Hauptteil des Gedichtes, in dem Georg immer konkreter auf rezente politische Umstände Bezug nimmt. ${ }^{236}$ Dem Her-

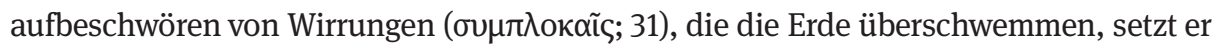

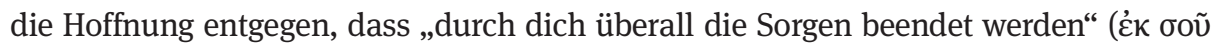

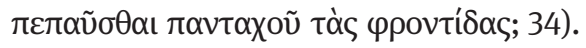

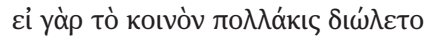

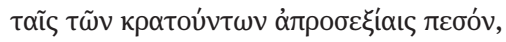

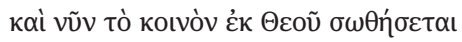

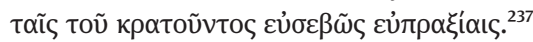

Denn wenn das Gemeinwesen oft zugrunde gerichtet wurde und durch die Unaufmerksamkeiten der Herrschenden fiel, so wird nun das Gemeinwesen durch Gott gerettet werden mittels der Wohltaten desjenigen, der fromm herrscht.

Die Rettungsleistung, die der Dichter dem geplagten Gemeinwesen in Aussicht stellt, wird als von Gott ausgehend und durch den frommen Kaiser umgesetzt gedacht. In Vers 40 konkretisieren sich die abstrakten Verfehlungen, derer Georg Herakleios' Vorgänger beschuldigt: Mit den „scharfen, durch den Tyrannen zugefügten Wunden“ ( Phokas; anstatt den gestürzten Kaiser beim Namen zu nennen, etabliert er das Attribut

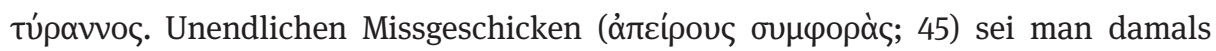

233 Frendo, 1984, 174 und Ma. Whitby 1998, 260 sehen hierin eine Orpheus-Referenz. Es ist bemer-

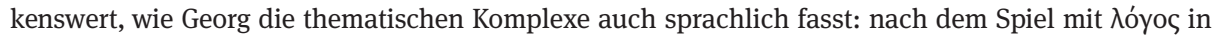
Heracl. ex Afr. 1- 3 nun durch den Begriff sowie Ableitungen des Begriffes $\theta$ ń sowie das Gegensatzpaar

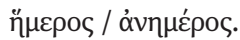

234 Bereits Sternbach $(1891,35)$ hat herausgestellt, dass bei Georg von Pisidien $\beta \alpha \alpha \rho \beta \alpha \rho o$ für Avaren steht; vgl. außerdem Pertusi 1959, 83 Anm. 21.

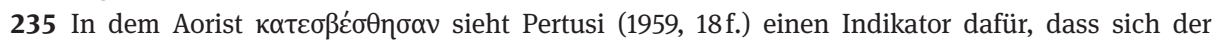
Konflikt mit Avaren und Persern zum Zeitpunkt der Verfassung des Gedichtes zumindest temporär beruhigt habe, was ihm zufolge plausibel nur um 619/20 hätte vermittelt werden können, daher seine spätere Datierung des Gedichtes; vgl. dazu Sternbach 1891, 35f. und Frendo 1984, 167-171, die ebenfalls

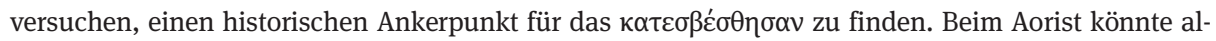
lerdings auch einfach der Aspekt, das Einmalig/Ereignishafte, das Vergangenheitstempus überschatten; anstatt die vage Aussage auf einen konkreten historischen Zusammenhang beziehen zu wollen, sehe ich darin eher die positive Erwartungshaltung des Dichters.

236 Vgl. Raum 2019, 141f. zu der Art und Weise, wie Georg die Bedrohungen heraufbeschwört, denen das Gemeinwesen ausgesetzt war.

237 Heracl. ex Afr. 35-38. 
ausgesetzt gewesen „aufgrund des über die Angelegenheiten (des Staates) herr-

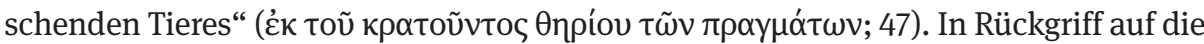
Jagd-Metaphorik findet der Begriff des $\theta n ́ \rho$, der zuvor in Zusammenhang mit Persern und Avaren fiel, nun auch auf Phokas Anwendung. ${ }^{238}$ Der gestürzte Kaiser wird nicht nur entmenschlicht, sondern vom Dichter in seinen Verbrechen gegen das Gemeinwesen auf eine Stufe mit den äußeren Feinden, den Barbaren, gestellt. Die Tendenz, äußere und innere Feinde semantisch anzugleichen, auf die etwa im Zusammenhang mit der Calcatio colli, der rituellen Unterwerfungsgeste als Teil des erweiterten Krönungsrituals, bereits hingewiesen wurde, ${ }^{239}$ findet sich also auch hier wieder.

Dem Panorama des Schreckens, als das der Dichter Phokas' Herrschaft entwirft, steht Herakleios' Bereitschaft entgegen, den langen Weg übers Meer auf sich zu nehmen

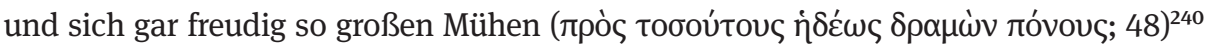
zu stellen: „dem Sturm Einhalt zu gebieten, durch den das Gemeinwesen ins Verderben ging “ ( Phineas habe Herakleios sich dabei durch seinen Glauben leiten lassen. Dem rhetorischen Vergleich mit dem alttestamentarischen Phineas lohnt es, weiter auf den Grund zu gehen. Im Buch Numeri 25 tritt der Priester Phineas, Sohn des Eleasar, als Retter seines Volkes auf: Als einer der Israeliten mit einer Moabiterin vor aller Augen Unzucht treibt, während Moses mit der Gemeinde vor dem Stiftszelt Andacht hält, erschlägt Phineas das Paar. Aufgrund des religiösen Eifers, der sich in dieser Tat äußert, erlischt Gottes Zorn und die Plage, die die Israeliten zuvor heimgesucht und zahlreiche Todesopfer gefordert hat, nimmt ein Ende. Durch die Synkrisis ${ }^{241}$ mit dem frommen Phineas erscheint die gewaltsame Usurpation in Georgs Gedicht als eine gottesfürchtige Handlung, mit der Herakleios das von Phokas begangene Sakrileg am Gemeinwesen rächt und zum Retter des römischen Volkes aufsteigt; der grausame Mord am Vorgänger wird zum salvatorischen Akt: „Von da an befreitest du uns von dem tyrannischen Unheil

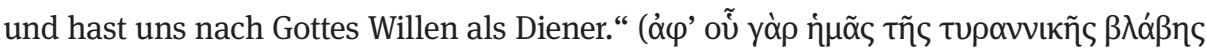

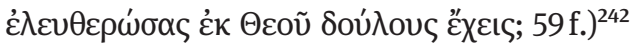

$238 \mathrm{Zu}$ Phokas als $\theta$ ń $\rho$ vgl. Meier 2014b, 161, der auf den apokalyptischen Subtext dieses Begriffs verweist (siehe Apk 13) sowie auf den Umstand, dass Onpíov im medizinischen Kontext auch ,Geschwür bezeichnen kann. Außerdem ebd. 168-170 allgemein zur Tendenz in den Quellen, Phokas zu entmenschlichen; vgl. außerdem ders. 2015, 177.

239 Dazu siehe oben S. $125 \mathrm{f}$.

240 Siehe dazu Meier 2015, 177, der unter anderem in dem Begriff róvoı einen Verweis auf den mythischen Herakles sieht; der Bedeutung des Begriffs róvot im Werk des Georg von Pisidien werde ich mich an späterer Stelle noch eingehend widmen; siehe unten S. $200 \mathrm{f}$.

241 Zur rhetorischen Figur der Synkrisis vgl. Rapp 2010.

242 Vgl. Frendo 1984, 175f. zu der Phineas-Referenz, der jedoch einen wesentlich konkreteren Verweis darauf sieht, dass Phokas laut Chron. Pasch. AD 610 in einer Kirche Asyl suchte, dort jedoch gefangen genommen und am darauffolgenden Tag hingerichtet wurde. Laut Frendo werde hier das eigentliche Sakrileg der Missachtung von Kirchenasyl in die Entfernung des Frevlers aus dem heiligen Raum umgedeutet; das halte ich allerdings für etwas weit hergeholt; siehe außerdem Ma. Whitby 1994, 212; 
Die gerade zitierten Verse bringen Georgs Konzeption von Herakleios’ Herrschaft

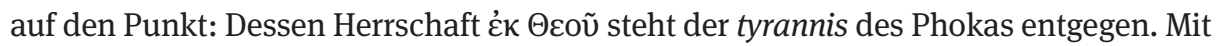
der basileia ek theou rekurriert Georg auf ein Konzept, das sich mit der fortschreitenden Christianisierung römischer Monarchie ab dem 4. Jahrhundert im Herrschaftsdiskurs verfestigt hatte und das dazu diente, die Legitimität bzw. Eignung des regierenden Kaisers unter Verweis auf dessen spezifisches Verhältnis zur göttlichen Sphäre zu betonen; ${ }^{243}$ das aus dem klassischen Griechenland stammende Konzept des tyrannos als Antipode des rechten und gerechten Herrschers ließ sich nahtlos an diese Idee anfügen. ${ }^{244}$ Mit der Wertung der herakleischen Herrschaft als gottgegeben greift der Dichter erneut - wie mit der Tyrannen-Topik - auf ein Motiv zurück, das bereits im Krönungsritual Anwendung gefunden hatte: Schon mit der Wahl des Sakralraumes als Ort der Krönung hatte eine besondere Nähe zwischen Herakleios und der sakralen Sphäre betont werden sollen. Zum Abschluss drückt der Dichter schließlich seine Hoffnung aus, dass das römische Gemeinwesen mit Gottes Hilfe und unter Herakleios' Herrschaft endlich in den Genuss des Friedens kommen möge, ${ }^{245}$ dass sich also nach der Beendigung von Phokas' Schreckensherrschaft auch die außenpolitische Bedrohung würde einhegen lassen.

Das Frühwerk des Dichters, mit dem er sich dem neuen Kaiser als Poet empfiehlt, ${ }^{246}$ rekurriert hinsichtlich der Idee eines christlichen Kaisertums auf konventionelle Topoi, die durch Euseb von Caesarea angelegt worden waren und sich mit der Herausbildung einer hauptstädtischen Monarchie in Konstantinopel verfestigten: Die Frömmigkeit des Kaisers wird zu dessen zentralem Charakteristikum erhoben, das seine Wahl durch Gott begründet und seine Position legitimiert. ${ }^{247}$ Die kaiserliche Imago - die Art und Weise also, wie Herakleios' Herrschaft in der Öffentlichkeit repräsentiert und verhandelt wurde - war jedoch keineswegs statisch. Die Sakralisierung des Kaisers, die sich im 5. und 6. Jahrhundert als zentrales Instrument der Herrschaftssicherung herauskristallisiert hatte, fand im Laufe von Herakleios' Herrschaft neue Ausdrucksformen. Im Kapitel 5 gilt es, diese Entwicklung anhand des Oeuvres des Georg von Pisidien nachzuvollziehen. Die eher konventionelle Perspektive auf den Kaiser, wie sie sich noch in Georgs gerade besprochenen Frühwerk äußert, wurde mit der Zeit durch innovative Ansätze ergänzt, die auf die Eigenheiten der herakleischen Herrschafts-

\footnotetext{
Ma. Whitby 2002, 160; Meier 2014b, 158f. Kai Trampedach hat mich darauf hingewiesen, dass Phineas im Zusammenhang mit den Makkabäer-Aufständen als Urbild aller Zeloten herangezogen wurde.

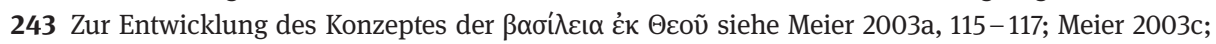
Diefenbach 1996, 39 f.; Pfeilschifter 2013, 76 - 85; zu diesem Konzept in Anwendung auf Herakleios vgl. Ma. Whitby 1998, 252f. und Meier 2014b, $159 \mathrm{f}$.

244 Zum túpavvos in spätantikem Deutungshorizont Szidat 2010, 27f. und zur Funktion dieser Benennung Meier 2014b, 165-168.

245 Heracl. ex Afr. 63-83.

246 Siehe Heracl. ex Afr. 86-89; zu dem von Georg angestrebten Patronage-Verhältnis siehe Ma. Whitby 1998, 252; Ma. Whitby 2003, 175; Lauxtermann 2003, 38f.; Howard-Johnston 2010, 17; Meier 2014b, $157 \mathrm{f}$.
}

247 Olster 1994, 51f.: Heracl. ex Afr. als Georgs „most conservative” Gedicht. 
praxis reagierten. ${ }^{248}$ Trotz dieser Dynamik sollte die Diffamierung des Phokas jedoch - nicht nur bei Georg von Pisidien - ein wichtiger Teil der Rede über die herakleische Herrschaft bleiben, wie eine Reihe an Beispielen verdeutlicht.

Im Jahr 615 entstand ein Sendschreiben, mit dem der konstantinopolitaner Senat sich an den persischen Großkönig wandte. Das Gesuch um Frieden, um die Beilegung des Krieges zwischen den beiden benachbarten Großmächten, richtete sich zwar explizit an Chosroes II., scheint allerdings auch in Konstantinopel veröffentlicht worden zu sein; ${ }^{249}$ die Formulierungen sprechen demnach ebenso eine Bevölkerung an, die durch die rezenten innen- wie außenpolitischen Entwicklungen verunsichert war. ${ }^{250}$ Herakleios' Usurpation wird dabei als Befreiung des Gemeinwesens von den Zwängen

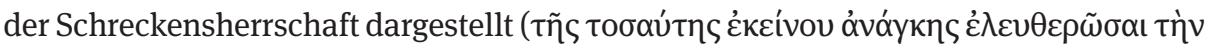

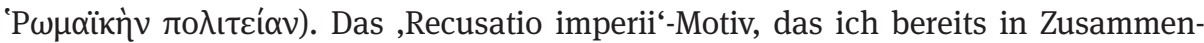
hang mit dem Krönungsritual besprochen habe, findet auch hier Anwendung, wenn

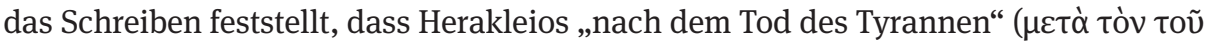

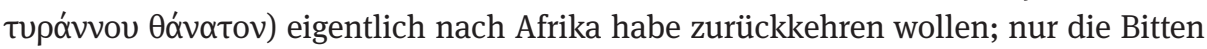
der Senatoren hätten ihn dazu bewegt, die Herrschaft zu übernehmen. ${ }^{251}$

Besonders prominent begegnet die Diffamierung der Phokas in den Historien des Theophylakt Simokattes, die nach 628 vollendet wurden. Die gesamte narrative Komposition des Werkes kulminiert im Sturz des tragischen Helden Maurikios. Ab dem Moment der Ankunft des aufständischen Balkan-Heeres auf dem Hebdomon wird Phokas konsequent als túpavvos bezeichnet; ${ }^{252}$ in seiner Erhebung identifiziert Theophylakt den Grund für das Unglück des römischen Gemeinwesens. ${ }^{253}$ Während Herakleios im erzählenden Teil der Historien keine zentrale Stellung einnimmt - bis auf wenige Vorausblicke reicht der Text nicht über die Erhebung des Phokas hinaus -, bringt der Dialog, der das Geschichtswerk einleitet, das Verhältnis von neuem zu altem Kaiser, wie Theophylakt es deutet, auf den Punkt. ${ }^{254}$ In der Form eines Zwiege-

248 Siehe dazu auch Meier 2014b, 159f.

249 Das Chron. Pasch. enthält zwei Dokumente, die in der Regel als authentisch gewertet werden: besagtes Sendschreiben (AD 615) und die Depesche des Herakleios nach dem Frieden mit Persien (AD 628). Hinsichtlich der kaiserlichen Depesche wird explizit gemacht, dass sie öffentlich in Konstantinopel verlesen wurde; ich halte es für plausibel, dass es sich im Falle des Sendschreibens ähnlich verhielt und dass der Text auf diesem Wege Aufnahme in der Osterchronik fand; zu dem Sendschreiben siehe Whitby/Whitby 1989, 162 Anm. 444.

$250 \mathrm{Im}$ Jahr zuvor hatten die Perser Jerusalem eingenommen; 615 war ein persisches Kontingent unter dem General Shahin bis an den Bosporus vorgedrungen; dazu siehe unten S. $178 \mathrm{f}$.

251 Priskos, dem Herakleios laut Nik. Brev. 1 die Herrschaft angetragen haben soll, findet hier indes keine Erwähnung mehr; zu diesem Zeitpunkt war er bereits kaltgestellt worden.

252 Theoph. Sim. Hist. 8.10 ff.; siehe dazu Tinnefeld 1971, 51f.; Meier 2014b, 163-165.

253 Theoph. Sim. Hist. 8.12.14.

254 Zum Dialog siehe Hunger 1978, 314; Schreiner 1985, 13f., 29f.; Whitby/Whitby 1986, 3-5; Mi. Whitby 1988, 40-46. Die Datierung des Dialogs ist umstritten: Während das Geschichtswerk als Ganzes erst nach 628 vollendet wurde, könnte der Dialog durchaus früher verfasst und erst später mit den Historien verbunden worden sein; so Schreiner 1985, 13f.; Frendo 1988, 149f.; Speck 1993, 212-217; vgl. Olajos 1981, 17-18 und Efthymiadis 2010, 171 mit Anm. 6; dagegen Mi. Whitby 1988, 41; Whitby/ 
sprächs zwischen den Personifikationen der Geschichte und der Philosophie feiert der Dialog die Wiederbelebung seiner beiden Protagonistinnen durch Herakleios nach langer Leidensphase unter Phokas; anstatt konkrete Personennamen zu nennen, bewegt sich der Autor dabei gänzlich auf der Ebene der Allegorie. ${ }^{255}$ Phokas erscheint als „kalydonischer Tyrann“, der den Kaiserpalast stürmte: „in eiserner Rüstung, der Halbbarbar, aus dem Geschlecht der Zyklopen, der allerausschweifendste Kentaur im ehrenvollen Purpurkleid, dem die Kaiserherrschaft nur eine Arena für Trunkenbolde war“. ${ }^{256}$ Die Gleichsetzung mit auswärtigen Feinden, die Entmenschlichung, die Phokas bereits bei Georg von Pisidien wiederfuhr, findet auch hier ihren Ausdruck, allerdings im Rahmen eines mythologischen Deutungshorizontes. Aus dem kalydo-

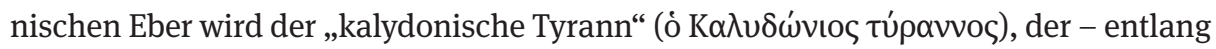

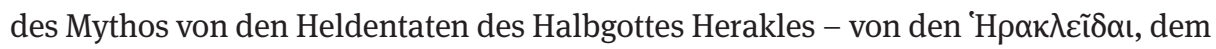
Geschlecht der Herakliden, zur Strecke gebracht wird. Nachdem die personifizierte

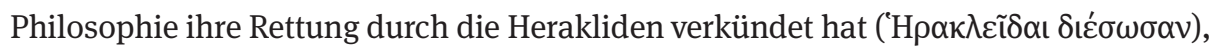
stimmt auch die Geschichte in den Lobgesang ein und vergleicht ihre eigene Wiedererweckung mit derjenigen der Alkestis durch einen „Übel abwehrenden Herakles“. ${ }^{257}$ An die Stelle der Dichotomie von tyrannis und basileia ek theou tritt in Theophylakts Dialog, entsprechend der Orientierung des Autors an klassischen Vorbildern, ein mythologisierender Kampf zwischen Gut und Böse. In Analogie zum mythischen Helden und Halbgott Herakles stellt sich Herakleios der Tyrannis des Phokas entgegen; seine Rettungs- bzw. Restitutionsleistung beziehen sich nun nicht aufs Gemeinwesen, sondern auf eine Kulturtradition. ${ }^{258}$

Whitby 1986, 3f. Anm. 5 und Meier 2014b, 163f. mit Anm. 84 (für den Dialog als „integraler Bestandteil des Geschichtswerkes“).

255 Siehe Frendo 1988, 149.

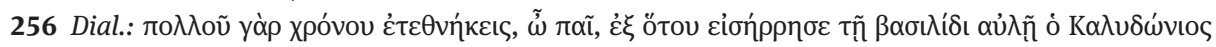

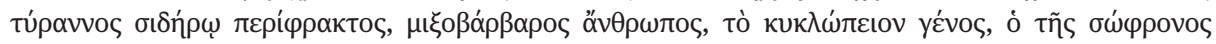

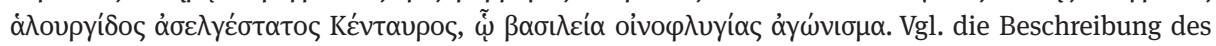
Phokas entlang der selben Schmäh-Kategorien in Theoph. Sim. Hist. 8.10.4. Zu den Trinkgewohnheiten des Phokas vgl. den Eklat im Hippodrom, wie er etwa bei Joh. Ant. fragm. 319 und Theoph. Conf. AD 6101 (De Boor 296f.) überliefert ist; dazu unten S. $148 \mathrm{f}$.

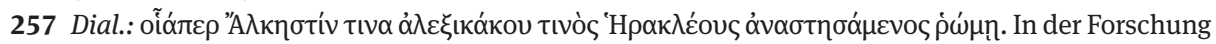
wird über die Identifizierung dieses Retters der Geschichte gestritten, da die allegorische Sprache teilweise zur Verwirrung bei den Zuweisungen führt. Während ein Lager hierin - vor allem aufgrund

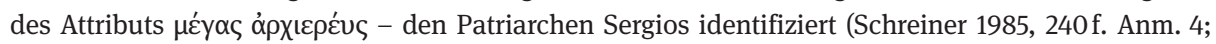
Whitby/Whitby 1986, 4 Anm. 9; Mi. Whitby 1988, 33 Anm. 20), sehen andere darin weiterhin den Herakleios angesprochen (Hunger 1978, 315; Frendo 1988, 144 f. Anm. 11; Speck 1993, 212 mit Anm. 83; Meier 2015, 168 mit Anm. 8). Ich schließe mich letzterer Einschätzung an; der Herakles-Alkestis-Mythos findet sich auch in Georg. Pis. Heracl. (1.71-73) mit explizitem Bezug auf den Kaiser. Zu der Bezeichnung des Herakleios als Hohepriester siehe unten S. 279-299.

$258 \mathrm{Zu}$ der Herakles-Herakleios-Analogie siehe vor allem Meier 2015; ebd. $167 \mathrm{f}$. zu der TheophylaktPassage. Meier interpretiert zeitgenössische Evidenz dahingehend, dass Herakleios vor allem in den Gedichten des Georg von Pisidien über den Herakles-Vergleich an Christus angeglichen wurde; vgl. Ma. Whitby 1994, 208. 
Selbst nach 628, als Herakleios mit seinem Sieg über die Perser und der Rückgewinnung der Ostprovinzen eine weitere spektakuläre Leistung vorweisen konnte, wurde die Phokas-tyrannos-Topik im Lob des Herrschers weiterhin bemüht, wie die Heraclias des Georg von Pisidien belegt:

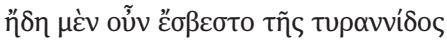

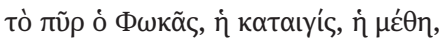

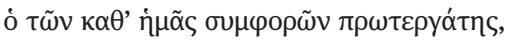

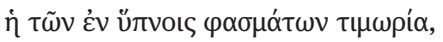

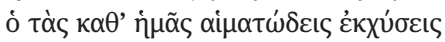

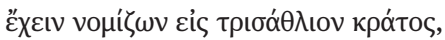

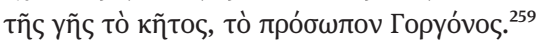

Also war bereits gelöscht worden das Feuer der Tyrannei, Phokas, der Wirbelsturm, die Trunksucht, der Urheber des bei uns herrschenden Unglücks, die Rache der Erscheinungen im Traum, der das Ausgießen von Blut unter uns in seiner dreifach-unheilsamen Kraft hatte, das Seeungeheuer der Erde, das Gesicht der Gorgo.

Dieses Ungeheuer habe Herakleios nicht mit der List eines Perseus besiegt, sondern mit Hilfe eines Bildnisses der Jungfrau, der Theotokos. ${ }^{260}$ Mit der Tötung des „tyrannischen Monsters“ ( Herakles übertroffen und die gesamte Stadt, Konstantinopel, gerettet. ${ }^{261}$

Der Überblick darüber, wie die zwei gewaltsamen Machtwechsel von 602 und 610 während der Regierung des Herakleios gedeutet wurden, lässt klare Tendenzen erkennen. Die Diffamierung des Phokas als Tyrann, aus der heraus Herakleios als strahlender Retter des Gemeinwesens erscheinen konnte, wurde in verschiedenen Medien propagiert. Eine besonders elaborierte Formulierung fand sich im Gerne der Panegyrik, dem sowohl die Gedichte des Georg von Pisidien als auch, im weiteren Sinne, der Dialog des Theophylakt zuzurechnen sind; ${ }^{262}$ doch die Diffamierung blieb keinesfalls auf das elitäre Umfeld, in dem die Adressaten derartiger Äußerungen zu vermuten sind, beschränkt. ${ }^{263}$ Bereits in der spezifischen Inszenierung von Herakleios’ Krönung angelegt, an der ein repräsentativer Querschnitt der hauptstädtischen Bevölkerung aktiv teilgehabt hatte, wurde die Diffamierung zum integralen Teil eines

259 Georg. Pis. Heracl. 2.5-11.

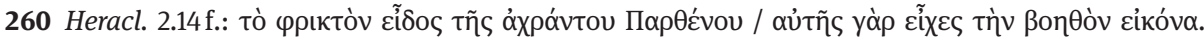
Dazu passt die bei Theoph. Conf. AM 6102 (De Boor 289) überlieferte Nachricht, dass Herakleios auf seinem Weg von Afrika nach Konstantinopel Bildnisse der Theotokos an den Masten seiner Schiffe habe befestigen lassen; vgl. dazu allerdings oben S. $100 \mathrm{f}$.

261 Heracl. 2.21-23; siehe dazu Meier 2015, 175. Weitere Belege zur Tyrannen-Metaphorik bei Georg von Pisidien - Tyrannos mit klarem Bezug auf Phokas: In Bonum 58; Bell. Avar. 49f.; Tyrannoi im Plural: In Bonum 96; Heracl. 1.148; Tyrannis abstrakt: Exped. Pers. 2.93; Heracl. 1.151. Meier 2014b, 166 Anm. 55 weist darauf hin, dass die Tyrannen-Metaphorik bei Georg von Pisidien auch auf auswärtige Feinde angewandt wird.

262 Der kommunikative Kontext von Panegyrik bzw. Georgs panegyrischer Epik im Speziellen wird unten Kap. 5.1 noch genauer beleuchtet.

263 Ma. Whitby 1998, 251 geht davon aus, dass die kürzeren Gedichte Georgs nicht nur im Palast, sondern auch vor einem breiteren Publikum, gar in der Hagia Sophia vorgetragen wurden; zu der Wirkung, die Georgs Gedichte auf ein Publikum haben konnten, und der Frage der Reichweite siehe Lauxtermann 2003, 58. 
breiten öffentlichen Diskurses, wie er sich sowohl in Textzeugnissen als auch in der Gestaltung des städtischen Raumes manifestierte.

Die Schmähung des Vorgängers erfüllte eine Reihe miteinander verschränkter Funktionen. Die kollektive Erinnerung an die Herrschaft des Phokas als schreckliches Gewaltregime zeitigte auf die hauptstädtische Gesellschaft, durch anhaltende politische Instabilität verunsichert, eine integrative Wirkung: Klare Feindbilder und Schuldzuweisungen boten Orientierung und zogen eine klare Linie zwischen altem und neuem Regime. Überkommene Loyalitätsverhältnisse konnten dadurch bewältigt und neue Bindungen - mit Herakleios im Zentrum des sozialen Netzwerkes - gefestigt werden. Was sich im Krönungsritual bereits angedeutet hatte, wurde demnach in der Erinnerungspolitik über Jahrzehnte hinweg verstetigt. In der Schmähung des Phokas, der 602 noch von einer jubelnden Menge vor den Toren der Stadt empfangen worden war, fand sich der Kitt, dessen es bedurfte, um die hauptstädtische Gesellschaft im Ganzen, aber auch die im Jahr 610 neu geschaffenen Hierarchien zusammenzuhalten. Mit dem Bild des Tyrannen Phokas wurde darüber hinaus eine Kontrastfolie etabliert, anhand derer das Profil des neuen Kaisers Herakleios noch deutlicher hervortreten konnte - je nach Kontext erschien er als gotterwählter Herrscher, als mythischer Halbgott und/oder als Retter und Restitutor eines geschundenen Gemeinwesens. Dabei fällt auf, dass Herakleios - zumindest den erhaltenen Quellen nach zu urteilen - stets als Empfänger derartiger Zuschreibungen auftritt, anstatt diese selbst zu äußern. Ein solches Arrangement bot Platz für die Selbst-Inszenierung des Kaisers als demütiger und frommer Wohltäter an der römischen Gesellschaft, wie sie sich bereits in seiner Recusatio imperii geäußert hatte. Dass die Tyrannen-Topik über Jahrzehnte hinweg verlässlich herangezogen wurde, zeigt, dass eine derartige Erinnerungspolitik ganz im Sinne des neuen Regimes gewesen sein muss. ${ }^{264}$

Der nachhaltige Erfolg der herakleischen Erinnerungspolitik ist evident: Mit der Diffamierung des Phokas etablierte sich hinsichtlich der beiden Machtwechsel von 602 und 610 im hauptstädtischen Kontext eine hegemone Deutung, die aufgrund ihrer enormen Sogwirkung alternative Erzählungen im Abgrund des Vergessens verschwinden ließ. Somit verwundert es kaum, dass die Erinnerung an den Tyrannen Phokas und an Herakleios als Retter des römischen Gemeinwesens, wie von Mischa Meier bereits eindrücklich gezeigt, bis in die moderne Historiographie nachklingt.

264 Vgl. die Deutung von Meier 2014b, bes. 172-174; er weist einerseits auf die strukturelle Ähnlichkeit der Machtergreifungen des Phokas und des Herakleios hin, aufgrund derer sich Herakleios umso deutlicher von seinem Vorgänger habe abgrenzen müssen; andererseits gehe es darum, angesichts einer aus den Fugen geratenen Ordnung (nach langer Zeit wieder gewaltsame Machtwechsel) neue Ordnungsdiskurse zu etablieren. 


\section{Remilitarisierung des Kaisertums}

Zwei gewaltsame Machtwechsel innerhalb von acht Jahren hatten das politische Klima Konstantinopels destabilisiert. Die Erhebung des Phokas schuf einen Präzedenzfall: Nachdem die hauptstädtische Konfiguration von Monarchie dem regierenden Kaiser vor allem im 6. Jahrhundert einen recht hohen Grad an Sicherheit geboten hatte, lag es nun wieder im Rahmen des Möglichen, die Machtverhältnisse in Konstantinopel durch militärischen Druck von außen zu beeinträchtigen. Während Aufstände des Heeres in den Provinzen in den Jahrhunderten zuvor die Machtverhältnisse in der Hauptstadt nicht maßgeblich ins Wanken gebracht hatten, konnte eine aggressive Positionierung von Truppenverbänden nun direkte Auswirkungen auf die politische Lage in Konstantinopel zeitigen, Eigendynamiken in Gang setzen und Entscheidungsprozesse beeinflussen. Es war jedoch nicht die militärische Schlagkraft, die das Ringen um Hoheit übers römische Reich entschied; Heereskontingente allein - ob Söldnertruppen oder reguläre Soldatenverbände - konnten nach wie vor keinen Kaiser machen, erst recht nicht in der Provinz. Die Stimmung bzw. Akzeptanz der Hauptstadt blieb weiterhin der ausschlaggebende Faktor monarchischer Herrschaft. Die Erhebung eines Kaisers konnte auch im frühen 7. Jahrhundert nur in Konstantinopel unter Beteiligung der maßgeblichen städtischen Gruppen und unter Berücksichtigung etablierter Verhaltensnormen über die Bühne gehen.

Nachdem Phokas' Erhebung neue Handlungsspielräume eröffnet hatte, gelang mit der afrikanischen Revolte und der daraus resultierenden Erhebung des Herakleios die Probe aufs Exempel. Das strategische Kalkül der Herakleioi ging auf: Nach der Rekrutierung eines aus römischen Truppen und maurischen Söldnern zusammengesetzten Heeres, der Sicherung Afrikas, Ägyptens sowie weiterer Teile der Küste des süd-östlichen Mittelmeerraumes als Machtbasis, gelang es ihnen, inneraristokratische Zerwürfnisse und bestehende Animositäten gegen Phokas für die eigenen Zwecke zu nutzten; Herakleios wurde zum Augustus gekrönt. Die Entscheidung der Usurpatoren, die Ambitionen auf den Thron durch die Konsulatsprägungen in den eroberten Gebieten deutlich herauszustellen, den eigentlichen Akt der Erhebung allerdings erst in Konstantinopel vollziehen zu lassen, erwies sich als kluger Schachzug; sie zeugt von einem eingehenden Verständnis der machtpolitischen Verhältnisse sowie einem sensiblen Umgang mit daraus resultierenden Erwartungshaltungen. Hauptstädtische Interessensgruppen wiederum zeigten ein gesteigertes Selbstbewusstsein in Hinblick auf die Beeinflussung politischer Entscheidungsprozesse: Angesichts der Instabilität von Loyalitätsverhältnissen nutzten verschiedene Individuen bzw. Gruppierungen die auftretenden Verwerfungen, um sich selbst innerhalb des kaiserlichen PatronageSystems möglichst gut zu positionieren und den Kandidaten, von dem sie sich den größtmöglichen persönlichen Vorteil erhofften, zum Kaiser zu machen.

Die gewaltsame Aneignung des Kaiseramtes durch einen Kandidaten von außerhalb der Stadt war 602 mit Phokas als praktizierbare Option in den Erfahrungsraum der Römer eingeschrieben und durch Herakleios 610 verfestigt worden. Die 
Schwelle zur Usurpation hatte sich entscheidend gesenkt. Phokas' Sturz acht Jahre nach seiner Erhebung zeigt, als wie fragil sich die Zustimmung erweisen konnte, die einem Prätendenten bei dessen Krönung ostentativ auf den Straßen der Hauptstadt, in der Hagia Sophia und dem Palast entgegengebracht worden war. Für Herakleios lag die entscheidende Herausforderung darin, in einer derart instabilen politischen Konstellation seine Position zu sichern und eine Wiederholung des Szenarios, mit dem er selbst an die Macht gekommen war, zu verhindern. Es galt einerseits, die Unterstützung der Hauptstadt zu verstetigen, und andererseits, dem Aufbegehren eines weiteren Prätendenten, welcher mit militärischen Ressourcen aus der Provinz die Stimmung in Konstantinopel zu seinen Gunsten beeinträchtigen konnte, vorzubeugen. Wie in diesem Kapitel deutlich wird, stellte Herakleios sich dieser Herausforderung, indem er im Bereich der Militär- und Familienpolitik innovative Akzente setzte.

\subsection{Die Regierung des Phokas - eine Kontrastfolie}

Um die innovativen Akzente der herakleischen Politik besonders deutlich hervortreten zu lassen, gilt es zunächst, einen Blick auf die Regierungspraxis seines Vorgängers Phokas zu werfen. ${ }^{1}$ Die folgende Analyse steht unter der Prämisse, dass es sich bei Phokas' Herrschaft bis zu dem Zeitpunkt seines Sturzes nicht um ein illegitimes Gewaltregime handelte, sondern - im Rahmen der strukturellen Voraussetzungen römischer Monarchie - um eine reguläre und legitime Regierung. ${ }^{2}$ Wie im vorigen Kapitel nachvollzogen, verunglimpfen Quellen, die nach dem Machtwechsel von 610 entstanden sind, Phokas durchweg als Tyrannen; dieser erinnerungspolitische Schachzug zielte auf die Stärkung der Herrschaft des Herakleios ab, die im Kontrast zum Vorgänger als glorreiche basileia ek theou konzipiert werden konnte. Im Vordergrund der Berichterstattung der hauptstädtischen Chronisten stehen daher meist die Auseinandersetzungen zwischen Phokas und verschiedenen Individuen und Gruppierungen in Konstantinopel, die das negative Bild untermauern, allerdings nur einen - wenn auch nicht unbedeutenden - Aspekt seiner Herrschaft darstellen. ${ }^{3}$

David M. Olster hat herausgearbeitet, dass sich der Herrschaftswechsel von 602 trotz der spektakulären Hinrichtung des Maurikios, auf die sowohl Quellen als auch Forschung in der Regel den Fokus richten, durch ein recht hohes Maß an Kontinuität

1 Dieses Unterkapitel hat nicht den Anspruch, die Phokas' Herrschaft vollumfänglich abzudecken, sondern richtet vielmehr den Fokus auf Aspekte, die für das Verständnis politischer Dynamiken in Konstantinopel besonders relevant sind.

2 Dazu siehe oben S. $104 \mathrm{f}$.

3 Das negative Phokas-Bild verstetigte sich über die Regierungszeit des Herakleios hinaus sowohl in östlichen wie auch westlichen Traditionen und wurde auch in der modernen Forschung allzu oft unkritisch rezipiert (zusammengetragen bei Meier 2014b, 139-145). Die rezente Forschung indes hat wiederholt den Versuch einer Neubewertung von Phokas' Herrschaft unternommen; siehe etwa Olster 1993, 1-21, 67-80. 
auszeichnete. ${ }^{4}$ Abgesehen von den männlichen Mitgliedern der Kaiserfamilie fielen nur einige ausgewählte Amtsträger dem neuen Regime zum Opfer: Petros (Maurikios' Bruder), Komentiolos und weitere Militärs, die sich als Befehlshaber der Balkantruppen unbeliebt gemacht hatten, sowie der Prätorianerpräfekt Konstantin Lardys, der gemeinsam mit Maurikios nach Kleinasien geflohen war. Dass Phokas einige Verwandte in höchste Ämter beförderte - seinen Bruder Domentziolos zum Magister officiorum und dessen gleichnamigen Sohn zum Curopalates und Magister militum per Orientem - entspricht wiederum typischen monarchischen Verhaltensmustern. ${ }^{5}$ Abgesehen davon behielt er die Amtsträger, die sein Vorgänger eingesetzt hatte, weitestgehend bei bzw. beförderte diese gar: Priskos, den Maurikios sowohl gegen die Perser als auch gegen die Avaren eingesetzt hatte, stieg unter Phokas zum Comes excubitorum und gar Schwiegersohn des Kaisers auf. Erst im Zuge wiederholter Unruhen und (vermeintlicher) Verschwörungen aus den Reihen der hauptstädtischen Aristokratie begann Phokas, sich prominenter Individuen, die seine Position zu untergraben drohten, zu entledigen - nicht zuletzt der restlichen Überlebenden des gestürzten Kaiserhauses. ${ }^{6}$

Im Winter 602/03 wusste Phokas Konstantinopel vorerst hinter sich - zumindest die Mehrheit der Bevölkerung, deren Stimmung sich als maßgeblich für die Besetzung des Thrones erwiesen hatte. Doch bereits kurz nach seiner Krönung sollte dem ehemaligen Zenturio von verschiedenen Seiten Widerstand entgegenschlagen; es begann mit Unruhen im Heer: Im Laufe des Jahres 603 brachte der römische General Narses Edessa in Mesopotamien in seine Gewalt und nahm mit der Bitte um militärische Unterstützung Kontakt zum Perserkönig Chosroes II. auf. Im Gegensatz zu den Meutereien der vergangenen Jahrzehnte ging es nun nicht um Fragen der Truppenversorgung; Narses erhob sich stattdessen dezidiert gegen Phokas, indem er sich auf die Rechtmäßigkeit der Familie des gestürzten Maurikios berief. ${ }^{7}$ Der Aufstand in Edessa stand offenbar mit dem Auftauchen eines Mannes in Verbindung, der sich als Maurikios' Sohn Theodosios ausgab und behauptete, dem Massaker an der kaiserlichen Familie entkommen zu sein - ob es sich dabei tatsächlich um den 591 zum Augustus gekrönten Sohn des Maurikios handelte, war wohl nicht einmal den Zeitgenossen ganz klar. ${ }^{8}$

4 Olster 1993, 67-69; dazu auch De Vleeschouwer 2019, $445 \mathrm{f}$.

5 PLRE IIIA, Domnitziolus 1 und 2 (417f.); ein weiterer Bruder des Phokas, Komentiolos (PLRE IIIA, Comentiolus 2 [326]) befehligte 610 das im Osten stationierte Heer; siehe zu Letzterem Kaegi 1973, 308 310 und allgemein zu Phokas’ Förderung der eigenen Familie ebd. 312.

6 Olster 1993, 69-72.

7 Zur Revolte des Narses siehe Sebeos 31 (Thomson/Howard-Johnston I, 58); Theoph. Conf. AM $6095-$ 6097 (De Boor 294-302); Mich. Syr. 10.25 (Chabot II, 379); Stratos 1968, 59-61; Kaegi 1981, 140 f. und Olster 1993, 82-89.

8 Gemäß Sebeos krönte Narses den angeblichen Theodosios und präsentierte diesen dem Chosroes, der persönlich nach Edessa kam (Sebeos 31 [Thomson/Howard-Johnston I, 58]); außerdem soll Ps.Theodosios mit dem persischen Heer nach Armenien vorgerückt sein, wo er sich den Bewohnern von Karin als Kaiser präsentierte (Sebeos 33 [Thomson/Howard-Johnston I, 63]). Laut Anon. Guidi (Nöldeke 
Angesichts des Kaiserwechsels in Konstantinopel witterte auch Chosroes selbst die Gunst der Stunde. Die machtpolitische Konstellation zwischen den beiden Großmächten hatte sich gegenüber dem Ende des vorigen Jahrhunderts umgekehrt: Interne Konflikte schwächten nun das römische Reich, dessen militärische Kräfte zusätzlich durch die Auseinandersetzungen mit den Avaren an der Donaugrenze beansprucht wurden. ${ }^{9}$ Abgesehen von der vermeintlichen Loyalität gegenüber seinem einstmaligen Wohltäter Maurikios sah Chosroes nun die Chance, den Spieß umzudrehen und die Gebiete, die er 591 als Gegenleistung für römische Unterstützung hatte abtreten müssen, zurückzugewinnen. ${ }^{10}$ Während sich Narses in Edessa nicht halten konnte - Phokas' Neffe Domentziolos brachte die Aufständischen zum Aufgeben und führte Narses nach Konstantinopel, wo ihn das Todesurteil erwartete -, verzeichneten die persischen Truppen unter der Führung des Großkönigs schnell erste Erfolge. Im Jahr 604 fiel nach längerer Belagerung die umkämpfte Grenzfestung Dara, die erst unter Maurikios wieder in römische Hände gekommen war. ${ }^{11}$ Die Auseinandersetzungen zwischen den beiden Großmächten beschränkten sich allerdings während der frühen Regierungsjahre des Phokas auf die mesopotamische Grenzregion; von weitreichenden Eroberungen sollten die Ostprovinzen noch einige Jahre verschont bleiben. ${ }^{12}$

In diesem Zusammenhang ist bemerkenswert, dass Phokas nach seiner Krönung die Hauptstadt bzw. deren direktes Umland trotz der erneut aufflammenden Unruhen in den Provinzen offenbar nicht mehr verließ. Sein Vorgänger Maurikios hatte wiederholt versucht, sich entgegen monarchischer Gewohnheiten des 5. und 6. Jahrhunderts durch persönliche Vorstöße nach Thrakien der Armee anzunähern. Nicht zuletzt die deutliche Missbilligung, mit der das hauptstädtische Palastumfeld auf derartige Aktivität reagierte, hatte ihn jedoch dazu gezwungen, seine Unternehmungen einzu-

15f.) veranlasste Chosroes gar, den angeblichen Theodosios vom nestorianischen Katholikos in einer Kirche nach römischer Sitte krönen zu lassen. Er soll ihm ein Heer gestellt haben, mit dem Ps.Theodosios nahe Dara auf römische Truppen traf, diesen allerdings unterlag; ähnlich auch die Chronik von Seert (Scher 500f.), gemäß der sich Chosroes mit Unterstützung des Katholikos durch einen Brief an die Römer wandte und forderte, Theodosios solle seinem Vater auf dem Thron folgen.

9 Theoph. Conf. AM 6096 (De Boor 292): nach einem Friedensvertrag mit dem Khagan konnte Phokas die Truppen an die Kriegsschauplätze im Osten schicken.

$10 \mathrm{Zu}$ der Frage nach der Motivation des Chorsroes II. siehe De Vleeschouwer 2019, 439-441.

11 Die syrischen Quellen datieren die Einnahme von Dara auf 604, so etwa Mich. Syr. 10.25 (Chabot II, 378); Theoph. Conf. AM 6098 (De Boor 293) dagegen ins Jahr 605/6; siehe dazu Mango/Scott 1997, 422 Anm. 4; zur Datierung auch Flusin 1992 II, 71-74 und Olster 1993, 95.

12 Der Konflikt zwischen Rom und Persien wird bei Bonner 2019, 267-311 aus sassanidischer Sicht detailliert beschrieben. Sowohl die Abfolge als auch die absolute Chronologie des frühen Stadiums des römisch-persischen Krieges ist umstritten; zur Quellenlage und einer Rekonstruktion siehe Stratos 1968, 58-66; Flusin 1992 II, 70 -83; Bonner 2019, 280 -282; Olster 1993, 81-97; ebd. 98 - 100 die tabellarische Auflistung aller relevanten Quellen mit den jeweiligen Datierungen der Ereignisse. Zu der Eroberung von Mesopotamien und Armenien siehe auch De Vleeschouwer 2019, 441-444; zu den Konflikten zwischen Römern und Persern im 6. und frühen 7. Jahrhundert siehe den Überblick in Meier 2019a, $1020-1035$. 
stellen. ${ }^{13}$ Phokas machte keine Anstalten, an das Ringen seines Vorgängers um innovative Positionierungsmöglichkeiten anzuknüpfen. Trotz oder gerade wegen seines militärischen Hintergrundes konzentrierte Phokas sich auf den städtischen Interaktionsraum; der Unterstützung des Balkanheeres, dem er selbst entstammte, schien er sich sicher zu sein und erachtete es offenbar nicht als notwendig, im militärischen Sektor persönlich aktiv zu werden. Die Revolte des Generals Narses konnte eingehegt werden. Nachdem der Kaiser das Balkanheer 603 in Folge eines Friedensschlusses mit dem Avaren-Khagan an den östlichen Kriegsschauplatz verlegt hatte, ging von den Truppen, die gegen die Perser kämpften, offenbar keine weitere Bedrohung für Phokas aus. ${ }^{14}$

Ein in der Forschung viel diskutiertet Aspekt von Phokas' Herrschaft ist dessen enge Beziehung zum Papst in Rom. Dass der frisch gekrönte Kaiser sein Bildnis und das seiner Ehefrau, der Augusta Leontia, nach Rom schickte, wo Papst Gregor diese feierlich empfing und im kaiserlichen Palast auf dem Palatin aufstellen ließ, ${ }^{15}$ entspricht gängiger kaiserlich-diplomatischer Praxis. ${ }^{16}$ Auch die durchweg positive Reaktion des Gregor auf den Machtwechsel in Konstantinopel - in einem seiner Briefe preist er die Erhebung des Phokas gar als Befreiung von Maurikios ${ }^{17}$ - überrascht nur vordergründig. Während die ältere Forschung sich schwer tat, ihr Bild von Phokas als blutrünstigem Tyrannen mit dessen Bestätigung durch Gregor zu vereinbaren, haben jüngere Publikationen eine Reihe an Faktoren ins Spiel gebracht, die die Kommunikation zwischen Kaiser und Papst in anderem Lichte dastehen lassen. ${ }^{18}$ Zunächst ist erneut festzuhalten, dass Phokas' Krönung von den Zeitgenossen als reguläres Prozedere und nicht etwa als illegitime Ermächtigung wahrgenommen wurde; Gregor hatte daher keinen Grund, die Geschehnisse in Konstantinopel per se zu verurteilen. Dazu kommt, dass das Verhältnis zwischen Konstantinopel und Rom unter Maurikios einen empfindlichen Dämpfer erlitten hatte. Im Zusammenhang mit dem Drei-KapitelStreit weigerten sich die Bischöfe von Mailand, Aquileia und Istria, den päpstlichen Direktiven nachzukommen; im Jahr 553 kam es zum Istrischen Schisma. Der Konflikt gewann an politischer Brisanz, als die abtrünnigen Bischöfe bei den langobardischen Königen Anklang fanden. In seinen Bemühungen um die Beilegung des Schismas setzte der Papst Gregor auf Konstantinopolitaner Unterstützung in Person des in Ravenna residierenden Exarchen. Der Exarch Smaragdus, der sich gegenüber der römischen Sache als offen gezeigt hatte, wurde von Maurikios abgesetzt; bei seinem

13 Dazu siehe oben S. $74 \mathrm{f}$.

14 Theoph. Conf. AM 6096 (De Boor 292) zur Verlegung des Balkanheeres.

15 Greg. Epist. 13.1 (Hartmann); die Bilder erreichten Rom am 25. April 603.

16 Phokas schickte auch einen Gesandten (Lilis) zu Chosroes II., um diesen von seiner Erhebung zu unterrichten, siehe Theoph. Sim. Hist. 8.15.2-6.

17 Glückwunschschreiben des Gregor an Phokas: Greg. Epist. 13.34 (Hartmann) = 13.32 (Norberg); außerdem Greg. Epist. 13.41 (Hartmann) = 13.39 (Norberg). Auch Phokas' Frau Leontia erhielt einen Brief von Gregor: Greg. Epist. 13.42 (Hartmann) = 13.40 (Norberg). Siehe zu diesen Briefen ausführlich Olster 1993, 169 -172; Ekonomou 2007, 46 f.; siehe auch Meier 2014b, 140 f. Anm. 5 zu den Reaktionen in der Forschung.

18 Vor allem Ortenberg West-Harling 2016; De Vleeschouwer 2019; vgl. auch Meier $2014 b$. 
Nachfolger Romanus (im Amt 589-596) stieß Gregor mit seinen Anliegen auf taube Ohren. ${ }^{19}$ Die bereits angespannten Beziehungen erreichten einen weiteren Tiefpunkt, als Maurikios den Patriarchen von Konstantinopel mit dem Attribut ,ökumenisch“ versah und damit dessen Hoheit über den Papst in Rom feststellte. Auch Gregors Versuche, die Konflikte mit den Langobarden, die Italien bedrohten, auf friedlichem Wege beizulegen, trafen auf Seiten der von Konstantinopel entsandten Amtsträger nicht auf die erhoffte Unterstützung. ${ }^{20}$ Vor diesem Hintergrund ist es kaum verwunderlich, dass Gregor angesichts des Machtwechsels am Bosporus auf eine neuerliche Verbesserung seiner Beziehung zum Kaiser - und damit eine Stärkung seiner Position in Italien - setzte.

Der frisch gekrönte Phokas sollte Gregors Hoffnungen nicht enttäuschen. Zunächst ersetzte er den Exarchen Callinicus mit Smaragdus, der sich in seiner ersten Amtszeit bereits als kooperativ gegenüber dem Heiligen Stuhl in Rom erwiesen hatte. Eben dieser Smaragdus war es auch, der dem Phokas im Jahr 608 ein Ehrenmonument auf dem Forum Romanum errichten ließ - das letzte seiner Art in der Antike -, von dem heute noch der Säulenschaft in situ zu sehen ist. Die auf der Basis angebracht Inschrift feiert Phokas für seine Milde und Frömmigkeit sowie seine Bemühungen um Frieden in Italien. ${ }^{21}$ Phokas setzte sich nicht nur für eine Beruhigung der Konfrontation mit den Langobarden ein, sondern machte auch die von Maurikios betroffene Entscheidung hinsichtlich der kirchlichen Hierarchie rückgängig: In einem kaiserlichen Edikt des Jahres 607 betonte Phokas die Vorrangstellung des Papstes gegenüber dem Patriarchen von Konstantinopel. ${ }^{22}$ Darüber, wie der Konstantinopolitaner Klerus einen derartigen Schritt aufnahm, lässt sich aufgrund des Mangels an Quellen nur spekulieren; er wird allerdings kaum zu Phokas' Beliebtheit in der Hauptstadt am Bosporus beigetragen haben. ${ }^{23}$ Im folgenden Jahr veranlasste Phokas einen entscheidenden Schritt in Richtung der Christianisierung paganer Monumente im Römischen Stadtzentrum, indem er Gregors Nachfolger Bonifaz das Pantheon überließ; 609 wurde der ehemalige Tempel zur Kirche Santa Maria ad Martyres um-

19 Zum Istrischen Schisma und der Positionierung des Maurikios in diesem Zusammenhang siehe Ortenberg West-Harling 2016, 200 f.; De Vleeschouwer 2019, 455; zu dem Exarchen Romanus siehe Ravegnani 2011, 54-63.

20 Ortenberg West-Harling 2016, 201.

21 CIL 6, 1200; zu Smaragdus siehe Ravegnani 2011, 50 - 54 (erste Amtszeit); 66 - 68 (zweite Amtszeit). 22 Lib. Pont. 68 (Bonifacius III); Dölger 1976, Nr. 155; Olster 1993, 169; Ekonomou 2007, 49 weist darauf hin, dass Phokas damit Justinian folgte.

23 Kurz zuvor war Phokas offenbar mit dem Patriarchen Kyriakos aneinandergeraten, als Kyriakos sich Phokas’ Versuch, Maurikios' Witwe Konstantina aus der Hagia Sophia zu entfernen, widersetzte (Theoph. Conf. AM 6098 [De Boor 293]). Kyriakos verstarb im Jahr 606; ihm folgte Thomas nach, zu dessen Verhältnis zu Phokas keine Informationen erhalten sind. Nach Thomas' Tod wurde Sergios am 18. April 610 zum Patriarchen erhoben, der sich als Schlüsselfigur in Herakleios' Regierung erweisen sollte; zu Sergios siehe Van Dieten 1972, 1-56; ebd. 1 zur Erhebung. Zu Phokas' Religionspolitik, die unter anderem eine erneute Verschärfung des Konfliktes mit den miaphysitischen Gemeinden im Osten mit sich brachte, siehe Stratos 1968, $74 \mathrm{f}$. 
geweiht und von Phokas mit reichen Geschenken ausgestattet. ${ }^{24}$ Die zwischen 602 und 610 amtierenden Päpste konnten also von der Herrschaft des Phokas deutlich profitieren; ihre vollumfängliche Unterstützung dieses Kaisers bedarf keiner weiteren Erklärung. Warum Phokas sich so deutlich für italische Belange einsetzte und dabei auch eine Verstimmung des Patriarchen von Konstantinopel in Kauf nahm, ist dagegen weniger offensichtlich. Deutlich wird zumindest, dass es der Sicherheitslage im von Langobarden bedrohten Italien zuträglich war, wenn Kaiser und Papst an einem Strang zogen. Dies mag für Phokas nicht zuletzt vor dem Hintergrund bedeutsam gewesen sein, dass sich im Osten erneut der Konflikt mit den Persern entfacht hatte und Ressourcen bedacht eingesetzt werden mussten. ${ }^{25}$

Die Päpste in Rom waren nicht die einzige spirituelle Autorität, zu der Phokas in guter Beziehung stand. Die Quellen geben Hinweise darauf, dass der Kaiser engen Kontakt mit einigen prominenten Heiligen Männern pflegte - einer mit religiösem Prestige und Autorität ausgestatteten Personengruppe, deren Nähe und Unterstützung auch seine Vorgänger stets gesucht hatten. ${ }^{26}$ Die Vita des Heiligen Theodor von Sykeon, vollendet nach Herakleios' Tod, berichtet, wie Phokas den Heiligen im hauptstädtischen Palast empfing und durch ihn von einer Krankheit geheilt wurde; Theodors Ermahnung, Phokas solle vom Blutvergießen ablassen, um nicht Gottes Zorn auf sich zu ziehen, ist dabei aller Wahrscheinlichkeit nach der retrospektiven Verunglimpfung des Kaisers als mordlustiger Tyrann geschuldet. ${ }^{27}$ Nicht nur Phokas selbst, sondern auch dessen bereits erwähnter Neffe Domentziolos stand in engem Kontakt mit Theodor; nach dem Machtwechsel von 610 setzte sich der Heilige gar bei Herakleios für seinen Schützling ein und verhinderte dessen Hinrichtung. ${ }^{28}$ Ein Gedicht des Sophronios, des späteren Patriarchen von Jerusalem, ist außerdem ein Indiz dafür, dass Phokas mit dem Heiligen Kosmas in Kontakt stand. ${ }^{29}$ Der fromme Kaiser habe so das Gedicht - im Zusammenhang mit dem Prozess um Menas, einem Abt aus Alexandria, vom Heiligen Kosmas Rat erbeten. Kosmas' göttlich inspirierte Erkenntnis von Menas' Unschuld habe Phokas sich zu Herzen genommen und den Abt umgehend freigesprochen. Im Gegensatz zu der Vita des Theodor wurde Sophronios' Gedicht nach dem Machtwechsel von 610 nicht angepasst und bietet damit ein authentisches Zeugnis davon, wie der Kaiser von seinen Zeitgenossen im monastischen Milieu dar-

24 Lib. Pont. 69 (Bonifacius IV); Ekonomou 2007, 50.

25 Siehe De Vleeschouwer 2019, 457 zu dem „mutually beneficial relationship“ zwischen Kaiser und Papst.

26 Zur Interaktion von Kaiser und Heiligen Männern siehe Pfeilschifter 2013, 434-450.

27 Vit. Theod. Syk. 133; siehe dazu Olster 1993, 174 f. und Meier 2014b, 156 f. mit Anm. 51. Maurikios hatte bereits mit Theodor in Kontakt gestanden (Vit. Theod. Syk. 54, 82, 97) und auch Herakleios sollte dessen Nähe suchen (ebd. 154f., 166); zu Theodor von Sykeon und Phokas siehe auch Van Ginkel 2002, $229-231$.

28 Vit. Theod. Syk. 140, 152.

29 Soph. Anacr. 21. 
gestellt werden konnte: nämlich entlang traditionell enkomiastischer Kategorien als

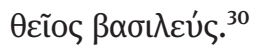

Trotz der problematischen Quellenlage ist zumindest in Grundzügen nachzuvollziehen, wie Phokas sich im hauptstädtischen Sozialgefüge positionierte. Eine Notiz des Theophanes lässt darauf schließen, dass er an Weihnachten 603, etwas mehr als ein Jahr nach seiner Krönung, den Konsulat antrat und dieses Ereignis feierte, indem er traditionsgemäß durch die Straßen der Hauptstadt zog und die versammelte Bevölkerung mit Spenden bedachte. Der Antritt dieses Amtes, das spätestens seit Justin II. mit kaiserlicher Würde im Allgemeinen und der Erhebung eines neuen Kaisers im Speziellen verbunden war, wurde auch auf Münzen angezeigt: Die Averse von Gold- und Bronzeprägungen zeigen Phokas in Konsulatstracht. ${ }^{31}$

Beim Blick auf die Münzen sticht außerdem ins Auge, dass Phokas im Gegensatz zu seinen Vorgängern ein Individualportrait auf den Münzen abbilden ließ. Nachdem die Kaiser des 5. und 6. Jahrhunderts allesamt idealisiert (d. h. entindividualisiert) und bartlos auf den Aversen der verschiedenen Nominale erschienen waren, kann der charakteristische Spitzbart des Phokas kaum anders denn als bewusste Abkehr von dieser Bild-Tradition gewertet werden. ${ }^{32}$ Philip Grierson schlägt vor, die bärtige Darstellung als Verweis auf Phokas’ „plebeian background” und seine abrupte Erhebung zum Kaiser, die keine Zeit für „cultural acclimatization” geboten habe, zu deuten. ${ }^{33}$ Dabei scheint Grierson allerdings zu vernachlässigen, dass es sich bei Münzbildern kaum um kontingente Nebenprodukte politischer Prozesse handelte, sondern vielmehr um bewusst komponierte Äußerungen der kaiserlichen Repräsentationsstrategie. Phokas war es offenbar daran gelegen, sich zu einem gewissen Grad von seinen Vorgängern abzuheben. ${ }^{34}$

$\mathrm{Zu}$ beachten ist in diesem Zusammenhang jedoch nicht nur Phokas' Repräsentation, sondern auch die Modi seiner Interaktion mit den herrschaftsrelevanten Gruppen in Konstantinopel. Nachdem die Krönung und sein Einzug in die Stadt weitestgehend ohne Störungen abgelaufen waren, sah sich der neue Kaiser schnell mit wiederkehrenden Problemen konfrontiert: Einerseits formierte sich in aristokrati-

30 Soph. Anacr. 21.99. Eine eingehende Analyse des Gedichtes findet sich bei Olster 1993, 172-174, 182, der darauf hinweist, dass der Charakter des Gedichtes ein primär hagiographischer ist; herausragender Protagonist ist demnach nicht Phokas, sondern der göttlich inspirierte Heilige Kosmas. Das Gedicht offenbare somit eher einen Einblick ins monastische, nicht unbedingt in hauptstädtisch-palatiale Milieu. 31 Theoph. Conf. AM 6096 (De Boor 420); siehe Olster 1993, 178f. mit Fig. 3f.; zu der Verbindung von Konsulat und Erhebung siehe ebd. 176-179.

32 DOC II.1, 88-94 zu Portraits auf frühbyzantinischen Münzen. Zu Phocas’ Münzen siehe MIB II, 76-83, Taf. 29-36; DOC II.1, 147-206, Taf. 1-7.

33 DOC II.1, 89f. (Zitat 90). Grierson verweist außerdem darauf, dass ab dem frühen 7. Jahrhundert Christus vermehrt mit Bart dargestellt wurde, und äußert die Vermutung, dass Phokas sich daran orientiert haben könnte. Gegen die These von Grierson, die Darstellung sei der abrupten Erhebung geschuldet, spricht auch, dass Phokas Zeit seiner Herrschaft nicht von dieser Darstellungskonvention abrückte.

$34 \mathrm{Zu}$ Münzen als Kommunikationsmedium siehe unten S. 168-170. 
schen Kreisen eine Opposition, die sich formal auf das Erbe des ermordeten Maurikios berief; ${ }^{35}$ andererseits erwies sich die Kommunikation zwischen Phokas und der hauptstädtischen Bevölkerung als zunehmend dysfunktional. ${ }^{36}$ Obwohl Phokas einen Großteil der hohen Amtsträger, die sein Vorgänger Maurikios eingesetzt hatte, beibehielt, hatte der unerwartete Herrscherwechsel von 602 die Hauptstadt in Gewinner und Verlierer gespalten und damit die Dynamiken des Patronagesystems, das sich um den Kaiser rankte, angeheizt. ${ }^{37}$ Widerstand gegen Phokas formierte sich jedoch nicht etwa in einer standesbewussten hauptstädtischen Elite, die den Emporkömmling nicht in ihren Reihen akzeptierte; nachdem Maurikios' Sturz Bewegung in die politische Hierarchie gebracht hatte, versuchten Individuen bzw. Fraktionen innerhalb der hauptstädtischen Amtselite vielmehr, sich gewinnbringend zu positionieren bzw. die machtpolitische Zurücksetzung, die ihnen wiederfahren war, zu kompensieren. ${ }^{38}$

Im Zentrum des Widerstandes, der sich kurz nach Phokas’ Krönung zu formieren begann, standen Germanos, der Schwiegervater von Maurikios' ältestem Sohn Theodosios, und Konstantina, Maurikios' Witwe. Nachdem Germanos bereits nach Maurikios' Flucht aus der Hauptstadt im November 602 seine Ambitionen auf den Kaiserthron erklärt hatte, versuchte er im Jahr 603 erneut, das hauptstädtische Volk, ohne dessen Rückendeckung ein Regimewechsel undenkbar war, für sich zu gewinnen. In seinem Zusammenschluss mit Konstantina berief er sich auf die Rechtmäßigkeit der gewaltsam gestürzten Kaiserfamilie, scheiterte aber wie bereits im Jahr zuvor an der entschiedenen Ablehnung der grünen Zirkuspartei, die weder ihm noch Konstantina wohlgesinnt war. Phokas stellte die beiden Unruhestifter daraufhin in Klöstern kalt. ${ }^{39}$ Zwei Jahre später flammte der Konflikt jedoch erneut auf: Hochrangige Amtsträger, unter ihnen der Prätorianerpräfekt Theodor, schmiedeten Pläne, Phokas während der Pferderennen in dessen Loge im Hippodrom zu ermorden. Als die Verschwörung aufgedeckt wurde, nutzte Phokas die Gelegenheit, sich einer ganzen Reihe von Männern, die bereits unter Maurikios aufgestiegen waren und nach dem Machtwechsel vorerst ihre Positionen beibehalten hatten, zu entledigen. Auch Germanos sowie die letzten weiblichen Überlebenden des ehemaligen Kaiserhauses - Konstantina und ihre Töchter -, fielen den Säuberungen zum Opfer. ${ }^{40}$ Erneut fanden die Hinrichtungen vor den Augen der Öffentlichkeit statt. ${ }^{41}$

35 Zu der Opposition von Seiten der Aristokratie siehe Olster 1993, 69- 72 und Pfeilschifter 2013, 589 f., 593. $36 \mathrm{Zu}$ den Unruhen und Ausschreitungen in Konstantinopel unter Phokas siehe Olster 1993, 76-79; Pfeilschifter 2013, 590 - 592; vgl. auch Al. Cameron 1976, 253 f., 282f. und Roberto 2010, 59 f.

37 Die „dynamic of patronage and faction”, die Phokas’ Herrschaft beeinträchtigte, arbeitet detailliert Olster 1993, 68-80 heraus (Zitat 76).

38 Vgl. die Rekonstruktion von Phokas' Regierung bei Olster 1993, 165-182.

39 Chron. Pasch. AD 603 (695); Theoph. Conf. AM 6098 (De Boor 293).

40 Auch hier soll der Konflikt mit dem angeblichen Überleben des Theodosios in Verbindung gestanden haben, siehe Theoph. Conf. AM 6099 (De Boor 294).

41 Chron. Pasch. AD 605 (696); Theoph. Conf. verteilt den Bericht über die Verschwörung auf zwei Einträge: AM 6099 (De Boor 294) und AM 6101 (De Boor 297f.). Zu der Opposition von Seiten der Aristokratie vgl. Olster 1993, 69-72 und Pfeilschifter 2013, 589f., 593. 
In diesem Zusammenhang ist zu beobachten, dass wiederholt der Verweis auf das Erbe des Maurikios instrumentalisiert wurde, um Unterstützung zu mobilisieren. Basis bzw. Hintergrund dieser Strategie war das Gerücht, Maurikios’ ältester Sohn, der Augustus Theodosios, sei dem Massaker vom November 602 entkommen und habe sich nach Persien absetzen können, um Chosroes II. um Hilfe zu ersuchen. Armenische und syrische Quellen berichten von dem Auftauchen des Theodosios im Grenzgebiet zwischen dem römischen und persischen Reich im Zusammenhang mit dem erneuten Ausbruch des Krieges zwischen den beiden Großmächten. Laut der GuidiChronik soll Theodosios gar mit Chosroes' Unterstützung vom nestorianischen Katholikos zum Kaiser gekrönt worden sein; Sebeos berichtet, Theodosios habe sich den Bewohnern des armenischen Karin als Kaiser präsentiert. ${ }^{42}$ In hauptstädtischen Quellen findet das Auftreten des mutmaßlichen Theodosios indes nur verhältnismäßig geringe Beachtung. ${ }^{43}$ Dies mag entweder daran liegen, dass das Gehabe an der Grenze schlichtweg keine direkten politischen Auswirkungen auf Konstantinopel zeitigte (Kaiser war nur, wer Konstantinopel kontrollierte, und Theodosios war weit davon entfernt), oder dass das Regime alles daran tat, um derartige Nachrichten zu unterdrücken. ${ }^{44}$ Theophanes Confessor bringt immerhin den erneuten Ermächtigungsversuch, den Germanos und Konstantina schlussendlich mit ihrem Leben bezahlten, damit in Verbindung, dass sich in Konstantinopel das Gerücht von Theodosios’ Überleben verbreitet habe. ${ }^{45}$ Nicht zuletzt die harschen Maßnahmen, mit denen Phokas der Intrige begegnete, sprechen dafür, dass das Gerücht trotz der Unbeliebtheit der gestürzten Kaiserfamilie auch in der Hauptstadt eine gewisse Wirkung entfalten konnte.

Die Frage, ob es sich bei dem jungen Mann tatsächlich um den Sohn des Maurikios handelte, ist nicht nur schwerlich zu beantworten, sondern im Rahmen dieser Arbeit geradezu irrelevant. Um machtpolitisches Ringen erneut zu entfachen, reichte

42 Anon. Guidi (Nöldeke 15f.); Sebeos 31 (Thomson/Howard-Johnston I, 58): Krönung des Theodosios durch den aufständischen General Narses; 33 (Thomson/Howard-Johnston I, 63): Theodosios mit dem persischen Heer in Armenien; siehe auch Chronik von Seert (Scher 500f.); dazu Booth 2019, bes. 794807. Der Umstand, dass verschiedene östliche Quellen unabhängig voneinander das Auftauchen des Theodosios thematisieren, zeigt, welches Aufsehen dies dort erregte. Ob der Bericht von einer Krönung authentisch ist, bleibt allerdings dahingestellt. Theodosios war bereits gekrönt worden, ein erneuter Vollzug des Rituals also eigentlich nicht notwendig; dass er sich in der Provinz als Kaiser präsentierte, ist indes durchaus plausibel. Zur weiteren Theodosios-Überlieferung im Osten siehe auch Schilling 2008, $282 \mathrm{f}$.

43 Nur Theoph. Conf. AM 6095 (De Boor 291), der sich bei der Zusammenstellung seiner Chronographie unter anderem der syrischen Tradition bediente, verweist darauf. $\mathrm{Zu}$ der Theodosios-Überlieferung siehe Stratos 1968, 55f.; Olster 1993, 89, $91 \mathrm{f}$.

44 Auch für Herakleios war die Möglichkeit, dass Theodosios noch am Leben war, äußerst unangenehm; Theophylakt Simokattes (Hist. 8.13.3-6, 15.8f.), der dem herakleischen Regime nahestand, tat alles daran, die Gerüchte zwar aufzugreifen, dann aber zu entkräften, indem er betont, dass auch Theodosios mit seinem Vater hingerichtet worden sei.

45 Theoph. Conf. AM 6099 (De Boor 294f.); vgl. auch (weniger konkret) Theoph. Sim. Hist. 8.15.8. f.; vgl. Chron. Pasch. AM 605. 
das Gerücht bzw. die durchaus realistische Möglichkeit seines Überlebens. Theodosios hatte als Sohn des ehemaligen Kaisers zwar kein wie auch immer geartetes Recht auf den Thron, aber dynastisches Prestige wog durchaus schwer. Die angebliche Präsenz eines weiteren Augustus - Theodosios war von seinem Vater 591 in Konstantinopel gekrönt worden -, diente verschiedenen Akteuren als Anlass, um in Opposition zu Phokas eine erneute Verschiebung der politischen Machtkonstellation anzustreben: sowohl Akteuren innerhalb der hauptstädtischen Elite als auch dem Perserkönig Chosroes II., der die Konstellation nutzte, um unter Berufung auf seine Bindung zu Maurikios' Familie Gebietsverluste wieder gutzumachen. Doch unter welchen Vorwänden auch immer - den Phokas-Gegnern in Konstantinopel gelang es vorerst nicht, die nötige Unterstützung zu mobilisieren.

Zusätzlich zu den Intrigen aus der hauptstädtischen Elite erwies sich auch die Stimmung innerhalb der hauptstädtischen Bevölkerung als fragil. Selbst die grüne Zirkuspartei, die Phokas' Krönung noch maßgeblich mit eingeleitet hatte, zeigte sich wankelmütig. Erneut erschütterten Aufstände die Hauptstadt; bereits im Jahr 603 gingen Teile der Mese sowie das Prätorium in Flammen auf. ${ }^{46}$ Derartige Unruhen sind zu einem gewissen Grad als typische Ausschreitungen der Konstantinopolitaner Demen zu interpretieren; nicht unbedingt gegen den Kaiser direkt gerichtet, konnten sie auch zwischen verfeindeten Fraktionen innerhalb der Bevölkerung aufflammen in der Regel zwischen der grünen und der blauen Zirkuspartei. ${ }^{47}$ Davon abgesehen sind allerdings auch konkrete Konfrontationen zwischen Kaiser und Bevölkerung nachzuvollziehen. Phokas überreizte die Gunst, die ihm im November 602 noch recht einmütig entgegengebracht worden war. Als er im Jahr 607 den einflussreichen General Priskos mit seiner Tochter Domentzia verheiratete, kam es während der Hochzeitsfeierlichkeiten zum Eklat: Für die Spiele im Hippodrom installierten die Zirkusparteien Bildnisse des frisch vermählten Paares neben denen des Phokas und seiner Frau, der Augusta Leontia. Phokas empfand eine derartige Aufstellung, die als recht unverhohlener Kommentar zur Nachfolgeregelung verstanden werden konnte, als anmaßend und drohte den Verantwortlichen mit harten Strafen; nur der Druck der versammelten Bevölkerung im Hippodrom ersparte den beiden Demarchen, den Sprechern der Zirkusparteien, die Todesstrafe. ${ }^{48}$ Der Vorfall beeinträchtigte nicht nur das Verhältnis zwischen Phokas und der Bevölkerung, sondern führte auch dazu, dass der gekränkte Priskos sich von seinem Schwiegervater abwandte und schließlich entscheidend zum Gelingen der Usurpation des Herakleios beitrug. Während der Konflikt anlässlich der Hochzeitsfeier oberflächlich noch hatte entschärft werden können, kam es wenige Jahre darauf zur Eskalation im Hippodrom: Johannes von

46 Chron. Pasch. AD 603 (De Boor 695), bei dem Aufstand verbrannte der Demarch der Grünen, Johannes Kroukis, auf der Mese, siehe zum Aufstand der „Grünen unter Kroukis“ auch die Doctrina Jacobi (Dagron/Déroche 128).

47 Siehe Pfeilschifter 2013, 590 f. mit Verweis auf Al. Cameron 1976, 282.

48 Zum Eklat bei der Hochzeit siehe Joh. Ant. fragm. 319; Theoph. Conf. AM 6099 (De Boor 294); vgl. Nikeph. Brev. 1.; vgl. Al. Cameron 1976, 253 und Pfeilschifter 2013, 593-596. 
Antiochia und Theophanes Confessor, der das Ereignis ins Jahr 610 datiert, überliefern den gegen Phokas gerichteten Schmähgesang: „Wieder einmal hast du aus dem Becher getrunken. Wieder einmal hast du den Verstand verloren. “49 Der im 11. Jahrhundert schaffende Chronist Kedrenos gibt darüber hinaus entscheidende Informationen zum Kontext: Phokas sei zu spät und offensichtlich betrunken zu den Spielen erschienen; einer Aufforderung des versammelten Volkes, sich zu erheben, kam er nicht nach, woraufhin ihm die bereits zitierte Beleidigung entgegenschleudert wurde. ${ }^{50}$ Öffentliche Hinrichtungen, die der erboste Phokas daraufhin als kollektive Strafmaßnahme anordnete, führten dazu, dass die Situation nur noch weiter außer Kontrolle geriet: Die grüne Zirkuspartei setzte das Praetorium sowie weitere Gebäude der Innenstadt in Brand. Laut Theophanes soll Phokas die Grünen in Folge dessen mit Sanktionen belegt haben, indem er sie von der Ausübung öffentlicher Ämter ausschloss. ${ }^{51}$

Der Grund für die Eskalation dieses letztgenannten Konfliktes scheint, dass Phokas nicht angemessen auf die Verhaltenserwartungen seiner Gegenüber, der versammelten Bevölkerung bzw. der Zirkusparteien, einging. Das Aufeinandertreffen von Kaiser und Bevölkerung im Hippodrom hatte sich in den zweihundert Jahren der hauptstädtischen Monarchie als kommunikativer Schlüsselmoment herauskristallisiert: Sets an zeremoniellen Versatzstücken strukturierten die Interaktion zwischen dem Kaiser im Kathisma, umgeben von seiner Familie, der Amtselite und den Garden, und der Masse an Menschen auf den Rängen; gleichzeitig konnten beide Seiten auch spontan auf aktuelle Gegebenheiten reagieren und damit in einen situativen Aushandlungsprozess eintreten. ${ }^{52}$ Das Maß an Flexibilität und möglicher Spontanität durfte allerdings nicht überstrapaziert werden. Phokas missachtete basale Anforderungen an kaiserliches Verhalten: Dem Mangel an Respekt (Zuspätkommen, betrunkener Zustand) folgte die Verweigerung von Interaktion (er ging nicht auf die Impulse der Bevölkerung ein), was eine weitere Eskalationsstufe einleitete (explizite Beleidigung und Bestrafung). Als Phokas keine Gnade walten ließ, war das Ausgreifen der Gewalt geradezu unvermeidbar.

Nachdem die maßgeblichen städtischen Gruppen sich im November 602 hinter Phokas gestellt und damit den Consensus universorum demonstriert hatten, von dem der Erfolg einer Krönung abhing, genoss der Kaiser in Konstantinopel einen gewissen

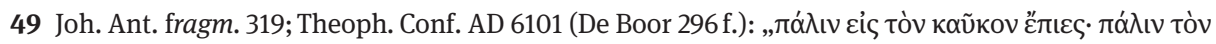

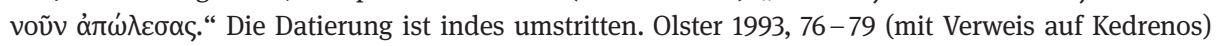
plädiert dafür, dass diese Episode im Zusammenhang mit dem Aufstand steht, der vom Chron. Pasch. ins Jahr 603 verortet wird; dagegen Pfeilschifter 2013, 590 - 592. Ich halte eine Spätdatierung gemäß Theophanes auch für wesentlich plausibler.

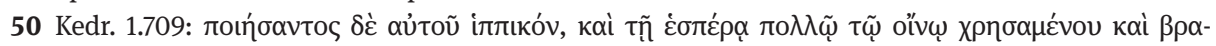

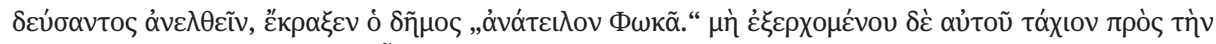

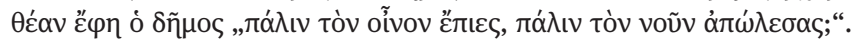

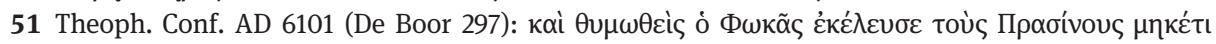

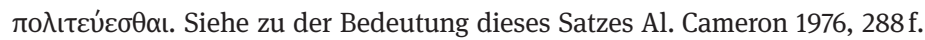

52 Zur Interaktion zwischen Kaiser und Volk im Hippodrom siehe Al. Cameron 1976, 157-192. 
Vertrauensvorschuss. ${ }^{53}$ Unsensibles, ja geradezu fahrlässiges Verhalten gegenüber der hauptstädtischen Bevölkerung untergrub allerdings sukzessive die Akzeptanzbasis seiner Herrschaft. ${ }^{54}$ Ob Phokas' Verhalten dem Umstand geschuldet war, dass er aufgrund seiner Herkunft schlichtweg nicht mit den Finessen des Protokolls vertraut war, bleibt dahingestellt; Fauxpas wie der oben geschilderte führten jedenfalls dazu, dass er selbst den Rückhalt der grünen Zirkuspartei, die maßgeblich zu seiner Erhebung beigetragen hatte, verlor. Innerstädtische Herausforderer wie Germanos hatten ihrerseits nicht die maßgebliche Unterstützung mobilisieren können; als sich jedoch Herakleios 610 mit seiner Flotte Konstantinopel näherte, bedurfte es nicht mehr viel, dass sowohl prominente Vertreter der städtischen Elite als auch der ausschlaggebende Anteil der hauptstädtischen Bevölkerung, angeführt erneut von der grünen Zirkuspartei, sich auf dessen Seite schlugen und Phokas auf verlorenem Posten zurückblieb.

Phokas gelang es nicht, die ihm im November 602 entgegengebrachte Akzeptanz zu verstetigen. Sein Scheitern lässt sich zu einem gewissen Grad mit dem Umstand begründen, dass er den Vertrauensvorschuss durch fahrlässiges Verhalten recht bald verspielte. Der Überblick über Phokas' Regierung hat allerdings auch deutlich gemacht, dass er sich als Kaiser insgesamt durch eine konservative Regierungspraxis auszeichnete: Bis auf wenige Ausnahmen, etwa der innovativen Darstellung auf Münzen, hielt er an den Handlungsmustern fest, wie sie sich im Laufe der zweihundert Jahre hauptstädtischer Monarchie als Instrumente der Herrschaftssicherung etabliert hatten. ${ }^{55}$ Die wiederholte Enttäuschung von Verhaltenserwartungen an den Kaiser in Kombination mit Phokas' Unfähigkeit, den Herausforderungen seiner Zeit mit innovativen Akzenten entgegenzutreten, bereitete die Grundlage dafür, dass Herakleios' Usurpation Erfolg haben konnte. Die Konzentration auf die Hauptstadt reichte offenbar nicht mehr aus, um den regierenden Kaiser gegen potentielle Herausforderer - vor allem Herausforderer von außerhalb - zu immunisieren.

\subsection{Vom sesshaften Kaiser zum Heerführer}

Wie bereits zu Beginn dieses Kapitels betont, lag Herakleios' zentrale Herausforderung darin, eine erneute Wiederholung des Szenarios zu verhindern, durch das er selbst auf den Thron gekommen war. Es galt, die Fehler, die Phokas Thron und Leben gekostet hatten, zu vermeiden und sowohl Konstantinopel als auch den militärischen

53 Als Phokas Maurikios' Witwe Konstantina aus der Hagia Sophia zu entfernen suchte (Theoph. Conf. AM 6098, [De Boor 293]), tat er genau das, was einige Jahre zuvor in Hinblick auf Maurikios die Stimmung in Konstantinopel hatte kippen lassen: die Missachtung des Kirchenasyls; im Gegensatz zu 602 kam Phokas aber damit davon.

54 Vgl. Mi. Whitby 2000a, 109: „Phocas seems to have been insensitive to the niceties of the emperor's ceremonial existence within the capital ...”

55 Vgl. Olster 1993, 184: „He [Phocas] appears as a typical sixth-century ruler confronted with challenges that traditional solutions could no longer solve.“ 
Sektor, der sich zuletzt vermehrt als Risikofaktor für die Stabilität monarchischer Herrschaft erwiesen hatte, unter Kontrolle zu halten. In diesem Zusammenhang traf Herakleios eine folgenschwere Entscheidung: Er begann, sich persönlich im militärischen Bereich zu betätigen. Während in der Forschung in der Regel seine späteren Kampagnen gegen die Perser, die mit der Rückgewinnung der Ostprovinzen endeten, im Fokus des Interesses stehen, wird im Folgenden deutlich, dass Herakleios bereits kurz nach seiner Krönung von etablierten monarchischen Verhaltensweisen abrückte, wiederholt die Hauptstadt verließ und sich persönlich an die Kriegsschauplätze begab.

Zwei gewaltsame Machtwechsel in weniger als einem Jahrzehnt hatten Hauptstadt und Reich destabilisiert. Nachdem sich das Kräftemessen der römischen und persischen Heere an der Ostgrenze über Jahre hinweg in der Waage gehalten hatte, zogen die Kämpfe in Ägypten, die mit der Revolte der Herakleioi einhergingen, wichtige Kräfte von der Front ab und schwächten die römische Verteidigung. Die Perser spielten ihren Vorteil aus: 609 eroberten Chosroes' Truppen den wichtigen Stützpunkt Edessa, im August 610 gelang die Überquerung des Euphrats. Die Lage verschärfte sich, als erneut Unruhen im römischen Heer ausbrachen: Wie bereits 602/03, als der General Narses sich gegen Phokas aufgelehnt hatte, reagierte auch 610/11 ein in Syrien stationierter Kommandeur mit Befehlsverweigerung auf den Machtwechsel in Konstantinopel: Komentiolos, Magister militum per Orientem und Bruder des gestürzten Phokas. $^{56}$

Die Revolten des Narses und Komentiolos unterscheiden sich von den militärischen Unruhen, die vor allem während der Regierung des Maurikios verstärkt aufgetreten waren und dessen Sturz mitbedingt hatten, insofern, als sie nicht in Folge unpopulärer kaiserlicher Entscheidungen (Soldkürzungen etc.) ausbrachen; stattdessen richteten sie sich gegen einen als inakzeptabel empfundenen Machtwechsel in Konstantinopel. ${ }^{57}$ Zumindest im Falle des Narses wird deutlich, dass er sich in seinem Handeln auf das gestützte Kaiserhauses - bzw. auf Theodosios als angeblich Überlebenden - berief; ${ }^{58}$ ähnliches wird man auch im Falle des Komentiolos vermuten können, auch wenn die Vita des Theodor von Sykeon als einzige Quelle dies nicht explizit macht. ${ }^{59}$ Für Komentiolos war die Revolte indes auch eine Flucht nach vorne,

56 Vit. Theod. Syk. 153; dazu Kaegi 1973, 312-316 und ders. 1981, 141-144; PLRE IIIA, Comentiolus 2 (326).

57 Laut Kaegi 1981, 139, 143 etablierte sich im Syrien-Heer im frühen 7. Jahrhundert eine Art „,conservative force”, die mit entschiedener Ablehnung auf die rasch aufeinander folgenden Machtwechsel in der Hauptstadt reagierte.

58 Dazu siehe oben S. 140.

59 Komentiolos' Revolte ist nur in Vit. Theod. Syk. 153 überliefert; die hauptstädtischen Quellen verschweigen sie. Dieser Befund lässt sich folgenermaßen erklären: Theodors Kloster in Sykeon war aufgrund seiner geographischen Nähe zu Ankyra direkt von der Anwesenheit des meuternden Heeres betroffen - die Gesandten aus Konstantinopel, die Komentiolos zum Aufgeben bewegen sollten, machten dort Station (siehe ebd.). Das Schweigen der hauptstädtischen Quellen könnte darauf hin- 
da ihm als Bruder des gestürzten Kaisers bewusst gewesen sein muss, dass seine Karriere, wenn nicht gar sein Leben unter dem neuen Regime verwirkt war; die ihm unterstellten Truppen bestanden zumindest teilweise aus dem ehemaligen Balkanheer, sodass eine gewisse Loyalität zu Phokas, der aus ihren Reihen stammte, nicht verwundert. ${ }^{60}$ Im Gegensatz zu Narses, der seine Truppen in Edessa gesammelt und keine Anstalten gemacht hatte, weiter gen Westen vorzurücken, führte Komentiolos das Syrienheer eigenmächtig zum Überwintern ins kleinasiatische Ankyra. Im Winter 610/11 stand also erneut ein aufständisches Heer nicht allzu weit von der Hauptstadt und gemahnte an die Geschehnisse des Herbstes 602, als der Druck des Balkanheeres, das auf Konstantinopel vorrückte, Maurikios' Sturz eingeleitet hatte. Obwohl immerhin der Bosporus die Soldaten unter Komentiolos' Befehl von Konstantinopel trennte, stellte die Revolte ein empfindliches Risiko für Herakleios' noch junge Herrschaft dar. ${ }^{61}$ Der Kaiser schickte mehrere Gesandtschaften, um mit Komentiolos zu verhandeln, der jedoch nicht auf die Friedensgesuche einging. Die Frage, ob Komentiolos tatsächlich plante, weiter Richtung Konstantinopel zu marschieren bzw. gar selbst einen Usurpationsversuch zu unternehmen, bleibt angesichts des jähen Endes der Revolte jedoch offen. ${ }^{62}$ Über den Hintergrund des Armeniers Justin, der Komentiolos des Nachts ermordete, ist weiter nichts bekannt. In jedem Fall hatte die Entwicklung in Kleinasien erneut gezeigt, wie dringend Herakleios den militärischen Sektor in den Griff bekommen musste. ${ }^{63}$ Die Meuterei des Syrien-Heeres zeitigte nicht nur innensondern auch außenpolitische Folgen: Im Laufe des Jahres 611 besetzten die Perser die syrischen Zentren Antiochia, Apamea und Emesa; unter Führung des Generals Shahin stieß ein persisches Kontingent gar über Armenien bis nach Kleinasien vor und besetzte Caesarea, die Hauptstadt Kappadokiens. ${ }^{64}$

weisen, dass die dem Herakleios wohlgesinnten Quellen diese unschöne Episode nach ihrer Beilegung lieber unerwähnt ließen.

60 Kaegi 1973, 313f. mit Anm. 13.

61 Siehe Kaegi 1973, 321f., der jedoch die Revolten des Narses und Komentiolos in einer Linie mit denen unter Maurikios, etwa der Monokarton-Revolte, liest.

62 Gemäß der Vit. Theod. Syk. 153, die bekanntlich erst nach Herakleios’ Tod vollendet wurde, kursierte zumindest das Gerücht, dass das Heer unter Komentiolos die Hauptstadt angreifen wolle (Festugière 1970, 128, Zeilen 49-52); dazu Kaegi 1973, 315.

63 Kaegi 1973, 317-319 verweist außerdem auf eine Reihe von Münzen, die darauf hindeuten, dass Herakleios' Herrschaft in Kleinasien zunächst alles andere als unumstritten war. Eine kleine Gruppe von Bronzemünzen (Folles) verzeichnet das 9. Regierungsjahr des Phokas; dieser wurde allerdings kurz vor dem Antritt seines 9. Jahres von Herakleios gestürzt. Anstatt diese Münzen der Prägestätten Antiochia und Kyzikos' als Fehlemissionen zu sehen, könnten sich in diesen auch die noch unklaren Machtverhältnisse des Winters 610/11 widerspiegeln. Kaegi bringt die These ein, dass lokale Prägestätten den Ausgang der Revolte des Komentiolos abwarteten, bevor sie schließlich auf die herakleischen Münztypen umstellten.

64 Zum Vorrücken der Perser siehe Flusin 1992 II, 70 - 83. Flusin diskutiert auch die komplizierte Quellenlage: Die verlässlichsten Informationen lassen sich den syrischen und auch armenischen Quellen entnehmen, während die griechischen - vor allem Theoph. Conf. - mit Vorsicht zu genießen sind. Zur Einnahme Caesareas siehe Vit. Theod. Syk. 153; Sebeos 33 - 34 (Thomson/Howard-Johnston I, 
Die Spannungen zwischen oströmischem Kaiser und hohen militärischen Funktionsträgern, die in Kapitel 2 bereits als einen maßgeblichen Faktor politischer Entscheidungsprozesse identifiziert wurden, lassen sich exemplarisch an den Entwicklungen des Sommers 612 verdeutlichen, als es im Feldlager bei Caesarea zum Showdown zwischen Herakleios und seinem ehemaligen Verbündeten Priskos kam. ${ }^{65}$ Nachdem Komentiolos ermordet worden war, fügten sich seine Truppen offenbar ohne weitere Probleme der hauptstädtischen Befehlsgewalt. Als neuen Kommandeur im Kampf gegen die Perser, die inzwischen Kleinasien bedrohten, bestellte Herakleios den Priskos. ${ }^{66}$ Priskos hatte einen wichtigen Beitrag zum Gelingen von Herakleios' Usurpation geleistet, indem er, schenkt man den Quellen Glauben, die Aufständischen über einen längeren Zeitraum hinweg mit Informationen über die Lage in Konstantinopel versorgte und sich im entscheidenden Moment, als Herakleios' Flotte im hauptstädtischen Hafen ankerte, mit den ihm untergebenen Exkubitoren gegen seinen Schwiegervater Phokas wandte. ${ }^{67}$ Herakleios zeigte sich erkenntlich, indem er Priskos nicht nur im Amt des Comes excubitorum beließ, ${ }^{68}$ sondern ihm darüber hinaus auch das Kommando als Magister militum per Orientem und damit die Befehlsgewalt über einen Großteil des römischen Feldheeres übertrug. Das Verhältnis zu dem erfahrenen Militär und Machtpolitiker Priskos, der in Konstantinopel als Patrikios über entscheidende Machtressourcen verfügte, stellte Herakleios allerdings vor ein Dilemma: Einerseits benötigte er gerade in der kritischen Anfangsphase seiner Herrschaft dessen Unterstützung - ihm blieb also kaum etwas anderes übrig, als Priskos' Machtbasis durch ein weiteres Kommando noch zu verbreitern; andererseits stellte Priskos, dessen Loyalität zum regierenden Kaiser sich bereits wiederholt als fragil erwiesen hatte, gerade aufgrund seiner Machtfülle für Herakleios ein schwer kalkulierbares Risiko dar.

Nachdem Priskos das Kommando gegen die Perser angetreten hatte, die im Laufe des Jahres 611 bis nach Kleinasien vorgedrungen waren, gelang es ihm, das vom persischen General Shahin befehligte Heer im kappadokischen Caesarea einzuschließen. Etwa ein Jahr dauerte die Belagerung an. Priskos' Chancen standen gut; angesichts der schlechten Versorgungslage der Perser ging man auf römischer Seite davon aus, dass ein Triumph nicht mehr allzu lange auf sich warten lassen würde. ${ }^{69}$ Doch es kam anders: Im Sommer des folgenden Jahres konnten die Perser unerwartet

64-66); Theoph. Conf. AM 6103 (De Boor 299); Mich. Syr. 11.1 (Chabot II, 400); Chron. 1234, 92 (Chabot I, 177f.); siehe Flusin 1992 II, 81-83.

65 Zu dieser Episode siehe Kaegi 1973, 325-328; ders. 1981, 145-147; ders. 2003, 68-71; Pfeilschifter 2013, 68-70; Raum 2019, 133f.,

66 Vit. Theod. Syk. 153; Nik. Brev. 2; ob dem Priskos tatsächlich das Amt des Magister militum per Orientem übertragen wurde, wird aus den Quellen nicht ganz deutlich; vgl. PLRE IIIB, Priscus 6 (10521057, hier 1057).

67 Siehe oben Kap. 3.2.

68 Vit. Theod. Syk. 153; zur späteren Absetzung des Priskos siehe Chron. Pasch. AD 612; Vit. Theod.

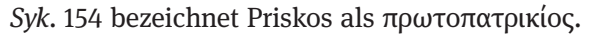

69 Zur Erwartung eines römischen Triumphes siehe Vit. Theod. Syk. 153. 
aus der Befestigung ausbrechen und sich, von den Römern ungehindert, auf heimatliches Gebiet durchschlagen. ${ }^{70}$

In diesem Zusammenhang traf Herakleios eine überraschende Entscheidung. Etwa eineinhalb Jahre nach seiner Krönung verließ er erstmals Konstantinopel und machte sich auf den Weg zu den römischen Truppen nach Caesarea - laut Nikephoros, um sich mit Priskos zu beraten, der sich dort weiterhin aufhielt. ${ }^{71}$ Der Zeitpunkt erweist sich als bewusst gewählt: Nach dem Misserfolg gegen die Perser war Priskos' Stellung angekratzt; Herakleios nutzte seinerseits die Gelegenheit, um die Machtfülle des erfahrenen Generals einzuhegen und die kaiserliche Autorität über den militärischen Sektor zu betonen. Im Feldlager kam es allerdings zum Eklat: Während die Soldaten Herakleios' Präsenz sicherlich begrüßten, machte Priskos deutlich, dass ihm das kaiserliche Eindringen in seinen Zuständigkeitsbereich überhaupt nicht gefiel. Seine Reaktion auf den hohen Besuch, wie sie Nikephoros' Breviarium überliefert, hätte deutlicher kaum sein können. Der General begegnete Herakleios geradezu mit Respektlosigkeit; er entzog sich dessen Gesprächsgesuchen, indem er sich krankstellte, und lästerte gar öffentlich gegen den Kaiser: „Aber der andere [i.e. Priskos] sagte, wie im Scherz, dass es sich für den Kaiser nicht gebühre, den Palast zu verlassen und unter den weit entfernten Streitkräften zu verweilen. “72 Das Zitat - egal ob man es als authentisch wertet oder nicht - trifft die strukturellen Charakteristika oströmischer Monarchie an der Wende vom 6. zum 7. Jahrhundert mit einer Präzision und gleichzeitig Abstraktion auf den Punkt, die man in den Quellen meist vergeblich sucht. ${ }^{73}$ Wie bereits im Zusammenhang mit Maurikios' Versuchen, sich einige Jahrzehnte zuvor

70 Zur Belagerung Caesareas durch Priskos und dem Ausbruch der Perser siehe Vit. Theod. Syk. 153; Sebeos 34 (Thomson/Howard-Johnston I, 66): mit Angabe der Dauer (ein Jahr) und Zeitpunkt des Ausbruchs (offenbar Frühsommer); siehe dazu Kaegi 1973, 324- 328 und Flusin 1992 II, 81-83.

71 Nik. Brev. 2. Dies mag in der Tat der offiziell verlautbarte Anlass gewesen sein (vgl. Vit. Theod. Syk. 154). Die Belagerung Caesareas wird bei Nikephoros allerdings nicht erwähnt. Keine der Quellen macht explizit, dass Herakleios sich erst nach dem Ausbruch der Perser nach Caesarea begab; dies ist allerdings der plausibelste Ablauf und erklärt auch, warum Nikephoros den Kontext des Besuches nicht erwähnt - die Perser waren bei Herakleios’ Ankunft bereits über alle Berge (im wahrsten Sinne des Wortes). Vit. Theod. Syk. thematisiert Herakleios' Abstecher nach Caesarea (154) nach der Belagerung der Stadt durch Priskos (153); siehe Kaegi 1973, 325 zur Chronologie. Folgt man dem Bericht der Vit. Theod. Syk. 154, könnte Herakleios' Aufbruch gar ein recht spontaner gewesen sein - also in direkter Reaktion auf das Eintreffen der Nachricht vom Ausbruch der Perser. Die Vita schildert nämlich, dass Herakleios und Sergios den Heiligen Theodor nach Konstantinopel eingeladen hatten; als dieser in der Hauptstadt eintraf, habe sich herausgestellt, dass Herakleios vor kurzem nach Caesarea aufgebrochen war. Wäre Herakleios' Besuch länger geplant gewesen, ist davon auszugehen, dass Theodor, dessen Kloster an einem der wichtigsten Postrouten durch Kleinasien lag, davon in Kenntnis gesetzt wurde und seine Reise nach Konstantinopel angepasst hätte; siehe dazu Kaegi 1973, 327. Zur absoluten Chronologie siehe unten S. 155 Anm. 75.

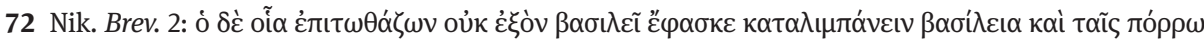

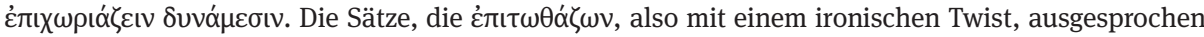
werden, treffen die Gemengelagen, auf die sie sich beziehen, ja bekanntlich oft besonders gut.

73 Vgl. Pfeilschifter 2013, 69. 
persönlich als Feldherr zu engagieren, ${ }^{74}$ so tritt auch hier wieder zu Tage, wie fest die Bindungen waren, die die oströmischen Kaiser an das hauptstädtische Umfeld ketteten. Priskos interpretierte Herakleios' Vorstoß ganz richtig: Er sah sich durch dessen Besuch in seinem Kompetenzbereich, dem militärischen Sektor, gestört; in Reaktion darauf versuchte er, den Kaiser mit Verweis auf vorherrschende Verhaltenserwartungen in dessen Schranken zu verweisen, räumlich umrissen durch den hauptstädtischen Palast.

Ohne die genauen Abläufe des Aufeinandertreffens zwischen Priskos und Herakleios im Feldlager bei Caesarea im Detail nachvollziehen zu können, lässt sich festhalten, dass der Kaiser letztendlich am längeren Hebel saß: Er beorderte bei seinem eigenen Abzug aus Caesarea auch den General in die Hauptstadt zurück; diesem blieb offenbar nichts anderes übrig, als sich zu fügen. ${ }^{75}$ Doch das Ringen zwischen Kaiser und Feldherr war damit noch nicht zu Ende; die letzte Runde wurde nach beider Rückkehr nach Konstantinopel im Herbst 612 eingeläutet. Erneut ist es Nikephoros, der den ausführlichsten Bericht liefert: Unter dem Vorwand, ihn zum Paten seines neugeborenen Sohnes Herakleios Konstantin zu machen, soll Herakleios Priskos in den Palast gebeten haben; dort stellte er ihn vor dem Patriarchen, den Mitgliedern des Senates und Vertretern des Volkes bloß, enthob ihn seiner Ämter und ließ ihn vom Patriarchen zum Kleriker weihen. ${ }^{76}$

Der von Nikephoros dargelegte Ablauf erscheint plausibel. Die Aussicht, Priskos zum Paten des männlichen Erstgeborenen des Kaisers zu machen, entspricht Mustern,

74 Dazu siehe oben S. $74 \mathrm{f}$.

75 Eine gemeinsame Rückkehr legt Nik. Brev. 2 nahe; die Rückkehr erfolgte laut Nikephoros, da Herakleios ein Sohn geboren worden war und sein Cousin Niketas in Konstantinopel eintraf. Diese Verbindung ist allerdings unwahrscheinlich, wenn man davon ausgeht, dass Herakleios sich erst nach dem Ausbruch der Perser in Caesarea einfand und der Ausbruch sich im (Früh-)Sommer 612 ereignete denn Herakleios Konstantin wurde bereits am 3. Mai 612 geboren (Chron. Pasch. AD 612; Theoph. Conf AM 6103 [300]). Vit. Theod. Syk. 154 legt außerdem nahe, dass sich Niketas bereits in Konstantinopel befand, als Herakleios in Caesarea weilte - anstatt auf Herakleios zu treffen, trat der Heilige in Konstantinopel mit Niketas in Kontakt und heilte diesen von einer Krankheit; als Herakleios sich der Stadt näherte, ritt Niketas ihm entgegen; siehe dazu Kaegi 1973, 325 f. Folgende Chronologie lässt sich für die Caesarea-Episode meiner Ansicht nach plausibel rekonstruieren. Sommer 611: Perser werden in Caesarea eingeschlossen; (Früh-)Sommer 612: Ausbruch der Perser nach etwa einem Jahr (siehe Sebeos 34 [Thomson/Howard-Johnston I, 66]); kurz darauf Ankunft des Herakleios; Spätsommer/Frühherbst 612: Rückkehr des Herakleios (und Priskos) nach Konstantinopel. Der Zeitpunkt der Rückkehr wird in den Quellen nicht spezifiziert; am 4. Okt. 612 wurde allerdings Epiphania, Herakleios' erstgeborene Tochter, gemäß Chron. Pasch. AD 612 in Konstantinopel zur Augusta gekrönt. Obwohl Chron. Pasch. Herakleios' Teilnahme am Krönungsritual nicht explizit macht, ist doch davon auszugehen, dass der Kaiser auf seine Anwesenheit bei einem derart wichtigen öffentlichen Ereignis Wert legte (den Termin konnte er ja selbst festlegen). Das Chron. Pasch. gibt außerdem an, Priskos sei am 5. Dez. seines Amtes als Comes excubitorum entkleidet worden (vgl. Nik. Brev. 2); allerspätestens dann waren also beide wieder aus Caesarea zurück.

76 Nik. Brev. 2; Priskos' Absetzung und seine Exilierung ins Kloster werden durch das zeitgenössische Chron. Pasch. AD 612 bestätigt, das allerdings zum Kontext (Herakleios’ Abstecher nach Caesarea und die Auseinandersetzung zwischen den beiden Männern) schweigt. 
die in Kapitel 2 als typisch für die oströmische Monarchie herausgearbeitet wurden: Herausragende Militärs konnten ihr soziales Prestige nutzen, um sich mit dem Kaiserhaus zu verbinden und dadurch ihren Einfluss noch zu vergrößern. Phokas hatte Prikos bereits seine einzige Tochter zu Frau gegeben; Herakleios stellte dem mächtigen General nun, trotz bestehender Unstimmigkeiten, in Form der Patenschaft eine Verbindung mit dem neuen Kaiserhaus in Aussicht. ${ }^{77}$ Doch während Herakleios im Feldlager, dem Kompetenzbereich des Generals, offenbar nicht viel gegen Priskos hatte ausrichten können, standen ihm nun, zurück im hauptstädtischen Umfeld, mehr Möglichkeiten zur Verfügung; er konnte sich des Störfaktors, als welcher Priskos sich erwiesen hatte, entledigen. Priskos' Absetzung, die Ermächtigung des Kaisers gegenüber dem militärischen Funktionsträger, fand im Palast vor Vertretern der Gruppen statt, auf deren Akzeptanz Herakleios angewiesen war. Durch ihre Anwesenheit sanktionierten Senat und Vertreter des Volkes diesen Akt; Herakleios setzte ein deutliches Zeichen kaiserlicher Autorität. An Priskos' Stelle übertrug er das Amt des Comes excubitorum seinem Cousin Niketas. ${ }^{78}$ Als Oberbefehlshaber über das Heer im Osten ernannte der Kaiser seinen Bruder Theodor; außerdem rehabilitierte er Philippikos, den Schwager des Maurikios, der nach erfolgreicher militärischer Karriere von Phokas exiliert worden war. ${ }^{79}$

Nach der Konfrontation im Palast stellte Herakleios sich Priskos' Privatgarden, den Bukellariern, und verkündete, diese unter guten Konditionen in die kaiserlichen Kontingente einzugliedern: Die Soldaten ihrerseits begrüßten den neuen Dienstherren mit Akklamationen. ${ }^{80}$ Bukellarier, zahlenmäßig starke Privattruppen, die auch innerhalb der Stadtmauern Konstantinopels agierten und nicht direkt der kaiserlichen Befehlsgewalt unterstanden, konnten politischen Akteuren als Druckmittel gegenüber dem Monarchen dienen. Als Priskos sich etwa im Oktober 610 gegen Phokas positioniert hatte, hatte er nicht nur die Exkubitoren, sondern auch seine Bukellarier zusammengezogen und mit diesen Truppen in die gewaltsamen Auseinandersetzungen eingegriffen, die in den Häfen entbrannt waren. ${ }^{81}$ Indem Herakleios die Privatgarde des Priskos nun an seine Person band, neutralisierte er deren widerständiges Potential.

Mit Prikos’ Absetzung hatte Herakleios einen ernstzunehmenden Konkurrenten aus dem Weg geschafft; doch in Hinblick auf die Sicherung des militärischen Sektors

77 Die Taufe des Herakleios Konstantin erfolgte in der Tat kurz darauf (Nik. Brev. 5).

78 Chron. Pasch. AD 612 gibt das Datum von Priskos’ Absetzung den 5. Dez. 612 an. Vit. Theod. Syk. 154 hingegen adressiert Niketas bereits mit dem Titel des Comes excubitorum, als Herakleios sich noch mit Priskos in Caesarea befindet; dabei handelt es sich aber aller Wahrscheinlichkeit nach um eine Ungenauigkeit: die Übertragung des Amtes an Niketas kann plausibel nur nach der Absetzung des Priskos stattgefunden haben, wie sie in Chron. Pasch. und Nik. Brev. 2 konsistent geschildert wird; siehe dazu Kaegi 1973, 327 f. Zu Niketas vgl. außerdem PLRE IIIB, Niketas 7 (940 - 943) und Rapp 2004.

79 PLRE IIIB, Theodorus 163 (1277-1279); PLRE IIIB, Philippicus 3 (1022-1026). Vgl. Kaegi 2003, 70 f. zu den Ämterbesetzungen.

80 Nik. Brev. 2.

81 Zu den Bukellariern siehe oben S. 43-45; zu Priskos’ Eingreifen in die Kämpfe siehe oben S. 101103. 
reichte ihm dies offenbar nicht aus. Kein Jahr, nachdem er aus Caesarea zurückgekehrt war, verließ Herakleios erneut die Hauptstadt, um diesmal noch weiter nach Osten vorzudringen: Im Frühjahr 613 brach er gemeinsam mit seinem Bruder Theodor gen Syrien auf, wo sich die Perser bereits seit mehreren Jahren festgesetzt hatten. ${ }^{82}$ Doch es zeigte sich rasch, dass das römische Heer der persischen Übermacht kaum etwas entgegenzusetzen hatte. Eine Schlacht nahe Antiochia endete für die Römer in einer desaströsen Niederlage. Auch bei den Kilikischen Pforten unterlagen die kaiserlichen Truppen, sodass die Perser Tarsos einnehmen konnten. Nachdem die römische Verteidigung Syriens zusammengebrochen war, stand Chosroes' Truppen auch der Weg nach Palästina offen. ${ }^{83}$ Die Armenische Geschichte des Sebeos als einzige Evidenz für die Syrien-Episode gibt keinen Hinweis auf Herakleios' weiteren Verbleib; es ist allerdings davon auszugehen, dass dieser sich unter dem Eindruck der Niederlage auf den Rückweg nach Konstantinopel machte.

Im Zusammenhang mit dieser Kampagne ist zunächst eine Beobachtung zu machen, die Herakleios' Umgang mit Heiligen Männern betrifft. Die Vita des Theodor von Sykeon berichtet, wie Herakleios seine Reise von Konstantinopel nach Syrien unterbrach, um dem Heiligen während der Fastenzeit in dessen Kloster einen Besuch abzustatten. Nachdem die beiden Männer gemeinsam in der Kirche gebetet hatten, drängte Herakleios jedoch auf einen raschen Aufbruch; weder Theodors Geschenke habe Herakleios annehmen wollen noch dessen Einladung zum gemeinsamen Essen; stattdessen vertröstete er den Heiligen mit dem Versprechen eines erneuten Besuches auf dem Rückweg von Syrien. Enttäuscht von einer derart harschen Behandlung habe Theodor nicht nur Herakleios' Niederlage gegen die Perser prophezeit, sondern darüber hinaus festgestellt, dass diese durch die Annahme der gesegneten Geschenke hätte verhindert werden können. ${ }^{84}$ Theodor verstarb am 22. April 613, also noch bevor Herakleios Sykeon auf seinem Rückweg von Syrien passierte.

Diese Episode befremdet: Warum schlug Herakleios Theodors Angebote aus? Walter E. Kaegi meint, dass der Kaiser gegenüber dem Heiligen Vorbehalte gehegt habe, da dieser eine enge Verbindung zur Familie seines Vorgängers Phokas pflegte. ${ }^{85}$ Eine derartige Deutung überzeugt allerdings nicht, da verschiedene Gelegenheiten überliefert sind, bei denen Herakleios sich dezidiert um ein Nahverhältnis mit Theodor bemühte: Er ehrte ihn nicht nur durch ein privates Treffen im kaiserlichen Palast kurz nach seiner Rückkehr aus Caesarea, ${ }^{86}$ sondern ließ auch Theodors Überreste nach dessen Tod in die Hauptstadt überführen; ein anlässlich dieser Translation

82 Laut Vit. Theod. Syk. 166 begleitete ihn Niketas, laut Sebeos 34 (Thomson/Howard-Johnston I, 68) sein Bruder Theodosios.

83 Sebeos 34 (Thomson/Howard-Johnston I, 68); zu der Kampagne von 613 siehe Stratos 1968, 105107; Kaegi 1973, 328f. und ders. 2003, 75-77; außerdem Greatrex/Lieu 2002, $189 \mathrm{f}$.

84 Vit. Theod. Syk. 166. Hierbei handelt es sich um ein für hagiographische Literatur typisches Vaticinium ex eventu; siehe auch Van Ginkel 2002, 231.

85 Kaegi 2003, 76.

86 Vit. Theod. Syk. 155. 
verfasstes Enkomium schildert, wie der Kaiser den Reliquien persönlich einen gebührenden Empfang bereitete. ${ }^{87}$ Wie bereits sein Vorgänger versuchte also auch Herakleios, von der spirituellen Autorität des Heiligen Theodor zu profitieren.

Der Gehalt dieser Episode wird deutlich, wenn man die narrative Strategie der Vita einkalkuliert. ${ }^{88}$ Ziel einer jeden Hagiographie war es, die Heiligkeit und spirituelle Wirkmächtigkeit des Protagonisten unter Beweis zu stellen; dies konnte durch die Aneinanderreihung von Wundererzählungen geschehen, durch die Zuschreibung von Prophezeiungen wie der obigen (Vaticinia ex eventu), die sich dann selbstverständlich bewahrheiten, aber auch, indem Ereigniszusammenhänge mit einer spezifischen Deutung belegt bzw. gar zu einem gewissen Grad in ihrem Wahrheitsgehalt gebeugt wurden. Das Grundgerüst der Geschehnisse des Frühjahrs 613 ist Folgendes: Herakleios besuchte Theodor auf seinem Weg nach Syrien; dort erlitt er eine Niederlage und kehrte nach Konstantinopel zurück. Dass Herakleios direkt nach seinem Besuch in Sykeon eine Niederlage erlitt, spricht - denkt man entlang hagiographischer Erzählstrategie - nicht unbedingt für die spirituelle Wirkmächtigkeit des Heiligen. Um die ,Verantwortung“ von Theodor abzuwälzen, konstruierte der Autor der Vita - so die These - eine alternative Erzählung, in der Herakleios dessen Segensgaben mutwillig zurückwies und damit seine Niederlage einleitete. In Herakleios' Ablehnung der Speisung könnte man indes einen wahren Kern vermuten. Die mit dem Kaiser reisenden Soldaten mussten auf dem Weg nach Syrien versorgt werden, was zum größten Teil durch lokale Kapazitäten geleistet wurde; der Kaiser könnte den Heiligen und dessen Kloster als Zeichen der Wertschätzung von der Pflicht der Truppenversorgung entbunden haben. Herakleios' Entgegenkommen wurde - folgt man der These Jahrzehnte später durch den Hagiographen als Zurückweisung umgedeutet.

Über das Treffen mit Theodor hinaus gibt das kaiserliche Engagement in Syrien allerdings auch Anlass für weitere Überlegungen, da es die Risiken von Herakleios' persönlichem Engagement als Heerführer verdeutlicht. Während der Aufenthalt des Kaisers bei den römischen Truppen in Caesarea 612 nicht - soweit rekonstruierbar mit Kampfhandlungen einhergegangen war, stellte sich das römische Heer unter Herakleios' Befehl im darauffolgenden Jahr den persischen Aggressoren und wurde dabei zwei Mal in Folge geschlagen. Wie nah Herakleios den konkreten Kampfhandlungen in Syrien kam, tut für die hier gewählte Perspektive nichts zur Sache. Als wichtiger erweist sich folgender Umstand: Indem er im Gegensatz zu seinen Vorgängern wieder persönlich als Heerführer fungierte, konnte Herakleios in weit höherem Maße als in den Jahrhunderten der sesshaften Kaiser in der Wahrnehmung der Öffentlichkeit für die Niederlage der römischen Truppen verantwortlich gemacht werden.

Darüber, wie das Syrien-Debakel in Konstantinopel aufgenommen wurde, schweigen die Quellen; in hauptstädtischen Texten findet die Episode überhaupt

87 Zum Enkomium siehe Kirch 1901.

88 Ich verdanke diese Idee einem Gespräch mit Efthymios Rizos in Oxford. 
keine Erwähnung. ${ }^{89}$ Insofern lassen sich dahingehend nur abstrakte Überlegungen anstellen. Felix K. Maier hat in seiner Habilitationsschrift den Prozess nachvollzogen, der in einer hauptstädtischen Konfiguration von Monarchie mündete und damit das politische System Ostroms über zwei Jahrhunderte maßgeblich prägte. Entlang seines Paradigmas des Imperator-Dilemmas ${ }^{90}$ hat er einen Sachverhalt, der in der Forschung bereits wiederholt beobachtet wurde, in seiner Entwicklungslogik beleuchtet: Über Jahrhunderte hinweg hatte die Idee eines Basileus polemikos - eines Kaisers, der sich persönlich auf dem Schlachtfeld engagierte und dadurch die Propagatio imperii vorantrieb - die Herrschaftspraxis wie die Erwartungen an die römischen Kaiser geprägt. Dieses Ideal konnte im Laufe des vierten Jahrhunderts allerdings nicht mehr aufrechterhalten werden, als erhöhter außenpolitischer Druck und innerrömische Zerwürfnisse aggressive Kriegsführung zunehmend riskant machten. ${ }^{91}$ Um politischer Instabilität als Folge militärischer Niederlagen vorzubeugen, verlegten sich die Kaiser vermehrt auf diplomatische Mittel - und enttäuschten damit die an sie gerichteten Verhaltenserwartungen. Das Sesshaftwerden in Konstantinopel - ein Prozess, der nach Maier bereits unter Theodosios I. eingeleitet wurde ${ }^{92}$ - bot den Kaisern neue Positionierungsmöglichkeiten jenseits von persönlichem militärischem Engagement; als ewige Sieger repräsentiert, konnten sich die nichtkriegerischen Kaiser zu einem gewissen Grad gegen die Konsequenzen militärischer Niederlagen immunisieren. ${ }^{93}$ Mit der hauptstädtischen Konfiguration von Monarchie ging, so der Konsens der Forschung, eine Stabilisierung kaiserlicher Herrschaft einher. ${ }^{94}$ Nach zwei gewaltsa-

89 Die hauptstädtischen Quellen, die allesamt nach Herakleios' Sieg über die Perser 628 entstanden sind, können es sich leisten, diese unrühmliche Episode der frühen Regierungsjahre einfach zu verschweigen. Die Frage, wie eine römische Niederlage wahrgenommen wurde und wie der Kaiser diese zu bewältigen suchte, wird an späterer Stelle in Zusammenhang mit der Schlacht am Yarmuk 636 genauer diskutiert. Allgemein zur Wahrnehmung und Bewältigung militärischer Niederlagen vgl. Stoll 2016. 90 Eine Definition findet sich in Maier 2019, 7.

91 Die Kaiser Julian und Valens fielen im Kampf: Ersterer während des Perserfeldzuges 363, Letzterer bei der Schlacht von Adrianopel 378. Zu Umgestaltung politischer Hierarchien aus prekären Situationen (Niederlagen) heraus siehe Maier 2019, $339 \mathrm{f}$.

92 Maier 2019, zusammenfassend 451-462; vgl. auch oben S. $31 \mathrm{f}$.

93 Zur spätantiken Siegesideologie siehe vor allem McCormick 1986. Es ist an dieser Stelle festzuhalten, dass die militärische Performance des römischen Heeres durchaus auch Einfluss auf die sesshaften Kaiser zeitigen konnte: Einerseits dienten errungene Siege dem kaiserlichen Prestige (zur Aneignung militärischer Siege durch die sesshaften Kaiser siehe oben S. 64-66); andererseits gingen auch Niederlagen nicht gänzlich an ihnen vorbei. Der Kaiser wurde weiterhin als Garant für das Wohl des Reiches verstanden; in einem christlichen Deutungsrahmen konnten Extremzustände wie etwa militärische Niederlagen und deren Folgen für die Bevölkerung den Schluss nach sich ziehen, der Kaiser habe die Gunst Gottes verspielt und damit Unglück übers römische Reich gebracht - und eine derartige Wahrnehmung konnte wiederum Akzeptanzverlust nach sich ziehen. Militärische Niederlagen konnten außerdem auch ganz konkrete Auswirkungen auf die politische Hierarchie Konstantinopels zeitigen: Nachdem die Perser 574 die Grenzfestung Dara eingenommen hatten, konnte Justin II. sich nicht mehr an der Macht halten und musste - folgt man der oben S. 69f. dargelegten Argumentation - dem Tiberios das Feld räumen.

94 Dazu siehe oben S. $27 \mathrm{f}$. 
men Machtwechseln in Folge, die im Militär ihren Ursprung genommen hatten, schien das Verweilen in Konstantinopel allerdings im frühen 7. Jahrhundert für den Kaiser keine praktikable Option mehr - vor allem angesichts eines erneut entflammten Konfliktes mit den Persern; zu groß war die Gefahr einer erneuten Aggression von Seiten der Truppen bzw. exponierter Feldherren. Mit seiner Remilitarisierung - indem er erneut als Basileus polemikos das Kommando über die Truppen übernahm - versuchte Herakleios, eine Antwort auf diese Entwicklung zu geben. Die Immunisierung gegen militärische Niederlagen, die die sesshaften Kaiser zu einem gewissen Grad hatten aufrecht erhalten können, setzte er dabei allerdings aufs Spiel; die Imago des ewigen Siegers war mit der Realität eines in der Schlacht gegen die Perser unterlegenen Kaisers schwer vereinbar.

Herakleios war nach seiner erfolgreichen Usurpation darum bemüht, die kaiserliche Autorität über den militärischen Sektor wiederherzustellen und damit einem erneuten Machtwechsel - bzw. dem Versuch eines militärischen Funktionsträgers, einen solchen einzuleiten - vorzubeugen. Der desaströse Ausgang der Kampagne von 613 machte allerdings die Risiken allzu deutlich, die für den Kaiser mit persönlicher Kriegführung einhergingen: Eine Niederlage hatte das Potential, die prekäre Akzeptanzgrundlage in der Hauptstadt weiter zu schwächen. Soweit den Quellen zu entnehmen, gab es in Folge der Syrien-Episode keinen ernstzunehmenden Versuch, Herakleios' Herrschaft etwa durch erneute Meutereien oder gar eine Usurpation in Frage zu stellen. Doch der Kaiser ruderte dennoch zurück: Vorerst sah er von einem erneuten Engagement als Heerführer ab und konzentrierte sich auf Konstantinopel. Es sollte beinahe ein Jahrzehnt dauern, bis er die Hauptstadt erneut verließ.

\subsection{Eine Dynastie im Entstehen}

Während der Ansturm der Perser im Osten des Reiches kaum unter Kontrolle gebracht werden konnte, begann Herakleios seine Basis in bzw. von Konstantinopel aus zu sichern und setze dabei besonders in dem Bereich der Familienpolitik bemerkenswerte Akzente. Wie seine Vorgänger war auch er nach seiner Erhebung darum bemüht, ein durch klare Loyalitätsbeziehungen konstituiertes Umfeld aufzubauen und die wichtigsten (vor allem militärischen) Ämter mit Vertrauten, wenn nicht gar Verwandten, zu besetzen. Nach Priskos' Entmachtung rückte - wie oben geschildert Herakleios' Cousin, der Patrikios Niketas, in das Amt des Comes excubitorum nach; ${ }^{95}$ seine Loyalität hatte Niketas bereits vor dem Machtwechsel von 610 unter Beweis gestellt, als er im Auftrag der Herakleioi Ägypten sicherte. ${ }^{96}$ Niketas war allerdings nicht nur in militärischer Mission aktiv: Quellen belegen, dass er in Ägypten auch

95 Chron. Pasch. AD 612.

96 Dazu siehe oben S. 95. 
administrative Autorität genoss und gar in religiöse Angelegenheiten eingriff. ${ }^{97}$ Über die Vergabe zentraler Ämter hinaus zeigte Herakleios sich bemüht, die Bande zu seinem Cousin weiter zu stärken, indem er diesen zum Paten seines erstgeborenen Sohnes Herakleios Konstantin machte. ${ }^{98}$ Anlässlich der Taufe wurde Herakleios Konstantin außerdem mit Niketas’ Tochter Gregoria verlobt; die Ehe wurde im Jahr 630 geschlossen. ${ }^{99}$ Selbst im Stadtbild Konstantinopels fand das enge Verhältnis der beiden Cousins Ausdruck: Auf einem der hauptstädtischen Fora ließ Herakleios dem Niketas eine auf Säulen thronende Reiterstatue errichten - eine außergewöhnliche Ehrung, die in derartiger Form in der Regel dem Kaiser vorbehalten war. ${ }^{100}$ Den Oberbefehl über die im Osten stationierten Truppen, der anfänglich weiterhin von Priskos vereinnahmt worden war, übertrug Herakleios an seinen Bruder Theodor, der bereits das zivile Amt des Curopalates innehatte - ein weiteres Beispiel dafür, dass militärische und zivile Kompetenzen sich nach einer Phase der formal strikteren Trennung nun wieder zunehmend $\mathrm{zu}$ vermischen begannen. ${ }^{101}$ Außerdem rehabilitierte Herakleios den Philippikos, einen erfahrenen Militär und Schwager des Maurikios, der von Phokas exiliert worden war. ${ }^{102}$ Dass Herakleios' Netzwerk auch über den militärischen Sektor bzw. das direkte hauptstädtische Umfeld hinausging, verdeutlicht das Beispiel des Johannes, Patriarch von Alexandria: Als Sohn einer einflussreichen zypriotischen Familie wurde Johannes ohne klerikale Vorgeschichte 609/610 auf Niketas' Drängen hin zum Patriarchen geweiht. Als die persische Invasion Flüchtlinge

97 Siehe PLRE IIIB, Niketas 7 (940 - 943). In der Regel geht die Forschung davon aus, dass Niketas das Amt des Praefectus augustalis von Ägypten besetzte und als solcher auch an der Schlichtung von Auseinandersetzungen zwischen den miaphysitischen Gemeinden von Alexandria und Antiochia beteiligt war (dazu explizit Olster 1985); siehe etwa Rapp 2004, 124 und Kaegi 2003, 53.

98 Siehe Rapp 2004, 132f.; die Quelle, auf die Rapp sich bezieht (Nik. Brev. 5), erwähnt an keiner Stelle explizit, dass Niketas als Pate des Jungen fungierte. Dass es sich so verhielt, ist allerdings durchaus plausibel - auch vor dem Hintergrund, dass zuvor dem Priskos die Patenschaft versprochen worden war (Nik. Brev. 2); nach Priskos’ Absetzung wäre Niketas demnach nicht nur ins Amt des Comes excubitorum nachgerückt, sondern auch als Pate des designierten Thronfolgers. Rapp schlägt außerdem vor, dass gemeinsam mit Niketas auch Johannes, der Patriarch von Alexandria, als Pate des Herakleios Konstantin fungierte und sich demnach 612/613 auch in Konstantinopel aufhielt (Rapp 2004, 131-133); dies ist allerdings anhand der erhaltenen Quellen nicht eindeutig belegbar.

99 Nik. Brev. 5 (Verlobung); Nik. Brev. 17 (Eheschließung).

100 Nik. Brev. 5; vgl. Mango 1990, 175 f.; der Reiterstatue sind wohl zwei Epigramme aus der Anthologia

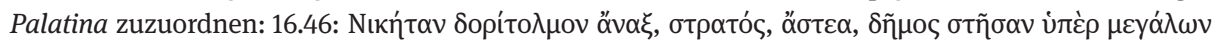

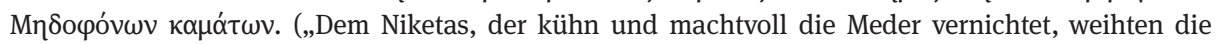

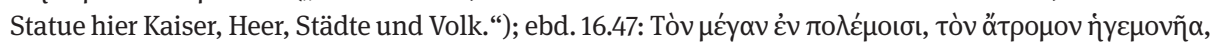

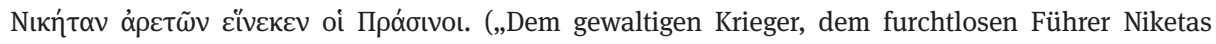
weihte, der Größe zum Ruhm, dieses die Grüne Partei.“). Auf welchen Sieg über die Perser sich das erste Epigramm bezieht, bleibt unklar.

101 PLRE IIIB, Theodorus 163 (1277-1279); vgl. zu militärischen und zivilen Karrieren S. $39 \mathrm{f}$.

$102 \mathrm{Zu}$ Philippikos siehe Sebeos 34 (Thomson/Howard-Johnston I, 67); Nik. Brev. 2; vor dessen Bestellung zum Feldherrn hatte Herakleios den Philippikos bereits im Zusammenhang mit der Revolte des Komentiolos als Boten mit einem Friedensangebot nach Ankyra geschickt; siehe Vit. Theod. Syk. 152; PLRE IIIB, Philippicus 3 (1022-1026); siehe Kaegi 2003, 70 f. zu den Ämterbesetzungen. 
aus der Levante nach Ägypten trieb, übernahm Johannes an Niketas’ Seite auch administrative Aufgaben. ${ }^{103}$

Die kaiserlichen Bemühungen, die eigene Familie zu stärken, äußerten sich über besagte Ämterbesetzungen hinaus ganz besonders darin, dass Herakleios seine Kinder in außerordentlichem Maße in den Fokus der Öffentlichkeit rückte. Seine Frau Eudokia gebar am 7. Juli 611 eine Tochter, Epiphania, und am 3. Mai 612 einen Sohn, Herakleios den Jüngeren, der den Beinamen „Neuer Konstantin“ trug. Nach dem frühen Tod Eudokias im August 612 wurde ihre Tochter Epiphania am 4. Oktober desselben Jahres in der Stephans-Kapelle im Palast zur Augusta gekrönt. ${ }^{104} \mathrm{Am}$ 22. Januar 613 schließlich krönte Herakleios ebendort auch seinen knapp einjährigen Sohn Herakleios Konstantin zum Augustus. Der Krönung war die Taufe des Jungen im Palast vorausgegangen. ${ }^{105}$

Dass römische Kaiser ihre leiblichen Söhne zum Augustus erhoben und damit die Nachfolge indizierten, war durchaus gängige Praxis. Theodosios I. verfuhr derart mit seinen beiden Söhnen Arkadios und Honorios; Arkadios krönte seinen Sohn Theodosios II. und auch Maurikios, der nach Arkadios erstmals wieder einen Sohn hatte, welcher das frühe Kindesalter überlebte, verfuhr dementsprechend. ${ }^{106}$ Dynastische Bindungen wogen in Hinblick auf monarchische Sukzession weiterhin schwer. ${ }^{107}$ Doch selbst vor diesem Hintergrund erfolgte die Designation in Herakleios' Fall bemerkenswert früh - Herakleios Konstantin war bei seiner Krönung noch nicht einmal ein Jahr alt. In Bezug auf die Designation von Maurikios' Sohn Theodosios wurde bereits herausgearbeitet, dass diese zu einem Zeitpunkt erfolgte, als der Kaiser sich dazu genötigt sah, seine Herrschaft abzusichern: Unruhen in Persien ließen Maurikios keine andere Wahl, als mit den römischen Truppen in den Konflikt einzugreifen; bewaffnete Auseinandersetzungen mit dem Erzfeind bargen allerdings das Risiko, die

103 Zu Johannes’ Aktivitäten in Ägypten siehe Van Ginkel 2002, 232-234; Kaegi 2003, 80 f. und Rapp 2004. Zu der hagiographischen Tradition zu Johannes dem Almosengeber siehe oben S. 19. Rapp arbeitet heraus, dass Niketas und Johannes durch die rituellen Verwandtschaftsbeziehungen der adelphopoiesis und synteknia miteinander verbunden waren (siehe ebd., bes. 124 f.; vgl. Kaegi 2003, 59). Sie betont außerdem die Erklärungsnot der Hagiographen, Johannes als eher untypischem Heiligem Mann im Rahmen des Genres gerecht zu werden (ebd. 123f.). Erst als die Perser auch Ägypten besetzt hatten, kehrte Johannes nach Zypern zurück, wo er kurz darauf verstarb.

104 Geburt Epiphanias: Chron. Pasch. AD 611; Theoph. Conf AM 6102 (299); Geburt Herakleios Konstantin: Chron. Pasch. AD 612; Theoph. Conf AM 6103 (300); zum Tod der Eudokia siehe ebd. und Nik. Brev. 3 zur Beerdigung in der Apostelkirche; zu der Krönung der Epiphania siehe Chron. Pasch. AD 612; Theoph. Conf AM 6104 (300).

105 Zur Krönung des Herakleios Konstantin siehe Chron. Pasch. AD 613; Theoph. Conf AM 6104 (300) gibt als Termin den 25. Dezember 612 an; es gibt allerdings keinen Grund, das Zeugnis des Chron. Pasch. anzuzweifeln, da die Regierungsjahre des Herakleios Konstantin ab dem 22. Januar und nicht ab Dezember gerechnet wurden; siehe Whitby/Whitby 1989, 156 Anm. 436; vgl. Olster 1982, 399.

106 PLRE I, Flavius Arcadius 5 (99); PLRE I, Honorius 3; Leppin 2003, 127-133 zur Sicherung der Dynastie unter Theodosios I.; zu Theodosios’ Nachfolgeregelung auch Börm 2015a, 258; zur Krönung des Theodosios II. siehe Chron. Pasch. AD 402; zu Theodosios, Sohn des Maurikios, siehe oben S. $72 \mathrm{f}$.

107 Zur Bedeutung von Dynastie bei der Nachfolgeregelung siehe und Börm 2015a. 
politische Hierarchie der Hauptstadt zu destabilisieren. Bevor Maurikios weitere Schritte unternahm, krönte er seinen Sohn. ${ }^{108}$ Theodosios I. erhob seinen jüngeren Sohn Honorios im Alter von neun Jahren zum Augustus, als die Situation im Westen des Reiches ihm zu entgleiten drohte: Nach dem unerwarteten Tod des jungen Valentinian II. im Jahr 392 hatte der Heermeister Arbogast eigenmächtig Eugenius als Kaiser proklamiert. Bevor Theodosios gegen den Usurpator ins Feld zog, krönte er nach Arkadios demonstrativ auch seinen zweiten Sohn Honorios, der nach Theodosios’ Tod 395 tatsächlich die Herrschaft im Westen des Reiches übernahm. ${ }^{109}$ Erklärungsbedürftig ist demnach nicht der Umstand, dass ein Kaiser seinen leiblichen Sohn zum Augustus erhob, sondern vielmehr der genaue Zeitpunkt, zu dem dieser Akt erfolgte. ${ }^{110}$

Die frühe Krönung von Epiphania und Herakleios Konstantin ist vor dem Hintergrund der prekären Situation zu verstehen, in der sich Herakleios zu Beginn seiner Regierung befand. In diesem Zusammenhang konnte die Designation seines Sohnes zum Nachfolger für Herakleios eine Reihe positiver Konsequenzen zeitigen: die Stärkung des Verhältnisses zu den hauptstädtischen Akzeptanzgruppen, die Etablierung einer klar umrissenen Dynastie (in Abgrenzung zu möglichen Konkurrenten) und die Benennung nicht nur eines Nachfolgers, sondern gleichzeitig eines Stellvertreters.

Die Krönungen gaben Herakleios die Möglichkeit, mit den verschiedenen Gruppen der Hauptstadt in Interaktion zu treten, was besonders bei der Erhebung des Herakleios Konstantin deutlich wird. Wie bereits im vorigen Kapitel gezeigt, adressierte das Krönungsritual sukzessive verschiedene Öffentlichkeiten. Konträr zum Ablauf von Herakleios' eigener Krönung begannen die Feierlichkeiten für seinen Sohn im Palast, genauer gesagt der Stephanskirche, wo sich die säkulare und klerikale Elite der Hauptstadt versammelt hatte. Nachdem Herakleios dort die eigentliche Krönung vollzogen hatte - die Rolle des Koronators fiel nun wieder dem Vater anstelle des Patriarchen $\mathrm{zu}$-, wurde der junge Augustus ins Kathisma des Hippodrom gebracht, von Demen und Senatoren akklamiert und schließlich in die Hagia Sophia geführt, wo ein weiterer Gottesdienst in Anwesenheit der Gemeinde stattfand. ${ }^{111}$ Indem Herakleios seinen Sohn krönte und den Eliten ebenso wie der Bevölkerung Konstantinopels präsentierte, konnte er den Moment des performativen Consensus universorum, der seine eigene Herrschaft eingeleitet und ihn im Oktober 610 zum Kaiser gemacht hatte, wiederholen und sich der Akzeptanz der hauptstädtischen Gruppen versichern.

Dass Kaiser, die mit ihrem Vorgänger nicht verwandtschaftlich verbunden waren, sich in besonderem Maße darum bemühten, eine eigene Dynastie zu etablieren, ist per

108 Dazu siehe oben S. $72 \mathrm{f}$.

109 Siehe Leppin 2003, 208 zur Krönung des Honorius und ders. 2003, 205-216 zur Usurpation des Eugenios; außerdem Szidat 1979.

110 Eine klare Vorstellung davon, in bzw. ab welchem Alter Söhne der Kaiser bereit waren, neben ihren Vätern in den Rang des Augustus einzutreten, bestand nicht. Es lag in der Entscheidung des Senior Augustus, den Zeitpunkt festzulegen.

111 Der Ablauf der Krönung wird in Chron. Pasch. AD 613 geschildert. 
se nicht verwunderlich. ${ }^{112}$ Im Falle des Herakleios bestand aufgrund eines konkreten Störfaktors allerdings noch höhere Dringlichkeit. Bereits Phokas hatte sich mit dem Problem konfrontiert gesehen, dass nach dem Machtwechsel von 602 Gerüchte vom Überleben des Augustus Theodosios, Maurikios' ältestem Sohn, kursierten, die als politisches Argument gegen ihn instrumentalisiert werden konnten. Derartige Gerüchte waren offenbar auch beinahe zehn Jahre später noch nicht ganz ausgemerzt; laut der Armenischen Geschichte des Sebeos wies der Perserkönig Chosroes II. Herakleios' Delegation mit dem Verweis darauf zurück, dass er den Theodosios als Kaiser der Römer betrachte. ${ }^{113}$ Herakleios befand sich in einem Dilemma: Einerseits versuchte er, Phokas' Sturz und seinen Griff nach der Macht als Rache für das Massaker an Maurikios darzustellen; ${ }^{114}$ andererseits hielt sich mit dem angeblichen Theodosios ein ernstzunehmender Konkurrent. Allein das hartnäckige Gerücht von dessen Überleben konnte das neue Regime in Konstantinopel destabilisieren. Herakleios begegnete diesem Dilemma, indem er den Fokus auf die eigene Familie lenkte und die Erinnerung an Maurikios’ Erbe(n) durch die Etablierung einer eigenen, fest in der Hauptstadt verankerten Dynastie überschrieb. ${ }^{115}$ Mit der Krönung des Herakleios Konstantin - also der unmissverständlichen Benennung eines Nachfolgers - kam er darüber hinaus einflussreichen Akteuren zuvor, die danach trachten konnten, sich im Sinne des eigenen Machtzuwachses in die Nachfolgeregelung einzumischen.

Dass Herakleios seinen Sohn derart früh zum Augustus krönte, macht schließlich auch den Zusammenhang zwischen Familien- und Militärpolitik deutlich. Die Erhebung im Januar 613 erfolgte unmittelbar bevor Herakleios im Frühjahr 613 nach Syrien aufbrach, um das römische Heer im Kampf gegen die Perser anzuführen; Sebeos

112 Verwandtschaftliche Bindungen zum Vorgänger konnten auch ex post noch hergestellt werden: so geschehen bei Markian, der nach seiner Krönung die Schwester seines Vorgängers Theodosios II. heiratete, und bei Anastasios, der die Witwe des Zenon ehelichte. Die einzigen oströmischen Kaiser, die im 5. und 6. Jahrhundert nicht mit der Familie des Vorgängers verbunden waren, waren Leon I. und Justin I. Leon I. erhob seinen Enkel Leon II. zum Augustus und Justin I. seinen Neffen Justinian erst zum Caesar und schließlich zum Augustus.

113 Sebeos 34 (Thomson/Howard-Johnston I, 66); zu der Delegation des Herakleios an Chosroes siehe auch Theoph. Conf. AM 6105 (De Boor 300); Mich. Syr. 11.1 (Chabot II, 400); Chron. 1234, 91 (Chabot I, 177). Bis auf Theophanes Confessor berichtet keine griechische Quelle von einer derartigen Delegation und Theophanes' Information könnte durchaus aus der syrischen Tradition stammen; Mango/Scott 1997, 430 f. Anm. 1 zweifeln deshalb die Historizität der Delegation an. Der in Chron. Pasch. AD 615 erhaltene Brief des Senates an Chosroes gibt überdies an, Herakleios habe nach seiner Erhebung aufgrund der chaotischen politischen Lage keine Gelegenheit gefunden, sich mit einer Delegation dem Chosroes vorzustellen.

114 Dies äußert sich in Chron. Pasch. AD 615 und Nik. Brev. 2.

115 Theophylakt Simokattes, der sein Geschichtswerk nach dem Ende des Perserkrieges 628 vollendete und Herakleios wohlgesinnt war, war offensichtlich darum bemüht zu betonen, dass Theodosios ebenso wie sein Vater und seine Brüder im November 602 starb; siehe Hist. 8.13.3 - 6, 8.15.8f. Zu dieser Problematik ausführlich Booth 2019. 
macht den Kausalzusammenhang dieser beiden Ereignisse explizit. ${ }^{116}$ Als Herakleios die Hauptstadt entgegen gängiger Verhaltenserwartungen an den Monarchen erstmals für längere Zeit verließ, um an der Spitze der römischen Truppen gegen die Perser zu ziehen, hatte er nicht nur ein klares Statement hinsichtlich seiner Nachfolge gesetzt; mit Herakleios Konstantin befand sich außerdem weiterhin ein Augustus in Konstantinopel - ein Augustus, der trotz seines jungen Alter zumindest die Funktion als zeremonieller Mittelpunkt des hauptstädtischen Beziehungsgeflechtes ausfüllen konnte. Die Anwesenheit des Herakleios Konstantin garantierte, dass Konstantinopel trotz Herakleios' vorübergehender Abwesenheit auf ihn bzw. seine Familie bezogen blieb. Die stabilisierende Wirkung dieser Konstellation in Hinblick auf Herakleios' Herrschaft sollte sich indes erst über ein Jahrzehnt später vollends offenbaren.

\subsubsection{Münzprägung}

Die gemeinsame Herrschaft von Vater und Sohn wurde ab 613 nicht nur im offiziellen Datierungsformular angegeben, ${ }^{117}$ sondern fand ihren Ausdruck auch in der Münzprägung: Alle ab 613 ausgegebenen Nominale stellten nicht Herakleios allein, sondern das kaiserliche Kollegium, seine Familie bzw. die von ihm zu begründende Dynastie in den Vordergrund. Im Gegensatz zu der Münzprägung früherer Jahrhunderte, die sich durch eine Vielzahl von Typen - die spezifische Kombination von Bild- und Textelementen - ausgezeichnet und teilweise sehr differenziert auf aktuelle Ereignisse reagiert hatte, ist in der Spätantike eine fortschreitende Schematisierung von Bildprogramm und Beischriften nachzuvollziehen. ${ }^{118}$ Dieser Entwicklung entspricht auch die herakleische Münzprägung; doch gerade die Beobachtung von deren genereller Uniformität einerseits und den wenigen Modifikationen des Prägeprogramms andererseits ermöglichen wichtige Rückschlüsse darauf, wie Herakleios seine Herrschaft konzipierte und repräsentierte.

Ein Überblick über die herakleischen Münzen offenbart folgende Charakteristika: ${ }^{119}$ Prägungen der Jahre 608-610 aus Karthago, Alexandria und Zypern, die Herakleios und seinen Vater durch Tracht und Beischrift als Konsuln auszeichnen, fanden nach der Krönung keinen Widerhall mehr; ihr bereits betonter Ausnahme-

116 Sebeos 34 (Thomson/Howard-Johnston I, 57f.): „At that time Heraclius made his son Constantine king; he put him in the charge of the senate, entrusted him to all the magnates of the palace, and confirmed him on the throne of his kingdom. He himself, having adopted the title of general, with his brother T‘ēodos gathered the multitude of his troops and set out for Asorestan, to the region of Antioch."

117 Chron. Pasch. AD 613.

118 Siehe Maier 2019, 81-85 mit weiterer Literatur zur Analyse spätantiker Münzprägungen.

$119 \mathrm{Zu}$ den herakleischen Münzen siehe DOC II.1, 216-221, Taf. 8-22; außerdem detailliert zu den verschiedenen Prägestätten und Nominalen MIB III, 83-122, Taf. 1-19. 
charakter wird damit nochmals verdeutlicht. ${ }^{120}$ Die Averse der Solidi, die ab Oktober 610 in Konstantinopel geprägt wurden, ${ }^{121}$ ziert stattdessen die frontale Büste des Herakleios in militärischer Tracht, mit Rüstung und Paludamentum. Auf dem bärtigen Kopf trägt er eine Krone mit seitlichen Pendilien, einem frontal über einer Scheibe aufragenden Kreuz und rückwärtigem Federschmuck, in der rechten Hand ein Kreuz. Als Beischrift finden sich leicht variierende Akronyme von DOMINUS NOSTER HERACLIUS PERPETUUS AUGUSTUS. Auf den Reversen prangt das bereits bekannte Stufenkreuz mit der Beischrift VICTORIA AUG(USTI). Diese Darstellung orientiert sich weitestgehend an den über Jahrhunderte etablierten Konventionen römischer-imperialer Münzprägung, die das Brustbild des Kaisers der Regel nach - mit selteneren Ausnahmen $^{122}$ - in militärischer Tracht präsentierte und ab dem 4. Jahrhundert sukzessive durch christliche Symbolik ergänzte. ${ }^{123}$ Wie bereits bei seinem Vorgänger Phokas fand allerdings auch bei Herakleios ein individualisierter Portraittyp Anwendung, dessen Züge sich vor allem in einer über die Jahre changierenden Barttracht äußern. ${ }^{124}$

Während das Revers-Bild auch nach 613 praktisch unverändert blieb, erschien auf dem Avers der Solidi neben dem Portrait des Herakleios nun auch das seines Sohnes Herakleios Konstantin, umgeben von der Beischrift D(OMINI) N(OSTRI) HERACLIUS ET HERA(CLIUS) CONST(ANTINUS) P(ER)P(ETUI) AUGUSTI. Der Junior Augustus befindet sich kleiner als der Senior und ohne Bart auf der vom Betrachter aus rechten, also hierarchisch untergeordneten Seite. ${ }^{125}$ Nach der Krönung seines Sohnes 613 wurde Herakleios auf keinem Nominal mehr allein abgebildet, sondern immer in Begleitung des Herakleios Konstantin: Auf den Aversen der Kupfermünzen erscheinen die beiden Kaiser in der Regel stehend anstatt im Brustbild; ${ }^{126}$ auf den Silber-Hexagrammen, die 615 eingeführt wurden, in thronender Position. ${ }^{127} \mathrm{Ab} 632$ stieß dann mit Heraklonas, Herakleios' Sohn aus seiner zweiten Ehe mit Martina, ein dritter Protagonist auf dem Avers der Solidi hinzu: Die zwei Büsten bzw. thronenden Figuren

$120 \mathrm{Zu}$ den Konsulatsprägungen siehe oben S. 95-97.

121 Solange keine bemerkenswerten Abweichungen $\mathrm{zu}$ verzeichnen sind, werde ich mich im Folgenden auf die Prägungen aus Konstantinopel konzentrieren; zu anderen Prägestätten siehe DOC II.1, $230-241$.

122 Ausnahmen sind etwa Prägungen, die den Antritt eines kaiserlichen Konsulates anzeigen und den Kaiser entsprechend in der Tracht der Konsuln darstellen, Beispiele verschiedener Kaiser des 6. Jahrhundert in DOC I, 378 (Index s.v. „Consular robes and insignia”); außerdem Doppelportraits, die ich im Folgenden noch eingehender besprechen werde.

123 Zur Entwicklung der Münzprägung im 7. Jahrhundert siehe DOC II.1, 65-68; außerdem Olster 1982, 399.

124 Zu den Portraits siehe DOC II.1, 88-94; zu Phokas’ Münzen siehe oben S. 145.

125 Zum neuen Münztyp siehe DOC II.1, 221-223, 247-249; zur Datierung außerdem Grierson 1959 und Bellinger 1966. Eine Übersicht über die verschiedenen Nominale findet sich auch in MIB III, 83122 mit Taf. 1-19.

126 Kupfer-Prägungen: DOC II.1, 225-229, 274-307.

127 Silber-Hexagramme: DOC II.1, 270-274; zur Einführung des Silber-Hexagramms 615 siehe Yannopoulos 1978 und DOC II.1, 17-18, 115-117. 
weichen damit drei frontal stehenden Figuren. ${ }^{128}$ Mit dem Wechsel vom Einzel- zum Doppelportrait im Jahr 613 wandelte sich auch die Tracht des bzw. der Abgebildeten: Anstatt Rüstung und Paludamentum tragen die beiden Augusti Chlamys (den beinahe bodenlangen Purpurmantel) und eine mit Kreuz versehene Krone - die militärische Tracht wich also der zivilen. ${ }^{129}$ Das zivile Gewand etablierte sich als ein kontinuierliches Merkmal auf allen Nominalen der herakleischen Münzprägung, durchbrochen allein von einem kurzzeitig ausgegebenen Bronze-Typ der Jahre 629-631. ${ }^{130}$ Es lässt sich also eine auf den ersten Blick paradoxe Entwicklung konstatieren: Während die sesshaften Kaiser des 5. und 6. Jahrhunderts auf den Münzen an militärischer Repräsentation festhielten, brachen ausgerechnet Prägungen des Herakleios, der erstmals wieder persönlich Truppen ins Feld führte, mit dieser Tradition.

Dieses Paradox löst sich jedoch, wenn man die herakleischen Münzen im Kontext spätrömischer Präge- und Darstellungskonventionen bewertet. Doppelportraits zweier Augusti auf Münzen sind keine grundsätzliche Neuerung. Sie dienten bereits in den vorangehenden Jahrhunderten als Instrument, um Herrschaftskonstellationen, Familienverhältnisse und Nachfolgeregelungen zu indizieren; sowohl Kaiserkollegen als auch Eheleute wurden in Doppelportraits dargestellt. Im 4. Jahrhundert finden sich Mehrfachportraits regelmäßig auf Goldprägungen: Während der Avers dem bzw. im Falle einer Samtherrschaft - einem der Augusti vorbehalten war, konnte auf den Reversen die spezifische Herrschaftskonstellation zum Ausdruck gebracht werden; Konstantin zeigte sich in der Mitte seiner Söhne, die Augusti Theodosios und Valentinian I. erschienen in Eintracht. ${ }^{131}$ Ähnlich verhielt es sich auch im 5. Jahrhundert: Während ihres jeweiligen Kondominats wurden Leo I. und Leo II. (473/4), Leo II. und Zeno (474) sowie Basiliskos und Markos (475/6) auf den Reversen der Solidi nebeneinander in thronender Position und zivilem Gewand dargestellt; die Averse trugen weiterhin das typische Kaiserportrait des Senior Augustus in militärischer Tracht. ${ }^{132}$ Ab dem 6. Jahrhundert fanden Doppelportraits schließlich auch auf dem Avers An-

128 MIB III, 85. Heraklonas wurde 632 zum Caesar gekrönt, siehe Theoph. Conf. AM 6108 (De Boor 301), der das Ereignis allerdings einen Indiktions-Zyklus zu früh ansetzt, siehe Mango/Scott 1997, 433 Anm. 2. Vgl. Nik. Brev. 19, ohne absolute Datierung, allerdings mit der Angabe, dass dies nach der Rückkehr des Herakleios in die Hauptstad in Folge des Sieges über die Perser erfolgte. 638 wurde Heraklonas dann zum Augustus befördert, siehe De cerim. 2.27; Nik. Brev. 25. Der Statuswechsel des Heraklonas vom Caesar zum Augusuts 638 wird auf den Solidi durch eine Modifikation der Kopfbedeckung angezeigt, siehe DOC II.1, 223-225. Auf den Silber-Hexagrammen und Kupfer-Nominalen wurde Heraklonas erst nach seiner Krönung zum Augustus 638 einbezogen; siehe DOC II.1, 225-229. 129 Olster 1982, 399.

130 Vgl. DOC II.1, 76-78 zum Kaiser im zivilen Gewand; zu der Ausnahme siehe ebd., 74, 226-228 (Follis Class 5) und unten S. 235f.

131 Siehe MacCormack 1981, 202f. mit Taf. 44-50. Vgl. ein Solidus-Exagion aus Bronze, das auf dem Avers Theodosios I. mit seinen beiden Söhnen Arkadios und Honorios darstellt, siehe Kalavrezou 2003, 51, Abb. 9a f.

132 Leon I. \& Leon II.: RIC X, Taf. 24 Nr. 636 - 638; Leon II. \& Zenon: RIC X, Taf. 27 Nr. 803 f.; Basiliskos und Markus: RIC X, Taf. 29 Nr. 1019, $1022 \mathrm{f}$. 
wendung. Nach seiner Erhebung zum Augustus am 4. April 527 erschien Justinian neben seinem Onkel auf den Aversen der Solidi, ebenfalls thronend und mit Chlamys. ${ }^{133}$ Auch Justin II. und Tiberios erschienen im Doppelportrait; allerdings zierten in diesem Fall Büsten anstatt thronender Figuren die Averse der Solidi. ${ }^{134}$ Ab Justin II. etablierte sich außerdem die Praxis, die zur Augusta erhobene Ehefrau des regierenden Kaisers neben diesem stehend auf dem Avers abzubilden - so geschehen bei Justin II. und Sophia, Tiberios und Anastasia, Maurikios und Konstantina sowie Phokas und Leontia. ${ }^{135}$ Diese Form der stehenden Doppelportraits eines Ehepaares findet sich allerdings nicht auf den Solidi, sondern allein auf den weniger wertigen Kupfer-Nominalen.

Die herakleische Münzprägung eignete sich ab 613 bestehende Typen des Doppelportraits an und übertrug diese konsequent auf die Averse aller Nominale: Büsten auf den Solidi, stehende Figuren auf den Kupfer-Münzen sowie thronende auf den ab 615 ausgegebenen Silber-Hexagrammen. ${ }^{136}$ Die Entscheidung zugunsten der zivilen Chlamys als typischer Tracht der Doppelportraits griff dabei auf etablierte Konventionen zurück. In den Chlamys-tragenden Doppel- bzw. Dreierportraits auf allen herakleischen Münz-Nominalen offenbart sich die Kombination symbolischer Darstellungsformen, welche traditionell einerseits mit Kondominat, andererseits mit Familienbeziehungen verbunden waren. ${ }^{137}$ Bei der Beobachtung dieser Traditionsbezogenheit darf allerdings die Eigenheit der herakleischen Prägungen nicht aus dem Blick verloren werden. Dass die Konsequenz, mit der Herakleios’ Münzen den Fokus auf die kaiserliche Familie richteten, wahrlich außergewöhnlich war, offenbart sich besonders im Vergleich zu den Prägungen seines Vorgängers Maurikios. Maurikios, der als erster Kaiser nach Arkadios wieder einen leiblichen Sohn hatte, krönte diesen zwar 590 zum Augustus, ließ die Erhebung jedoch nicht auf Münzen vermerken zumindest nicht konsequent: Theodosios als designierter Nachfolger findet sich nur auf Kupfermünzen der Chersones; während der Avers weiter Maurikios und Konstantina vorbehalten ist, erscheint der Junior Augustus nur auf dem Revers. ${ }^{138}$

Über die ikonographische Kontextualisierung der herakleischen Münzen hinaus stellt sich die Frage, welche Wirkung die Prägungen im Rahmen politischer Kommunikation und kaiserlicher Repräsentation entfalteten. Lässt sich in dem spezifi-

133 DOC I, 57-61 mit Taf. 12.

134 MIB II, 51 mit Taf. 10; DOC I, 263; Grierson 1955, 64f.; Olster 1982, 400.

135 Olster 1982, 399f. Zu Justin II. und Sophia siehe MIB II, 44-49 mit Taf. 4-8. Doppelportraits von Maurikios und Konstantina sind, soweit ich sehe, nur auf Kupfermünzen aus Thessaloniki und der Chersones bezeugt; siehe MIB II, 68 - 75 mit Taf. 26, 28; zu Phokas und Leontia siehe MIB II, 80 - 83 mit Taf. $32-35$.

136 Eine Übersicht über die verschiedenen Nominale findet sich in MIB III, 83-122 mit Taf. 1-19 und DOC II.1, 216-383 mit Taf. 8-22.

137 Siehe Olster 1982, 401.

138 Siehe Olster 1982, 400 f.; MIB II, 74 f. mit Taf. 28. Dass Theodosios kaum auf Münzen Beachtung findet, passt zu der Notiz im Chron. Pasch. AD 590, dass er zwar von Maurikios gekrönt, aber nicht von der Öffentlichkeit akklamiert oder in die offiziellen Register aufgenommen wurde. 
schen Bild- und Textprogramm tatsächlich die gezielte Öffentlichkeitsarbeit des Herakleios erkennen? ${ }^{139}$ Im Laufe des Prinzipats wurde die Münzprägung sukzessive in die kaiserliche Administration eingegliedert; die über das Reich verteilten Prägestätten operierten in der Regel nicht individuell, sondern wurden zentral gesteuert. Die Entwicklung von Bild- und Textprogramm der Münzen geschah demnach zumindest herrschernah bzw. konnte vom regierenden Kaiser gezielt beeinflusst werden. Frisch geprägte Münzen fanden in verschiedenen Kontexten Anwendung: Den größten Ausgabeposten stellte die Finanzierung des römischen Heeres dar; Münzen wurden an Soldaten aller Dienstgrade ausgezahlt, sie fanden ihren Weg in die Verwaltung, den kaiserlichen Hof, finanzierten kaiserliche Bautätigkeit, wurden im Zuge von öffentlichen Geldspenden in Umlauf gebracht, zirkulierten von dort aus weiter und drangen bis in die entlegensten Winkel des Reiches (und sogar darüber hinaus) vor. ${ }^{140}$ Trotz fortschreitender Erkenntnisse hinsichtlich antiker Münzproduktion und -Zirkulation wird die Frage nach der kommunikativen Wirkung des Prägeprogramms weiterhin kontrovers diskutiert; der Auffassung von Münzen als ,Propagandamedium‘ kaiserlicher Repräsentation, gar als Nachrichtenmedium, steht die These gegenüber, dass die retrospektive Analyse einzelner Typen dazu verleite, deren differenzierte Wahrnehmung durch die zeitgenössischen Rezipienten zu überschätzen. ${ }^{141}$ Joachim Szidat schließt sich in einem Aufsatz zu Münzen des Kaisers Julian zwar insgesamt eher dem Lager der Skeptiker an; allerdings gesteht er ein, dass Prägeprogramme durchaus Themen aufgreifen und betonen konnten, die - aufgrund ihrer Präsenz in anderen Medien - potentiellen Rezipienten bereits als Teil eines breiteren öffentlichen Diskurses vertraut waren. ${ }^{142}$ Diese vorsichtige Einschätzung lässt sich auch auf die herakleische Münzprägung anwenden. ${ }^{143}$ Die Quellen geben eine Reihe von Hinweisen darauf, dass Herakleios nicht nur die Erhebung seines Sohnes zum Augustus öffentlich zelebrierte, sondern die Präsenz eines Kollegen und designierten Nachfolgers über das Ereignis der Krönung hinaus regelmäßig betonte und damit das Kondominat in der öffentlichen Wahrnehmung zu verstetigen suchte. ${ }^{144}$ Dass Herakleios

139 Methodische Fragen im Zusammenhang mit der Aus- und Bewertung von Münzen adressiert ausführliche Wienand 2012, 43-86; außerdem Maier 2019, 81-85.

140 Wienand 2012, 43f. Zu Prägestätten im 7. Jahrhundert siehe DOC II.1, 33-53 und MIB III, 14-20. 141 Diese Debatte vollzieht Wienand 2012, 45 f. nach; außerdem Maier 2019, 82f., beide mit weiterer Literatur. Die Skeptiker berufen sich in der Regel auf Jones 1956.

142 Szidat 1981, $30 \mathrm{f}$.

143 Dass eine angemessene Wertung von Münzprägung, von deren kommunikativer Funktion und Wirkung, ein tiefes Verständnis des numismatischen Metiers voraussetzt, hat Wienand 2012 eindrucksvoll gezeigt; eine derartige Tiefenuntersuchung kann ich an dieser Stelle nicht leisten.

144 Dies wird vor allem in den Situationen deutlich, als Herakleios die Hauptstadt verließ und seinen Sohn dezidiert als Stellvertreter installierte, siehe Sebeos 34 (Thomson/Howard-Johnston I, 68). Auf die Nennung des Herakleios Konstantin im reichsweit geltenden Datierungsformular habe ich bereits hingewiesen; siehe Chron. Pasch. AD 613. Obwohl es dafür in den Quellen keinen expliziten Hinweis gibt, gehe ich davon aus, dass das Bild des Herakleios Konstantin nach seiner Krönung, entsprechend 
Konstantin - im Gegensatz zu Theodosios einige Jahrzehnte zuvor - derart früh und konsequent auf allen Nominalen als Augustus neben seinem Vater erschien, entspricht dieser Praxis; die These, dass das Prägeprogramm als Teil einer gezielten Öffentlichkeitspolitik des Kaisers zu werten ist, wird dadurch untermauert.

Zuletzt hat Johannes Wienand in Bezug auf die Münzprägung Konstantins gezeigt, dass eine Berücksichtigung der Distributionskontexte für das Verständnis des kommunikativen Gehaltes von Münzen unerlässlich ist. Verschiedene Nominale wurden an unterschiedliche Gruppen ausgehändigt bzw. erreichten diese durch Münzumlauf: Während Solidi bzw. Gold-multipla in der Regel hohen Funktionsträgern vorbehalten waren, drangen Kupferprägungen $\mathrm{zu}$ wesentlich breiteren Kreisen von Zivilbevölkerung und Heer vor. Anhand von Bild-Text-Kombinationen, die zwischen Nominalen differenzierten, konnte der Kaiser - so Wienand in Bezug auf Konstantin - die Bedürfnisse und Erwartungen unterschiedlicher Gruppen gezielt adressieren. ${ }^{145} \mathrm{Im}$ Vergleich zu den konstantinischen Prägungen zeichnen sich die verschiedenen Nominale unter Herakleios durch einen recht hohen Grad an Homogenität aus. Die Avers/Revers-Gestaltungen weichen zwar im Detail, wie oben gezeigt, durchaus voneinander ab (Büsten, thronende/stehende Figuren); der semantische Gehalt des Prägeprogramms wird dadurch jedoch nur in Ausnahmen signifikant beeinträchtigt. ${ }^{146}$ Die Betonung der kaiserlichen Familie zieht sich ab dem Jahr 613 derart stringent über alle Typen und Nominale, dass zumindest in diesem Zusammenhang der Aspekt der Distributionskontexte vernachlässigt werden kann. Im Münzprogramm offenbart sich Herakleios’ Ambition, seine Familie im Sinne einer zu gründenden Dynastie an der Spitze des Gemeinwesens zu verankern und diesen zentralen Aspekt seiner Herrschaft gegenüber einem möglichst breiten Querschnitt der Gesellschaft zu kommunizieren. ${ }^{147}$

etablierter Praxis, in die Provinzen geschickt wurde und dort sowohl beim Heer als auch in den Städten neben dem des Vaters präsent war.

$145 \mathrm{Zu}$ dem Begriff ,Distributionskontext` siehe Wienand 2012, 47; außerdem detailliert ebd. 66-86. 146 Signifikante Abweichungen sind folgende: Die ab 615 eingeführten Silber-Hexagramme tragen auf dem Revers die Beischrift DEUS ADIUTA ROMANIS als Reaktion (so die Vermutung) auf die sich weiter zuspitzende außenpolitische Krise; zu den Silber-Hexagrammen siehe DOC II.1, 17f., 115-117, 270 - 274, Taf. 10. Ab 615/6 erschien auf den Aversen der Kupfer-Nominale neben den beiden Augusti eine weibliche Person, dazu siehe im Folgenden. Wie bereits erwähnt wurden Herakleios und Herakleios Konstantin zwischen 629 und 631 auf den Folles in militärischer Tracht und nicht wie sonst in Zivil dargestellt; dazu siehe S. $235 \mathrm{f}$.

$147 \mathrm{Ob}$ und wie die herakleische Münzprägung wahrgenommen wurde, ist eine andere Frage. Eine mögliche Antwort liefert Johannes von Nikiu (116.3) in Bezug auf Ägypten. Die Passage verdeutlicht allerdings auch, dass die Wahrnehmung eklatant vom ursprünglichen Aussageziel abweichen konnte: "And some said: 'The death of Heraclius is due to his stamping the gold coinage with the figures of the three emperors - that is, his own and of his two sons on the right hand and on the left - and so no room was found for inscribing the name of the Roman empire.' And after the death of Heraclius they obliterated those three figures." Übers. nach Charles 1916. 


\subsubsection{Endogamie}

Der letzte Aspekt in Zusammenhang mit Herakleios' Familienpolitik ist gleichzeitig der in der Forschung umstrittenste. Nach dem frühen Tod seiner ersten Frau Eudokia heiratete Herakleios seine Nichte Martina, die Tochter seiner Schwester - eine Ehe, mit der er gegen römisches Recht verstieß. ${ }^{148}$ Die inzestuöse, im christlichen Sinne als sündhaft wahrgenommene Verbindung sorgte bereits bei Herakleios' Zeitgenossen für Irritation, ${ }^{149}$ prägte die Erinnerung an den Kaiser im negativen Sinne ${ }^{150}$ und stieß zuletzt bei Historiker/innen auf Unverständnis. Nikephoros verurteilt Herakleios für

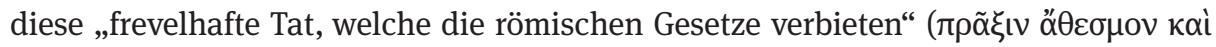

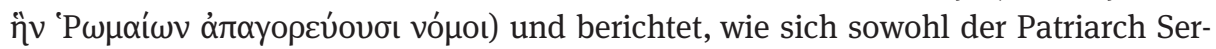
gios als auch die Zirkusparteien im Hippodrom gegen die Verbindung ausgesprochen hätten; Herakleios indes habe an seiner Entscheidung festgehalten und die Ehe schließen lassen. ${ }^{151}$ Warum setzte sich Herakleios mit einer derartigen Entscheidung über geltendes Recht und Moralvorstellungen hinweg? Die Forschung konnte auf diese Frage noch keine befriedigende Antwort formulieren; ${ }^{152}$ Erklärungsmodelle, die das Gefühlsleben des Kaisers in den Vordergrund stellen, sind methodisch kaum valide. ${ }^{153}$ Die hier gewählte Herangehensweise indes legt nahe, dass sich in Herakleios' Hochzeit mit der eigenen Nichte eine endogame Familienpolitik äußert, die - analog zu den bereits geschilderten Maßnahmen - auf die Stärkung der Herrschaftsverhältnisse und Abwehr potentieller Konkurrenten abzielte.

Bereits die Datierung von Herakleios' zweiter Hochzeit bereitet Probleme. Allein Theophanes Confessor gibt eine absolute Chronologie, welche die Eheschließung

148 Gemäß Cod. Theod. 3.12.1 (Gesetz aus dem Jahr 342) waren Ehen zwischen Onkel und Nichte untersagt; siehe dazu Kaegi 2003, $106 \mathrm{f}$; zu Martina siehe Garland 1999, 63-72.

149 Entgegen der Annahme von Speck 1988, 268- 270 und ders. 1997, 463 Anm. 54, dass die Kritik an der Ehe prinzipiell nur a posteriori ausgesprochen worden sei, zeugt Ant. Strateg. (Conybeare 516) davon, dass die Ehe bereits von Zeitgenossen als sündhaft empfunden wurde.

150 Nik. Brev. 11, 20; Chron. 1234, 98 (Chabot I, 182f.); Mich Syr. 11.3a (Chabot II, 410).

151 Nik. Brev. 11; dazu Speck 1988, 267-271 und Mango 1990, 179f. Zu der Reaktion der Zirkusparteien vgl. Al. Cameron 1976, 339f., der die Stelle anders als Mango liest: Die Grünen hätten die Hochzeit unterstützt, nur die Blauen seien dagegen gewesen. Nikephoros berichtet außerdem von zwei Söhnen des Paares, Flavios und Theodosios, die beide behindert gewesen seien, was der Autor wiederum als gerechte Strafe für die unrechtmäßige Verbindung versteht. $\mathrm{Zu}$ diesen beiden Söhnen siehe Mango 1990, 179f. Dabei ist zu bedenken, dass manche Passagen des Breviariums - bzw. die von Nikephoros genutzten Quellen - Herakleios dezidiert kritisch gegenüberstehen. Die Frage, ob sein Bericht von den Ausschreitungen im Zusammenhang mit der Hochzeit authentisch ist, ob es also wirklich zu derartigen Szenen kam oder ob es sich dabei eher um eine retrospektive Verurteilung handelt, sollte zumindest bedacht werden.

152 Kaegi 2003, 107 stellt fest: „Heraclius tried to create new stability and resolve his dynastic problems by marrying Martina.” Allerdings erörtert er nicht, inwiefern die Ehe ein stabilisierende Wirkung hätte haben können.

153 So verfahren etwa Frolow 1953, 103 und Speck 1988, 33- 43. 
bereits kurz nach Eudokias Tod, ins Jahr 613/14, ansetzt. ${ }^{154}$ Der Chronograph fügt außerdem hinzu, Martina sei anlässlich der Hochzeit zur Augusta erhoben und im Augustaion, dem Empfangssaal im kaiserlichen Palast, durch den Patriarchen Sergios gekrönt worden. Nikephoros hingegen legt mit seiner relativen Chronologie nahe, dass die Hochzeit erst circa ein Jahrzehnt später, kurz vor Beginn der großen Gegenoffensive gegen die Perser, stattfand. ${ }^{155}$ Diese Diskrepanz ist schwer aufzulösen, zumal sowohl Theophanes als auch Nikephoros bisweilen schwerwiegende chronologische Ungenauigkeiten aufweisen. ${ }^{156}$ Zeitgenössische Quellen erwähnen die Hochzeit nicht; die Osterchronik vermerkt lediglich, dass Martina ihren Ehemann begleitete, als dieser im Frühjahr 624 gen Osten aufbrach. ${ }^{157}$ Sicher ist zunächst also nur dieser Terminus ante quem.

Ein weiterer Faktor, der bei der Datierungsfrage in Betracht gezogen werden kann, ist eine Modifikation der Kupfermünzen: Nachdem ab 613 das stehende Doppelportrait von Herakleios und Herakleios Konstantin die Averse geziert hatte, wurde ab 615/ 16 ein neuer Typ mit drei stehenden Figuren ausgegeben, datierbar durch die Beischrift des Regierungsjahres auf dem Revers. ${ }^{158}$ Die vom Betrachter aus links abge-

154 Theoph. Conf. AM 6105 (De Boor 300).

155 Nik. Brev. 11. Auch in der westsyrischen Tradition (Chron. 1234, 98f. [Chabot I, 182f.]; Mich Syr. 11.3a [Chabot II, 410]) wird die Verbindung erst in Zusammenhang mit Herakleios' Perserfeldzug erwähnt. Es ist allerdings nicht auszuschließen, dass die potentiell bereits länger geschlossene Ehe für die syrischen Chronisten erst im Zusammenhang mit der Präsenz von Herakleios und Martina im Osten erwähnenswert schien.

$156 \mathrm{Zu}$ chronologischen Ungenauigkeiten: Theoph. Conf. AM 6108 (De Boor 301), entsprechend 615/ 16, etwa vermerkt, dass Herakleios Konstantin den Konsulat antrat und seinen Halbbruder, „den anderen Konstantin“ (also Heraklonas), zum Caesar erhob. Dies geschah allerdings nachweislich erst im Jahr 632 (siehe Mango/Scott 1997, 433 Anm. 2). Theophanes scheint an dieser Stelle im Indiktionszyklus verrutscht zu sein - Indiktion 5 entspricht sowohl 615/16 als auch 631/32; siehe Speck 1988, 33-43 und Zuckerman 1995, 115. Befürworter einer späten Hochzeit argumentieren, dass Theophanes aufgrund seiner um 15 Jahre vorgezogenen Datierung der Erhebung des Heraklonas zwangsläufig auch die Hochzeit von dessen Eltern habe früher ansetzen müssen; siehe dazu unten. Ohne absolute Datierung berichtet Nikephoros erst von der Hochzeit (Brev. 11), dann von der Eroberung Jerusalems durch die Perser (Brev. 12) von 614 und direkt im Anschluss darauf von Herakleios' Aufbruch nach Osten über Pontos nach Lazica, der erwiesenermaßen 624 stattfand. Dies zeugt davon, dass Nikephoros die Ereigniszusammenhänge primär assoziativ und thematisch, nicht unbedingt chronologisch ordnete.

157 Chron. Pasch. AD 624. Der Umstand, dass selbst das Chron. Pasch., das dem Herakleios dezidiert positiv gegenübersteht und auf dem Höhepunkt des kaiserlichen Erfolges ca. 630 verfasst wurde, die Hochzeit nicht erwähnt, könnte mit der öffentlichen Missbilligung dieses Schrittes zusammenhängen. 158 Siehe die Tabelle in DOC II.1, 226; Zuckerman 1995, 114. Die Prägungen mit drei stehenden Figuren liefen bis 628/9, als diese wiederum durch Herakleios und Herakleios Konstantin in militärischer Tracht abgelöst wurden (DOC II.1, 226-228; der Wechsel wird deutlich von Taf. 6, 104 auf 105a.3). Prägungen provinzieller Münzstätten variieren leicht: Aus Karthago finden sich auch Silberprägungen, allerdings mit drei Büsten; ebenfalls drei Büsten auf den Bronzemünzen aus Rom und Ravenna; von der Chersones zwei stehende Figuren auf dem Avers und eine auf dem Revers - wie bereits bei den Münzen des Maurikios. 
bildete Figur zeichnet sich durch weibliches Gewand sowie eine aufwändigere Krone mit langen Pendilien aus; wie ihr männliches Pendant auf der rechten Seite trägt sie einen mit Kreuz besetzten Globus. ${ }^{159}$ Analog zu den sonstigen Prägungen ist die mittige Figur, die mit einem Stabkreuz in der Hand ihre Beisteher überragt, zweifelsohne als Herakleios zu lesen und die männliche Figur zu seiner Rechten als Herakleios Konstantin. Da die drei stehenden Figuren jedoch den Platz weitestgehend ausfüllen, wurde bei der Prägung auf eine benennende Beischrift verzichtet; somit stellt sich die Frage nach der Identität der weiblichen Figur. In Frage kommen entweder Herakleios' 612 zur Augusta gekrönte Tochter Epiphania oder seine zweite Ehefrau, die ebenfalls zur Augusta gekrönte Martina; in der Forschung finden sich Plädoyers für beide. Befürworter Martinas gehen entsprechend von einer Frühdatierung der Hochzeit gemäß Theophanes aus; ${ }^{160}$ Befürworter Epiphanias von einer Spätdatierung entlang Nikephoros' Bericht. ${ }^{161}$ Argumentiert man indes rein auf der Basis numismatischer Evidenz, so lässt sich festhalten, dass die Abbildung der Ehefrau des Kaisers auf den Aversen von Kupfermünzen seit Justin II. Tradition hatte. ${ }^{162}$ Die Tochter eines regierenden Kaisers war hingegen zuvor noch nie auf Münzen erschienen; es sollten noch zweihundert Jahre vergehen, bis byzantinische Prinzessinnen nachweislich in der Münzprägung berücksichtigt wurden. ${ }^{163}$

In Hinblick auf die herakleischen Münzen wurde herausgearbeitet, dass das Prägeprogramm sich zwar durch eine Reihe von Eigenheiten auszeichnete, dass sich die Gestaltung der Typen allerdings an etablierten Traditionen und Konventionen orientierte. Eine plötzliche und weitgehend unvermittelte Abbildung der Tochter des Kaisers entspricht kaum dem Charakter der herakleischen Prägungen - seine Ehefrau

159 Abbildungen siehe MIB III, Taf. 11 Nr. 161f., und DOC II.1, Taf. 12 Nr. 90a.1-96; zu Kronen der Kaiserinnen siehe ebd. 84 mit Abbildungen auf S. 82.

160 Für eine Frühdatierung Grierson in DOC II.1, 227 für 613/14; ebenso Olster 1982, 401; Whitby/ Whitby 1989, 167 Anm. 452; Garland 1999, 62. Geht man von einer Frühdatierung der Hochzeit aus, bleibt nur die Frage, warum Martina nicht direkt nach der Hochzeit (gemäß Theophanes 613/4), sondern erst 615/6 auf den Münzen erschien; dieselbe Frage ließe sich allerdings auch in Bezug auf Epiphania stellen, die ja bereits 612 zur Augusta erhoben worden war. Grierson in DOC II.1, 227 schlägt vor, dass die Aufnahme der Augusta in die Münzprägung mit der Geburt eines Sohnes zusammengehangen haben könnte (vgl. Theoph. Conf. AM 6101 [301]); zu den Söhnen von Herakleios und Martina siehe S. 174 Anm. 169.

161 Zuckerman 1995 argumentiert explizit für eine Spätdatierung; das Verschwinden der weiblichen Figur ab 628/629 bringt er damit in Zusammenhang, dass Epiphania 628 in Richtung Osten aufbrach, wo sie den Khagan der Türken ehelichen sollte. Dies erscheint mir jedoch wenig überzeugend - das Verschwinden der Epiphania/Martina könnte vielmehr darin begründet liegen, dass die beiden Augusti nach dem Sieg über die Perser in militärischer Tracht anstatt in ziviler dargestellt wurden und eine Frau in dieses Bildprogramm nicht gepasst hätte. Für eine späte Datierung der Hochzeit auch Mango 1990, 79f.; Speck 1997a und Kaegi 2003, 106. Speck 1988, 33-43, der auch von einer Spätdatierung ausgeht, verkompliziert die Situation unnötig, indem er annimmt, dass auf den Münzen erst Epiphania und ab 624 Martina abgebildet ist.

162 Dazu siehe oben S. 168.

163 Genauer gesagt Töchter des Kaisers Theophilos (829-842); siehe Zuckerman 1995, 120. 
mit einzubeziehen, wie es seine Vorgänger seit Justin II. getan hatten, hingegen schon. Die weibliche Figur als Martina zu identifizieren, ist auch vor dem Hintergrund der kommunikativen Funktion von Münzen plausibler: Als Rezipient der Prägungen war es die Bevölkerung gewöhnt, kaiserliche Ehefrauen auf den Aversen der Münzen zu sehen und die weibliche Figur auf Kupfernominalen auch als eben solche zu erkennen. ${ }^{164}$

Bevor ich zu einem abschließenden Urteil hinsichtlich der Datierung der Hochzeit komme, lohnt es sich, die anfangs geäußerte Frage, warum Herakleios eine derartige Verbindung einging, in die Überlegung mit einzubeziehen. Die Ehe zwischen Herakleios und Martina war nicht die einzige innerhalb der Familie, die zwischen nahen Verwandten geschlossen wurde: Anlässlich der Taufe seines Sohnes Herakleios Konstantin im Jahr 613 verlobte der Kaiser den Jungen mit Gregoria, der Tochter seines Cousins Niketas; die Ehe wurde im Jahr 630 geschlossen. ${ }^{165}$ Dieser Befund legt nahe, dass Herakleios ganz gezielt eine endogame Heiratspolitik verfolgte, wie sie auch in anderen vormodernen Monarchien gang und gäbe war, etwa bei den Ptolemäern eine endogame Heiratspolitik, die die verschiedenen Familienstränge noch enger miteinander verflocht: Herakleios entschied sich nicht, Martina zu heiraten; er entschied sich, seine Nichte zu heiraten. ${ }^{166}$ Mit der endogamen Heiratspolitik reagierte Herakleios auf die gängige Praxis hoher militärischer Funktionsträger, sich durch Heiratsallianzen mit der kaiserlichen Familie zu verbinden und dadurch Einfluss auf die Nachfolgeregelung zu nehmen. Dieses Phänomen, das als typisch für die politischen Prozesse des 5. und 6. Jahrhunderts identifiziert wurde, war zuletzt in der Person des Priskos erneut zu Tage getreten. ${ }^{167}$ Herakleios zeigte sich seinerseits darum bemüht, eine Dynastie zu begründen; er verfolgte dieses Ziel nicht nur, indem er seinen Sohn äußert früh zum Augustus erhob, sondern auch, indem er seine Familie konsequent von potentiellem Einfluss von außen abzuschotten suchte. ${ }^{168}$ Vor diesem Hintergrund halte ich es für plausibel, dass Herakleios nach dem Tod seiner ersten Frau 612 die familiäre Situation schnellstmöglich wieder zu konsolidieren suchte, anstatt über ein Jahrzehnt unverheiratet $\mathrm{zu}$ bleiben. Ich plädiere also dafür, die Hochzeit gemäß Theophanes’ Datierung ins Jahr 613/14 zu setzen - kurz nachdem Herakleios von der katastrophalen Syrien-Kampagne in die Hauptstadt zurückgekehrt war. ${ }^{169}$ Die weibliche Figur auf den Kupfer-Münzen identifiziere ich dementsprechend als Martina.

164 Auch der Umstand, dass die weibliche Figur nur auf den Kupfernominalen auftaucht, entspricht der ab Justin II. etablierten Praxis.

165 Nik. Brev. 5 (Verlobung); Nik. Brev. 17 (Eheschließung).

$166 \mathrm{Zu}$ Ehen zwischen Onkel und Nichte in der herodianischen Dynastie siehe Mitterauer 1991, $296 \mathrm{f}$. 167 Dazu siehe oben S. 153-156.

168 Vgl. Treadgold 1997, 289f.: „Presumably Heraclius hoped that blood relatives would be less likely than other connections to plot against his foundering government."

169 Herakleios und Martina hatten gemeinsam eine Reihe von Kindern: Theoph. Conf. AM 6106 (De Boor 301) vermerkt, Martina habe im Jahr nach der Hochzeit, also 615/16, einen Sohn zu Welt gebracht, 
Indem Herakleios seine Nichte heiratete, verstieß er gegen geltendes römisches Recht. ${ }^{170}$ In anderen Rechtstraditionen indes wurde die Ehe zwischen Onkel und Nichte nicht nur geduldet, sondern gar befürwortet: so etwa im mosaischen Recht des Alten Testamentes. ${ }^{171}$ In den Quellen gibt es keinerlei Hinweis darauf, dass Herakleios sich hinsichtlich seiner Verbindung zu Martina explizit auf alttestamentarisches Recht berief. Es ist jedoch allgemein anerkannt, dass das Alte Testament im Christentum der Spätantike als Referenzrahmen hoch im Kurs stand und dass gerade oströmische Kaiser sich in ihrer Herrschaftskonzeption und -ausübung mit alttestamentarischen Typen in Verbindung brachten bzw. im öffentlichen Diskurs mit diesen in Verbindung gebracht wurden. ${ }^{172}$ Dass auch Herakleios sich auf das Alte Testament bezog, zeigt der Umstand, dass einer der Söhne von Herakleios und Martina auf den Namen David getauft wurde ein Name, der keinesfalls zum Standardrepertoire monarchischer Nomenklatur zählte. ${ }^{173}$ Doch selbst wenn man diese Hypothese - die Berufung auf alttestamentarisches Recht - für plausibel hält, ist festzuhalten, dass dieser Aspekt der herakleischen Familienpolitik offenkundig in der Öffentlichkeit nicht auf Resonanz stieß; einer moralischen Verurteilung der Eheschließung beugte er jedenfalls nicht vor.

der durch den Patriarchen Sergios auf den Namen Konstantin getauft wurde. Dieser Konstantin, nicht zu verwechseln mit dem 612 geborenen Herakleios Konstantin, wird in keiner anderen Quelle erwähnt. Nik. Brev. 11 berichtet, dass Martina und Herakleios zwei Söhne mit Behinderung bekommen hätten, Flavius und Theodosios. Ebd. 18 wird vermerkt, dass zwei Söhne und zwei Töchter des Paares während des Perserkrieges verstorben seien. Theodosios war aber 629/39 noch am Leben, als er mit Nike, der Tochter des persischen Generals Shahrbaraz, vermählt wurde (Nik. Brev. 17). Insofern könnte man die beiden verstorbenen Söhne mit Konstantin und Flavius identifizieren; siehe Mango/Scott 1997, $431 \mathrm{f}$. Anm. 2. Während des Perserfeldzuges (625/626) kam schließlich ein weiterer Sohn zur Welt (Nik. Brev. 12), der 632 zum Caesar erhoben wurde. Er trug offenbar ebenfalls den Taufnamen Konstantin, zumindest gemäß dem Zeugnis des Theoph. Conf. AM 6108 (De Boor 301), der berichtet, wie Herakleios Konstantin seinen Bruder, den „kleinen Konstantin“, zum Caesar krönte. Es bleibt zu bemerken, dass Theophanes' Datierung falsch ist: Die Erhebung zum Caesar geschah in der 5. Indiktion, allerdings erwiesenermaßen erst einen Zyklus später, also 632 (siehe Mango/Scott 1997, 433 Anm. 2). Dieser Konstantin nahm dann den Namen Herakleios an, wie Datierungsformulare der 630er Jahre zeigen (siehe ebd.); unter diesem Namen wurde er 638 auch zum Augustus erhoben (Nik. Brev. 25 und De cerim. 2.27). In der Forschung firmiert er in der Regel unter dem Diminutiv Heraklonas; siehe dazu DOC II.2, 389f. und PLRE IIIA, Heraclonas (Heraclius) (587 f.). Nach dem Tod seines Vaters und Halbbruders Herakleios Konstantin im Jahr 641 war er für kurze Zeit alleiniger Augustus; Joh. Nik. 119.18 betont, er sei zu diesem Zeitpunkt noch ein Kind gewesen. Ihn mit dem Konstantin zu identifizieren, dessen Geburt Theophanes für das Jahr 615/6 vermerkt, ist daher nicht möglich.

$170 \mathrm{Zu}$ Endogamie im Christentum und Heiratskonventionen in der Spätantike siehe Mitterauer 1991 und O’Roark 1996; Mitterauer 1991, 299 zur Gesetzgebung im 4. Jahrhundert, die die Hochzeit von Onkel und Nichte unter Todesstrafe stellte; siehe das Verbot in Cod. Theod. 3.12.1.

171 Mitterauer 1991, 296.

172 Rapp 2010; Magdalino/Nelson 2010; zu alttestamentarischen Modellen für oströmische Kaiser im 6. Jahrhundert, insbesondere Salomon, siehe Viermann (im Druck).

173 In der Forschung wird oft Herakleios' Bezug auf den alttestamentarischen König David betont; diesen Befund diskutiere ich in unten S. 274-279 im Detail. Zu Herakleios' Sohn siehe PLRE IIIA, David 8 (390). 


\subsection{Abkehr von Konstantinopel}

Die Frage, die dieses Kapitel zu beantworten sucht, ist, warum es unter Herakleios zu einer sukzessiven Remilitarisierung des Kaisertums kam. Dass der Kaiser nach zweihundert Jahren der hauptstädtischen Monarchie mit etablierten Verhaltensweisen brach und wieder persönlich in den Krieg zog, ist in vielerlei Hinsicht erklärungsbedürftig. Wie bereits an anderer Stelle betont, brachte die Remilitarisierung des Kaisertums neue Herausforderungen mit sich. Herakleios' Syrien-Kampagne des Jahres 613 hatte die Risiken deutlich gemacht, die dem persönliche Engagement des Kaisers als Oberbefehlshaber inhärent waren: Die Niederlagen der römischen Truppen unter Herakleios' Führung zeitigten nicht nur fatale Auswirkungen auf die Verteidigung Syriens und der Levante, sie brachten das Bild des Kaisers als ewiger Sieger, wie es sich im Laufe des 5. und 6. Jahrhunderts verfestigt hatte, empfindlich ins Wanken. Herakleios zog sich in Folge dessen nach Konstantinopel zurück und verbrachte das nächste Jahrzehnt wie seine Vorgänger im kaiserlichen Palast. Die Hochzeit mit seiner Nichte, setzt man diese wie oben nahegelegt ins Jahr 613/614 an, diente nach der erlittenen Niederlage der weiteren Sicherung und Konsolidierung seiner Familie als Herrscherdynastie - eine Strategie, deren Grundstein er bereits in den Jahren zuvor gelegt hatte.

Nachdem Herakleios 613 aus Syrien zurückgekehrt war, offenbarte sich langsam aber sicher das volle Ausmaß der außenpolitischen Krise, in die das oströmische Reich schlitterte. Die Niederlage bei Antiochia war bei weitem nicht die letzte, die das römische Heer gegen die Perser verbuchen musste. Seitdem sich die sassanidische Dynastie im Jahr 224 n.Chr. etabliert hatte, schwankte das Verhältnis der beiden Großmächte Rom und Persien zwischen kriegerischen Auseinandersetzungen und längeren Perioden des Waffenstillstandes. Auch im 6. Jahrhundert hielten sich diplomatische Bemühungen um Stabilität einerseits und gewaltsame Konfrontation andererseits die Waage, wobei die Perser bisweilen bis weit in römische Gebiete vordrangen: Nach der Eroberung Antiochias im Jahr 540 etwa hinterließen sie die Stadt in Schutt und Asche. ${ }^{174}$ Es war also nicht das erste Mal, dass persische Truppen derart weit im Westen standen, doch ihr Vorrücken im frühen 7. Jahrhundert zeichnete sich durch eine eigene Qualität aus: Während die Armee des Großkönigs zuvor nach Plünderungen stets wieder auf heimisches Territorium zurückgekehrt war - allein in den grenznahen Gebieten Mesopotamiens und Armeniens wechselte bisweilen die politische Oberhoheit - setzte sie sich nun auf römischem Territorium fest. Mit den Niederlagen von Herakleios' Truppen in Nordsyrien und Kilikien war die Landverbindung zwischen Konstantinopel und den süd-östlichen Provinzen abgeschnitten; den Persern stand der Weg nach Syrien und Palästina offen. Ohne Aussicht auf militärische Unterstützung kapitulierte Damaskus vor der Übermacht der Angreifer unter

174 Zu Römern und Sassaniden siehe zuletzt Börm 2016 und Bonner 2019, außerdem Greatrex/Lieu 2002. 
dem Befehl des persischen Generals Shahrbaraz; mit Caesarea Maritima fiel auch die Provinzhauptstadt Palästinas in dessen Hände. ${ }^{175}$

Im Jahre 614 schließlich ereignete sich eine Tragödie von außerordentlichem Ausmaß: Die Eroberung Jerusalems, des Zentrums des christlichen Glaubens, durch die Perser. Als Shahrbaraz' Truppen vor den Mauern der Stadt auftauchten, bemühte sich der Patriarch Zacharias um eine friedliche Übergabe - Gegenwehr schien auch hier angesichts der mangelhaften Verteidigungslage zwecklos. Doch die Jerusalemer Bevölkerung war gespalten; innerhalb der Zirkusparteien wurden Stimmen laut, dass die kampflose Auslieferung an den Feind nicht hinzunehmen sei. Die Situation eskalierte und es gelang, die Besatzer vorerst aus der Stadt zu vertreiben. ${ }^{176}$ Zacharias' Bemühungen, den Schaden in Grenzen zu halten, erwiesen sich als zwecklos: Nach mehreren Monaten der Belagerung kam es schließlich zur gewaltsamen Einnahme der Stadt. Die christlichen heiligen Stätten wurden geplündert und der Patriarch gemeinsam mit Teilen der Bevölkerung in die persische Hauptstadt Ctesiphon deportiert. Im Gepäck der Perser befand sich nicht zuletzt die wichtigste Reliquie der Christenheit, das Heilige Kreuz aus der Jerusalemer Grabeskirche. ${ }^{177}$ Im Zuge der Eroberung entluden sich schließlich auch Spannungen zwischen jüdischen und christlichen Bevölkerungsgruppen; Berichte von jüdischen Massakern an Christen machten die Runde. ${ }^{178}$ Die über Jahrhunderte aus Jerusalem verbannten Juden be-

175 Flusin 1992 II, 79 mit Anm. 54 und Greatrex/Lieu 2002, 190.

176 Ant. Strateg. (Conybeare 504f.) und Sebeos 34 (Thomson/Howard-Johnston I, 68f.); vgl. Flusin 1992 II, 142-147; zu den Demenunruhen in der Levante vgl. Olster 1993, 101-115. Bei Grabungen auf dem Giv'ati Parkplatz südlich der osmanischen Stadtmauern wurde ein Münzschatz mit 264 herakleischen Solidi gefunden; siehe Bijovski 2010. Deren Untersuchung hat ergeben, dass ausnahmslos alle Stücke nicht nur ins Jahr 613 datieren, sondern mit demselben Stempel geprägt wurden, aller Wahrscheinlichkeit nach in einer temporär eingerichteten Prägestätte in Jerusalem, welche die für die Verteidigung gegen die Perser notwendigen Geldmittel zur Verfügung stellen sollte. Das Vorhandensein des Stempels vor Ort, welcher hauptstädtischen Exemplaren extrem ähnelt, weist darauf hin, dass zumindest im Laufe des Jahres 613 noch offizielle Kommunikation zwischen Konstantinopel und Palästina möglich gewesen sein muss. Darüber hinaus offenbart das Gebäude, innerhalb dessen der Hort geborgen wurde, einen der wenigen Zerstörungshorizonte, die bisher mit der persischen Eroberung von Jerusalem verknüpft werden konnten.

177 Sophr. Anacr. 14.69-102 (Klage über die Eroberung); Ant. Strateg. (Conybeare 504-508); Chron. Pasch. AD 614; Sebeos 34 (Thomson/Howard-Johnston I, 68-70); Theoph. Conf. AM 6106 (De Boor 300 f.); weitere Quellen im Überblick bei Flusin 1992 II, 129-136. Zur Rekonstruktion der Ereignisse siehe Fulsin 1992 II, 151-172; Kaegi 2003, 78-81; Greisiger 2014, 32-45; Bonner 2019, 282-287; zu den Bewältigungsstrategien siehe Flusin 1992 II, 136-140.

178 Siehe etwa Ant. Strateg. (Conybeare 508; vgl. ebd. 514-516); Theoph. Conf. AM 6106 (De Boor 300 f.). Das Ausmaß der Zerstörung und der Massaker an der christlichen Bevölkerung wurde zuletzt wiederholt relativiert; vgl. Wheeler 1991; Avni 2010; Stoyanov 2011b und ders. 2011a, 11-23. Gleichzeitig hat allerdings auch archäologische Evidenz zum Verständnis der Geschehnisse 614 beitragen können: So wurde etwa nahe des Mamilla-Beckens ein Massengrab entdeckt, welches anhand einer beiliegenden Münze des Phokas plausibel mit der Eroberung Jerusalems - bzw. gar mit dem Bericht des Ant. Strateg. (Conybeare 508) - in Verbindung gebracht wird; siehe Reich 1993, 109; Avni 2010, 36 f., 39 f. mit Verweisen auf die Grabungsberichte; außerdem Bijovski 2010, 66. 
grüßten die Perser, von deren Präsenz sie offenbar zumindest vorübergehend profitieren konnten. Doch ihre Hoffnungen auf eine Wiedererrichtung des jüdischen Tempels, die zeitweilig geschürt wurden, sollten sich auch unter zoroastrischer Oberhoheit nicht erfüllen. ${ }^{179}$

Die Eroberung und Plünderung Jerusalem war der vorläufige Höhepunkt der desaströsen Entwicklungen im Osten, die sich nun auch in Konstantinopel kaum mehr verharmlosen ließen. Es gelang zwar, zwei Reliquien aus dem Heiligen Land in die Hauptstadt zu retten, den Heiligen Schwamm und den Heiligen Speer, die in der Hagia Sophia von der versammelten Gemeinde verehrt wurden; ${ }^{180}$ doch auch diese Inszenierung vermochte den tragischen Verlust des Heiligen Landes kaum zu kompensieren. Die Besetzung Syriens und Palästinas hatte das oströmische Reich wichtiger Einnahmequellen beraubt; der Krieg an der Ostgrenze und die diplomatischen Bemühungen, die Avaren im Westen ruhig zu halten, zehrten darüber hinaus an den finanziellen Reserven. Vor diesem Hintergrund ließ Herakleios ab dem Jahr 615 einen neuen Münztypus in Umlauf bringen, das Silber-Hexagramm, dessen Prägung mit einer gesetzlich vorgeschriebenen Halbierung des Edelmetall-Wertes einherging. ${ }^{181}$ Auch in seiner Gestaltung nahm das Hexagramm Bezug auf die prekäre Lage des römischen Reiches: Während auf dem Avers - wie auf den andere Nominalen auch die beiden Augusti Herakleios und sein ältester Sohn Herakleios Konstantin abgebildet waren, trug das Revers ein Stufenkreuz mit dem Schriftzug Deus adiuta Romanis - „Gott hilf den Römern“. ${ }^{182}$

Doch die göttliche Hilfe blieb vorerst aus. Im Jahr nach der Eroberung Jerusalems rückte der persische General Shahin mit seinen Truppen bis nach Chalkedon am Bosporus vor. Ein persisches Heer stand somit erstmals in Sichtweite der Hauptstadt. Die Römer waren sich ihrer Schwäche bewusst und darauf bedacht, den Schaden einzudämmen. Herakleios setzte mit einer Flotte über den Bosporus über und ehrte Shahin mit Geschenken. Nachdem beide Seiten sich auf die Entsendung einer römi-

$179 \mathrm{Zu}$ jüdischen Reaktionen auf die Eroberung Jerusalems siehe Wheeler 1991; Sivan 2000; Van Bekkum 2002; zuletzt Greisiger 2014, 46 - 62 mit der These, dass für kurze Zeit der jüdische Kult auf dem Tempelberg wieder eingerichtet werden konnte; vgl. dazu bereits Mango 1992, 3-6. Eine Zusammenstellung hebräischer Texte, die aus diesem Kontext heraus entstanden sind, findet sich bei Reeves 2006.

180 Chron. Pasch. AD 614; die Datierung der Reliquienüberführung wurde allerdings zuletzt wiederholt in Zweifel gezogen und anstatt für das Jahr 614 für 629 plädiert, also nach der Rückgewinnung der Ostprovinzen; dazu siehe die ausführliche Diskussion bei Speck 2000 und Klein 2001, beide mit Verweis auf Ericsson 1968, die von einer Störung des einzigen Manuskriptes des Chron. Pasch. ausgeht. Kaegi 2003, 189 übernimmt die Spätdatierung. Zu der Problematik mit der Passage im Chron. Pasch. siehe Whitby/Whitby 1989, 157 Anm. 438. Trotz berechtigter Bedenken halte ich die Datierung ins Jahr 614 für plausibler.

181 Siehe Chron. Pasch. AD 615 mit Anmerkung von Whitby/Whitby 1989, 158f. Anm. 441; auch die Bronze-Münzen wurden in den darauffolgenden Jahren in ihrem Wert reduziert (siehe ebd.) und Hendy 1985, $494 \mathrm{f}$.

182 Kaegi 2003, 90 f.; zum Hexagramm Yannopoulos 1978 und DOC II.1, 17-18, 115-117. 
schen Delegation nach Ctesiphon geeinigt hatten, zog Shahin ab. Tatsächlich machten sich drei hochrangige Männer auf den Weg nach Persien, ein demütiges Friedensgesuch im Gepäck. ${ }^{183}$ In der persischen Hauptstadt angekommen wurden die Hoffnungen allerdings schnell zunichte gemacht: Chosroes ging weder auf das römische Friedensgesuch ein noch gewährte er den Gesandten die Rückkehr in die Heimat. ${ }^{184}$ Der Großkönig war sich seiner überlegenen Stellung bewusst und nutzte diese gezielt aus: Nachdem die Perser sich in Palästina festgesetzt hatten, drangen sie ab 616 bis nach Ägypten vor; 619 fiel ihnen schließlich die letzte römische Bastion Alexandria in die Hände. ${ }^{185}$ In dem von den Langobarden bedrohten Italien brachen derweil wiederholt Unruhen aus; ein Usurpationsversuch des Exarchen von Ravenna, Eleutherios, der sich im Jahr 619 offenbar zum weströmischen Kaiser krönen lassen wollte, verlief allerdings schnell im Sande. ${ }^{186}$

Das erste Jahrzehnt von Herakleios' Regierung war alles andere als erfolgreich; das römische Gemeinwesen musste realpolitisch wie psychologisch harte Schläge einstecken. Ein Gebietsverlust von außerordentlichem Ausmaß schwächte Reich und Hauptstadt; von den östlichen Provinzen konnte nur Kleinasien noch mit Mühe und Not unter römischer Kontrolle gehalten werden, geschützt durch die Bergzüge, die das anatolische Plateau nach Osten und Süden abschranken. ${ }^{187}$ Der Schock, den die Plünderung Jerusalems und der Raub der Kreuzreliquie bei der Bevölkerung ausgelöst hatten, saß tief. Allgemeine Verunsicherung griff um sich. Liturgische Neuerungen deuten darauf hin, dass der Bedrohung durch eine gemeinschaftliche Intensivierung

183 Chron. Pasch. AD 615 (706-709); Act. Anast. Pers. 8; Sebeos 38 (Thomson/Howard-Johnston I, 78f.); Nik. Brev. 6f.; siehe auch Theoph. Conf. AM 6107 (De Boor 301). Hinsichtlich der Datierung von Shahins Vorstoß nach Chalkedon sind sich die Quellen uneins; bisweilen wird das Ereignis mit der Belagerung Konstantinopels 626 vermischt (so etwa Sebeos); vgl. die eingehende Rekonstruktion bei Flusin 1992 II, 83-93, außerdem Stratos 1968, 115-117; Mango 1990, 176f.; Thomson/Howard-Johnston 1999 II, 210 - 213 und Kaegi 2003, 83-86. Es spricht nichts gegen die Datierung ins Jahr 615, wie sie Chron. Pasch. gibt; der Eintrag gibt außerdem einen Brief des Konstantinopolitaner Senats an Chosroes II. wieder, der - wie andere offizielle Dokumente in dieser Chronik - als authentisch eingeschätzt werden kann.

184 Zum Schicksal der Gesandten siehe Nic. Brev. 7.

185 Zur Eroberung Ägyptens siehe Stratos 1968, 111-114; Kaegi 2003, 91-93; Howard-Johnston $1999,3$. 186 Lib. Pont. 71 (Bonifatius); Paul. Diac. Hist. Lang. 4.34; siehe PLRE IIIa, Eleutherius (435f.); Kaegi 2003, 93f.; Ravegnani 2011, 69f. Eleutherios war 616 als Exarch nach Ravenna gesandt worden, nachdem sein Vorgänger Johannes und dessen Stab einem Aufstand zum Opfer gefallen waren. Nach weiteren Auseinandersetzungen mit den Langobarden beanspruchte Eleutherios das weströmische Kaisertum; der genaue Anlass, der ihn zu diesem Schritt bewegte, ist kaum zu rekonstruieren. Er bat den Bischof von Ravenna, ihn zu krönen; dieser jedoch verwies darauf, dass Eleutherios dies lieber in Rom vom Papst vornehmen lassen solle. Auf dem Weg nach Rom wurde Eleutherios von kaisertreuen Truppen gestellt und ermordet; seinen Kopf schicke man nach Konstantinopel. Dazu, dass es immer wieder einmal zu Bemühungen kam, nach 476 erneut einen weströmischen Kaiser einzusetzen, siehe Börm 2008.

$187 \mathrm{Zu}$ der außerordentlich angespannten Lage, in der sich das oströmische Reiche befand, siehe Raum 2019, 135-138. 
öffentlicher Religiosität begegnet wurde. ${ }^{188}$ Ein Nachlassen der persischen Dominanz war indes nicht in Sicht; Chosroes' Truppen hatten sich in den eroberten Gebieten als neue Machthaber eingerichtet. ${ }^{189}$ In der Hauptstadt machte sich die Okkupation der Ostprovinzen mit fatalen Folgen für die Versorgungslage bemerkbar. Die kostenfreie öffentliche Brotversorgung, ein Privileg der hauptstädtischen Bevölkerung, wurde erst an den Preis von drei Bronze-Folles pro Laib gebunden und schließlich ganz ausgesetzt. ${ }^{190}$ Konstantinopel litt unter Hungernöten und einem erneuten Ausbrechen der Pest. ${ }^{191}$ Anfang der 620er Jahre war die Staatskasse derart beansprucht, dass Kirchenschätze aus dem Besitz der Hagia Sophia eingeschmolzen wurden, um die Vorräte an Gold- und Silbermünzen zur Finanzierung des Krieges aufzustocken. ${ }^{192}$

In diesem Zusammenhang berichtet Nikephoros, Herakleios habe angesichts der aussichtslosen Situation geplant, Konstantinopel $\mathrm{zu}$ verlassen und nach Libyen überzusetzen; er habe gar ein mit Reichtümern beladenes Schiff dorthin geschickt, das allerdings auf dem Weg gekentert sei. ${ }^{193}$ Nur die Initiative der hauptstädtischen Bevölkerung und des Patriarchen hätten den Kaiser dazu gebracht, von seinen Plänen abzurücken und in Konstantinopel zu bleiben. ${ }^{194}$ Die Authentizität dieser Episode ist fragwürdig, zumal das Breviarium (bzw. Nikephoros' Quelle) nachweislich wiederholt Ereigniszusammenhänge mit legendenhaften Elementen ausschmückt. ${ }^{195}$ Wie in den letzten Kapiteln deutlich wurde, zeichnete sich Herakleios' Handeln während seiner Usurpation, aber auch nach der Krönung durch ein hohes Maß an Verständnis machtpolitischer Zusammenhänge aus. Sich in die ehemalige Heimat abzusetzen, hätte seiner Herrschaft den Boden entzogen; die Hauptstadt am Bosporus hinter sich zu lassen und als Kaiser in Afrika zu residieren, war zu diesem Zeitpunkt schlicht-

188 Nach der Eroberung Jerusalems fanden zwei symbolträchtige Reliquien aus dem Heiligen Land ihren Weg nach Konstantinopel und wurden dort in der Hagia Sophia verehrt (Chron. Pasch. AD 614; siehe Diskussion des Datums oben S. 178 Anm. 180). Im Jahr darauf etablierte der Patriarch Sergios einen neuen liturgischen Gesang (Chron. Pasch. AD. 615). Dieser Prozess wird von Mischa Meier als Liturgisierung beschrieben; siehe etwa ders. 2016.

189 In Ägypten übernahmen die Perser die römischen Münzstätten, siehe Greatrex/Lieu 2002, 196. 190 Chron. Pasch. AD 618 (711) mit Anmerkungen von Whitby/Whitby 1989 164, Anm. 449.

191 Nik. Brev. 8, ähnlich ebd. 12. Die Pest brach offenbar auch in anderen Teilen des Reiches aus, siehe Kaegi 2003, 102-105.

192 Kirchenschätze: Theoph. Conf. AM 6113 (De Boor 302f.) und Nik. Brev. 11. Gemäß der Parast. synt. chron. 42.7-10 soll Herakleios auch den Bronze-Ochsen auf dem Theodosios-Forum eingeschmolzen haben, um Truppen zu finanzieren.

193 Reichtümer im Meer zu versenken scheint fürs frühe 7. Jahrhundert geradezu zum Topos geworden zu sein; angesichts der heranrückenden Flotte des Herakleios soll auch Phokas Staatsschätze ins Meer geworfen haben; siehe Joh. Nik. 110.4 und dazu Kaegi 2003, 88. Das Motiv, dass ein reich beladenes Schiff Richtung Libyen geschickt wurde, mag allerdings auch ein Reflex davon sein, dass Herakleios von Konstantinopel aus versuchte, die dortige Verteidigung gegen die Perser mit Ressourcen zu unterstützen.

194 Nik. Brev. 8; Kaegi 2003, 88f. mutmaßt, Herakleios habe versucht, die hauptstädtische Bevölkerung mit seinen Abwanderungsplänen unter Druck zu setzten, um seine Sparpolitik durchzubringen. 195 Diesen Sachverhalt werde ich in Bezug auf Nik. Brev. 24f. unten Kap. 6.2.2 im Detail zeigen. 
weg nicht möglich. Was Nikephoros als Herakleios’ Auswanderungspläne wiedergibt, sind meiner Ansicht nach Reflexe von Gerüchten, welche in Konstantinopel zirkulierten und die Verunsicherung der dortigen Bevölkerung zum Ausdruck brachten. ${ }^{196}$ Dass Versuche des regierenden Kaisers, sich graduell von Konstantinopel zu lösen, auf strikte Missbilligung stießen, hatte bereits Maurikios' vorsichtiger Vorstoß nach Thrakien einige Jahrzehnte zuvor unter Beweis gestellt. ${ }^{197}$ Unter Herakleios verhielt es sich nicht anders. Die Anwesenheit des Kaisers in Konstantinopel wurde gerade in prekären Situationen nicht nur vom Palast-Umfeld, sondern auch von der hauptstädtischen Bevölkerung eingefordert. Selbst Georg von Pisidien als Dichter panegyrischer Epen kam nicht umhin, die Irritation zu thematisieren, die sich in Konstantinopel Bahn brach, als der Kaiser sich sukzessive der hauptstädtischen Öffentlichkeit zu entziehen begann, um sich im Umkehrschluss dem Militär anzunähern und persönlich als Heerführer zu agieren. ${ }^{198}$

Im Jahr 622 verließ Herakleios tatsächlich erneut die Hauptstadt. Den Sommer 622 verbrachte er mit den römischen Soldaten in Kleinasien und konnte gar einen Sieg gegen persische Einheiten verzeichnen. Nachdem ihm die Avaren, die weiterhin Thrakien bedrängten, keine andere Wahl gelassen hatten, als in die Hauptstadt zurückzueilen und sich der Problematik persönlich anzunehmen, machte Herakleios sich im Frühjahr 624 wieder auf den Weg gen Osten. Diese Kampagne führte ihn über die Grenzen Kleinasiens hinaus bis ins persische Kernland. Was als eine sprichwörtliche Himmelfahrtsmission anmutet, zeitigte letztendlich den erhofften Erfolg. Der militärische Druck durch die Römer brachte die innerpersischen Machtverhältnisse in Bewegung: Chosroes II. wurde gestürzt und sein Sohn Kavadh Seiroe folgte ihm nach; der neue Großkönig sandte umgehend ein Friedensangebot an die Römer, das die Räumung der besetzten Provinzen beinhaltete. Mit dem Sieg im Rücken kehrte Herakleios nach über vier Jahren nach Konstantinopel zurück. ${ }^{199}$

Dass die Hauptstadt Herakleios in den Jahren der Abwesenheit die Treue halten und er nach über vier Jahren als Sieger würde zurückkehren können, war Anfang der 620er Jahre, als der Kaiser Konstantinopel erneut den Rücken kehrte, keinesfalls absehbar. Im Gegenteil: Der Machtwechsel von 610 hatte verdeutlicht, wie schnell die Stimmung in Konstantinopel kippen konnte. Die Hauptstadt im Jahr 622 für einen Sommer und ab 624 für mehrere Jahre am Stück zu verlassen, war für Herakleios demnach nicht etwa der logische bzw. folgerichtige Schritt, als der er in der Forschung bisweilen dargestellt wird. Stattdessen barg die kaiserliche Entscheidung eine Reihe

196 Bereits nach Phokas' Sturz habe Herakleios laut Chron. Pasch. AD 615 signalisiert, wieder nach Afrika zurückkehren zu wollen, da sein Ziel, der Sturz des Tyrannen und die Rache des Maurikios, erreicht sei. Es wurde bereits betont, dass hierin keine tatsächliche Absicht zu vermuten ist; stattdessen ist der Topos vom zögerlichen und demütigen Herakleios als Teil einer gezielten Repräsentationsstrategie zu verstehen; siehe oben S. 120 mit Anm. 196.

197 Theoph. Sim. Hist. 5.16.2-4.

198 Georg. Pis. Exped. Pers. 1.112-125; ähnlich ders. Heracl. 2.122-132.

199 Diese Abläufe werden im Detail unten S. 230 - 232 nachvollzogen. 
an schwerwiegenden Risiken: Neben dem Risiko der persönlichen Niederlage banden über Jahrhunderte gefestigte Verhaltenserwartungen den Kaiser an Konstantinopel; gegen diese Erwartungen zu verstoßen, konnte die Akzeptanzbasis der Hauptstadt empfindlich destabilisieren. Auch eine vermeintlich überragende militärische Expertise lässt sich kaum als Grundlage für die kaiserliche Entscheidung anführen, als Feldherr zu agieren. ${ }^{200}$ Herakleios stammte zwar aus einer Familie hochdekorierter und erfahrener Militärs (sein Vater hatte sich unter Maurikios als Magister militum im Perserkrieg hervorgetan); im Gegensatz zu seinen Vorgängern Phokas und Maurikios hatte er selbst jedoch vor seiner Krönung offenbar keine substantielle Erfahrung als aktiver Befehlshaber gesammelt. ${ }^{201}$ Die Eroberung Ägyptens hatte im Zuge der afrikanischen Revolte sein Cousin Niketas gestemmt. Erst als die Rebellen den südlichen Mittelmeerraum hatten militärisch sichern können, bestieg Herakleios ein Schiff und segelte unbehelligt bis nach Konstantinopel, wo die kurzen Kampfhandlungen in den Häfen primär zwischen den hauptstädtischen Parteien ausgefochten wurden. ${ }^{202} \mathrm{Ab}$ gesehen von dem gescheiterten Vorstoß nach Syrien im Jahr 613 hatte der Kaiser also keine bzw. wenig militärische Praxiserfahrung, als er sich 622 bzw. 624 erneut als Befehlshaber an die Spitze der römischen Truppen setzte. ${ }^{203}$

Herakleios’ Maßnahme ist kaum anders zu erklären, als dass ihm nach über einem Jahrzehnt auf dem Thron schlichtweg keine andere Wahl blieb, als die Flucht nach vorne zu wagen, um seine Herrschaft zu sichern. Hinsichtlich dieser Entscheidung griffen außen- und innenpolitische Faktoren aufs Engste ineinander. In der Regel wird Herakleios’ Entscheidung, persönlich die Position des Oberbefehlshabers einzunehmen, mit der geradezu aussichtslosen Situation in den Ostprovinzen in

200 Dies legt etwa Lee 2007, 37 nahe: „A man of his experience could not sit in Constantinople leaving others to get their hands dirty.” Allerdings sieht auch Lee die Gefahr, die für Herakleios vom militärischen Sektor ausging (siehe ebd.): „Perhaps the Phocas episode had made him and his advisers realize that, whatever the risks on the battlefield, it was not an option to distance himself from the army and risk another usurper emerging from that quarter.” Bisweilen wird gar auf den wagemutigen Charakter des Kaisers verwiesen; zudem habe ihm seine afrikanische Herkunft eine globale Perspektive auf römische Herrschaft ermöglicht, angesichts derer Konstantinopel an Bedeutung verloren habe; so etwa Pfeilschifter 2013, 68: „Der Kaiser war mit knapp 40 Jahren noch relativ jung und unternehmungslustig, seine erfolgreiche Usurpation gegen Phokas hatte in ihm vielleicht die Überzeugung reifen lassen, er sei ein überragender Feldherr, und, am wichtigsten, er hatte die meiste Zeit seines Lebens in der Provinz verbracht, fern vom Hof und fern von Konstantinopel. Die Stadt war ihm nicht unbedingt Maß aller Dinge, in seiner Erfahrungswelt umfasste das Reich wesentlich mehr als den Bosporus.“

201 Tatsächlich ist über Herakleios’ frühe Jahre in Africa recht wenig bekannt; vgl. die recht weit ausgeschmückte biographische Rekonstruktion in Kaegi 2003,19-57. Allerdings ist anzunehmen, dass die Quellen es in irgendeiner Form verzeichnet hätten, wenn Herakleios sich vor seiner Fahrt nach Konstantinopel militärisch hervorgetan hätte.

202 Dazu siehe oben Kap. 3.2.

203 Das mag auch der Grund dafür sein, dass Georg von Pisidien ausführlich thematisiert, wie Herakleios sich vor seinem Aufbruch nach Persien mit Büchern zurückgezogen habe, um Militärstrategie zu studieren; Georg. Pis. Heracl. 2.118-121. 
Verbindung gebracht: ${ }^{204}$ Die Aggression der Perser hatte bislang unbekannt Ausmaße angenommen und zeitigte destabilisierende Auswirkungen - sowohl materiell wie auch psychologisch - auf die sensible Gemengelage in Konstantinopel. Die in dieser Arbeit gewählte Perspektive legt allerdings nahe, dass Herakleios mit seiner Remilitarisierung nicht allein auf die Bedrohung durch die Perser, sondern auch auf innenpolitische Instabilität und eine latente Bedrohung aus dem militärischen Sektor reagierte. ${ }^{205}$ Konstantinopel war und blieb auch im frühen 7. Jahrhundert Dreh- und Angelpunkt monarchischer Herrschaft, die Akzeptanz der hauptstädtischen Gruppen deren Basis; dies hatten nicht zuletzt die beiden Machtwechsel von 602 und 610 gezeigt, die nur erfolgen konnten, da sich die relevanten hauptstädtischen Interessensgruppen von dem jeweils regierenden Kaiser abwandten. Gleichzeitig hatte sich allerdings auch herausgestellt, dass Impulse aus dem Militär die Stimmung in Konstantinopel wesentlich direkter beeinträchtigen konnten, als dies in den Jahrhunderten zuvor der Fall gewesen war. Herakleios hatte mit seiner geglückten Usurpation, die ihn von der Provinz in den kaiserlichen Palast katapultierte, die Probe aufs Exempel erbracht. Angesichts dieser Entwicklung bot Konstantinopel dem Kaiser keinen adäquaten Schutz mehr; an den Praktiken der sesshaften Vorgänger auf dem Kaiserthon festzuhalten, wie es noch sein Vorgänger Phokas getan hatte, reichte nicht mehr aus, um an der Macht zu bleiben. Indem Herakleios sich an die Spitze der römischen Truppen setzte, zielte er darauf ab, die kaiserliche Autorität über den militärischen Sektor zu festigen und damit potentiell destabilisierenden Impulsen, wenn nicht gar einer erneuten Usurpation, vorzubeugen. Anstatt den militärischen Sektor inmitten eines Perserkrieges ambitionierten und potentiell unberechenbaren Generälen zu überlassen, wie es seine Vorgänger getan hatten, setzte er sich selbst als oberster Feldherr an die Spitze der römischen Truppen. Mit seiner persönlichen Präsenz auf dem Schlachtfeld näherte Herakleios sich auch in wesentlich höherem Maße als seine sesshaften Vorgänger den römischen Soldaten an. Auf Seiten des Heeres wurde eine derart hergestellte Nahbeziehung sicherlich positiv aufgenommen; eine engere Bindung an den Kaiser versprach den Soldaten Prestige, wenn nicht gar konkrete materielle Vorteile. ${ }^{206}$

204 So etwa Treadgold 1997, 287-301; Walter E. Kaegi beleuchtet die Situation in seinen Publikationen aus verschiedenen Perspektiven: In Herakleios' Kampagnen von 612 und 613 sieht er dessen Versuch, die unruhige Armee wieder fester an den Kaiser zu binden (Kaegi 1981, 147 f.); hinsichtlich des erneuten Aufbruchs von 622 und 624 legt auch er nahe, dass dem Kaiser angesichts des Verlustes der Ostprovinzen keine andere Wahl geblieben sei (ders. 2003, 109). Howard-Johnston 2010, 252f. meint, Herakleios habe durch sein Feldherrentum von ,private affairs”, also der Ehe mit Martina, ablenken wollen. $205 \mathrm{Zu}$ der Frage nach den Hintergründen der Remilitarisierung des Kaisertums unter Herakleios vgl. Raum 2019; ebd. 144f., 146f. wird nahegelegt, dass es Herakleios daran gelegen war, die Loyalität der Soldaten zu ihm zu stärken.

206 Kurz nach seiner Rückkehr nach Konstantinopel 476 verkündete Kaiser Zenon den Soldaten, dass er sie im Kampf gegen die Goten anführen würde. Die Begeisterung auf Seiten der Soldaten, die eine derartige Nachricht auslöste, war allerdings nur von kurzer Dauer: Als Zenon sich doch für einen Verbleib in der Hauptstadt entschied, brach unter den Soldaten Unruhe aus, der der Kaiser nur be- 
Als Herakleios gen Osten aufbrach, musste er gegen die Zentripetalkräfte - die Verhaltenserwartungen der hauptstädtischen Interessengruppen - ankämpfen, die ihn nach Jahrhunderten der sesshaften Monarchie geradezu an Konstantinopel ketteten. Um die Erweiterung seines Handlungsspielraumes entgegen etablierter Konventionen durchsetzen zu können und gleichzeitig seine Akzeptanzbasis zu sichern, traf Herakleios eine Reihe praktischer Vorkehrungen. Während seine zweite Ehefrau Martina ihn auf dem Feldzug begleitete, ließ er, wie bereits bei der Syrien-Kampagne des Jahres 613, auch in den 620er Jahren seinen Sohn Herakleios Konstantin sowie dessen ältere Schwester, die Augusta Epiphania, in der Hauptstadt zurück. ${ }^{207}$ Damit im hauptstädtischen Beziehungsgeflecht keine Leerstelle entstand, die Anlass für eine erneute Usurpation hätte bieten können, kompensierte Herakleios die eigene Abwesenheit durch die Präsenz des Junior Augustus. Mit dem Patriarchen Sergios und dem Patrikios Bonos, der als Statthalter für den Kaiser agierte, installierte Herakleios ein operatives Führungsduo, das ihm in den Jahren seiner Abwesenheit von der Hauptstadt die Treue hielt. ${ }^{208}$

Herakleios’ Allianzen sowohl im klerikalen als auch im säkularen Feld erwiesen sich als erstaunlich stabil. Besonders in dem Patriarchen Sergios, der noch unter Phokas berufen worden war, fand Herakleios einen loyalen Verbündeten, der die Geschicke der Hauptstadt nicht nur in den Jahren kaiserlicher Abwesenheit verlässlich lenkte, sondern auch mit Herakleios an einem Strang zog, als es in den 630er Jahren darum ging, einen religionspolitischen Kompromiss zu erzielen. ${ }^{209}$ Dass Kaiser und Patriarch von Konstantinopel derart gut zusammenarbeiteten, war keinesfalls selbstverständlich: Im Laufe des 5. und 6. Jahrhundert waren die kirchliche und die weltliche Instanz wiederholt in erbitterten Machtkämpfen aneinandergeraten. ${ }^{210}$ Wie genau sich das persönliche Verhältnis zwischen Herakleios und Sergios gestaltete, ist kaum zu rekonstruieren; allerdings entsteht der Eindruck einer gegenseitigen Ab-

gegnen konnte, indem er die enttäuschten Soldaten vorzeitig auf die Winterquartiere verteilte und sich auf eine kostspielige diplomatische Lösung des Konfliktes mit den Goten einließ; siehe Malch. fragm. 18.3. Malchos begründet Zenons Rückzieher mit Feigheit; Pfeilschifter 2013, 63 dagegen meint, dass die Möglichkeit des persönlichen Scheiterns für Zenon doch zu riskant gewesen sei; weitere Erklärungsansätze für diesen Sinneswandel liefert Errington 1983.

207 Chron. Pasch. AM 624.

208 Theoph. Conf. AM 6113 (De Boor 303); die genaue Stellung des Bonos ist unklar; die Ämter des Magister militum praesentalis oder Magister officiorum stehen zur Debatte, siehe PLRE IIIa, Bonus 5 (242-244) und Haldon 1984, 444-446. Bonos vereinte offenbar militärische und zivile Kompetenzen. Nähere Informationen zu ihm sind nicht verfügbar; allerdings scheint es, dass er erst unter Herakleios Karriere machte und diesem entsprechend verpflichtet war. Dass Bonos noch vor dem Persersieg verstarb (Chron. Pasch. AD 627), mag für Herakleios, für den allzu große Machtfülle in einem weltlichen Amtsträger stets eine potentielle Bedrohung darstellen konnte, von Vorteil gewesen sein.

209 Besonders deutlich wurde der Wert von Sergios' Anwesenheit in Konstantinopel im Zusammenhang mit der Doppelbelagerung durch Perser und Avaren im Jahr 626; diese Konstellation untersuche ich unten Kap. 5.3 im Detail; zur Religionspolitik siehe unten Kap. 6.1.3.

210 Zu dem Verhältnis zwischen Kaisern und Patriarchen (bzw. der hauptstädtischen Geistlichkeit) siehe Pfeilschifter 2013, 355-451. 
hängigkeit: Herakleios musste - vor allem angesichts seiner Abwesenheit - auf Sergios als zentrale Autoritäts- und Identifikationsperson in Konstantinopel vertrauen können; Sergios profitierte von einem guten Verhältnis zum Kaiser insofern, als er die Herabsetzungen, die das Konstantinopolitaner Patriarchat unter Phokas hatte hinnehmen müssen, ${ }^{211}$ kompensieren und seine eigene Position stärken konnte. Doch loyale Verbündete allein reichten Herakleios kaum aus, um Konstantinopel über die langen Jahre seiner Abwesenheit zu sichern; im folgenden Kapitel wird deutlich, dass die kaiserliche Entscheidung, wieder persönlich als Feldherr zu agieren, auch kommunikativ bewältigt werden musste.

211 Dazu siehe oben S. 143. 


\section{Der schwitzende Kaiser}

Die vorigen Kapitel haben sich mit der Frage auseinandergesetzt, warum Herakleios als erster Kaiser seit über zweihundert Jahren wieder für längere Zeit die Hauptstadt Konstantinopel verließ, um an der Spitze seiner Truppen in den Krieg zu ziehen. Nachdem zwei gewaltsame Machtwechsel das römische Gemeinwesen innenpolitisch destabilisiert hatten, bestand Herakleios' zentrale Herausforderung darin, einer erneuten Usurpation aus dem militärischen Sektor vorzubeugen. Das hauptstädtische Umfeld, das den Kaisern des 5. und 6. Jahrhunderts ein recht hohes Maß an Sicherheit geboten hatte, erwies sich als zunehmend fragil; angesichts externer Impulse war die Bevölkerung allzu gewillt, einem alternativen Kandidaten für den Kaiserthron zu akklamieren. Gleichzeitig sah sich Herakleios nach seiner Erhebung zum Kaiser mit einer außenpolitischen Katastrophe von bislang unbekanntem Ausmaß konfrontiert die Eroberung der Ostprovinzen durch die Perser, die entschiedenes Handeln erforderte. Um seine Herrschaft zu stabilisieren, verfolgte Herakleios eine proaktive Politik und setzte er sich selbst als oberster Feldherr an die Spitze der römischen Truppen. Das nun folgenden Kapitel widmet sich den Auswirkungen, die Herakleios' Remilitarisierung des Kaisertums auf das hauptstädtische Umfeld zeitigte, und vollzieht nach, im Rahmen welcher Diskurse die plötzliche Abwesenheit des Monarchen im hauptstädtischen Kommunikationsraum von seinen Zeitgenossen bewältigt werden konnte.

Herakleios' Bruch mit etablierter Regierungspraxis wird nicht nur in der modernen Geschichtswissenschaft als bemerkenswert erachtet; dass auch seine Zeitgenossen die kaiserliche Entscheidung als außergewöhnlich wahrnahmen, zeigt eine Passage aus der Expeditio Persica des Georg von Pisidien, die kurz nach Herakleios' Kampagne von 622 entstand. Der Panegyriker kommt nicht umhin, das gespaltene Meinungsbild $\mathrm{zu}$ thematisieren, das die hauptstädtische Öffentlichkeit angesichts Herakleios’ Transgression prägte: ${ }^{1}$

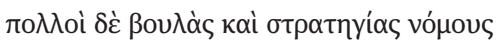

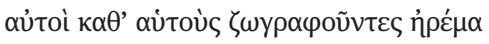
है

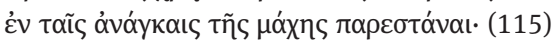

Viele aber malten selbst für sich allein die Beschlussfassungen und die Gesetze der Feldherrenschaft aus und sagten, es sei notwendig, dass die Macht des Kaisers in den Zwängen des Kampfes beistehe.

1 Bislang wurden nur italienische Übersetzungen von Georgs Gedichten veröffentlicht (Pertusi 1959, Tartaglia 1998). Weder die lang angekündigte englische Übersetzung von Mary Whitby noch die deutsche von Federico Montinaro, die sich seit einigen Jahren in Arbeit befindet, lagen mir vor; daher erachte ich es für sinnvoll, immer wieder längere Abschnitte der Gedichte in deutscher Übersetzung, von mir angefertigt, in den Text zu integrieren. 


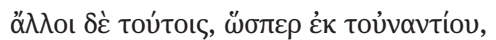

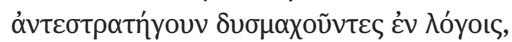

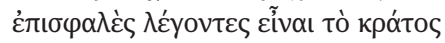

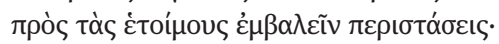

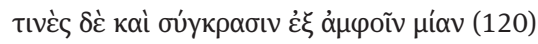

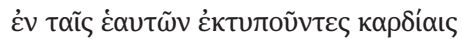

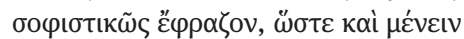

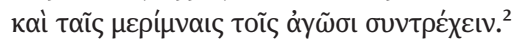

Andere jedoch, wie von der Gegenseite, hielten diesen entgegen und kämpften vergeblich mit Worten, indem sie sagten, dass es gefährlich sei, die Macht (des Kaisers) den tatsächlichen Gefahren auszusetzen.

Manche aber bildeten in ihren Herzen eine eigene Mischung aus den beiden Meinungen und sagten sophistisch, (es sei nötig,) sowohl zu bleiben als auch den Sorgen im Kampf zu begegnen.

Der Gruppe, die angesichts der akuten Bedrohung durch die Perser ${ }^{3}$ ein Engagement des Herakleios auf dem Schlachtfeld guthieß, standen - so der Dichter - harsche Kritiker entgegen: Dass Herakleios persönlich als Feldherr in den Krieg ziehe, sei schlichtweg zu gefährlich. Wie bereits in Hinblick auf andere Konstellationen deutlich wurde, stießen Versuche des Kaisers, sich von der Hauptstadt zu entfernen, um im militärischen Sektor aktiv zu werden, auf explizite Missbilligung. ${ }^{4}$ Mit der бúyкрабıৎ, der Mischung aus den beiden entgegengesetzten Meinungen, bezieht der Dichter sich im oben zitierten Abschnitt schließlich, so könnte man meinen, auf den vom Kaiser tatsächlich implementierten Kompromiss: Herakleios selbst stellte sich dem Kampf; mit seinem Sohn Herakleios Konstantin, der bereits 613 zum Augustus gekrönt worden war, blieb allerdings ein Vertreter kaiserlicher Würde dauerhaft in der Hauptstadt. ${ }^{5}$

Die Art und Weise, wie Herakleios' Herrschaft im Konstantinopel des frühen 7. Jahrhunderts wahrgenommen wurde, findet im poetischen Oeuvre des Georg von Pisidien, dessen Analyse im Zentrum dieses Kapitels steht, einen besonders eloquenten Ausdruck. Als Gelegenheitsschriften reagierten zumindest manche dieser Gedichte ganz direkt auf rezente Ereigniszusammenhänge und eröffnen damit einen Einblick in den Aushandlungsprozess, der sich im Konstantinopel der 620er Jahre hinsichtlich der Möglichkeiten und Grenzen kaiserlicher Herrschaftspraxis entspann. ${ }^{6}$ Anhand der Gedichte lässt sich aufzeigen, wie Herakleios' innovative Politik im hauptstädtischen Kommunikationsraum sukzessive mit einer spezifischen Deutung versehen wurde, die zu der Bewältigung seiner Transgression beitrug und somit die kaiserliche Position stabilisierte. Um gerade das Prozesshafte in den Vordergrund zu stellen, unterscheide ich im Folgenden zwischen drei Zeitphasen, die - repräsentiert jeweils durch eines oder mehrere Gedichte - spezifische Herausforderungen sowohl an den Kaiser wie an den Dichter stellten. Die Analyse wird verdeutlichen, dass Georg

2 Exped. Pers. $1.112-123$.

3 Georg leitet die Passage ein, indem er ein düsteres Bild der außenpolitischen Lage zeichnet (Exped. Pers. 104-111): „Die schwarze Nacht der Feinde breitete sich über die gesamte Oikumene aus.“ ( $\dot{\eta}$ vù

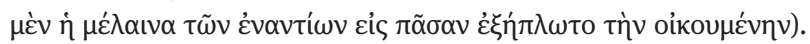

4 Zum Versuch des Maurikios, sich in Thrakien zu engagieren, siehe Theoph. Sim. Hist. 5.16.2-4; zur Kritik des Priskos an Herakleios’ Vorstoß nach Caesarea im Jahr 612 siehe Nik. Brev. 2.

5 Zur Kritik an Herakleios’ Entscheidung siehe Ma. Whitby 1998, 258f.; Leppin 2020, 302.

6 Die Art und Weise, wie Georg von Pisidien in seinem Gedicht In Heraclium ex Africa redeuntem die Machtergreifung des Herakleios verarbeitete, habe ich bereits oben Kap. 3.4 herausgearbeitet. 
ein Kaiserbild entwarf, das den Anforderungen seiner Zeit gerecht wurde und damit von traditionellen Modellierungen der kaiserlichen Imago abrückte, wie sie sich im Laufe des 5. und 6. Jahrhunderts herausgebildet hatten. Dieses neuartige Kaiserbild zeichnet sich durch drei zentrale Charakteristika bzw. Motive aus, die in unterschiedlicher Ausformung in allen drei behandelten Phasen $\mathrm{zu}$ erkennen sind: ${ }^{7}$ (1) Georg spricht Herakleios konsequent als strategos, als Feldherr, an; ${ }^{8}$ (2) der Dichter betont die kaiserlichen ponoi, seine Mühen; ${ }^{9}$ (3) der Kaiser schwitzt. ${ }^{10}$ In Synthese wird nicht nur die semantische Vielschichtigkeit und Anpassungsfähigkeit dieser Motive verdeutlicht, sondern auch ihre kommunikative Funktion.

\subsection{Den Kaiser loben - Panegyrik im Kontext}

Fragt man nach der kommunikativen Funktion der hier untersuchten Quellen, bedarf es zuerst eines eingehenderen Blicks auf Georgs Schaffen und auf den Kontext, innerhalb dessen sein Oeuvre überhaupt eine Wirkung entfalten konnte. Bei den Gedichten handelt es sich um primär orale Medien; sie wurden komponiert, um vor einem Publikum vorgetragen zu werden. Eine Zirkulation in schriftlicher Form, die den Ursprung dafür legte, dass die Texte bis in die heutige Zeit tradiert wurden, war sekundär. ${ }^{11}$ Wie haben wir uns nun diese Rezitation vorzustellen? Während zumindest einige von Georgs Gedichten einen deutlichen Bezug auf rezente Ereigniszusammenhänge vorweisen und damit der Zeitpunkt ihrer Komposition und Rezitation eingegrenzt werden kann, finden sich keine expliziten Hinweise auf den Rahmen, innerhalb dessen sie vorgetragen wurden. ${ }^{12}$ Mary Whitby als eine der besten Kennerinnen von Georgs Oeuvre geht davon aus, dass sich zumindest die kürzeren Gedichte (etwa In Heraclium ex Africa redeuntem oder In Restitutionem S. Crucis) an eine breitere Öffentlichkeit richteten, dass sie gar - analog zu der Siegesdepesche, die Konstanti-

7 Die Gedichte des Georg sind derart komplex, dass man noch eine ganze Reihe anderer Besonderheiten herausarbeiten könnte; ich beschränke mich hier ganz bewusst auf die oben genannten drei Charakteristika, da sie in Zusammenhang mit der Fragestellung dieser Arbeit besonders aussagekräftig sind. Besonderes Verdienst in der Erschließung und Interpretation von Georgs Oeuvre kommt Mary Whitby zu (1994, 1995, 1998, 2002, 2003).

8 Zum strategos-Attribut siehe etwa Exped. Pers. 1.35, 1.126, 2.19, 2.244, 3.52, 3.280, 3.374, 3.427; Heracl. 1.138, 1.177, 1.201.

$9 \mathrm{Zu}$ den ponoi siehe In Heracl. ex Afr. 48; Exped. Pers. 1.198, 2.65, 2.104, 3.88, 3.103, 3.111, 3.308, 3.321, 3.322; In Bonum 57, 90 f., 100 f., 114f.; Bell. Avar. 247, 265; Heracl. 1. 94, 1.137, fragm. 13.

10 Zum Schwitzen siehe Exped. Pers. 1.210, 3.101, 3.408; In Bonum 95, 161; Heracl. 1.146, 1.197, 1.205, 1.299.

$11 \mathrm{Zu}$ den Eigenheiten der schriftlichen Überlieferung siehe Lauxtermann 2003, $57 \mathrm{f}$. Zu der Publikation und nachträglichen Zirkulation von Manuskripten panegyrischer Reden siehe Wienand 2012, 27. 12 Aussagen zum Ort der Rezitation und dem anwesenden Publikum, wie sie etwa als Lemmata in der Manuskripttradition der Ekphasis des Paulos Silentiarios erhalten sind (siehe z. B. Bell 2009, 193f.), sucht man bei Georg von Pisidien vergeblich. 
nopel 628 aus Persien erreichte ${ }^{13}$ - in der Hagia Sophia vor versammelter Gemeinde verlesen wurden. Die längeren Gedichte, welche in diesem Kapitel untersucht werden, indes situiert Whitby - entsprechend der Ekphrasis des Paulos Silentiarios und Goripps Lob auf Justin II. aus dem 6. Jahrhundert ${ }^{14}$ - im zeremoniellen Kontext des Palastes. ${ }^{15}$ Angesichts der komplexen Sprache und der raffinierten Verweise, die oft nicht nur mit biblischen, sondern auch mit mythischen und historischen Referenzen spielen, scheint mir der Vortrag vor einem gelehrten Publikum, das derartige Finessen verstehen und wertschätzen konnte, in der Tat am wahrscheinlichsten. ${ }^{16}$

Alle hier im Detail analysierten Gedichte zeichnen sich durch Lob und Überhöhung des Herakleios aus; das enkomiastische Element ist geradezu ubiquitär. Doch während die Expeditio Persica und die Heraclias den Kaiser uneingeschränkt in den Vordergrund stellen, wenden sich In Bonum und Bellum Avaricum auch an andere Akteure der Hauptstadt, an Herakleios' Statthalter Bonos bzw. den Patriarchen Sergios. Die beiden erstgenannten Gedichte, dem Kaiser gewidmet, wurden präsentiert, als Herakleios sich in Konstantinopel befand; über die Annahme hinaus, dass die Verse im zeremoniellen Kontext des kaiserlichen Palastes rezitiert wurden, macht diese Beobachtung plausibel, dass auch der Kaiser selbst in einem seiner prunkvollen Empfangssäle dem Vortrag beiwohnte. ${ }^{17}$ Als Georg die beiden letztgenannten Gedichte komponierte, weilte Herakleios dagegen im Feldlager; seine Abwesenheit bot Raum für das Lob seiner beiden wichtigsten Verbündeten in der Hauptstadt, Bonos und Sergios. ${ }^{18}$

13 Chron. Pasch. AD 628.

14 Zur Ekphrasis siehe Ma. Whitby 1985; Macrides/Magdalino 1988 und Bell 2009, 79-95; zu Goripp siehe Av. Cameron 1976a.

15 Ma. Whitby 1998, 251; siehe auch Lauxtermann 2003, 58 zu der Wirkung, die Georgs Gedichte auf ein Publikum haben konnten, und der Frage der Reichweite.

16 Selbst bei den kürzeren Gedichten habe ich Zweifel, ob sie vor einem derart breiten Publikum vorgetragen wurden wie von Ma. Whitby angenommen. Georgs Gedichte unterscheiden sich in ihrer Sprache und Komplexität von Medien, die sich erwiesenermaßen an ein breiteres Publikum richteten und von diesem auch verstanden werden sollten, wie etwa Predigten, liturgische Hymnen oder die besagte Siegesdepesche, die in der Hagia Sophia verlesen wurde (Chron. Pasch. AD 628). Die Art und Weise, wie liturgische Hymnen sich an ein breites Publikum wandten und von diesem auch verstanden werden konnten, hat Koder 1999 herausgearbeitet; er betitelt diese Gattung daher gar als „Massenmedium des sechsten Jahrhunderts“ (ders. 2005, 22). Keines dieser Merkmale erkenne ich in Georgs Gedichten wieder.

17 Der Kaiser wird wiederholt in der 2. Person angesprochen, siehe z. B. Exped. Pers. 1.35-50. Auch Tartaglia 1998, 15; Ma. Whitby 2002, 162f. und Howard-Johnston 2010, 21 gehen von der Anwesenheit des Kaisers bei der Rezitation aus.

$18 \mathrm{Vgl}$. auch das Gedicht In resurrectionem Christi, das das Osterfest feiert, sich aber auch ganz explizit an den jungen Augustus Herakleios Konstantin wendet. Während Howard-Johnston 2010, 18f. das Gedicht kurz nach der Krönung des Jungen im Jahr 613 ansetzt, plädiert Lauxtermann 2019, 29-35 für eine Datierung in die späten 620er Jahre, als Herakleios nicht in Konstantinopel anwesend war; vgl. Tartaglia 1998, 21f. Die späte Datierung scheint auch mir plausibler. 
Über Jahrzehnte hinweg entwickelte Georg von Pisidien ein äußerst facettenreiches Portrait des Herakleios als Kaiser; doch bedeutet dies, so die Frage, dass das vom Dichter entworfene Kaiserbild mit Herakleios' Selbstrepräsentation deckungsgleich war bzw. als solche zu analysieren ist? ${ }^{19}$ Georg von Pisidien wird in der Forschung gerne als Herakleios' ,Hofpoet‘ betitelt. ${ }^{20}$ Eine solche Einordnung, die suggeriert, der Dichter als Lobredner gebe in Auftragsarbeit schlichtweg kaiserliche Propaganda wieder, tendiert allerdings dazu, mögliche Dynamiken politischer Kommunikation zu verschleiern. ${ }^{21}$ Der Umstand allein, dass die Gedichte sich durch einen enkomiastischen Charakter auszeichnen, dass sie Herakleios (ebenso wie Sergios, Bonos und Herakleios Konstantin) poetisch überhöhen, lässt noch keine eindeutigen Rückschlüsse zum Verhältnis zwischen Dichter und Kaiser zu.

In seiner Arbeit zu Kaiser Konstantin I. reflektiert Johannes Wienand den geschichtswissenschaftlichen Umgang mit Herrscherpanegyrik; seine Erkenntnisse lassen sich auch auf den Untersuchungsgegenstand dieser Arbeit übertragen. ${ }^{22}$ Wienand plädiert dafür, den Lobredner nicht lediglich als „Sprachrohr kaiserlicher Propagan-

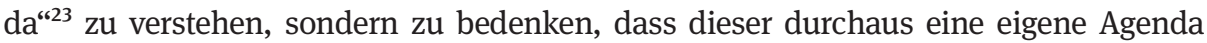
verfolgen konnte; unter dem Deckmantel des Herrscherlobes konnte Panegyrik auch implizit hortative Elemente aufweisen. Im zeremoniellen Interaktionsraum des Palastes seien dem Redner, so Wienand, jedoch gleichsam klare Grenzen des Sagbaren gesetzt gewesen: Er musste den Bedingungen eines streng reglementierten, „normativ strukturierten Diskursumfeldes“224 gerecht werden, sich auf die Erwartungshaltungen seines Publikums - nicht zuletzt die des Kaisers - einrichten, um seiner Agenda Geltung zu verschaffen. Zumindest eine „Nähe zur jeweils aktuellen herrscherlichen Selbstbeschreibung“25 sei demnach Voraussetzung für rhetorischen Erfolg. Wenn der Lobredner kaiserliche Selbstdarstellung einerseits aufgriff und andererseits durch spezifische

19 In der Tat lässt sich nachweisen, dass Georg auf Impulse des Kaisers reagierte; so komponierte er etwa das Gedicht In Restitutionem S. Crucis, nachdem die kaiserliche Depesche mit den freudigen Nachrichten aus Jerusalem in der Hauptstadt eingetroffen war (siehe Rest. Cruc.103f.). Material, das in gleichem Umfang wie Georgs Gedichte über die Selbstdarstellung des Herakleios Auskunft geben könnte, existiert nur in geringem Maße; allein die in Chron. Pasch. AD 628 erhaltene Siegesdepesche ist vergleichbar; siehe dazu unten S. 232-234.

20 Ludwig 1991, 128; Ma. Whitby 1998, 248 („court poet”); ebd. 296 Georg als „Heraclius’ publicist” (ebenso in dies. 2002, 157, 172); Lauxtermann 2003, 39. Ma. Whitby 1998, 251 nimmt an, dass es sich vor allem bei den Gedichten mit längeren narrativen Passagen um Auftragsarbeiten handelte. Vgl. HowardJohnston 1992 und 2010, 284-295 mit der These, dass Herakleios bei Georg eine „official history” seiner Feldzüge in Auftrag gab, die dann als ein hybrides Prosa-Vers-Werk verwirklicht wurde, dass nur in Ausschnitten erhalten sei; gegen diese These Ma. Whitby 2002, 168-172.

21 Siehe Leppin 2020, 306 mit ähnlicher Skepsis.

22 Wienand 2012, 26- 43 mit einer umfassenden Auflistung der Literatur, auf deren Reproduktion ich hier verzichten werde; vgl. zum Umgang mit Herrscherpanegyrik Omissi 2018, 41-67; zu Panegyrik und Herrscher-Zeremoniell siehe auch MacCormack 1981, 1-14.

23 Wienand 2012, 27.

24 Wienand 2012, 31.

25 Wienand 2012, $40 \mathrm{f}$. 
Elemente anreicherte, fungierte er als „kommunikative Scharnierstelle zwischen Kaiser und Auditorium“ ${ }^{26}$ - ein Auditorium, das im Palast von Konstantinopel vorrangig aus der weltlichen Funktionselite sowie hohen Vertretern des Klerus bestand. In einem konsensorientierten Aushandlungsprozess zwischen dem Herrscher und seinen Gegenübern konnten demnach anhand von Panegyrik verschiedene Positionen und Interessen vermittelt werden.

Versteht man Panegyrik nicht etwa als monodirektionale Setzung, in der sich allein ein Geltungsanspruch des Empfängers äußerte, sondern als bidirektionale Kommunikationsform, so stellt sich schließlich die Frage, welche Agenda Georg von Pisidien in sein Herrscherlob einfließen ließ. Seinen Titeln nach zu schließen war Georg Kleriker und Amtsträger im hauptstädtischen Patriarchat. ${ }^{27}$ Der Patriarch Sergios nimmt - neben dem Kaiser - eine zentrale Rolle in Georgs Werk ein; er scheint sogar wiederholt Gedichte in Auftrag gegeben zu haben. ${ }^{28}$ Spricht aus Georgs Versen also die Sicht seines direkten Vorgesetzen, des Patriarchen Sergios, auf den Kaiser? Ist Georg als Advokat dessen zu verstehen, was die hauptstädtische Kirche vom Kaiser erwartete? In den folgenden Detailanalysen wird deutlich, wie eng Georg kaiserliche Herrschaft einerseits und kirchliche (genauer gesagt patriarchale) Hoheit andererseits miteinander verflocht.

\section{2 „Wie einer von uns“ - der kriegführende Kaiser}

\subsubsection{Herakleios' Kampagne in Kleinasien}

Nachdem Herakleios' erstes Engagement am Kriegsschauplatz im Jahr 613 in einem Debakel geendet hatte, wagte er im Jahr 622 einen weiteren Vorstoß. Am 5. April brach der Kaiser nach Kleinasien auf, nachdem er am Tag zuvor noch in Konstantinopel an den Osterfeierlichkeiten teilgenommen hatte. ${ }^{29}$ Sein minderjähriger Sohn, der Augustus Herakleios Konstantin, blieb unter Aufsicht des Patriarchen Sergios und des Patrikios Bonos in der Hauptstadt zurück. ${ }^{30}$ Per Schiff setzte Herakleios mit seiner Entourage nach Pylai im Süden des Golfes von Nikomedia über, im Gepäck das Acheiropoieton - ein Bildnis Christi, das als nicht von Menschenhand gemalt in

26 Wienand 2012, 42. Besonders in Bezug auf das Schaffen des Bischofs Eusebius unter Konstantin arbeitet Wienand heraus, wie Lobredner eigene und gleichzeitig dem spezifischen Umfeld angepasste Akzente setzen konnten. Vgl. auch Meier 2003c, der postuliert, dass Konstantin mit dem Euseb'schen Konzept der christlichen basileia nicht sonderlich viel anfangen konnte (bes. ebd. 132).

27 Dazu siehe oben S. 12f.

28 Während in den Gedichten kein expliziter Verweis darauf zu finden ist, dass Herakleios Georg beauftragte, verhält es sich in Bezug auf Sergios anders; in Bell. Avar. 125-129 spricht der Dichter den Patriarchen direkt an: Auf dessen Bitten hin werde er sich erneut ans Dichten machen.

29 Georg. Pis. Exped. Pers. 1.112-125 zu den unterschiedlichen Reaktionen in der Hauptstadt; zum Aufbruch am Tag nach Ostern: Georg. Pis. Exped. Pers. 1.132-138; Theoph. Conf. AM 6113 (De Boor 302). 30 Theoph. Conf. AM 6113 (De Boor 303); dazu siehe auch oben S. 184. 
Konstantinopel verehrt wurde - als Palladion der Expedition. ${ }^{31}$ Um die römischen Einheiten, nach den Niederlagen der letzten Jahre stark in Mitleidenschaft gezogen, wieder kampfbereit zu machen, wurden sie zuerst im kleinasiatischen Bithynien gesammelt. Herakleios überwachte persönlich die Restrukturierungen und Militärübungen. ${ }^{32}$ Im Sommer 622 rückte das römische Heer gen Osten vor, um sich dem Feind zu stellen, der unter der Führung des Generals Shahrbaraz bereits in Pontus stand und von dort aus das Anatolische Plateau bedrohte. Nachdem die beiden Heere versucht hatten, sich an den unübersichtlichen Bergpässen zu Armenien gegenseitig auszumanövrieren, kam es im Spätsommer schließlich zu einer Feldschlacht zwischen Römern und Persern, aus der Herakleios' Truppen siegreich hervorgingen. ${ }^{33}$ Kleinasien hatte fürs Erste gesichert werden können und Herakleios war es gelungen, einen vor allem psychologisch wertvollen Sieg zu erringen. Doch die Hauptstadt sah sich bereits einer erneuten Bedrohung von Westen her ausgesetzt: Als die Avaren erneut in Thrakien einfielen, war Herakleios gezwungen, sein Heer zum Überwintern in Armenien einzuquartieren und selbst nach Konstantinopel zurückzukehren. ${ }^{34}$

\subsubsection{Die Expeditio Persica}

Georg von Pisidien komponierte und präsentierte die Expeditio Persica, mit der er auf die Kleinasien-Kampagne des Kaisers zurückblickte, während Herakleios ab dem Herbst 622 vorrübergehend wieder in der Hauptstadt weilte. ${ }^{35}$ Entlang einer für das

31 Acheiropoieton: Georg. Pis. Exped. Pers. 1.139-151; Pylai: Exped. Pers. 2.8-11; Theoph. Conf. AM 6113 (De Boor 303).

32 Militärübungen: Georg. Pis. Exped. Pers. 2.39-65, 116-148 (ebd. 2.163-169 wird die Heterogenität der Truppen beschrieben, bestehend aus Männern unterschiedlichster Herkunft; ebd. 2.86f. erneut zum Acheiropoieton), Theoph. Conf. AM 6113 (De Boor 303).

33 Manöver und Schlacht werden ausführlich geschildert bei Georg. Pis. Exped. Pers. 2.206-3.304 und Theoph. Conf. AM 6113 (De Boor 304-306).

34 Rückkehr nach Konstantinopel: Georg. Pis. Exped. Pers. 3.305-321; Theoph. Conf. AM 6113 (De Boor 306). Georg. Pis. beschreibt, dass die Präsenz des Kaisers in Konstantinopel dringend gebraucht wurde; diese Dringlichkeit ist plausibel mit der Bedrohung durch die Avaren in Verbindung zu bringen; zu den darauffolgenden Maßnahmen zur Einhegung der Avaren siehe unten S. $206 \mathrm{f}$.

35 Eine intensive Analyse der Expeditio Persica hat zuletzt Leppin 2020 vorgelegt. In diesem Zusammenhang stellt sich die Frage, wie Georg an die detaillierten Informationen kam, mit denen er die Expeditio Persica ausschmückte. Es wurde wiederholt die Vermutung aufgestellt, dass Georg Herakleios’ Feldzug persönlich begleitete; siehe Pertusi 1959, 13f.; Tartaglia 1998, 15; Howard-Johnston 1999, 8 mit Verweis auf Georg. Pis. Exped. Pers. 2.122-126. Für mich ist diese Passage allerdings kein Beweis für Georgs Augenzeugenschaft; darin wird vielmehr deutlich, wie der Dichter eine eindringliche Stimmung kreierte, die es seinen Zuhörern in Konstantinopel erleichterte, sich die Taten des Kaisers in Kleinasien vor Augen zu führen. Die Frage, wie Georg an seine Informationen kam, lässt sich mit Verweis auf Indizien beantworten, die nahelegen, dass die Hauptstadt regelmäßig mit Informationen aus dem Feldlager versorgt wurde; abgesehen von der berühmten Siegesdepesche in Chron. Pasch. AD 628 siehe z. B. Theoph. Conf. AM 6116 (De Boor 312f.): „Von dort aus konnte der Kaiser Briefe nach 
Genre typischen Captatio benevolentiae breitet der Dichter seine Absicht aus: Von den zahlreichen Mühen des Kaisers wolle er erzählen.

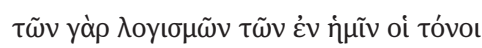

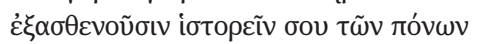

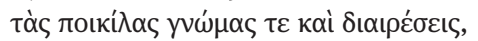

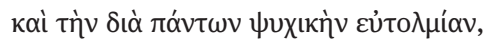

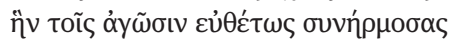

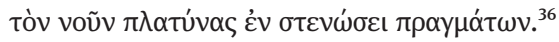

\begin{abstract}
Denn die Kraft meiner Gedanken erweist sich als schwach darin, zu erzählen sowohl von den verschiedenen Absichten als auch Unterschieden deiner Mühen, und von dem andauernden Wagemut deiner Seele, die du perfekt vereint hast mit den Kämpfen, deinen Geist erweiternd in der Enge der Umstände.
\end{abstract}

Gleich zu Beginn des Gedichts wird die Situation auf den Punkt gebracht, an welcher Georg von Pisidien sich rhetorisch abarbeiten musste: der Umstand, dass Herakleios selbst als Feldherr agierte. „Der Kaiser stellte sich persönlich dem Kampf gegen die

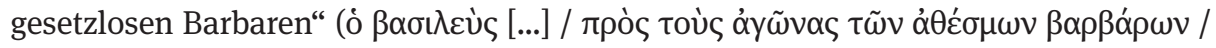

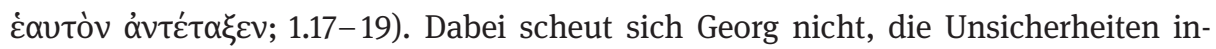
nerhalb der Bevölkerung Konstantinopels zu thematisieren, die durch eine derartige Entscheidung ausgelöst wurden. ${ }^{37}$ Den unterschiedlichen Meinungen darüber, ob es angemessen sei, dass der Kaiser persönlich in den Krieg ziehe, wie sie oben bereits zitiert wurden, setzt der Dichter eine emphatische Ansprache an Herakleios entgegen: „Du aber, oh Feldherr - denn das warst du ja auch für alle - hast diese Dinge lieber

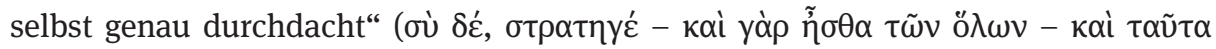

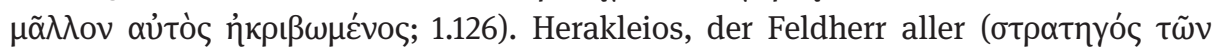
ö $\lambda \omega v$ ), habe in einer derart schwierigen Situation Gott zum Richter gemacht ( $\Theta \varepsilon o ̀ v$

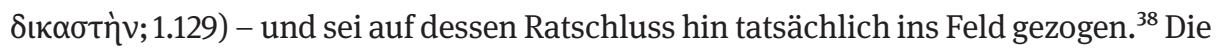
umstrittene Entscheidung, die Hauptstadt zu verlassen und sich als Feldherr zu betätigen, wird hiermit aus der göttlichen Sphäre abgeleitet und dadurch sanktioniert.

Herakleios' Feldherrentum spielt auch im weiteren Verlauf des Gedichtes eine zentrale Rolle: Als der Kaiser das römische Heer in Bithynien für die Kämpfe vorbereitet, nähert sich der Dichter der Thematik mit einer Reihe rhetorischer Fragen:

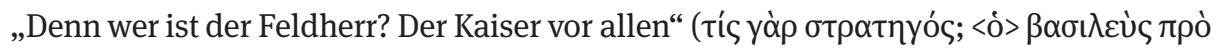
$\tau \tilde{\omega} v$ ö $\lambda \omega v$; 2.19). Im Vergleich mit Alexander dem Großen erweist sich Herakleios

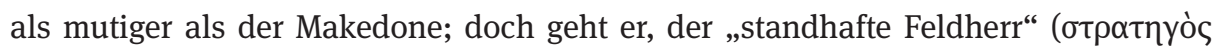

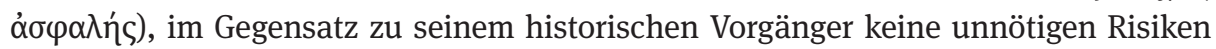

Byzantium schicken, in denen er all seine Maßnahmen beschreib, und damit große Freude in der Stadt

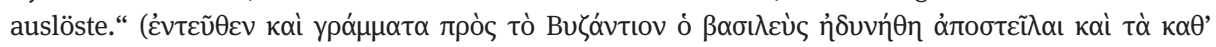

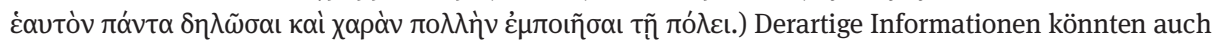
als Grundlage für Georgs Gedicht gedient haben.

36 Exped. Pers. $1.45-50$.

37 Siehe die oben zitierte Passage Exped. Pers. 1.112-123.

38 Vgl. Exped. Pers. 1.17-19: Der vollen Verse lauten hier: „In deinen (i. e. Gottes) Befehl vertrauend

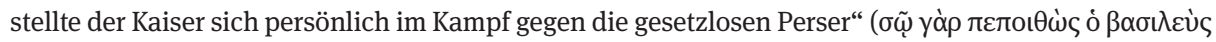

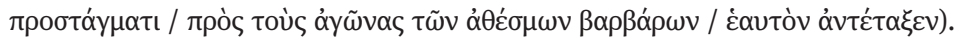


ein. ${ }^{39}$ Die Gegenüberstellung mit dem persischen Kommandeur, dem „Feldherren der

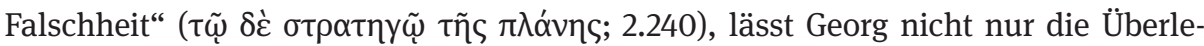

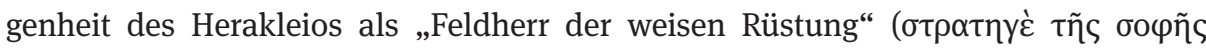

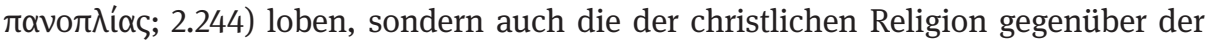
zoroastrischen: „Jener verehrt das Feuer, du aber, oh Mächtigster, erhöhst das Kreuz“

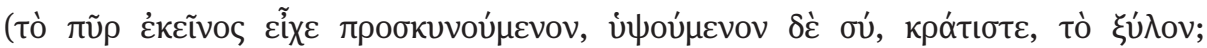
2.252f.). ${ }^{40}$ Das Attribut des strategos kommt neben Herakleios schließlich noch Gott selbst zu: Georg preist diesen als „Feldherr alles Himmlischen und Irdischen“

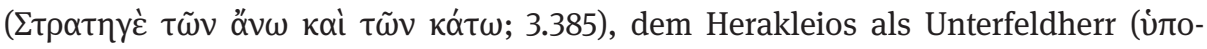

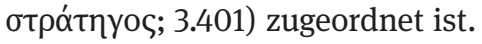

Der Begriff strategos ist deswegen bemerkenswert, da es sich dabei nicht etwa um ein typisches kaiserliches Epithet wie basileus oder despotes handelt; es ist vielmehr in der Spätantike die offizielle griechische Bezeichnung für die Magistri militum, die obersten Befehlshaber der römischen Armee. ${ }^{41}$ Über Jahrhunderte hatten Magistri militum ihre in den Provinzen erarbeitete Machtposition genutzt, um politische Entscheidungsprozesse in der Hauptstadt zu beeinflussen. ${ }^{42}$ Dass Herakleios' mit der Regierungspraxis seiner Vorgänger brach und sich wieder persönlich an die Spitze des römischen Heeres stellte, zielte unter anderem darauf ab, derartigen Ermächtigungsversuche, die ihn ja selbst an die Macht gebracht hatten, vorzubeugen und eine weitere Usurpation zu verhindern. ${ }^{43}$ Die Remilitarisierung des Kaisertums - der Versuch, kaiserliche Autorität über das Militär wiederherzustellen - äußerte sich nicht nur in Herakleios' Regierungspraxis, sondern fand mit der Expeditio Persica auch im Diskurs einen Niederschlag: Indem Georg den Kaiser konsequent als strategos anspricht, der in der Befehlskette allein Gott über sich stehen hat, wird Herakleios' Vereinnahmung des militärischen Sektors sprachlich umgesetzt.Vor einem Publikum, das im kaiserlichen Palast zivile ebenso wie militärische Amtsträger umfasste, ließ der Dichter hinsichtlich der Spitze der militärischen Hierarchie keine Fragen offen.

Das Portrait jedoch, welches Georg vom Kaiser entwarf, geht weit über dessen Funktion als strategos hinaus. Als es im Osten Kleinasiens zur direkten Konfrontation zwischen römischem und persischem Heer kommt, hat Herakleios seinen großen

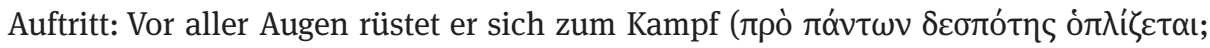
3.92), macht Schild und Bogen bereit. Die Wirkung auf die Soldaten bleibt nicht aus:

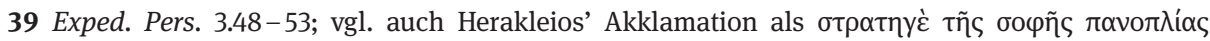
(ebd. 2.244); die Weisheit und Umsicht des Herakleios wird stets betont - immer wieder fallen Begriffe

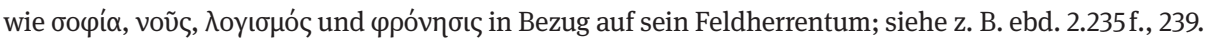
Zu Herakleios’ Qualitäten als Feldherr, wie Georg sie darstellt, vgl. Leppin 2020, $299 \mathrm{f}$.

40 Darin bezieht sich Georg meiner Ansicht nach nicht direkt auf die Kreuzreliquie, sondern das Kreuz als Symbol des Christentums; der Umstand, dass die Kreuzreliquie aus der Jerusalemer AnastasisKirche sich zu dem Zeitpunkt in der Hand der Perser befand, findet in der Expeditio Persica keine Erwähnung.

41 Wassiliou-Seibt 2017, 789f.

42 Dazu siehe oben Kap. 2.3.

43 Dazu siehe oben Kap. 4; 4.2. 


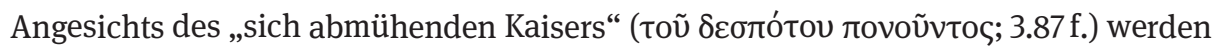
auch sie angespornt, sich dem Kampf zu stellen. Daraufhin folgt die detaillierteste Beschreibung des Kaisers in der Expeditio Persica, die Georg zwei namenlosen Soldaten in den Mund legt, welche sich ganz darüber im Klaren sind, wie ungewöhnlich es ist, den Kaiser auf dem Schlachtfeld zu sehen.

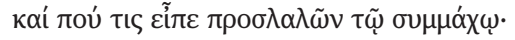

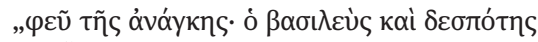

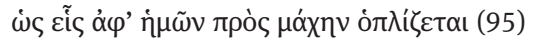

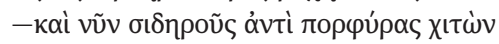

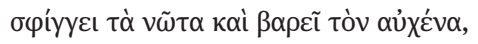

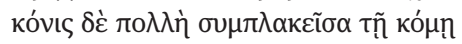

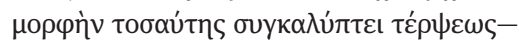

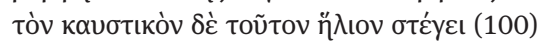

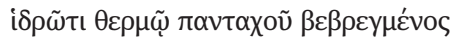

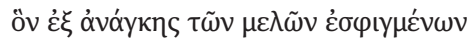

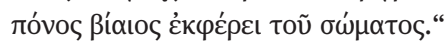

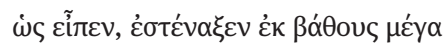

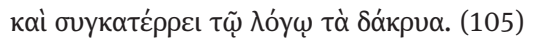

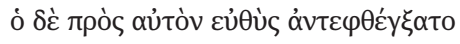

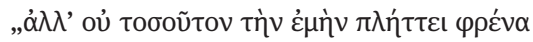

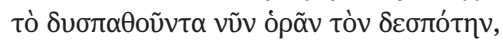

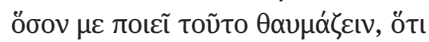

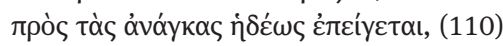

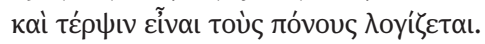

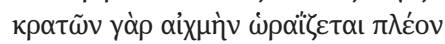

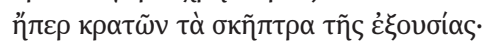

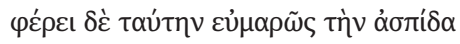

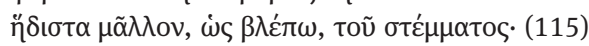

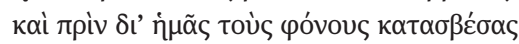

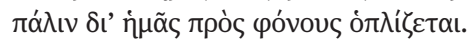

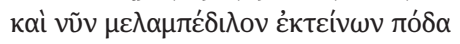

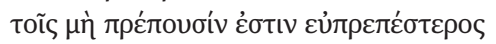

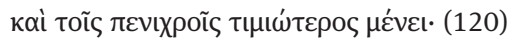

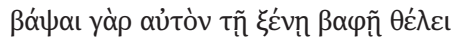

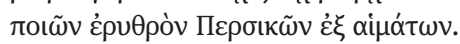

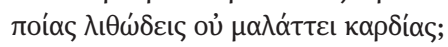

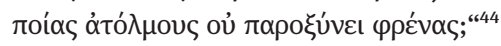

Und irgendeiner sprach seinen Mitstreiter an: „Oh was für ein Schicksal, der Kaiser und Herr rüstet sich wie einer von uns für den Kampf - und nun umschließt ein Gewand aus Eisen statt aus Purpur seinen Rücken und drückt auf seinen Nacken; viel Staub ist in sein Haar eingeflochten und verhüllt seine derartig vergnügliche Gestalt und er erträgt diese brennende Sonne, überall durchnässt von warmem Schweiß, den die gewaltsame Mühe zwangsläufig, da seine Gliedmaßen fest (von der Rüstung) umschlossen sind, aus seinem Körper herausträgt.“

Das gesagt, stieß er aus der Tiefe einen lauten Seufzer aus und es flossen Tränen zusammen mit den Worten herab. Der andere aber antwortete ihm sofort:

„Nicht so sehr trifft es mein Herz, nun den leidenden Herrn zu sehen, wie es mich derart staunend macht, dass er frohen Mutes zu den Zwängen hineilt und die Mühen als Freude begreift.

Denn es schmückt ihn mehr, die Lanze festzuhalten, als die Zepter der Macht, mit Geschicklichkeit aber trägt er diesen Schild, sogar wesentlich lieber, wie ich sehe, als die Königsbinde. Und wie er früher die Gemetzel um unsertwillen ausgelöscht hat, rüstet er sich nun von Neuem wegen uns für die Gemetzel. Und den schwarzbeschuhten Fuß jetzt ausstreckend ist er durch die nicht angemessenen Schuhe noch schicklicher und bleibt durch die armseligen noch ehrenhafter.

Denn er will ihn (i.e. den Fuß) eintauchen in eine fremde Farbe, ihn rot färbend von dem persischen Blut. Welche steinernen Herzen erweicht dies nicht? Welche mutlosen Seelen werden dadurch nicht angeregt?“

Aus dem Blickwinkel der zwei Soldaten, deren Augenzeugenschaft als Beglaubigungsstrategie dient, präsentiert der Dichter Herakleios entlang des Gegensatzes 
zwischen kaiserlicher Hoheit und der rauen Umgebung des Schlachtfeldes. Statt purpurnem Gewand als Symbol monarchischer Würde und Alleinstellung trägt der Kaiser die eiserne Rüstung; seine Bereitschaft, körperliche Mühen auf sich zu neh-

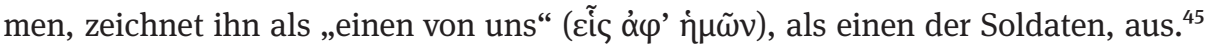
Diese konkrete Körperlichkeit steht im Zentrum von Georgs Kaiserbild: ${ }^{46}$ Als der Staub des Schlachtfeldes die Gestalt des entrückten Palastkaisers verdeckt, offenbart sich ein alternatives Bild: das des sich abmühenden, schwitzenden Kaisers. Zepter und Krone werden durch militärische - mehr noch: soldatische - Attribute ersetzt: Speer und Schild sind nicht nur der Umgebung angemessen, sondern dienen gar als Auszeichnung, als Schmuck. Außerhalb der Hauptstadt lässt Herakleios also gemäß dem Dichter seine erhabene Position hinter sich; die Mühsal des Schlachtfeldes auf sich nehmend, zeigt er sowohl Demut als auch militärische Tugend. Doch gerade in dieser demonstrativen Herabsetzung ist seine Erhöhung, die auch in der Bewunderung durch die Soldaten zum Ausdruck kommt, bereits angelegt: Die schwarzen Soldatenstiefel, die er anstelle der purpurnen trägt, finden durch persisches Blut die angemessene Veredlung.

Die kommunikative Funktion des Kaiserbildes, welches Georg in der Expeditio Persica entwirft, deutet sich an, wenn man den Kontext der Panegyrik erneut in die Überlegung einbezieht. Die Art und Weise, wie der Dichter den Kaiser darstellt, ist nicht unbedingt als Reflex dessen zu lesen, wie Herakleios tatsächlich auf dem Schlachtfeld mit dem Heer interagierte, sondern wie man sich diese Interaktion in der Hauptstadt vor Augen rief. ${ }^{47}$ Ebenso wie Herakleios' Remilitarisierung als ein Experiment zu verstehen ist, auf das der Kaiser sich angesichts der instabilen innenpolitischen Lage einließ, so ist auch Georgs Panegyrik ein Experiment mit innovativen Ausdrucksformen: Die poetische Herausforderung bestand darin, Herakleios' Bruch mit etablierten Verhaltenserwartungen positiv zu deuten und damit gleichzeitig ein Narrativ zu entwickeln, das in der Hauptstadt, vor allem im Palastkontext, akzeptabel und anschlussfähig war. Wie oben bereits dargelegt, wurde das Gedicht nach Herakleios’ Rückkehr aus Kleinasien in Konstantinopel vorgetragen. Während die hauptstädtische Elite in einem der prunkvollen Empfangssäle der Erzählung von den Heldentaten ihres Kaisers auf dem Schlachtfeld lauschte, sah sie eben diesen vor sich dem Zeremoniell entsprechend in zivilem Gewand, mit Krone und Zepter auf seinem Thron erhöht. ${ }^{48}$ Der Kontrast zwischen dem schwitzenden Herakleios einerseits, der sich wie einer der Soldaten auf dem Schlachtfeld abmüht, und kaiserlicher Erha-

45 Zum Ideal des Kaisers als commiles siehe Maier 2019, $26 \mathrm{f}$.

46 Siehe Ma. Whitby 1998, 255f.; Leppin 2020, 300.

47 Ich lese die Expeditio Persica nicht als authentischen Bericht dessen, was sich in Anatolien abspielte; dagegen siehe Raum 2019, 145f., die davon ausgeht, dass aus Georgs Gedichten abzulesen ist, wie Herakleios mit den Soldaten interagierte. Dass der hauptstädtische Diskurs durchaus eklatant von der Politik abweichen konnte, die Herakleios in den Provinzen implementierte, zeigt eine Analyse von Georgs Contra Severum im Zusammenhang mit der herakleischen Religionspolitik; siehe unten S. 293 -296. 48 Zum kaiserlichen Zeremoniell siehe Pfeilschifter 2013, 85-99. 
benheit andererseits ist bereits im Gedicht angelegt; beim Vortrag im Palastumfeld indes entfaltete dieser Kontrast erst seine volle Wirkung. Was auf den ersten Blick geradezu unvereinbar erscheint, trug, wie im Folgenden deutlich wird, zur Verarbeitung und Bewältigung von Herakleios’ Transgression bei.

Die Mechanismen hinter der Rekonfiguration des Kaiserbildes in Georgs Panegyrik treten vor allem dann zutage, wenn man die Entwicklung der kaiserlichen Imago im 5. und 6. Jahrhunderts in die Überlegung einbezieht. Das Kaiserbild, das sich entlang des Sesshaftwerdens römischer Monarchen in Konstantinopel herausbildete und über Jahrhunderte verfestigte, zeichnet sich durch zwei komplementäre Aspekte aus, die im Folgenden zumindest im Ansatz auszuführen sind: Triumphalismus und Sakralisierung.

Wie bereits im Kapitel 2 besprochen, wurde die Repräsentation des Kaisers als Sieger mit der Festigung einer hauptstädtischen Monarchie von konkreten militärischen Erfolgen entkoppelt. Monarchische Sieghaftigkeit entwickelte sich zu einer dem Kaiser ab dem Moment seiner Krönung inhärenten Qualität; anstatt sich durch die Betonung charismatischer Momente auf dem Schlachtfeld zu profilieren, wie es die Kaiser im vierten Jahrhundert getan hatten, ${ }^{49}$ avancierten die sesshaften Kaiser zu ewigen Siegern. ${ }^{50}$ Militärische Repräsentation indes verlor auch in den Jahrhunderten des hauptstädtischen Kaisertums keineswegs an Bedeutung: Auf den Aversen der Münzen erschienen selbst minderjährige Kaiser in militärischer Tracht; ${ }^{51}$ ihre offizielle Titulatur zierten weiterhin die typischen Cognomina devictarum gentium. ${ }^{52}$ Die Stabilität oströmischer Herrschaft im 5. und 6. Jahrhundert basierte nicht zuletzt auf dem Umstand, dass die unkriegerischen Kaiser die militärischen Erfolge ihrer Generäle im hauptstädtischen Kontext auf sich übertragen konnten: Nach dem Vandalensieg des Jahres 534 stand nicht etwa der General Belisar im Zentrum der triumphalen Feier-

49 Siehe etwa Konstantin, der als „blutbefleckter Kaiser“ (Wienand 2011) für seinen Sieg im Bürgerkrieg gefeiert wird. Dazu, wie militärische Sieghaftigkeit im 3. und 4. Jahrhundert präsentiert wurde, siehe auch Hebblewhite 2017, 33-70.

50 Diefenbach 1996, 58; Meier 2009a, 260; Pfeilschifter 2016, 4, jeweils unter Verweis auf die grundlegende Arbeit von McCormick 1986 zu „eternal victory”; zur Siegesideologie der hauptstädtischen Monarchie siehe Lee 2007, 37-50; vgl. auch Treitinger 1938, 168-170, der sich eher auf die mittelbyzantinische Zeit konzentriert. Zu der Verschränkung von soldatischer Tugend und christlichen Werten in der Spätantike, auch in Bezug auf die Kaiser, siehe Stewart 2016.

51 Siehe die Zusammenstellungen in DOC und MIB; außerdem Lee 2007, 48: „It is tempting to see this more pronounced military emphasis, which remained standard in the east into the sixth century, as an attempt to compensate for the lack of direct military involvement on the part of Arcadius and his successors, although there was no comparable move in the west."

$52 \mathrm{Zu}$ den Cognomina devictarum gentium siehe McCormick 1986, 22, 41 und zu Siegesbeinamen Rösch 1978, 53-61; Justin II. etwa, der weder militärische Erfahrung noch militärischen Erfolg vorzuweisen hatte, trug den Titel Imperator Caesar Flavius Iustinus fidelis in Christo mansuetus maximus benefactor Alamannicus Gothicus Francicus Germanicus Anticus Alanicus Vandalicus Africanus pius felix inclitus victor ac triumphator semper Augustus (Rösch 1978, 168). 
lichkeiten, sondern Justinian. ${ }^{53}$ Der Triumph akzentuierte kaiserliche Sieghaftigkeit sowohl ephemer im Zeremoniell ${ }^{54}$ als auch in nachhaltigerer visueller Form: So zierten etwa mehrere monumentale Statuen, die Justinian in Rüstung und zu Pferde als Persersieger feierten, den öffentlichen Raum Konstantinopels. ${ }^{55}$

Die sakrale Überhöhung eines Herrschers ist kein Alleinstellungsmerkmal der Spätantike; angesichts der fortschreitenden Christianisierung römischer Monarchie entwickelten sich ab dem 4. Jahrhundert allerdings spezifische Auffassungen davon, in welchem Verhältnis der Kaiser zur transzendenten Sphäre stand. Monotheismus und Monarchie gingen eine organische Verschränkung ein: Der Kaiser wurde nicht mehr als göttlich, sondern als von Gott erwählt erachtet - als dessen Stellvertreter auf Erden. In dieser basileia ek theou äußerte sich die Nahbeziehung zwischen irdischem und himmlischem Herrscher außerdem darin, dass der Kaiser sich in seiner Regierungspraxis auf Gott als Vorbild bezog: Mit der Idee einer mimesis theou bzw. imitatio dei orientierte der Monarch seine Herrschaft an himmlische Sphären. ${ }^{56}$ Die Sakralisierung des christlichen Kaisers war jedoch keineswegs statisch; entlang der umrissenen Konstanten brachte sie im Diskurs ebenso wie in der Praxis unterschiedlichste Ausformungen hervor. ${ }^{57}$ Im 5. Jahrhundert etwa ging die fortschreitende Bindung der Monarchen an Konstantinopel, wie Steffen Diefenbach herausgearbeitet hat, mit einer Liturgisierung der Interaktionsformen einher: Das ritualisierte Aufeinandertreffen zwischen dem Kaiser und der hauptstädtischen Bevölkerung im städtischen Raum wurde mit religiösen bzw. kirchlichen Elementen aufgeladen, die den Aspekt kaiserlicher Frömmigkeit und Demut in den Vordergrund rückten. Indem sich der Kaiser

53 Dazu siehe oben S. 65. Dem Vandalensieg wird in der Regel auch ein Gold-Medaillon des Justinian zugeordnet: Auf dem Avers erscheint ein nimbierter Justinian in militärischer Tracht, umgeben von der Umschrift d(omi)n(us) Iustinianus p(ater) p(atriae) aug(ustus); auf dem Revers wird Justinian in gleicher Ausstattung zu Pferd abgebildet; vor ihm her schreitet eine Victoria mit Trophäen, versehen mit der Umschrift salus et gloria Romanorum; siehe MIB I, 46f. mit Abbildung Taf. 14 Nr. 1; Meier, 2003a, 153f. Anm. 267.

54 Vgl. auch die Panegyrik auf Anastasios nach dem Sieg über die Isaurier; siehe Croke 2008.

55 Keine der Statuen ist erhalten; zur ersten Statue, die nach dem römischen Sieg über die Perser bei Dara (530) errichtet wurde, finden sich zwei Epigramme in der Anthologia Palatina (Anth. Palat.16.63f. = Anth. Planud. 62f.); in der ersten Inschrift wird Justinian als „Meder-schlachtender Kaiser“ ( $\beta \alpha \sigma ı \lambda \varepsilon \tilde{v}$

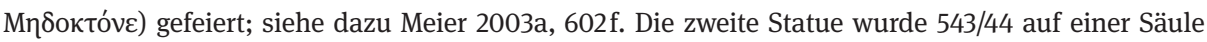
inmitten des Augusteion errichtet: Laut der Beschreibung des Prokop (Aed.1.2.7-12) war der Kaiser in der Rüstung des Achill dargestellt, trug jedoch weder Schwert noch Lanze noch sonstige Waffen, sondern allein einen Globus mit Kreuz, „durch das alleine er Königsherrschaft und Kriegsmacht er-

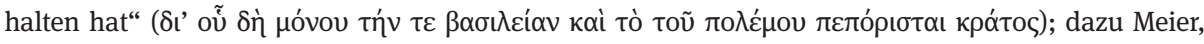
2003a, 599-607 mit weiteren Angaben.

56 Zur Sakralisierung des christlichen Kaisers siehe Martin 1984; Diefenbach 1996, bes. 39; Meier 2003c; Pfeilschifter 2013, 76-85; Leppin 2013; zur basileia ek theou siehe auch oben S. 133.

57 Leppin 2013 unterscheidet zwischen drei Formen des christlichen Kaisertums (bzw. deren Rechtfertigung): der christozentrischen, der alttestamentarischen und der hierokratischen (siehe bes. ebd. 208); Meier 2017 zeichnet einen alternativen Ablauf und lässt die Entwicklung im messianischen Kaisertum gipfeln, als dessen Repräsentanten er Herakleios sieht; siehe ebd. 542f. 
öffentlich herabsetzte (etwa durch das Ablegen seiner Insignien), stellte er eine „affektive Nahbeziehung“ zu seinem Umfeld her, was in Hinblick auf seine Herrschaft stabilisierende Wirkung zeitigte und die Akzeptanz der hauptstädtischen Bevölkerung sicherte. ${ }^{58}$ Charismatische Momente entstanden nun nicht mehr auf dem Schlachtfeld, sondern in einem religiös aufgeladenen, städtischen Umfeld. ${ }^{59}$ Die Sakralisierung des Kaisertums konnte sich aber auch darin äußern, dass der Monarch sich als Wahrer des orthodoxen Glaubens inszenierte, bzw. ein entsprechendes Verhalten von ihm erwartet wurde; die oströmischen Kaiser nahmen bisweilen gar eine dem Priestertum ähnliche Funktion ein. ${ }^{60}$ Unter der Herrschaft Justinians zeichnete sich schließlich ein vorläufiger Höhepunkt der Sakralisierungstendenzen ab - eine Entwicklung, die Mischa Meier unter dem Begriff der „Hypersakralisierung“ zusammenfasst. ${ }^{61}$ Vor allem in seinen späten Regierungsjahren bildete Justinian eine transzendente Herrscherimago aus; asketisch anmutende Praxis ${ }^{62}$ einerseits und zeremonielle Überhöhung andererseits verorteten ihn eher im Bereich des Heiligen bzw. Göttlichen als des Menschlichen: In den Worten des Paulos Silentiarios hat der Kaiser ,jegliche menschliche Natur besiegt“ ( Justinian offenbart sich schließlich auch die Verschränkung von Triumphalismus und Sakralisierung. In Prokops Beschreibung des Mosaiks, welches die Chalke, das prunkvolle Eingangstor zum kaiserlichen Palast, zierte, werden Justinian und Theodora für die Siege über Goten und Vandalen, vom General Belisar errungen, gefeiert;

58 Zitat: Diefenbach 1996, 52; Diefenbach (1996, 2002) arbeitet das Phänomen der Liturgisierung etwa in Zusammenhang mit den Reliqientranslationen nach Konstantinopel im 5. Jahrhundert heraus, anhand derer die Stadt, die über keine starke christliche Tradition verfügte, eine eigenständige Sakraltopographie herausbilden konnte. Zur ostentativen Zurschaustellung kaiserlichen Frömmigkeit siehe auch Meier 2007b und Kelly 2013; zuletzt Diefenbach 2019, bes. 63-78.

$59 \mathrm{Zu}$ charismatischer Herrschaft entlang der Typologie von Max Weber siehe Gehrke 1982.

60 Diefenbach 1996, 58; Meier 2003c, 145, 147. Nach dem Tod des Zenon forderte die hauptstädtische Bevölkerung einen frommen und orthodoxen Kaiser, siehe De cerim. 1.92. Im 5. Jahrhundert wurde der Kaiser gar bisweilen als Priester akklamiert: beim Konzil von Ephesos (ACO II 1.1 [Schwartz, 138.25 - 29])

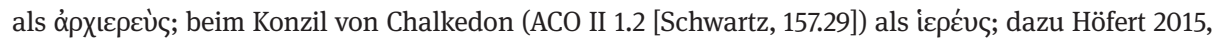
199f. Zu dem Phänomen der Angleichung von Kaiser und Priester siehe umfassend Dagron 2003.

61 Meier 2016: Die Hypersakralisierung sei, so Meier, einhergegangen mit bzw. bedingt worden durch eine umfassende Liturgisierung der Gesellschaft (vgl. ders. 2012, 229-236) als Antwort auf enttäuschte eschatologische Naherwartungen und die Katastrophenerfahrungen des 6. Jahrhunderts; diese Hypersakralisierung habe schließlich zu einer Erosion des hauptstädtischen Akzeptanzsystems beigetragen; siehe dazu auch ders. 2017, 529-538.

62 Laut Prokop (Aed. 1.7.7-11) habe Justinian sich von wilden Kräutern und Wasser ernährt; seine Nachtruhe habe er der Sorge um das Gemeinwesen willen vernachlässigt; vgl. auch Prok. Hist. arc. 13.23-30, wo dieses Bild ins Negative gewandt wird. Dazu, mit weiteren Beispielen, siehe Meier 2016, 85f.; Leppin 2013, 214f. sieht in Justinian ein Beispiel für „hierokratische Rechtfertigung des Kaisertums“.

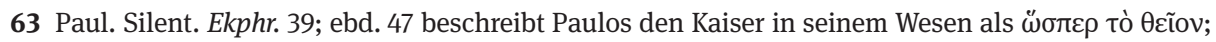
siehe dazu Meier 2016, 87 f. Diefenbach 2019, 92-108 arbeitet heraus, wie die Idee des Kaisers als imago dei unter Justinian betont wird. 
der Senat bringt dem Kaiserpaar dabei, so Prokop, „gottgleiche Ehren“ (iooӨćous tl$\mu \alpha \dot{s})$ entgegen. ${ }^{64}$

Die Art und Weise, wie Georg von Pisidien Herakleios in der Expeditio Persica portraitiert, steht nicht nur im Kontrast zur erhabenen Position des Kaisers als Empfänger der Panegyrik, sondern unterscheidet sich auch von monarchischer Repräsentation des 5. und 6. Jahrhunderts: Vor dem Hintergrund eines entrückten, geradezu entkörperlichten Kaiserbildes unter Justinian ist Herakleios' explizite, soldatische Körperlichkeit auf dem Schlachtfeld umso bemerkenswerter. ${ }^{65}$ Nachdem charismatische Momente im 5. und 6. Jahrhundert, wenn überhaupt, aus einem urbanreligiösen Umfeld erwachsen waren, nahm der Dichter Herakleios’ Transgression zum Anlass, das militärische Charisma des Herrschers wiederzubeleben: Durch die Vergegenwärtigung von Herakleios’ Mühen und Entbehrungen rückt die Expeditio Persica die umstrittene Präsenz des Kaisers auf dem Schlachtfeld ins Zentrum der Panegyrik. In der Rede vom schwitzenden Kaiser wird der charismatische Moment vor der versammelten Funktionselite im Palast nachempfunden. Herakleios' militärisches Charisma indes ist spezifisch konnotiert: Während noch im vierten Jahrhundert martialische Gewaltanwendung das Schlüsselmoment des Kaiserlobes hatte darstellen können, ${ }^{66}$ verweist Georgs Darstellung auf einen anderen, einen christianisierten

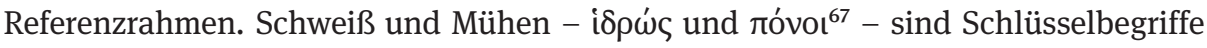
hagiographischer Literatur, wie etwa die Einleitung der Vita des Heiligen Jakob aus Theodorets Historia religiosa verdeutlicht.

Nachdem wir die Kämpfe jener Helden erzählt haben, welche bereits als Sieger in der Tugend ausgerufen wurden, wollen wir nun in Kürze auch berichten über die Tugendmühen und den Kampfschweiß und die glänzenden und ausgezeichneten Siege der Männer, welche noch leben und großartig streiten und die Vorgänger durch ihren Schweiß noch zu überbieten streben. Wenn

64 Prok. Aed. 1.10.17-19; siehe Meier 2003a, 153 mit Anm. 267. Vgl. auch Olster 1994, 30 - 34 zu „Christian Imperial Triumphalism”, allerdings nicht in Bezug auf den Kaiser, sondern das Römische Reich.

$65 \mathrm{Zu}$ soldatischer Repräsentation und explizit männlich konnotierten Tugenden in der Spätantike vgl. Stewart 2016. In seinem Ausblick aufs 7. Jahrhundert schließt Stewart (S. 322): „In this highly charged climate, Heraclius' propaganda naturally fell back on Old Testament and classical examples of warrior-leaders protected by God, manfully defending their religion and their lands.“

66 Eine 313 nach dem Sieg über Maxentius gehaltene Panegyrik auf Konstantin (Pan. Lat. 12[9]) kulminiert in dem Bild des Kaisers, der nach der Schlacht - völlig erschöpft vom Dahinschlachten seiner (römischen!) Feinde - mit blutigen Händen (cruentas manus) von seinen Unterfeldherren aufgefunden wird (ebd. 12[9].9.3-10.3); siehe dazu Wienand 2011.

67 Meier 2015, 177 mit Anm. 67 vermerkt ebenfalls die bevorzugte Nutzung des Begriffes Tóvoı bei Georg von Pisidien; er versteht dies allerdings im Zusammenhang mit der Herakles/Herakleios-Analogie als Verweis auf die in der Antike sprichwörtlichen Mühen des Herakles. Ohne Meiers Interpretation ausschließen zu wollen - der Begriff kann durchaus verschiedene Bedeutungsebenen haben -, scheint mir doch der asketische Aspekt stärker zu sein. 
wir so deren Leben schildern, wollen wir zugleich den künftigen Geschlechtern ein nutzbringendes Andenken an diese Großen hinterlassen. ${ }^{68}$

Georg modelliert das Bild des kriegführenden Kaisers entlang des Vorbildes Heiliger Männer: ${ }^{69}$ Herakleios' persönliches Engagement auf dem Schlachtfeld, seine endlosen Mühen im Kampf für das römische Gemeinwesen entsprechen asketischer Praxis; auch der vom Dichter häufig bemühte Begriff ảyẃv, Kampf bzw. Wettstreit, ist durch die Nutzung in hagiographischer Literatur christlich konnotiert. ${ }^{70}$ Diese Beobachtung wird durch den Umstand unterstützt, dass Georg das Schwitzen des Kaisers mit katharsis, spiritueller Reinigung, verbindet: Durch das Ausstoßen des Schweißes triumphiert Herakleios nicht nur über die Barbaren, sondern auch über die Sünden. ${ }^{71}$

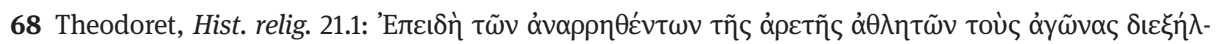

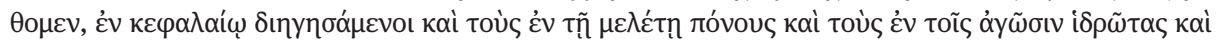

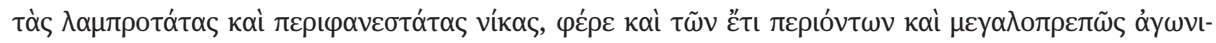

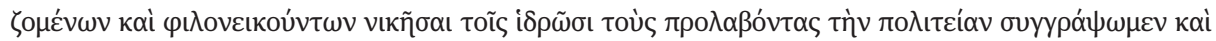

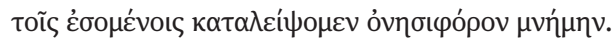

69 In der Laudatio Anastasii, seinem einzig erhaltenen Prosa-Werk, bedient sich Georg von Pisidien

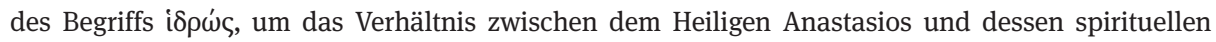
Mentor, dem Abt des Anastasios-Klosters nahe Jerusalem, zu beschreiben; in Laud. Anast. 15 dankt

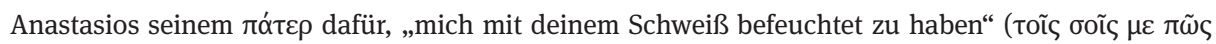

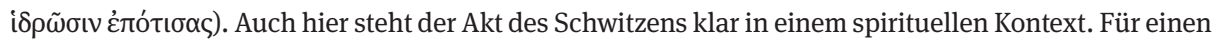

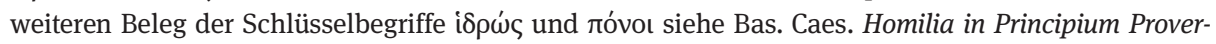
biorum (PG 31.421.12-14): „Selbst wenn er das verliert, was er sich durch zahllose Mühen und Schweiß angeeignet hat, aufgrund eines Angriffs des Dämonen, wie durch einen wilden Sturm, versunken in der

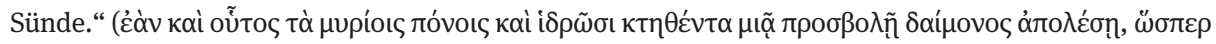

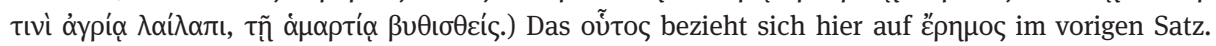
Leppin 2020, 299 zieht ebenfalls eine Verbindung zwischen der Darstellung des Herakleios und der Heiliger Männer, führt dazu allerdings keine konkreten Parallelen auf. Das Studium Heiliger Männer der Spätantike, basierend auf den Arbeiten von Peter Brown, ist derart umfassend, dass ich es hier nicht umreißen kann; siehe zuletzt zusammenfassend Kosinski 2016, 6-16.

70 Zum óyóv in hagiographischer Literatur siehe Kosinski 2016, 36 Anm. 62: Der Begriff bezeichnet in der Regel den asketischen Wettstreit, in den der Asket als Athlet ( $\dot{\alpha} \theta \lambda \eta \tau$ ๆns) eintritt; so auch in der oben zitierten Theodoret-Passage. $\mathrm{Zu}$ dieser Begriffsfamilie bei Georg von Pisidien siehe etwa Exped.Pers. 1.49; Heracl. 1.202, 1.216.

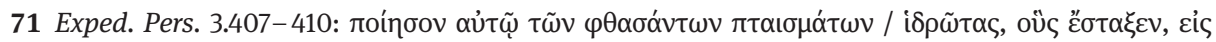

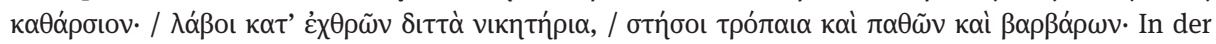
Forschung wurden die $\pi \tau \alpha i ́ \sigma \mu \alpha \tau \alpha$, die Verfehlungen, von denen Herakleios sich durch die asketische Praxis reinigt, als Verweis des Dichters auf konkrete Sünden des Kaisers, etwa die Hochzeit mit seiner Nichte, verstanden; so etwa Pertusi 1959, 160; Tartaglia 1998, 135 Anm. 132; zuletzt auch Leppin 2020, 300 f. Howard-Johnston 2010, 33f. stellt die These auf, dass Georg mit diesen vermeintlich kritischen Versen die kaiserliche Gunst verspielte und entsprechend über mehrere Jahre nicht mehr vom Kaiser direkt beauftragt wurde. Wäre die tatsächlich der Fall, so lässt sich indes kaum erklären, warum Georg ca. vier Jahre später die Idee der Reinigung von den Verfehlungen in Bezug auf Herakleios wiederholt (In Bonum 160 f.). Ich verstehe in diesen Versen keine (versteckte) Kritik an konkreten Handlungen des Kaisers, sondern vielmehr einen Verweis auf die allgemeine Sündhaftigkeit der Menschen, gegen welche auch die Asketen ankämpfen; ähnlich Ma. Whitby 1995, 120 f.; dies. 1998, 256 f. 
Georgs Beschreibung des Herakleios als asketischer Krieger-Kaiser ist in Relation zu einem umfassenderen Phänomen zu verstehen, das in der Forschung als Sakralisierung von Krieg zusammengefasst wird. Während in der Spätantike die Anzahl römischer Soldaten mit christlichem Glauben stetig wuchs, während im Kriegsvollzug und im Alltag des Heeres christliche Symbole, Riten und Bräuche ihre paganen Äquivalente ergänzten bzw. ersetzten, blieb die Begründung und Deutung kriegerischer Konflikte zunächst weitestgehend auf einen profanen, genuin römischen Referenzrahmen bezogen. ${ }^{72}$ Erst ab dem 6. Jahrhundert lässt sich im oströmischen Reich eine zunehmende, gar systematische Verschränkung von Krieg und Religion beobachten, eine Sakralisierung bzw. Liturgisierung von Krieg, ${ }^{73}$ die die Grundlage dessen legte, was in der Forschung bisweilen gar als byzantinische Ausformung von ,Heiligem Krieg ' beschrieben wird. ${ }^{74}$ Reliquien und Ikonen bzw. heilige Objekte im Allgemeinen nahmen im Kriegsvollzug eine zunehmend wichtige Rolle ein: Maurikios wagte seinen Vorstoß ins thrakische Kriegsgebiet unter dem Zeichen des Kreuzes; ${ }^{75}$ Herakleios ließ, glaubt man Theophanes Confessor, Marienikonen an den Masten seiner Flotte anbringen, als er nach Konstantinopel aufbrach, um Phokas zu stürzen. ${ }^{76}$ Im frühen 7. Jahrhundert avancierte das Acheiropoieton, ein nach christlichem Glauben nicht von Menschenhand angefertigtes Bildnis Christi, in Konstantinopel zum zentralen Schutz ebenso wie Sieg versprechenden Objekt - nicht zuletzt in Zusammenhang mit den sich verschärfenden außenpolitischen Bedrohungen. ${ }^{77}$

72 Siehe Meier 2009a, 259f. mit Beispielen und weiterer Literatur. Unter Justinian kam es zu einer semantischen Verflechtung von Religion und Krieg, die aber noch sehr unkonkret war, so stellt der Kaiser etwa in seiner Konstitution De auctore Gott als alleinig Verantwortlichen in kriegerischen Angelegenheiten heraus; siehe dazu auch Meier 2003a, 108-113; Leppin 2011, 119f. Siehe auch Iust.

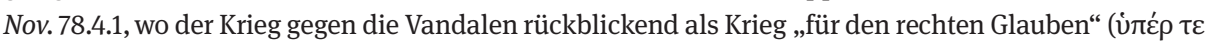

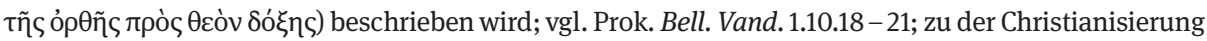
von Siegesfeierlichkeiten siehe McCormick 1986, 100 -111. Während Pfeilschifter 2016 ausgehend von einer engen Definition von Triumph dafür plädiert, dass die Verschränkung von Triumph und Christentum nur schleppend vonstattenging, zeigt Diefenbach 2019, 63 - 65 mit Blick auf Theodosios II., dass Siegesfeierlichkeiten im weiteren Sinne bereits im 5. Jahrhundert religiös konnotiert waren.

73 Meier 2009a, 267-269, der dieses Phänomen wiederum im Zusammenhang mit der umfassenderen Liturgisierung der oströmischen Gesellschaft beschreibt.

$74 \mathrm{Zu}$ der Frage, ob man in Bezug auf Byzanz von ,Heiligem Krieg“ sprechen kann, siehe Stouraitis 2012; außerdem Flaig 2007 zu einer „Typologie“ heiligen Krieges; vgl. Kolbaba 1998; Regan 2003, der in Herakleios den ersten Kreuzfahrer sieht; Stoyanov 2011a, 25-44 zu „Christian Ideology of Warfare in the East Roman/Byzantine World and Sasanian Persia”.

75 Theoph. Sim. Hist. 5.16.11.

76 Theoph. Conf. AM 6102 (De Boor 298) in expliziter Berufung auf Georg von Pisidien; zur Problematik dieser Stelle siehe jedoch oben S. 101. Zu der wachsenden Bedeutung von Ikonen siehe Av. Cameron 1979b, bes. 23, die diese Entwicklung als Integrationsleistung eines bedrohten römischen Reiches versteht, welche von den Kaisern ab Justin II. gezielt vorangetrieben wurde (ebd. 4).

77 Das sog. Kamuliana-Bild wurde 574 nach Konstantinopel gebracht (Kedr. 1.685); unter Maurikios wurde es von dessen Generälen gegen die Perser mitgeführt; siehe Av. Cameron 1979b, 22-24; zu Acheiropoieta (im Zusammenhang mit der Belagerung von Konstantinopel in 626) vgl. auch Hurbanic 2019, 317-321. 
Auch in der Expeditio Persica kommt das Acheiropoieton prominent zur Geltung: Herakleios führt es gemäß Georg von Pisidien mit sich, als er nach Ostern gen Osten aufbricht, ${ }^{78}$ und trägt es in der Hand, als er sich in Bithynien dem versammelten römischen Heer stellt. ${ }^{79}$ In der Rede, die der Dichter Herakleios daraufhin in den Mund legt, bettet Georg den Konflikt und somit auch den kaiserlichen Kampf in einen religiösen Deutungsrahmen ein: „In Gott vertrauend (...) rüste ich mich“ - so Herakleios zu den Soldaten - „wie einer von euch für die Mühen. Denn es schickt sich, dass wir, als seine Schöpfungen, vorgehen gegen die Feinde, die Erschaffenes verehren. ${ }^{\text {(80 }}$ Der Krieg zwischen Römern und Persern erscheint vor dem hauptstädtischen Publikum als Krieg zwischen Christen und Götzenanbetern, die mit ihren blutigen Opfern Kirchen schänden; ${ }^{81}$ den Feueranbetern tritt Herakleios unter dem Zeichen des Kreuzes entgegen. ${ }^{82}$ In Zusammenhang mit der Kampagne von 624 finden sich in der Chronik des Theophanes Confessor weitere Ansprachen des Herakleios an seine Soldaten, die aller Wahrscheinlichkeit nach aus verlorenen Versen des Georg von Pisidien übernommen wurden: Der Kaiser spornt darin sein Heer an, sich den Gefahren des Kampfes zu stellen, da dies zu ewigem Leben führe, und stellt ihnen für ihre Leistungen die Märtyrerkrone in Aussicht. ${ }^{83}$ Dabei sei zu bemerken, dass die Kreuzreliquie, welche die Perser 614 aus Jerusalem nach Ctesiphon verschleppt hatten, in den zeitgenössischen Kommentaren zu Herakleios' Kampagne gegen die Perser noch keine Rolle spielt; erst nachdem Chosroes’ Nachfolger Seiroe den Römern ein Friedensan-

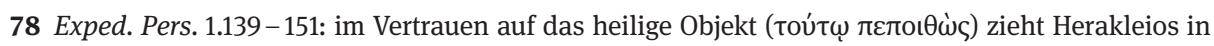
den Kampf; vgl. dazu Av. Cameron 1979b, 23.

79 Exped. Pers. $2.85 \mathrm{f}$.

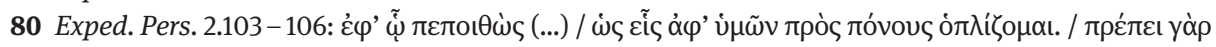

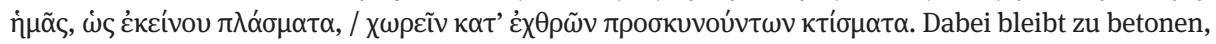
dass Herakleios' Rede mit einer Reflektion zur guten/gerechter Herrschaft auf Basis der Gesetze (vouoí) beginnt; ebd. 88-97. Kurz darauf beschreibt Georg die Interaktion des Kaisers mit dem heterogenen Heer erst mit Verweis auf Orpheus und dann durch eine Analogie zum Pfingstwunder (ebd. 2.163 - 174). 81 Exped. Pers. 2.105-115; zur religiösen Aufladung der Perserfeldzüge siehe Howard-Johnston 1999, $39 \mathrm{f}$; außerdem mit einem breiteren Fokus (nicht nur in Bezug auf den Kaiser) Stoyanov 2011a, 45-75. Vgl. dazu auch einen angeblich von Chosroes II. an Herakleios gesandten Brief in Sebeos 38 (Thomson/ Howard-Johnston I, 79-81), der voll ist von Beleidigungen der christlichen Religion; bei diesem Brief, den Herakleios erst in der Hauptstadt und dann vor den Soldaten präsentierte, handelte es sich aller Wahrscheinlichkeit nach um eine römische Fälschung (siehe Howard-Johnston 2010, 91; Greisiger 2014, 80 f; vgl. Van Dieten 1972, 10 f.), die dazu dienen sollte, auf römischer Seite religiösen Eifer zu entfachen.

82 Siehe Exped. Pers. 2.252f.; vgl. dazu Greisiger 2014, 78 - 81, der allerdings die Reden des Kaisers als authentische Zitate und nicht als Schöpfungen des Dichters versteht.

83 Theoph. Conf. AM 6114 (De Boor 307); ebd. AM 6115 (310f.); siehe dazu Olster 1994, 62f.; Stouraitis 2012, 244. Im 10. Jahrhundert versuchte der Kaiser Nikephoros, allen im Kampf gegen die Araber gefallenen Soldaten den Märtyrer-Status zukommen zu lassen, allerdings war er damit nicht erfolgreich; dazu Stouraitis 2012, 245-247. 
gebot gemacht hatte, wurde das Kreuz zur Verhandlungssache und konnte schließlich von Herakleios persönlich nach Jerusalem zurückgebracht werden. ${ }^{84}$

Trotz seines Fokus auf das militärische Geschehen versäumt es Georg von Pisidien nicht, zum Ende der Expeditio Persica auch das Verhältnis zwischen dem Kaiser und Konstantinopel noch einmal zu spezifizieren. Als die Hauptstadt nach der Wieder-

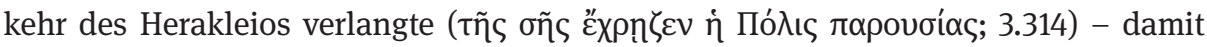
scheint der Dichter auf die erneute Bedrohung durch die Avaren anzuspielen ${ }^{85}$-, habe dieser sich vom Heer gelöst und für neue Mühen bereit gemacht. „Nach der Art eines

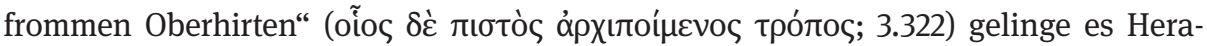

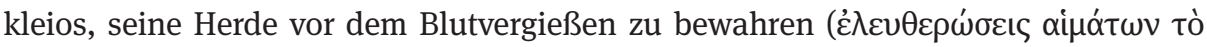

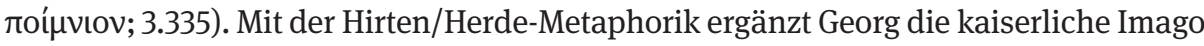
um ein weiteres Element: In seiner Fürsorge für die bedrohte Stadt agiert Herakleios nach dem Vorbild des Guten Hirten Christus - eine Verbindung, die durch den Wunsch nach der Parusie des Kaisers ( $\left.\pi \alpha \rho \sigma \sigma^{\prime} \alpha\right)$ noch verstärkt wird. ${ }^{86}$

Mit der Expeditio Persica portraitierte Georg von Pisidien den Kaiser als strategos, betonte also dessen Autorität über das Militär; indem er Herakleios als asketischen, geradezu heiligmäßigen Krieger-Kaiser darstellte, akzentuierte er jedoch gleichzeitig dessen christliche Persona: ${ }^{87}$ Georgs Präsentation des Herakleios speiste sich aus dessen umstrittener Präsenz auf dem Schlachtfeld, war aber vor einem hauptstädtischen Publikum anschlussfähig. ${ }^{88}$ Denn die Sinnangebote, die Georg der im Palast von Konstantinopel versammelten Elite darbrachte, griffen sowohl bekannte Topoi als auch gesamtgesellschaftliche Tendenzen auf, die den hauptstädtischen Diskurs des frühen 7. Jahrhunderts bestimmten. Georgs Modellierung des kriegführenden Kaisers nahm nicht so sehr Bezug auf den reichen Fundus römischer bzw. hellenischer Vergangenheit bzw. auf das Ideal des Krieger-Kaisers, ${ }^{89}$ das Herakleios’ Vorgänger bis ins

84 Es wäre wohl zu riskant gewesen, den Fokus allzu sehr auf das Kreuz zu lenken, dessen Verbleib zumindest auf Seiten der Römer in den Jahren nach 614 eher ungewiss war.

85 Pertusi 1959, 160.

86 Auf diese Parallele hat bereits Meier 2015, 184 hingewiesen: Im ersten Petrusbrief (1 Petr 5.4) wird

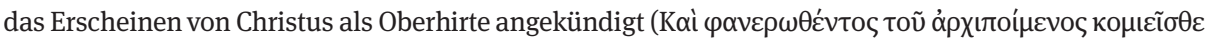

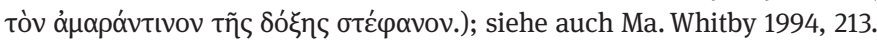

87 Vgl. Leppin 2020; dieses Bild christlichen Kaisertums sollte im 10. Jahrhundert voll zur Geltung kommen, wie ein liturgischer Text (ed. Petit 1904) auf den Kaiser Nikephoros Phokas (963-969) zeigt. Nachdem er als Kaiser persönlich gegen die Araber gekämpft hatte, fiel Nikephoros einem Coup zum Opfer; nach seinem Tod wurde er in den Klöstern des Berges Athos als Heiliger verehrt. In einem Akolouthia, einem liturgischen Text, erhalten in einem der klösterlichen Codices, wird Nikephoros als strategos, als Asket und als Märtyrer bezeichnet; seine Mühen und sein Schweiß im Kampf gegen die ungläubigen Araber wird gelobt; zu diesem Text siehe Spanos/Zarras 2009, 71-73.

88 Vgl. Ma. Whitby 2002, 164.

89 Vgl. Ma. Whitby 1994, 216: „Approached from the perspective of the traditions of classical imperial panegyric, George's depiction of Heraclius appears extraordinary.” Über diesen Umstand sollten auch die zahlreichen Verweise des Georg auf eine historische und mythische Vergangenheit nicht hinwegtäuschen; zur typischen rhetorischen Synkrisis mit historischen wie mythischen Figuren siehe Ma. 
4. Jahrhundert propagiert hatten; das Kaiserbild, wie es uns hier entgegentritt, ist eine idiosynkratische, den Bedürfnissen seiner Zeit angemessene Neuschöpfung - einer Zeit, in der sich die römische Bevölkerung mit innenpolitischer Instabilität und außenpolitscher Bedrohung unbekannten Ausmaßes konfrontiert sah. ${ }^{90}$ In einer Umgebung, die durch umfassende Liturgisierungs-Tendenzen geprägt war, brachte Georg heilige Objekte zur Geltung und erhob Herakleios nicht nur zum Athleten im AskeseWettbewerb, sondern zum Vorkämpfer des Christentums gegen die zoroastrischen Perser. Dem hauptstädtischen Bedürfnis nach kaiserlicher Fürsorge begegnete der Dichter schließlich mit der Betonung der unendlichen Mühen, denen sich der Kaiser in christusgleicher Manier zum Wohle seiner Herde aussetzte. Das Spannungsverhältnis zwischen kaiserlicher Erhabenheit und gezielter Erniedrigung, dessen sich bereits die Kaiser des 5. Jahrhunderts bedient hatten, wenn sie barfuß durch die Stadt zogen, ${ }^{91}$ wurde aus dem hauptstädtischen Kontext gelöst, aufs Schlachtfeld übertragen und anhand eines aus der Hagiographie bekannten Askese-Diskurs ausgestaltet; mit der Rede vom schwitzenden Kaiser brachte Georg Herakleios' Charisma im zeremoniellen Interaktionsraum des Palastes zur Geltung, in dem sich die weltliche wie geistliche Elite Konstantinopels versammelt hatte.

Ich lese die Expeditio Persica als eine Bewältigungsstrategie für Herakleios' Transgression; Georg von Pisidien schuf ein schlüssiges Narrativ, das den Kaiser „gegenüber potentiellen oder faktischen Gegendiskursen immunisierte“. ${ }^{22}$ Der Umstand, dass Herakleios Konstantinopel trotz des Widerstandes des städtischen Umfeldes verlassen hatte, wurde in den Worten des Dichters zu einem frommen, von Gott sanktionierten Unterfangen; sein persönliches Vorgehen gegen die Perser, die weiterhin die römischen Ostprovinzen besetzt hielten und das römische Gemeinwesen einer bis dahin beispiellosen Zerreißprobe aussetzten, erschien dabei nicht nur wünschenswert, sondern geradezu notwendig. Als das Gedicht in Konstantinopel präsentiert wurde, war wohl abzusehen, dass Herakleios' Kampagne des Jahres 622 nicht sein letzter aktiver Vorstoß in den militärischen Sektor bleiben würde. Georgs Narrativ lieferte demnach nicht nur eine retrospektive Deutung der kaiserlichen Un-

Whitby 1994, 205-212; Olster 1994, 52. Zum römischen Ideal des basileus polemikos in seinen verschiedenen Ausformungen siehe Maier 2019, 24-37.

90 Anders Olster 1994, 52-54, nach dessen Ansicht die Expeditio Persica weitestgehend traditionellen panegyrischen Topoi folgt, die nur lose mit christlichen Elementen verbunden wurden.

$91 \mathrm{Zu}$ dem Phänomen kaiserlicher humilitas (christlich konnotiert) und deren kommunikativer Funktion im städtischen Umfeld siehe zuletzt Diefenbach 2019, bes. 108-110; mit Blick auf die ostentative Zuschaustellung kaiserlicher Demut (Fokus auf Theodosios II. und Justinian) kommt er zu dem Schluss: „Demonstrationen von Demut stellten die Göttlichkeit des Kaisers nicht in Frage, im Gegenteil: Sie machten sie sogar sichtbar“ (Zitat ebd. 109). Die Quellen bieten keinen Hinweis darauf, dass Herakleios in Konstantinopel aktiv als humilis princeps auftrat, dass er etwa seine Insignien ablegte, wie es sein Vorgänger bisweilen getan hatten; die Erniedrigung vollzieht sich vielmehr in der Rede vom Kaiser, wie sie in Georgs Gedichten offenbar wird.

92 Zu Panegyrik als Kontingenzbewältigung (in Bezug auf Konstantin I.) siehe Wienand 2012, 41f.; Zitat ebd. 42. 
ternehmung, sondern legte damit auch die Basis dafür, dass die Hauptstadt Herakleios' Engagement als Feldherr auch in Zukunft akzeptieren würde.

\section{3 „Obwohl er fort war, war er da“ - der abwesende Kaiser}

\subsubsection{Herakleios’ Gegenoffensive und die Belagerung Konstantinopels}

Herakleios' außenpolitischer Fokus hatte im ersten Jahrzehnt seiner Regierung auf dem Krieg gegen Chosroes gelegen. Regelmäßig wiederkehrendes Aufflammen der Auseinandersetzungen in Thrakien banden dabei jedoch dringend benötigte Ressourcen. 622 musste Herakleios seine Kampagne in Kleinasien abbrechen, als der Khagan erneut Konstantinopel von Westen her bedrohte. Um sich auf den persischen Kriegsschauplatz konzentrieren zu können, galt es, die kräftezehrende Avarenproblematik so weit wie möglich einzuhegen: Konstantinopel zeigte sich offen für einen nachhaltigen Frieden mit dem Khagan. Für den Frühsommer des Jahres 623 wurde ein Treffen auf höchster Ebene anberaumt. Herakleios verließ die Hauptstadt gemeinsam mit zahlreichem Gefolge, bestehend aus Amtsträgern, Klerikern und Zivilbevölkerung, während sich der Khagan mit nicht minder großer Entourage den Langen Mauern von Westen her näherte. Man hatte sich in Herakleia verabredet, der Metropole am Marmarameer, um im dortigen Hippodrom die Einigung der beiden Machthaber mit Pferderennen zu beschließen. Die römische Delegation war bis nach Selmybria gekommen, kurz vor dem Südende der Langen Mauern, als sie von einem Hinterhalt der Avaren überrascht wurde. Herakleios gelang die Flucht, doch Beute und Gefangene fielen in die Hände der Feinde. Erst nachdem sie in den folgenden Tagen das konstantinopolitaner Hinterland bis vor die theodosianischen Mauern geplündert hatten, zogen sich die Avaren wieder bis an die Donau zurück. ${ }^{93}$

93 Chron. Pasch. AD 623 (712f.); Nik. Brev. 10; Theoph. Conf. AM 6110 (De Boor 301f.); außerdem die Andeutung in der Predigt In depositionem pretiosae vestis 2, übers. von Av. Cameron 1979a, 49 und bei Georg. Pis. Bell. Avar. 108-124. Die Datierung des avarischen Hinterhaltes ist problematisch, sie schwankt zwischen der Einordnung des Chron. Pasch. ins Jahr 623 und der des Theoph. Conf. auf 617 bzw. 619. Für eine Frühdatierung Baynes 1912b und Av. Cameron 1979a; für eine Spätdatierung überzeugend Whitby/Whitby 1989, 203 - 205 und Mango 1990, 178 f.; Pohl 2002, 245 - 248; vgl. auch HowardJohnston 1999, 14f.; Kaegi 2003, 118 -121 und Hurbanic 2011 (ausführlich zu dem missglückten Treffen in Thrakien). In der Predigt In depositionem pretiosae vestis wird berichtet, wie die Marien-Reliquie aus der Blachernenkirche, die zu diesem Zeitpunkt noch nicht durch die Erweiterung der Stadtmauer geschützt war, nach den missglückten Friedensverhandlungen erst zum Schutz vor der avarischen Plünderung in die Stadt gebracht und dann durch Patriarch und Kaiser gemeinsam wieder in die Blachernenkirche zurückgeführt wurde. Die Predigt, die anlässlich eines Jahrestages der Rückführung gehalten wurde, weiß noch nichts von der avarischen Belagerung der Hauptstadt 626. Av. Cameron 1979a, 43f. plädiert angesichts ihrer Datierung des avarischen Hinterhaltes ins Jahr 619 dafür, dass die Rückführung 620 erfolgte. Geht man allerdings davon aus, dass der avarische Hinterhalt 623 erfolgte, so muss die Rückführung noch im selben Jahr - nach dem Rückzug der Avaren - erfolgt sein, siehe 
Mit dem Hinterhalt vor Herakleia hatten die Avaren sich als unzuverlässig erwiesen. Auch beträchtliche Tributzahlungen an den Khagan, die Herakleios noch im Anschluss an dessen Plünderung Thrakiens tätigte, werden nur schwerlich dazu beigetragen haben, das Vertrauen in eine nachhaltige Kooperation zu festigen. ${ }^{94}$ Doch die prekäre Sicherheitslage in Thrakien konnte nicht weiter berücksichtigt werden; zu dringlich war ein entschiedenes Vorgehen gegen die Perser. Nachdem die Kampagne des Jahres 622 zumindest der hauptstädtischen Öffentlichkeit gegenüber als Erfolg hatte vermittelt werden können, setzte Herakleios zwei Jahre später alles auf eine Karte und rüstete sich für einen erneuten Vorstoß nach Osten. ${ }^{95}$ Ressentiments gegen Persien wurden noch geschürt, indem ein vermeintlich von Chosroes an Herakleios gesandter Brief voller Beleidigungen gegen Kaiser, römisches Reich und christliche Religion in der Hagia Sophia öffentlich verlesen wurde - weder in Konstantinopel noch im Feldlager verfehlte die Zurschaustellung dieses Schriftstückes ihre Wirkung: Das Vorgehen gegen den persischen Erzfeind schien die einzig angemessene Antwort. ${ }^{96}$ Am verheißungsvollen Feiertag der Verkündigung des Herrn, dem 25. März 624, setzte Herakleios gemeinsam mit seinen beiden Kindern aus erster Ehe, Epiphania und Herakleios Konstantin, sowie seiner zweiten Ehefrau Martina nach Kleinasien über. Ostern feierte die kaiserliche Familie gemeinsam nahe Nikomedia, wo erneut Truppen für den Feldzug bereitgemacht wurden. Während Herakleios mit Martina kurz darauf nach Osten aufbrach, kehrten seine Kinder nach Konstantinopel zurück; angesichts des ungewissen Schicksals der Expedition war es essentiell, dass sich mit

Mango 2000, 19f. Van Dieten 1972, 20 f. meint, dass die Rückführung nach der Belagerung von 626 stattfand; dies ist allerdings nicht plausibel, da sich der Kaiser laut der Predigt zum Zeitpunkt der Rückführung in Konstantinopel befand (siehe Av. Cameron 1979a, 51), was 626/627 nicht der Fall war, 623 allerdings schon.

94 Laut Nik. Brev. 13 zahlte Herakleios vor seinem Aufbruch in den Osten 200.000 Solidi an den Khagan und übergab ihm Geiseln (Herakleios' unehelichen Sohn Atalarich und seinen Neffen Stephan); zum Friedensschluss auch Theoph. Conf. AM 6111 (De Boor 302), wobei angesichts von Theophanes' problematischer Chronologie unklar ist, ob dieser sich auf die Vorbereitung der Kampagne von 622 oder 624 bezieht. Georg. Pis. Heracl. 1.98 - 102 verweist auf einen zu Winterbeginn abgeschlossenen Friedensvertrag, der Herakleios die Möglichkeit gegeben habe, sich auf den Kampf gegen die Perser zu konzentrieren; siehe den Kommentar von Pertusi 1959, 273.

95 Zu der Kampagne ab 624 siehe Stratos 1968, 151-172, 197-222; Howard-Johnson 1999; Greatrex/ Lieu 2002, 200 -225; Kaegi 2003, 122-191; Bonner 2019, 294-311 aus sassanidischer Perspektive. Es geht an dieser Stelle nicht darum, die Bewegungen des Herakleios im Detail nachzuvollziehen; dafür sei auf die obigen Publikationen verwiesen.

96 Der Brief, der bei Sebeos 38 zitiert wird, enthält zahlreiche Bibel-Zitate und -Anspielungen (Thomson/Howard-Johnston I, 80 mit Anm. 496-499), sodass sich - geht man von der grundsätzlichen Authentizität von Sebeos' Zitat aus - die Vermutung aufdrängt, dass es sich bei dem Brief um eine römische Fälschung handelte, vgl. Thomson/Howard-Johnston 1999 II, 214 und Howard-Johnston 2010, 91. 
dem Augustus Herakleios Konstantin weiterhin ein Vertreter kaiserlicher Macht in Konstantinopel befand. ${ }^{97}$

Im Gegensatz zu den Manövern des Jahres 622 blieben Herakleios’ Aktivitäten nun nicht auf Kleinasien beschränkt. Nach Station im kappadokischen Caesarea änderte das römische Heer seine Richtung und bewegte sich nach Nordosten, passierte die Mündung des Euphrat nahe Theodosiopolis und erreichte das armenische Dvin. Die relative Sicherheit, die das anatolische Plateau den kaiserlichen Truppen zuvor noch geboten hatte, ließ Herakleios nun hinter sich. Das römische Heer stand auf feindlichem Gebiet. Vorerst sah man sich allerdings kaum mit Gegenwehr konfrontiert; die persischen Einheiten waren größtenteils in Syrien und Mesopotamien stationiert, wo Chosroes die römische Gegenoffensive erwartet hatte. Herakleios konnte von dem Überraschungsmoment profitieren: Von Armenien aus wandte er sich nach Süden in Richtung des persischen Kernlandes, die Atropatene. Chosroes, der sich zu diesem Zeitpunkt in seiner Residenz in Ganzak befand, sah sich einer direkten Gegenüberstellung nicht gewachsen und zog seinerseits gen Süden ins Zagros-Gebirge. Das schutzlose Ganzak wurde von den römischen Truppen verheert; auch der nahegelegene Feuertempel von Takht-i-Sulaiman fiel in ihre Hände: Zehn Jahre, nachdem die Perser Jerusalem eingenommen und das Heilige Kreuz entwendet hatten, wurde nun die wichtigste zoroastrische Kultstätte von den Römern zerstört und entweiht. Anstatt Chosroes weiter zu folgen, wandte sich das römische Heer daraufhin nach Nordosten, eine Schneise der Verwüstung hinter sich lassend, und bezog Winterquartiere im kaukasischen Albanien nahe der Stadt Partaw. ${ }^{98}$ Von dort aus versuchte Herakleios, das zahlenmäßig unterlegene römische Heer zu stärken, indem er Koalitionen mit lokalen Machthabern Albaniens, Iberiens und Armeniens anstrebte. ${ }^{99}$ Auch zu den Türken, die jenseits der mächtigen Gebirgskette des Kaukasus siedelten, wurde eine römische Delegation geschickt. ${ }^{100}$

Das Jahr 625 verbrachten die römischen Truppen größtenteils in Transkaukasien. Chosroes indes hatte sich von der Überraschung erholt und raffte alle verfügbaren Kräfte unter den Generälen Shahraplakan, Shahrbaraz und Shahin zusammen, um die Römer von Südwesten her einzukreisen und mögliche Fluchtwege abzuschneiden. Doch nach komplizierten Manövern gelang es Herakleios mit seinen vergleichsmäßig beweglichen Verbänden, alle drei persischen Heereskontingente zu besiegen. Auch den Winter 625/6 verbrachten die Römer weitab von Konstantinopel, nördlich des

97 Chron. Pasch. AD 624 (713f.); Speck 1988, 101-107 spricht sich für einen Beginn der Kampagne im Jahr 623 (statt 624) aus, allerdings nicht überzeugend; vgl. dazu Whitby/Whitby 1989, $204 \mathrm{f}$.

98 Georg. Pis. Heracl. 2.153-166 und ebd. 2.167-230 ausführlich zur Bedeutung der Zerstörung des Feuertempels; Sebeos 38 (Thomson/Howard-Johnston I, 81); Movses Dasxuranci 2.10 (Dowsett 78f.); Theoph. Conf. AM 6114 (De Boor 306 - 308); zur Zerstörung von Takht-i-Sulaiman/Adur-Gushnap siehe Bonner 2019, $297 \mathrm{f}$.

99 Movses Dasxuranci 2.10 (Dowsett 79f.).

100 Movses Dasxuranci 2.12 (Dowsett 86f.); dazu Bonner 2019, $298 \mathrm{f}$. 
Van-Sees. ${ }^{101}$ Nachdem Chosroes’ Generäle trotz gesammelter Anstrengungen die römische Invasion in Transkaukasien nicht hatten einhegen können, änderten sie zu Beginn des Jahres 626 erneut ihre Strategie. Mehrere Verbände rüsteten sich für einen Parallelschlag auf Kleinasien: Während Shahrbaraz' Einheiten sich in Syrien sammelten, machte sich Shahin für eine Invasion im Norden bereit. Von diesen Plänen in Kenntnis gesetzt, orientierte auch Herakleios sich mit seinen Truppen wieder nach Westen. Angesichts der besseren Versorgungslage nahm er einen Umweg über Nordsyrien in Kauf und konnte noch vor dem Heer des Shahrbaraz die Kilikischen Pforten durchqueren. Doch anstatt nach Konstantinopel zurückzukehren, richtete Herakleios sich mit seinen Truppen bei Sebasteia in Kappadokien ein, von wo aus er den nördlichen Zugang nach Kleinasien über Armenien kontrollieren konnte. Nachdem prophylaktisch Verstärkung zur Verteidigung der Hauptstadt abgeordnet worden war, gelang es den Römern tatsächlich, die von Armenien anrückenden Truppen Shahins abzufangen und zu besiegen. ${ }^{102}$ Shahrbaraz allerdings, von Süden kommend, stand nun der Weg nach Konstantinopel offen.

Zeitgleich braute sich auch in Thrakien von Seiten der Avaren erneut Gefahr zusammen. Die Nervosität in der Hauptstadt stieg; Herakleios’ Abwesenheit schmerzte nun umso mehr. ${ }^{103}$ Nach Jahrzehnten geprägt von politischer Instabilität, desaströsen Nachrichten aus dem Osten und zunehmender Versorgungsknappheit lagen die Nerven blank. Zuletzt konnte im Mai 626 nur knapp ein Aufstand innerhalb der Stadtmauern verhindert werden, der sich an Fragen der Brotversorgung entzündet hatte: Ein Amtsträger, Johannes mit dem sprechenden Beinahmen Seismos, hatte angeordnet, die Brotrationen der Scholai, der kaiserlichen Garden, zugunsten der in bzw. um die Stadt stationierten Soldaten einzuziehen und allgemein die Brotpreise zu erhöhen. Militärische Belange standen angesichts der feindlichen Bedrohung an erster Stelle. Doch die Städter beugten sich nicht ohne Weiteres dem Vorrang des Militärs. Während der Pfingstfeiertage versammelten sich die benachteiligten Garden gemeinsam mit einer wachsenden Menschenmenge in der Hagia Sophia, um gegen Johannes' Initiative zu demonstrieren. Allein das gemeinsame Eingreifen des Patriarchen Sergios, des Prätorianerpräfekten Alexander sowie weiterer hoher Amtsträger, einhergehend mit dem Versprechen, Johannes abzusetzen und die Brotversorgung zu

101 Sebeos 38 (Thomson/Howard-Johnston I, 81-83); Theoph. Conf. AM 6115 (De Boor 308-312). Die Bewegungen des Jahres 625 sind schwer im Detail zu rekonstruieren, siehe Zuckerman 2002 mit einer alternativen Chronologie (vgl. Howard-Johnston 1999, $17 \mathrm{f}$. und Thomson/Howard-Johnston 1999 II, 216-217).

102 Sebeos 38 (Thomson/Howard-Johnston I, 82 f); ausführlich Theoph. Conf. AM 6116 (De Boor 312314); zu den Bewegungen der Jahre 624-626 vgl. auch Thomson/Howard-Johnston 1999 II, 214-218. Zur Verstärkung nach Konstantinopel und dem Sieg über Shahin siehe Theoph. Conf. AM 6117 (De Boor 315). Dass in der Hauptstadt noch vor Beginn der Belagerung Verstärkung eingetroffen war, macht auch Chron. Pasch. AD 626 (718) deutlich; vgl. Whitby/Whitby 1989, 172 Anm. 461, außerdem Georg. Pis. Bell. Avar. 278-283.

103 Georg. Pis. In Bonum bringt die Stimmung kurz vor dem Beginn der Belagerung zum Ausdruck. 
gewährleisten, konnte die Lage entschärfen. ${ }^{104}$ Konstantinopel war also nicht gerade in bester Verfassung, um sich der militärischen Konfrontation zu stellen, die sich nun in Thrakien zusammenbraute.

Im vergangenen Jahrhundert waren wiederholt nichtrömische Verbände bis in direkte Nähe der Hauptstadt vorgedrungen: Hunnen, Kotriguren und zuletzt Avaren hatten Thrakien bis ins Hinterland Konstantinopels heimgesucht und durch Plünderungen beträchtlichen Schaden angerichtet. ${ }^{105}$ Während die von Anastasios errichtete Lange Mauer, die die thrakische Halbinsel ca. 40 Kilometer westlich von Konstantinopel in Nord-Süd-Richtung durchzog, schwer zu bemannen war und nur unzuverlässigen Schutz gegen feindliche Einfälle bot, hatte die Theodosianische Stadtmauer stets ihre Funktion erfüllt: Diesen massiven Wall zu bezwingen, hatten die Feinde bislang noch nicht einmal versucht. Im Sommer des Jahres 626 sollte sich dies ändern. ${ }^{106}$

Die Schwäche der römischen Position war den Avaren nicht entgangen; ${ }^{107}$ trotz der massiven Tributzahlungen, die Herakleios vor seinem Aufbruch 624 getätigt hatte, rüstete sich der Khagan zur Offensive. Bei Adrianopel sammelte er seine Verbände mit dem erklärten Ziel, Konstantinopel einzunehmen. Am 29. Juni überwand eine zahlenmäßig starke avarische Vorhut die Langen Mauern und zwang die römische Verteidigung, innerhalb der Theodosianischen Mauern Schutz zu suchen. Teile dieser Vorhut überquerten gar die Zuflüsse des Goldenen Hornes und gelangten bis nach Sycae/Galata. Von den dortigen Anhöhen aus nahmen die Avaren durch Feuerzeichen Kontakt mit den Persern auf, die inzwischen unter Shahrbaraz' Führung die asiatische Seite des Bosporus erreicht und nach der Plünderung Chalkedons bei Chrysopolis ihr Lager aufgeschlagen hatten. Konstantinopel war eingekreist. Weitere diplomatische Anstrengungen der Römer, die Avaren zu einer friedlichen Lösung $\mathrm{zu}$ bewegen, scheiterten. Es blieb nichts anderes übrig, als die in der Stadt anwesenden bewaffneten Einheiten unter der Leitung des Patrikios Bonos, dem Herakleios vor seiner

104 Die Unruhen um Johannes Seimos sind allein in Chron. Pasch. AD 626 (715f.) überliefert; siehe den Kommentar bei Whitby/Whitby 1989, 169 Anm. 456. Ericsson 1968 argumentiert - auf Basis der Annahme einer Störung des Manuskriptes - für eine Datierung ins Jahr 615 anstatt ins Jahr 626, dem schließt sich PLRE IIIA, 702 (Ioannes 237) an. Dagegen allerdings überzeugend Whitby/Whitby 1989, 203-205; siehe auch Kaegi 2003, 133. Welche Position Johannes genau innehatte, bleibt unklar, eventuell Stadtpräfekt oder Praefectus annonae.

$105 \mathrm{Zu}$ der Bedrohung Thrakiens durch die Avaren im frühen 7. Jahrhundert siehe Pohl 2002, 237-248. 106 Die Hauptquellen zur Belagerung von Konstantinopel 626 sind Theod. Sync. De obsid; Georg. Pis. Bell. Avar; Chron. Pasch. AD 626; Nik. Brev. 13; Theoph. Conf. AM 6117 (De Boor 316) nur sehr oberflächlich; siehe Barišic 1955; Stratos 1968, 173-196; Speck 1980; Howard Johnston 1995 und ders. 1999, 19-22; Pohl 2002, 248-255; Kaegi 2003, 133 -141; zuletzt Hurbanic 2019; Meier 2019a, 15-26; Bonner 2019, 299-301.

107 Siehe Georg. Pis. Bell. Avar. 58-66. 
Abreise die politische Verantwortung in der Hauptstadt übertragen hatte, für eine Belagerung bereitzumachen. ${ }^{108}$

Am 29. Juli 626 schließlich erreichte auch der avarische Hauptverband gemeinsam mit verbündeten slavischen Kontingenten die Theodosianische Stadtmauer. Die martialische Machtdemonstration des Khagans verfehlte ihren Zweck nicht: Innerhalb der Stadtmauern brach Angst und Schrecken aus beim Anblick der schieren Masse an Feinden, die sich mitsamt ihren Belagerungsmaschinen über die gesamte Länge der Halbinsel ausgebreitet hatten, vom Marmarameer bis zum Goldenen Horn. Ihre Fähigkeiten als Belagerer hatten die Avaren bereits mehrfach unter Beweis gestellt, zuletzt im nordgriechischen Thessaloniki. ${ }^{109}$ Angesichts der barbarischen Übermacht richtete sich in Konstantinopel die Hoffnung auf übernatürliche Unterstützung: Mit einer Schar von Priestern und einem Christus-Bildnis in den Händen prozessierte der Patriarch Sergios durch die Straßen und entlang der Mauern - ein verzweifelter Versuch, die Moral in der umzingelten Stadt aufrecht zu halten. ${ }^{110}$ Zwei Tage nach Ankunft des Khagans brachen tatsächlich Kämpfe aus. Die avarischen Attacken richteten sich vorerst gegen ausgewählte Bereiche der Landmauer um das Polyandrion-Tor: Vorstöße der slavischen Infanterie konnten zwar von den Römern eingehegt werden, doch der konzentrierte Einsatz zahlreicher Belagerungsmaschinen brachte Zweifel auf, wie lange die Verteidiger derartigem Ansturm würden standhalten können. ${ }^{11}$ Bonos sah sich zu einem weiteren diplomatischen Vorstoß gezwungen: Eine hochrangige römische Delegation, bestehend aus weltlichen und geistlichen Würdenträgern, wurde $\mathrm{zu}$ Verhandlungen ins avarische Lager geschickt. Doch das Angebot erneuter Tributzahlungen machte auf den Khagan, sich seiner momentanen Überlegenheit bewusst, keinen Eindruck mehr: Mit Verweis auf seine Allianz mit den Persern, deren Gesandte sich ebenfalls bei ihm eingefunden hatten, setzte er die Räumung Konstantinopels als Bedingung für eine friedliche Beilegung des Konflikts. ${ }^{112}$

Nachdem die Verhandlungen ohne Ergebnis zu Ende gegangen waren, erweiterten die Avaren die Angriffsfläche, um die Konzentration der Verteidiger vom Ansturm auf die Mauer im Westen der Stadt abzulenken. Neben den Belagerungsmaschinen kamen nun auch Boote zum Einsatz, größtenteils Einbäume, die über Land bis nach Konstantinopel transportiert worden waren. Einerseits begab sich eine avarische Flotte auf die asiatische Küstenseite, um den persischen Alliierten, die nicht über Schiffe

108 Siehe Chron. Pasch. AD 626 (716-718), wonach eine Musterung ergab, dass sich ca. 12.000 Kavalleristen in Konstantinopel befanden; zum Vergleich: Für die avarische Vorhut wird eine Zahl von 30.000 angegeben.

$109 \mathrm{Zu}$ Belagerung Thessalonikis siehe Pohl 2002, $242 \mathrm{f}$.

$110 \mathrm{Zu}$ Sergios Theod. Sync. De obsid. 17; auch Georg von Pisidien betont wiederholt die Bedeutung des Sergios, siehe etwa Bell. Avar. 226-245 und 366-373 (auch hier Verweis aufs Acheiropoieton). Siehe Van Dieten 1972, 12-19, der die Belagerung mit Fokus auf Sergios rekapituliert.

111 Zur Stimmung in der Stadt Georg. Pis. Bell. Avar. 214-225 und Theod. Sync. De obsid. 17.

112 Chron. Pasch. AD 626 (719-722); zur Delegation auch Theod. Sync. De obsid. 20 f. und Georg. Pis. Bell. Avar. 311-347. 
verfügten, das Überqueren des Bosporus zu ermöglichen; ${ }^{113}$ andererseits ließ der Khagan Boote nahe der Brücke des Heiligen Kallinikos im Norden der Stadt sammeln, um von den Wassern des Goldenen Hornes aus die schlechter gesicherte Nordseite der Stadt anzugreifen. ${ }^{114}$ Doch plötzlich begannen sich die Geschicke zugunsten der belagerten Hauptstadt zu wenden. Einer römischen Flotte gelang es, die avarischen Boote mit den Persern an Bord abzufangen und zu versenken. ${ }^{115}$ Zumindest von Süden her drohte nun keine Gefahr mehr. Als slavische Kontingente schließlich am 7. August auf ihren Einbäumen das Goldene Horn herunterruderten, zeigte sich die römische Verteidigung vorbereitet. Durch ein Täuschungsmanöver zum vorschnellen Angriff ermutigt, erlag die Masse der Slaven der römischen Flotte. Auf dem Wasser nördlich der Stadt wurde ein wahres Blutbad angerichtet; allein die herrenlosen Einbäume trieben weiter auf den Bosporus zu, bevor sie von den Römern an Land gezogen und verbrannt wurden. Schließlich gelang armenischen Hilfstruppen am Nordende der Landmauern nahe der Blachernenkirche ein Ausfall, dem weitere Feinde zum Opfer fielen. ${ }^{116}$

Die Strategie des Khaghans war nicht aufgegangen. Nach der erdrückenden Niederlage am Goldenen Horn sah er sich gezwungen, auch von den Landmauern abzurücken. Den Avaren blieb nichts anderes übrig, als die Belagerungsmaschinen in Brand zu setzen und sich nach Westen hin zurückzuziehen. Innerhalb der Mauern wich die Angst der Euphorie; die Spolien des Sieges, die abgeschlagenen Köpfe der Feinde, wurden auf den Mauern präsentiert. Nur mit Mühe konnte Bonos die Bevölkerung davon abhalten, in das weiterhin unsichere Umland der Stadt auszuströmen. ${ }^{117}$ Wenige Tage später erreichte eine Abordnung der Herakleios unter der Führung seines Bruders Theodor die Stadt mit weiterer Verstärkung. Auch die Perser zogen sich schließlich vom Bosporus zurück. ${ }^{118}$ Die Eroberung Konstantinopels hatte abgewandt werden können. In der Stadt war man sich einig, wem dieser unerwartete Sieg zu verdanken war: Nicht etwa der erfolgreichen militärischen Verteidigung, sondern dem

113 Theod. Sync. De obsid. 22; Chron. Pasch. AM 626 (723f.)

114 Chron. Pasch. AM 626 (720); Nik. Brev. 13.

115 Der Bericht des Chron. Pasch. bricht hier aufgrund des Fehlens einer Manuskriptseite ab; Theod. Sync. De obsid. $23 \mathrm{f}$.

116 Zur Seeschlacht auf dem Goldenen Horn siehe Theod. Sync. De obsid. 32f.; Nik. Brev.13, außerdem sehr impressionistisch Georg. Pis. Bell. Avar. 396-501.

117 Chron. Pasch. AM 626 (725f.); Theod. Sync. De obsid. $34 \mathrm{f}$.

118 Ankunft des Theodor: Chron. Pasch. AD 626 (726); der genaue Zeitpunkt des Abzuges der Perser bleibt unklar: Laut Theod. Sync. De obsid. 37 zogen die Perser wenige Tage nach den Avaren ab, laut Theoph. Conf. AM 6117 (De Boor 316) überwinterte Shahrbaraz bei Chalkedon; eine rasche Rückkehr nach Persien scheint indes wesentlich plausibler. In einigen späteren Quellen findet sich die Angabe, Herakleios und Shahrbaraz hätten im Nachklang der Belagerung ein Bündnis gegen Chosroes geschlossen; dabei handelt es sich allerdings kaum um eine authentische Nachricht, sondern um nachträgliche Legendenbildung, siehe Mango 1985, 107-109; Howard-Johnston 1999, 22 Anm. 68; vgl. auch Kaegi 2003, 148 f. 
Eingreifen der Jungfrau Maria, die von ihrem Heiligtum in Blachernae aus persönlich den entscheidende Schlag gegen die slavischen Einbäume veranlasst hatte. ${ }^{119}$

\subsubsection{In Bonum und Bellum Avaricum}

Während Herakleios dem Vortrag der Expeditio Persica aller Wahrscheinlichkeit nach persönlich beigewohnt hatte, war das Setting, im Rahmen dessen die nächsten Gedichte des Georg von Pisidien vorgetragen wurden, ein anderes: Das Publikum, das sich zusammenfand, um der Rezitation zu lauschen, mag dem von 622 durchaus geähnelt haben, bestehend aus der weltlichen und geistlichen Elite Konstantinopels; Herakleios selbst jedoch weilte weiterhin am Kriegsschauplatz. In Georgs In Bonum ist die steigende Nervosität in der Hauptstadt angesichts der avarischen Bedrohung bereits deutlich zu spüren, was eine Komposition im Frühjahr bzw. Frühsommer 626 nahelegt. ${ }^{120}$ Georgs Bellum Avaricum entstand, als die Belagerung überstanden, die Erinnerung daran allerdings noch frisch war. ${ }^{121}$ Nachdem zuvor herausgearbeitet wurde, wie Georg von Pisidien nach der Kampagne von 622 die kaiserliche Aktivität als Feldherr entwarf, konkretisiert sich nun die Frage, wie die Hauptstadt - vor allem in Zeiten der akuten Krise - mit der langfristigen Abwesenheit des Kaisers umging und welche Auswirkung diese Konstellation auf das politische Umfeld zeitigte.

Welche Herausforderung die Abwesenheit des Kaisers für den Dichter darstellte, macht bereits In Bonum deutlich. Äußerlich als ein Lob von Herakleios' Statthalter, dem Patrikios Bonus, ausgewiesen, arbeitet das Gedicht sich effektiv an dem Umstand ab, dass Herakleios bei den Truppen weilt, anstatt der Hauptstadt in der prekären Situation beizustehen. ${ }^{122}$ Georg schwankt zwischen dem Versuch, das Engagement des Kaisers als Feldherr positiv dastehen zu lassen, und der Notwendigkeit, auf die Angst und das zunehmende Unbehagen, das offenbar in der Hauptstadt um sich griff, einzugehen. Herakleios erscheint als neuer Herakles, versehen mit dem Epithet des

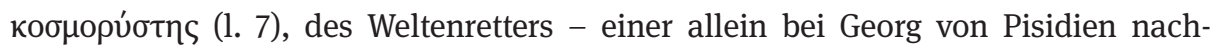
weisbaren Wortschöpfung, deren Gehalt allerdings erst im nächsten Unterkapitel ganz deutlich wird. ${ }^{123}$ Das Bild des sich abmühenden Kaisers, wie Georg es in der Expeditio

119 Im Jahr nach der Belagerung wurde die Marienkirche von Blachernae, die bislang außerhalb der Mauern gelegen hatte, durch eine Erweiterung des Verteidigungswalles eingefasst; siehe Chron. Pasch. AD 627 (726) und Nik. Brev. 13.

120 Howard-Johnston 2010, 21f.; Tartaglia 1998, 16.

121 Bell. Avar. 165-168; siehe Pertusi 1959, 215; Tartaglia 1998, 16f. und Peltomaa 2009, 298. Speck 1980, 19, nimmt an - nicht überzeugend -, dass das Gedicht erst nach Herakleios' Sieg gegen die Perser verfasst wurde (ebd. 19), dagegen Van Dieten 1985, 150, 157.

122 Siehe dazu Olster 1994, 54-56; Meier 2015, 178-180.

123 Meier 2015, 178f.; zu dem Herakles/Herakleios-Vergleich vgl. oben S. 135 f. 
Persica entwickelt hat, kommt auch hier wieder zum Tragen; die ponoi werden erneut zum Schlüsselbegriff: ${ }^{124}$

ảkì yà

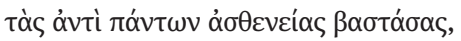

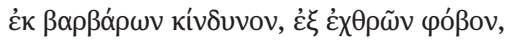

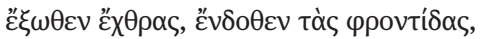

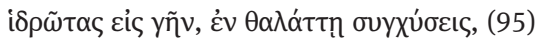

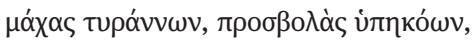

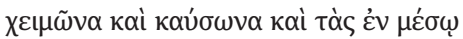

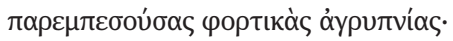

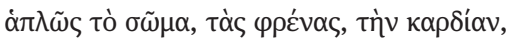

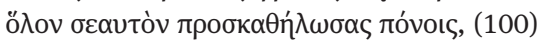

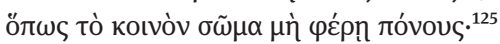

Denn stets hast du dich für uns den Mühen gestellt, hast du Schwächen für alle getragen, die von den Barbaren ausgehende Gefahr, die Angst vor den Feinden, die Bedrohungen von außen, die Sorgen von innen,

den Schweiß zu Lande, die Verwirrungen auf dem Meer, die Kämpfe gegen die Tyrannen, die Angriffe durch Untergebene, Winter und Hitze und die mühsamen schlaflosen Nächte, die sich inmitten der Ereignisse einstellen.

Kurz gesagt: den Körper, die Gedanken, das Herz, dich selbst in Gänze nagelst du an die Mühen, damit der gemeinschaftliche Körper keine Mühen tragen muss.

Die Abwesenheit des Kaisers versucht der Dichter zu kompensieren, indem er auf die außerordentliche Nahbeziehung zwischen Herakleios und seinem Mitstreiter (ouvó$\pi \lambda \omega$; 6) Bonos verweist, die geprägt ist von Freundschaft und Liebe: ${ }^{126}$ „Eine Seele

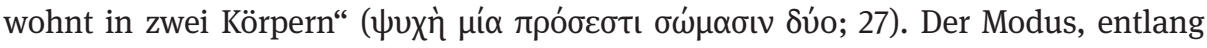
dessen das Verhältnis der beiden Männer beschrieben wird, erinnert dabei auffallend an die metaphysische Einheit zwischen einem transzendenten Gott und dem menschgewordenen Jesus Christus. „Denn es wird nicht geteilt noch verteilt, sondern ist gleichzeitig außen und innen, so wie der Herr [i.e. Herakleios] in dir [i.e. Bonos] ist, auch wenn er scheinbar entfernt ist. “127 Doch selbst angesichts des Trostes, den Bonos der Stadt spendet, kommt Georg nicht umhin, sich schließlich flehend an den abwesenden Kaiser zu wenden: „Auch wenn du dich wegbewegst zu der persischen Wolke und du gefangen bist in dem barbarischen Hagelsturm, komm zu uns!“128 Der Kaiser erscheint als Hoffnung stiftende Lichtgestalt; ${ }^{129}$ um die Beziehung zwischen ihm und seiner Hauptstadt zu charakterisieren, bedient sich Georg einer Arzt/Patientund Eltern/Kind-Metaphorik, ${ }^{130}$ die die Hoffnung auf kaiserliche Fürsorge an der leidenden Bevölkerung unterstreicht, bevor er sich erneut an Herakleios wendet:

124 In Bonum 160 f. zu dem Schweiß, den Herakleios für alle ausgießen würde - auch hier steht das Schwitzen in Zusammenhang mit Reinigung von Fehltritten; dazu siehe oben S. 201 mit Anm. 71.

125 In Bonum 91-101.

126 In Bonum 14-45; siehe dazu Ma. Whitby 1998, 264.

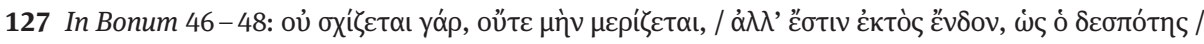

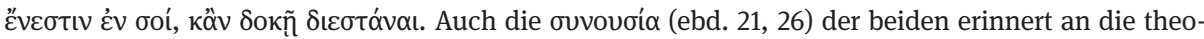
bzw. christologischen Debatten um das Verhältnis zwischen Gott und Gottessohn; darauf weist auch Meier 2015, 179f. hin, der schließt: „Christus und Herakleios werden austauschbar (...).“

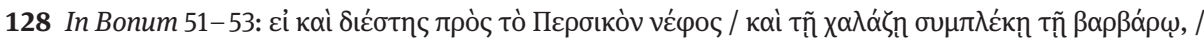

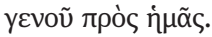

129 In Bonum 53-55, 132.

130 In Bonum 56-110. 
„Dennoch, werde rechtzeitig zum Helfer und schütze die leuchtende Pupille der ganzen Erde, die allberühmte Stadt. “131

Wie Herakleios' umstrittene Entscheidung, an der Spitze seiner Truppen in den Krieg zu ziehen, auf das hauptstädtische Umfeld rückwirkte, offenbarte sich besonders deutlich im Angesicht der avarischen Bedrohung. Im 5. und 6. Jahrhundert hatten sich die sesshaften Kaiser als zentrale Identifikations-, wenn nicht gar Heilsfiguren Konstantinopels, der basileussa polis, etabliert. In Momenten einer wie auch immer gearteten Krise nahm der Kaiser über seine praktische Kompetenz als Entscheidungsträger hinaus gleichsam die Funktion als (spiritueller) Kristallisationspunkt für Hoffnungen und Erwartungen der hauptstädtischen Bevölkerung ein. Über seine regelmäßige Teilnahme an liturgischen Prozessionen hinaus äußerte sich dieser Sachverhalt etwa darin, dass der Monarch recht spontan auf Ausnahmesituationen reagieren konnte: Als im Jahr 447 ein Erdbeben Konstantinopel erschütterte, leitete Theodosios II. barfüßig Buß- bzw. Bittprozessionen auf dem Hebdomon an; ${ }^{132}$ als die Kutriguren 559 Thrakien verwüsteten und auch die Hauptstadt in Angst und Schrecken versetzten, machte sich Justinian persönlich auf, um die Reparaturen an den Langen Mauern zu überwachen. ${ }^{133}$ Während Herakleios im Herbst 622 noch aus Kleinasien nach Konstantinopel geeilt war, um sich persönlich der Avaren-Problematik anzunehmen, und entsprechend von Georg von Pisidien als Oberhirte seines Volkes gelobt werden konnte, wurde der Kaiser 626 seiner Fürsorgefunktion nicht gerecht; um die Perser weiter in Schach zu halten, blieb er bei den Truppen. Die Präsenz des minderjährigen Augustus Herakleios Konstantin tröstete dabei offenbar nur unzureichend über die Abwesenheit des Vaters hinweg: In In Bonum tritt er zwar gemeinsam mit seinen Geschwistern auf, allerdings nicht, um Herakleios’ Position auszufüllen, sondern um sich als ein weiterer Bittsteller für die Rückkehr des Vaters einzusetzen. ${ }^{134}$

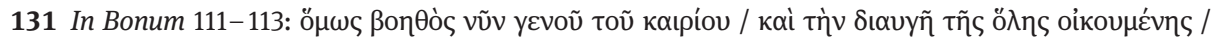

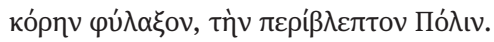

132 Diefenbach 2002, 24f.; spontane Prozessionen konnten auch aufgrund von positiven Nachrichten abgehalten werden.

133 Theoph. Conf. AM 6051 (De Boor 234); nachdem sein Werk in Thrakien vollbracht war, zog Justinian im triumphal anmutenden Adventus in die Hauptstadt ein, siehe Av. Cameron 1979b, 8f.; McCormick 1986, 67; Meier 2003a, 304f. Vgl. auch das Kontakion „Auf Erdbeben und Brände“ des Romanos Melodos, in dem die Zerstörungen der Nika-Aufstandes einer für Justinian äußerst entgegenkommenden Deutung unterworfen werden: Der Kaiser erscheint als Mittler zwischen seinem Volk und einem erst zornigen und schließlich gnädigen Gott; zu dem Kontakion siehe Barkhuizen 1995; Viermann (im Druck).

134 In Bonum 116-127. Ein anderes Gedicht des Georg von Pisidien spricht Herakleios Konstantin hingegen sehr direkt an, nämlich In resurrectionem Christi (siehe Ma. Whitby 1998, 265). Darin wird der junge Augustus aufgefordert, mit seiner Eloquenz die Mühen seines Vaters zu loben (112-117) und sich nach dessen Vorbild wie ein Heraklide $(106,120)$ für den Kampf vorzubereiten (118). Auch im Bellum Avaricum hat Herakleios Konstantin keinen prominenten Auftritt (nur $257 \mathrm{f}$.). 
In dieser prekären Situation bemühte sich Georg von Pisidien um die Vergegenwärtigung des abwesenden Kaisers. ${ }^{135}$ Die Nichterfüllung der kaiserlichen Fürsorgefunktion versuchte der Dichter zu kompensieren, indem er dessen endlose Mühen für das Wohl der Allgemeinheit in den Fokus stellte; das Unbehagen indes, das in der Hauptstadt angesichts von Herakleios' Transgression um sich griff, kann auch die Panegyrik nicht übertünchen. Dass der Kaiser in den emotionalen Appellen wiederholt in der zweiten Person angesprochen wird, könnte man schließlich als Hinweis auf das Setting der Präsentation lesen. Wurde In Bonum im kaiserlichen Palast nicht etwa vor Herakleios Konstantin, sondern vor dem leeren Thron vorgetragen, der gleichermaßen transzendente kaiserliche Würde und die von Herakleios hinterlassene Leerstelle symbolisierte? ${ }^{136}$

Während In Bonum nicht umhin kommt, die enttäuschten Erwartungen an den Kaiser deutlich zum Ausdruck zu bringen, und darum ringt, die prekäre Situation mit einer sinnstiftenden Deutung zu versehen, hat sich die Stimmung im Bellum Avaricum $^{137}$ gedreht: Konstantinopel war es inzwischen gelungen, die Belagerer zu schlagen; das Gedicht blickt auf die prekäre Situation zurück und feiert den unerwarteten Triumph: „Ich möchte euch erzählen“ - so Georg von Pisidien - „von dem Anlass für diese Worte, von dem kürzlich erfolgten Kampf. “138 Welche Position konnte Herakleios innerhalb dieser Erzählung einnehmen - in der Erinnerung an einen Sieg, an dem er nicht beteiligt gewesen war?

Zunächst nimmt Georg auf Anschuldigungen gegen Herakleios Bezug, wie sie offenbar in Konstantinopel zirkulierten, nämlich dass dieser nicht angemessen für die Sicherheit der Stadt vorgesorgt habe, bevor er nach Asien aufgebrochen war; das Problem, dass der Kaiser seine Fürsorgefunktion nicht erfüllt hatte, trieb den Dichter also auch im Bellum Avaricum noch um. Herakleios, der stets alles angemessen er-

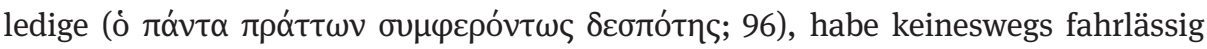
gehandelt, so Georg, sondern mit Wort und Tat versucht, den Avaren-Khagan, diese

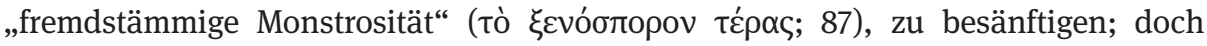
während selbst wilde Tiere sich durch gutes Zureden und freundliche Gesten beru-

135 Vgl. Ma. Whitby 1998, 269: „The special task of Heraclius' publicist was to keep the absent emperor in the minds of the citizens of the capital, to gloss over internal dissensions and reassure the people that Heraclius had their interests at heart and was acting on their behalf, even when problems in Constantinople made his absence hard to accept."

136 Ma. Whitby 2002, 161 vermutet, dass In Bonum nicht nur in der Hauptstadt vorgetragen, sondern auch an den abwesenden Kaiser übersandt wurde.

137 Einen ausführlichen Kommentar des Bellum Avaricum liefert Speck 1980, dessen Interpretationen allerdings meiner Ansicht nach oft derart weit hergeholt und fragwürdig sind, dass ich im Folgenden nur sporadisch darauf verweisen werde; vgl. Van Dieten 1985, der einen ganzen Aufsatz geschrieben hat, um auf die Schwächen von Specks Publikation hinzuweisen.

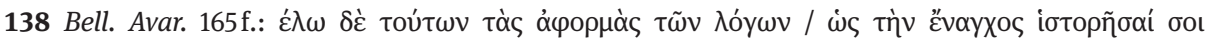

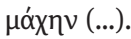


higen ließen, sei dies bei Menschen mitunter nicht der Fall. ${ }^{139}$ Ähnlich wie bereits in In Bonum wird Herakleios' Abwesenheit daraufhin nicht nur in eine sinnstiftende Erzählung eingepasst, sondern - unter Rückgriff auf bereits etablierte Motive - explizit positiv konnotiert. Anstatt in der Hauptstadt verdiente Erleichterung von seinen

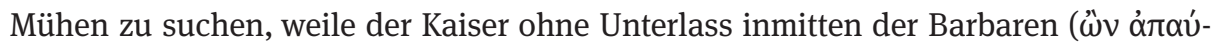

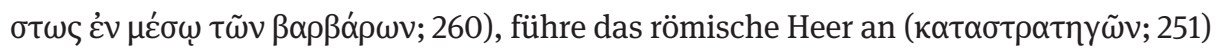

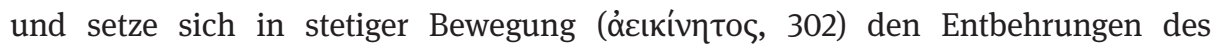
Schlachtfeldes aus; ${ }^{140}$ unterdessen habe er es nicht versäumt, Konstantinopel in der Krise beizustehen: Seine Fürsorge aus der Ferne wiege die körperliche Absenz auf; er

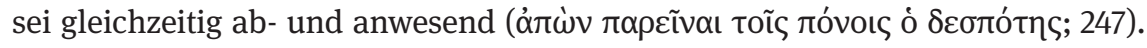

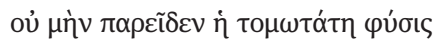

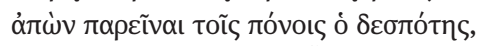

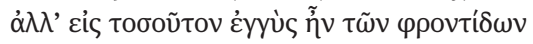

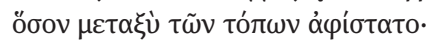

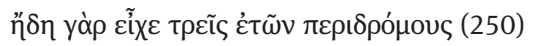

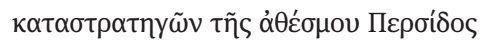

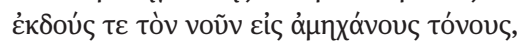

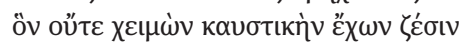

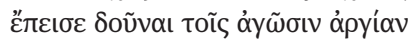

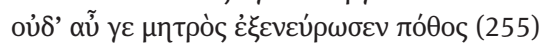

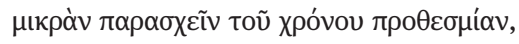

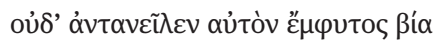

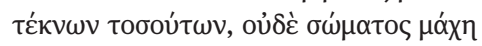

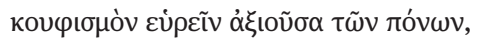

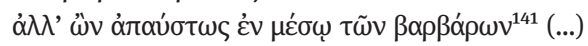

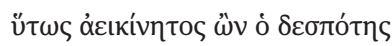

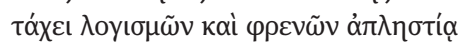

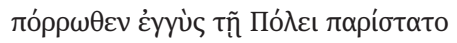

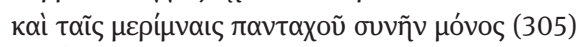

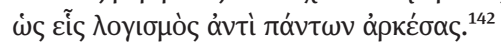

Freilich versäumte es der Kaiser - von ehrenvollem Charakter - nicht, an den Mühen (der Verteidigung) teilzuhaben, obwohl er abwesend war; stattdessen war er in solchem Maße nahe in Gedanken, wie er räumlich entfernt war.

Zu diesem Zeitpunkt zog er bereits drei Jahren gegen das gesetzlose Persien ins Feld, seinen Verstand unlösbarer Anspannung aussetzend; weder überzeugte ihn der Winter mit seiner brennenden Kälte, eine Pause von den Kämpfen zu geben, noch bewegte ihn wiederum die Sehnsucht nach seiner Mutter dazu, eine kleine Frist seiner Zeit darzubringen, noch trug ihn die natürliche Macht der Liebe zu seinen solchen Kindern davon, noch war der Kampf des Körpers es ihm wert, Erleichterung von den Mühen zu finden; stattdessen war er ohne Unterlass inmitten der Barbaren (...) So muss sich der Herr ewig in seiner unersättlichen Schnelligkeit an Verstand und Herz bewegen, aus der Ferne steht er nahe der Stadt und er allein lebt überall mit den Sorgen, sodass ein Geist ausreichte für alle.

Als sich die Belagerung der Hauptstadt abzeichnete, habe Herakleios entschieden

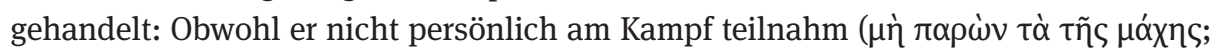

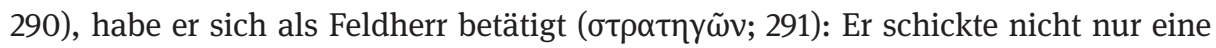

139 In Bell. Avar. 85-107 wird die Grausamkeit des Avaren-Khagans geschildert sowie Herakleios' Versuche der Beschwichtigung. Hierin findet sich wohl ein Verweis auf die vom Kaiser getätigten Zahlungen an die Avaren. Auch Phokas wurde von Georg von Pisidien als Tier verunglimpft; siehe Heracl. ex Afr. 47.

140 Auch im Bellum Avaricum erinnert Georg wieder daran, dass Herakleios den „Tyrannen“ Phokas zur Stecke gebracht hat (49-57); vgl. zur Bedeutung dieses Motivs siehe oben Kap. 3.4.

141 Bell. Avar 246-260.

142 Bell. Avar 302-306. 
Depesche mit genauen Anweisungen für die Verteidigung nach Konstantinopel, ${ }^{143}$ die von der Bevölkerung prompt in die Tat umgesetzt wurden, ${ }^{144}$ sondern auch ein Kontingent seines Heeres - die eigene Sicherheit für die Rettung des Gemeinwesens vernachlässigend. ${ }^{145}$

So sehr Georg von Pisidien Herakleios' Sorge um das Gemeinwesen auch betont, rechnet das Bellum Avaricum sowohl die Verantwortung als auch den Ruhm für den Sieg primär anderen Akteuren zu. Dem Führungsduo, durch dessen Initiative Konstantinopel in Georgs Erzählung der Bedrohung Herr werden kann, gehört der Patriarch Sergios an, der Auftraggeber des Gedichtes; ${ }^{146}$ doch steht an seiner Seite nicht etwa der zuvor gelobte Patrikios Bonos - er spielt im Bellum Avaricum keine große Rolle mehr ${ }^{147}$-, sondern die Theotokos, die Mutter Gottes. ${ }^{148}$ Im Zentrum des Gedichtes spricht Georg Sergios direkt an: Durch seine Werke und Gottes Willen sei die

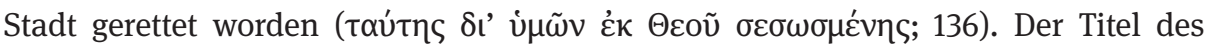
strategos, des Befehlshabers, den Georg in der Expeditio Persica als Attribut des Herakleios etabliert hatte, wird nun dem Patriarchen zugerechnet: „Heil dir, oh Feldherr

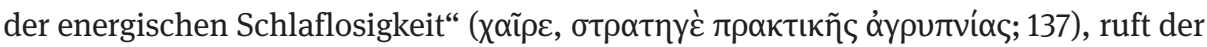

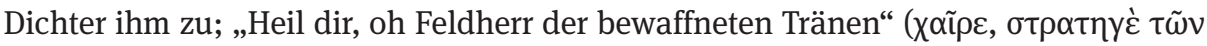

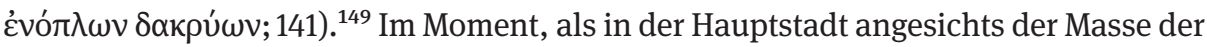
Barbaren vor den Mauern die Hoffnung schwindet, ${ }^{150}$ liegt in der Verbindung zwischen Sergios und der Theotokos der Schlüssel zur Rettung:

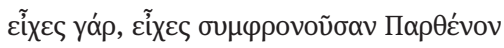

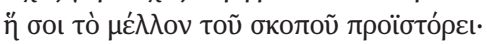

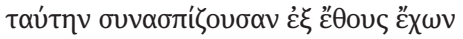

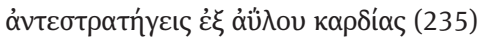

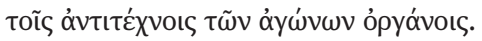

Denn du hattest, du hattest die Jungfrau als Gleichgesinnte, die dir den wahrscheinlichen Ausgang enthüllt; du hast sie wie gewohnt als Schildgefährtin und hast dich aus dem stofflosen Herzen heraus den gegnerischen Kriegsmaschinen der Kämpfe entgegengestellt.

An Stelle der aktiven Kriegsführung des Herakleios, wie sie in der Expeditio Persica im Detail ausgemalt wurde, rückt nun die spirituelle Autorität des Patriarchen in den Fokus, mit der dieser sich den Barbaren entgegenstellt: „Als Bogen hast du die

143 Bell. Avar. 266-279; 288-292.

144 Bell. Avar. 293-301: Die gute Zusammenarbeit zwischen abwesendem Kaiser und den Verteidigern in der Stadt wird betont.

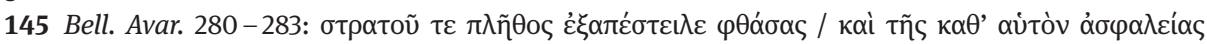

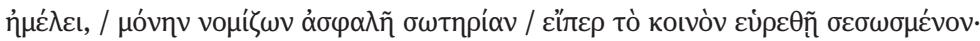

146 Die Beauftragung kommt in Bell. Avar. 125-129 zum Ausdruck.

147 In Bell. Avar. 313 etwa könnte man einen Verweis auf Bonos vermuten, allerdings wird er nie beim Namen genannt.

148 Das Gedicht beginnt mit einer Anrufung der Theotokos (Bell. Avar. 1-15); siehe dazu Hurbanic 2019, 249.

149 Bell. Avar. 142-144: Sergios' Tränen verbrennen den Mut der Barbaren und bieten dem Blutvergießen Einhalt; zu Tränen als Attribut der Sergios siehe Ma. Whitby 1998, 267f.; vgl. Bell. Avar. 239. 150 Bell. Avar. 223-225. 


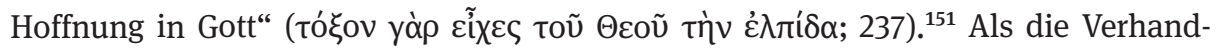
lungsversuche der Römer ins Leere laufen und die Avaren erneut die Mauern attackieren, eilt Sergios zum Ort des Geschehens - bewaffnet mit dem Acheiropoieton, der nicht von Menschenhand gemalten Christusikone. ${ }^{152}$ Seine „Schildgefährtin“ (ouv $\alpha$ -

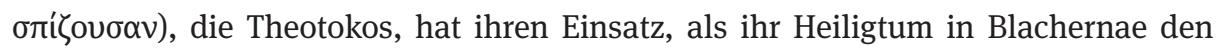
Barbaren zum Opfer fällt und feindliche Einbäume versuchen, das Goldene Horn zu

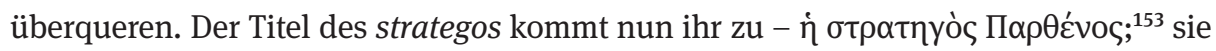

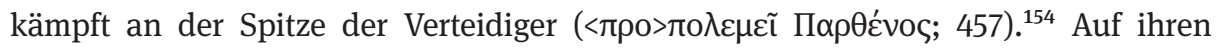
Einsatz hin spricht ihr Sohn, Christus, der himmlische Richter, Konstantinopel den Sieg zu. ${ }^{155}$

Der Patriarch und die Theotokos werden im Bellum Avaricum sprachlich derart eng angeglichen, dass bisweilen schwer nachvollziehbar ist, wer gerade angesprochen wird; ${ }^{156}$ doch damit nicht genug: Im Zuge dieses Angleichungsprozesses werden die beiden mit Variationen des Attributes strategos versehen, das Georg zuvor aufs engste

151 Ausgeführt in Bell. Avar. 137-143.

152 Bell. Avar. 370 - 373; vgl. Theod. Synk. De obsid. 17; es stellt sich die Frage, um welches Acheiropoieton es sich hierbei handelt. Das Acheiropoieton von Kamuliana hatte Herakleios auf seiner Kampagne von 622 mitgenommen (siehe oben S. 191f.). War es 624 in Konstantinopel geblieben, oder spielt Georg von Pisidien hier auf ein anderes Acheiropoieton an? Letzteres vermutet Van Dieten 1972, 15f., 174-178 gegen die Annahme von Pertusi 1959, 143, $220 \mathrm{f}$., dass es sich bei der Ikone aus dem Bellum Avaricum um eine Theotokos-Ikone handelt. Zu den Acheiropoieta im Zusammenhang mit der Belagerung siehe auch Hurbanic 2019, 317-321; Pentcheva 2006, 43f.; zur Ikonen-Verehrung während der Belagerung und in Erinnerung an dieses Ereignis ebd. 37-59. In der Forschung ist umstritten, ob neben der Christus-Ikone (also dem Acheiropoieton, das sowohl bei Georg von Pisidien als auch bei Theodor Synkellos erwähnt wird), auch Marien-Ikonen in Prozessionen mitgeführt wurden. Pentcheva 2002 argumentiert auf Basis einer eingehenden Analyse der Quellen dafür, dass Marien-Ikonen 626 noch keine Rolle spielten. Der Marienkult sei im frühen 7. Jahrhundert noch auf Reliquien fokussiert gewesen; die Verbindung zwischen Marien-Ikonen und dem Schutz der Stadt dagegen sei als Phänomen erst nach dem Ikonoklasmus aufgetreten; dem widerspricht Speck 2003. Ich stimme Pentcheva dahingehend zu, dass es keine klaren Belege für die Nutzung von Marien-Ikonen während der Belagerung 626 gibt.

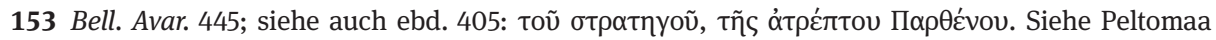
2009, 298 und zum Einsatz der Theotokos Hurbanic 2019, 216-218.

154 Siehe auch Bell. Avar. 451-456: Während das direkte Eingreifen der Theotokos in anderen Quellen noch plastischer geschildert wird (dazu siehe die Analyse der Predigt des Theodor Synkellos im Folgenden), relativiert Georg dies zu einem gewissen Maße, indem er die Passage mit einem oíl $\tilde{a}_{\mathrm{l}}$ (ebd. 451) einleitet.

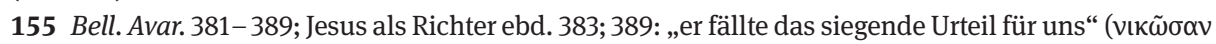

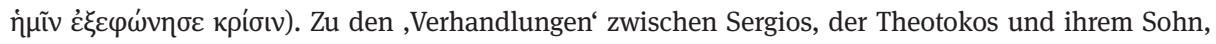
Jesus Christus, siehe die Analyse der relevanten Verse bei Pentcheva 2002, 5-9. Angesichts des Blutbades, das auf dem Goldenen Horn an den Avaren angerichtet wurde, erhebt Georg Sergios zum „neuen Moses“, der den Pharao, die Avaren, im Roten Meer zur Strecke bringt (ebd. 493-497); siehe Pertusi 1959, 224. Theod. Synk. De obsid. 17, 24 greift den Moses-Vergleich auf.

156 Siehe besonders Bell. Avar. 130 -140, wo Sergios als Mutter angesprochen wird, die sich um die Stadt kümmert; dazu siehe Trilling 1978, 258; Ma. Whitby 1998, 266f.; vgl. Peltomaa 2009, 298. Zu Sergios und der Theotokos siehe Ma. Whitby 2020. 
an Herakleios gekoppelt hatte. In Georgs Erinnerung an die überwundene Krise treten anstelle des Herakleios also zwei alternative strategoi in den Vordergrund, die die aktive Schutz- und Fürsorgefunktion des abwesenden Kaisers übernehmen und der Stadt als Identifikationsfiguren dienen. Während der Dichter seinen Auftraggeber und Vorgesetzten Sergios glänzen lässt, nimmt selbst der junge Augustus Herakleios Konstantin - zu diesem Zeitpunkt bereits 14 Jahre alt - im Bellum Avaricum nur eine passive Rolle ein; ${ }^{157}$ die Funktion des Vaters kompensiert nicht er, sondern der Patriarch. ${ }^{158}$ Als spirituelles Führungsduo treten Sergios und die Theotokos indes nicht in Konkurrenz zur Autorität des Herakleios, der weiterhin in Persien kämpft; ihr Einsatz lässt Raum für den Kaiser, dessen Mühen um das Gemeinwesen der Dichter nicht müde wird, gegenüber seinem Publikum zu vergegenwärtigen - durch Georgs Verse ist Herakleios in der Tat in Konstantinopel „anwesend, obwohl er abwesend ist“. Mit Herakleios, Sergios und der Theotokos etabliert Georg von Pisidien eine Trinität der strategoi.

Mit seiner Hervorhebung der Theotokos steht Georg keineswegs alleine da; das Bellum Avaricum ist eine von vielen Stimmen, die die Muttergottes als übernatürliche Beschützerin der Hauptstadt preisen. Dass Konstantinopel seine Rettung dem Einschreiten der Theotokos zu verdanken habe, entwickelte sich zu einem wirkmächtigen und langlebigen Topos, der in verschiedensten Ausformungen nachzuvollziehen ist und im Laufe der Jahrhunderte auch auf andere Bedrohungen - etwa Belagerungen durch Araber oder Bulgaren - übertragen wurde. ${ }^{159}$ Um das Bellum Avaricum und die Art und Weise, wie das Gedicht Herakleios’ Abwesenheit bewältigt, im hauptstädtischen Kommunikationskontext $\mathrm{zu}$ verorten, ist im Folgenden ein kursorischer Blick auf allgemeine Trends sowie weitere zeitgenössische Quellen zu werfen.

Wie Averil Cameron in einigen richtungweisenden Publikationen deutlich gemacht hat, spielte die Muttergottes sowohl in der Sakraltopographie der Hauptstadt als auch in der Vorstellungswelt ihrer Bewohner bereits vor 626 eine wichtige Rolle;

157 Herakleios Konstantin erscheint allein in den letzten Versen des Gedichtes (Bell. Avar. 535-541), als Georg ihm den Sieg widmet - zu dem er allerdings keinen aktiven Beitrag geleistet hat; vgl. Ma. Whitby 1998, 264. Ma. Whitbys Auffassung, dass die enge Verbindung zwischen Herakleios und Herakleios Konstantin wiederholt durch Georg betont wird, würde ich allerdings relativieren; der Thronfolger spielt bei Georg kaum eine Rolle, der ganz klar Sergios als alleinigen (menschlichen) Verantwortungsträger aufbaut.

158 Als Ort der Rezitation könnte der Palast des Patriarchen anstelle des kaiserlichen Palastes gedient haben.

159 Mango 2000, 22; siehe auch Van Esbroeck 1976 zu einer in georgischer Übersetzung erhaltenen Chronik zu den Belagerungen Konstantinopels. In der Kommemoration verschwammen mit der Zeit die Grenzen zwischen den verschiedenen Belagerungen; so wurde am Samstag vor Mariä Verkündigung, der mit der Belagerung durch die Araber 719 in Verbindung stand (siehe Wellesz 1956, 152) auch der Belagerung von 626 gedacht: Die Feier wurde mit dem Akathistos-Hymnos begangen; siehe Frolow 1944, 97; Van Esbroeck 1976, 79. 
ihre Verehrung wurde von den Kaisern gezielt gefördert. ${ }^{160}$ Die Blachernenkirche vor den Toren der Stadt, die seit ihrer Stiftung im 5. Jahrhundert durch kaiserliche Initiativen immer weiter ausgebaut wurde, ${ }^{161}$ beherbergte das Gewand der Jungfrau eine Reliquie, die unter Leon I. aus dem Heiligen Land nach Konstantinopel gebracht worden war. ${ }^{162}$ Spätestens im 6. Jahrhundert etablierte die Blachernenkirche sich als wichtigste hauptstädtische Kultstätte der Theotokos; ihre Lage knapp außerhalb der theodosianischen Stadtmauer exponierte die Kirche zwar bei feindlichen Angriffen, ${ }^{163}$ trug aber gleichzeitig auch zu ihrem apotropäischen Status als ideelles Verteidigungsbollwerk Konstantinopels bei. Eine Predigt, die rekapituliert, wie das Gewand der Jungfrau in den frühen 620er Jahren angesichts plündernder Avaren kurzzeitig in die Stadt in Sicherheit gebracht werden musste und sich dabei als wunderwirkende Reliquie offenbarte, versieht Konstantinopel mit dem Epithet Theotokoupolis, Stadt der Theotokos. ${ }^{164}$ Doch erst die Doppelbelagerung des Sommers 626 erhob die Muttergottes zur unumstrittenen ,Schutzgottheit' Konstantinopels; mit alljährlich stattfindendem, ritualisiertem Gedenken wurde ihre Rettungsleistung fest im kollektiven Gedächtnis der Hauptstadt verankert. ${ }^{165}$

Neben dem Bellum Avaricum findet sich die mit Abstand ausführlichste Rekapitulation der Belagerung in einer Predigt des Theodor Synkellos. ${ }^{166}$ Der genaue Anlass des Vortrages lässt sich nicht mehr mit Sicherheit bestimmen; der Jahrestag des Sieges über die Belagerer, der in der Forschung wiederholt vorgebracht wird, ${ }^{167}$ scheint indes plausibel - ebenso wie die Annahme, dass Theodors Predigt nach dem Bellum Avaricum entstand. ${ }^{168} \mathrm{Im}$ Gegensatz zu Georgs Gedicht, das sich an einen exklusives Kreis

160 Av. Cameron 1978, 1979a, 1979b (ebd. bes. 22 zur engen Verbindung zwischen Marienkult und kaiserlicher Sphäre); außerdem Mango 2000. Die Bedeutung der Marienverehrung vor dem 7. Jahrhundert wurde bereits durch Frolow 1944, 93-97 betont. Vgl. zum Marien-Kult in Konstantinopel allgemein Pentcheva 2006.

161 Zur Blachernenkirche siehe Janin 1969, 161-171; Mango 1998; Mango 2000, 19.

$162 \mathrm{Zu}$ der Reliquie (sowie weiteren Marien-Reliquien in Konstantinopel) und der Überlieferung der zugehörigen Legende siehe Mango 2000, 19f.; Shoemaker 2008.

163 Nach der Belagerung von 626 wurde das Blachernenviertel mit einer eigenen Mauer abgesichert; Chron. Pasch. AD 627.

164 Mango 2000, 20; Av. Cameron 1979a übersetzt in ihrem Aufsatz nur den zweiten Teil der Predigt, die in der Regel Theodor Synkellos zugeschrieben wird; zur Datierung der Predigt sowie der zugrundeliegenden Ereignisse siehe oben S. 14, 206 mit Anm. 93.

165 Ein rezenter Überblick über den Theotokos-Kult in Konstantinopel findet sich in Hurbanic 2019, 250 - 259. Av. Cameron 1979b, 5f. vergleicht die Theotokos mit der Athena Promachos; zur Theotokos als Stadtgottheit nach antiken Vorbildern siehe Pentcheva 2006, 16-21; zu Konstantinopels „,supernatural defenders“ siehe Baynes 1949.

166 Eingehende Untersuchungen der Predigt finden sich bei Peltomaa 2009 und Hurbanic 2016; siehe außerdem den Kommentar zu der französischen Übersetzung von Makk 1975.

167 Barišic 1955, 373; Hurbanic 2016, 272.

168 Für eine Datierung des Bellum Avaricum vor Theodors Predigt siehe Barišic 1955, 373; Pertusi 1959, 215; Van Dieten 1985, 175; Tartaglia 1998, 16f.; anders Speck 1980, 18f., 24- 26 und Howard-Johnston 2010, 147 (in Berufung auf Speck), die dafür plädieren, dass das Bellum Avaricum nach Theodors 
(die geistliche und weltliche Elite der Hauptstadt) richtete, spricht die Predigt qua Genre ein breiteres Publikum an: die in einer der städtischen Kirchen versammelte Gemeinde.

Im Zentrum der Predigt steht unumstritten die wundersame Errettung der Stadt durch die Theotokos: „Solch große Wunder und Zeichen zeigt nun die Gottesgebärerin gegenüber dieser Stadt durch die Menschenliebe Gottes. “169 Während Georg ihr Eingreifen in den Kampf im Bellum Avaricum noch vorsichtiger in Form eines Gleichnisses geschildert hatte, ${ }^{170}$ lässt die Predigt die metaphorische Ebene hinter sich: „Es wurde ganz deutlich gezeigt, dass die Jungfrau allein diesen Kampf gekämpft und diesen

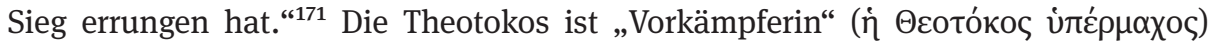
Konstantinopels; ${ }^{172}$ die ganze Stadt wird Augenzeuge davon, wie sie von ihrer Kirche in Blachernae aus die bedrängten römischen Verteidiger rettet und die Feinde niedermacht. ${ }^{173}$

Der Gehalt der Predigt indes ist mit der Würdigung der Theotokos noch nicht ausgeschöpft: Zahlreiche Verweise auf das Alte Testament dienen Theodor dazu, dem Erlebten - dem Trauma der Belagerung ebenso wie dem Sieg - durch die Einpassung in einen heilsgeschichtlichen Rahmen einen Sinn zu geben, der über das Ereignis an sich hinausgeht. Beim Blick auf das alttestamentarische Jerusalem kommt Theodor zu dem Schluss, dass das Schicksal der jüdischen Hauptstadt auf das der römischen vorausweist, dass die damals getätigten Prophezeiungen sich also allein auf Konstantinopel anwenden lassen; die Errettung des Sommer 626 sei bereits in den Schriften angelegt gewesen. ${ }^{174}$ In der Vision des Ezechiel zu den Völkern Gog und Magog, die Israel bedrängen, erkennt Theodor die Avaren wieder; ${ }^{175}$ das Jerusalem der Prophezeiung verweist entsprechend auf Konstantinopel: „Welchen anderen Ort könnte man den wahren Nabel der Erde nennen anstelle dieser Stadt, in der Gott die Herrschaft der Christen etabliert hat (...)." ${ }^{\text {176 }}$ Die Identifizierung der Hauptstadt als zweites oder gar eigentliches Jerusalem, wie sie bereits seit dem 5. Jahrhundert immer

Predigt entstand. Warum ich es für plausibel halte, dass die Predigt nach dem Bellum Avaricum entstand, wird im Folgenden deutlich.

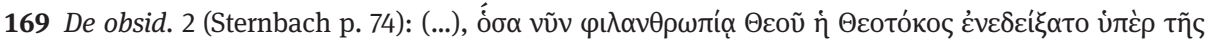

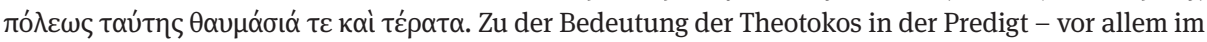
Verhältnis zum Akathistos-Hymnos - siehe Peltomaa 2009, bes. 287-295.

170 Siehe Bell. Avar. 451-456.

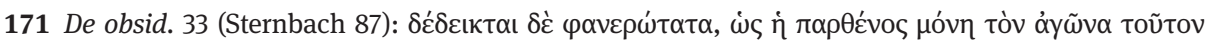

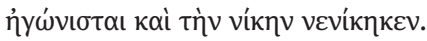

172 De obsid. 13 (Sternbach 79); zu diesem Epithet siehe Peltomaa 2009, 293f. mit weiteren Belegen. 173 De obsid. 19, 33 (Sternbach 82, 87). Ebd. 39 (Sternbach 90) zur Augenzeugenschaft der gesamten Stadt; die Theotokos erringt den Sieg mit Worten und Gedanken, nicht mit Waffen.

174 De obsid. 2f., 5, 38, 43 (Sternbach 74f., 89, 92).

175 De obsid. 40 - 44 (Sternbach 90-93); Hurbanic 2016, 280 - 288 weist darauf hin, dass Gog und Magog eschatologisch konnotiert sind; außerdem betont er (bes. 273) den antijüdischen Charakter der Predigt, so auch Olster 1994, 73-78.

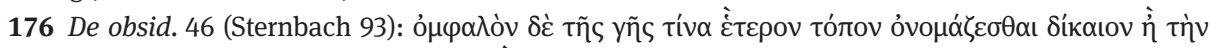

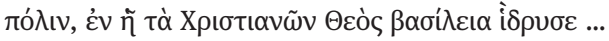


wieder in verschiedenen Variationen getätigt wurde, ${ }^{177}$ entfaltete zu einem Zeitpunkt, als das altbekannte Jerusalem bereits seit über einem Jahrzehnt in den Händen der Perser war, eine ganz besondere Wirkmächtigkeit. ${ }^{178}$ Anstelle der heiligen Stadt in Palästina wird diejenige am Bosporus zum Nabel der Welt.

Vor dem Hintergrund meiner Analyse des Bellum Avaricum sticht darüber hinaus ins Auge, wie Theodor Synkellos seine weltlichen Akteure im Verhältnis zum übernatürlichen Rettungswerk positioniert. Während das Bellum Avaricum Sergios durch die Angleichung der Attribute auf eine Ebene mit Herakleios und der Theotokos stellt, ist die Gewichtung in der Predigt eine andere. Ähnlich wie in Georgs Gedicht wird die Abwesenheit des Kaisers thematisiert, sein Engagement im Kampf gegen die Perser,

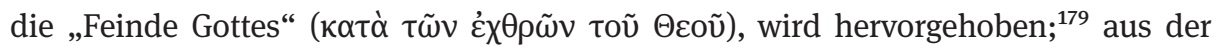
Ferne dirigiert der Kaiser, der „Diener Gottes“, die Verteidigung der Hauptstadt. ${ }^{180}$ Doch trotz seiner Abwesenheit steht Herakleios weiterhin unangefochten an der Spitze des Geflechtes an weltlicher und spiritueller Wirkmächtigkeit, das Theodor entwirft: Konstantinopel erfährt übernatürliche Hilfe aufgrund des frommen und

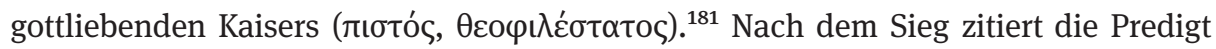
Herakleios' Dankgebet, das ihn als von Gott bestellten Hirten der hauptstädtischen Bevölkerung ausweist. ${ }^{182}$ Ausgehend von einer Prophezeiung des Jesaja („Dies sagt der Herr unser Gott: Ich werde diese Stadt schützen, um sie zu retten für mich und für meinen Diener David." ${ }^{183}$ schließt Theodor mit dem Bild des Herakleios als neuer König David: „Auch unser Kaiser ist David aufgrund seiner Frömmigkeit gegenüber Gott und aufgrund seiner Milde gegenüber den Untertanen." ${ }^{184}$ Sergios, den Theodor

$177 \mathrm{Zu}$ Konstantinopel als neuem Jerusalem siehe beispielsweise Külzer 2000, bes. 58f.; Guran 2009 und Hurbanic 2016, 277 Anm. 24 mit weiterer Literatur; vgl. auch den Sammelband von Wienand/Klein (im Druck).

178 Siehe dazu Olster 1994, 72-98; Hurbanic 2016, 277-279.

179 De obsid.11 (Sternbach 78); ebd. wird betont, dass der Kaiser sein Bestes gegeben habe, die Avaren zu besänftigen, bevor er in den Osten aufgebrochen sei und die Hauptstadt Gott und der Jungfrau anvertraut habe; ähnlich ebd. 7, 12 (Sternbach 76, 78f.) mit einem Gebet des Herakleios für die Rettung der Stadt und Rechtfertigung seiner Abwesenheit.

180 De obsid. 14 (Sternbach 80): „Denn der Diener Gottes war trotz seiner Abwesenheit der Befehls-

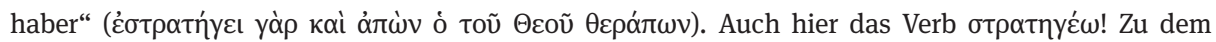
Briefverkehr zwischen dem Kaiser und der Hauptstadt siehe auch ebd. 51 (Sternbach 95f.).

181 De obsid. 3 (Sternbach 75): ,Wie könnte diese Stadt nicht eher als jenes andere Jerusalem Waffenhilfe und göttliche Unterstützung erlangen, da sie von Gott einen so überaus gottliebenden Kaiser

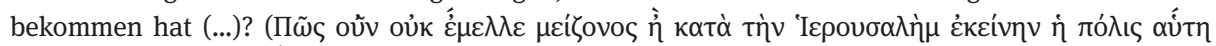

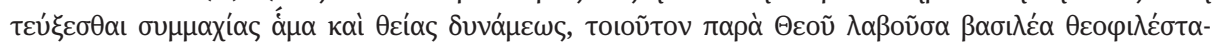
tov...); ebd. 52 (Sternbach 96) wird auch die Orthodoxie der Kaiserfamilie betont.

182 De obsid. 51 (Sternbach 95f.).

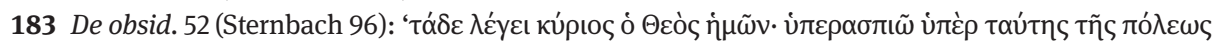

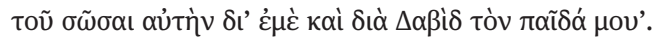

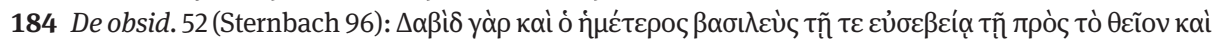

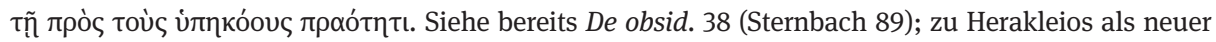
David siehe ausführlich unten S. 274-279. 
als neuen Propheten Jesaja bezeichnet, steht hinter Herakleios an zweiter Stelle. ${ }^{185}$ Das Engagement des Patriarchen wird indes auch hier betont: Mit einer Ikone bewaffnet schreitet er die Stadtmauern ab und ruft als neuer Moses die Bevölkerung zum Gebet auf. ${ }^{186}$ Nach dem Abzug der Avaren führt er die triumphalen Feierlichkeiten an, die nun liturgisch, in Form religiöser Riten, vollzogen werden. ${ }^{187}$ Auch Bonos wird gewürdigt, als er während der Belagerung die Direktiven des Kaisers in die Tat umsetzt. ${ }^{188}$ Als dritter hauptstädtischer Akteur tritt nun Herakleios Konstantin auf, dem - so Theodor - der Vater bei seinem Aufbruch gen Osten den kaiserlichen Thron anvertraut hatte: ${ }^{189}$ Bei Verhandlungen mit den Feinden wird der junge Augustus als Ansprechpartner und Entscheidungsinstanz gezeichnet. ${ }^{190}$ Entlang des DavidGleichnisses nimmt Herakleios Konstantin schließlich die Position des Salomon ein: „Nach dem Beispiel Davids möge der Herr ihn [i.e. Heakleios] mit Siegen krönen, seinen Sohn aber, der mit ihm regiert, möge er gemäß dem Salomon weise und friedliebend machen. “191 Herakleios Konstantin wird also nicht nur als Stellvertreter seines Vaters gewürdigt; die dynastische Komponente, die in Herakleios' Repräsentationsstrategie eine entscheidende Rolle spielte, wird durch die David/SalomonAnalogie noch betont.

Die Predigt des Theodor Synkellos entwirft ein Bild der Einheit. Mehr noch als das Bellum Avaricum des Georg von Pisidien, das den Patriarch Sergios als maßgeblich aktiven Akteur in den Vordergrund rückt, integriert die Predigt den abwesenden Kaiser vor der versammelten Gemeinde in die Erinnerung an den durch die Theotokos erwirkten Sieg: Herakleios' Autorität steht über dem operativen Dreigestirn in Konstantinopel - Sergios, Bonos und Herakleios Konstantin. Während Martin Hurbanic basierend auf Theodors Gog und Magog-Verweis dafür plädiert, dass die Predigt das kürzlich Erlebte ,as prologue to the end of this world” versteht, ${ }^{192}$ erscheint mir deren

185 De obsid. 3, 13 (Sternbach 75, 79); vgl. Av. Cameron 1979b, $21 \mathrm{f} .:$ „Still absent on campaign when the oration was delivered, it is nonetheless the emperor, not the patriarch, who occupies the most prominent position that could be accorded to a human in relation to the divine."

186 De obsid. 15, 17 (Sternbach 80f.).

187 De obsid. 52 (Sternbach 96). Nachdem spätantike Siegesfeierlichkeiten lange noch durch römische/säkulare Traditionen geprägt waren, überwiegt hier offenbar, zumindest in der Erinnerung, der religiöse Aspekt; vgl. Pfeilschifter 2016.

188 De obsid. 12, 14 (Sternbach 78f.).

189 De obsid. 7 (Sternbach 76); vgl. ebd. 13 (Sternbach 79): Die Kinder des Kaisers beten in einer Theotokos-Kapelle im Palast.

190 De obsid. 20 (Sternbach 82): Delegation wird zum Khagan ausgesandt.

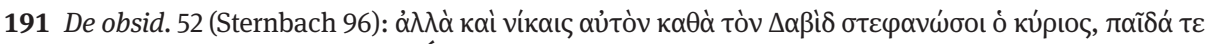

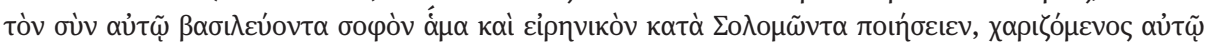

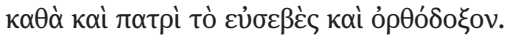

192 Hurbanic 2016, Zitat S. 280; Gog und Magog sind, basierend auf den Bibel-Stellen Ez 38f. und Apk 20.7f., in der Regel apokalyptisch konnotiert (siehe dazu Van Donzel/Schmidt 2010, 11-14; Greisinger 2014, 218f.). Mir scheint allerdings, dass Theodor die wilden Völker hier primär als weiteren Beweis dafür anbringt, dass sich in Konstantinopel Prophezeiungen aus dem Alten Testament verwirklichen. 
triumphaler Ton mit der Erwartung einer nahenden Apokalypse nur schwerlich vereinbar. Theodor Synkellos setzte ein Zeichen städtischen Selbstbewusstseins: Als eigentliches Jerusalem und Nabel der Welt erweist sich das siegreiche Konstantinopel als von Gott und der Theotokos privilegiert; anlässlich der Siegesfeierlichkeiten lässt Theodor Sergios um den Schutz der Stadt in Ewigkeit bitten. ${ }^{193}$

Zwei nicht-narrative Zeugnisse vervollkommnen schließlich das Panorama der Marienverehrung. Der sog. Akathistos-Hymnos, ein Marien-Hymnos, der im Stehen gesungen wurde (daher der Name), war im frühen 7. Jahrhundert bereits fester Bestandteil der hauptstädtischen Liturgie; ${ }^{194}$ nach der Belagerung von 626 wurde allerdings ein zweites Proömium hinzugefügt, das Maria nicht nur als Jungfrau und Muttergottes, sondern explizit als Retterin Konstantinopels feiert. ${ }^{195}$ Wenn am 7. August alljährlich des Endes der Belagerung gedacht wurde, fanden die Verehrung der Theotokos und die Würdigung des durch sie erwirkten Sieges besonders in diesem

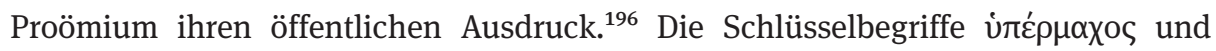

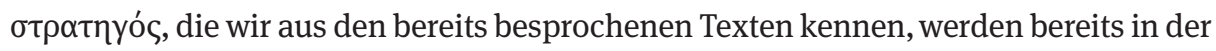
ersten Zeile auf die Theotokos angewandt:

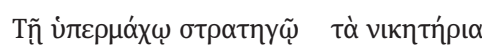

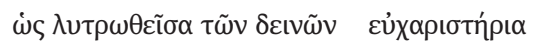

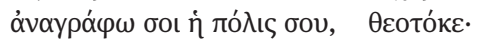

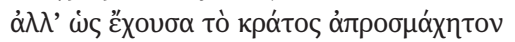

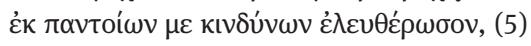

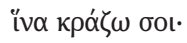

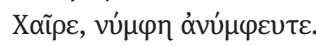

Der Verteidigerin und Generälin gebühren die Lieder des Sieges, von den Gefahren befreit bringt dir deine Stadt Dankeshymnen entgegen, oh Gottesgebärerin.

$\mathrm{Du}$, die du unbesiegbare Macht innehast, befreie mich von jeglicher Gefahr, damit ich dir zurufen kann: Sei gegrüßt, unverheiratete Braut. ${ }^{197}$

In der Anthologia Graeca sind schließlich zwei Epigramme überliefert, die gemäß der Manuskript-Lemmata aus der Feder des Georg von Pisidien stammen und in der

Unten Kap. 5.5 werde ich die verschiedenen Modi eschatologischer Deutungsmuster und ihre Ausformung im frühen 7. Jahrhundert thematisieren.

193 De obsid. 52 (Sternbach 96).

194 Peltomaa 2001, 21-24. Wellesz 1956 geht davon aus (ebd. 152-154), dass der Hymnos ursprünglich von Romanos Melodos (Mitte des 6. Jahrhunderts) komponiert wurde; anders Peltomaa 2001, bes. 113f., die für eine Entstehung bereits im 5. Jahrhundert im Nachklang des Konzils von Ephesos (431) plädiert; vgl. Pentcheva 2006, 12-16.

195 Für eine Datierung des zweiten Proömiums in Reaktion auf die Belagerung von 626 siehe Van Dieten 1972, 19; Av. Cameron 1979b, 6, 22; Peltomaa 2001, 21 f.; Peltomaa 2009, 284f., 295. Wellesz 1956, 152 stellt noch die missglückte Belagerung der Araber 717/8 als Möglichkeit der Komposition des zweiten Proömiums zur Diskussion; dafür sprechen sich Speck 1981, 169- 171 und Hurbanic 2019, 270 277 aus.

196 Av. Cameron 1979b, 22.

197 Für den Text siehe Peltomaa 2009, 297; vgl. auch Peltomaa 2011 zu den Epitheta der Theotokos,

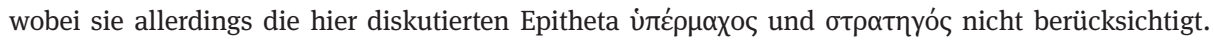


Blachernenkirche angebracht waren. ${ }^{198}$ In komprimierter Form schlagen die Epigramme einen bereits bekannten Ton an und lassen die Theotokos gegen die Barbaren

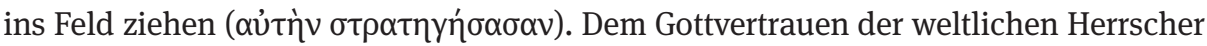
(Herakleios und Herakleios Konstantin) steht im ersten der beiden Epigramme die

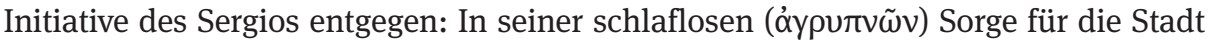

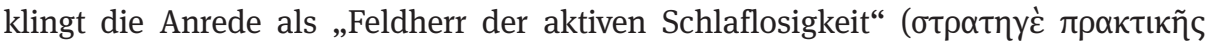

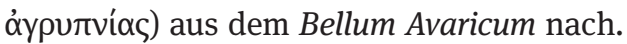

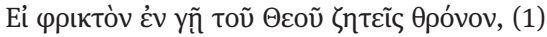

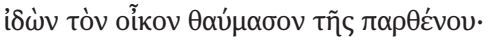

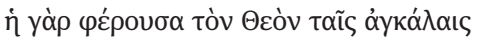

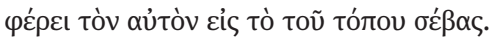

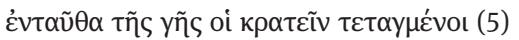

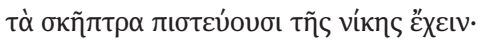

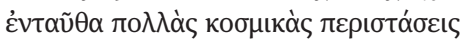

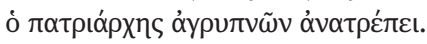

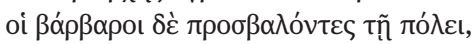

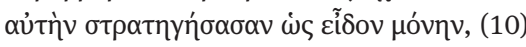

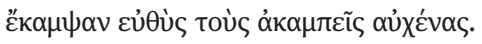

Wenn du auf Erden Gottes fürchterlichen Thron suchst, dann erblicke das Haus der Jungfrau und bewundere es. Sie nämlich, die Gott in den Armen trug, trägt eben diesen zur Verehrung dieses Ortes.

Hier vertrauen diejenigen, die zum Herrschen über die Erde eingesetzt wurden, darauf die Zepter des Sieges zu halten. Hier wendet der Patriarch, schlaflos, viele kosmische Unglücke ab.

Die Barbaren aber, die gegen die Stadt anstürmten, beugten schnell ihre unbeugsamen Nacken, als sie sahen, dass sie allein die Feldherrin war. ${ }^{199}$

Wie sind die hier besprochenen Zeugnisse - Bellum Avaricum, Theodors Predigt, der Hymnos und die Inschrift aus der Blachernenkirche - zueinander in Beziehung zu setzen? Während sie sich hinsichtlich der Wirkmächtigkeit der Theotokos einig sind, lassen sich bei der relativen Positionierung der weltlichen Akteure graduelle Unterschiede beobachten: Der abwesende Kaiser (ergänzt durch seinen Sohn Herakleios Konstantin) und der hauptstädtische Patriarch werden in ihrer Fürsorge um Konstantinopel stets als komplementär dargestellt; welcher der beiden Akteure - Herakleios oder Sergios - in seinem Verhältnis zur himmlischen Sphäre besonders herausgehoben wird, schwankt indes. ${ }^{200}$ Das formal verbindende Element zumindest dreier der vier Texte liegt in der Nutzung des Attributes strategos, das die Jungfrau Maria als Verantwortliche für den Sieg über die Avaren ausweist - allein in Theodors Predigt ist es nicht wiederzufinden. Das Bild der Theotokos als militärische Führerin fand offenbar in verschiedensten kommunikativen Kontexten Anklang: Es kam im

198 Anth. Graec. 1.120f. = Georg. Pis. Epigr. 95f. (Tartaglia 496-499); im Manuskript Paris Gr. 1630 (14. Jh.) sind beide Epigramme unter Georgs Namen erhalten. Eines der Epigramme ist Teil von L. Sternbachs Edition des Manuskriptes Paris Suppl. Gr. 690; siehe Sternbach 1892, no. LIXb. Zu dem Setting der Inschriften in der Blachernenkirche siehe Pentcheva 2006, 62f.; für eine eingehende Interpretation der Epigramme siehe Ma. Whitby 2020.

199 Anth. Graec. 1.120 = Georg. Pis. Epigr. 95 (Tartaglia 496). Die zweite Inschrift (Anth. Graeca $1.121=$ Georg. Pis., Epigr. 96 [Tartaglia 496f.]) ist ähnlich im Ton, würdigt allerdings allein die Theotokos: Die Feinde habe sie nicht mit dem Speer besiegt, sondern ins Meer gestürzt - ein Verweis auf die Seeschlacht auf dem Goldenen Horn.

200 Dabei sei festzuhalten, dass weitere zeitgenössische Quellen hinsichtlich der weltlichen Akteure wiederum ganz andere Schwerpunkte setzen: Der Bericht in Chron. Pasch. AD 626 etwa erwähnt Sergios gar nicht, stimmt allerdings auch in die Würdigung der Theotokos ein. 
sprachlich anspruchsvollen Bellum Avaricum zur Geltung, das vor der hauptstädtischen Elite vorgetragen wurde, und wurde gleichsam mit dem Akathistos-Hymnos vor bzw. von der versammelten Gemeinde besungen. Die hier vollzogene Analyse legt nahe, dass Georg von Pisidien eine zentrale Rolle dabei spielte, dieses Bild zu propagieren; das Spiel mit dem Attribut strategos, dessen semantische Breite besonders das Bellum Avaricum deutlich macht, tritt als zentrales Charakteristikum seines dichterischen Oeuvres hervor. Diese Beobachtung legt die Hypothese nahe, Georg von Pisidien nicht nur als Autor der Blachernen-Epigramme, sondern auch des AkathistosProömiums zu identifizieren. ${ }^{201}$

Anhand des Attributs strategos lässt sich schließlich noch einmal der Prozess vor Augen führen, im Zuge dessen die Abwesenheit des Herakleios in einer für Konstantinopel äußerst kritischen Situation bewältigt werden konnte. Nachdem er den strategos-Titel mit der Expeditio Persica in Bezug auf Herakleios etabliert hatte, übertrug Georg ihn in der Erinnerung an die Belagerung auf Sergios und die Theotokos. Damit ließ er nicht nur seinem Auftraggeber, dem Patriarchen, eine besondere Ehrung zukommen, sondern stabilisierte gleichzeitig die politische Hierarchie: Die Leerstelle, die Herakleios durch seine Abwesenheit hinterlassen hatte, wurde durch eine spirituelle Instanz - die Personalunion zwischen Sergios und der Theotokos - befüllt, die nicht in direkte Konkurrenz zur Autorität des Kaisers trat. Dem Bedürfnis der hauptstädtischen Bevölkerung nach einer Identifikationsfigur begegnete Georg, indem er sich der Marienverehrung als eines bereits etablierten Trends bediente und sie auf die Umstände des Jahres 626 anpasste; parallel dazu vergegenwärtigte der Dichter den Kaiser durch die Rede von dessen endlosen Mühen vor dem hauptstädtischen $\mathrm{Pu}$ blikum. Theodor Synkellos griff mit seiner Predigt die Impulse des Georg von Pisidien auf und formte daraus ein eigenes Narrativ, welches er in noch höherem Maße als Georg durch Aspekte kaiserlicher Repräsentation, etwa die dynastische Komponente, anreicherte.

Der Prozess, den Konstantinopel in Folge der Doppelbelagerung des Sommers 626 durchlief, ist ein Paradebeispiel einer sozialen Integrationsleistung: ${ }^{202}$ Eine kollektive Sinngebung konnte das traumatische Ereignis nicht nur bewältigen; sie trug darüber hinaus auch zur Stärkung der sozialen Gemeinschaft sowie der politischen

201 Die Frage nach dem Autor des Akathistos-Proömiums ist in der Forschung umstritten; bisweilen hielt man gar den Patriarchen Sergios selbst für den Autor, siehe Van Dieten 1972, 19f. Anm. 67; Wellesz 1956, 152. Speck 1981, 169 - 171 hingegen plädiert für den Patriarchen Germanos (im Amt 715-730) als Autor, der das Proömium nach der arabischen Belagerung 717/8 komponiert habe; siehe zuletzt die eingehende Diskussion bei Hurbanic 2019, 270-277, der ebenfalls Germanos für den Autor hält (ebd. 276). Die Identifizierung von Georg als Autor wird von Peltomaa 2009, 298 als Option aufgeworfen; vgl. Stratos 1968, 196.

$202 \mathrm{Zu}$ der Funktion von Konflikterzählungen und ihrem Fortbestehen zum kulturellen Gedächtnis vgl. die theoretische Annäherung bei Koschorke 2012, 211-247. 
und religiösen Hierarchien bei. ${ }^{203}$ Dass es in Konstantinopel während oder nach der Belagerung nicht zur Usurpation kam, dass die Hauptstadt ihrem abwesenden Kaiser die Treue hielt, liegt unter anderem darin begründet, dass der Öffentlichkeit ein äußerst wirkmächtiges Deutungsmuster präsentiert wurde, in welchem Herakleios weiterhin ein zentraler Platz zukam. Dieses Deutungsmuster, das sich um die Rettungsleistung der Theotokos entfaltete, wurde auf verschiedensten Ebenen kommuniziert - gegenüber dem elitären Palastumfeld ebenso wie gegenüber der im Gottesdienst versammelten Gemeinde - und durch regelmäßige Erinnerung in Wahrnehmung und Gedächtnis der hauptstädtischen Bevölkerung verstetigt. Sollte es alternative, möglicherweise gar kaiserkritische Deutungsmuster gegeben habe, wurden diese erfolgreich überdeckt. ${ }^{204}$ Da Herakleios' Abwesenheit durch spirituelle Instanzen kompensiert wurde, blieb kein Raum mehr für weltliche Konkurrenz. Anstatt einen alternativen Kandidaten für den Kaiserthron zu unterstützen, projizierte die Bevölkerung Konstantinopels ihre Hoffnungen und Erwartungen auf Sergios und die Theotokos; möglichen Herausforderern wurde von vorne herein der Wind aus den Segeln genommen. In Sergios hatte Herakleios einen wichtigen Verbündeten gefunden. ${ }^{205} \mathrm{Im}$ Zusammenhang mit der Belagerung gelang es dem Patriarchen zwar - nicht zuletzt über Georg als Sprachrohr -, eigene Interessen durchzusetzen und seine Machtposition in Konstantinopel auszubauen; dabei trat er allerdings nicht in direkten Wettstreit zum Kaiser. Die beiden Männer waren durch ein gegenseitiges Abhängigkeitsverhältnis miteinander verbunden und ergänzten sich sowohl praktisch als auch hinsichtlich der Kompetenzen, die ihnen im öffentlichen Diskurs zugeschrieben wurden.

Im Rückblick auf dieses Kapitel lässt sich festhalten, dass zwei Entwicklungen des frühen 7. Jahrhunderts - die Steigerung der Marienverehrung einerseits und die Lockerung der physischen Bindung des Kaisers an seine Hauptstadt andererseits - in einem spezifischen Verhältnis zueinander stehen: Zwischen ihnen herrscht nicht nur eine zeitliche Korrelation, sondern auch eine kausale Verbindung. Dass die Marienverehrung nach 626 einen vorläufigen Höhepunkt erreichte, ist als Folge der langfristigen Abwesenheit des Kaisers von seiner Hauptstadt zu verstehen.

203 Vgl. Av. Cameron 1979b, 6: „Thus the siege and its triumphant conclusion became a demonstration of the intimate connection of the emperor, patriarch and people, all under the protection of the warrior-Virgin."

204 Obwohl Herakleios - vor allem auch in der Nachwelt - keineswegs unumstritten war, haben hinsichtlich der Belagerung von 626 keine explizit kaiserkritischen Deutungen überlebt; dass sie existierten, lässt sich allein aus dem massiven Rechtfertigungsdruck erschließen, den man sowohl bei Georg von Pisidien als auch bei Theodor Synkellos zu spüren meint.

205 Herakleios' Statthalter Bonos starb im Jahr nach der Belagerung; siehe Chron. Pasch. AD 627. 


\section{4 „Feldherr des kosmischen Geburtstages“ - der siegreiche Kaiser}

\subsubsection{Friedensschluss mit den Persern}

Die Bedrohung Konstantinopels war vorerst abgewandt worden, sodass Herakleios, der sich weiterhin fernab der Hauptstadt befand, seinen Fokus von Kleinasien wieder auf den Osten richten konnte. ${ }^{206} 627$ begab sich der Kaiser mit seinen Truppenverbänden nach Lazica an der Ostküste des Schwarzen Meeres. In Transkaukasien hatte sich währenddessen eine eigene Dynamik entwickelt: Die türkischen Stammesverbände, mit denen Herakleios bereits Jahre zuvor in Kontakt getreten war, hatten 626 erstmals mit größeren Kontingenten den Kaukasus überschritten und waren in Albanien eingefallen. Nicht nur die dort ansässige Bevölkerung geriet in Aufruhr; auch für die Perser, unter deren Vorherrschaft die betroffenen Gebiete standen, stellte das Eingreifen einer weiteren Partei auf dem transkaukasischen Kriegsschauplatz ein Problem dar. Nach der Einnahme des albanischen Partaw wandten sich die Türken nach Westen und begannen im Sommer 627, das iberische Tiflis zu belagern, das bis dato unter der Kontrolle einer persischen Garnison gestanden hatte. Die Römer ihrerseits setzten sich von Lazica aus nach Osten in Bewegung. Das Umland von Tiflis, wo die beiden Heere aufeinandertrafen, bot schließlich die Kulisse für ein Gipfeltreffen zwischen Herakleios und dem Anführer der Türken, dem Yabghu Khagan. Die beiden Männer erwiesen sich gegenseitig die höchsten Ehren, bekräftigten ihre Allianz gegen die Perser und setzten schließlich mit vereinten Kräften die Belagerung von Tiflis fort. ${ }^{207}$

206 Der genaue Ablauf sowie die Chronologie der römischen Manöver ab dem Sommer 626 sind schwer zu rekonstruieren, da die Hauptquelle Theophanes an dieser Stelle nachweisbar fehlerhaft ist, siehe Howard-Johnston 1999, 22f. Die Geschichte des Movses Dasxuranci gibt ein detailliertes, allerdings auch nicht immer unproblematisches Bild von Herakleios' Kampagne 627/628, dazu Zuckerman 2007. Howard-Johnston (ebd.) nimmt an, dass Herakleios Ende 626 nach Konstantinopel zurückkehrte, um dort zu überwintern; allerdings muss Howard-Johnston selbst eingestehen, dass es in den Quellen keinerlei Hinweise dafür gibt (Anm. 69). Nachdem er bereits zwei Jahre im Feld überwintert hatte, spricht meiner Meinung nach nichts dafür, dass sich Herakleios 626/7 in Konstantinopel aufhielt, nachdem sich dort die Wogen nach dem Sieg über die Avaren wieder geglättet hatten. Einen knappen Überblick über Herakleios' Kampagnen gegen die Perser gibt Meier 2019a, 1033-1035.

207 Zum Einfall der Türken in Transkaukasien und ihrer Allianz mit den Römern siehe Movses Dasxuranci 2.11f. (Dowsett 85-88) und Theoph. Conf. AM 6117 (De Boor 316). Zum Treffen zwischen Herakleios und dem Yabghu Khagan besonders ausführlich Nik. Brev. 12, laut dem Herakleios diesem gar seine Tochter Epiphania zur Frau angeboten haben soll, dazu Zuckerman 1995 (bes. 117). Sowohl bei Theoph. Conf. als auch bei Nik. (hier ohne absolute Chronologie) wird von dem Treffen vor der Belagerung Konstantinopels durch die Avaren berichtet; dies ist allerdings nicht plausibel. Eine überzeugende Rekonstruktion der Geschehnisse, ausgehend von einer eingehenden Analyse des Berichtes des Movses Dasxuranci, bietet Zuckerman 2007, bes. 413-415, der das Treffen überzeugend in den Sommer 627 datiert; vgl. auch Stratos 1968, 197-203; Howard-Johnston 1999, 23f., 40-42 und 
Als in Tiflis nach mehreren Wochen nicht der erhoffte Erfolg hatte erzielt werden können - die Zitadelle der Stadt hielt sich weiterhin gegen den feindlichen Ansturm -, zog Herakleios mit seiner Armee sowie türkischen Kontingenten nach Süden in Richtung des persischen Kernlandes. Der Yabghu Khagan blieb in Iberien zurück. Ein persisches Heer unter der Führung des Feldherrn Shahraplakan konnte Herakleios' Vorrücken nichts entgegensetzen und auch der Verstärkung unter seinem Kollegen Razadh, überstürzt aus Mesopotamien herbeigeschickt, blieb vorerst nichts anderes übrig, als die römisch-türkischen Verbände aus sicherem Abstand zu verfolgen. Erneut drang Herakleios bis weit in persisches Gebiet vor: Im Herbst 627 durchquerte er die Atropatene, überschritt das Zagros-Gebirge und erreichte schließlich Niniveh im Herzen Mesopotamiens. Entgegen der Strategie der vorigen Jahre suchte er nun - zur Überraschung der Perser - auch während der Wintermonate die Konfrontation. Im flachen Umland der Stadt kam es am 12. Dezember 627 zur offenen Feldschlacht zwischen Römern und Persern. Obwohl sich die türkischen Verbündeten aufgrund der rauen Bedingungen bereits zu einem früheren Zeitpunkt wieder gen Norden zurückgezogen hatten, gelang Herakleios' Armee ein deutlicher Sieg: Die persischen Einheiten wurden dezimiert, der General Razadh fiel, Beutegut sowie Gefangene gerieten in die Hände der Römer. Mit dem Erfolg im Rücken bewegte sich das römische Heer weiter gen Süden, ohne auf nennenswerte Gegenwehr zu treffen, und plünderte schließlich die königliche Residenz in Dastagert, die Chosroes selbst nur wenige Tage zuvor verlassen hatte, um angesichts der feindlichen Invasion nach Ctesiphon zu fliehen. Anstatt weiter bis zur persischen Hauptstadt vorzurücken - die Brücken waren von den Persern zerstört worden -, zog Herakleios sich im Februar 628 mit seinen verbliebenen Einheiten in die relativ sichere Atropatene zurück. Nahe der Stadt Ganzak schlug das römische Heer seine Lager auf, um dort die restlichen Wintermonate $\mathrm{zu}$ verbringen. ${ }^{208}$

Die Schlacht bei Niniveh und die darauffolgenden Plünderungen des persischen Kernlandes zeitigten vor allem auf psychologischer Ebene deutliche Auswirkungen. Während die römischen Truppen gestärkt aus der Konfrontation hervorgingen und Herakleios einen enormen Prestigegewinn verbuchen konnte, begann die angespannte Lage in Persien überzukochen. Das Fundament von Chosroes' Herrschaft bröckelte, Opposition wurde laut: Der persische Großkönig hatte sich nicht als fähig

Kaegi 2003, 141-146. Zur letzten Phase des Krieges aus sassanidischer Sicht siehe Bonner 2019, 301304.

$208 \mathrm{Zu}$ den Manövern des Jahres 627, der Schlacht bei Niniveh und den darauffolgenden Plünderungen siehe Chron. Pasch. AD 628 (729f. mit Verweis auf bzw. Paraphrase einer Depesche, die am 15. März nach Konstantinopel geschickt wurde und die Geschehnisse ab dem 17. Okt. abdeckt); Movses Dasxuranci 2.12 (Dowsett 88-90); Sebeos 38 (Thomson/Howard-Johnston I, 83f.); Anon. Guidi (Nöldeke 28). Die ausführliche Erzählung in Theoph. Conf. AM 6118 (De Boor 317-319) gibt wohl den Inhalt der kaiserlichen Depesche wieder; außerdem mit wenig konkreten Informationen Nik. Brev. 14; zusammenfassend Howard-Johnston 1999, 24f.; Thomson/Howard-Johnston 1999 II, $218-220$ und ausführlicher Stratos 1968, 204-222; Kaegi 2003, 156-74. Zur absoluten Chronologie siehe die Diskussion bei Flusin 1992 II, 265-281 unter Berücksichtigung der Act. Anast. Pers. 
erwiesen, das Kernland seines Reiches gegen feindliche Übergriffe zu schützen. ${ }^{209}$ Während Herakleios mit seinem Heer im Winterlager bei Ganzak eingeschneit wurde, nahmen in Ctesiphon die Dinge ihren Lauf. Angesichts der prekären innenpolitischen Lage sowie Chosroes' nachlassender Gesundheit wurde die Nachfolgefrage virulent. Dem ältesten Sohn des Großkönigs, Kavadh Seiroe, gelang es, die schwache Position seines Vaters zum eigenen Vorteil zu nutzen. Mit Unterstützung aus den Reihen des persischen Adels und militärischer Absicherung konnte er jeglichen Zweifel hinsichtlich der Nachfolge im Keim ersticken: Nachdem Chosroes in Ctesiphon festgesetzt worden war, ließ Seiroe sich am 25. Februar zum Großkönig krönen. Wenige Tage später wurde Chosroes gemeinsam mit seinen weiteren Söhnen, Seiroes' Halbbrüdern, hingerichtet. ${ }^{210}$

Die militärische Konfrontation mit den Römern fortzuführen, stand für Seiroe, der vor allem um Stabilität bemüht war, nicht zur Debatte. Nach seiner Krönung schickte er postwendend Gesandte los, um Herakleios ein umfassendes Friedensangebot zu unterbreiten. Am 24. März erreichte die Delegation das römische Lager bei Ganzak, wo man die Entwicklungen in Persien bereits mit Spannung vernommen hatte. Das Blatt hatte sich gewendet: Während frühere Kommunikation des Großkönigs gegenüber dem römischen Kaiser an Herabsetzungen nicht gespart hatte, befand sich der frisch gekrönte Seiroe nun in der schwächeren Position. Versöhnliche Töne wurden angeschlagen: Als Zeichen persischen Wohlwollens sollten alle Kriegsgefangenen befreit und die besetzten römischen Territorien geräumt werden. Die Frage der konkreten Grenzziehung nach dem Friedensschluss zwischen den beiden Großmächten war im Frühjahr 628 noch nicht abschließend geregelt; doch nachdem Herakleios seinerseits eine Delegation zu Seiroe nach Ctesiphon geschickt hatte, um seine Befürwortung eines Friedens zu signalisieren, hatte die römische Armee im Osten vorerst ihre Schuldigkeit getan. Ein Sendschreiben informierte die Hauptstadt im Detail über die erfreulichen Entwicklungen im Osten; am 15. Mai 628, dem Pfingstsonntag, wurde der Text, der im Chronicon Paschale erhalten ist, vor der versammelten Gemeinde in der Hagia Sophia verlesen. ${ }^{211}$ Anfang April ließ Herakleios die Lager in Ganzak ab-

209 Siehe Movses Dasxuranci 2.12 (Dowsett 89f.) zur Kritik an Chosroes II.; vgl. Howard-Johnston 2010, 114f.; wie die Leistungen des Herakleios und seines Heeres gegenüber der Hauptstadt kommuniziert wurden, zeigen die Depeschen in Chron. Pasch. AD 628.

210 Die absolute Chronologie ist in Chron. Pasch. AD 628 (729) bezeugt; siehe auch Sebeos 39 (Thomson/Howard-Johnston I, 84f.); Anon. Guidi (Nöldeke 29f.) und Nik. Brev. 15; vgl. Stratos 1968, 223-229; Thomson/Howard-Johnston 1999 II, 221-223; Kaegi 2003, 174 f. Der Bericht des Theoph. Conf. (AM 6118 [De Boor 326f.]) erweckt den Eindruck, dass Herakleios und Seiroe bereits vor dessen Krönung in Kontakt gestanden hatten; dies wird allerdings nicht durch die anderen Quellen gedeckt. Chron. Pasch. AD 628 (730) beschreibt, wie Herakleios vom Winterlager in Ganzak aus Spähtrupps aussandte, um über den Verbleib des Chosroes unterrichtet zu bleiben. Zum Sturz des Chosroes II. siehe Bonner 2019, 304-307; ebd. 307-310 zu den Faktoren, die Herakleios' Sieg bedingten.

211 Von dem Austausch der Gesandtschaften wird ausführlich in Chron. Pasch. AD 628 berichtet, das die Depesche wiedergibt, die nach dem 8. April aus Persien losgeschickt und am 15. Mai in Konstantinopel verlesen wurde. Angehängt findet sich der Brief des Seiroe an Herakleios und dessen 
brechen; über Armenien gelangte er wieder auf römisches Territorium. ${ }^{212}$ Angesichts der Bedeutung, welche die Hauptstadt weiterhin für die Stabilität römischer Monarchie hatte, scheint es plausibel, dass Herakleios sich nach dem Friedensschluss schnellstmöglich auf den Rückweg in die Hauptstadt machte, um seinen Triumph zu feiern, und dort im Spätsommer bzw. Herbst desselben Jahres eintraf. ${ }^{213}$

\subsubsection{Die Heraclias}

Vor der Analyse der Heraclias des Georg von Pisidien soll der Blick darauf gelenkt werden, wie Herakleios selbst seinen Sieg über die Perser gegenüber der hauptstädtischen Öffentlichkeit kommunizierte. In der Gegenüberstellung von kaiserlicher Selbstdarstellung und Fremdzuschreibung wird sich schließlich noch einmal ausdrücklich Wert und Funktion von Panegyrik offenbaren.

Das Sendschreiben, das Herakleios anlässlich des Friedensschlusses mit Kavadh Seiroe nach Konstantinopel schickte, ist das mit Abstand aussagekräftigste Ego-Dokument, das aus seiner Regierungszeit erhalten ist; ungetrübt durch den Blick bzw. die Interpretation Dritter gibt der Text Aufschluss über die kaiserliche Selbstdarstellung. Als Anrede des Herakleios an die hauptstädtische Bevölkerung konzipiert, zeichnet sich das Schreiben durch einen durchweg religiösen Ton aus. Es beginnt mit einer Variation des feierlichen Psalmes 99, der die Gemeinde zum Lob Gottes aufruft; weitere Bibel-Zitate folgen. ${ }^{214}$ Die religiöse Deutung des Krieges zwischen Rom und Persien, wie sie bereits verbreitet wurde, während der Konflikt noch in vollem Gange war, kommt auch hier wieder zum Tragen: Chosroes, der konsequent als „Feind Gottes“

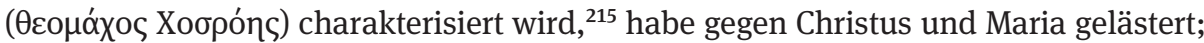

Antwort; die beiden Dokumente können jedoch aufgrund der Beschädigung des einzigen Manuskriptes nur in Teilen rekonstruiert werden (siehe Oikonomides 1971); der rekonstruierte Text (ebd. 273) legt

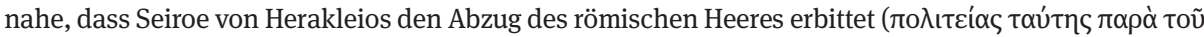

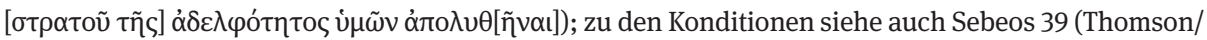
Howard-Johnston I, 85f.). Laut Nik. Brev. 15 forderte Herakleios bei den Verhandlungen von Seiroe die Kreuzreliquie zurück; ob dies allerdings tatsächlich bereits zu diesem Zeitpunkt eine Rolle spielte, ist fraglich. Zum Verhandlungsobjekt wurde das Kreuz ohne Zweifel in Zusammenhang mit der Usurpation des Shahrbaraz; dazu siehe unten S. 262f. Vgl. stark verkürzt Theoph. Conf. AM 6118 (De Boor 327), dessen Angabe, Seiroe habe Herakleios das Kreuz zurückgegeben und den Patriarchen Zacharias befreit, nicht korrekt ist. Zum Friedensschluss vgl. auch Mich. Syr. 11.3 (Chabot II, 409) und Agapius (Vasiliev 465).

212 Chron. Pasch. AD 628 (734) zur Rückkehr über Armenien, so auch Act. Anast. Pers. 43.

213 Die Datierung von Herakleios' Einzug in Konstantinopel wird in Kap. 6.1.1 eingehend diskutiert. 214 Siehe dazu Whitby/Whitby 1989, 183 Anm. 484; den gleichen Psalm zitiert in Theoph. Sim. Hist. 4.16.23 der Bischof Domentianos nach der Rückgewinnung von Martyropolis von den Persern unter Maurikios.

215 Dies wiederholt sich mehrmals über das Dokument; eine Variation ist tòv $\theta \varepsilon o \mu i ́$ ontov Xoopónv. 
als Strafe für seine Blasphemie sei er in die Feuer Satans gefallen. ${ }^{216}$ „Gott und die Theotokos haben uns“ - so Herakleios - „und unserem gottliebenden Expeditionscorps über menschliches Verstehen hinaus geholfen“; 217 man habe Chosroes derart militärisch in die Enge getrieben, dass sein Sohn Seiroe ihn überwältigen konnte. Der ausführliche Bericht darüber, wie der diplomatische Kontakt zu Seiroe verlief, endet damit, dass der Kaiser erneut sein Gottvertrauen ausdrückt, die Gemeinde zum Gebet aufruft und seine Hoffnung auf ein Wiedersehen zum Ausdruck bringt. Chosroes' Vergehen liegt in dieser Darstellung nicht etwa in seiner Besetzung der römischen Provinzen, sondern in seiner Blasphemie gegen die christliche Religion; das militärische Verdienst beansprucht der Kaiser nicht für sich, sondern würdigt stattdessen primär Gott und die Theotokos.

Die Depesche verweist auf zwei weitere Dokumente, die ebenfalls in der Hagia Sophia verlesen wurden: Das Schreiben des Seiroe an den Kaiser, mit dem dieser sein Friedensangebot übermittelte, und Herakleios' Antwort. Die beiden Dokumente sind auch in der Osterchronik angehängt, allerdings aufgrund der Beschädigung des einzigen Manuskriptes nur in Fragmenten erhalten. ${ }^{218}$ Hinsichtlich ihrer Wortwahl scheinen beide Texte den Konventionen diplomatischer Korrespondenz zwischen den benachbarten Großmächten Rom und Persien zu entsprechen. Seiroe adressiert Herakleios als seinen Bruder ( $\alpha \delta \varepsilon \lambda \varphi \tilde{\omega} \dot{\eta} \mu \tilde{\omega} \nu)$ und führt diese Metaphorik der Gleich-

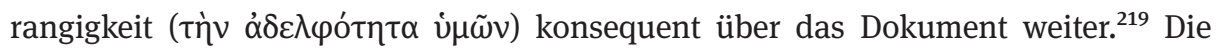

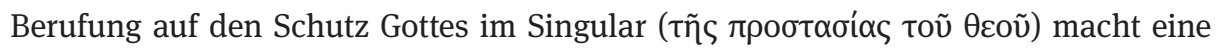
Deutung im christlichen Sinne möglich. Einer ähnlich mehrdeutigen Sprache hatte sich bereits Chosroes II. bedient, als er im Jahr 590 Maurikios um Hilfe gegen den Usurpator Baram Chobin bat. 220 Seiroe kündigt Zugeständnisse an die Römer an (Freilassung aller Gefangenen) und bringt seine Hoffnung auf Frieden deutlich zum

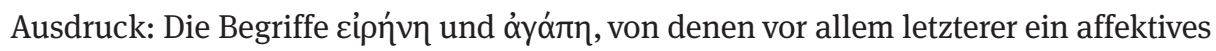
Nahverhältnis suggeriert, finden im Text wiederholt Anwendung. Die wenigen erhaltenen Zeilenfragmente von Herakleios' Antwort sind weniger aussagekräftig. Das Breviarium des Nikephoros indes legt nahe, dass Herakleios den Perserkönig im Gegenzug als Sohn ansprach; seine überlegene Stellung brachte er damit also nicht nur gegenüber dem Großkönig, sondern auch beim Verlesen der Kommunikation in

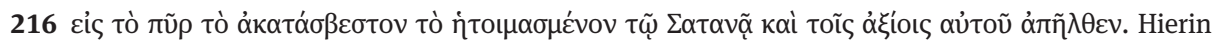
könnte man einen Verweis auf den Feuerkult der Perser lesen.

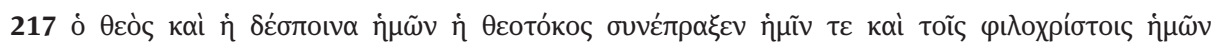

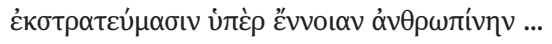

218 Whitby/Whitby 1989, 188 geben nur den Beginn von Seiroes Schreiben in Übersetzung wieder; der umfassendste Rekonstruktionsversuch findet sich bei Oikonomides 1971.

219 Siehe Whitby/Whitby 1989, 188f. Anm. 491 und zu dem diplomatischen Vokabular Mi. Whitby 1988, 204-206; Oikonomides 1971, 275 merkt an, dass Seiroe von der pompösen Titulatur absieht, von der etwa sein Urgroßvater Chosroes I. bei der Aushandlung des fünfzigjährigen Friedens mit Justinian 562 noch Gebrauch gemacht hatte.

220 Theoph. Sim. Hist. 4.11; siehe Whitby/Whitby 1989, 188f. Anm. 491. Zu der Legende von der Taufe des Chosroes II. siehe Schilling 2008, 235-277. 
Konstantinopel klar zum Ausdruck. Außerdem forderte Herakleios laut Nikephoros die Rückgabe der Kreuzreliquie, welche die Perser 614 aus Jerusalem entwendet hatten. ${ }^{221}$

Fragt man nach Aspekten kaiserlicher Selbstdarstellung in Folge des Persersieges, ist das Augenmerk noch auf einen weiteren Umstand zu richten: Wie in der Forschung bereits wiederholt vermerkt, passte Herakleios nach 628 die kaiserliche Titulatur an. $\mathrm{Zu}$ Beginn seiner Regierung nutzte der Kaiser in offiziellen Dokumenten - wie seine Vorgänger auch - die traditionelle Titulatur, die aus dem römischen-imperialen Re-

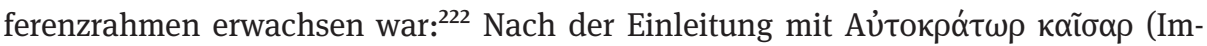

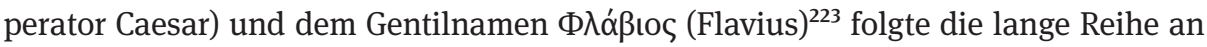
Sieges- und Triumphalbeinamen. ${ }^{224}$ Eine im März 629 veröffentlichte Gesetzesnovelle indes verzichtet vollkommen auf die bis dato typische Titulatur und benennt Hera-

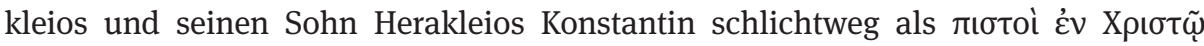
$\beta \alpha \sigma ı \lambda \varepsilon i \widetilde{\varsigma}$ - als christusgläubige Herrscher. ${ }^{225}$ Der griechische Titel basileus, der zuvor bereits in informellen Zusammenhängen, etwa in literarischen Quellen, als Bezeichnung des römischen Kaisers Anwendung gefunden hatte, ging damit in die offizielle Titulatur ein. ${ }^{226}$ In der Forschung wurde eine ganze Reihe von Erklärungen für diese Änderungen vorgebracht: Nach seinem Sieg über Persien habe Herakleios den basileus-Titel angenommen, der zuvor dem persischen Großkönig vorbehalten gewesen sei; ${ }^{227}$ in der Änderung spiegle sich ein „constitutional change” hin zu einer ,absoluten Monarchie' wieder; der Kaiser habe sich von einer (vermeintlich) verwandtschaftli-

221 Nik. Brev. 15. Ob Nikephoros tatsächlich aus dem gleichen Dokument zitiert, das der Osterchronik beigegeben war, ist fraglich. Mango 1990, 183 hält dies für unwahrscheinlich, da Nikephoros sonst keine Kenntnis der Osterchronik zeigt. Allerdings ist nicht auszuschließen, dass Nikephoros (oder seine Quelle) über andere Wege Zugang zu dem Dokument hatten. Oikonomides 1971, 278 und Whitby/ Whitby 1989, 188f. Anm. 491 halten die Informationen bei Nikephoros für authentisch. Die Verhandlungen zum Kreuz kamen erst in Zusammenhang mit der Usurpation des persischen Generals Shahrbaraz in Fahrt; dazu siehe unten S. 262f.

222 Siehe den Überblick über die Entwicklung der Titulatur von Justinian bis Herakleios bei Rösch 1978, 101-107.

223 Auch Herakleios’ Vorgänger trugen den Gentilnamen Flavius, der auf Konstantin I. zurückgeht, siehe Rösch 1978, 107 Anm. 179.

224 Siehe Rösch 1978, 170 (Nr. 58-61).

225 Siehe die Novelle in Konidaris 1982, 84; zur Datierung ebd. 57-60. Es ist allerdings darauf hinzuweisen, dass dieser Wechsel nicht ganz abrupt kam: Eine frühere Novelle (zur Datierung Rösch 1978,

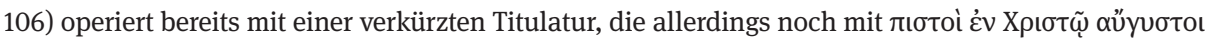
endet; siehe Rösch 1978, 170 Nr. 59. Herakleios Konstantin wurde ab seiner Krönung zum Augustus im Jahr 613 in der Titulatur ebenso wie in der offiziellen Datumsangabe berücksichtigt; zu Letzterem siehe Chron. Pasch. AD 613.

226 Siehe Shahid 1972, 295 f. Zuckerman 2010 vollzieht vor allem anhand papyrologischer Evidenz die Entwicklung der kaiserlichen Titulatur in der zweiten Hälfte des 7. Jahrhunderts nach; vgl. auch Rösch 1978, 170 f. Die kaiserliche Titulatur blieb nach Herakleios’ Anpassung nicht statisch; neben dem pistos en Christo basileus kamen auch andere Elemente wie autokrator wieder zum Tragen.

227 Siehe Bury 1930, 109. 
chen Verbindung zur armenisch-königlichen Familie der Arsakiden inspirieren lassen. ${ }^{228}$ Zuletzt hatte die These besondere Konjunktur, der basileus-Titel trage messianisch-eschatologische Implikationen, da er auf das himmlische Königreich Christi verweise; ${ }^{229}$ der Kaiser habe damit auf alttestamentarische Könige Bezug genommen, besonders auf David, den Vorfahren Christi, in dessen Tradition er sich sah. ${ }^{230}$ Meiner Ansicht nach drückt sich in der Alleinstellung des pistos en Christo, das wohlgemerkt auch vor Herakleios schon Teil der offiziellen Titulatur gewesen war, ${ }^{231}$ vor allem die Betonung eines umfassend christlichen Referenzrahmens aus, der zu diesem Zeitpunkt nicht nur das Verständnis kaiserlicher Herrschaft, sondern die gesamte Gesellschaft prägte - ein Referenzrahmen, der sich auch in der oben diskutierten Depesche offenbart: Herakleios präsentiert sich als frommer Herrscher. Der Wegfall der traditionell römischen Elemente, teilweise bestehend aus lateinischen Lehnwörtern, zugunsten des griechischen basileus lässt sich außerdem vor dem Hintergrund einer fortschreitenden Gräzisierung verstehen. ${ }^{232}$

Während die bisher besprochene Evidenz vor allem religiös konnotierte Deutungen des Persersieges offenbart, findet sich in der Münzprägung ein Hinweis darauf, dass Herakleios durchaus auch den militärischen Aspekt seiner Verdienste betonte. Ab dem Zeitpunkt, als 613 neben Herakleios auch sein Sohn Herakleios Konstantin auf den Aversen aller Münzen erschienen war, wurden beide Augusti in zivilem Gewand dargestellt. ${ }^{233} \mathrm{Im}$ Jahr 628/9, also nach der Beendigung des Konfliktes mit den Persern, kam es jedoch zu einer weiteren Anpassung auf den Kupfernominalen der Konstantinopolitaner Prägestätte, deren Averse nun Herakleios in militärischer Tracht und mit langem Bart, seinen Sohn weiterhin in Zivil zeigen; eine Bei-

228 Shahid 1972, 308-313 und ders. 1980/81; siehe auch die Zusammenstellung der verschiedenen Thesen bei Chrysos 1978, 31-33, der eine ausführliche Untersuchung diplomatischer Sprachregelungen bietet; zuletzt zur Änderung der Titulatur Greisiger 2014, 129-131.

229 Shahid 1972, 307 f.; Spain Alexander 1977, 232f.; Magdalino 2007, 19; vgl. auch Stoyanov 2011a, 66f.; Greisiger 2014, 131.

230 Kresten 2000; Meier 2015, 187 und ders. 2017, 541f. Die Titeländerung wird entsprechend mit Herakleios' Restitutio Crucis in Verbindung gebracht, mit der er auf die Rückführung der Bundeslade nach Jerusalem durch König David angespielt habe. Dabei wird indes gerne ausgeblendet, dass die Änderung des Titels zu einem Zeitpunkt (spätestens März 629) erfolgte, als noch nicht absehbar war, dass Herakleios die Kreuzreliquie würde wiedergewinnen und rückerstatten können (März 630). Zu der Datierung der Restitutio Crucis und den Verhandlungen zwischen Herakleios und Shahrbaraz, die der Rückführung vorausgingen, siehe S. 262-264 mit Anm. 43. Kresten 2000 folgt allerdings der meiner Ansicht nach nicht überzeugenden These Paul Specks, die Restitutio Crucis bereits ins Jahr $628 \mathrm{zu}$ datieren. Zu Herakleios' mutmaßlicher David-Imitatio siehe unten S. 274-279.

231 Justin II. nahm die lateinische Variante (fidelis in Christo) in seine Titulatur auf, siehe Rösch 1978, 62f. und ebd. $168-170$.

232 Zum hellenischen/christlichen Hintergrund des Titels basileus siehe Shahid 1972, 302-305; zur De-Romanisierung ebd. 317: Die ursprünglich negativen Konnotationen des Titels rex/basileus spielten zu diesem Zeitpunkt keine Rolle mehr; zur Gräzisierung als Kontext für die Titel-Änderung siehe Ostrogorsky 1963, 89.

233 Dazu siehe oben Kap. 4.3.1. 
schrift fehlt. Dieser Typ hielt sich bis nach 638, als mit der Krönung des Heraklonas zum Augustus eine weitere Person auf den Aversen der Kupfermünzen erschien und Herakleios' militärische Tracht wieder der zivilen wich. ${ }^{234}$ Interessant ist dabei, dass der militärische Aspekt erst nach Herakleios’ Sieg Eingang in die Münzprägung fand, nicht etwa während seines Feldzuges, und dass dies nur auf dem am wenigsten wertigen Nominal geschah. Herakleios' Darstellung als Feldherr richtete sich offenbar nicht an die Elite des Reiches, die mit Goldmünzen in Berührung kam, sondern an die Masse der Bevölkerung und der Soldaten.

Nach dem Überblick über die kaiserliche Selbstdarstellung wende ich mich nun wieder der Panegyrik zu, genauer gesagt der Heraclias, die nach der Rückkehr des Kaisers nach Konstantinopel und - aller Wahrscheinlichkeit nach - vor dessen Rückerstattung des Heiligen Kreuzes im März 630 entstand. ${ }^{235}$ Die Töne, die Georg von Pisidien in diesem Gedicht anschlägt, könnten im Vergleich zu der oben besprochenen Sieges-Depesche kaum unterschiedlicher sein. Im Rückblick auf Herakleios' Kampagnen der letzten Jahre greift Georg auf bereits etablierte Motive zurück und entwickelt sie weiter: Während es zuvor galt, Herakleios' persönliche Kriegsführung bzw. die langfristige Abwesenheit zu rechtfertigen, kann der Dichter nun den Triumph voll ausschöpfen und die Rückkehr des Kaisers in die Hauptstadt feiern. Das Attribut des strategos, mit welchem Georg zuletzt auch Sergios und die Theotokos versehen hatte, kommt nun wieder Herakleios zu. Das Lob des Kaisers als Feldherr vollzieht der Dichter zuerst im Vergleich mit großen Persönlichkeiten der Vergangenheit: Plutarch solle von seinen Parallelviten berühmter Feldherren ablassen und sich stattdessen dem Kaiser zuwenden, denn „damit beschreibst du sie alle“ (үра́ Herakleios übertrifft nicht nur Alexander den Großen, ${ }^{236}$ sondern auch Timotheus von

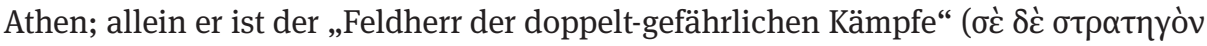

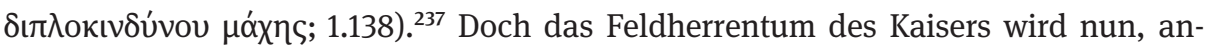
gesichts des Sieges, gleichsam auf eine neue Ebene gehoben; Herakleios steigt auf

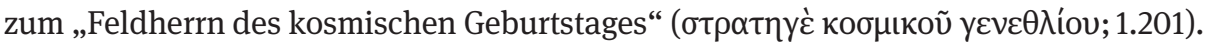

234 Siehe DOC II.1, 226-229 mit Taf. 13; MIB III, 103f. Die Änderung der Prägung ging mit einer Münzreform einher, die den Edelmetallgehalt wieder aufwertete.

235 In Heracl. 1.212-218 thematisiert Georg Herakleios' Rückkehr in die Hauptstadt (siehe dazu auch Kap. 6.1.1); auf die Rückerstattung des Kreuzes, ein Ereignis, das auch in Konstantinopel großes Aufsehen erregte und dem Georg ein eigenes Gedicht widmete, findet sich zumindest in dem erhaltenen Text kein Hinweis. Zum Datum der Rückerstattung des Kreuzes siehe S. 264 Anm. 43. Der Text bricht in der zweiten Akroasis der Heraclias inmitten der Erzählung ab; zu der Frage, ob es einen dritten Gesang gab und ob dieser sich durch Fragmente, die in Theophanes Confessor und der Suda erhaltenen sind, rekonstruieren lässt, siehe Ma. Whitby 2002, 168-172, die die Forschungslage zusammenfasst und sowohl die Position von Pertusi (1959, 23 - 30) und die komplexe Argumentation von Howard-Johnston (1992; zuletzt 2010, 284-295) diskutiert.

236 Plutarch und Alexander der Große: Heracl. 1.110 -121; zu den Bezügen auf historische Figuren siehe Shahid 1980/81 (obwohl der Titel des Aufsatzes keineswegs darauf hindeutet).

237 Heracl. 1.131-139 zu Timotheus. Georg vergleicht den Kaiser außerdem mit Appelles und Demosthenes (ebd. 1.93-96) und lässt den großen Scipio verstummen (ebd. 1.97f.). 
Die zentrale Passage, in der der Dichter den Kaiser erneut direkt anspricht, lohnt es im Ganzen zu zitieren:

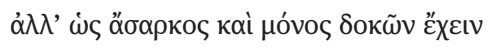

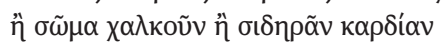

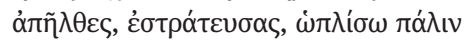

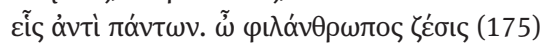

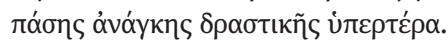

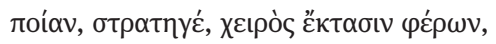

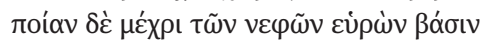

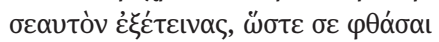

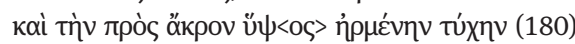

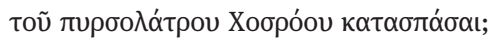

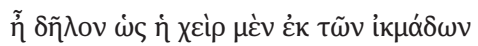

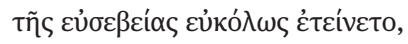

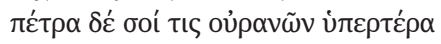

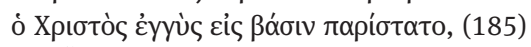

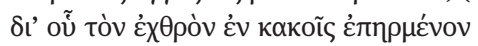

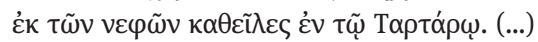

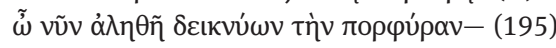

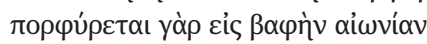

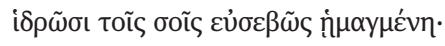

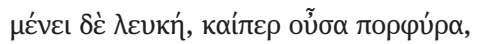

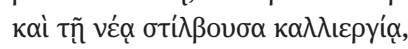
öбov

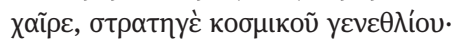

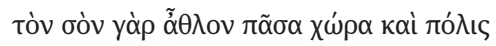

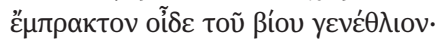

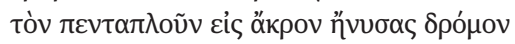

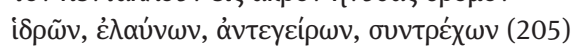

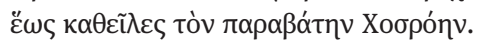

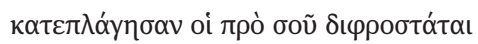

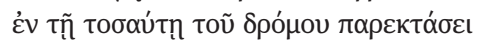

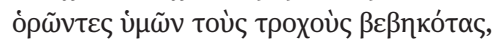

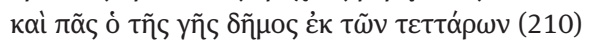

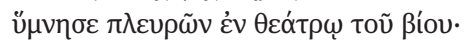

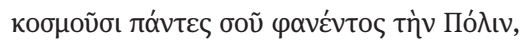

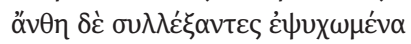

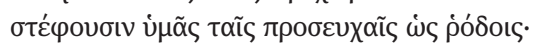

Aber geradezu fleischlos und einsam schienst du entweder einen Körper aus Bronze oder ein Herz aus Eisen zu haben; du gingst weg, du führtest das Heer an, du rüstetest dich von Neuem: einer gegen alle. Oh menschenliebendes Brennen, jeden tatsächlichen Zwang übersteigend.

Oh Feldherr, welche Reichweite der Hand tragend, welche Stufe bis in die Wolken findend hast du dich selbst ausgestreckt, um zuvorzukommen und das sich zu den höchsten Höhen erhebende Glück des Feueranbeters Chosroes herabzureiBen?

Wahrlich scheint es, dass die Hand sich aus den Flüssen der Frömmigkeit erfreut herausgestreckt hat. Als Stein, gewissermaßen höher als die Himmel, stand dir Christus nahe bei als Stütze, mit dessen Hilfe du den Feind, der sich in seinen Freveln erhoben hatte, aus den Wolken heraus im Tartaros vernichtest. (...) Oh, nun zeigst du den wahren Purpur - denn er wurde zu Purpur gemacht in einer ewigen Färbung, durch deinen Schweiß auf fromme Weise in Blut getränkt. Aber er bleibt ganz hell, obwohl er purpurn ist, und glänzt durch deine neue Wohltat: je mehr er getragen wird, umso mehr wird er erleuchtet. Heil dir, oh Feldherr des kosmischen Geburtstages; jedes Land und jede Stadt nämlich weiß, dass dein Kampfpreis der tatsächliche Geburtstag des Lebens ist. Du hast den fünffachen Weg bis zum Gipfel vollendet: schwitzend, schlagend, antreibend, rennend, bis du den Übeltäter Chosroes zur Strecke gebracht hast.

Die Streitwagenlenker vor dir haben sich erschreckt als sie nach einer derartigen Ausdehnung des Weges deine stehenden Wagenräder sahen; und das gesamte Volk der Erde aus allen vier Himmelsrichtungen sang Hymnen im Theater des Lebens.

Bei deinem Anblick schmücken alle die Hauptstadt, lebendige Blüten zusammentragend, und sie krönen dich mit Gebeten wie mit Rosen. 


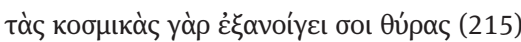

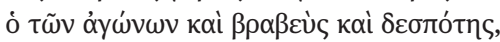

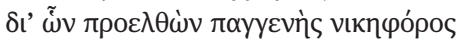

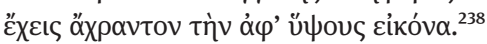

Denn die kosmischen Pforten öffnet dir der Richter und zugleich Herr der Wettkämpfe (i.e. Gott); durch diese vorschreitend als Sieger über alle Geschlechter hältst du in der Hand das unbefleckte himmlische Bildnis.

Georg lässt den betont körperlichen Kaiser der Expeditio Persica aufleben, wenn er auf Herakleios' Verdienst als Feldherr zurückblickt; ${ }^{239}$ mit dynamischen Verbperioden - ein Stilmittel, das sich in seinen Gedichten des Öfteren findet ${ }^{240}$ - ruft er die kaiserlichen Mühen ins Gedächtnis: „schwitzend, schlagend, antreibend, rennend“

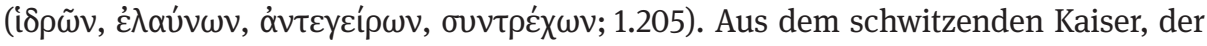
als einer der Soldaten in den Kampf zog, wird jedoch nach dem Sieg eine „geradezu

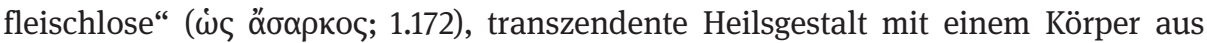
Bronze und einem Herz aus Eisen. Mit dem Bild des Herakleios, der den wahren

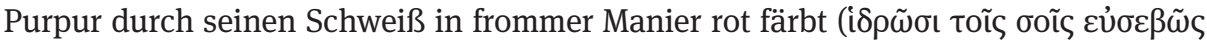
ஸ̣ $\mu \alpha y \mu \varepsilon ́ v \eta ; 1.197)$, wird Georg dem meritokratischen Charakter römischer Monarchie gerecht: Der Kaiser hat sich den Purpur als zentrale Insignie kaiserlicher Herrschaft durch seine zahllosen Mühen verdient; das Blutvergießen am persischen Feind indes ist kein martialischer Akt, sondern eine im christlichen Sinne fromme Tat. Im Purpur wird Herakleios zur Lichtgestalt: „Indem er den Schweiß seiner Mühen ausgoss“ ('่v

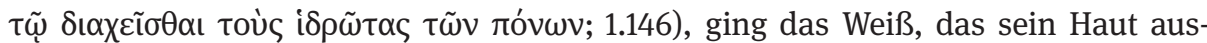
zeichnete, bevor er sich der brennenden Sonne auf dem Schlachtfeld aussetzte, in sein Herz über. ${ }^{241}$ Ebenso wie den strategos-Titel behält Georg von Pisidien also auch das der Hagiographie entlehnte Vokabular bei und kombiniert diese beiden Elemente nun mit einer dem Anlass angemessenen Renovatio-Rhetorik. ${ }^{242}$ Der Kampfpreis für Herakleios' Sieg über Persien und die Rückgewinnung der besetzten Gebiete entspricht

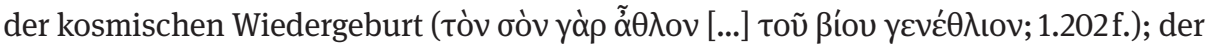
asketische Krieger-Kaiser wird erleuchtet und in einen geradezu heiligmäßigen Status erhoben. Mit Unterstützung Christi habe er, auf Basis seiner vorbildlichen Frömmig-

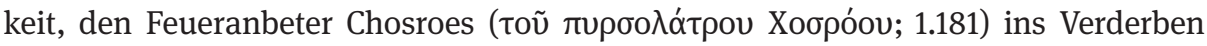
gerissen.

Herakleios’ Nähe zur sakralen Sphäre kommuniziert Georg schließlich auch durch das Spiel mit dem Begriff eikon. Den Tyrannen Phokas habe der Kaiser mit Hilfe eines

238 Heracl. 1.172-218.

239 Auch hier betont er noch einmal die Notwendigkeit eines persönlichen Engagements des Kaisers

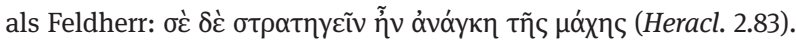

240 Siehe Exped. Pers. 3.333; Heracl. 1.174, 2.138.

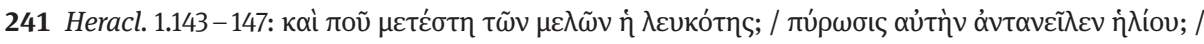

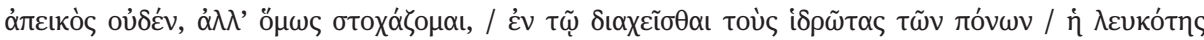

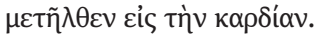

242 Unter Justinian lässt sich - auch in Zusammenhang mit militärischem Erfolg - eine ähnliche Idee der Renovation bzw. Restauration nachvollziehen; siehe dazu Meier 2003a, 165-182. 
Bildnisses der Theotokos besiegt ( $\alpha$ ữ̃ y yà

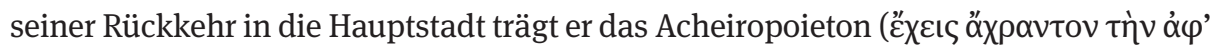

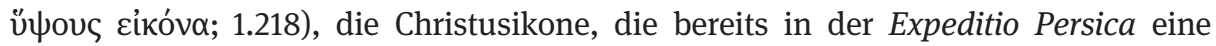
zentrale Rolle gespielt hatte. Das grandiose Verdienst des Herakleios schätzend, habe

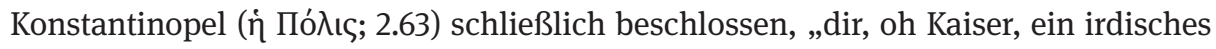
Bild zu malen, obwohl du im Himmel bereits einen anderen Maler hast“ (ypá povбıv

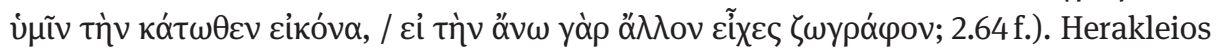
wird selbst zur Ikone; in einer Zeit, in der heilige Bilder bereits hoch in Konjunktur standen, ${ }^{244}$ etabliert der Dichter ein Triptychon, bestehend aus der Theotokos, Christus und dem Kaiser, dessen Bildnis ähnlich wie das Acheiropoieton nicht (bzw. nicht nur) von Menschenhand gemacht ist.

Georgs Wortschöpfung des kosmorustes, des Weltenretters, die wie bereits in In Bonum auch hier mit einer Herakles-Herakleios-Analogie eingeleitet wird, ${ }^{245} \mathrm{kommt}$ nun zur vollen Geltung: In Abgrenzung zu den profanen Taten des mythischen Herakles steigt Herakleios in den Hades herab, um seine Alkestis, die Ökumene, wie-

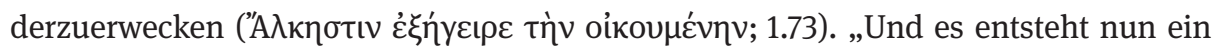

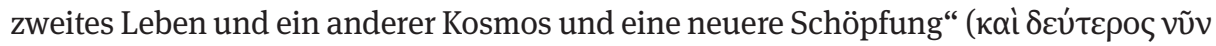

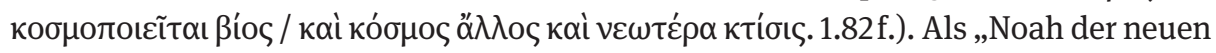

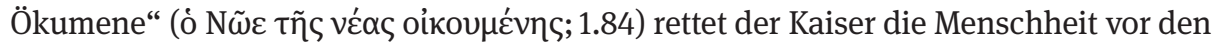
Fluten des Chosroes ebenso wie vor ihren Sünden. ${ }^{246}$ Laut Mischa Meier spitzt sich die Herleitung des kosmorustes über Herakles und Noah auf eine nur oberflächlich verschleierte Herakleios-Christus-Analogie zu. ${ }^{247}$ Diese Analyse hat indes gezeigt, dass dieser Christus-Verweis nur eine von vielen sich ergänzenden Bedeutungs- und Referenzebenen in Georgs Gedichten ist.

Herakleios' Rückkehr in die Hauptstadt erhebt der Dichter in den letzten oben zitierten Versen zu einem Ereignis von kosmischer Relevanz. Wenn Gott dem Kaiser als

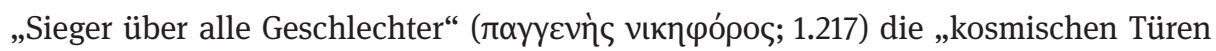

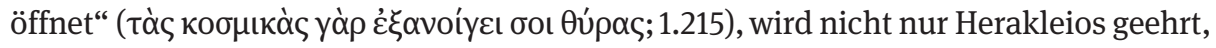
sondern auch Konstantinopel, das hier erneut die Stellung des Zentrums des christlichen Kosmos einnimmt. ${ }^{248}$ Vor diesem Hintergrund ist es auch plausibel, dass eine Passage in der Chronik des Theophanes Confessor, der erwiesenermaßen wiederholt

243 Heracl. 2.13-16.

244 Zur Ikonenverehrung siehe vor allem Av. Cameron 1979b.

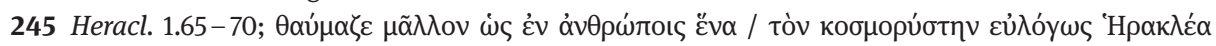

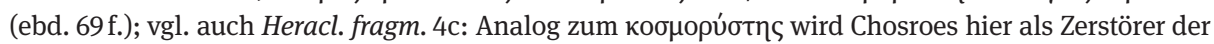

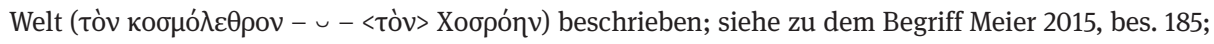
weitere Belege bei Georg von Pisidien in Cont. Sev. 452 und Hex. 1800.

246 Heracl. $1.84-92$.

247 Siehe bereits Ma. Whitby 1994, 214 f.; Meier 2015, bes. 181-183; außerdem ders. 2017, 540f.; entsprechend beschreibt er die Ausgestaltung römischer Monarchie unter Herakleios als „messianisches Kaisertum“ (ebd. 538-543).

248 Vgl. besonders die Predigt des Theodor Synkellos, die Konstantinopel als wahres Jerusalem und Nabel der Welt beschreibt; siehe oben S. 221-225. 
Gebrauch von Georgs Oeuvre machte, auf nicht überlieferte Verse des Dichters zurückgeht. ${ }^{249}$ Herakleios' Feldzug gegen die Perser wird explizit mit dem göttlichen Schöpfungswerk gleichgesetzt:

Der Kaiser aber, der sechs Jahre lang Krieg gegen Persien geführt hatte, machte im siebten Jahr Frieden und kehrte unter großer Freude nach Konstantinopel zurück, wobei er eine gewisse mystische Vision erfüllte. Denn Gott vollendete in sechs Tagen die gesamte Schöpfung und rief den siebten Tag zum Tag der Rast aus. So unterzog sich auch dieser, der Kaiser, vielen Mühen über sechs Jahre hinweg, bevor er im siebten Jahr unter Frieden und Freude in die Stadt zurückkehrte und sich zur Ruhe setzte. ${ }^{250}$

Das Spannungsverhältnis zwischen Erniedrigung und Erhöhung, anhand dessen Georg 622/3 Herakleios' Charisma vor den hauptstädtischen Funktionsträgern vergegenwärtigte, löst sich nach dem Sieg - einem Verdienst, das gemäß der gerade zitierten Stelle dem göttlichen Schöpfungswerk entspricht - zugunsten kaiserlicher Erhabenheit auf. Das entrückte Bild universaler Sieghaftigkeit, das Georg nun vom Kaiser zeichnet, deckt sich mit dessen neuerlicher Position im hauptstädtischen Palast, in den er nach jahrelanger Abwesenheit zurückgekehrt war.

Zum Ende dieses Kapitels stellt sich die grundsätzliche Frage, wie Herakleios' Selbstdarstellung zu Georgs Kaiserbild in Beziehung steht. Das Verhältnis lässt sich meiner Ansicht nach folgendermaßen fassen: Während dem Kaiser in seiner Repräsentation Grenzen des Sagbaren gesetzt waren, stand dem Panegyriker ein wesentlich größerer Spielraum zur Verfügung. ${ }^{251}$ Bei der Modellierung einer kaiserlichen Imago ergaben die beiden Sprecherperspektiven in Kombination ein vielschichtiges Spektrum, das Antworten auf die verschiedenen Erwartungen an den Kaiser formulieren konnte. Herakleios berief sich offenbar nicht nur bei seiner Krönung, sondern auch nach Jahren auf dem Thron noch auf Maurikios, stellte seine Usurpation als Rache an den Verbrechen des Phokas dar und betonte damit den Aspekt der Kontinuität. Georg von Pisidien hingegen schuf ein Kaiserbild, das vollkommen ohne den Bezug auf Maurikios auskam und Herakleios’ Herrschaft vielmehr von seinen Vorgängern abhob. ${ }^{252}$ In seiner Depesche, die vor der versammelten Bevölkerung in der Hagia Sophia

249 Pertusi 1959, 292, 307 geht davon aus, dass es Teil des dritten Akroasis der Heraclias war; vgl. Mango/Scott 1997, 457 f.; siehe auch Meier 2015, 187; zu Theophanes' Nutzung von Georg von Pisidien siehe oben S. 100f. Der göttlichen Schöpfung hat Georg von Pisidien darüber hinaus ein ganzes Gedicht gewidmet, das Hexaemeron (,Sechstagewerk'), welches ich zum Ende dieses Kapitels noch eingehender diskutieren werde.

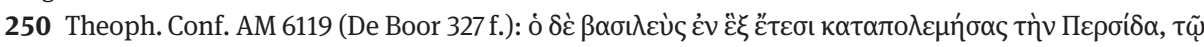

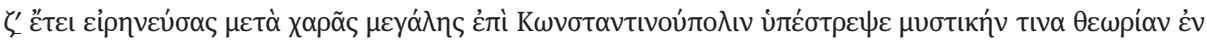

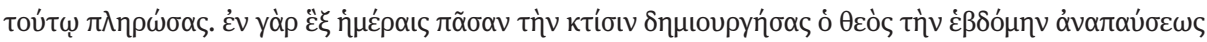

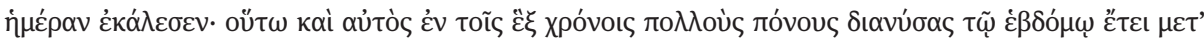

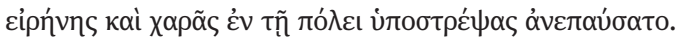

251 Zum Wert der Panegyrik vgl. Meier 2015, 169f. und 192.

252 Zu Herakleios’ Berufung auf Maurikios siehe oben S. 120. Eine ähnliche Beobachtung macht Ludwig 1991, 93. 
verlesen wurde, präsentiert sich Herakleios entlang konventioneller Kategorien als frommer Kaiser. Wenn er das Hauptverdienst an dem Sieg über die Perser den himmlischen Instanzen zuerkennt und sich selbst dabei in einer Geste der Demut im Hintergrund hält, erinnert dies an Justinians berühmte Konstitution Deo Auctore aus dem Jahr 530, in welcher der Kaiser allein den „Beistand des allmächtigen Gottes“ für das Schicksal des römischen Reiches verantwortlich macht. ${ }^{253}$ Georg dagegen entwarf, wie Mary Whitby pointiert in dem Titel eines Aufsatzes zum Ausdruck bringt, im Laufe der 620er Jahre ,a new image for a new age”, das weit über die konventionelle Betonung einer gottgegebenen Herrschaft, einer basileia ek theou hinausgeht. ${ }^{254}$ Ein zentrales Charakteristikum dieses Bildes ist, dass es nicht schlichtweg kaiserliche Erhabenheit ins Zentrum rückt, sondern - in Kontrast zu der Idee des Kaisers als ewiger Sieger - auf den meritokratischen Aspekt römischer Monarchie verweist. In seinen Gedichten entwickelt Georg von Pisidien eine wahrhafte ,Ponologie‘, eine Lehre der kaiserlichen Mühen (ponoi) zum Wohle des Gemeinwesens, als Ausdruck von dessen exzeptioneller Frömmigkeit. ${ }^{255}$ Vor einem hauptstädtischen Publikum, genauer gesagt: der hauptstädtischen Elite, diente diese Ponologie dazu, Herakleios' Transgression - den Umstand, dass er sich über mehrere Jahre am Stück von Konstantinopel entfernte - in eine anschlussfähige Erzählung einzupassen und dadurch zu bewältigen; die Vergegenwärtigung des schwitzenden Kaisers im Palast machte dessen Abwesenheit akzeptabel. Ausgehend von Herakleios' Aktivität als Feldherr entwickelte der Dichter nicht nur die militärische, sondern auch die sakrale Komponente des Kaiserbildes gegenüber etablierten Modellierungen weiter und reagierte damit auf die Anforderungen des hauptstädtischen Umfeldes: Georg zeichnet Herakleios als asketischen Krieger-Kaiser in einem religiös konnotierten Konflikt. Die funktionale Leerstelle, die Herakleios in Konstantinopel hinterließ und die vor allem während der Belagerung von 626 schmerzlich zu spüren war, kompensierte der Dichter, indem er mit dem Patriarchen Sergios und der Theotokos ein spirituelles Führungsduo installierte, das nicht in Konkurrenz zur kaiserlichen Macht trat. Während Herakleios sich selbst angesichts des Sieges gegenüber der Bevölkerung noch zurückhaltend, demütig und fromm präsentierte, ${ }^{256}$ konnte er sich nach seiner

253 Deo auctore nostrum gubernantes imperium, quod nobis a caelesti maiestate traditum est, et bella feliciter peragimus et pacem decoramus et statum rei publicae sustentamus: et ita nostros animos ad dei omnipotentis erigimus adiutorium, ut neque armis confidamus neque nostris militibus neque bellorum ducibus vel nostro ingenio, sed omnem spem ad solam referamus summae providentiam trinitatis: unde et mundi totius elementa processerunt et eorum dispositio in orbem terrarum producta est. Dazu siehe Meier, 2003a, 107-113 und Leppin 2011, 119f. Diefenbach 2019, 100 - 108 arbeitet heraus, wie sich die Demut des Kaisers, der die Verantwortung für militärischen Erfolg allein Gott zuerkennt, und dessen Erhöhung als imago dei gegenseitig bedingen.

254 Ma. Whitby 1994.

255 Vgl. Ma. Whitby 1994, $215 \mathrm{f}$.

256 Meier 2017, 540 interpretiert die Evidenz dahingehend, dass Herakleios sich zu Beginn seiner Regierung noch konventionell als „vorbildlich frommer Herrscher“ darstellte, diese Bemühungen aber bald aufgab. Ich dagegen meine, dass Herakleios eben diese Repräsentation mit Fokus auf die 
Rückkehr nach Konstantinopel im Palastumfeld vom Panegyriker in transzendente Sphären hochloben lassen: In Georgs Worten wurde der Kaiser nach seinem Triumph als Agent einer kosmischen Wiedergeburt im Stile der göttlichen Schöpfung in das hauptstädtische Beziehungsgeflecht reintegriert. ${ }^{257}$

\subsection{Der Kaiser und die Eschatologie}

Um das Panorama der Deutungen von Herakleios' Sieg über die Perser abzurunden, wende ich mich zuletzt dezidiert der Frage zu, wie dieses Verdienst von seinen Zeitgenossen im Verhältnis zur christlichen Heilsgeschichte wahrgenommen wurde; dass eine derartige Einordnung prinzipiell vollzogen wurde - etwa indem man den kaiserlichen Triumph mit der göttlichen Schöpfung parallelisierte -, hat das vorige Unterkapitel bereits angedeutet. Um den Blick für die in Konstantinopel relevanten Diskurse zu schärfen, beginne ich mit einem Exkurs in die Ostprovinzen. Ebenso wie die plötzliche und langjährige Abwesenheit des Kaisers von der Hauptstadt bewältigt werden musste, machte die Anwesenheit des Kaisers in den Ostprovinzen - mehr noch: deren Rückgewinnung von den Persern - Eindruck auf das dortige Umfeld. Ein syrischer Text, die sog. Alexanderlegende, die sich wie die bereits behandelten Quellen in der überlieferten Form als Gelegenheitsschrift qualifizieren lässt, bietet einen Einblick in zeitgenössische Diskurse. Bei dem Text handelt es sich um eine Bearbeitung des Stoffes des Alexanderromanes, eine legendenhafte Ausgestaltung von Leben und Taten eines christianisierten Alexanders des Großen. Etablierte Erzählbausteine - Alexanders Zug zum Ende der Welt und der Bau eines Tores im Kaukasusgebirge - werden mit Verweisen auf rezente politische Entwicklungen im Umfeld des anonymen Autors angereichert. ${ }^{258}$

Gemäß der Legende lässt Alexander im Kaukasusgebirge ein metallenes Tor bauen, um die wilden Völker des Nordens, hier als Gefolgschaft der Könige Gog und Magog bzw. als Hunnen bezeichnet, auszusperren. ${ }^{259}$ In dieses Tor wird auf Geheiß des Makedonenkönigs eine Inschrift geschnitten, die besagt, dass die Hunnen am Ende von 826 Jahren erstmals die Nationen überfallen werden und dass Gott nach 940

Frömmigkeit beibehielt, während sein Umfeld - etwa Georg von Pisidien - das Kaiserbild weiterentwickelte; das ist ein nicht unerheblicher Unterschied; vgl. zu der Evidenz, die Herakleios' Sieg reflektiert, auch Greisiger 2014, 82-85.

257 Die Herausforderungen, die mit der Rückkehr des Kaisers nach Konstantinopel auf einer praktischen Ebene einhergingen, werde ich im nächsten Kapitel besprechen.

258 Übersetzung des syrischen Textes bei Budge 1889, 144-158. Eine umfangreiche Aufarbeitung des Alexanderstoffes, wie er im 7. Jahrhundert nachzuvollziehen ist, und der Überblendung mit apokalyptischem Gedankengut findet sich bei Greisiger 2014, 183-285.

259 Van Donzel/Schmitt 2010, 16-21 weisen darauf hin, dass die ältere Erzählung von Alexanders Torbau in der Alexanderlegende erstmals mit den apokalyptisch konnotierten Völkern Gog und Magog verbunden wurde; siehe auch ausführlicher zum Gog-und-Magog-Motiv im frühen 7. Jahrhundert Greisiger 2014, 217-223. 
Jahren, erzürnt von den Sünden der Menschheit, die eingeschlossenen Völker erneut loslassen werde; ein Ereignis, das in Zusammenhang mit dem Kommen eines anderen Königs und dem Ende der Welt steht. ${ }^{260}$ Aus dem Kampf zwischen allen Völkern der Welt, der daraufhin entbrennt, werde das Königreich der Griechen, das dem römischen Reich gleichgesetzt wird, siegreich hervorgehen - soweit die Inschrift. ${ }^{261} \mathrm{Nach}$ dem Bau des Tores stellt sich Alexander dem persischen König Turbalak; auf Alexanders Bitten hin erscheint Gott mit seinen himmlischen Streitwagen und führt dessen Heer zum Sieg über die Perser. Aus dem Mund des gefangenen Königs Turbalak erfolgt dann eine weitere Prophezeiung: Bei Vollendung der Welt werde Rom alle anderen Königreiche unterwerfen; es werde herrschen bis zum Ende aller Zeit und das weltliche Reich dem kommenden Messias übergeben. ${ }^{262}$

Wie in der Forschung bereits wiederholt herausgestellt wurde, korrespondieren die in der Inschrift genannten Jahreszahlen - die Jahre 826 und 940 der seleukidischen Ära entsprechen 514/515 und 628/629 n. Chr. - mit tatsächlichen Einfällen von Volksstämmen von jenseits des Kaukasus: 514/515 brachen die Sabir-Hunnen durch die Kaukasuspässe und plünderten Armenien; 628/629 war geprägt durch die Präsenz der Türken, die nach ihrem Bündnisschluss mit Herakleios das Gebiet südlich des Kaukasus heimsuchten. ${ }^{263}$ Bei der Tor-Inschrift handelt es sich also um ein Vaticinium ex eventu, um einen narratologischen Trick: Ein Ereignis, meist eines der rezenten Vergangenheit, wird dabei in eine Prophezeiung gefasst und einer autoritativen Instanz der Vergangenheit in den Mund gelegt; diese sagt dann die Zukunft, die für den Rezipienten des Textes bereits eingetreten ist, voraus und verifiziert sich damit automatisch selbst. Vaticinia ex eventu werden bevorzugt in prekären Situationen angewandt: Wenn die Lebenswelt einer Gemeinschaft außer Kontrolle gerät, kann die vermeintliche Prophezeiung als Mittel genutzt werden, die Gegenwart durch ein autoritatives Deutungsangebot zu bewältigen. Im christlichen Kontext leisten derartige Vaticinia meist eine Einordnung von gewissen Ereignissequenzen in die göttliche vorbestimmte Heilsgeschichte. Christliche Zeitwahrnehmung wird konstituiert durch die Genesis als Anfangs- und die zweite Wiederkunft Christi, die Parusie, als Endpunkt. Wird einer Ereignissequenz durch ein Vaticinium ein fester heilsgeschichtlicher Standort im Verhältnis zur Parusie zugewiesen, so ermöglicht diese Zuordnung automatisch auch eine Aussage über das, was noch kommen muss. Vaticinia ex eventu bieten ihren Rezipienten also nicht nur eine Deutung der Gegenwart, sondern strukturieren auch die Zukunft und können bisweilen mit recht klaren Handlungsanleitungen einhergehen.

Daraus lässt sich folgender Schluss ziehen: 628/629 ist der Terminus post quem für die Abfassung der Alexanderlegende - zumindest in der vorliegenden Form. Nach

260 Der Text (Budge 1889, 154) ist an dieser Stelle korrupt; siehe dazu Greisiger 2014, 234.

261 Text der Inschrift in Budge 1889, 154f.; außerdem in deutscher Übersetzung bei Greisiger 2014, $231 \mathrm{f}$. und $239 \mathrm{f}$.

262 Siehe Budge 1889, 158 und Greisiger 2014, 241.

263 Reinink 1983, 1-10. Zu dem Bündnis zwischen Herakleios und den Türken siehe oben S. $229 \mathrm{f}$. 
der oben geschilderten Logik des Vaticinium ex eventu dürfte die Entstehungszeit außerdem recht nah an der prophezeiten Ereignissequenz liegen. Aus dem Umstand, dass sich im Text keine Anzeichen für die Eroberung der Araber finden, denen zwischen 634 und 636 Palästina, Syrien und Mesopotamien zum Opfer fielen, ergibt sich außerdem ein Terminus ante quem. ${ }^{264}$ Ob der Autor von Herakleios’ Rückführung der Kreuzreliquie wusste, muss offenbleiben. Zum Ende berichtet die Legende zwar, dass Alexander nach Jerusalem geht, um zu beten, und nach seinem Tod einen silbernen Thron für den Messias dorthin stiftet; ${ }^{265}$ doch dieses Motiv muss nicht zwangsläufig auf Herakleios' Restitutio Crucis verweisen: Die Erzählung von einem Besuch Alexanders in Jerusalem, bei dem er im jüdischen Tempel betet, ist erstmals bei Josephos nachzuvollziehen und seitdem als ein Standardmotiv in die Alexandertradition eingegangen. ${ }^{266}$

Vor diesem Hintergrund lässt sich die Alexanderlegende als Kommentar zu der Situation in den römischen Ostprovinzen lesen - einem Umfeld, das von Krieg und wiederholten Machtwechseln destabilisiert war; angesichts der dogmatischen Differenzen zwischen den miaphysitischen Gemeinden der Region und der chalkedonensischen Position Konstantinopels nahmen selbst Christen die Rückkehr römischer Autorität nicht durchweg positiv wahr. ${ }^{267}$ Dass die dortige Bevölkerung plötzlich mit der Präsenz eines römischen Kaisers konfrontiert war, kann durchaus als epochales Ereignis (im positiven oder negativen Sinne) eingestuft worden sein. Entlang der oben geschilderten Mechanismen des Vaticinium ex eventu bringt der Text nach der vorläufigen Beendigung des Krieges eine spezifische Deutung der rezenten Ereigniszusammenhänge vor; diese Deutung kulminiert in der heilsgeschichtlichen Relevanz des römischen Reiches, welches das apokalyptische Szenario als einzige Macht überdauern und die Herrschaft des Messias einleiten werde. Mit der Schilderung des Kampfes gegen die Perser zieht der Text nicht nur eine typologische Verbindung zwischen dem Makedonenkönig, der hier als Verehrer des christlichen Gottes auftritt, und dem erfolgreichen Feldherren Herakleios; Alexander dient darüber hinaus auch als Medium: Anhand seiner Prophezeiungen wird die Bedeutung von Herakleios' Sieg erhellt. $^{268}$

264 Siehe die ausführliche Revision der Datierungsfrage bei Reinink 1983, 1-10 und Greisiger 2014, 233f. Außerdem Shoemaker 2018, 79-86, der noch einmal betont, dass der Text wohl schon in einer früheren Version aus dem frühen 6. Jahrhundert zirkulierte und dann nach Herakleios' Persersieg angepasst wurde (bes. 82f.).

265 Budge 1889, 158; bereits zu Beginn des Textes legt Alexander das Gelübde an Gott ab, den Thron für den Messias nach Jerusalem zu stiften, siehe ebd. 146.

266 Siehe Greisiger 2014, 204-210 und ebd. 210-213 zum Motiv des Thrones des Messias; vgl. außerdem Reinink 1985, 279-281, der nicht ganz deutlich macht, ob der Autor der Alexanderlegende seiner Ansicht nach auf Herakleios' Restitutio Crucis Bezug nimmt oder nicht.

$267 \mathrm{Zu}$ den miaphysitischen Gemeinden in Syrien und Mesopotamien, die sich immer weiter von römischer Autorität abkapselten, siehe Frend 1979, 335-344; Reinink 1985, 263 f.

268 Eine ausführliche Interpretation der Alexanderlegende findet sich bei Greisiger 2014, 231-242; vgl. auch Stoyanov 2011a, 62f.; Shoemaker 2018, 79-86. 
Dass der Krieg zwischen Rom und Persien und nicht zuletzt die Verheerungen durch die Türken bei der betroffenen Bevölkerung Endzeit-Ängste auslösten, wurde in der Forschung wiederholt thematisiert. ${ }^{269}$ In diesem Kontext liegt der Wert der Alexanderlegende darin, dass sie die apokalyptische Stimmung bündelt und in eine rombzw. kaiserfreundliche Richtung leitet: Die umstrittene Präsenz der Römer, ihre neuerliche Hoheit über den Nahen Osten, wird dezidiert positiv konnotiert; für den Einfall der Türken von jenseits des Kaukasus, der die Bevölkerung in Angst und Schrecken versetzte, macht der Text nicht etwa Herakleios' Bündnis-Politik verantwortlich, wie andere Quellen es tun, sondern Gott, der damit menschliche Sünden bestraft. ${ }^{270}$ Die Legende interpretiert die rezenten Ereignisse zwar im Zusammenhang mit dem Ende der Welt, leistet also eine spezifische heilsgeschichtliche Einordnung, schafft dabei jedoch gleichzeitig einen positiven Ausblick, wie Lutz Greisiger prägnant formuliert: „Die Abtretung der Herrschaft an Christus ist in eine zweite, eschatologische Ebene projiziert und so von dem byzantinischen Sieg gleichsam abgekoppelt; zwischen beide Ereignisse wird eine christlich-imperiale Heilszeit eingeschoben." Die Alexanderlegende bietet also eine „imperial-postmillenaristische Deutung von Herakleios’ Sieg“, die möglichen rom- bzw. kaiserkritischen Deutungen entgegenwirkt. ${ }^{271}$ Herakleios kommt dabei nicht die Stellung des Messias zu, aber die des Wegbereiters eines messianischen Zeitalters, das den Ostprovinzen nun bevorstehe. Gerd Reininks These, die Alexanderlegende sei in einem chalkedonensischen, pro-römischen Milieu entstanden und habe nicht nur die römische Herrschaft über die rückgewonnenen Ge-

269 Reinink 2002, bes. 82f.; Magdalino 2007, 18 f.; Greisiger 2013; Shoemaker 2018, 74-79. Siehe zum Beispiel Movses Dasxuranci 2.9 (Dowsett 75), der - in Rückgriff auf zeitgenössisches Material - den Einfall der Türken nach Albanien beschreibt: „For there came and fell upon us that of which Our Saviour, humanely yielding to the patient attention of the chosen twelve, spoke in the life-bringing gospel concerning the times of tribulation ...“.

270 Vgl. Greisiger 2014, 235 - 237. In der fränkischen Chronik des Fredegar (4.66), die um 650 entstand, ist es Herakleios, der das von Alexander gebaute Tor öffnet; allerdings nicht, um Gog und Magog bzw. die Türken hineinzulassen, sondern „die Hagarener, auch Sarazenen genannt“. Fredegar verwechselt hier also die Türken mit den Arabern; zu Fredegars Bericht von den arabischen Eroberungen siehe Esders 2009. Auch in Movses Dasxuranci (2.12 [Dowsett 87]) öffnet Herakleios den barbarischen Horden die Tore.

271 Beide Zitate bei Greisiger 2014, 242 (postmillenaristisch bedeutet, dass das zweite Kommen Christi, die Parusie, erst in Folge eines tausendjährigen Friedenreiches angenommen wird); zu der eschatologischen Konzeption in der Alexanderlegende siehe auch Reinink 2002, 90. Neben der Alexanderlegende gibt es noch das Alexanderlied, das in Versform einen ganz ähnlichen Stoff behandelt und laut Reinink (1983, 11f.) ebenfalls zwischen 628 und 636, allerdings nach der Legende entstanden ist. Die positive Deutung des Römischen Reiches wird in dem Lied allerdings nicht reproduziert. Anstatt ins Friedensreich Christi überzuleiten, wird Rom ebenso durch die heranstürmenden Völker Gog und Magog vernichtet (siehe ebd. und ders. 1985, 280 f.). In der Gegenüberstellung der beiden Quellen zeigt sich, wie umstritten die heilsgeschichtliche Bedeutung Roms in den kirchenpolitisch fragmentierten Ostprovinzen war; vgl. zu den beiden Texten Shoemaker 2018, 79-86; siehe ebd. 86-89 zu der Anpassung eschatologischer Deutungen angesichts der Eroberungen der Araber. 
biete sichern, sondern auch den Weg für das religionspolitisches Einigungswerk ebnen sollen, dem Herakleios sich ab 628 widmete, ist durchweg einleuchtend. ${ }^{272}$

Um den Gehalt der Alexanderlegende in einem breiteren Kontext angemessen zu erfassen, seien an dieser Stelle allgemeine Bemerkungen zur christlichen Eschatologie eingeschoben: Eschatologisches Denken, also die Deutung von Ereigniszusammenhängen im Rahmen göttlicher Heilsökonomie und in Bezug zu einem wie auch immer gearteten eschaton (dem Weltende), war integraler Teil dessen, wie sowohl Juden als auch Christen sich und ihre Position in der Welt wahrnahmen. Christliche Eschatologie speiste sich aus verschiedenen Referenzen des Alten wie des Neuen Testamentes, aus denen sich nur schwerlich ein konsistentes Deutungsmodell gewinnen ließ: Die Lehre von den vier danielischen Weltreichen stand neben der Auffassung des römischen Reiches als katechon (die Institution, die das Kommen des Antichristen aufhält) und einem millenaristischen Modell, das die Weltgeschichte - analog zum Schöpfungsbericht der Genesis - in sechs Jahrtausende und einen ebenfalls tausendjährigen Weltsabbat gliedert. ${ }^{273}$ Sowohl dem römischen Reich wie auch den Kaisern wurden im Rahmen eschatologischer Deutungsmuster verschiedene Funktionen bzw. Positionen zugewiesen. Ausgehend von der Idee der Vergänglichkeit alles Irdischen und der Annahme eines nahenden Weltendes wohnte der Eschatologie tendenziell subversives bzw. herrschaftskritisches Potential inne, das bestehende Hierarchien in Frage stellen konnte; derartige Denkmuster ließen sich allerdings durchaus auch in eine affirmative bzw. herrschaftsstabilisierende Richtung lenken: ${ }^{274}$ Ausgehend von der Angleichung weltlicher Monarchie und himmlischer Gottesherrschaft, deren systematische Grundlage Eusebius von Caesarea gelegt hatte, entwickelte sich in der Spätantike die Idee des römischen Reiches als Vorläufer bzw. Wegbereiter einer christlichen Heilszeit, wobei die ideellen Grenzen zwischen diesen beiden Phasen, zwischen dem irdischen und dem himmlischen Reich, bisweilen verschwammen; in jedem Fall lenkte eine derartige Deutung von dem Aspekt einer alles konsumierenden Apokalypse ab. ${ }^{275}$

272 Reinink 1985, bes. 266 und 280, der den anonymen Autor der „Propagandaschrift“ gar noch konkreter in Edessa bzw. Amida verortet. Für eine breite Zirkulation des Textes spricht, dass die KoranTradition zu Alexander dem Großen auf der syrischen Alexanderlegende basiert; siehe Shoemaker 2018, 80. Zu Herakleios Religionspolitik siehe unten Kap. 6.1.3.

273 Magdalino 2007, 4; Greisiger 2014, 111-114; ausführlicher mit Berücksichtigung verschiedener Traditionsstränge und Entwicklungsdynamiken Shoemaker 2018, 11-63. Zu spätantiker/byzantinischer Apokalyptik siehe außerdem Mango 1980, 201-217; Alexander 1985; Brandes 1990. Eine kritische Revision der Forschung zu spätantiker Apokalyptik bei Av. Cameron 2017.

274 Die beiden Extreme werden beleuchtet bei Shoemaker 2018, 11-37.

275 Grundlegend ist hier Podskalsky 1972 zu „byzantinischer Reichseschatologie“; zu reichsaffirmativer Eschatologie siehe Magdalino 2007, 10-15 und Shoemaker 2008, 38-42; zur Konkurrenz verschiedener eschatologischer Deutungen unter Justinian siehe Scott 1985. 
In der Forschung gilt das frühe 7. Jahrhundert als Hochphase eschatologischen Gedankengutes und apokalyptischer Naherwartung. ${ }^{276}$ Ohne diese Beobachtung grundsätzlich anzuzweifeln, möchte ich an dieser Stelle für ein differenzierteres Vorgehen plädieren; anstatt vereinzelte Äußerungen der raum- wie zeitgebundenen Quellen als generell gültig zu verallgemeinern, sollte in der Analyse zwischen verschiedenen Entstehungs- und Kommunikationskontexten unterschieden werden. ${ }^{277}$ Indem im Folgenden die bereits besprochene Alexanderlegende mit anderen Quellen kontrastiert wird, die ebenfalls im Zusammenhang mit Herakleios' Krieg und Sieg über die Perser entstanden, kann herausgearbeitet werden, in welch unterschiedlichen Qualitäten sich eschatologische Deutungen, selbst die herrschaftsaffirmativen, äußern konnten.

Eschatologie basiert stets auf einem individuellen und kontextgebundenen Deutungsprozess; die Alexanderlegende, die aus einem spezifischen Kontext im Nahen Osten erwuchs, offenbart eine von vielen möglichen Ausformungen. Mit der Frage, ob sich derartige Deutungsmuster auch in Konstantinopel nachvollziehen lassen, schlage ich den Bogen zurück von der Provinz in die Hauptstadt. Dass die Bevölkerung Konstantinopels ebenso wie die Christen im Nahen Osten dazu tendierte, die eigene Lebenswelt in eschatologischen und teilweise gar konkret apokalyptischen Kategorien wahrzunehmen, wurde in der Forschung bereits herausgearbeitet. ${ }^{278}$ Auch in den Quellen, die im hauptstädtischen Kontext in Zusammenhang mit Herakleios' Perserkrieg bzw. -sieg entstanden, ist die eschatologische Perspektive durchaus präsent; in ihrer Qualität hebt sie sich allerdings deutlich von den Ausformungen ab, die

276 Diese These wird besonders in den zahlreichen Arbeiten von Mischa Meier propagiert, der nicht nur das frühe 7. Jahrhundert, sondern die Spätantike im Allgemeinen vor dem Hintergrund (enttäuschter) eschatologischer Naherwartung interpretiert; siehe zuletzt Meier 2016. Auch Meiers monumentales Buch zur Völkerwanderung (2019) ist von dieser Prämisse durchdrungen (siehe vor allem 953-1088); siehe auch Meier 2020. Ebenso wie Meier sieht auch Shoemaker 2018 das Entstehen des Islams vor dem Hintergrund eschatologischer Stimmungen im östlichen Mittelmeerraum.

277 Zur Vorsicht im Umgang mit eschatologischem Quellenmaterial hat zuletzt vor allem auch Averil Cameron (2017) aufgerufen; dabei relativiert sie die Annahme, dass apokalyptisches Denken charakteristisch für die spätantike Welt als Ganzes zu verstehen sei; es handele sich vielmehr um regionale und ephemere Phänomene. Ich kann mich Camerons Apell vollumfänglich anschließen.

278 Vor allem fürs späte 5. und 6. Jahrhundert lassen sich akute Naherwartungen nachvollziehen; tiefgreifende Verunsicherungen konnten sich in Endzeitängsten kanalisieren; siehe dazu Magdalino 2007, 4- 7; Brandes 1997 zu Naherwartungen unter Anastasios; außerdem Meier 2012, 226-230, der die fortschreitende Liturgisierung der Gesellschaft als Reaktion auf enttäuschte Endzeiterwartungen versteht; vgl. Shoemaker 2018, 66-74. Allerdings halte ich es für problematisch, davon auszugehen, dass die gesamte römische Gesellschaft ab ca. 500 n. Chr. konstant das Ende der Welt vor Augen hatte; unter derartigen Voraussetzungen wäre eine Gesellschaft kaum funktional - und das Bemerkenswerte an der römischen Gesellschaft in der Spätantike ist gerade, dass sie trotz zahlreicher Bedrohungen funktional blieb. 
in den Ostprovinzen nachzuvollziehen sind: Ich unterscheide diesbezüglich im Folgenden zwischen akuter und nicht akuter Eschatologie. ${ }^{279}$

Eine Passage in den Historien des Theophylakt Simokattes kommt der Alexanderlegende zumindest formal am nächsten, da auch hier die Technik des Vaticinium ex eventu angewandt wird. Kurz vor seiner Wiedereinsetzung 591 weissagt der Perserkönig Chosroes II., dass in Zukunft zuerst die Perser die Römer beherrschen würden; auf einen Sieg der Römer folge dann „ein Tag ohne Abend“ und „ein besseres Leben“. ${ }^{280}$ Während die Alexanderlegende ein akut apokalyptisches Szenario entwirft, indem sie die eigene Lebenswelt mit dem Ende der Welt und dem - wenn auch fernen - Kommen des Messias in Verbindung bringt, gibt die Prophezeiung bei Theophylakt für die Zeit nach Herakleios' Sieg über die Perser eine ebenso positive wie unbestimmte Zukunftsperspektive, die das eschaton schlichtweg ausblendet. Ähnlich verhält es sich in der oben zitierten Schöpfungsanalogie aus der Chronographie des Theophanes, die Herakleios' siegreiche Rückkehr mit dem siebten Tag der Genesis gleichsetzt und dabei auf millenaristische Modelle anspielt. ${ }^{281}$ Es erfolgt also eine heilsgeschichtliche Einordnung, allerdings ohne dabei das nahende bzw. bereits präsente Weltende heraufzubeschwören; die Gegenwart wird vielmehr mit einer messianischen Heilszeit überblendet, herbeigeführt durch Herakleios' Triumph. Bereits vor dem Friedensvertrag von 628 lässt sich diese Muster in der Predigt des Theodor Synkellos nachvollziehen: Anhand des Rekurses auf alttestamentarische Prophezeiungen etabliert er Konstantinopel als das eigentliche Jerusalem; der Belagerung durch Avaren und dem römischen Sieg kommt eine Position in der göttlichen Heilsökonomie zu, die nicht etwa in der Annahme einer nahenden, alles konsumierenden Apokalypse, sondern in der Hoffnung auf das ewige Bestehen der Stadt kulminiert. ${ }^{282}$

In den Ostprovinzen des römischen Reiches, wo die politischen Verwerfungen des frühen 7. Jahrhunderts besonders akut zu spüren waren, florierte akut eschatologisches Gedankengut; die Alexanderlegende ist nur eines von vielen Beispielen. Selbst romfreundliche Zeugnisse passten die Ereigniszusammenhänge im Allgemeinen sowie die Aktivität des Herakleios im Speziellen, gipfelnd in seiner Rückführung der Kreuzreliquie, in akut eschatologische Szenarien ein. Das Potential derartiger Denkmuster offenbarte sich im Laufe des siebten Jahrhunderts, als mit der Apokalypse des

279 Der Begriff „urgent eschatology” findet sich bei Shoemaker 2018, 65. Reinink 2002, 92 dagegen sieht keinen qualitativen Unterschied in den Eschatologien der Hauptstadt und der Ostprovinzen.

280 Theoph. Sim. Hist. 5.15.5 - 7. Die Prophezeiung enthält auch Zeitangaben: Die Dominanz der Perser über die Römer starte in der dritten Jahrwoche (also nach 21 Jahren), der Sieg der Römer ereigne sich in der fünften Jahrwoche, was in etwa den Ereignissen des frühen 7. Jahrhunderts entspricht; siehe dazu Schreiner 1985, 320 Anm. 784; Whitby/Whitby 1986, 153 Anm. 80; Magdalino 2007, 18f.; mit bisweilen konfligierenden Interpretation der Stelle Reinink 2002, 86-89; Stoyanov 2011a, 63f.; Greisiger 2014, 115f.; zuletzt Shoemaker 2018, 76-78.

281 Theoph. Conf. AM 6119 (De Boor 327 f.); vgl. Greisiger 2014, 112.

282 Siehe oben S. 221-225. 
Ps.-Methodius und ihrer Prophezeiung vom letzten römischen Kaiser, der in Jerusalem abdankt, eine Erzählung geschaffen wurde, die sich über den gesamten Mittelmeerraum verbreitete. ${ }^{283}$ In Konstantinopel indes entwickelten akut eschatologische Deutungen - zumindest im frühen 7. Jahrhundert - offenbar keine nachhaltige Wirkung. Während sich fürs 6. Jahrhundert nachvollziehen lässt, wie akute Endzeitängste und herrschaftsaffirmative Eschatologien sich bisweilen die Waage hielten, ${ }^{284}$ gibt es im 7. Jahrhundert schlichtweg keine Evidenz dafür, dass die hauptstädtische Bevölkerung ihre Lebenswelt in konkret apokalyptischen Kategorien wahrnahm - weder in zeitgenössischen Quellen noch in der späteren Tradition. Aus diesem Befund schließe ich nicht, dass derartiges Gedankengut in der Hauptstadt nicht ebenfalls grassierte; ich meine vielmehr, dass herrschaftsaffirmative Deutungsmuster, die die Stabilität und Langlebigkeit römischer Herrschaft betonten, wirkmächtiger waren, den Diskurs bestimmten und alternative Interpretationen erfolgreich überlagerten.

Als ein Agent dieser herrschaftsaffirmativen und stabilisierenden Deutungsmuster kommt zum Ende dieses Kapitels noch einmal Georg von Pisidien ins Bild, der aller Wahrscheinlichkeit nach auch der Urheber der bei Theophanes überlieferten Schöpfungsanalogie ist. ${ }^{285}$ Die Art und Weise, wie er Herakleios nach dessen Sieg über die Perser zeichnet, könnte man im weitesten Sinne als eschatologisch bezeichnen, da der Dichter den Beginn eines neuen, messianisch konnotierten Zeitalter heraufbeschwört. Anstatt allerdings das eschaton $\mathrm{zu}$ thematisieren oder gar auf mögliche apokalyptische Naherwartungen anzuspielen, lenkt Georg den Blick auf Herakleios als Schlüsselfigur einer positiven Zukunft: Der Lohn für den Schweiß seiner Mühen

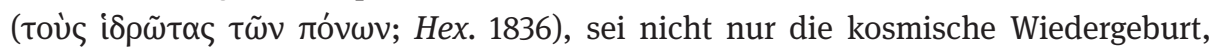
sondern auch die eigene Unsterblichkeit und die seines Geschlechtes. ${ }^{286}$

Neben der Heraclias äußert sich dieses Konzept auch in Georgs elaboriertestem Werk, in dem er die göttliche Schöpfung bzw. die Erschaffung des Kosmos feiert - in der Regel unter Hexaemeron bekannt, ist der griechische Titel Kosmospoeia wohl treffender. ${ }^{287}$ Anders als die bisher diskutierten Gedichte ist die Kosmospoeia keine Gelegenheitsschrift; es handelt sich nicht primär um einen Kommentar zu rezenten Ereigniszusammenhängen. Allein im Epilog des Gedichtes rückt der siegreiche He-

283 Zu Ps.-Methodios siehe Reinink 1988 und 1993; Shoemaker 2018, 48-59.

284 In Hinblick auf die Herrschaft des Justinian wurde dies vor allem durch Scott 1985 aufgearbeitet; siehe außerdem Magdalino 2007, 5-18; Scott 2012; Shoemaker 2018, 70 -72. Zur Wirkmächtigkeit eschatologischen Gedankenguts unter Justinian siehe Meier 2003a.

285 Hiermit widerspreche ich einigen Stimmen in der Forschung, die Georgs späte Gedichte als dezidiert eschatologisch verstehen, so etwa Reinink 2002, 92 und Shoemaker 2018, 79: „In his panegyrics on Heraclius, George of Pisidia paints his patron's triumph in deep eschatological hues.”

286 Hex. 1836f. und Heracl. 2.29-33; interessant ist an dieser Stelle, dass Georg mit dem Begriff $\alpha \varphi \theta \alpha \rho \sigma i \alpha$ spielt, der zentral war für die christologische Lehre, die Justinian kurz vor seinem Tod erfolglos durchzusetzen versuchte, den Aphthartodoketismus (siehe dazu Uthemann 1999, 79f.; Leppin 2011, 332f.). Hierin könnte man einen weiteren Verweis darauf sehen, dass Georg Herakleios und Christus semantisch angleicht; siehe dazu bereits oben S. 204.

287 Tartaglia 1998, 25-29. 
rakleios in den Fokus. ${ }^{288}$ Dort entwirft Georg eine Kosmologie, die sich um den triumphierenden Kaiser gruppiert, und rekurriert damit auf die Heraclias, wo er Hera-

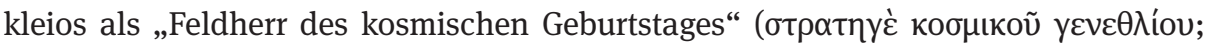
Heracl. 1.201) anspricht. Mit seinem Sieg über die Perser erweist sich Herakleios als

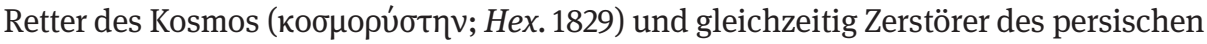

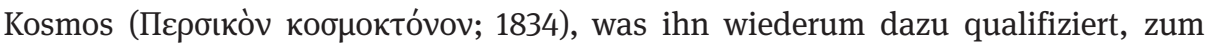
Herrscher über den Kosmos aufzusteigen ( 1835). In diesem Entwurf nimmt Konstantinopel eine Stellung im Zentrum des Kosmos ein: Die himmlischen Pforten entsprechen den irdischen; in Konstantinopel befinden sich die Pforten der Bewohner des Kosmos ( 1826). ${ }^{289}$

Die Kosmopoieia ist ein Lob der Schöpfung, das vor dem Hintergrund des kaiserlichen Rettungs- bzw. Neuerungswerk den Blick in eine positive, heilvolle Zukunft eröffnet - und gleichzeitig ein Lob Konstantinopels als Zentrum des Kosmos. Während Georg von Pisidiens Oeuvre aller Wahrscheinlichkeit nach in dem elitären Kontext des kaiserlichen Palastes zu verorten ist, hat die im Laufe dieses Kapitels diskutierte Evidenz gezeigt, dass diese elitären Diskurse durchaus auch auf eine breitere Öffentlichkeit ausstrahlten bzw. sich ihrerseits aus allgemeinen Trends speisten. An Georgs Gedichten lässt sich nicht nur nachvollziehen, wie Herakleios’ Transgression - seine langjährige Abwesenheit - in der Hauptstadt durch positive Deutungsangebote bewältigt werden konnte, sondern auch, wie Konstantinopel im gleichen Zuge ihr städtisches Selbstbewusstsein stärkte. Seitdem sich die oströmischen Kaiser im 5. Jahrhundert dauerhaft am Bosporus niedergelassen hatten, hatte sich die Alleinstellung Konstantinopels - sei es als neues Rom oder neues Jerusalem - sukzessive im städtischen Bewusstsein verankert. ${ }^{290}$ Angesichts der zahlreichen Bedrohungen und Umwälzungen, mit denen sich das römische Reich im 7. Jahrhundert konfrontiert sah, wurde dieses Selbstbild nicht etwa brüchig, sondern erreichte vielmehr ein neues Level; die Idee einer besonderen Nahbeziehung zur Theotokos, die nicht zuletzt in Zusammenhang mit Herakleios’ Abwesenheit einen vorläufigen Höhepunkt erreichte, sollte sich noch angesichts vieler Herausforderungen als wirkmächtig erweisen. Obwohl sich die physische Bindung des Monarchen an die Hauptstadt lockerte, offenbart sich für das Konstantinopel des frühen 7. Jahrhunderts ein Bild städtischer Integra-

288 Die genaue Datierung des Gedichtes bzw. dessen Fertigstellung ist umstritten, siehe Olster 1991 für eine Datierung ins Jahr 638; dagegen überzeugend Ma. Whitby 1995, bes. 115 und Howard-Johnston 2010, 24 für eine frühere Datierung kurz nach dem Persersieg; vgl. auch Ludwig 1991 (bes. 123f. zur Datierungsfrage) und Speck 1998.

289 Ähnlich bereits in der Heracl. 1.215 (siehe die Übersetzung oben); siehe Ma. Whitby 1995, 119f. Ludwig 1991, 115 f. dagegen sieht in den irdischen Toren einen Verweis auf Jerusalem (so auch Greisiger 2014, 84), was allerdings angesichts der Parallele in der Heraclias nicht überzeugt. Auch Sergios nimmt in der Kosmopoieia wieder eine zentrale Rolle ein, siehe Ludwig 1991, 119f. und Ma. Whitby 1995, 128; Georg bedient sich dabei erneut der für ihn typischen Methode, die bisweilen offenlässt, welchen Akteur er gerade anspricht.

290 Siehe etwa Dagron 1974. 
tion; ${ }^{291}$ in einem derartigen Umfeld konnten apokalyptische Schreckensszenarien nicht greifen. Diese Entwicklung bedingte meines Erachtens auch die erstaunliche Resilienz, mit der Konstantinopel sich in den folgenden Jahrzehnten trotz zahlreicher innerer wie äußerer Bedrohungen und einer fortschreitenden Fragmentierung des Reiches als Zentrum des Imperiums, des römischen Kosmos, behaupten konnte. ${ }^{292}$

291 Während die beiden gewaltsamen Machtwechsel von 602 und 610 in der Forschung in der Regel als traumatische Erfahrungen für die hauptstädtische Bevölkerung thematisiert werden (siehe etwa Meier 2014b), offenbart sich für mich bereits in den spezifischen Abläufen der Machtwechsel - wie oben Kap. 3.3.2 anhand der Krönungsrituale gezeigt - ein starkes und ungebrochenes städtisches Selbstbewusstsein.

292 Vgl. Haldon 2016 zu der Frage, wie sich das römische Reich trotz anhaltender Bedrohung halten konnte. 


\section{Zwischen Triumph und Katastrophe}

Beinahe dreißig Jahre, nachdem Chosroes II. infolge des Sturzes seines Verbündeten Maurikios den Krieg gegen Rom erklärt und sukzessive die Ostprovinzen bis an die Grenze Anatoliens besetzt hatte, vier Jahre nachdem Herakleios auf seine Himmelfahrtsmission ins persische Kernland aufgebrochen war, hatte sich nun tatsächlich das Blatt gewendet: Ein entscheidender militärischer Sieg, der die persischen Truppen bis zur Handlungsunfähigkeit dezimiert hätte, war zwar nicht errungen worden - die Schlacht von Niniveh sollte in ihrer militärischen Bedeutung nicht überschätzt werden; doch interne Instabilität und Verwerfungen innerhalb der persischen Elite, befeuert durch den Einfall der römischen Truppen, hatten Herakleios in die Hände gespielt. Nach Chosroes' Sturz war es der römische Kaiser, der sich nach Jahrzehnten der Schwäche beim politischen Kräftemessen im Nahen Osten wieder in die stärkere Position aufgeschwungen hatte. Doch mit dem Friedensangebot des Seiroe im März 628 sollte bei Weitem noch nicht das letzte Wort im Konflikt zwischen Rom und Persien gesprochen sein. ${ }^{1}$ Über zwei Jahre würde es stattdessen dauern, bis die Details der Beziehungen der beiden Großmächte zueinander ausgehandelt und praktisch umgesetzt werden konnten. Eine exakte chronologische Rekonstruktion der Abläufe dieser zwei Jahre ist angesichts der extrem problematischen und oft widersprüchlichen Quellenlage kaum möglich. ${ }^{2}$ Anstatt im Folgenden den Eindruck einer konzisen Erzählung zu erwecken, soll die Aufmerksamkeit vielmehr auf die für meine Fragestellung entscheidenden Entwicklungen gelenkt werden: Herakleios’ Bemühungen, seine Rückkehr in die Hauptstadt nach langer Abwesenheit möglichst positiv zu gestalten, sowie sein Ringen darum, die römische Hoheit in den Ostprovinzen zu festigen. Das Kapitel endet mit Blick auf eine Entwicklung, welche die Kräfteverhältnisse im Nahen Osten erneut ins Wanken brachte: Ab 633/634 sahen sich die römischen Ostprovinzen mit den Vorstößen der muslimischen Araber konfrontiert. Die römische Verteidigung, durch Jahrzehnte des Krieges mit Persien geschwächt, hatte dem Aggressor nicht viel entgegenzusetzen. Wenige Jahre nach ihrer spektakulären Rückgewinnung durch Herakleios wurden die Ostprovinzen bis an die Grenze Kleinasiens erneut der römischen Kontrolle entzogen; Herakleios' Restitutionswerk war dahin.

Das vorherige Kapitel hat nachvollzogen, wie Herakleios' Erfolg in der Öffentlichkeit besprochen wurde. Dabei hat sich gezeigt, wie wichtig es ist, bei der Analyse zwischen verschiedenen Kommunikationskontexten $\mathrm{zu}$ unterscheiden: Die spezifischen Anforderungen und Erwartungen, die das hauptstädtische Umfeld an den Kaiser richtete, resultierten in einer Repräsentation kaiserlicher Sieghaftigkeit, die sich deutlich von Diskursen unterschied, wie sie in den rückgewonnenen römischen

$1 \mathrm{Zu}$ den Abläufen siehe oben Kap. 5.4.1.

2 Zuletzt hat Zuckerman 2013 versucht, alle Quellen zusammenzubringen und ein Itinerar herauszuarbeiten; das Ergebnis ist zwar beeindruckend, aber im Detail bisweilen nicht ganz überzeugend, siehe die Diskussion im Folgenden.

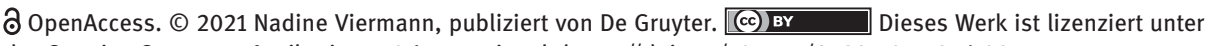
der Creative Commons Attribution 4.0 International. https://doi.org/10.1515/9783110711356-007 
Ostprovinzen zu beobachten sind. Während in den Ostprovinzen, die wesentlich direkter von den machtpolitischen Verwerfungen der letzten Jahrzehnte betroffen waren, akut eschatologisches Gedankengut florierte, oszillierte der Diskurs in Konstantinopel zwischen zwei komplementären Polen: Der ostentativen Zurückhaltung des Herakleios stand dessen Überhöhung durch Georg von Pisidien gegenüber, der seinen kriegführenden Kaiser angesichts des Sieges zum Agenten eines neuen, positiven Zeitalters erhob. Die nun folgende Analyse wird herausarbeiten, wie sich Herakleios' Rückkehr in die Hauptstadt praktisch gestaltete.

\subsection{Mit dem Sieg im Rücken}

\subsubsection{Rückkehr nach Konstantinopel I}

Im März 628 hatte der neue persische Großkönig Kavadh Seiroe zugesichert, die von den Persern besetzten Gebiete zu räumen; in der Praxis waren diese Konditionen allerdings nicht ohne Weiteres umzusetzen. Von dem Umsturz in Ctesiphon und der militärischen Kursänderung in Kenntnis gesetzt, weigerten sich die persischen Truppen, dem Befehl des neuen Großkönigs nachzukommen und die römischen Provinzen freizugeben. Die erneute Einrichtung einer römischen Verwaltung, eine zentrale Voraussetzung für die effektive Konsolidierung der Provinzen, gestaltete sich also schwierig. Anstatt einer friedlichen Räumung der Gebiete, wie sie den beiden Herrschern vorgeschwebt hatte, kam es erneut zu bewaffneten Zusammenstößen zwischen den persischen Besatzern und den aus dem Osten zurückkehrenden römischen Truppen unter der Führung von Herakleios' Bruder Theodor: Die persische Garnison im strategisch wichtigen Zentrum Edessa in Nordmesopotamien etwa widersetzte sich lange einer Übernahme durch die Römer; die jüdische Bevölkerung stand dabei auf ihrer Seite. Doch selbst nach dem Rückzug der Perser herrschte keine Einigkeit: Als Herakleios selbst in Edessa eintraf, verweigerte der miaphysitische Bischof der Stadt ihm die Kommunion. ${ }^{3}$ Auch der herausragende General des zurückliegenden Krieges, Shahrbaraz, dessen Loyalität gegenüber der persischen Zentrale sich zuletzt bereits unter Chosroes als fragil erwiesen hatte, machte vorerst keine Anstalten, dem Befehl nachzukommen und aus dem von ihm eroberten Gebiet abzurücken. ${ }^{4}$

3 Siehe Chron. 1234, 102 (Chabot I, 185); Hoyland 2011, 79-81; die griechischen Quellen schweigen dazu. Zur militärischen Konsolidierung der Ostprovinzen vgl. Flusin 1992 II, 282-288.

4 Von der Weigerung des Shahrbaraz berichtet allein Sebeos 39 (Thomson/Howard-Johnston I, 86); ebd. 39 (Thomson/Howard-Johnston I, 84f.) wird außerdem vermerkt, dass Shahrbaraz dem Chosroes angesichts der römischen Invasion nicht zu Hilfe kam; aus ebd. 40 (129) ist zu schließen, dass Shahrbaraz sich in Alexandria aufhielt. In späteren Quellen (Theoph. Conf. AM 6118 [De Boor 323f.]; Mich. Syr. 11.3 [Chabot II, 408f.]; Chron. 1234, 98[Chabot I, 181f.]) findet sich wiederholt der Bericht (offenbar ausgehend von der Geschichte des Theophilos von Edessa, siehe Howard-Johnston 2010, 203f.), dass Chosroes den Shahrbaraz bereits 626 habe beseitigen wollen und der General in Reaktion darauf eine 
Der Osten war also mit der Vereinbarung des Frühjahrs 628 keinesfalls befriedet und Herakleios begab sich in den darauffolgenden Jahren wiederholt persönlich an die jeweiligen Krisenherde. Doch nachdem zumindest die akute Gefahr eines aggressiven Chosroes beseitigt worden war, musste der Kaiser seine Aufmerksamkeit auch verstärkt wieder der Hauptstadt zuwenden: Während der zurückliegenden Jahre war das Schicksal des römischen Reiches auf Messers Schneide gestanden; Konstantinopel hatte sich ohne die psychologisch wichtige Präsenz des Kaisers in der Stadt einer feindlichen Belagerung erwehren müssen. Die hauptstädtische Bevölkerung, die durch die Felddepeschen im Detail über den erfolgreichen Ausgang der römischen Expedition in Kenntnis gesetzt worden war, erwartete den Senior Augustus bereits sehnsüchtig. ${ }^{5}$ Auf welchem Wege, wann genau und wie oft Herakleios allerdings an den Bosporus zurückkehrte und wie lange er sich in den folgenden Jahren dort aufhielt, ist angesichts der diffusen Quellenlage umstritten. ${ }^{6}$ Mir scheint es indes plausibel, dass Herakleios sich nach dem Friedensschluss mit Seiroe schnellstmöglich nach Konstantinopel begab und dort im Spätsommer oder Herbst 628 eintraf. ${ }^{7}$

Indem Herakleios sich als Kaiser entgegen der Gewohnheit seiner Vorgänger von Konstantinopel entfernt hatte, hatte er mit etablierter monarchischer Verhaltenspraxis gebrochen. Dass diese Transgression im hauptstädtischen Sozialgefüge bewältigt werden konnte, war nicht zuletzt dem Umstand geschuldet, dass es Akteuren in der Hauptstadt gelang, eine positive Deutung von Herakleios’ Aktivität als Feldherr zu etablieren. Doch ebenso wie die Abwesenheit des Kaisers hatte bewältigt werden müssen, stellte auch seine Rückkehr eine praktische wie kommunikative Herausforderung dar. Nachdem Konstantinopel sich über vier Jahre hinweg selbst überlassen gewesen war und anstelle des Kaisers zunehmend alternative Akteure in den Fokus der Öffentlichkeit gerückt waren, musste Herakleios nun wieder in das hauptstädtische Beziehungsgeflecht integriert werden. Der Sieg über die Perser bot sicherlich eine erfolgversprechende Basis, wenn es darum ging, diese Reintegration möglichst gewinnbringend $\mathrm{zu}$ vollziehen; doch anstatt die Modi dieses Prozesses nach Gutdünken gestalten zu können, musste sich Herakleios, wie im Folgenden deutlich wird, erneut in das enge Korsett hauptstädtischer Verhaltenserwartungen fügen. Herakleios' Rückkehr nach Konstantinopel stand im Bezug zu einer jahrhundertealten Tradition römisch-imperialer Triumphalpraxis und reagierte gleichzeitig auf spezifische Anforderungen seiner Zeit.

Der Triumph war ein Schlüsselmoment römisch-imperialer Herrschaft. Nachdem in Zeiten der Republik siegreiche Feldherren mit ihren Soldaten in Rom eingezogen

Koalition mit Herakleios eingegangen sei; dabei handelt es sich aber aller Wahrscheinlichkeit nach um ein Gerücht; vgl. etwa Flusin 1992 II, 289; Mango 1985, 107-109; Kaegi 2003, 150 -153. Zu den Bewegungen des Shahrbaraz seit dem Sommer 626 in Chalkedon siehe auch Stratos 1968, 231-234.

5 Verlesung der Siegesdepesche in der Hagia Sophia: Chron. Pasch. AD 628 (727); ebd. (734) zur Rückkehr über Armenien, so auch Act. Anast. Pers. 43.

6 Vgl. Stratos 1968, 237.

7 Eingehende Überlegungen zur Datierung siehe unten S. 256-260. 
waren, blieb der Triumph seit der Einrichtung der Alleinherrschaft durch Augustus dem Kaiser vorbehalten. Mit den strukturellen Verschiebungen, die die römische Monarchie seit dem dritten Jahrhundert durchlief, änderten sich auch die Parameter, innerhalb derer sich Siegesfeierlichkeiten entfalteten: Als die Bindung der Kaiser an die alte Hauptstadt Rom zu erodieren begann, lockerte sich sukzessive auch das Monopol Roms als Austragungsort von Triumphen. Mit der Festigung einer hauptstädtischen Konfiguration von Monarchie in Konstantinopel avancierte schließlich die neue Kapitale am Bosporus zum Kristallisationspunkt für die Zurschaustellung kaiserlicher Sieghaftigkeit. Parallel zu dieser geographischen Verlagerung ist eine Anpassung des zeremoniellen Vollzuges zu beobachten: Mit der fortschreitenden Christianisierung römischer Monarchie seit Konstantin wurde der Triumph seiner pagan-religiösen Konnotation entkleidet; der Zug durch die Stadt, als dessen Höheund Endpunkt der Jupiter-Tempel auf dem Kapitol fungiert hatte, verlor gegenüber den Feierlichkeiten im Hippodrom an Bedeutung. ${ }^{8}$ Ein entscheidender Faktor für die Entwicklung römischer Triumphalpraxis in der Spätantike war der Umstand, dass die Kaiser ab dem 5. Jahrhundert das römische Heer nicht mehr persönlich anführten, sondern dieses Geschäft ihren Generälen überließen. ${ }^{9}$ Wie ich im Kapitel 2 bereits betont habe, lag die Stabilität oströmischer Herrschaft nicht zuletzt darin begründet, dass es den Kaisern vor allem im frühen 6. Jahrhundert gelang, die von Generälen errungenen Siege konsequent auf die eigene Person zu beziehen; in Konstantinopel blieb selbst dem unkriegerischen Kaiser die Repräsentation von Sieghaftigkeit weitestgehend vorbehalten. Mit der Bindung monarchischer Herrschaft an die neue Hauptstadt wich bei Triumphen das dynamische Element des Einzuges endgültig einer Feier im Hippodrom, die sich auf den im Kathisma thronenden, statischen Kaiser ausrichtete. ${ }^{10}$ Gleichzeitig vollzog sich jedoch auch eine Ausdifferenzierung der Triumphalpraxis: Siegesfeierlichkeiten der sesshaften Kaiser wurden durch verschiedene zeremonielle Versatzstücke angereichert und mit anderen Formen öffentlicher Interaktion kombiniert, etwa liturgischen Prozessionen, sodass zunehmend auch christliche Elemente Eingang in den Vollzug fanden. ${ }^{11}$ Im frühen 7. Jahrhundert verschoben

\footnotetext{
8 Siehe dazu grundlegend McCormick 1986, 35-79. Die Entwicklung kaiserlicher Siegesfeierlichkeiten hat zuletzt Diefenbach 2019 untersucht; ein konziser Überblick findet sich ebd. 65-69; zum römischen Triumph in der Spätantike siehe auch Pfeilschifter 2016. Während Kaiser in der alten Hauptstadt Rom an eine starke Tradition gebunden waren, konnten sie Siegesfeierlichkeiten in den Provinzen und auch in der neuen Hauptstadt Konstantinopel in wesentlich höherem Maße nach ihrem Gutdünken gestalten, was zu einer Dynamisierung in der Entwicklung des Zeremoniells beitrug.

9 Siehe McCormick 1986, 47 f.; „imperial triumphal entries were now deprived of their drama”.

10 Dies wird besonders deutlich beim Vandalentriumph des Justinian, bei dem sowohl der besiegte König Gelimer als auch der General Belisar, der den Sieg errungen hatte, dem Kaiser im Kathisma ihre Ehrerbietung darbrachten; zu dem Triumph siehe, mit verschiedenen Deutungen hinsichtlich der Details, Meier 2003a, 150 -165; Börm 2013; Diefenbach 2019, 92-100; Meier 2019b.

11 Siehe McCormick 1986, 100-111 zur Christianisierung kaiserlicher Siegesfeierlichkeiten. McCormick merkt an (ebd. 111), dass spezifisch christliche Siegesfeierlichkeiten sich lange Zeit unabhängig von säkularen Zeremonien herausbildeten; zu einer Verschränkung von Siegesfeierlichkeiten und li-
} 
sich die Parameter erneut: Herakleios war nicht nur der erste oströmische Kaiser seit Theodosios I., der das Heer persönlich in den Provinzen anführte, sondern auch der erste Kaiser seit über 200 Jahren, der persönlich für einen militärischen Triumph verantwortlich zeichnete und entsprechend als Sieger nach Konstantinopel zurückkehrte. ${ }^{12}$ Herakleios' Einzug in die Hauptstadt nach über vierjähriger Abwesenheit war ein Ereignis sondergleichen. ${ }^{13}$

Um Herakleios' Reintegration ins hauptstädtische Sozialgefüge nachzuvollziehen, müssen zuerst eine Reihe an Fragen zur Rekonstruktion des Ereignisses adressiert werden. Während die Heraclias des Georg von Pisidien, soweit erhalten, den kaiserlichen Einzug nur mit einigen sehr allgemein gehaltenen Versen thematisiert, ${ }^{14}$ bieten spätere Quellen detailliertere Berichte. Laut Theophanes sammelte sich die Bevölkerung, angeführt von Sergios und dem Augustus Herakleios Konstantin, Herakleios' ältestem Sohn, am asiatischen Ufer des Bosporus, in Hiereia, um den Kaiser in Empfang zu nehmen; unter Dankeshymnen begab man sich daraufhin gemeinsam

turgischen Prozessionen sei es vor allem ab dem späten 6. Jahrhundert gekommen. Diesen Umstand betont auch Pfeilschifter 2016, der zu dem Schluss kommt, dass der römische Triumph bis ins 6. Jahrhundert einen säkularen Charakter behalten habe. Pfeilschifters Bewertung liegt allerdings eine sehr enge Definition von Triumph zugrunde, siehe ebd. 457-465, bes. 461. Eine derartig strikte Trennung zwischen Triumph, Adventus, liturgischer Prozession etc. halte ich in der Analyse der spätantiken Evidenz nicht unbedingt für zielführend. Anstatt in Triumph und Nicht-Triumph zu unterteilen, erscheint es mir vielmehr sinnvoll zu beobachten, welche zeremoniellen Versatzstücke je nach Anlass in einer bestimmten Art kombiniert wurden. Als Siegesfeierlichkeit betrachte ich dabei für die Spätantike ganz allgemein die Inszenierung eines militärischen Erfolges. Auch Diefenbach 2019 zieht, wenn ich richtig sehe, keine derart strenge Differenzierung; ebd. 63-78 lenkt er den Fokus erneut auf den Umstand, dass Siegesfeierlichkeiten bereits unter Theodosios II. mit religiösen bzw. liturgischen Elementen angereichert werden konnten: Als in Konstantinopel die Nachricht von der Niederschlagung des Usurpators Johannes eintraf, brach Theodosios die Spiele im Hippodrom ab und zog gemeinsam mit der versammelten Bevölkerung in eine der städtischen Kirchen, um zu beten (Sokr. Hist. eccl. 7.23.11f.). Dass dem öffentlichen Auftreten des Kaisers nicht nur bei Siegesfeierlichkeiten ein triumphaler Charakter innewohnte, haben McCormick 1986, 21, 95 und Diefenbach 2019, $67 \mathrm{f}$. mit Anm. 15 betont.

12 Theodosios I. war mehrfach im Nachklang eines militärischen Erfolges in Konstantinopel eingezogen. 380, nur wenige Jahre nach seiner Erhebung, feierte er einen Sieg über die Goten (Zos. 4.33.1 gibt leider nur spärliche Informationen); 386 zog er in Folge des Sieges über die Greutungen unter dem König Odotheus gemeinsam mit seinem Sohn Arkadios in die neue Hauptstadt ein (Consularia Constantinopolitana ad a. 386; Marc. Com. Chron. ad a. 386); siehe McCormick 1986, 42f. und Diefenbach 2019, 69 Anm. 17. In diesen Zusammenhang ist auch die Errichtung der Theodosios-Säule auf dem Forum Tauri einzuordnen. Es bleibt zu betonen, dass bereits der Sieg von 386 nicht vom Kaiser persönlich, sondern von dessen Magister militum Promotus errungen worden war.

13 Während seiner Regierung muss Herakleios bereits mehrfach in die Hauptstadt eingezogen sein: nach seinem missglückten Feldzug von 613 und nach der Kampagne von 622/623; davon gibt es allerdings keine Zeugnisse. Allein die Rückkehr des Kaisers nach Konstantinopel in Folge seines Aufenthaltes in Caesarea fand knappe Erwähnung in Vit. Theod. Syk. 154: Der Text erwähnt, Herakleios' Cousin Niketas sei ihm aus der Stadt entgegengeritten, um ihn zu empfangen; siehe McCormick 1986, 71 Anm. 126.

14 Georg. Pis. Heracl. 1.210 - 218, fragm. 54. 
in die Stadt. ${ }^{15}$ Während Theophanes Herakleios' Einzug in die Hauptstadt nach dem Friedensschluss mit Seiroe verortet (entsprechend 628/629), schildert Nikephoros die Rückkehr erst in Folge des kaiserlichen Abstechers nach Jerusalem, der in der Forschung in der Regel in den März 630 datiert wird: ${ }^{16}$ Mit Spielen im Hippodrom, bei denen der begeisterten Bevölkerung vier Elefanten vorgeführt wurden, habe Herakleios seinen mehrtätigen Triumph gefeiert. ${ }^{17}$

Will man diese beiden Berichte miteinander vereinbaren, so liegt die einfachste Lösung in der Annahme, dass Theophanes und Nikephoros sich auf zwei unterschiedliche Ereignisse beziehen: ${ }^{18}$ Entlang dieser These ließen sich nicht nur die konfligierenden Datierungen vereinbaren - Theophanes beschreibt einen Einzug vor, Nikephoros einen Einzug nach der Restitutio Crucis -, sondern auch der Umstand, dass die Berichte inhaltlich keinerlei Überschneidungen aufweisen. Diese Lösung halte ich allerdings für unbefriedigend. Meiner Ansicht nach beziehen sich Theophanes und Nikephoros auf dasselbe Ereignis, das in den Herbst des Jahres $628 \mathrm{zu}$ datieren ist. ${ }^{19}$ Angesichts der andauernden Bedeutung Konstantinopels für die Sicherung monarchischer Herrschaft scheint es plausibel, dass Herakleios nach seinem Erfolg im Osten schnellstmöglich in die Hauptstadt zurückkehrte; nachdem er die kaiserliche Autorität über den militärischen Sektor gefestigt hatte, galt es nun, dem hauptstädtischen Umfeld die nötige Aufmerksamkeit zukommen zu lassen. Die Feierlichkeiten mit militärischem Charakter (Präsentation der Kriegselefanten etc.), wie Nikephoros sie schildert, scheinen eine direkte Reaktion auf die Beendigung des Krieges im Jahr 628 zu sein; nach der Restitutio Crucis Jahre später hätte eine derartige Inszenierung kaum mehr Sinn ergeben. ${ }^{20}$ Die Tatsache, dass die beiden Zeugnisse sich

15 Theoph. Conf. AM 6119 (De Boor 328); vgl. Sebeos 39 (Thomson/Howard-Johnston I, 86). Theophanes' Bericht geht aller Wahrscheinlichkeit nach auf nicht erhaltene Verse des Georg von Pisidien zurück. Pertusi 1959, 292, 307 geht davon aus, dass er Teil des dritten Akroasis der Heraclias war; vgl. Mango/Scott 1997, 457 f.; siehe auch Meier 2015, 187. Ein Teil des Berichtes wurde oben bereits diskutiert S. $239 \mathrm{f}$.

16 Zur Datierung der Restitutio Crucis siehe unten S. 264 Anm. 43. Nik. Brev. 18 beendet seinen Bericht der Restitutio Crucis indes mit dem Zusatz, dass dies in der zweiten Indiktion (628/9) geschehen sei; darauf basiert der Eintrag in der Suda (Adler II, 582). Folgt man der fundierten Annahme, dass die Restitutio Crucis am 21. März 630 vollzogen wurde, kann diese Angabe nicht stimmen; doch anstatt hier einen Fehler bei der Indiktions-Zahl zu vermuten, könnte man die zweite Indiktion auch auf Herakleios' Einzug in Konstantinopel beziehen, der (ohne weitere Datums-Angabe) in direkter Folge darauf (Brev. 19) behandelt wird.

17 Nik. Brev. 19.

18 Diese Lösung wählt Kaegi 2003, 185f., 215 ohne weitere Diskussion; vgl. Mango 1990, 186.

19 Von einer raschen Rückkehr nach Konstantinopel gehen auch Stratos 1968, 239f. und HowardJohnston 1999, 26 aus. Ein in Herakleios' Namen veröffentlichtes Gesetz vom 21. März 629 könnte als Indiz dafür gelesen werden, dass der Kaiser sich zu diesem Zeitpunkt in der Hauptstadt aufhielt, so etwa Pertusi 1959, 234 und Konidaris 1982, 58-60. Laut Zuckerman 2013, 203 zog Herakleios erst im September 629 in Konstantinopel ein.

20 Dazu kommt, dass Herakleios sich nach seinem Aufenthalt in Jerusalem nicht direkt wieder nach Konstantinopel begab, sondern sich im Osten religionspolitischen Angelegenheiten widmete; siehe 
inhaltlich kaum überschneiden, lässt sich aus dem Umstand erklären, dass Theophanes und Nikephoros (bzw. ihre Quellen) den Fokus ihres jeweiligen Berichtes auf unterschiedliche Aspekte von Herakleios’ Rückkehr lenken. Diese Beobachtung trägt nicht zuletzt auch zum Verständnis der Inszenierung bei, die sich aus zwei nur lose miteinander verbundenen Sequenzen zusammensetzte: Empfang und Einzug einerseits, Hippodromspiele andererseits.

Der Empfang in Hiereia stand in der Tradition des Adventus-Zeremoniells, des kaiserlichen Einzuges in eine Stadt, das keinen per se militärischen Hintergrund hatte. ${ }^{21}$ Wie bereits Justinians Einzug des Jahres 559 - nach einer persönlichen Inspektion der Langen Mauern in Thrakien kehrte der Kaiser nach Konstantinopel zurück $^{22}$ - wurde auch Herakleios' Adventus von 628 stattdessen explizit religiös aufgeladen: Die Sequenz, im Zuge derer die städtische Bevölkerung Herakleios in Empfang nahm und vom militärisch konnotierten Äußeren in den zivilen Raum der Hauptstadt überführte, wurde mit Elementen liturgischer Prozessionen angereichert (Olivenzweige und Lichter, Dankeshymnen an Gott), wie sie im städtischen Raum Konstantinopels auch unter Teilnahme der Kaiser bereits über Jahrhunderte praktiziert worden waren. ${ }^{23}$ Neben dem ältesten Sohn des Kaisers, Herakleios Konstantin, der mit seinem Kniefall vorm Vater die dynastische Komponente der herakleischen Herrschaft demonstrierte, kam dem Patriarchen Sergios dabei eine herausgehobene Stellung zu. Indem schließlich auch Vertretern der Bevölkerung eine aktive Funktion zugewiesen wurde, demonstrierte die Sequenz gleichsam die Einheit des hauptstäd-

Mango 1990, 186 und die ausführliche Rekonstruktion unten S. 283-286. Entsprechend erachte ich die Chronologie des Nikephoros für falsch; dass die relativen Datierungen im Breviarium mit Vorsicht zu genießen sind, wurde bereits betont.

21 Pfeilschifter 2016, $475 \mathrm{f}$. betont, dass das Adventus-Zeremoniell sich besonders dafür eignete, in einen spezifisch christlichen Kontext eingepasst zu werden; vgl. zu Herakleios’ Adventus MacCormack 1981, 86 - 89, die allerdings nicht zwischen den zwei Phasen des Zeremoniells (1. Einzug; 2. Feierlichkeiten in der Stadt) unterscheidet. Zum Adventus allgemein siehe MacCormack 1972.

22 Ein ausführlicher Bericht dieses Einzuges findet sich in De cerim. 1 App. (Reiske 497 f.): Nachdem er die Stadt durch das Charision-Tor betreten hatte, begab sich Justinian zum Gebet in die Apostel-Kirche; auf der Mese erwarteten ihn Vertreter der Bevölkerung mit einem Kerzen-Spalier. Als der Kaiser den Palast betrat, wurde er mit triumphalen Akklamationen empfangen; siehe dazu McCormick 1986, 67; Leppin 2011, 321f. Der Unterschied zum Einzug von 628 besteht darin, dass das Treffen mit der hauptstädtischen Bevölkerung sich bei Herakleios' Einzug außerhalb der Stadt vollzog, sodass das Element des Überführens vom militärisch konnotierten Äußeren ins zivile Innere der Stadt noch stärker betont wurde. Hinsichtlich Justinians Einzug ist bemerkenswert, dass Theoph. Conf. AM 6051 (De Boor 234) zwar dessen Aktivität an den Langen Mauern, nicht aber die Details seiner Rückkehr erwähnt, wie sie das Zeremonienbuch wiedergibt; ähnlich wie bei Herakleios' Rückkehr sieht man also auch hier, dass verschiedene Überlieferungslinien den Fokus auf jeweils spezifische Aspekte des Geschehens lenken können.

23 McCormick 1986, 72; zur Herausbildung eines städtischen Zeremoniells und den Positionierungsund Repräsentationsmöglichkeiten des Kaisers innerhalb dieses Zeremoniells siehe Diefenbach 1996, bes. 43 - 52. Darüber, auf welchem Wege genau Herakleios sich in die Stadt begab, ob er etwa auf dem Weg in Kirchen Halt machte, geben die Quellen leider keine Auskunft. 
tischen Sozialgefüges: Herakleios’ Rückkehr wurde zum Moment städtischer Selbstvergewisserung. ${ }^{24}$

Das vorige Kapitel hat deutlich gemacht, wie der Krieg gegen die Perser im Allgemeinen und Herakleios’ Aktivität als Feldherr im Speziellen im hauptstädtischen Diskurs in einen religiösen Deutungszusammenhang eingepasst wurden. Diese Deutung konnte auch auf den Moment des Sieges übertragen werden: Theophanes - aller Wahrscheinlichkeit nach in Rückgriff auf Georg von Pisidien - beschreibt Herakleios' Rückkehr analog zum siebten Tag der göttlichen Schöpfung, dem Tag der Rast. ${ }^{25}$ In der Gestaltung von Herakleios' Einzug, soweit dieser sich aus Theophanes' Chronographie rekonstruieren lässt, war die religiöse Deutung zumindest in Grundzügen bereits praktisch angelegt. Was Georg von Pisidien kurz darauf in der Heraclias in Worte fasste - die Transformation vom schwitzenden Kaiser zum erhabenen Lichtwesen -, äußerte sich also bereits im Zeremoniell, im Zuge dessen der kriegführende Kaiser nach langer Abwesenheit in das Beziehungsgeflecht der Hauptstadt reintegriert wurde.

Innerhalb der Stadtmauern entfaltete sich daraufhin eine Sequenz, die sich - zumindest soweit sich dies aus Nikephoros' Bericht erschließen lässt - aus einem anderen Referenzrahmen speiste. Anstelle des religiösen Charakters überwogen nun Versatzstücke, die einer säkularen Triumphalpraxis entstammten, wie sie sich im konstantinopolitaner Kontext ab dem 4. Jahrhundert herausgebildet hatte. Die andächtige Stimmung, welche beim Aufeinandertreffen in Hiereia geherrscht hatte, wich nun einer typisch triumphalistischen Konfrontation: Mit Akklamationen begrüßten die Städter ihren Kaiser, der seinerseits Geldspenden verteilte und die Rückerstattung des Kirchenvermögens anordnete, das er zur Finanzierung des Krieges eingezogen hatte. ${ }^{26}$ Mittelpunkt der mehrtätigen Feierlichkeiten war der Hippodrom, der sich in den Jahrhunderten hauptstädtischer Monarchie als Kristallisationspunkt der Repräsentation kaiserlicher Sieghaftigkeit herausgestellt hatte. ${ }^{27}$ Über die Ausgestaltung der Spiele gibt Nikephoros nur unzureichend Auskunft. Es scheint jedoch plausibel, dass Herakleios gemäß der Tradition hauptstädtischer Siegesfeierlichkeiten - im Kathisma thronte, wo

24 Vgl. Diefenbach 1996, 49f., der in Bezug auf das 5. Jahrhundert den Adventus (sowohl den des Kaisers als auch das Empfangen von Reliquien) als identitätsstiftendes Moment für die städtische Gemeinschaft beschreibt.

25 Siehe dazu oben S. 240.

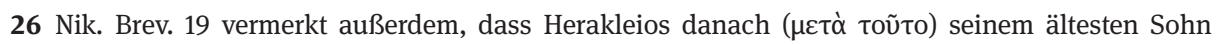
Herakleios Konstantin den Konsulat übertragen und Heraklonas, seinen Sohn aus der Ehe mit Martina, zum Caesar erhoben habe. Diese Erhebung fand nachweisbar 632 statt; siehe Mango/Scott 1997, 433 Anm. 2. Dass Nikephoros die Erhebung in direkte Verbindung mit den Siegesfeierlichkeiten setzt, könnte als Argument gegen meine Datierung der Siegesfeierlichkeiten ins Jahr 628 genutzt werden. Dennoch halte ich an der These fest, da Nikephoros wiederholt Ungenauigkeiten in der relativen Chronologie aufweist. Nach der Notiz von der Erhebung seiner Söhne durch Herakleios fährt Brev. 20 mit dem Bericht über die Eroberungen der Araber fort.

27 Auf die andauernde Bedeutung des Hippodroms habe ich bereits im Zusammenhang mit den erweiterten Krönungsritualen im frühen 7. Jahrhundert hingewiesen; dazu siehe oben S. $122 \mathrm{f}$. 
er die Huldigungen der Bevölkerung entgegennahm und die Spiele überwachte. Aus der Position des Feldherrn rückte er nun wieder in die typische Rolle der hauptstädtischen Kaiser: die des entrückten Siegers. Die vier Elefanten, die durch den Hippodrom geführt wurden, scheinen als Zurschaustellung von Beute indes im Vergleich zu dem spektakulärsten Triumph des 6. Jahrhunderts, dem Vandalentriumph unter Justinian, eher mager. Nach dem Sieg über die Perser - oder genauer gesagt: dem Friedensvertrag mit Chosroes' Nachfolger Kavadh Seiroe - ließen sich in Konstantinopel kaum Spolien vorzeigen. Während Justinian nach einem Erfolg gegen die Perser, errungen von seinen Generälen, im Stadtbild durch mehrere Reiterstatuen als Sieger verewigt worden war, ${ }^{28}$ blieb dergleichen unter Herakleios offenbar aus. ${ }^{29}$

Für Herakleios’ Rückkehr nach langjähriger Abwesenheit, mit einem Persersieg im Rücken, gab es im Konstantinopel des frühen 7. Jahrhunderts keinen Präzedenzfall. Die Strukturen, die die kaiserliche Repräsentation im öffentlichen Raum ebenso wie die Interaktion mit der Bevölkerung bedingten, waren durch Jahrhunderte sesshafter Kaiser geformt worden. Als die Position des Kaisers und die des Feldherrn unter Herakleios wieder in einer Person zusammenfielen, bestand die Herausforderung darin, diese Personalunion im Zeremoniell nicht nur sichtbar, sondern auch im Sinne einer Stabilisierung von Herrschaft nutzbar zu machen. Seine Wiedereingliederung in die Hauptstadt erfolgte durch ein hybrides Ritual, das die zwei Hauptsequenzen - Empfang/Einzug und Siegesfeier, jeweils gespeist aus distinkten Referenzrahmen - nur lose aneinanderreihte, anstatt sie organisch zu verschränken. Während Georg von Pisidien den Kaiser im panegyrischen Diskurs zum Feldherrn des kosmischen Geburtstages hochloben konnte, ${ }^{30}$ war Herakleios' praktischer Handlungsspielraum im normativ regulierten Umfeld der Hauptstadt weiterhin beschränkt. Die traditionell anmutenden Feierlichkeiten im Hippodrom kamen dem Bedürfnis des städtischen Umfeldes nach derartigen Inszenierungen nach; dabei entsteht der Eindruck, dass Herakleios seinen persönlich erfochtenen, militärischen Erfolg in Konstantinopel nur in Maßen ausleben konnte, was nicht zuletzt daran gelegen haben mag, dass die Strukturen einer hauptstädtischen Monarchie kaum Platz für den kriegführenden Kaiser boten. Einige Jahre später sollte Herakleios jedoch einen weiteren Triumph feiern - in einem Umfeld, das weit weniger als die Hauptstadt von Verhaltenserwartungen an den Kaiser geformt war. ${ }^{31}$

28 Dazu siehe oben S. 69 Anm. 179.

29 Vgl. McCormick 1986, 71f. und Pfeilschifter 2013, 475 zu Herakleios’ Rückkehr; letzterer misst allerdings der Adventus-Sequenz wesentlich größere Bedeutung zu als den Feierlichkeiten innerhalb der Stadt.

30 Dazu siehe oben S. 240 - 242. Hierin zeigt sich erneut der Wert der Panegyrik, die zu einem gewissen Grad im Diskurs kompensiert, was in der Praxis nur schwerlich umsetzbar war.

31 In diesem Zusammenhang bedanke ich mich für Anregungen von Johannes Wienand, der seine Arbeit zu Herakleios bislang noch nicht veröffentlicht hat. 


\subsubsection{Herakleios in Jerusalem - die Restitutio Crucis}

Während Herakleios in heimatliches Gebiet zurückkehrte, nahmen die Unruhen um die Besetzung des persischen Thrones eine neue Wendung: Nur acht Monate nach seiner Erhebung verstarb Seiroe und wurde von seinem minderjährigen Sohn Ardashir beerbt. ${ }^{32}$ Die Regierung in Ctesiphon hatte sich bereits zuvor bei der Kontrolle des versprengten persischen Heeres als quasi handlungsunfähig erwiesen; die Reichweite der Zentralmacht war massiv geschwächt. Dass sich dies unter Ardashir grundlegend ändern würde, war kaum abzusehen. Wollte Herakleios seine Anliegen - die endgültige Räumung der römischen Ostprovinzen durch die Besatzer - umgesetzt sehen und weitere militärische Konfrontation vermeiden, musste er sich auf eine Kooperation mit Shahrbaraz einlassen, der auf Seiten der Perser über die entscheidenden Ressourcen verfügte. Gesandtschaften zwischen Herakleios und dem General wurden ausgetauscht; beide zeigten sich für eine Zusammenarbeit offen und die persischen Truppen begannen tatsächlich mit dem Rückzug. ${ }^{33}$ In diesem Zusammenhang machte Herakleios sich erneut auf den Weg in den Osten.

Im Kapitel 4 wurden die Gründe für Herakleios’ Bruch mit etablierter monarchischer Verhaltenspraxis herausgearbeitet. Dass er als erster Kaiser seit über zweihundert Jahren Konstantinopel verließ, um an der Spitze der römischen Truppen in den Krieg zu ziehen, resultierte aus zwei miteinander verschränkten Entwicklungen: der außenpolitischen Bedrohung durch die Perser einerseits und dem Umstand andererseits, dass es im frühen 7. Jahrhundert verstärkt zu Unruhen und Ermächtigungsversuchen aus dem militärischen Sektor kam. Das hauptstädtische Umfeld bot dem sesshaften Kaiser offenbar nicht mehr die nötigen Ressourcen, um interne Konkurrenz einzuhegen. Um seine Herrschaft zu sichern, war Herakleios darum bemüht, die kaiserliche Autorität über den militärischen Sektor - und damit einhergehend auch die Stabilität seiner Position in Konstantinopel - zu sichern. Als die Perser 628 tatsächlich bezwungen werden konnten, sanktionierte der Erfolg Herakleios' transgressive Maßnahme gegenüber dem hauptstädtischen Umfeld. Doch obwohl der akute militärische Konflikt vorerst beigelegt war, blieb der Kaiser auch nach seiner triumphalen Rückkehr nicht in Konstantinopel.

Dass Herakleios die Hauptstadt erneut verließ, zieht zwei Schlussfolgerungen nach sich: einerseits in Hinblick auf die Möglichkeit dieser Maßnahme, andererseits in Hinblick auf die zugrundeliegende Intention. Herakleios' Abkehr von Konstantinopel war in den 620er Jahren gegenüber der dortigen Öffentlichkeit mit der Notwendigkeit seines persönlichen Engagements im Perserkrieg plausibilisiert worden; eine derartige Rechtfertigung gab es nach dem Friedensschluss nicht mehr. Herakleios indes hatte mit seiner Politik einen Paradigmenwechsel eingeleitet und dem hauptstädti-

$32 \mathrm{Zu}$ der sassanidischen Thronfolge siehe Bonner 2019, 313-317.

33 Zum Tod des Seiroe siehe etwas Sebeos 40 (Thomson/Howard-Johnston I, 87 f.) mit Kommentar bei Thomson/Howard-Johnston 1999 II, 222f. und Chron. 1234, 103 (Chabot I, 186); vgl. Flusin 1992 II, 289; Howard-Johnston 1999, 27 f.; Kaegi 2003, 184 f. 
schen Umfeld ein erweitertes Maß an Handlungsspielraum abgerungen; die enge physische Bindung des Monarchen an Konstantinopel, die das 5. und 6. Jahrhundert geprägt hatte, war gelockert und wich langsam aber sicher neuen Standards. Der Kaiser konnte es sich leisten, der Hauptstadt erneut den Rücken zuzukehren. Doch warum machte Herakleios von diesem erweiterten Handlungsspielraum Gebrauch, anstatt sich nach seinem Triumph in der Hauptstadt zur Ruhe zu setzen? Geht man davon aus, dass die grundsätzliche Motivation hinter politischen Entscheidungen des Kaisers in Machterhalt und Sicherung der Herrschaft lag - welche Folgen ein Akzeptanzentzug haben konnte, hatten die gewaltsamen Machtwechsel von 602 und 610 allzu deutlich gezeigt -, eröffnet sich folgende Erklärung: Selbst der Sieg über die Perser konnte Herakleios nicht gegen potentielle Kritiker und Herausforderer immunisieren; er musste sich weiterhin um die Sicherung seiner Position bemühen. ${ }^{34}$

Nach ersten Annäherungen zwischen Herakleios und Shahrbaraz kam es im Sommer des Jahres 629 zu einem persönlichen Treffen der beiden Männer in Arabissos im Anti-Taurus. Bei den dort stattfindenden Verhandlungen konnte eine formale Einigung erreicht werden: Herakleios würde Shahrbaraz bei dessen Griff nach dem persischen Thron unterstützen; Shahrbaraz seinerseits willigte ein, alle Gebiete diesseits des Euphrats zu räumen. ${ }^{35}$ Wie bereits einige Jahre zuvor, als es um eine römische Allianz mit dem türkischen Khagan gegangen war, unterfütterten die beiden Machthaber ihren Pakt auch nun mit der Aussicht auf eine familiäre Verbindung: Shahrbaraz' Sohn Niketas wurde in den Rang eines Patrikios erhoben und seine Tochter Nike mit einem von Herakleios' Söhnen aus zweiter Ehe, Theodosios, verlobt. ${ }^{36}$ Abgesehen von der Gebietsfrage erwies sich in Arabissos jedoch ein weiteres römisches Anliegen als zentral: die Forderung nach der Rückgabe des Heiligen Kreuzes, welches nach der Eroberung Jerusalems 614 von Shahrbaraz nach Ctesiphon verschleppt worden war.

Die Eroberung Jerusalems durch die Perser und die Deportation der Kreuzreliquie aus der Anastasis-Kirche nach Ctesiphon hatten Schockwellen durch den gesamten christlichen Mittelmeerraum gesandt. Welches Schicksal genau der umkämpften Reliquie in persischen Händen widerfuhr, ist angesichts einer legendenhaften Aus-

34 Dass selbst ein prestigeträchtiger Sieg über die Perser den Kaiser in Konstantinopel nicht grundsätzlich absichern konnte, zeigt bereits die Regierung Justinians: Nur wenige Jahre, nachdem er den Sieg Belisars über die Perser von 530 in der Hauptstadt hatte auf die eigene Person beziehen können, brach der Nika-Aufstand aus (532), der ihn beinahe den Thron kostete.

35 Siehe Sebeos 40 (Thomson/Howard-Johnston I, 87f.) mit Kommentar bei Thomson/HowardJohnston 1999 II, 223f. (ebd. zur Grenzziehung entlang des Euphrats) und für die Datierung Chron. 724 in Palmer 1993, 18, wo auch berichtet wird, dass die beiden Männer anlässlich des Paktes eine der Eirene geweihte Kirche errichteten.

36 Nik. Brev. 17 ist die einzige Quelle für diese familiäre Bindung; vgl. Mango 1985, 105f. Im Gegensatz zu Sebeos 40 (Thomson/Howard-Johnston I, 87 f.) geht hier die Initiative für ein Treffen von einem unterwürfigen Shahrbaraz aus. Zum Treffen in Arabissos siehe Mango 1985, 110-112; Flusin 1992 II, 288-291; vgl. auch Stratos 1968, 245-248; Kaegi 2003, 187-189 zuletzt Booth 2019, 781-784, 823 auch zu den Gründen für die Ortswahl. 
schmückung durch die Quellen kaum zu rekonstruieren. ${ }^{37}$ Im Zusammenhang mit der byzantinischen Offensive gegen die persischen Aggressoren ab 622 scheint die Rückgewinnung des Heiligen Kreuzes den öffentlichen Diskurs noch nicht bestimmt zu haben; ${ }^{38}$ erst nachdem Herakleios die Perser hatte bezwingen können, trat das Kreuz wieder auf die öffentliche Agenda. Wann genau die Reliquie zur konkreten Verhandlungssache wurde - ob bereits im Frühjahr des Jahres 628 oder erst im Sommer 629, im Zuge des Treffens zwischen Herakleios und Shahrbaraz -, lässt sich indes angesichts einer teils diffusen Überlieferung schwer bestimmen. ${ }^{39}$ Das innenpolitische Chaos, in dem das persische Reich nach der Ermordung des Chosroes II. versank, machte eine rasche Rückerstattung jedenfalls vorerst nicht möglich. Erst mit der Allianz zwischen Herakleios und Shahrbaraz geriet die Angelegenheit in Bewegung.

Mit römischen Hilfstruppen konnte Shahrbaraz tatsächlich Ctesiphon einnehmen und den minderjährigen Vertreter der sassanidischen Dynastie, den Großkönig Ardashir, überwältigen. ${ }^{40}$ Auch Shahrbaraz hielt seinen Teil der Abmachung ein: Das Heilige Kreuz wurde dem römischen General David übergeben, der es im nordsyrischen Hierapolis wiederum Herakleios persönlich aushändigte. ${ }^{41}$ Aufregung und Euphorie griffen um sich, als Herakleios sich mit der Reliquie und großem Gefolge in

37 Zum Kreuz in Persien siehe Payne 2015, 177-180. Mir geht es an dieser Stelle nicht um die Frage, ob es sich bei dem Objekt, das Herakleios übergeben wurde, tatsächlich um die Reliquie aus der Anastasis-Kirche handelte; entscheidend ist vielmehr, dass die Zeitgenossen daran glaubten, dass es sich so verhielt; vgl. dazu die kritische Bewertung bei Zuckerman 2013, bes. 216-218.

38 Keine der Quellen, die Herakleios' Konter-Offensive vor dem Sieg über die Perser thematisiert, erwähnt das Kreuz; siehe Drijvers 2002, 182.

39 Laut Nik. Brev. 15 forderte Herakleios die Kreuz-Reliquie bereits bei den Verhandlungen mit Seiroe zurück; die Notiz bei Theoph. Conf. AM 6118 (De Boor 327), Seiroe habe Herakleios die Kreuzreliquie ausgehändigt, ist offenkundig falsch. Bei Sebeos 40 (Thomson/Howard-Johnston I, 88) wird die Rückgabe des Kreuzes zwischen Herakleios und Shahrbaraz verhandelt; ähnlich in Chron. 1234, 103 (Chabot I, 186).

40 Gemäß al-Tabari wurde der junge Ardashir am 27. April 630 ermordet; die Eroberung Ctesiphons durch Shahrbaraz und die Rückgabe des Kreuzes erfolgten allerdings schon früher; siehe Flusin 1992 II, 297, 306-309.

41 Ant. Strateg. (Conybeare 516); Anon. Guidi (Nöldeke 31f.); Chron. Seert (Scher 556); Mich. Syr. 11.7 (Chabot II, 427); die Angabe bei Theoph. Conf. AM 6118 (De Boor 327), dass das Kreuz bereits durch Seiroe zurückgegeben wurde, ist nicht authentisch; siehe dazu Flusin 1992 II, 295-297 und Stratos 1968, 248-250, 384-387. Chron. 1234, 103 (Chabot I, 186) beschreibt die Ankunft der Reliquie in Hierapolis besonders detailliert: „Heraclius came out from Mabbugh to greet the Cross on its arrival and he took possession of it with due solemnity" (übers. in Palmer 1993, 142). Das Empfangen der Reliquie durch Herakleios erinnert an die Reliquientranslationen nach Konstantinopel, bei denen das heilige Objekt von Kaiser und Bevölkerung in die Stadt überführt wurde; dazu siehe Diefenbach 2002. Zuletzt haben Klein 2001, Zuckerman 2013 (besonders ausführlich) und Booth 2014, 155f. dafür argumentiert, dass das Kreuz zuerst nach Konstantinopel gebracht wurde, wo es am 14. Sept. 629 in der Hagia Sophia erhöht wurde, bevor Herakleios mit der Reliquie nach Jerusalem aufbrach; damit folgen sie in Teilen Theoph. Conf. AM 6120 (De Boor 328). Man würde allerdings meinen, dass etwa Georg. Pis. eine längere Präsenz des Kreuzes in der Hauptstadt, zumindest in seinem Gedicht In Restitutionem S. Crucis, kommentiert hätte. Ich halte diese These daher nicht für plausibel. 
Richtung Jerusalem in Bewegung setzte. ${ }^{42}$ Die christliche Bevölkerung Palästinas war sich der Außerordentlichkeit dessen bewusst, was sich im Frühjahr des Jahres 630 vor ihren Augen abspielte: Die bedeutendste christliche Reliquie, die von ihrer legendären Auffindung durch Konstantins Mutter Helena bis zum Raub durch die Perser in der Jerusalemer Grabeskirche aufbewahrt worden war, fand nun - nach beinahe 15-jährigem babylonischem Exil - an ihren angestammten Ort zurück. Und mehr noch: Mit Herakleios betrat zum ersten Mal überhaupt ein christlicher Kaiser persönlich die Heilige Stadt; am 21. März 630 zog er mit dem Heiligen Kreuz in Jerusalem ein. ${ }^{43}$ Der anonyme Autor der Translatio corporis Sancti Anastasii Persae, aller Wahrscheinlichkeit nach selbst ein Augenzeuge, bringt den epochalen Charakter dieses Ereignisses besonders gut zum Ausdruck. ${ }^{44}$

„Denn es geschah etwas, das noch nie zuvor geschehen war. Keiner der christlichen Kaiser ist nämlich seit Menschengedenken je nach Jerusalem gekommen. Allein unser sanftmütigster und

42 Theoph Conf. AM 6120 (De Boor 328) und Eutychios (Breydy 108f.) berichten, Herakleios habe auf seinem Weg in Tiberias Halt gemacht und dort Mitglieder der jüdischen Gemeinde getroffen; nach versöhnlichen Gesten sollten die Spannungen zwischen jüdischer und christlicher Bevölkerung später allerdings erneut eskalieren; zu der Rekonstruktion von Herakleios' Itinerar nach der Übergabe des Kreuzes siehe auch Flusin 1992 II, 309-311.

43 Vor allem das Jahr der Restitutio Crucis ist umstritten: 628, 629, 630 und 631 stehen zur Debatte, wobei in der Forschung in der Regel der 21. März 630 akzeptiert wird. Eine besonders eingehende Rekonstruktion findet sich bei Flusin 1992 II, 293-309; siehe außerdem Baynes 1912a; Frolow 1953; Stratos 1968, 384-387; Pertusi 1959, 235f.; Grumel 1966. Speck 2000 datiert die Rückführung des Kreuzes bereits ins Jahr 628 (mit Verweis auf seine ausführlichere Untersuchung in ders. 1988, 327378), was allerdings der Logik des Ereignisverlaufes und auch der Evidenz der Quellen widerspricht. Vgl. außerdem Zuckerman 2013 (bes. 197 f.), der sich mit elaborierter Argumentation und Berücksichtigung aller Quellen dafür ausspricht, dass das Kreuz zweimal nach Jerusalem gebracht wurde: die erste Restitutio am 21. März 629, daraufhin Präsentation in Konstantinopel, dann erneute Rückführung nach Jerusalem am 30. März 630. Kern dieser Argumentation ist allerdings, dass Shahrbaraz Herakleios eine (gefälschte) Kreuzreliquie übergab, noch bevor er von Ägypten nach Persien zurückkehrte, um die Herrschaft in Ctesiphon zu übernehmen. Ich halte dies für zu konstruiert. Die meiner Ansicht nach überzeugende Datierung auf den 21. März 630 leitet sich aus folgenden Quellen ab: Die Transl. Anast. Pers. 1 gibt für Herakleios' Einzug in Jerusalem die dritte Indiktion (1. Sept. 629 - 31. Aug. 630) und sein 20. Regierungsjahr an (Okt. 629-630); Ant. Strateg. (Conybeare 516) nennt als Datum den 21. März, allerdings ist hier die Jahresangabe problematisch: Es wird zwar ebenfalls die dritte Indiktion, allerdings das 21. Regierungsjahr des Herakeios genannt, also 631. Der 21. März 630 wird durch Georg. Pis. Rest. Cruc. 104-116 untermauert, wo erwähnt wird, dass die Nachricht von der Rückerstattung am Feiertag des Lazarus in Konstantinopel eingetrafen - im Jahr 630 fiel dieser Feiertag auf den 31. März (abhängig von Ostern, 8. April 630): Die Reisezeit von zehn Tagen zwischen Jerusalem und Konstantinopel ist für einen Eilboten durchaus realistisch. In den Jahren 628 und 631 lag Ostern derart früh, dass eine Ankunft der Nachricht in der Hauptstadt am Feiertag des Lazarus nicht mit der Rückerstattung am 21. März überein gebracht werden kann; höchstens 629 steht damit noch zur Debatte (Ostern 16. April).

44 Der Text entstand kurz nach der Translatio der Gebeine des Heiligen Anastasios in ein nahe Jerusalem gelegenes Kloster; siehe dazu Flusin 1992 I, $95 \mathrm{f}$. 
über alle Maßen frommer Kaiser wohnte uns bei zusammen mit dem lebensstiftenden Kreuz des Heilands in der dritten Indiktion und dem zwanzigsten Jahr seiner Herrschaft.“ ${ }^{*} 45$

Im Zuge der Christianisierung römischer Monarchie rückte Jerusalem als der Ort von Tod und Auferstehung Christi zunehmend in den Fokus kaiserlicher Politik. Mit dem Bau der Anastasis-Kirche über Golgatha und dem Grab Christi hatte bereits Konstantin I. das „neue Jerusalem (...) gegenüber dem altberühmten“, dem Jüdischen, an das der leere Tempelberg stets gemahnte, begründet. ${ }^{46}$ Die Anastasis-Kirche beherbergte nicht zuletzt auch die Überreste des Kreuzes, um dessen Auffindung sich mehrere Legenden rankten: Gemäß eines Überlieferungsstranges zeichnete Helena, die Mutter Konstantins, persönlich dafür verantwortlich. ${ }^{47}$ Auch im 5. und 6. Jahrhundert rissen kaiserliche Zuwendungen an Jerusalem nicht ab: Unter Justinian gipfelte derartiges Engagement im monumentalen Ausbau des Stadtzentrums, das mit der Nea-Kirche einen weiteren, symbolträchtigen Kultort gewann. ${ }^{48}$ Doch während Mitglieder der kaiserlichen Familie teilweise gar längerfristig in Jerusalem residierten, hatte bis ins Jahr 630 - wie der Autor der Translatio ganz treffend anmerkt - kein christlicher Kaiser persönlich den Fuß in die Heilige Stadt gesetzt; Herakleios war der erste. „Größte Freude und unbeschreiblicher Frohsinn ergriff die fernsten Winkel der Erde“449 - so die Reaktionen gemäß der Translatio.

Die spektakuläre Restitutio Crucis, die nicht nur Zeitgenossen in ihren Bann zog, ist der in der Forschung wohl meistbeachtete Aspekt von Herakleios' Herrschaft. Um nachzuvollziehen, welches politische Ziel der Kaiser mit seiner Reise nach Jerusalem verfolgte, werde ich mich sowohl um die Rekonstruktion des Ereignisses bemühen als auch die Frage adressieren, wie die Restitutio in verschiedenen Kontexten kommuniziert und gedeutet wurde. Dabei komme ich nicht umhin, auch die bisherige Forschung einer Revision zu unterziehen.

Wie bereits die Rückkehr des Herakleios nach Konstantinopel, so wurde auch der kaiserliche Einzug in Jerusalem - folgt man dem Bericht des Sebeos ${ }^{50}$ - als AdventusRitual vollzogen. ${ }^{51}$ Gemeinsam mit dem römischen Heer und dem kaiserlichen Gefolge

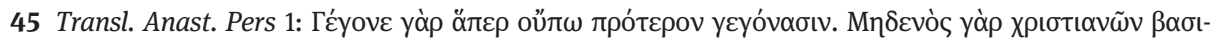

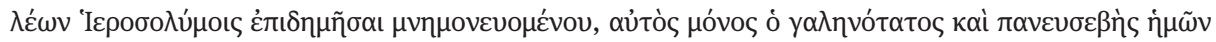

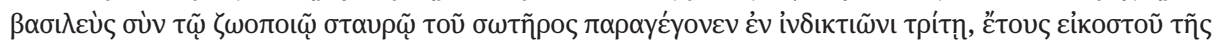

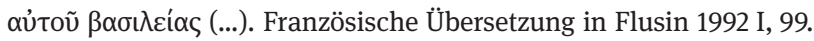

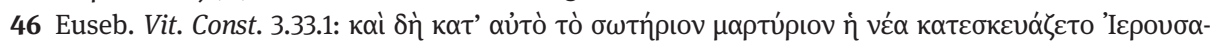

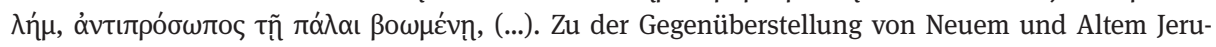
salem, wie sie sich im Bau der Anastasis-Kirche äußert, siehe Ousterhout 1990; Wilken 1992, 82-100. 47 Zur Auffindung des Kreuzes und der legendarischen Ausgestaltung siehe ausführlich Borgehammar 1991; Drijvers 1992; zusammenfassend Drijvers 2002, 179-181.

48 Diesen Prozess betrachtet Trampedach 2001 und ders. (im Druck); ders. 2015 zur Nea-Kirche Justinians; siehe allgemein auch die Beiträge des Sammelbandes Wienand/Klein (im Druck).

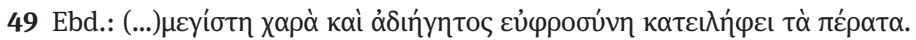

50 Sebeos 41 (Thomson/Howard-Johnston I, 90).

51 Vgl. Drijvers 2002, 185f.; Booth 2013a, 9 f. 
näherten Herakleios und seine Ehefrau Martina sich der Heiligen Stadt; ${ }^{52}$ die Bewohner Jerusalems empfingen das kaiserliche Paar und das Kreuz voller Ehrfurcht. So überwältigt sei die Menschenmenge gewesen, dass vor lauter Emotionen noch nicht einmal die liturgischen Hymnen gesungen werden konnten. ${ }^{53}$ Herakleios verteilte Almosen an die Menschenmenge ebenso wie an die Kirche; neben der Kreuzreliquie erstattete er auch weitere heilige Objekte zurück, die Jahre zuvor angesichts der persischen Eroberung in Sicherheit gebracht worden waren. ${ }^{54}$ In der Stadt traf Herakleios auf Modestos, der anstelle des im Exil verstorbenen Patriarchen Zacharias der Jerusalemer Kirche vorstand. Als der Kaiser das Kreuz dem versammelten Klerus präsentierte, konnte vor aller Augen die Unversehrtheit des Reliquiars und seines kostbaren Inhaltes bestätigt werden. ${ }^{55}$ Mit einer derartigen Inszenierung wurde nicht nur die Rückerstattung in die Anastasis-Kirche besiegelt, sondern auch die Authentizität der Reliquie - und nicht zuletzt die Validität von Herakleios' Restitution - nach den ungewissen Jahren in Persien öffentlich sanktioniert. ${ }^{56}$

Während die griechischen bzw. nahöstlichen Quellen keine weiteren Details zu Herakleios' Einzug in Jerusalem preisgeben, beruft sich die Forschung gerne auf eine lateinische Überlieferungstradition, ${ }^{57}$ die zuletzt von Stephan Borgehammar einer eingehenden Analyse und historischen Kontextualisierung unterzogen wurde. Als älteste Evidenz für diese lateinische Tradition identifiziert Borgehammar zwei liturgische Texte, die Reversio Sanctae Crucis und die Exaltatio Sanctae Crucis, die mit dem

52 Die Präsenz Martinas wird Ant. Strateg. (Conybeare, 516) entnommen; laut Sebeos 41 (Thomson/ Howard-Johnston I, 90) befanden sich auch die „Prinzen“ in Herakleios’ Gefolge. Dabei handelte es sich wohl um Kinder von Herakleios und Martina; Herakleios’ältester Sohn, der Augustus Herakleios Konstantin, war sicherlich als Vertreter des Vaters in Konstantinopel geblieben.

53 Das Weinen und Beten beim Einzug in Jerusalem schildert auch Georg. Pis. Rest. Cruc. 27-29. 54 Sebeos 41 (Thomson/Howard-Johnston I, 90).

55 Bereits der zeitgenössische Ant. Strateg. (Conybeare, 516) dokumentiert eine derartige Inszenierung; der Unversehrtheit der Reliquie widerspricht allerdings Ant. Strateg. (Conybeare 510 f.), wo von der Schändung des Kreuzes auf dem Weg nach Ctesiphon 614 berichtet wird. Die Unversehrtheit der Reliquie wird auch in der lateinischen Tradition betont (Exalt. S. Cruc. 4; ähnlich Revers. S. Cruc. 5), wo Chosroes das kostbare Reliquiar, das das Kreuz umschließt, auf seinem Thron als Rückenlehne nutzt. Noch ausführlicher ist Nik. Brev. 18, laut dem die Kleriker die Unversehrtheit des Siegels bestätigen, dann den Schlüssel des Reliquiars hervorholen, der in ihrem Besitz ist, und es vor aller Augen öffnen; siehe dazu Frolow 1953, 96 - 99; Flusin 1992 II, 311 f.; außerdem Zuckerman 2013, 217 f., der das Objekt, das Herakleios nach Jerusalem brachte, nicht für die 614 verschleppte Reliquie und die Inszenierung dementsprechend für eine Farce hält. Dass ich Zuckermans Argumentation nicht folge, habe ich bereits an anderer Stelle betont. Aus den Quellen wird deutlich, dass zeitgenössische Beobachter die Reliquie für authentisch hielten - und darum geht es letztendlich.

56 Mango 1992, 6 meint, dass diese Inszenierung dazu diente, zu zeigen, dass die Perser die Reliquie angemessen behandelt hätten - als Zeichen dafür, dass die Perser auf dem besten Weg seien, zum Christentum zu konvertieren; vgl. bereits ders. 1995, 105-118: Herakleios' dezidiertes Ziel sei es gewesen, die Perser, angefangen mit der Familie seines Verbündeten, des Generals Shahrbaraz, zu konvertieren.

57 So etwa Drijvers 2002, 187 f.; Kaegi 2003, 205f.; Greisiger 2014, 132-136; Meier 2019a, $1043 \mathrm{f}$. 
Fest der Kreuzerhöhung am 14. September in Verbindung stehen. ${ }^{58}$ Gemäß dieser Überlieferung nähert Herakleios sich, das Kreuz im Gepäck, Jerusalem vom Ölberg aus. Als er jedoch gedenkt, das Stadttor zu Pferd und in kaiserlichem Gewand zu durchqueren, ereignet sich ein Wunder: Die Steine des Tores fügen sich zusammen und versperren ihm den Weg. Der Grund für dieses Geschehen wird den Versammelten durch einen Engel offenbart: Während Herakleios seine kaiserlichen Insignien zur Schau stelle, sei Jesus Christus einst voller Demut auf einem Esel sitzend in Jerusalem eingezogen. Der Kaiser versteht den Wink, steigt vom Pferd, legt sein Ornat ab und nähert sich barfuß mit dem Kreuz in der Hand dem Tor; die Steine bewegen sich erneut und gewähren ihm diesmal den Durchgang. ${ }^{59}$ Borgehammar kommt in seiner eingehenden Analyse zu dem Schluss, dass der Ursprung der lateinischen Tradition spätestens in den 640er Jahren liegt und auf ein griechisches Original zurückgeht, das seinerseits zwischen 630 und 636 entstand. ${ }^{60}$ Folgt man Borgehammar, so scheint es in der Tat naheliegend, über die legendarische Ausschmückung Rückschlüsse nicht nur auf die unmittelbare Deutung der Restitutio Crucis, sondern auch auf das Ereignis selbst zu ziehen. Im Folgenden wird dieser Befund mit Fokus auf drei verschränkte Motive (Herakleios’ Akt der Demut, die Parallelisierung mit Christus und sein Einzug durch das Osttor) in einem breiten Kontext betrachtet.

Steckt in der Legende vom demütigen Herakleios ein wahrer Kern? Erwies der Kaiser dem Genius loci Jerusalems und der kostbaren Reliquie in seinen Händen die Ehre und entledigte sich beim Einzug in die Stadt tatsächlich seiner kaiserlichen Insignien? Dass ein römischer Kaiser sich öffentlich herabsetzte, um damit unter christlichen Vorzeichen seine Demut zu demonstrieren, erscheint vor dem Hintergrund monarchischer Herrschaftspraxis des 5. und 6. Jahrhunderts durchaus plausibel. Wenn die sesshaften Kaiser in Konstantinopel vor aller Augen ihre Insignien ablegten, sich gar aus dem geschützten Raum des Palastes herausbegaben, um sich unter die Menschen zu mischen, so demonstrierten sie damit nicht nur ihre Fröm-

58 Gemäß Borgehammar 2009, 148f., 160 gehen die beiden Texte auf eine gemeinsame Quelle zurück, haben aber keine Kenntnis voneinander. Die Herakleios-Überlieferung hat bereits Sommerlechner 2003 untersucht; ebd. 325-330 zum Fest der Kreuzerhöhung und den dazugehörigen liturgischen Texten. Die Reversio und Exaltatio Sanctae Crucis waren weit verbreitet (Borgehammar 2009, 146 nennt 200 - 300 Manuskriptbelege, die allerdings nicht weiter als bis ins 9. Jahrhundert zurückreichen) und fanden schließlich auch in die Legenda Aurea des Jacobus von Voragine Eingang; siehe dazu Sommerlechner 2003, 329f.

59 Rever. S. Cruc. 14-17; Exalt. S. Cruc. 17-21; Text bei Borgehammar 2009, 186-189, 198-201; Greisiger 2014, 132; Meier 2019a, $1043 \mathrm{f}$.

60 Borgehammar 2009, 148-160 mit ausführlicher Herleitung, zusammenfassend ebd. 157-160; Brandes 2002a, 35f. geht bereits von einer „totally unknown Eastern source” aus; dem folgt Greisiger 2014, 132f. Borgehammar 2009, 158f. weist zu Recht darauf hin, dass sich in Reversio und Exaltatio keine Spuren der Kritik an Herakleios finden, die in anderen lateinischen Quellen, wie etwa der Chronik des Fredegar, entstanden ca. 650, sehr prominent ist (Fredegar kritisiert explizit Herakleios' Verbindung zu seiner Nichte und seine Religionspolitik). Daher geht Borgehammar davon aus, dass diese Tradition zu einem Zeitpunkt ihren Ursprung nahm, als Herakleios noch auf der Höhe seines Erfolges und der Vorstoß der Araber noch nicht absehbar war. 
migkeit vor Gott, sondern stärkten auch die Bindung zur hauptstädtischen Bevölkerung. ${ }^{61}$ Der Geste kaiserlicher Demut indes war die Erhöhung inhärent; ein Gedanke, der bereits in der Passion und Auferstehung Christi angelegt war: In der stets kontrollierten öffentlichen Herabsetzung trat der Status des Souveräns umso deutlicher zutage. Dass im hauptstädtischen Kontext das Spannungsverhältnis zwischen Erniedrigung und Erhöhung auch in Hinblick auf Herakleios' Repräsentation eine Rolle spielte (in leicht abgewandelter Form), wurde im vorigen Kapitel herausgearbeitet. Doch wie verhielt es sich in Jerusalem? Inszenierte Herakleios sich bei seinem Einzug tatsächlich als demütiger Kaiser? Weder in den zeitgenössischen Texten noch in der späteren armenischen oder griechischen Überlieferung, die ich oben bereits zu Rate gezogen habe, finden sich Hinweise darauf. ${ }^{62}$

Einen Anhaltspunkt zur mutmaßlichen Demut des Kaisers bietet allein eines der wenigen bildlichen Zeugnisse, die mit Herakleios in Verbindung gebracht werden können. Der Türsturz einer Kirche im armenischen Mren, deren Bau anhand der Stifterinschrift auf 639/640 zu datieren ist, stellt - so die Deutung von Christina Maranci - die aus der Reversio bekannte Szene kaiserlicher Demut dar: ${ }^{63}$ Eine Figur in einfachem Gewand, gerade vom Pferd abgestiegen und vor einem Stabkreuz niederkniend, wird von Maranci als Herakleios in Jerusalem identifiziert. ${ }^{64}$ Dass die Kirche tatsächlich mit dem Kaiser in Verbindung steht, zeigt die Stifterinschrift, die vor einer Reihe armenischer Adliger den „siegreichen Kaiser Herakleios“ aufführt. Dennoch sollte die Deutung mit einer gewissen Vorsicht behandelt werden, da der Türsturz keine erklärende Beischrift trägt. ${ }^{65}$ Eine Interpretation der Darstellung, die den

61 Zur Funktion kaiserlicher Demut siehe Diefenbach 1996, 2002; zuletzt ders. 2019, 63 - 78; außerdem Meier 2007b und Kelly 2013; vgl. auch Greisiger 2014, 135.

62 Die Quellen wurden oben bereits genannt; dazu kommt noch ein Gedicht des Georg von Pisidien, welches das Eintreffen der freudigen Nachricht von der Restitutio Crucis in Konstantinopel verarbeitet, das ich im Folgenden genauer analysieren werde. Ant. Strateg. (Conybeare 516) weist auf Herakleios' gesetzeswidrige Verbindung zu seiner Nichte Martina hin; laut dem Text habe Herakleios bei seinem Besuch in Jerusalem Kritik der Kirchenoberen gefürchtet. Dass Herakleios in diesem Zusammenhang einen Akt der Buße bzw. Demut vollzog, erwähnt der Text allerdings nicht.

63 Maranci 2008/2009, 167-173; ihr folgt Borgehammar 2009, 166-168. Dass das Relief Herakleios' Restitutio Crucis darstellt, hat bereits Thierry 1997 angenommen, allerdings noch nicht in Verbindung mit der lateinischen Tradition.

64 Die Darstellung ist grob symmetrisch aufgebaut: Der als Herakleios interpretierten Figur links entspricht eine ähnlich große Figur, die von rechts kommend ebenfalls vor dem Kreuz niederkniet und durch ein Weihrauchgefäß in der Hand als Kleriker ausgezeichnet ist; in ihm erkennt Maranci den späteren Patriarchen Modestos. Das Stabkreuz in der Mitte wird von einer wesentlich kleineren Person getragen, die nicht näher identifiziert wird. Dem Pferd links entspricht rechts ein stilisierter Baum auf einem Hügel; siehe Abbildungen in Maranci 2008/2009.

65 Maranci 2008/2009, 170 beschreibt die Darstellung zu Recht als hapax. Die bildlichen Darstellungen, die zum Vergleich herangezogen werden könnten, datieren allesamt wesentlich später und stammen aus dem westlichen Mittelmeerraum (dazu ebd. 173). Alternative Interpretationen des Türsturzes (Darstellung armenischer Magnaten anstelle des Kaisers) präsentiert Maranci 2008/2009, $168 \mathrm{f}$. 
armenischen Kontext stärker in den Fokus rückt, erscheint durchaus auch plausibel. ${ }^{66}$

Folgt man indes Marancis Identifizierung, so lässt dies folgende Schlüsse zu: $\mathrm{Ob}$ Herakleios den Akt der Demut tatsächlich in eventu vollzog, ist nicht mehr zu bestimmen; dass die Berichte von vermutlichen Augenzeugen wie Antiochos Strategos und dem Autor der Translatio diesen Aspekt nicht erwähnen, könnte man eher als Argument dagegen anbringen. Sicher ist alleine, dass sich post eventum eine Deutung verbreitete, die die Demut des Kaisers ins Zentrum der Restitutio Crucis stellte. Diese Deutung wurde zwar weit gestreut - geht man tatsächlich davon aus, dass die lateinische Tradition und die Kirche in Mren auf dasselbe Narrativ zurückgehen -, schlug allerdings nur in wenigen Kommunikationskontexten Wurzeln: Während das Motiv das liturgische Gedenken an Herakleios im Westen bestimmte, ${ }^{67}$ findet sich in Konstantinopel keinerlei Spur davon, obwohl kaiserliche Demut dort durchaus als Repräsentationsmodus bekannt war. ${ }^{68}$

Es bleibt zuletzt auf Evidenz hinzuweisen, die nahelegen könnte, dass im Nahen Osten - also in dem Raum, in dem Borgehammar die Entstehung der Legende vermutet - die Idee des demütigen Kaisers zumindest latent fortlebte. Die Berichte vom Einzug des Kalifen Umar in Jerusalem 638 betonen seine einfache Kleidung, sodass man geneigt ist, hierin eine Herakleios-Imitatio zu vermuten. ${ }^{69}$ Für eine enge Verbindung zwischen Herakleios' Aktivität im Heiligen Land und der kurz darauf einsetzenden arabischen Expansion und Eroberung Jerusalems hat zuletzt Mischa Meier mit Nachdruck argumentiert. ${ }^{70}$ Die Apokalypse des Pseudo-Methodios aus dem späten 7. Jahrhundert schließlich kulminiert in der Prophezeiung vom letzten römischen Kaiser, der

66 Siehe Thierry 1997, die in den Reliefs der Kirche das Verdienst armenischer Adliger, unter anderem des David Saharuni, dokumentiert sieht. Darüber hinaus sei darauf hinzuweisen, dass armenische Texte vermerken, Herakleios sei mit dem Kreuz durch Armenien gezogen, bevor er sich nach Jerusalem begeben habe; siehe Flusin 1992 II, $30 \mathrm{f} \mathrm{f.} \mathrm{Die} \mathrm{Darstellung} \mathrm{könnte} \mathrm{also} \mathrm{durchaus} \mathrm{auch} \mathrm{eine} \mathrm{lokale}$ Tradition wiedergeben.

67 Dass das Gedenken an Herakleios im Westen keineswegs durchwegs positiv war, zeigt die Chronik des Fredegar (65), die ein sehr ambivalentes Bild des Kaisers zeichnet; zu Fredegar und seinem Bericht über Herakleios siehe zuletzt Esders 2009 und ders. 2018, bes. 134-137, 145-135. In der Kritik stand vor allem die Religionspolitik des Kaisers, dessen Monotheletismus im Westen auf Widerstand stieß. Das Schisma wurde auf dem dritten Konzil von Konstantinopel 680/681 beigelegt, der Monotheletismus verbannt. Danach scheint einer positiven Herakleios-Rezeption im Westen nichts mehr im Wege gestanden zu haben; vor allem Kreuzfahrer beriefen sich implizit wie explizit auf ihn; siehe dazu etwa Greisiger (im Druck).

68 Borgehammar 2009, 167 bringt diesen Befund auf den Punkt: „For the fact that some images take hold in some places but not in others, while other images fail to take hold at all - that is what creates the phenomenon we call history ..."

$69 \mathrm{Zu}$ Umar in Jerusalem siehe Theoph. Conf. AM 6127 (De Boor 339); Chron. 1234, 120 (Chabot I, 199f.) und Mich. Syr. 11.7 (Chabot II, 425f.); siehe Stratos 1972, 81f., 221 mit weiteren Quellen.

70 Meier 2019a, 1045-1048; Meier geht gar von einem „messianischen Konkurrenzverhältnis“ (Zitat ebd. 1047) zwischen Kaiser und Kalif, konkret zwischen Herakleios und Umar, aus; siehe auch Meier 2020. 
seine Krone in Jerusalem ablegt. ${ }^{71}$ Obwohl außer Frage steht, dass die apokalyptische Tradition von Herakleios' Abstecher nach Jerusalem beeinflusst wurde, bleibt zu betonen, dass das Motiv des Kaisers, der in Jerusalem abdankt, bereits älter sein könnte. Es ist also zumindest in Betracht zu ziehen, dass die Apokalypse sich auch aus anderen Quellen denn aus Herakleios' Ablegen der Insignien speisen konnte. ${ }^{72}$

Abgesehen von der Zuschaustellung von Demut gebührt auch dem Umstand Aufmerksamkeit, dass die lateinische Legende eine Reihe gar expliziter Parallelen zwischen Herakleios und Christus zieht. Wie einst der Heiland näherte sich demgemäß auch der Kaiser Jerusalem vom Ölberg aus; ${ }^{73}$ der Empfang der Bevölkerung mit Palmzweigen und Lichtern, wie ihn die Reversio nachvollzieht, gemahnt an den biblischen Palmsonntag. ${ }^{74}$ Und tatsächlich findet sich dieses Motiv im Zusammenhang mit der Restitutio Crucis auch in Konstantinopel: In dem Gedicht, das Georg von Pisidien verfasste, als die frohe Nachricht von Herakleios' Rückerstattung des Kreuzes in Konstantinopel eintraf, ${ }^{75}$ ruft der Poet den Ort der Kreuzigung Christi auf zu frohlocken: Dem Kaiser solle Golgatha Beifall klatschen: „Und wenn deine Steine keine Stimme haben, dann bereite neue Palmzweige vor, um dem neuen Sieger entgegen-

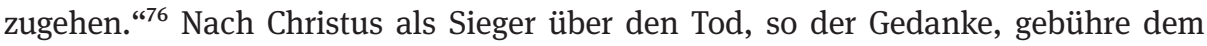
Kaiser als Sieger über Persien die Huldigung mit Palmzweigen. Hält man die Notiz aus der Reversio, Herakleios sei über den Ölberg in Jerusalem eingezogen, für authentisch, so lässt sich gar die These aufstellen, dass es sich bei der Christus-Parallelisierung nicht nur um eine nachträgliche legendarische bzw. panegyrische Deutung handelt, sondern dass Herakleios selbst sich mit seinem Einzug in Jerusalem dezidiert in die Tradition Christi stellte. ${ }^{77}$ Es bleibt allerdings zu erwähnen, dass die sonstigen Quellen keinen klaren Angaben zum kaiserlichen Itinerar machen. ${ }^{78}$

71 Zur Apokalypse des Ps.-Methodios siehe Reinink 1988, 1993.

72 Eine eingehende Analyse der relevanten apokalyptischen Tradition mit Diskussion der Datierungsfragen bietet Greisiger 2014, 172-180. Greisiger kommt indes zu dem Schluss, dass Herakleios' ostentative Demut, wie sie sich auch in der lateinischen Tradition äußert, die Entwicklung der apokalyptischen Tradition bedingte; siehe bes. 177-180. Ebd. 159-166 dazu, wie Herakleios Präsenz aus jüdischer Sicht verarbeitet wurde. Die Überlieferungstraditionen des apokalyptischen Schriftgutes sind derart komplex, dass ich sie hier nicht im Detail nachvollziehen kann; meine Argumentation kann auf eine detaillierte Berücksichtigung der Evidenz verzichten.

73 Dass Jesus sich vom Ölberg her Jerusalem näherte, halten fest: Mt 21.1-12; Mk 11.1-19; Lk 19.37-48. 74 Mt 21.5-7; Mk 11.8-10; Lk 19.36-40; Joh 12.12-18; dazu Greisiger 2014, 134. Zuletzt hat Christian Rollinger in seiner bislang unveröffentlichten Habilitation interessante Gedanken hinsichtlich einer möglichen Christus-Imitatio bei der Restitutio Crucis formuliert.

75 Diesen Kontext gibt Georg. Pis. Rest. Cruc. 104-115. Die Nachricht traf am Feiertag des Lazarus in Konstantinopel ein.

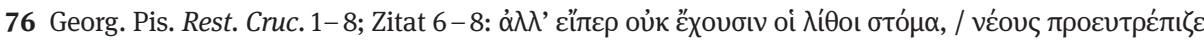

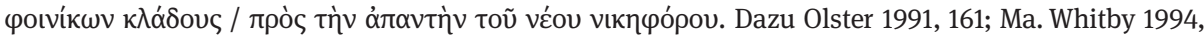
215; dies. 2002, 161; Meier 2015, 186; ders. 2017, 540.

77 So etwa Greisiger 2014, 134-136, 139.

78 Laut Theoph Conf. AM 6120 (De Boor 328) und Eutychios (Breydy 108f.) machte Herakleios auf dem Weg von Syrien nach Jerusalem in Tiberias am See Genezareth halt. Von dort aus hätte er dem Jordan 
Doch wie ist dieser Verweis auf Christus - ob bereits in eventu angelegt oder nicht - zu verstehen? Angesichts der generellen Tendenz der spätantiken Gesellschaft, die eigene Lebenswelt im Rahmen biblischer Exempla und Typologien zu begreifen und zu beschreiben, ist die Parallelisierung zwischen dem Einzug Christi in Jerusalem und dem des Herakleios nicht per se überraschend. Die imitatio Christi bzw. Dei, die Gestaltung der weltlichen Herrschaft nach himmlischem Vorbild, war seit Konstantin I. ein wiederkehrendes Motiv sowohl in der Rede über den Kaiser als auch in dessen Herrschaftspraxis und Selbstdarstellung. Wie mit Verweis auf Passagen aus Georg von Pisidien bereits im Kapitel 5 besprochen wurde, wurde auch Herakleios als Kaiser bereits vor seinem Sieg über die Perser bisweilen mit Christus überblendet. ${ }^{79}$ In diesem Zusammenhang hat sich in der Forschung zuletzt die Ansicht durchgesetzt, in Herakleios' Herrschaft offenbare sich eine distinkte, neuartige Herrschaftskonzeption, ein ,messianisches Kaisertum' mit eschatologischer Stoßrichtung; die Stilisierung als endzeitliche Erlöserfigur habe der Kaiser durch die Annäherung an den Messias Christus selbst gezielt befördert. ${ }^{80}$ Cyril Mango beschreibt die Restitutio Crucis gar als „a deliberatly apocalyptic act” ${ }^{81}$ Doch war Herakleios’ Einzug tatsächlich als Prolog zum Weltende konzipiert? Wie problematisch es sein kann, undifferenziert von einem eschatologischen Deutungsrahmen auszugehen, wurde bereits an anderer Stelle betont. ${ }^{82}$ Insofern lohnt es sich, die Evidenz, die von den Befürwortern einer eschatologischen/apokalyptischen Deutung der Restitutio Crucis angeführt wird, erneut zu beleuchten.

Gemäß dem Bericht des Antiochos Strategos zog Herakleios nicht etwa am Palmsonntag, sondern am 21. März in Jerusalem ein. ${ }^{83}$ Auch dabei handelte es sich um ein symbolträchtiges Datum: In der chronographischen Tradition, wie sie sich etwa in der hauptstädtischen Osterchronik äußert, stand der 21. März für die Erschaffung der Gestirne, also für den Beginn der Zeit. ${ }^{84}$ Geht man davon aus, dass Herakleios den Tag ganz bewusst wählte, lässt sich dies tatsächlich als ein starkes Statement lesen jedoch nicht unbedingt als ein apokalyptisches. Darin offenbart sich darin vielmehr der Gedanke, dass Herakleios' Wiedergewinnung der Ostprovinzen den Beginn einer neuen Zeit markierte, wie er sich bereits im Kaiserlob des Georg von Pisidien äußerte.

nach Süden folgen können, um dann von Osten her nach Jerusalem aufzusteigen; genauso hätte er aber auch den westlichen Weg wählen können.

79 Siehe dazu auch Meier 2015.

80 So vor allem Meier 2017, 540 - 543; bereits ders. 2015, 186-189; wesentlich ausführlicher und stets aus der Perspektive nahöstlicher Apokalyptik Greisiger 2014, 132-180; vgl. auch Shoemaker 2018, 76. 81 Mango 1980, 205; eine Erläuterung dessen, was genau an der Restitutio Crucis apokalyptisch ist, bleibt Mango allerdings schuldig; vgl. auch Drijvers 2002, 186-188; Shoemaker 2018, 76.

82 Siehe oben Kap. 5.5.

83 Das genaue Datum findet sich bei Ant. Strateg. (Conybeare 516). Geht man vom Jahr 630 aus, so zog Herakleios eineinhalb Wochen vor dem Palmsonntag in Jerusalem ein: Ostern fiel im Jahr 630 auf den 8. April; Palmsonntag (Sonntag vor Ostern) war demnach der 1. April.

84 Chron. Pasch. (Dindorf 26f.); dazu Flusin 1992 II, 314; Drijvers 2002, 186f.; Booth 2013a, 8f. und Zuckerman 2013, $203 \mathrm{f}$. 
Dieser Renovatio-Gedanke verweist gerade nicht auf ein wie auch immer geartetes Eschaton, sondern eröffnet einen positiven Blick in die Zukunft; ${ }^{85}$ Herakleios erscheint dabei als Agent eines neuen, heilvollen Zeitalters: Nach der Wiederherstellung der weltlichen Ordnung durch den Sieg über die Perser markierte er mit der Rückerstattung des Kreuzes an seinen angestammten Platz in der Anastasis-Kirche - so ließe sich diese Geste deuten - die Wiederherstellung der himmlischen Ordnung. ${ }^{86}$

Bei der Interpretation der Restitutio Crucis wurden neben den literarischen Quellen zuletzt wiederholt auch architektonische Hinterlassenschaften in die Diskussion einbezogen. Herakleios' Präsenz in der Heiligen Stadt könnte sich - so wird in der Forschung wiederholt gemutmaßt - in einem Ausbau des Tempelberges niedergeschlagen haben; als Evidenz für diese These dienen das Goldene Tor in der OstMauer des Tempelberges sowie die Struktur, die als muslimischer Felsendom bekannt ist. Der Bau des Goldenen Tores ist weder literarisch noch epigraphisch belegt; die Datierungen, die vom späten 6. Jahrhundert bis in früh-umayyadische Zeit rangieren, basieren auf architektonischen Merkmalen sowie der erhaltenen Baudekoration. ${ }^{87}$ Während eine Verbindung des Tores zu den muslimischen Bauten naheliegt, die in Folge der arabischen Eroberung auf dem Tempelberg entstanden, ${ }^{88}$ hat zuletzt eine alternative Hypothese Anklang gefunden: nämlich dass der Bau während des kurzen römischen ,Interregnums‘ 628-636 entstand; und mehr noch: dass das Tor dezidiert Herakleios' Einzug in die Heilige Stadt kommemorierte, der - folgt man der lateinischen Tradition, die ich oben besprochen habe - von Osten her erfolgte. ${ }^{89}$ Der Felsendom dagegen ist in seiner erhaltenen Form ein eindeutig muslimischer Bau; $;^{90}$ der oktagonale Grundriss indes gemahnt an spätantik-byzantinische Kirchen im Heiligen

85 Vgl. dazu oben S. 248-251.

86 Vgl. Mango 1992, 6: „The return of the Cross was meant to be a cosmic event.” Dass die Zeitgenossen sich der Bedeutung des 21. März im Speziellen bewusst waren, wird indes in keiner Quelle explizit. Da die letzten Folios des einzig erhaltenen Manuskripts der Osterchronik beschädigt sind, bleibt die These, dass der Text durch die göttliche Erschaffung der Gestirne am 21. März einerseits und Herakleios’ Restitutio Crucis am 21. März andererseits gerahmt wurde, zwar verlockend, aber nicht belegbar; vgl. Whitby/Whitby 1989, xif.

87 Siehe die ausführliche Beschreibung des Befundes bei Mango 1992 mit Diskussion der älteren Literatur.

88 Dass bereits der Kalif Umar auf dem Tempelberg Baumaßnahmen durchführen ließ, vermerkt etwa Theoph. Conf. AM 6135 (De Boor 342); dazu siehe Mango 1992, $1 \mathrm{f}$.

89 Peters 1983, 124-127; Peters stellt hier außerdem die gewagte These auf, dass das Osttor zur Zeit des Herakleios nicht auf den Tempelberg, sondern direkt in die Stadt führte; erst bei einer späteren Erweiterung der Tempel-Plattform nach Norden sei das Tor in die Umfassungsmauer des Tempelberges integriert worden. Für eine Zuschreibung des Osttores an Herakleios plädieren auch Mango 1992, bes. 6f.; Greisiger 2014, 147 f.; ebd. 136 weist Greisiger darauf hin, dass das Osttor im Mittelalter mit Herkleios' Einzug in Verbindung gebracht wurde.

90 Der Felsendom in seiner heute noch erhaltenen Form entstand - so der weitgehende Konsens der Forschung - im späten 7. Jahrhundert unter dem Kalifen 'Abd al-Malik; siehe Peters 1983, 131-133 und der Sammelband von Raby/Johns 1992. 
Land. ${ }^{91}$ Dieser Befund hat Francis E. Peters zu der Vermutung bewogen, dass der muslimische Bau nicht nur einen lokalen, christlichen Architekturtyp kopiert, sondern dass dem Felsendom die Baustruktur einer christlichen Kirche im wahrsten Sinne des Wortes zugrunde liegt - einer christlichen Kirche, deren Grundriss auf Herakleios' Initiative hin gelegt worden war. ${ }^{92}$ Angesichts des Umstandes, dass Jerusalem letztendlich nicht einmal ein Jahrzehnt in römischer Hand blieb, wäre ein Ausbau des Tempelberges gemäß diesem Gedankengang bei der Ankunft der Araber nicht sonderlich weit gediehen gewesen.

Um die Implikationen nachvollziehen zu können, die die These von einer herakleischen Bauinitiative mit sich bringt, ist ein Blick auf die Entwicklung und Bedeutung des Jerusalemer Tempelberges zu werfen. Nachdem die Römer den jüdischen Tempel 70 n. Chr. zerstört hatten, ließ Kaiser Hadrian auf dem Plateau in Folge des BarKochba-Aufstandes einen Jupiter-Tempel errichten; mit der fortschreitenden Christianisierung ab dem 4. Jahrhundert wurde der pagane Kultort jedoch aufgegeben. Aus christlicher Sicht avancierte der brach liegende Tempelberg in der Spätantike zum Mahnmal dafür, dass der Neue Bund mit der Anastasis-Kirche als kultischem Zentrum den Alten Bund, das Judentum, abgelöst hatte. ${ }^{93}$ Justinian ließ den Tempelberg bei seinem großangelegten Ausbau Jerusalems demonstrativ unberührt. ${ }^{94}$ Ein herakleisches Bauprogramm an und auf dem Tempelberg ließe sich dahingehend interpretieren, dass der Kaiser den Ort, an dem unter persischer Hoheit zumindest zeitweise der jüdische Kult wieder aufgenommen worden war, nun explizit dem Christentum aneignete, die Trennung von Altem und Neuen Bund aufhob und das Judentum symbolisch dem Christentum einverleibte. ${ }^{95}$ Folgt man der Zuschreibung, so eröffnen sich auch hier eschatologische Implikationen: Nicht nur die Konvertierung der Juden stand aus christlicher Sicht mit einem messianischen Zeitalter in Verbindung; ${ }^{96}$ auch der Bau eines neuen Tempels verwies sowohl in der jüdischen wie der christlichen

91 Zu nennen wären die Theotokos-Kirche auf dem Berg Garizim, die unter Kaiser Zenon an der Stelle des samaritanischen Tempels errichtet wurde, nachdem der Aufstand der Samaritaner niedergeschlagen worden war; außerdem die Kathisma-Kirche aus dem 6. Jahrhundert nahe Bethlehem; siehe Peters 1983, 127 f.; Greisiger 2014, $148 \mathrm{f}$.

92 Peters 1983; ihm folgt Sivan 2008, 48f. Dass Herakleios seinen Einzug in Jerusalem architektonisch kommemorierte, halte ich - angesichts der römisch-imperialen Tradition, kaiserliche Präsenz durch Bauinitiativen zu verewigen - prinzipiell für plausibel; vgl. Mango 1992, 6.

93 Greisiger 2014, 145f. In dem Brachliegen des Tempelberges bewahrheitete sich außerdem das Herrenwort: „Hier wird nicht ein Stein auf dem anderen gelassen werden, der nicht abgebrochen werden wird. “ Siehe Mt 24.2; Mk 13.2; Lk 21.6. Zum Ausbau eines neuen Jerusalems siehe Wilken 1992, 85-100.

94 Siehe Trampedach 2015; die berühmte Mosaik-Karte von Madaba aus der zweiten Hälfte des 6. Jahrhunderts versinnbildlicht diesen Zustand: Während sie die justinianischen Bauten, die NeaKirche und den Cardo Maximus deutlich wiedergibt, fehlt der Tempelberg in der Darstellung.

95 So Greisiger 2014, 145-150. Tatsächlich belegen einige Quellen, dass die jüdische Bevölkerung nach 628 verstärkt in den kaiserlichen Fokus rückte; gar von Zwangstaufen ist die Rede, siehe Greisiger 2014, 97-106; vgl. Drijvers 2002, 188-190; dazu siehe unten S. 287.

96 Greisiger 2014, 97-106. 
Vorstellungswelt auf eine kommende Heilszeit. ${ }^{97}$ So verlockend die Idee vom Ausbau des Tempelberges durch Herakleios und deren weitreichende Implikationen auch sind, so bleibt doch festzuhalten, dass es sich dabei um eine Hypothese handelt, die weder durch literarische noch durch archäologische Evidenz angemessen untermauert werden kann. ${ }^{98}$

Die Interpretation der Restitutio Crucis führt schließlich zu einem Aspekt, der sich in der rezenten Forschung - nicht zuletzt bei den Befürworten einer eschatologischen/ messianischen Deutung - geradezu als Allgemeinplatz verfestigt hat: Mit der Rückerstattung des Kreuzes habe Herakleios sich in die Tradition des alttestamentarischen Königs David gestellt, der seinerzeit die Bundeslade, das zentrale Kultobjekt des Judentums, nach Jerusalem gebracht hatte; und mehr noch: Der Bezug auf König David, auf den Urvater des Messias, ${ }^{99}$ sei unter Herakleios zum Schlüsselmoment kaiserlicher Repräsentation avanciert. ${ }^{100}$ Georg von Pisidien vergleicht in seinem Gedicht zur Restitutio Crucis in der Tat die Kreuzreliquie mit der Bundeslade - ausgehend von dem Umstand, dass beide Kultobjekte sich zeitweise in den Händen barbarischer Feinde befanden: Die Bundeslade war von den Philistern geraubt worden, ${ }^{101}$ das Kreuz von den Persern. Für den Dichter erweist sich das Kreuz als „neue Bundeslade“ (vé $\alpha$ кґ

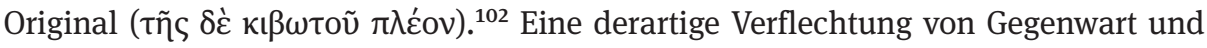
biblischer Vergangenheit, die sich auf das jüdische Erbe beruft, um die eigene Gegenwart mit Sinnbezügen aufzuladen, und im gleichen Zuge die Überlegenheit des

97 Bardill 2006, 342; siehe McKelvey 1969 zu Vorstellungen vom neuen/himmlischen Tempel im Alten und Neuen Testament. Greisiger 2014, 159-166 zeigt anhand von jüdischen Quellen, dass Herakleios' spektakuläre Präsenz in Jerusalem nicht ignoriert werden konnte, dass indes auf jüdischer Seite eine Gegendeutung etabliert wurde, „die zugleich das Gewicht, das er dem Ereignis beimaß, erkennen lässt, und präzise dessen imperial-propagandistische Intention zu treffen und außer Kraft zu setzen vermochte“ (Zitat ebd. 160).

98 Keine einzige literarische Quelle (weder zeitgenössisch noch später) dokumentiert römische bzw. herakleische Bauaktivität am bzw. auf dem Tempelberg. Eine eingehende (und unvoreingenommene) archäologische Untersuchung, die zur genaueren Datierung der Baustrukturen auf dem Tempelberg beitragen könnte, ist angesichts des weiterhin umstrittenen Status des Areals kaum möglich. Vgl. auch Howard-Johnston (im Druck), der in Hinblick auf einen herakleischen Ausbau Jerusalems noch weitreichendere Thesen aufstellt.

99 Die Idee, dass der Messias von David abstamme, entspringt einer Prophezeiung in 2. Sam 7.14-16; gemäß den Stammbäumen in Mt 1.1-17 und Lk 3.23-38 stammt Jesus von David ab.

100 Wander 1973,103f.; ders. 1975; Spain Alexander 1977; Trilling 1978, 250 f.; Ludwig 1991, 95; Drijvers 2002, 184 f.; Brandes 2002a, 19; Ludwig 2003; bes. 373-377; Borgehammer 2009, 161-163; Tsamadga 2010, 30 -33; Greisiger 2014, 139-145; Meier 2015, 187-189; ders. 2017, 541-543; ders. 2019 a, 1044. 1011 Sam 5.

102 Georg. Pis. Rest. Cruc. 73-77. Siehe dazu Pertusi 1959, 238; Borgehammar 2009, 162. Ludwig 1991, $97 \mathrm{f}$. sieht außerdem in Rest. Cruc. 71f., wo Herakleios bei der Rückerstattung des Kreuzes mit den Engeln tanzt, einen Reflex von 2 Sam 6.5, 14 - 15, wo David bei seinem Einzug in Jerusalem tanzt; vgl. die kritischen Anmerkungen dazu bei Ma. Whitby 2002, 162 Anm. 30. 
christlichen Kontextes betont, ist in der Spätantike durchaus typisch; ${ }^{103}$ auch für die typologische Verbindung zwischen Bundeslade und Kreuzreliquie finden sich weitere Belege. ${ }^{104}$ Dabei bleibt indes zu betonen, dass bei Georg der direkte Vergleich zwischen Herakleios und David, dem Restitutor der Bundeslade, gerade nicht gezogen wird. Diese Beobachtung dient als Anlass, die mutmaßliche David-Imitatio unter Herakleios einer Revision zu unterziehen.

Die David-Erzählung des Alten Testaments scheint in der Tat die ideale Vergleichsfolie und Projektionsfläche für die Herausforderungen, derer sich Herakleios im Laufe seiner Regierung stellen musste: Von Gott begünstigt kam David an die Macht, nachdem er sich gegen die herrschende Dynastie des Königs Saul hatte behaupten können; er zog in den Krieg, besiegte einen übermächtigen, nichtgläubigen Feind (den Philister Goliath), einigte sein Reich und brachte - wie bereits erwähnt mit der Bundeslade den zentralen Kultgegenstand seiner Glaubensgemeinschaft nach Jerusalem. David begründete eine bedeutende Herrscherfamilie, versündigte sich allerdings, als er die illegitime Verbindung mit Bathseba einging. ${ }^{105}$ Mit dem Verweis auf den alttestamentarischen König ließen sich potentiell kritische Aspekte von Herakleios' Herrschaft - die Umstände seiner Krönung, das persönliche Engagement im Krieg gegen die Perser und nicht zuletzt seine familiäre Situation - in einen autoritativen Referenzrahmen einordnen und damit sanktionieren. ${ }^{106}$ Die Überblendung von Herakleios und Christus, aus der der Kaiser als messianische Heilsfigur hervortritt, fände in der Annäherung an Christi Vorfahren David eine weitere Ausdrucksform. ${ }^{107}$ Die zentrale Frage ist indes, ob diese Verbindung, die aus der Sicht der Forschung so naheliegend scheint, auch von Herakleios selbst bzw. seinen Zeitgenossen gezogen wurde. Ist David tatsächlich die Schlüsselfigur, die den Weg zum Verständnis politischer Prozesse und Diskurse des 7. Jahrhunderts eröffnet? Lassen sich politische Maßnahmen wie etwa Herakleios’ persönliche Rückführung des Kreuzes tatsächlich

103 Siehe Viermann (im Druck) zu dem Motiv des Übertreffens des alttestamentarischen Königs Salomon; Rapp 2010 unterzieht die Modi, anhand derer eine christliche Gegenwart zum Alten Testament in Beziehung gesetzt werden konnte, einer eingehenden Untersuchung.

104 Ludwig 1991, 98-100; Greisiger 2014, 140 f. Die Verbindung von Bundeslade und Kreuz war allerdings nicht exklusiv; in Anth. Palat. 1.121, einem Bau-Epigramm in der Blachernenkirche, verfasst von Georg von Pisidien, wird der Vergleich zwischen Bundeslade und der Theotokos gezogen; zu den Epigrammen siehe oben S. $255 \mathrm{f}$.

105 Spain Alexander 1977, 226- 231 zeigt ausführlich die Parallelen auf; vgl. Greisiger 2014, 139. Seit der Christianisierung römischer Monarchie wurde David in der Rede über den Kaiser wiederholt als Referenz bemüht. Allerdings handelte es sich bei der überschaubaren Anzahl an Beispielen - so hat zuletzt Ueli Zahnd (2008, 74-80 mit Beispielen) betont - um Zuschreibungen von Seiten kirchlicher Würdenträger und nicht etwa um kaiserliche Selbstbeschreibungen. Besonders prominent ist der David-Bezug im späten 4. Jahrhundert in der Auseinandersetzung zwischen Ambrosius, dem Bischof von Mailand, und Theodosios I.; dazu siehe Leppin 2007. Zu dem Apsis-Mosaik im Katharinen-Kloster auf dem Sinai, das Justinian und David in Verbindung setzt, siehe Tsamakda 2010, 25-30.

106 Ludwig 2003, 370 - 377 sieht David als Referenzpunkt für den „guten Usurpator“, als den sich Herakleios zu stilisieren suche.

107 Ludwig 2003, bes. 369, 376; Meier 2015, 187-189. 
mit dem Verweis darauf erklären, dass der römische Kaiser sich in die Tradition des alttestamentarischen Königs stellte?

Nachdem bereits zuvor zwischen kaiserlicher Repräsentation und Fremdzuschreibung unterschieden und die Notwendigkeit betont wurde, den kommunikativen Zusammenhang bei der Analyse der Quellen einzubeziehen, sollen diese methodischen Prämissen auch hier das Vorgehen leiten. Der einzige Beleg dafür, dass Herakleios selbst eine Beziehung zu dem alttestamentarischen König herstellte, ist der Umstand, dass er seinem Sohn, der laut Theophanes Confessor am 7. November 630 zur Welt kam, als der Kaiser mit seiner Frau Martina nach der Restitutio Crucis weiterhin im Osten weilte, den Namen David gab; dieser Schritt ist insofern bemerkenswert, als der Name David nicht zum Standardrepertoire der Nomenklatur römischer/ christlicher Kaiser gehörte. ${ }^{108}$ Als ein weiteres Indiz für Herakleios’ Angleichung an David wird in der Forschung der Umstand angeführt, dass der Kaiser spätestens 629 anstelle der traditionell römischen Titulatur den Titel pistos en Christo basileus annahm und damit - so die Hypothese - auf den alttestamentarischen basileus David ebenso wie auf die baslieia Christi, Davids Nachfahren, verwies. Darauf, dass sich für die Änderung der Titulatur durchaus auch andere, naheliegendere Erklärungen anbringen lassen, habe ich bereits an anderer Stelle hingewiesen. ${ }^{109}$

Besondere Aufmerksamkeit kommt in der Forschung schließlich den sogenannten ,David-Plates' zu, einem Set von neun dekorativen Silberschalen, die in einem Hort auf Zypern gefunden wurden und Szenen aus dem Leben König Davids darstellen. ${ }^{110}$ Ausgehend davon, dass die Kontrollstempel eine Fertigung zwischen 613 und 629/30 belegen, wurde dafür plädiert, dass die Schalen nach bzw. in Reaktion auf Herakleios’ Triumph über die Perser entstanden: ${ }^{111}$ Als Objekte imperialer Repräsentation, eventuell gar vom Kaiser persönlich als Geschenk für einen Vertreter der oströmischen Elite in Auftrag gegeben, würdigten sie Herakleios' Verdienst. ${ }^{112}$ Ob die David-Dar-

108 Theoph. Conf. AM 6122 (De Boor 335); vgl. Mango/Scott 1997, 466 Anm. 6; Greisiger 2014, 141 f. 638 wurde David zum Caesar gekrönt (De cerim. 2.27). Es bleibt allerdings folgende Anmerkung: Hätte sich Herakleios tatsächlich als neuen David verstanden, wäre es wohl passender gewesen, seinen Sohn Salomon zu nennen.

109 Siehe oben S. $234 \mathrm{f}$.

110 Die größte Schale rekapituliert in drei Szenen den Kampf Davids gegen Goliath; die kleineren bilden ab, wie David nach seinem Sieg in die königliche Familie des Saul aufgenommen wurde; die Szenen entstammen der Erzählung in 2 Sam 16-18.

111 Siehe Spain Alexander 1977, bes. 236; Mundell-Mango 1994, 122-131. Eine Interpretation der Schalen bieten auch Wander 1973 und Trilling 1978, der sie hinsichtlich ihrer Bildsprache mit den Gedichten des Georg von Pisidien vergleicht. Dass die Szenen am Hofe des Königs Saul sich an zeitgenössischer kaiserlicher Repräsentation orientieren, spricht nicht unbedingt dafür, dass hier eine typologische Verbindung gezogen wird; bei der Darstellung alttestamentarischer Könige bediente sich die bildliche Kunst in anachronistischer Manier stets der aktuellen Kaiserikonographie als Chiffre für Herrscherwürde; siehe Tsamakda 2010, 29.

112 So Spain Alexander 1972, 237; Greisiger 2014, 139; Meier 2015, 188. Tsamakda 2010, 32f. hingegen weist die These zurück, dass die David-Plates mit Largitio-Schalen in Verbindung zu bringen sind, die von den Kaisern zu bestimmten Anlässen ausgegeben wurden. 
stellungen auf den Silberschalen tatsächlich auf kaiserliche Initiative hin rezente politische Entwicklungen kommentieren, ist jedoch erneut nicht mit Sicherheit zu belegen; auch hier sind alternative Deutungen möglich. In der Spätantike waren derartige Silberschalen durchaus gängig: Während sie in der Regel mythologische Szenen darstellten, könnte man in den David-Plates schichtweg den Versuch eines aristokratischen Milieus sehen, christliche Themen in diese Darstellungsform zu integrieren. ${ }^{113}$ Die gesicherte Evidenz dafür, dass Herakleios sich in seinem Handeln auf David bezog, bzw. sich dergestalt repräsentierte, ist demnach dürftig.

Wie sieht es nun mit Fremdzuschreibungen aus? Der einzige Beleg dafür, dass Herakleios' Handeln im hauptstädtischen Umfeld mit Bezug auf König David gedeutet wurde, findet sich in der bereits besprochenen Predigt des Theodor Synkellos, die vor dem Friedensschluss mit Persien entstand. ${ }^{114}$ Im erhaltenen Oeuvre des Georg von Pisidien dagegen ist der vermeintlich naheliegende David-Bezug überraschend unterrepräsentiert - und das trotz der offensichtlichen Vorliebe des Dichters für historische wie biblische Analogien; David tritt bei Georg wenn überhaupt als Psalmist, nicht etwa als Herrscher-Typos auf. ${ }^{115}$ Allein in Georgs nicht erhaltenen Versen ließen sich Belege für eine kaiserliche David-Mimesis vermuten. Die Chronik des Theophanes Confessor aus dem 9. Jahrhundert, die erwiesenermaßen Georg von Pisidien als Quelle nutzte, gibt in der Tat eine legendenhafte Erzählung wieder, die an Davids Kampf gegen Goliath erinnert: ${ }^{116}$ Bei einem Scharmützel mit den Truppen des Shahrbaraz soll der Kaiser eigenhändig einen riesenhaften Perser besiegt haben; die Parallele zum alttestamentarischen König wird jedoch erneut nicht explizit gemacht. ${ }^{117}$

113 Siehe Leader 2000 und Zahnd 2008, 82, der die Frage nach dem Fundkontext auf Zypern aufwirft und anstelle des kaiserlichen Palastes für „das häusliche Umfeld eines reichen Bürgers“ als Kontext der Schalen plädiert; siehe auch Tsamakda 2010, 30-33, die zwar den Thesen Leaders folgt, aber dennoch einen Bezug zum Perserkrieg herstellt.

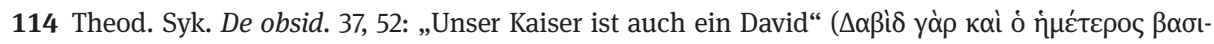
$\lambda \varepsilon \dot{c}()$. In der Predigt dient der David-Bezug einerseits dazu, Konstantinopel als das eigentliche Jerusalem zu etablieren, andererseits steht David als Chiffre für den frommen, siegreichen und von Gott begünstigten Herrscher; durch die Erweiterung auf Salomon kommt schließlich auch eine dynastische Komponente ins Spiel; siehe dazu oben S. 224. Vgl. Ludwig 1991, 95-97 zu der Predigt und $94-104$ zu den David-Bezügen unter Herakleios.

115 Siehe Ma. Whitby 1994, 218f.; Tsamakda 2010, 24f. In Exped. Pers. 2.113-115 lässt Georg Herakleios in einer Rede an seine Soldaten einen davidischen Psalm paraphrasieren, um den Kampf gegen die Perser mit einer religiösen Motivation zu untermauern; siehe außerdem die David-Verweise in Hex. 51-56, 90 f. (David als Psalmist) und In Alyp. 117f., die allerdings nicht in Bezug zu Herakleios stehen. Ein weiterer David-Verweis findet sich in der nach 628 entstandenen Geschichte des Theophylakt Simokattes (4.16): Die triumphale Rede des Bischof Dometianos nach der Rückgewinnung von Martyropolis von den Persern unter Maurikios bezieht sich in ihrem Lob Gottes auf David, allerdings auch hier ohne direkte Analogie zu Herakleios; zu dieser Rede siehe unten S. 298.

1161 Sam 17.

117 Theoph. Conf. AM 6116 (De Boor 314); besonders wenn Theophanes bemerkt, der Kaiser kämpfe in

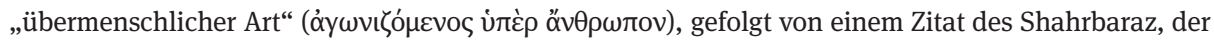
Herakleios für dessen mutigen Einsatz im Kampf lobt, fühlt man sich nicht etwa an David, sondern an 
Belege dafür, dass Herakleios in Analogie zu König David wahrgenommen wurde, finden sich indes in westlichen Quellen: Im bereits besprochenen Sermo de Exaltatione Sanctae Crucis, dessen Entstehung in die 640er-Jahre angesetzt wird, kommt es zum Zweikampf zwischen Herakleios und dem Sohn des Perserkönigs; Herakleios ruft Gott, „der du deinem Diener David den Sieg über Goliath gegeben hast“, um Hilfe an und gewinnt das Duell. ${ }^{118}$ Die fränkische Chronik des Fredegar aus den 650er Jahren wird noch deutlicher: Herakleios habe sich „wie ein zweiter David“ der Herausforderung des Zweikampfes gestellt. ${ }^{119}$ Anstatt davon auszugehen, dass die lateinischen Quellen den David-Verweis aus einer griechischen Tradition übernahmen, ${ }^{120}$ hat Ueli Zahnd zuletzt dafür argumentiert - meiner Ansicht nach überzeugend -, dass es vielmehr westliche Chronisten waren, die den legendarischen Stoff von Herakleios' Zweikampf aufnahmen und „die Parallelen zwischen Herakleios und David als erste explizit ausarbeiteten“. ${ }^{121}$

Allein folgende Überlegung ließe sich anstellen: In Hinblick auf die lateinische Herakleios-Tradition wurde bereits darauf hingewiesen, dass Motive wie das der kaiserlichen Humilitas in manchen Umfeldern Wurzeln schlugen, in anderen nicht. Ebenso könnte es sich mit dem David-Motiv verhalten haben. Folgt man der Hypothese, dass Herakleios einen Bezug auf König David selbst förderte - eine Hypothese, für die zumindest die Namensgebung seines Sohnes spräche - und sich mit seiner Restitutio Crucis gar an David orientierte, dann fand diese Intention in den Deutungen

Georg von Pisidiens Darstellung des Kaisers erinnert, wie ich sie im vorigen Kapitel herausgearbeitet habe. $\mathrm{Zu}$ impliziten David-Bezügen bei Theophanes und Nikephoros siehe Ludwig 1991, 100-102. Greisiger 2014, 142 meint, dass „die Gleichsetzung des Kaisers mit König David nach einigen Jahren offenbar so geläufig geworden [ist]“, dass auch seine Ehe mit Martina mit Verweis auf die Beziehung zwischen David und Bathseba kritisiert wurde; etwa Nik. Brev. 20 als Paraphrase des davidischen Psalms 51.5.

118 Exalt. S. Cruc. 9: donasti uictoriam seruo tuo Dauid aduersus Goliath. Interessant ist hier, dass die Reversio Sanctae Crucis, die gemäß Borgehammar auf dieselbe Quelle wie der Sermo zurückgeht, David nicht anführt; siehe dazu Borgehammar 2009, 161-163, 166.

119 Fred. Chron. 64: Hier verabredet sich Herakleios mit dem Großkönig persönlich zum Duell; dieser schickt jedoch einen General an seiner Stelle in den Kampf. Der Bericht vom Zweikampf zwischen Herakleios und dem persischen General Razates findet sich in leicht abgewandelter Form auch in Nik. Brev. 14 - allerdings ohne den expliziten David-Vergleich. Zur dem Zweikampf-Motiv siehe Speck 1988, 138f., 141-144; Speck geht davon aus, dass dieses Motiv aus einem nicht erhaltenen Herakleios-Roman stammt.

120 So mit Bezug auf Fredegar etwa Wander 1975.

121 Zahnd 2008, 82f.; Zitat ebd. 85. Im Westen habe die David-Imitatio im 8. Jahrhundert eine eigene Qualität erreicht, sei gar in eine „sakral-davidische Herrscheridee“ gemündet (ebd. 85), als sich etwa Pippin der Jüngere 754 von Papst Stephan zum König habe salben lassen (König David war durch Samuel gesalbt worden); durch die Salbung, die im oströmischen Reich erst im 13. Jahrhundert zum Einsatz kam, wurde die Kirche als zentrale Legitimationsinstanz anerkannt. Im 8. Jahrhundert häuften sich dann allerdings auch in Byzanz die David-Bezüge; siehe ebd. 83 - 87 und auch Ludwig 2003, 371373 zu Kaiser Basileios I. 
des Ereignisses durch seine Zeitgenossen kaum Widerhall. ${ }^{122}$ Doch warum schlug Herakleios' mutmaßliche David-Imitatio weder im christlichen Umfeld des Heiligen Landes noch in Konstantinopel Wurzeln? Ich sehe dafür keinen wirklich triftigen Grund, zumal Kaiser vor Herakleios durchaus im positiven Sinne mit David verbunden worden waren. ${ }^{123}$ Die Vermutung, dass die Eroberungen der Araber und das Scheitern der kaiserlichen Religionspolitik Herakleios' David-Imitatio ab absurdum führte und dieses Bild daher aus den Quellen verschwand, ${ }^{124}$ befriedigt nur bedingt: Es gibt eine ganze Reihe an Quellen, die den triumphalen Status quo der Jahre 628-634 wiedergeben; doch auch hier keine Spur von David. ${ }^{125}$ Es bleibt allein festzuhalten, dass die Forschung meiner Ansicht nach dazu tendiert, die Wirkmächtigkeit König Davids als Referenzpunkt kaiserlicher Selbstdarstellung und kaiserlichen Handelns unter Herakleios zu überschätzen. Dass der David-Vergleich in griechischen Quellen in Bezug auf Herakleios' Sieg über die Perser nicht explizit gezogen wird, selbst wenn er geradezu auf der Hand zu liegen scheint, mag schlichtweg daran liegen, dass dieses Motiv nie mit entsprechender Vehemenz kommuniziert wurde.

Bislang wurde vor allem dazu gemahnt, bei der Interpretation der Restitutio Crucis keine voreiligen Schlüsse zu ziehen. Das Ergebnis ist eher ernüchternd, da die gängigen Thesen - sei es die David-Mimesis oder der Ausbau des Tempelberges - aus dieser Perspektive einer ausreichenden Quellen-Basis ermangeln. Dabei sollte man allerdings nicht aus dem Auge verlieren, dass es durchaus Evidenz gibt, die einen Eindruck davon vermittelt, wie die Rückerstattung der Kreuzreliquie von Zeitgenossen wahrgenommen wurde; neben den Texten aus dem Umfeld Jerusalems, die ich oben bereits ausgewertet habe, gebührt dem Gedicht des Georg von Pisdien eine eingehendere Betrachtung.

Als die Nachricht von der Restitutio Crucis am Feiertag des Lazarus in Konstantinopel eintraf, fasste Georg von Pisidien die frohe Nachricht in Worte, die gleichsam

122 Vgl. allerdings Greisiger 2014, 151-156, der Evidenz dafür aufbringt, dass die „(Selbst-)Stilisierung des Kaisers als neuer David gerade im Nahen Osten sehr genau registriert wurde“ (Zitat ebd. 151); ich halte diese Evidenz allerdings für alles andere als eindeutig. Greisiger vermutet ebd., dass sich Herakleios mit der David-Stilisierung auch an jüdische Kontexte gerichtet haben könnte.

123 Siehe etwa das Kontakion „Auf Erdbeben und Brände“, das von Romanos Melodos in Zusammenhang mit der Einweihung von Justinians Hagia Sophia 537 komponiert und vor der hauptstädtischen Gemeinde vorgetragen wurde. In Strophe 18 wendet sich Justinian an Gott und bittet ihn, ihm wie David über Goliath den Sieg zu bescheren; siehe dazu Viermann (im Druck).

124 So Ludwig 2003, 376 und ähnlich Zahnd 2008, 83.

125 Greisiger 2014, 144 sieht den Grund dafür, dass die griechischen Quellen geradezu darum bemüht sind, Herakleios' David-Typologie zu verschleiern, darin, dass sie den Kaiser ,in eine heikle Nähe zu jenem davidischen Messias [rückte], den die Juden erwarteten“. Auch diese Erklärung leuchtet mir nicht ein, da ich bezweifle, dass das hauptstädtische Umfeld sich der jüdischen Aktivitäten in Jerusalem bewusst war. Ma. Whitby 1994, 219 schlägt als Grund dafür, dass Georg von Pisidien die DavidTypologie in Bezug auf Herakleios nicht bemüht, den Umstand vor, dass das eigenhändige Töten eines Gegners nicht in das Bild passt, das Georg vom Kaiser habe zeichnen wollen. 
das Verdienst des Kaisers wie auch die Wirkmächtigkeit der Reliquie würdigen. ${ }^{126}$ Die Jerusalem-Episode wird als letzter Akt des erfolgreichen „Kampfes für den Frieden“

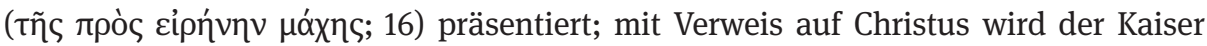
als „neuer Sieger“ ( nicht nur als Objekt, welches Herakleios aus der persischen Gefangenschaft an seinen angestammten Ort zurückbringt, sondern auch als wunderwirkende Waffe, mittels

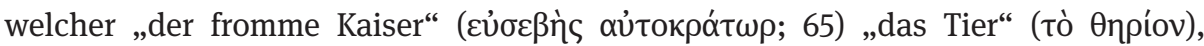
Chosroes, zur Stecke gebracht habe: „Er hat das Feuer niedergebrannt durch das entflammte Holz, das Chosroes als einfaches Holz gering schätzte, das er jedoch als eine Lanze in seinem Herz wiederfand. “128 Schließlich erhebt Georg die Reliquie gar zum Subjekt: Das Kreuz übergibt dem Kaiser die Feinde als „große Trophäe“ ( $\mu \varepsilon ́ \gamma \alpha$

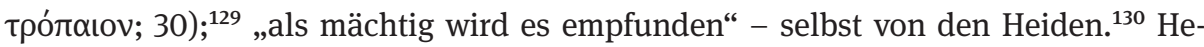
rakleios und die im Kreuz wirkende Macht werden dabei als Einheit beschrieben: „Nun hast du, oh Kaiser, die Macht der unter uns waltenden mystischen Kraft und es rühmt das ganze Land und die Stadt und der gesamte Kosmos in einem einzigen Zusammenklang die dir gegebene Gnade. “"131 Der kriegführende Kaiser der Expeditio Persica, dem die Rüstung besser stand als die Insignien kaiserlicher Hoheit, ${ }^{132}$ steht

126 Zum Eintreffen der Nachricht in Konstantinopel siehe Georg. Pis. Rest. Cruc. 104-116. Mischa Meier (2019, 1045 mit Anm. 109) sieht in dieser Passage Evidenz dafür, dass die Restitutio Crucis für Georg „ganz im Zeichen des unmittelbar drohenden Jüngsten Tages“ stand; diese These gründet auf den Versen 109-110: „Es gehört sich, so meine ich, dass der Auferstehung der Toten auch das erneute

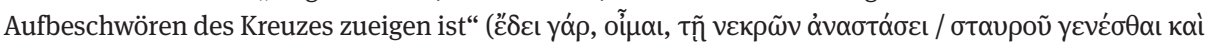
$\pi \alpha \dot{\lambda} \lambda \mathrm{v} \mu \eta v v \dot{\mu} \alpha \tau \alpha)$. Anstatt hierin einen expliziten Verweis auf den Jüngsten Tag zu sehen, sehe ich in darin eher ein Spiel mit dem Lazarus-Thema, das die letzten Verse des Gedichtes. bestimmt.

127 Dazu siehe oben S. 270.

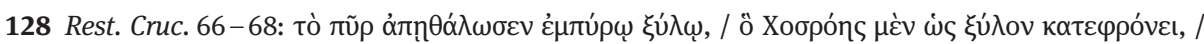

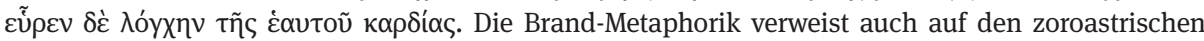
Feuerkult, auf den bereits in Rest. Cruc. 12-14 angespielt wurde. Zum Kreuz als Waffe vgl. bereits ebd. 19-24: Hier wird Herakleios als Held im Stile des Jason dargestellt, der das Goldene Vlies zurückgewann. Neben der Polemik gegen die Perser findet sich auch Polemik gegen die Juden, denen Georg zuruft, sie sollten endlich vom Irrglauben der Väter ablassen (ebd. 25f.).

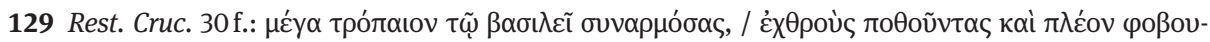
нદ́vous. Zu diesen Versen siehe Gigante 1975, $371 \mathrm{f}$.

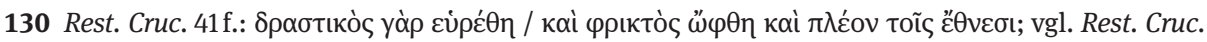
12-14. In ebd. 27-38 ist es das Kreuz selbst, das aufgrund der Sündhaftigkeit der Christen seine Heimat verließ, um sich schließlich zur Rückkehr zu entscheiden. Die Idee, dass Gott mit dem Verlust der Kreuzreliquie die Sündhaftigkeit der Christen strafte, findet sich auch in anderen zeitgenössischen Texten; siehe Booth 2013, 11 f. Booth (ebd., 10-14) weist außerdem auf alternative Deutungen der Restitutio Crucis hin: In einem Gedicht des Sophronios, des späteren Patriarchen von Jerusalem, das ebenfalls kurz nach dem Ereignis komponiert worden zu sein scheint, kommt Herakleios keine tragende Rolle zu.

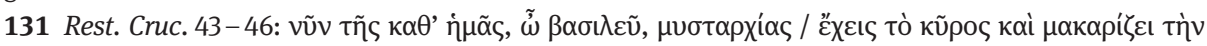

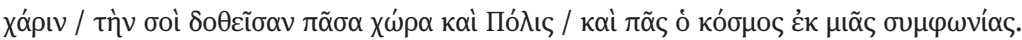

132 Georg. Pis. Exped. Pers. 3.112-115; zu der Weiterentwicklung des Bildes vom ,schwitzende Kaiser nach dem Sieg über die Perser siehe oben S. 236-238. 
nach seinem Sieg über dem Chaos der sich bekriegenden Völker: „Du selbst aber schweigst, der du die Krone und das Szepter trägst, wie ein Richter in Mitten der Ringer; gegen viele hast du gerungen, nun aber beendest du den Kampf.“133

Das Kernstück des Gedichtes nimmt nicht etwa der alttestamentarische König David ein, ${ }^{134}$ sondern ein römischer Kaiser: Konstantin der Große, der gemäß Georg

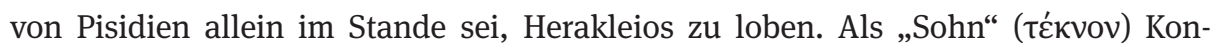
stantins erweist sich Herakleios, da er das in Aufruhr geratene römische Reich wieder in Ordnung gebracht habe. ${ }^{135}$ Die Leistung Konstantins, die Auffindung der Kreuzreliquie, ${ }^{136}$ wird von Herakleios indes noch überboten:

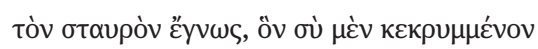

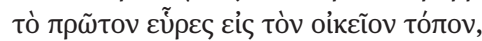

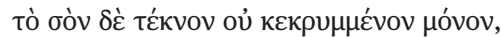

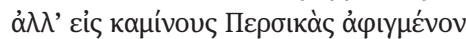

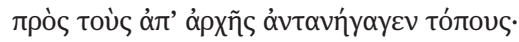

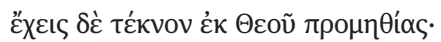

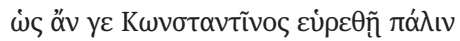

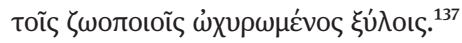

Du hast das Kreuz erkannt, das du zuerst gefunden hast, als es versteckt war an seinem angestammten Platz; dieses aber hat dein Sohn nicht nur, nachdem es versteckt wurde, sondern nachdem es in die persischen Feueröfen gelangt war, an seine ursprünglichen Orte zurückgebracht.

Du aber hast aufgrund der Vorsehung Gottes ein Kind. Als ein neuer Konstantin möge er befunden werden, gestärkt durch die lebensspendenden Hölzer.

Anstatt in eine alttestamentarische Genealogie ordnet der Dichter Herakleios und dessen Restitutio Crucis also in eine christlich-imperiale Tradition ein. ${ }^{138}$ Die kaiserliche Mühe um das Kreuz wird in Konstantinopel, in der Stadt Konstantins, also nicht etwa als David-Imitatio, sondern ganz explizit als Konstantin-Imitatio dargestellt. Im vorigen Kapitel habe ich durch den Vergleich zwischen der kaiserlichen Siegesdepesche von 628 und der Adaption des Georg von Pisidien gezeigt, dass der Dichter bei seiner Modellierung der kaiserlichen Imago durchaus eigene Impulse setzte; in diesem Fall ist die Depesche, die Herakleios von Jerusalem nach Konstantinopel sandte, ${ }^{139}$ nicht erhalten, ein direkter Abgleich also nicht möglich. Dass Georg sich mit dem Konstantin-Motiv durchaus an kaiserlicher Repräsentation orientierte, zeigt der Umstand, dass Herakleios mehrere seiner Söhne, angefangen mit dem 612 geborenen

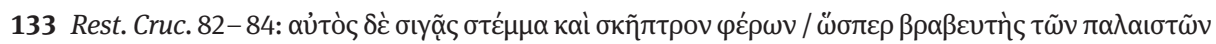

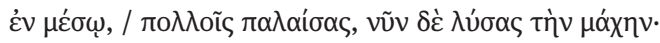

134 Booth 2013, 10 schreibt in Bezug auf Georgs Gedicht: „The emperor is also a new David, restoring to Jerusalem a powerful relic.” Derartige Aussagen sind irreführend, da das Gedicht den Kaiser gerade nicht als neuen David darstellt.

135 Rest. Cruc. 50 f.: „Applaudiere deinem Sohn, wie er deinen geretteten Besitz zeigt, den er als einen

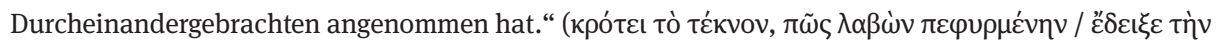

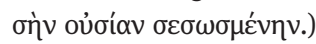

136 Die Auffindung der Kreuzreliquie, die in der Regel Konstantins Mutter Helena zugeschrieben wird, gebührt bei Georg von Pisidien Konstantin selbst.

137 Rest. Cruc. 56-63.

$138 \mathrm{Zu}$ dieser Tradition siehe Spain Alexander 1977, 225f.; Ludwig 1991, 98; Drijvers 2002, 181-184.

139 Dass es eine Depesche gab, zeigt Georg. Pis. Rest. Cruc. 103-114. 
Herakleios Konstantin, nach seinem großen Vorgänger benannte. ${ }^{140}$ Herakleios war nicht der erste Kaiser, der Konstantin als Vorbild evozierte bzw. derart dargestellt wurde; der Fokus auf die Kreuzreliquie, die Herakleios in eine direkte Beziehung zum ersten christlichen Kaiser setzte, brachte allerdings eine neue Ebene in diese Verbindung ein. ${ }^{141}$

Wie ist die Restitutio Crucis nun zu bewerten? Grundsätzlich folge ich der These, dass Herakleios mit der persönlichen Rückerstattung der Kreuzreliquie sein Profil als christlicher Kaiser zu schärfen gedachte. ${ }^{142}$ Damit adressierte er nicht nur die Hauptstadt, deren Akzeptanz er nach wie vor bedurfte, sondern auch die Bevölkerung der rückgewonnenen Ostprovinzen, wo die Wiederkehr der römischen Zentralmacht keineswegs nur positiv aufgenommen wurde. Nachdem Herakleios in Folge seiner siegreichen Rückkehr nach Konstantinopel kaum hatte Spolien vorzeigen können, erhob er das wiedergewonnene Kreuz - nicht zuletzt durch seine persönliche Rückerstattung nach Jerusalem - zur zentralen Trophäe für den kaiserlichen Triumph, bedeutsamer als jede Kriegsbeute. Seinen Einzug in Jerusalem konnte der Kaiser in einen vollumfassend christlichen Deutungszusammenhang stellen. Die Heilige Stadt bot Herakleios eine Bühne, die er flexibler bespielen konnte als das von gewachsenen Verhaltenserwartungen geprägte hauptstädtische Umfeld; die Ausstrahlung des Ereignisses indes reichte bis nach Konstantinopel, wie das Gedicht des Georg von Pisidien zeigt.

Der Überblick über die erhaltene Evidenz spricht dafür, dass sich in Bezug auf die Restitutio Crucis keine autoritative Deutung etablierte; abgesehen von dem Konsens, dass es sich bei Herakleios' Einzug um ein Ereignis sondergleichen handelte, war die Interpretation dessen, was sich im Frühjahr 630 im Heiligen Land abspielte, fragmentiert und stark vom jeweiligen Kommunikationskontext geprägt. Während sich im Westen eine lateinische Tradition herausbildete, die einen demütigen Herakleios Jahrhunderte später zu einem der Vorbilder der Kreuzfahrer-Bewegung werden ließ, ${ }^{143}$ fand in Konstantinopel vor allem die Verbindung zum ersten christlichen Kaiser

140 Spain Alexander 1977, 226 Anm. 50 weist außerdem darauf hin, dass mehrere Inschriften in Kleinasien sowohl Herakleios als auch seine Söhne als „Neuer Konstantin“ betiteln; Drijvers 2002, 181f. Der konstantinische Slogan en touto nika tauchte außerdem auf Münzen von Herakleios Konstantin oder Konstans II. auf; siehe dazu Greisiger 2014, 135 Anm. 248.

$141 \mathrm{Zu}$ Konstantin als Referenzpunkt siehe den Sammelband zu „New Constantines“ (Magdalino 1994); bes. Haldon 1994 mit Blick auf das gesamte 7. Jahrhundert. Drijvers 2002, 181 f. weist darauf hin, dass das Interesse an Konstantin im frühen 7. Jahrhundert offenbar anstieg: Mehrere Konstantins-Viten, in denen die Auffindung des Kreuzes einen wichtigen Platz einnehmen, stammen aus dieser Zeit.

142 Flusin 1992 II, 313: „Il était donc important, pour Héraclius, de se faire reconnâitre par une geste spectaculaire comme l'empereur chrétien, chef à la fois de l'État et de la chrétienté. C'est cette reconaissance qu'il cherche à obtenir en restaurant la Croix à Jérusalem." Zur Bewertung der Restitutio Crucis in der Forschung siehe außerdem Spain Alexander 1977, 225: Mit dem Akt habe sich Herakleios Kritikern entgegengestellt, die seine illegitime Ehe mit Martina anklagten; siehe bereits Frolow 1953, 101-105; vgl. Ant. Strateg. (Conybeare 516).

143 Siehe z. B. Regan 2003, 77; Paul 2012, 187-199; Greisiger (im Druck). 
Konstantin, hergestellt durch die Sorge um die Kreuzreliquie, Resonanz. Im nahöstlichen Raum setzten sich im Laufe des Jahrhunderts - vor allem auch unter dem Eindruck der arabischen Eroberungen, die die Gegend nur einige Jahre nach dem kaiserlichen Einzug in Jerusalem heimsuchten - eschatologische Deutungen durch; ob diese tatsächlich bereits in eventu von Herakleios angelegt waren, lässt sich nicht mehr mit Sicherheit feststellen. Was sich indes in Bezug auf die rückgewonnenen Ostprovinzen plausibel machen lässt, ist die These, dass Herakleios' Restitutio Crucis in engem Zusammenhang mit dem Versuch stand, die dogmatischen Streitigkeiten zu schlichten, welche seit Jahrhunderten die Christenheit spalteten; ${ }^{144}$ diesen Schlichtungsversuch werde ich nun einer genaueren Betrachtung unterziehen.

\subsubsection{Religionspolitik}

Nach seinem Aufenthalt in Jerusalem kehrte Herakleios nicht direkt nach Konstantinopel zurück, sondern bewegte sich in Richtung Nordosten, nach Syrien bzw. Mesopotamien; es galt einerseits, die Sicherung der römisch-persischen Grenzlinie zu überwachen, und andererseits, die Lage innerhalb der zurückgewonnenen Provinzen zu konsolidieren. ${ }^{145}$ Währenddessen kamen die politischen Geschicke Ctesiphons nicht zur Ruhe: Nur 40 Tage, nachdem Herakleios' Verbündeter Shahrbaraz im April 630 den jungen Ardashir hatte ermorden lassen und selbst zum Großkönig gekrönt worden war, erlag er selbst einem Attentat. ${ }^{146}$ Boran, eine Tochter des Chosroes II., die Shahrbaraz nach seiner Einnahme Ctesiphons geheiratet hatte, übernahm an dessen Stelle die Regierung. Sich ihrer schwachen Position bewusst, schickte sie im Sommer 630 eine Gesandtschaft zu Herakleios, angeführt durch den nestorianischen Katholikos Ishoyahb, um ihre Kompromissbereitschaft $\mathrm{zu}$ demonstrieren. ${ }^{147}$ Herakleios seinerseits befand sich nun erneut in der überlegenen Verhandlungsposition und wusste diese zu nutzen: Während im Zuge des Paktes mit Shahrbaraz der Euphrat als Grenze zwischen Rom und Persien festgelegt worden war, blieb Boran nichts anderes übrig, als nun einer Verschiebung weiter nach Osten zuzustimmen. Man einigte sich auf die für Rom äußerst günstige Linie des Jahres 591, die Maurikios durch die Unterstützung des Chosroes II. gegen den Usurpator Baram Chobin hatte erwirken können: Strategisch wichtige Gebiete Transkaukasiens fielen erneut an Rom. Damit

144 Frolow 1953, 101-105 und Stratos 1968, 251f. sehen die Restitutio Crucis als Vorspiel, das einen fruchtbaren Boden zur kaiserlichen Schlichtungspolitik bereiten sollte.

$145 \mathrm{Zu}$ der Sicherung der Grenzen siehe Transl. Anast. Pers. 1 (ebd. 3 verfolgt den Weg des Herakleios bis nach Konstantina am Euphrat) und Sebeos 41 (Thomson/Howard-Johnston I, 90 f.).

146 Bonner 2019, 315.

147 Tod des Shahrbaraz: Sebeos 40 (Thomson/Howard-Johnston I, 89); zur Delegation siehe Anon. Guidi (Nöldeke 32f.), Chron. Seert (Scher 557 f.); vgl. Flusin 1992 II, 320 - 322, außerdem Stratos 1968, 255f. und Kaegi 2003, 212f.; zur Regierung der Boran siehe Bonner 2019, 317. 
war es Herakleios schließlich gelungen, den Status quo der Jahre vor dem Ausbruch des Krieges unter Phokas wiederherzustellen. ${ }^{48}$

Nicht nur realpolitische Fragen nach Truppenstationierungen und Grenzziehungen bestimmten Herakleios' Aktivitäten in den Jahren nach dem Friedensschluss; ab etwa 630 begann er auch verstärkt, sich auf dem kirchen- bzw. religionspolitischen Feld zu betätigen. In dem Moment, als die Perser abgezogen waren, galt es, die Bevölkerung der ehemals besetzten Gebiete wieder auf eine Linie mit Konstantinopel zu bringen. Vor allem religiös begründete Unstimmigkeiten verhinderten eine Annäherung und den nachhaltigen Wiederaufbau von administrativen Strukturen im Sinne der Zentralmacht; dies hatte sich bereits in Edessa gezeigt, wo der lokale Bischof aufgrund religiöser Differenzen die Kommunion mit Herakleios verweigerte. ${ }^{149}$ Nach der Beruhigung des Verhältnisses zum Nachbarn Persien hatte nun religiöse Einigung höchste Priorität - eine Einigung, die nicht nur im obigen Sinne pragmatisch motiviert war, sondern gleichsam auch vor dem Hintergrund des Ideals einer im christlichen Glauben geeinten Ökumene stand. Sich auf die theologische Expertise des Patriarchen Sergios berufend, hatte der Kaiser die Einigung der Kirche bereits vor 628 auf seine Agenda gesetzt; ${ }^{150}$ nach der Rückgewinnung der Ostprovinzen verfolgte er dieses Ziel jedoch mit einer gesteigerten Vehemenz.

Eine derartige Zielsetzung war gewiss keine leichte. Das Zerwürfnis zwischen den verschiedenen christlichen Gemeinden der Levante und Ägyptens konnte auf eine mehrere Jahrhunderte alte Geschichte zurückblicken. Nach dem Konzil von Chalkedon vom Jahr 451, im Zuge dessen die dyophysitische Lehre - die Lehre von den zwei Naturen Christi - im Glaubensbekenntnis festgelegt worden war, hatten sich Syrien und Ägypten als Zentren einer miaphysitischen Opposition herauskristallisiert. ${ }^{151}$ Einigungsversuche von Seiten der Kaiser, welche sich zumindest ab Justin I. zu den Richtlinien des Konzils von Chalkedon bekannten, hatten die Kluft zwischen den Parteien eher vertieft als eingeebnet. Von einem Kompromiss war man auch im Jahr 628 weit entfernt. Die Rückgewinnung der Ostprovinzen durch Herakleios wurde von den dort ansässigen miaphysitischen Gemeinden nicht unbedingt positiv gesehen; mit der chalkedonensischen Zentralmacht in Konstantinopel verband man vor allem Repressionen, während die persischen Besatzer sich gegenüber den Miaphysiten tolerant gegeben hatten. ${ }^{152}$ Der enge Kontakt mit Persien nach 628 brachte nun auch

148 Die Einigung auf die Grenze von 591 ist in Sebeos 41 (Thomson/Howard-Johnston I, 90 f.) bezeugt. Zur Frage der Grenzziehung im Nachklang von Chosroes' Sturz siehe Howard-Johnston 1999, 27-29; zu der Verschiebung der Grenze unter Maurikios siehe Mi. Whitby 1988, 197-202, 304.

149 Dazu siehe oben S. 253.

150 Frendo 1988b, 16; Meyendorff 1989, 338f.

$151 \mathrm{Zu}$ der theologischen Kontroverse vor und im Anschluss an das Konzil von Chalkedon siehe Meyendorff 1989, 165-250; Lange 2012, 21-414; zu der Herausbildung der miaphysitischen Kirche siehe Frend 1972 und Menze 2008 für Syrien; Flusin 1992 II, 95-128 zum Verhältnis zwischen Chosroes II. und den christlichen Gemeinden in seinem Herrschaftsgebiet.

152 Siehe Stratos 1968, 283 - 286; zu den Miaphysiten unter persischer Vorherrschaft siehe Frend 1972, $336-339$. 
nestorianische Gemeinden wieder verstärkt mit ins Spiel: Auf persischem Boden hatte diese Spielart des Christentums, die bereits beim Konzil von Ephesos 431 als Häresie verurteilt worden war, ungestört ihre eigenen Strukturen ausbilden können. Dogmatisch standen die Nestorianer den Miaphysiten wiederum diametral entgegen: Während die Miaphysiten von einer - nämlich der göttlichen - Natur in Christus ausgingen, basierte die Lehre der Nestorianer auf einer deutlichen Trennung der menschlichen und göttlichen Naturen Christi, die über den chalkedonesischen Dyophysitismus noch hinausging. ${ }^{153}$

Viele Kaiser des 4. bis 6. Jahrhundert hatten sich in Hoffnung auf eine Kircheneinigung an christologischen Fragen bereits die Zähne ausgebissen - mit mehr oder weniger großem Schaden für die eigene Reputation. ${ }^{154}$ Doch davon ließ sich Herakleios in seinem ambitionierten Unterfangen nicht abschrecken. Nach der Restitutio Crucis begann er, mit einer Reihe hochrangiger Vertreter der verschiedenen christlichen Denominationen des Nahen Ostens ins Gespräch zu treten. Als Grundlage für die erhoffte Einigung propagierte er eine spezielle christologische Formel, gedeckt durch die theologische Expertise des Patriarchen Sergios von Konstantinopel; eine Formel, welche für alle konfligierenden Parteien gleichsam akzeptabel sein sollte: Anstatt weiter über ein oder zwei Naturen (physeis) Christi zu debattieren, lag ihr Kern in der Annahme einer einzigen göttlichen Energie (energeia) in Christus. Diese Formel war theologisch nicht innovativ; ihr Wert bestand vielmehr darin, dass sie sich einer Sprache bediente, die in der Vergangenheit von Kirchenvätern beider Seiten - sowohl Anhängern des Chalkedonense als auch dessen Gegnern - genutzt worden war. Konstantinopel setzte in seinem Ringen um Einigung also auf eine mutmaßlich gemeinsame Basis. ${ }^{155}$ Diese Lehre, wie sie sich im Laufe der 630er Jahre sukzessive herauskristallisierte, sollte unter dem Schlagwort Monoenergismus bzw. Monotheletismus in die theologischen Debatten eingehen. ${ }^{156}$

Im nordsyrischen Hierapolis, wo Herakleios zuvor bereits Station gemacht hatte, um die Kreuzreliquie in Empfang zu nehmen, traf er auf den einflussreichen mia-

$153 \mathrm{Zu}$ der nestorianischen Kirche in Persien siehe Lange 2012, 471-516; zu Christen in Persien siehe auch Schilling 2008 und Payne 2015.

154 Einen Überblick über die kaiserliche Religionspolitik bietet Lange 2012, 170 - 287; ebd. 288-363 zu Justinian; zu Letzterem auch Uthemann 1999; vgl. Meyendorf 1989, 28 - 38 zum Verhältnis von Kaiser und Kirche.

155 Vgl. Theoph. Conf. AM 6121 (De Boor 329f.). Zu dieser Formel siehe etwa Stratos 1968, 288 und Booth 2014, 188-200; zu den Vorläufern der Lehre von der mia energeia Lange 2012, 428- 446 und zu deren Vor- bzw. Ausarbeitung durch Sergios und Herakleios ebd. 534-552. Zu den theologischen Problemstellungen, die ich hier nicht weiter diskutieren werde, siehe Uthemann 1997 und Hovorun 2008; eine Zusammenstellung der relevanten Quellen zur monoenergetisch-monotheletischen Debatte bietet Winkelmann 1987; vgl. auch Winkelmann 2001.

$156 \mathrm{Zu}$ Beginn der 630er Jahre rankte sich die Debatte um die eine Energie; erst mit der Zeit trat der eine Wille in den Vordergrund, der dann auch den Namen des später verurteilten Dogmas prägte: Monotheletismus; siehe den Überblick über diesen Prozess bei Meyendorff 1989, 333-356 und Hovorun 2008, 55-72. 
physitischen Patriarchen von Antiochia, Athanasios den Kameltreiber, sowie eine Reihe von gleichgesinnten Bischöfen in dessen Gefolge. Obwohl beide Seiten nach mehrtägigen Gesprächen zu Glaubensfragen einen gewissen Grad an Kompromissbereitschaft gezeigt zu haben scheinen, bleibt unklar, ob es zu einer formalen Einigung kam. Athanasios jedenfalls starb kurz drauf, im Jahr $631 .^{157}$ Auch das bereits erwähnte Zusammentreffen mit dem Gesandten der persischen Königin Boran, dem nestorianischen Katholikos Ishoyahb, in Aleppo nutze Herakleios, um sein Einigungsprogramm voranzutreiben. Nachdem die beiden Männer sich gegenseitig ihre theologischen Positionen dargelegt hatten, zelebrierte Ishoyahb in Präsenz des Kaisers die Messe und gewährte ihm die Kommunion; Geschenke wurden ausgetauscht und Hochachtung bekundet, bevor Ishoyahb in seiner Funktion als Gesandter wieder nach Persien zurückkehrte. Die Formel von der einen Energie hatte hier offenbar Anklang gefunden. ${ }^{158}$ In Edessa begegnete Herakleios schließlich dem miaphysitischen Katholikos der armenischen Kirche, Ezr, der mit Aussicht auf großzügige Gegenleistungen die Einigungsformel akzeptierte. Auf einer Synode der armenischen Bischöfe in Theodosiopolis kurz darauf wurde gar die Union mit Konstantinopel bestätigt und das Chalkedonense anerkannt; doch es sollte nicht lange dauern, bis deutlich wurde, dass die Einigungsformel in Armenien nicht auf breitere Unterstützung hoffen konnte. Die Region kam weder administrativ noch kirchenpolitisch zur Ruhe, nachdem sie mit dem territorialen Zugeständnis von Boran größtenteils wieder unter römische Vorherrschaft gekommen war. ${ }^{159}$

Ägypten bereiste Herakleios nicht persönlich, installierte jedoch mit Kyros, dem ehemaligen Bischof von Phasis, einen engen Vertrauten als Patriarch von Alexandria. Neben kirchlicher Hoheit wurde diesem auch umfassende administrative Vollmacht übertragen. Seinem Konkurrenten, dem miaphysitischen Patriarchen Benjamin, der unter der persischen Besatzung uneingeschränkt sein Amt hatte ausüben können,

157 Das Treffen ist einerseits bei Theoph. Conf. AM 6121 (De Boor 329f.) überliefert, wo zumindest vordergründig eine Einigung auf die Lehre von der einen Energie erreicht wird - Herakleios soll Athanasios versprochen haben, ihn im Amt des Patriarchen von Antiochia zu bestätigen, wenn er sich zum Chalkedonense bekenne; andererseits bei Mich. Syr. 11.3 (Chabot II, 412), wo sich Athanasios nicht auf die Angebote des Herakleios einlässt, was zu Verfolgungen der Miaphysiten führt (ähnlich Chron. Seert [Scher 544]). Die Unterschiede spiegeln die Voreingenommenheit der jeweiligen Überlieferungstradition wieder: Theophanes steht für die Anhänger des Chalkedonense, Michael für die miaphysitische, d.h. jakobitische Kirche. Zu dem Treffen siehe Stratos 1968, 293-297; Frend 1972, 346f.; Flusin 1992 II, 321 mit Anm. 81 (zur Frage der Datierung); Kaegi 2003, 214; Lange 2012, 553 - 566 und Booth 2014, 202-204, der das Treffen auf den Winter 629/30 datiert, also vor den Abstecher nach Jerusalem, ausführlich dazu ebd. Anm. 63.

158 Chron. Seert (Scher 557-560); siehe dazu Flusin 1992 II, 319-327; Kaegi 2003, 212f.; Lange 2012, 566 - 570; Booth 2014, $201 \mathrm{f}$.

159 Sebeos 41 (Thomson/Howard-Johnston I, 91f.) und Narratio de rebus Armeniae (Garitte 287-311); siehe Stratos 1968, 291-293; Frend 1972, 345 f.; Thomson/Howard-Johnston 1999 II, 228; Kaegi 2003, 214 f.; Lange 2012, 571-575; Booth 2014, 200. 
blieb nur die Flucht. ${ }^{160} 633$ fand sich auch in Alexandria eine Synode ägyptischer Bischöfe zusammen, auf der unter Kyros' Federführung entlang der Kompromissformel von der einen Energie eine Einigungs-Erklärung erarbeitet werden konnte. Miaphysitische Gläubige bis hin zu prominenten Bischöfen traten mit den Repräsentanten der hauptstädtischen Linie in Kommunion. ${ }^{161}$

Schließlich sahen sich auch jüdische Gemeinden von Herakleios’ Konsolidierungspolitik tangiert - hier kam allerdings eine härtere Linie zum Einsatz. Nach seiner Restitutio Crucis erneuerte der Kaiser den Beschluss, der Juden den Zutritt zur Heiligen Stadt und dem direkten Umland verbot. ${ }^{162}$ Im Jahr 632 erließ er für Afrika ein Edikt, welches die Zwangstaufe von Juden anordnete. Dass derartige Maßnahmen tatsächlich weiträumig Anwendung fanden, ist zwar zweifelhaft; die Jahre nach der Rückgewinnung der Ostprovinzen waren allerdings - so viel lässt sich sagen - geprägt von antisemitischen Ressentiments und gewaltsamen Ausfällen gegen jüdische Gemeinden. ${ }^{163}$

Die Kompromissformel von der einen Energie fand zumindest in manchen Kreisen Anklang. Nach der Wiederherstellung römischer Hoheit im Osten schien also auch Herakleios' nächstes Ziel, die Einigung der christlichen Kirchen, zu Beginn der 630er Jahre bisweilen zum Greifen nahe. Selbst der Papst Honorius, bei dem Sergios brieflich für die Initiative Konstantinopels geworben hatte, signalisierte 634 sein Einverständnis. ${ }^{164}$ Doch nach anfänglichen Teilerfolgen formierte sich schnell entschlossene Opposition gegen die hauptstädtische Initiative - und das von beiden Seiten: Auf

160 Theoph. Conf. AM 6121 (De Boor 330) und zu den Vollmachten des Kyros: Chron. 1234, 118 (Chabot I, 197) und Hist. Patr. Alex. (Evetts 489f.); PLRE IIIA, Cyrus 17 (377f.).

161 Siehe Stratos 1968, 297-299; Kaegi 2003, 216; zur Synode Frend 1972, 349f.; Lange 2012, 575-581; Booth 2014, 205-207; die Einigungserklärung ist erhalten, mit Übers. bei Allen 2009, 169-173.

162 Theoph. Conf. AM 6120 (De Boor 328).

163 Zum Taufedikt siehe Doctrina Iacobi in Dagron/Déroche 2010, 31f. und Mich. Syr. 11.4 (Chabot II, 414); Diskussion bei Olster 1994, bes. 85 f., 123, 162; Kaegi 2003, 216f.; Greisiger 2014, 97-106; außerdem Speck 1997b, bes. 441-467; vgl. zu der antisemitischen Stimmung auch Av. Cameron 1994. Sowohl Fredegar Chron. 65 als auch Hist. Patr. Alex. (Evetts 492) berichten, Herakleios sei durch Astrologie offenbart worden, dass sein Reich an ein beschnittenes Volk fallen werde, woraufhin er die Zwangstaufen der Juden angeordnet habe. Laut Fredegar (ebd.) forderte Herakleios den fränkischen König Dagobert auf, die Juden in seinem Reich taufen zu lassen; Dagobert sei der Aufforderung nachgekommen; Variationen dieser Legende finden sich auch in arabischen Quellen. Siehe dazu Esders 2009, 2018, der dafür argumentiert, dass die Legende ursprünglich in einem chalkedonensischen Milieu in Syrien/Palästina entstand, das Herakleios aufgrund von dessen Religionspolitik feindlich gesinnt war; die Legende sei dann über die Kontakte der pro-chalkonensichen Partei um Sophronios und Maximos Confessor nach Italien - ein Schlüsselereignis ist hier das Lateran-Konzil von 649 - und schließlich zu Fredegar gelangt (siehe Esders 2018, 144-153).

164 Stratos 1968, 301; Kaegi 2003, 269 und ausführlicher Zocca 1992, bes. 110 -123; Lange 2012, 597601; der Briefwechsel in dieser Angelegenheit zwischen Sergios und Honorius mit Übers. bei Allen 2009, 183-209. Honorius brachte dabei eine Variation der Kompromissformel ins Spiel, die Lehre vom einen Willen Christi (hen thelema), die dann 638 in einem kaiserlichen Edikt, der Ekthesis, aufgegriffen wurde. 
lokaler Ebene entzog sich das Gros der miaphysitischen Gemeinden mit ihren gewachsenen Strukturen einer nachhaltigen Annäherung an Konstantinopel; ${ }^{165}$ der vehementeste Widerstand, der auch den Fortlauf der dogmatischen Debatte in den nächsten Jahrzehnten entscheidend prägen sollte, ging allerdings von Seiten prominenter Anhänger des Konzils von Chalkedon aus. Als Zentrum dieser Opposition erwies sich das monastische Umfeld Palästinas, als ihre Galionsfigur ein gewisser Sophronios: In den Klöstern der judäischen Wüste als Schüler des Johannes Moschos sozialisiert, bereiste Sophronios nach der Einnahme Jerusalems durch die Perser 614 das westliche Mittelmeer bis nach Rom und gewann dabei eine ansehnliche Reputation als strikter Verfechter des Chalkedonense. Spätestens 633 erhob er sich offen gegen die durch Sergios und Kyros propagierte Kompromissformel von der einen Energie, die er als unzulässige Verwässerung der orthodoxen Lehre verstand. 634 wurde er zum Patriarchen von Jerusalem gewählt, von wo aus er seine Position weiter vehement vertrat, während Palästina sich bereits mit den ersten Angriffen der Araber konfrontiert sah. ${ }^{166}$ Sophronios' Schüler Maximos, dem seine späteren Aktivitäten den Beinahmen Confessor einbrachten, führte den Kampf seines Mentors nach dessen Tod im Jahr 638 noch über mehrere Jahrzehnte hinweg weiter. ${ }^{167}$ Herakleios' Bemühungen um eine religiöse Einigung der römischen Ostprovinzen wurde indes zu diesem Zeitpunkt bereits durch das sukzessive Vorrücken der Araber zunichte gemacht.

An dieser Stelle geht es nicht darum, die theologischen Feinheiten der Debatte nachzuvollziehen, die durch Herakleios' Aktivitäten in den Ostprovinzen losgetreten wurde; ${ }^{168}$ die nun folgende Analyse ist stattdessen von den Fragen geleitet, warum der Kaiser sich auf dem Feld der Kirchenpolitik betätigte, wie sein Engagement zu bewerten ist und wie es im hauptstädtischen Kontext kommuniziert wurde.

Mit der strukturellen wie organisatorischen Verschränkung von römischem Imperium und christlicher Kirche ab dem 4. Jahrhundert fiel die Sorge um die Herstellung und Wahrung christlicher Einheit in den kaiserlichen Zuständigkeitsbereich. Diese Sorge war nicht zuletzt machtpolitisch motiviert: Je prominenter christlicher Glaube und kirchliche Strukturen im Reichszusammenhang, umso wichtiger wurde auch der funktionale Zusammenhalt der Kirche für die Aufrechterhaltung der öffentlichen Ordnung und die Stabilität des politischen Systems. „A divided Church would also mean a divided empire”, fasst John Meyendorff die Bedeutung eines

165 Siehe Stratos 1968, 302-304. Es bleibt allerdings auch zu betonen, dass die Lehre vom Monoenergismus/Monotheletismus vor allem in chalkedonensischen Gemeinden Syriens und Palästinas angenommen und auch nach der arabischen Eroberung beibehalten wurde, siehe dazu Tannous 2014. $166 \mathrm{Zu}$ der Opposition des Sophronios siehe vor allem Allen 2009 (mit den maßgeblichen Quellen); Booth 2014, 209-224, 228-241 und ders. 2013, 16-26, wo er nachvollzieht, wie sich die palästinensische Kirche angesichts der Eroberung durch die Araber von der Idee des Römischen Reiches als entscheidenden Faktors der christlichen Heilsgeschichte lossagte und somit von Konstantinopel emanzipierte; vgl. auch Kaegi 2003, 269-271 und bes. Schönborn 1972 zu Sophronios.

$167 \mathrm{Zu}$ Maximos Confessor siehe Booth 2014, 269-328.

168 Siehe zur theologischen Debatte zuletzt Winkelmann 2001, 13-21; Hovorun 2008; Lange 2012. 
einheitlichen Glaubensbekenntnisses für die Integration des römischen Reiches zusammen. ${ }^{169}$ Bereits Konstantin bemühte sich aktiv um die Schlichtung dogmatischer Spaltungen: Um den Dissens beizulegen, der durch die Lehren des Presbyters Arius losgetreten worden war, rief der Kaiser 324 das erste ökumenische Konzil in Nikaia zusammen, dem er auch persönlich vorstand. ${ }^{170}$ Seit dem dritten ökumenischen Konzil von Chalkedon 451 unter Kaiser Markian wurde das Glaubensbekenntnis als kaiserliches Gesetz proklamiert: Die Sorge um den rechten Glauben bzw. die rechte Gottesverehrung fiel somit offiziell in den Rahmen kaiserlicher Gestaltungskompetenz. ${ }^{171}$ Die Definition und Durchsetzung von Orthodoxie, die sich im Verhältnis von Gottvater und Sohn verdichtete, avancierte zur ,Staatsangelegenheit‘. Dabei stand der pragmatischen Bemühung um Frieden und Einheit der Gedanke einer Einigung der Christenheit unter römischer Ägide als heilsgeschichtlichen Versprechen zur Seite. ${ }^{172}$ Römische Monarchen beanspruchten nicht nur Synodalgewalt, indem sie Bischöfe zusammenriefen, sondern auch die Autorität, sich auf inhaltlicher Ebene in Glaubensstreitigkeiten einzumischen, was auf Seiten der Kleriker nicht selten auf Kritik stieß; ${ }^{173}$ vor allem Justinian tat sich dahingehend hervor, dass er besonders intensiv in theologische Debatten eingriff. ${ }^{174}$ Gleichzeitig erwartete ab dem 5. Jahrhundert vor allem das Konstantinopolitaner Umfeld von den Kaisern, sich als Wahrer der (chalkedonensischen) Orthodoxie $\mathrm{zu}$ beweisen ${ }^{175}$ - eine Erwartung, die nicht selten in

169 Meyendorff 1989, 33; die Bedeutung der Einigkeit des Christentums für die Aufrechterhaltung öffentlicher Ordnung betont auch Wienand 2016b, bes. 95f. - bereits Konstantins kirchenpolitische Initiativen seien vor diesem Hintergrund zu lesen. Diefenbach 2012, 59-66 gibt einen ausführlichen Überblick über die Forschung zu der Interdependenz zwischen politischen Strukturen und christlicher Kirche im 4. Jahrhundert (mit entsprechenden Literaturverweisen); dabei identifiziert er zwei konträre Ansätze: einerseits die Annahme eines „umfassenden kaiserlichen Integrations- und Normierungswillens“, andererseits „die Betonung eines kaiserlichen Regierungsstils, der stärker an den Maßgaben eines situativen und pragmatischen Reagierens auf lokale Probleme orientiert ist“ (Zitat ebd. 66).

$170 \mathrm{Zu}$ Konstantin auf dem Konzil von Nikaia siehe Wienand 2012, 415-420; dort mit weiterer Literatur. Zuvor hatte sich Konstantin bereits darum bemüht, den Donatisten-Streit in Afrika zu schlichten; dazu siehe Wienand 2016b.

171 Siehe Meyendorff 1989, 28-38 zum Verhältnis von Kaiser und Kirche; ebd. 165-206 zum Konzil von Chalkedon und seinen Folgen.

172 Zum heilsgeschichtlichen Aspekt der Kircheneinigung siehe Greisiger 2014, 121.

173 Die starke Position des oströmischen Kaisers in Bezug auf innerkirchliche bzw. theologische Angelegenheiten wurde in der Forschung bisweilen mit dem Begriff des Caesaropapismus beschrieben; zur Begriffsgeschichte siehe Dagron 2003, 282-312, der sich allerdings von dem Begriff distanziert. Zum Kaiser als Priester siehe Treitinger 1956, 124-144; Höfert 2015, 139-145, $197-229$.

174 Zur Religions- bzw. Kirchenpolitik Justinians siehe Uthemann 1999. Der Codex Iustinianus beginnt mit einem formalen Glaubensbekenntnis; siehe dazu Speigl 1995. Eine systematische Untersuchung, die die Entwicklung der kaiserlichen Religions- und Kirchenpolitik vor dem Hintergrund der funktionalen Interdependenz von politischen und kirchlichen Prozessen - und nicht zuletzt die Rolle der Kaiser in dieser Entwicklung - von Konstantin bis ins 6. bzw. 7. Jahrhundert untersucht, ist meines Wissens ein Desiderat; auch die Studie von Meyendorff 1989 leistet dies nur in Ansätzen.

175 Diefenbach 1996, 58; Meier 2003c, 145, 147. Nach dem Tod des Zenon forderte die hauptstädtische Bevölkerung einen frommen und orthodoxen Kaiser, siehe De cerim. 1.92. 
Konflikt zu kaiserlichen Bemühungen trat, die Gemeinden, die das in Chalkedon definierte Dogma nicht anerkannten, in die reichsumfassende Kirche zu reintegrieren. Empfand das hauptstädtische Umfeld kaiserliche Maßnahmen in diesem Sinne als unzulässig, konnte es zu Akzeptanzentzug kommen, der die Stabilität der Regierung empfindlich schwächte. ${ }^{176}$

So sehr sich die römischen Kaiser auch um die Einigung der Christenheit bemühten, konnte doch kein umfänglicher Erfolg erzielt werden. Anstelle einer konfessionellen Einigung vertieften sich die Gräben zwischen den verschiedenen Denominationen. Mit der Festigung der jakobitischen und koptischen Kirche bildeten sich im Osten des römischen Reiches ab dem 6. Jahrhundert alternative Organisationsstrukturen heraus, was nicht zuletzt den Zugriff der Zentralmacht auf die jeweiligen Gebiete beeinträchtigte. ${ }^{177}$ Auf die Spaltungen bzw. die Abweichung von dem, was in Konstantinopel als orthodox angesehen wurde, reagierten die römischen Kaiser mal mit Gesprächs- und Kompromissbereitschaft, mal mit gewaltsamen Sanktionen; keine der beiden Herangehensweisen erwies sich als nachhaltig. Seit Justin II. sahen sich die miaphysitischen Gemeinden des Ostens mit zunehmend harschen Restriktionen und zeitweise gar Verfolgungen von Seiten der Zentralmacht konfrontiert. ${ }^{178}$ Dass auch Herakleios sich auf dem Feld der Kirchenpolitik engagierte, ist also zunächst nicht verwunderlich. Mit dem Sieg über die Perser im Rücken diente seine Initiative primär der Festigung römischer Herrschaftsstrukturen in den Ostprovinzen und wurde gleichzeitig - wie ich im Folgenden ausführen werde - in der Hauptstadt im Sinne einer Profilschärfung des Kaisers im sakralen Feld aufbereitet. ${ }^{179}$

Während seine Vorgänger gegenüber den Miaphysiten einen konfrontativen Kurs eingeschlagen hatten, war Herakleios' Politik auf der praktischen Ebene von Kompromissbereitschaft geprägt; zeitweise lässt sich unter seiner Regierung gar ein recht hohes Maß an Toleranz ${ }^{180}$ gegenüber den nahöstlichen Kirchenstrukturen, die sich weiterhin strikt vom Chalkedonense abgrenzten, beobachten: 615/616 bemühte sich

176 Zum „Kampf um den rechten Glauben“ aus der hauptstädtischen Perspektive siehe Pfeilschifter 2013, 313-329. Der Sturz des Kaisers Basiliskos erfolgte 476 nach kurzer Regierung nicht zuletzt aufgrund dessen religionspolitischer Positionierung zugunsten der miaphysitischen Denomination; siehe dazu Redies 1997; Kolditz 2013; Pfeilschifter 2013, 564-584.

177 Zu dieser Entwicklung siehe die Monographie von Frend 1972; Meyendorff 1989, 266-280; zur Herausbildung einer miaphysitischen Kirche in Syrien siehe Menze 2008; Wood 2011 (Letzterer vor allem mit Blick auf die politische Theologie des syrischen Raumes).

178 Zur Religionspolitik des Justin II. siehe Av. Cameron 1976c; zu den Verfolgungen des Miaphysiten und einer daraus resultierenden Stärkung des antichalkedonensischen Widerstandes siehe Frend 1972, $316-335$.

179 Vgl. dazu Frendo 1988b, 17 f., der hinter der Kirchenpolitik vor allem die Ambition des Sergios und eine ,arrogance of invincibility” sieht.

180 Den Begriff der Toleranz in Zusammenhang mit der Kirchen- bzw. Religionspolitik Konstantins diskutiert Wienand 2016b, bes. 78-84. Demnach bedeutet Toleranz, dass als normativ falsch beurteilte Praktiken/Überzeugungen geduldet werden. Im Falle der Bemühungen des Chalkedonensers Niketas um eine inner-miaphysitische Kircheneinigung trifft der Begriff demnach tatsächlich zu. 
Niketas, Herakleios' Cousin, in seiner Funktion als Praefectus Augustalis von Ägypten, eine inner-miaphysitische Spaltung beizulegen, indem er Vertreter der koptischen und der jakobitischen Kirche in Alexandria zu Gesprächen zusammenbrachte. Davon, dass Niketas' Initiative im kaiserlichen Sinne war, ist auszugehen. ${ }^{181}$ Bereits kurz nach Herakleios' erfolgreicher Usurpation lassen sich also von offizieller Seite Bemühungen nachvollziehen, die römischen Ostprovinzen, die von jahrelangen inneren Unruhen (Revolte der Herakleioi, gewaltsame Ausschreitungen innerhalb der Städte) destabilisiert waren, durch eine deeskalierende Kirchenpolitik zu befrieden. Nachdem die Einigungsbemühungen angesichts der persischen Okkupation vorerst hatten auf Eis gelegt werden müssen, nahm Herakleios das Unterfangen nach dem Friedensvertrag von 628 erneut auf: Indem er die eine göttliche Energie Christi, die weder den chalkedonensischen noch den miaphysitischen Glaubensgrundsätzen widersprach, ${ }^{182}$ ins Zentrum seiner interkonfessionellen Verhandlungen rückte, setzte er auf das Erreichen eines Minimalkonsenses. Anstatt mit kaiserlichen Edikten einen Kompromiss zu erzwingen, wie es seine Vorgänger bisweilen versucht hatten, setzte Herakleios ab 630 auf Gespräche auf lokaler Ebene mit den jeweils prominenten Gemeindevertretern; eine überregionale Synode wurde vorerst nicht einberufen. Nicht zuletzt das Prestige, das der Erfolg gegen die Perser und zuletzt die Restitutio Crucis ihm als christlichem Kaiser eingebracht hatte, mag die Basis dafür bereitet haben, dass sein persönliches Engagement zumindest vorübergehend auf fruchtbaren Boden fiel. ${ }^{183}$

Neben der Notwendigkeit, die wiedergewonnenen Ostprovinzen auf kirchenpolitischer Ebene in den Reichszusammenhang einzubinden, lässt sich Herakleios' Initiative auch vor dem Hintergrund sehen, dass sich in den Jahren zuvor ein anderer Monarch um die Einigung der Christenheit bemüht hatte: der persische Großkönig. Chosroes II. veranlasste und förderte nicht nur den Wiederaufbau Jerusalems nach der Eroberung durch seine eigenen Truppen, ${ }^{184}$ sondern berief auch - ganz im Stile der römischen Kaiser - die christlichen Bischöfe seines Einflussbereiches zu Synoden zusammen, um die innerchristlichen Streitigkeiten zu schlichten: Bereits 612 versammelte er zum Zweck der Kompromissfindung Vertreter der Miaphysiten und Nestorianer in Ctesiphon; die theologischen Debatten überwachte er persönlich. ${ }^{185}$ Während die nestorianische Kirche im persischen Kernland weiterhin die Oberhand behielt, konnten die Miaphysiten in den besetzten Gebieten ohne Restriktionen der

181 Siehe dazu Olster 1985; Frendo 1988b, 12, 17; Greisiger 2014, $122 \mathrm{f}$.

$182 \mathrm{Zu}$ der Lehre von der einen Energie vor dem 7. Jahrhundert bei miaphysitischen und chalkedonesischen Autoren siehe Lange 2015, 415-446.

183 Vgl. Frend 1972, 343; Frendo 1988b, 16 f.

184 Dass Chosroes' Engagement in den griechischen (romfreundlichen) Quellen verschwiegen wird, ist kaum verwunderlich; es lässt sich indes aus Quellen erschließen, die dem persischen Kulturraum näherstanden: Sebeos 34 (Thomson/Howard-Johnston I, 70); Anon. Guidi (Nöldeke 29); siehe dazu Payne 2015, 183, der auch die Vertreibung der Juden aus Jerusalem durch die Perser, wenige Jahre nach der Eroberung 614, als eine an christliche Kaiser gemahnende Praktik liest (ebd. 183f.).

185 Payne 2015, 185, 187 f.: Ein Kompromiss kam offenbar nicht zustande. 
Zentralmacht ihre Strukturen ausbauen; die chalkedonensischen Gemeinden hingegen, welche die kirchenpolitische Linie der römischen Zentrale verfolgten, waren nun der politischen Unterstützung beraubt. ${ }^{186}$ Als die benachbarte Großmacht Persien also nicht nur weite Teile des östlichen Mittelmeerraumes in ihren Besitz brachte, sondern sich auch ganz aktiv als alternativer Rahmen für die Aushandlung und Verbreitung des christlichen Glaubens anbot, wurde die organische und geradezu exklusive Verbindung, die das Christentum mit dem römischen Reich gebildet hatte, in Frage gestellt. ${ }^{187}$ Dass Herakleios die Einigungspolitik nach der Rückgewinnung der Ostprovinzen derart vehement und mit persönlichem Einsatz vorantrieb, ist nicht zuletzt vor diesem Hintergrund zu verstehen: Es galt, den Bewohnern der Provinzen nicht nur die politische Vorherrschaft des römischen Reiches, sondern auch die religiöse Autorität des römischen Kaisers als Oberhaupt des Christentums gegen potentielle Konkurrenten vor Augen zu führen. Für eine derartige Motivation spricht nicht zuletzt der Umstand, dass sich Herakleios auch ganz dezidiert um eine Einigung mit der nestorianischen Kirche bemühte, die nach der Emigration ihrer Vertreter nach Persien lange Zeit nicht vorrangig auf der Agenda römisch-imperialer Kirchenpolitik gestanden hatte.

Beim Blick auf die monoenergetische Einigungspolitik kommt regelmäßig die Frage auf, ob tatsächlich Herakleios selbst als treibende Kraft hinter dieser Initiative stand oder ob nicht vielmehr der konstantinopolitaner Patriarch Sergios, selbst ein gebürtiger Syrer, als Strippenzieher zu identifizieren ist. ${ }^{188}$ Die Quellen zeichnen meiner Ansicht nach ein recht deutliches Bild: Die offenbar reibungslos funktionierende Zusammenarbeit zwischen Kaiser und Patriarch, die bereits im vorigen Kapitel in Zusammenhang mit Herakleios' Abwesenheit von der Hauptstadt betont wurde, griff auch auf dem Feld der Kirchenpolitik. Während Sergios den monoenergetischen Kompromiss auf theologischer Ebene bereits über Jahrzehnte vorbereitet und beworben hatte, ${ }^{189}$ stand Herakleios nach der Rückgewinnung der Ostprovinzen der Einigungsbemühung sowohl operativ als auch repräsentativ vor. ${ }^{190}$ Eine derartige Symbiose von Patriarch und Kaiser in kirchenpolitischen Angelegenheiten war keinesfalls selbstverständlich; Justinian hatte, wenige Jahre vor seinem Tod, aufgrund der von ihm favorisierten Lehre des Aphtartodoketismus mit dem Patriarchen Euty-

186 Frend 1972, 336-339; Frendo 1988b, 11; Meyendorff 1989, 340f.; Flusin 1992 II, $95-128 \mathrm{zu}$ Chosroes II. und den Christen; Payne 2015, 181-188 zu den christlichen Gemeinden unter persischer Herrschaft.

187 Booth 2014 zeigt in seiner Monographie, wie sich die Vorstellung einer christlichen Ökumene vom römischen Imperium als politischem Rahmen löste; dies geschah nicht nur während der persischen Okkupation und später angesichts der arabischen Expansion, sondern verstärkt auch von Seiten der ultra-chalkedonensischen Opposition gegen Herakleios' Einigungspolitik, die sich um Sophronios von Jerusalem und Maximos Confessor gruppierte.

188 Van Dieten 1972, 24 Anm. 82; Frendo 1988b, 10.

$189 \mathrm{Zu}$ der theologischen Grundlage siehe Lange 2012, 540 - 553.

190 Vgl. Greisiger 2014, 124: „War Sergios der intellektuelle Architekt der angestrebten Einigung, so fungierte Herakleios als deren pragmatischer Organisator.“ 
chios einen erbitterten Zwist ausgetragen, der schließlich in der Exilierung des Patriarchen eskalierte. ${ }^{191}$ Im Gegensatz dazu scheint Herakleios Sergios' theologischen Eingaben gefolgt zu sein, was die Annahme eines herrschaftspragmatischen Ansatzes seiner Schlichtungsversuche noch untermauert; im Gegensatz zu Justinian war Herakleios kein Theologe.

Vergleicht man jedoch den kompromissorientierten Ansatz, mit dem Herakleios der Lage in den Ostprovinzen Herr zu werden versuchte, mit der Art und Weise, wie diese Initiative vor einem hauptstädtischen Publikum besprochen wurde, so offenbart sich eine deutliche Diskrepanz. Einen Einblick in den konstantinopolitaner Diskurs bietet wieder einmal Georg von Pisidien, dessen Gedicht Contra Severum kaum anders denn als Kommentar zur kaiserlichen Einigungspolitik gelesen werden kann: Anstelle von Kompromissbereitschaft herrscht hier eine konfrontative Rhetorik vor, die nicht selten in offene Polemik ausartet. ${ }^{192}$ Hinsichtlich der Datierung des Gedichtes ist sich die Forschung uneins. ${ }^{193}$ Während die Komposition bisweilen mit der Veröffentlichung der Ekthesis im Jahr 638 in Verbindung gebracht wird, eines kaiserlichen Ediktes, das die monoenergetisch-monotheletische Kontroverse $\mathrm{zu}$ schlichten gedachte, ${ }^{194}$ halte ich eine Datierung in die frühen 630er Jahre für wesentlich plausibler - in die Zeit, als Herakleios die konfessionelle Einigung persönlich in den Ostprovinzen durchzusetzen suchte. ${ }^{195}$ Die Charakteristika des Gedichtes, die allen voran ins Auge stechen, sind Folgende: Georg stellt Herakleios als kompetenten und autoritativen Agenten auf dem religiösen Feld in den Vordergrund; der vom Kaiser ausgefochtene Kampf gegen die Häretiker steht auf einer Ebene mit dem gegen die ungläubigen Perser.

Das vordergründige Ziel des Gedichtes ist es, die Überlegenheit und Wahrheit des chalkedonensischen Glaubensbekenntnisses gegenüber den Miaphysiten zu bezeugen. Georg richtet seine Kritik vorrangig an Severos, den 538 verstorbenen Bischof von

191 Dazu siehe Uthemann 1999, 79-82; Meier 2003a, 289-291.

192 Vgl. Frendo 1988b, 17. Anders Larison 2019, bes. 166 f., der allerdings nicht zwischen dem Diskurs, wie wir ihn in Georg von Pisidien sehen, und Herakleios’ praktischen Maßnahmen unterscheidet: Ausgehend von Contra Severum schließt er, dass Herakleios eine strikte anti-miaphysitische Politik vertreten habe: „the idea of 'conciliatory' religious policies under Heraclius is not tenable.” (Zitat ebd. 167).

193 Der Sieg über die Perser wird in Cont. Sev. 24-33 thematisiert, ebd. 34 der Tod Chosroes' als terminus post quem.

194 So etwa MacCoull 1998, 76-79, die meint, im Gedicht intertextuelle Referenzen zur Ekthesis erkennen zu können (nämlich die Nutzung des Begriffs ektheseis [Cont. Sev. 677]), die ich allerdings nicht für aussagekräftig genug halte, um eine Spätdatierung zu untermauern; auch Larison 2019, 169f. äußert sich dahingehend kritisch; zur Ekthesis siehe unten S. 312f.

195 So auch Frendo 1988b, 17; Tartaglia 1998, 22-25; Ma. Whitby 1998, 271; Howard-Johnston 2010, 23f. geht gar davon aus, dass das von Herakleios in Auftrag gegebene Gedicht noch 629 vollendet wurde, bevor der Kaiser erneut gen Osten aufbrach; seiner Ansicht nach sei es unwahrscheinlich, dass ein derartig polemisches Gedicht nach dem Beginn der Einigungsgespräche entstanden sei. Dass sich allerdings die praktische Kompromissbereitschaft einerseits und die diskursive Polemik andererseits keineswegs ausschließen, wird im Folgenden deutlich. 
Antiochia, eine zentrale Identifikationsfigur der syrisch-miaphysitischen Kirche. Den Hauptteil des Gedichtes, der mit Bezugnahme auf eine Reihe prominenter Kirchenväter das theologische Argument ausbreitet, unterziehe ich hier keiner eingehenden Analyse, ${ }^{196}$ sondern konzentriere mich stattdessen auf Proömium und Epilog, die dem Herakleios gewidmet sind. Dank des besonders weisen Geistes ( $\varphi \rho \circ \nu \mu \omega \tau \alpha \dot{\tau} \tau \eta$

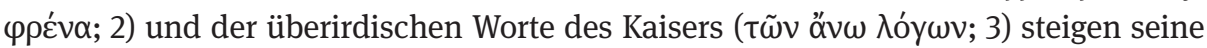

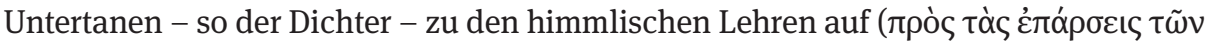

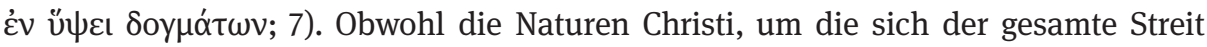
dreht, von den Menschen kaum zu erfassen seien, ${ }^{197}$ betont Georg von Pisidien die kaiserliche Kompetenz in dieser Angelegenheit. Zuerst blickt das Gedicht auf Hera-

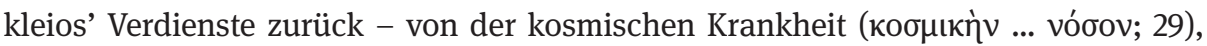
den Barbaren und Tyrannen, habe der Kaiser die Menschheit befreit ${ }^{198}$-, um dann auf dessen Nemesis, den inzwischen ermordeten Perserkönig Chosroes, überzuleiten: Dieser habe die Ordination von Bischöfen gefördert, die der Lehre des Severos folgten,

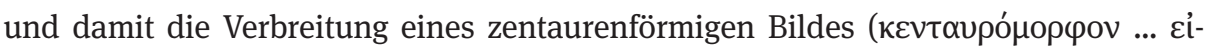
кóva; 43), des miaphysischen Irrglaubens, begünstigt - „unseren Glauben in Brand

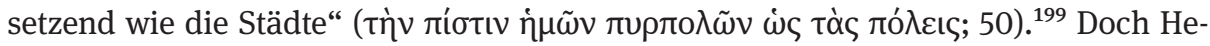

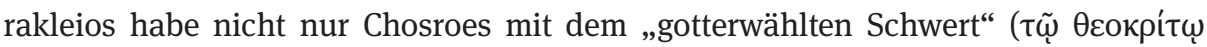
$\xi^{\prime}\left(\varphi \varepsilon \iota\right.$; 59) getötet, sondern auch den Aberglauben der Mager ausgemerzt. ${ }^{200}$ Die größte

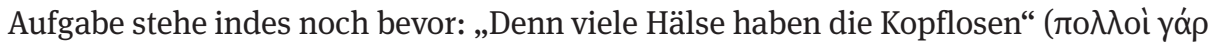

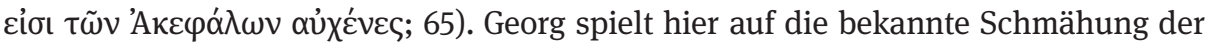
Miaphysiten als Akephaloi, als Kopflose, an, ${ }^{201}$ um dann unter Bezugnahme auf die bereits wohlbekannte Herakleios/Herakles-Analogie ${ }^{202}$ festzustellen, dass „unser

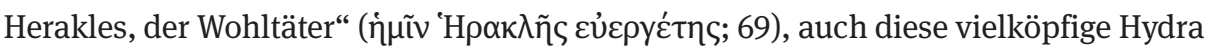
zur Strecke bringe: „Das tatkräftige und weise Feldherrentum wendet sich von den Barbaren hin zu den Schriften, damit derjenige, der die Barbaren überzeugt hat still zu halten, nun ebenso wie diese auch die Häresien vom Stillhalten überzeugt. “203 He-

196 Eingehende Interpretationen des Gedichtes, die auch die theologische Argumentation einschließen, finden sich bei MacCoull 1998 und Larison 2019; außerdem etwas knapper Tartaglia 1998, $22-25$.

197 Cont. Sev. 9-23.

198 Cont. Sev. 24-33.

199 Cont. Sev. 34-55.

200 Cont. Sev. 58-61. Ähnliches Lob auf Herakleios, das wohlbekannte Motive aufgreift, findet sich auch in Cont. Sev. 450-457; hier kommt auch das Epithet kosmorustes (dazu siehe oben S. 239 und Meier 2015, 185f.) erneut zum Einsatz; Herakleios wird außerdem analog zur mythologischen Figur des Orpheus gezeichnet; dazu MacCoull 1998, 75.

201 Diese Bezeichnung geht auf die Situation zurück, als sich die ulta-miaphysitischen Mönche Ägyptens von ihrem ,Oberhaupt', dem alexandrinischen Patriarchen Petros Mongos, lossagten, nachdem dieser Zenons Henotikon unterschrieben hatte; siehe Larison 2019, 175.

202 Dazu siehe oben S. 135 f.; zu dieser Stelle im Speziellen Meier 2015, $174 \mathrm{f}$.

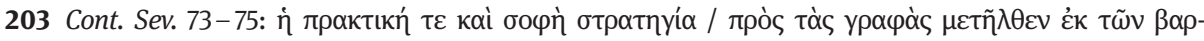

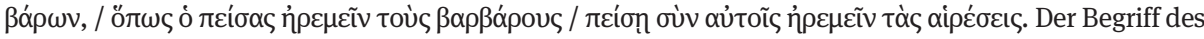
strategos bzw. der strategia in Bezug auf Herakleios ist zentral in Georgs Ouevre; siehe oben S. 194. 
rakleios' strategia, die er zuvor im Krieg gegen die Perser unter Beweis gestellt hat, richtet sich nun also auf die Auslegung der Heiligen Schriften. ${ }^{204}$ Als Basis dieses Unterfangens dient dem Kaiser die Inspiration durch den Heiligen Geist: „das Feuer

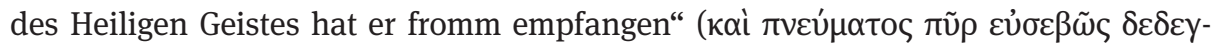

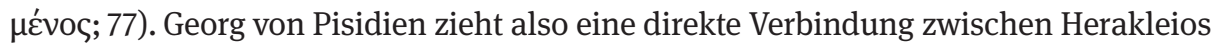
und der göttlichen Sphäre; eine Verbindung, die die theologische Initiative des Kaisers autorisiert: „Mit dieser Erkenntnis der Schriften eröffnet er [i.e. Herakleios] uns die von Gott geschriebenen Tafeln, die er in seinem Herzen trägt, nicht abgeschrieben aus Lehrbüchern, sondern vom göttlichen Finger eingeprägt. “205 In den Versen wird der Heilige Geist zum summachos des Kaisers, zum Kampfgefährten, „erst in Bezug auf die

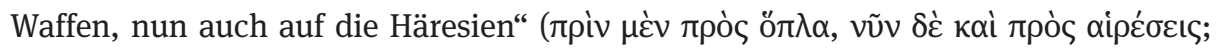
156f.). Das Gedicht schließt mit folgendem Bild: „So rennt Christus überall mit dir [i.e. Herakleios] gemeinsam; und überall zeigt er dich als den Sieger.“206

Liest man das Contra Severum als Sprechakt, der auf die spezifischen Anforderungen und Erwartungen des hauptstädtischen Umfeldes - genauer gesagt: weltlicher und kirchlicher Würdenträger ${ }^{207}$ - reagierte, so zeigt sich, dass religiöser Kompromiss, wie Herakleios ihn praktisch in den Ostprovinzen zu implementieren versuchte, im hauptstädtischen Umfeld nicht positiv konnotiert werden konnte; allein eine Rhetorik der Härte und Intoleranz versprachen offenbar vor einem derartigen Publikum eine kaiserliche Profilschärfung. ${ }^{208}$ Anstelle einer interkonfessionellen Einigung, wie sie der Kaiser in den Ostprovinzen durchzusetzen versuchte, stellt Georg von Pisidien Herakleios' Sieg über die Häresien in Aussicht - ein Sieg, der als logische Konsequenz aus dem bereits errungenen, gottgegebenen Triumph über die Perser resultiert. Die Konfrontation mit den Miaphysiten reduziert er dabei im Wesentlichen auf eine Polemik gegen den längst verstorbenen Bischof Severos als offensichtlichen Strohmann; auf eine differenzierte Bewertung der kirchenpolitischen Konstellation kommt es dem Dichter nicht an. ${ }^{209}$ Weder die Kompromissformel des Monoenergismus noch deren Entwickler, der Patriarch Sergios, werden in den Versen auch nur eines einzigen Wortes gewürdigt; die theologischen Details der interkonfessionellen Gespräche

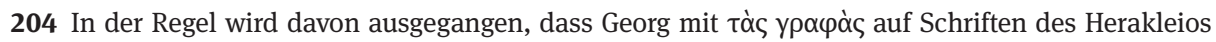
gegen die Miaphysiten anspielt (Tartaglia 1998, 23); mir scheint dagegen eher plausibel, dass er damit die Heilige Schrift oder die Schriften der Kirchenväter meint.

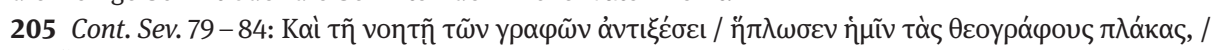

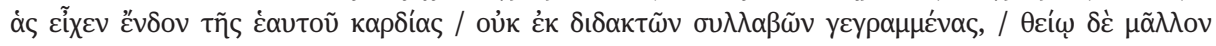

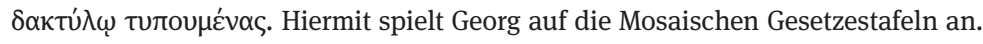

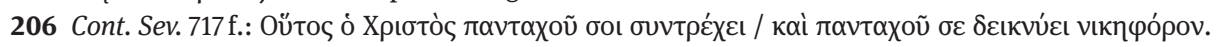
$207 \mathrm{Zu}$ Georgs Publikum siehe oben Kap. 5.1. Ich bezweifle, dass sich das Gedicht an miaphysitische Kreise richtete (davon geht etwa Tartaglia 1998, 23 aus); wie auch die anderen Gedichte Georgs, so richtete sich auch Contra Severum an ein hauptstädtisches Publikum.

208 Ähnliches hat Wienand 2016b, bes. 96 bereits in Bezug auf Konstantin beobachtet, wobei natürlich betont werden muss, dass die Umstände im frühen 4. Jahrhundert noch andere waren.

209 Allein in Cont. Sev. 706-712 könnte man einen Verweis auf Herakleios' Treffen mit Vertretern der miaphysitischen Kirchen vermuten; siehe dazu Kaegi 2000, 229f.; Larison 2019, 165. 
werden vernachlässigt. ${ }^{210}$ Dies ist besonders vor dem Hintergrund bemerkenswert, dass der Kleriker Georg damit seinen direkten Vorgesetzten, den Patriarchen, der in den früheren Gedichten oft als Protagonist glänzte, ausblendet; stattdessen stilisiert er Herakleios als Vorkämpfer und göttlich inspirierten Agenten der chalkedonensischen Orthodoxie. Dem Kaiser gesteht Georg eine direkte Verbindung zur göttlichen Erkenntnis zu; die Rolle der Kirche bzw. deren höchster Vertreter als zwischen himmlischer und irdischer Sphäre vermittelnde Instanz wird rundweg ausgespart. Bedenkt man das Ringen zwischen Kaiser und Kirche um die Deutungshoheit in theologischen und kirchenpolitischen Fragen, das die Verschränkung von römischer Monarchie und christlicher Kirche mit sich brachte, so ist diese Beobachtung bemerkenswert: Während Herakleios praktisch den theologischen Eingaben des Patriarchen Sergios folgte, erhob Georg ihn im Diskurs zur unangefochtenen religiösen Autorität, zum Eiferer für den rechten Glauben. ${ }^{211}$ Das Gedicht versucht, die Kirchenpolitik vor einem hauptstädtischen Publikum als weiteres Feld zu etablieren, auf dem Herakleios sich als - im chalkedonensischen Sinne - orthodoxer und sieghafter Kaiser profilieren kann; das Epithet des nikephoros, das der Dichter dem Kaiser bereits in den Versen auf die Restitutio Crucis antrug, ${ }^{212}$ kommt auch hier wieder zum Einsatz. ${ }^{213}$ Gleichzeitig schimmert im Contra Severum jedoch auch die hortative Qualität von Panegyrik durch: Georg machte mit seinem Gedicht eindrücklich klar, dass religiöser Kompromiss in der Hauptstadt keine akzeptable Option war.

Während Georgs Contra Severum unzweideutig einen Kommentar zu Herakleios' Kirchenpolitik abgibt, ist der Zusammenhang eines weiteren Textzeugnisses zwar nicht zweifelsfrei belegbar, zumindest aber plausibel: genauer gesagt des enkomiastischen Dialoges, der dem Geschichtswerk des Theophylakt Simokattes vorgeschaltet ist. Dieser Dialog wurde bereits in Bezug auf die konsequente Schmähung von Herakleios’ Vorgänger Phokas als Tyrann besprochen. Theophylakt Simokattes weiß vom Tode Chosroes'; das Geschichtswerk wurde also nach 628 vollendet. Den Dialog genauer zu datieren, ist aufgrund des Mangels an eindeutigen Hinweisen schwierig; eine Komposition in den frühen 630er Jahren wäre jedoch durchaus denkbar. ${ }^{214}$ Die bild-

210 Vgl. Tartaglia 1998, 24.

211 Soweit ich dies im Moment überblicken kann, ist die Art und Weise, wie Herakleios hier im Diskurs mit göttlicher Erkenntnis und theologischer Autorität ausgestattet wird, auch im Vergleich zu den vorigen Jahrhunderten bemerkenswert. Ohne diesem Aspekt einer genaueren Untersuchung widmen zu können, scheint mir, dass ähnlich starke Aussagen in Bezug auf Konstantin noch getätigt werden konnten, der als erster christlicher Kaiser über einen recht bereiten Handlungsspielraum verfügte. Seine Nachfolger konnten sich derartige Aussagen (bzw. Zuschreibungen) - angesichts der sukzessiven Festigung von Möglichkeiten und Grenzen kaiserlichen Handelns im kirchenpolitischen Sektor - kaum mehr leisten.

212 Rest. Cruc. 8.

213 Erst Jahre später, als Herakleios mit der Ekthesis einen Kommentar zur Einigungspolitik als kaiserliches Edikt proklamierte, sollte auch die hauptstädtische Öffentlichkeit mit Details der Kirchenpolitik konfrontiert werden; dazu siehe unten.

$214 \mathrm{Zu}$ den Datierungsfragen siehe oben S. 134 Anm. 254. 
hafte und metaphorische Sprache des Dialoges erschwert indes die Interpretation des Textes. Ein Aspekt, hinsichtlich dessen sich die Forschung kaum einig werden kann, ist die Frage, wer sich hinter dem „großen Hohepriester und Vorsitzenden der ge-

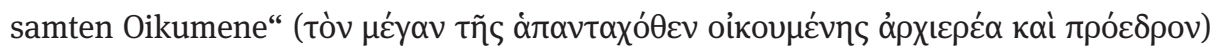
verbirgt, den eine der beiden Gesprächspartnerinnen, die personifizierte Philosophie, als ihren Retter identifiziert: Während ein Lager darin den Patriarchen Sergios erkennt, ${ }^{215}$ hält das andere nur die Identifikation mit Herakleios für plausibel. ${ }^{216}$

Dass ein römischer Kaiser in einer enkomiastischen Überhöhung als „Vorsitzender der gesamten Oikumene“ bezeichnet wird, verwundert kaum; was hingegen manchen Leser irritiert, ist das Epithet archiereus. Konnte der römische Kaiser tatsächlich als Hohepriester adressiert werden? Und mehr noch: Wenige Zeilen später beschreibt die

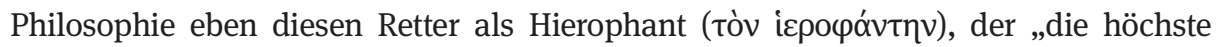

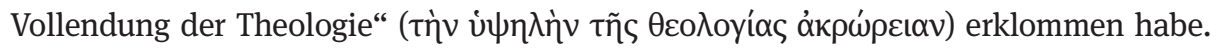
Dass römische Kaiser durchaus als Priester, als hiereus, bzw. als Hierophant angesprochen werden konnten, hat die Forschung bereits wiederholt betont: Diese Zuschreibung findet sich bei Euseb in Bezug auf Konstantin ${ }^{217}$ und in den Konzilsakten von Ephesos und Chalkedon in Bezug auf Theodosios II. bzw. Markian. ${ }^{218}$ Vor dem Hintergrund des Contra Severum, wo Georg von Pisidien Herakleios zum göttlich inspirierten Agenten der Orthodoxie macht, erscheint es nun auch kaum mehr weit hergeholt, den archiereus aus Theophylakts Dialog mit dem Kaiser zu identifizieren.

Um den semantischen Gehalt des Epithets archiereus bei Theophylakt zu verstehen, hilft ein Blick in den weiteren Text der Historien. Der Begriff archiereus kommt in dem Geschichtswerk ein weiteres Mal vor: in einer Predigt, die Theophylakt dem

215 So etwa Van Dieten 1972, 54f.; Schneider 1985, 240 f. Anm. 4; Whitby/Whitby 1986, 4 Anm. 9. Mi. Whitby 1988, 33 Anm. 20 unterscheidet textimmanent zwischen den Herakliden (i. e. Herakleios), die die Philosophie in den Kaiserpalast zurückgebracht hätten, und dem archiereus, der die Geschichte wiederbelebt habe.

216 Zur Identifizierung des archiereus mit Herakleios siehe Hunger 1978, 315; Frendo 1988a, $144 \mathrm{f}$. Anm. 11; Speck 1993, 212 mit Anm. 83; Meier 2015, 168 mit Anm. 8. Dafür, dass mit dem archiereus Herakleios gemeint ist, spricht auch der Umstand, dass die personifizierte Philosophie daraufhin ihre eigene Auferweckung mit der der mythischen Alkestis durch den „Übel abwehrenden Herakles“

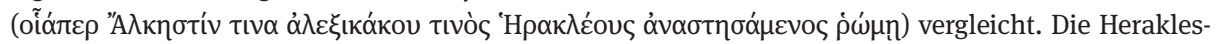
Analogie wurde zu Beginn des Dialoges bereits auf Herakleios bezogen; dass sie damit auf Sergios ausgeweitet würde (so etwa Whitby/Whitby 1986, 4 Anm. 10), halte ich für unwahrscheinlich; allgemein zur Herakles/Herakleios-Analogie, die sich nicht nur bei Theophylakt findet, siehe oben 135, 213, 239.

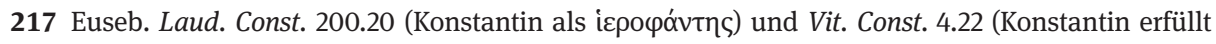

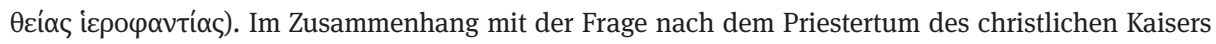

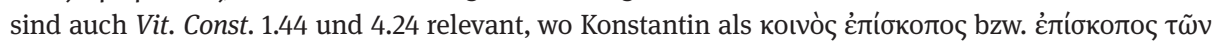
ÉkTós beschrieben wird; dazu Girardet 1980; Dagron 2003, 132-135; Höfert 2015, 139-141.

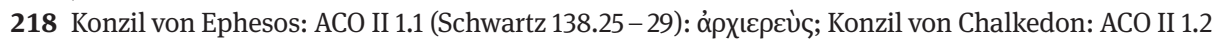
(Schwartz 157.29): ípévc. Höfert 2015, 199f. weist zu Recht darauf hin, dass das Priesterattribut nur eines von sehr vielen Epitheta ist, mit denen der jeweilige fromme Kaiser von den anwesenden Bischöfen gepriesen wird. 
Bischof Dometianos nach der Rückgabe der Stadt Martyropolis an die römischen Truppen im Jahr 590 in den Mund legt. ${ }^{219}$ In der Forschung wurde bereits mehrfach darauf verwiesen, dass der triumphalistische Duktus der Predigt viel eher in den Kontext von Herakleios' Sieg gegen die Perser (d.h. der Abfassungszeit der Historien) passt als in den längst vergangenen Perserkrieg unter Maurikios. ${ }^{20}$ Nachdem Theophylakts Dometianos zu Beginn seiner Rede die Kriegstrompeten des König David evoziert, ruft er dazu auf, Gott als den „obersten Feldherrn im Kriege“ (ả ... $\left.\dot{\varepsilon} v \pi 0 \lambda \varepsilon^{\prime} \mu о \iota \varsigma\right)$ zu preisen - Gott, „dessen Hohepriester in Ewigkeit nach der Ordnung des Melchisedek derjenige, der zur Rechten der Majestät sitzt, sowohl ist als auch genannt wird."221

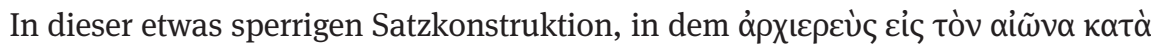

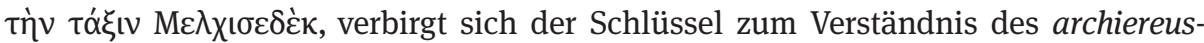
Begriffs. Im Alten Testament erwählt Gott den Melchisedek, den König von Salem, zum Priester, obwohl er nicht dem levitischen Amtspriestertum angehört. ${ }^{222}$ Mit dem oben zitierten Ausdruck greift Theophylakt wortwörtlich auf Stellen aus der Septuaginta und dem Neuen Testament zurück, in denen der Priesterkönig Melchisedek als Referenz angebracht wird. In Psalm 110 wendet Gott sich mit folgenden Worten an den König David: „Du bist der Oberpriester in Ewigkeit nach der Ordnung des Melchise-

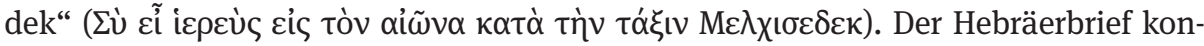
struiert ein Hohepriestertum Christi, das durch die Präfiguration des Melchisedek als unabhängig von der levitischen Linie und allein auf Gott rückführbar ist. „Christus wurde von Gott zum Hohepriester nach der Ordnung des Melchisedek ernannt“

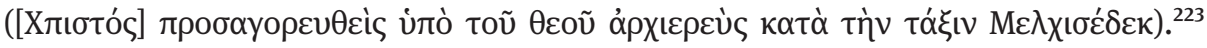
Byzantinische Texte schließlich nutzen die Figur des Melchisedek, um die ambivalente sakrale Position des römischen Kaisers zu beschreiben: Durch den Verweis auf

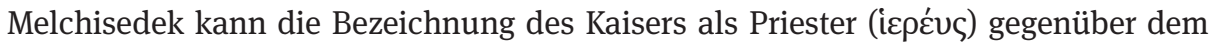
Klerus aufrecht gehalten werden, da dadurch der Kaiser eben nicht als amtlich ge-

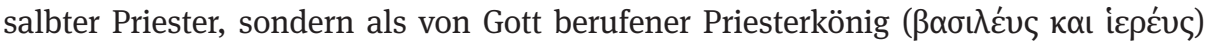
deklariert wird. ${ }^{224}$

$219 \mathrm{Zu}$ den Reden bei Theophylakt siehe Prinzig 1988, bes. 6-13; Efthymiadis 2010, 177-181.

220 Vgl. in diesem Sinne Whitby/Whitby 1986, 127 f. Anm. 65; Frendo 1988a, 152f.; Frendo 2001, 130; Howard-Johnston 2010, 145.

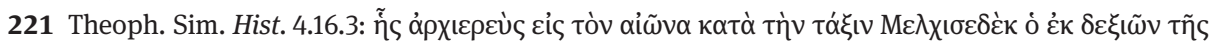

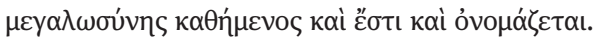

222 Gen $14.18-20$.

223 Auch hier (Hebr 7.1) wird die Doppel-Funktion des Melchisedek als König und Priester betont:

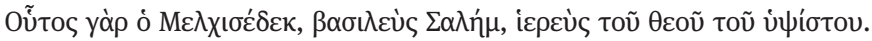

$224 \mathrm{Zu}$ der Figur des Melchisedek in der byzantinischen Kaiseridee vgl. Girardet 1980, bes. 575-579; Dagron 2003, 173-181 und neuerdings Höfert 2015, 141-143. In den ,Prozessakten` der Verhandlungen um Maximos Confessor in Konstantinopel 655 im Rahmen der monotheletischen Kontroverse unter Konstans II. wurde die Stellung des Kaisers anhand der Figur des Melchisedek diskutiert; siehe die Relatio motionis in: Allen 2002, 56 - 58 (= PG 90, 117); vgl. dazu Dagron 2003, 168 - 173 und Höfert 2015, 211-216. Bereits im späten 6. Jahrhundert beschreibt Venantius Fortunatus (Carm. 2.10) den fränki- 
Mit der typologischen Linie von Melchisedek über David und Christus konstruiert Theophylakt also einen archiereus als Priesterkönig, ausgestattet mit weltlicher wie geistlicher Autorität. Eine Identifizierung des archiereus im Dialog mit Herakleios gewinnt damit noch an Plausibilität. Während Herakleios sich in den Ostprovinzen persönlich um eine Kompromissfindung mit den nicht-chalkedonensischen Gemeinden bemühte, wurde in der Hauptstadt - so viel lässt sich aus den beiden hier besprochenen Quellen schließen - das Bild des Monarchen als kompetenter und göttlich sanktionierter Akteur auf dem religiösen Feld propagiert, als Priesterkönig; Herakleios' Repräsentation als frommer und siegreicher Kaiser gewann dadurch eine weitere wirkmächtige Facette.

Zuletzt möchte ich noch einmal auf die Frage nach der Intention der herakleischen Kirchenpolitik zurückkommen. Nachdem bisher vor allem die funktionale Reintegration der Ostprovinzen als Ziel der Einigungspolitik hervorgehoben wurde, sei zuletzt noch erwähnt, dass in der Forschung wiederholt auch die eschatologische Ebene der Annäherung an die nicht-chalkedonensischen Gemeinden ins Spiel gebracht wird: Die angestrebte Einigung aller Christen sei als ein Aspekt von Herakleios' Bemühungen $\mathrm{zu}$ verstehen, seine Herrschaft als messianisches Zeitalter $\mathrm{zu}$ stilisieren. ${ }^{225}$ Als Argument für diese These werden nicht nur die innerchristlichen Schlichtungsversuche angeführt, sondern auch der Umstand, dass Herakleios offenbar darum bemüht war, sowohl die Perser als auch die Juden zum Christentum zu konvertieren. Bereits in Hinblick auf Chosroes II. hatten sich Gerüchte verbreitet, der persische Großkönig habe sich zum Christentum bekannt. ${ }^{226}$ Mit dem Bündnisschluss zwischen Herakleios und dem persischen General Shahrbaraz 629 soll dann - dafür hat vor allem Cyril Mango plädiert - dessen Konvertierung und die seiner Familie einhergegangen sein. ${ }^{227}$ Gegen die Juden zeigte Herakleios dagegen eine härtere Hand: Die Quellen sprechen von repressiven Maßnahmen und Zwangstaufen. ${ }^{228}$ Doch stand dahinter tatsächlich die Idee der endzeitlichen Bekehrung der Völker aus der synoptischen Apokalypse?229 Ohne zu bezweifeln, dass Herakleios' Einigungspolitik sowohl die kompromissorientierte als auch die gewaltsame - in bestimmten Kontexten eschatologisch gedeutet werden konnte, gibt es doch meiner Ansicht nach erneut keine ausreichenden Belege dafür, dass eine derartige Deutung großflächig (vom Kaiser) propagiert wurde. Auch hier ließe sich eine herrschaftspragmatische Intention mutmaßen: Nachdem der jüdischen Bevölkerung Palästinas von den Per-

schen König Childebert als Melchisedech noster merito rex atque sacerdos / conplevit laicus religionis opus.

225 Greisiger 2014, 117-129.

226 Dazu Payne 2015, 164-166; zu der Legende von der Taufe des Chosroes II. siehe Schilling 2008, $235-277$.

227 Mango 1985, 105-117; ders. 1992, 6; siehe auch Greisiger 2013, 364; ders. 2014, 117-121; Payne 2015 , 197.

228 Dazu siehe oben S. 273 Anm. 95.

229 Mt 24,14; Mk 13.10; dazu Greisiger 2014, 117. 
sern ein erweiterter Handlungsspielraum zuerkannt worden war und bisweilen gar der Neubau des jüdischen Tempels in greifbare Nähe gerückt war, lag es Herakleios daran, diese Gruppe in ihre Schranken zu weisen und die christliche (Deutungs-)Hoheit über Jerusalem und das Heilige Land zu verdeutlichen. Doch unabhängig davon, was Herakleios mit seinen Maßnahmen im religiösen Bereich intendierte, erwiesen sich seine Bemühungen in den Ostprovinzen schnell als vergebens.

\subsection{Im Angesicht der Niederlage}

\subsubsection{Das Vorrücken der Araber}

Nur wenige Jahre, nachdem es Herakleios gelungen war, die Ostprovinzen von den persischen Besatzern zu befreien und zumindest weitgehend $\mathrm{zu}$ befrieden, sah sich die Levante erneut feindlichen Angriffen ausgesetzt; die Phase, in der der Kaiser seinen Triumph über Persien voll auskosten konnte, währte nur wenige Jahre. Während die hauptstädtische Initiative noch darauf zielte, die Einigung des wieder hergestellten Reiches voranzutreiben, sollten die gerade zurückgewonnenen Regionen im Laufe des nächsten Jahrzehntes schrittweise erneut dem Zugriff Konstantinopels entgleiten. ${ }^{230}$ Die Bedrohung hatte nun ihren Ursprung auf der arabischen Halbinsel; ab dem Ende des Jahres 633 drangen bewaffnete Verbände von Süden her nach Palästina ein. ${ }^{231}$

Begegnungen der Römer mit arabischen Stämmen - sowohl friedlich als auch kriegerisch - waren in der Spätantike keine Seltenheit. ${ }^{232}$ Dass sich mit dem Fortschreiten der 630er Jahre eine Bedrohung von bislang unbekannter Qualität ergeben würde, war aus römischer Sicht zu Beginn des Jahrzehnts kaum absehbar. Während das römische Reich und Persien sich bekriegt hatten, waren die vereinzelten Stämme der arabischen Halbinsel durch das Wirken Mohammeds geeint worden - weitgehend unbeachtet von den beiden Großmächten. Nachdem Abu Bakr, der 632 die Nachfolge des verstorbenen Mohammed angetreten hatte, sich im innerarabischen Bürgerkrieg hatte behaupten können, richtete sich der Fokus nun auf die angrenzenden Gebiete

230 Die arabische Eroberung ist in der Forschung ausgiebig thematisiert. In dieser Arbeit geht es nicht darum, die Details des sukzessiven Vorrückens zu klären bzw. die Diskussionen der Forschungsliteratur nachzuvollziehen; ein grobes Bild ist für meine Zwecke ausreichend. Es sei vor allem auf die ausführlichen Darstellungen bei Stratos 1972, 40 -116; Lilie 1976; Donner 1981; Kaegi 1992 verwiesen; außerdem Kaegi 2003, 229-299; Howard-Johnston 2010, 461-489; Meier 2019a, 1035-1088. Shoemaker 2018 zum eschatologischen Hintergrund der arabischen Eroberungen. Zu der problematischen Quellenlage hinsichtlich der arabischen Eroberung siehe Thomson/Howard-Johnston 1999 II, 233 - 238 und Kaegi 1992, 1-18; die arabischen Quellen werden hier nicht explizit aufgeführt.

231 Laut Theoph. Conf. AM 6123 (De Boor 336) wurden die arabischen Einfälle dadurch ausgelöst, dass die Römer aufgrund akuten Geldmangels die Tribut-Zahlungen an die arabischen Stämme, die die Grenzregionen sicherten, nicht tätigen konnten; ähnlich Nik. Brev. 20.

232 Siehe Kaegi 1992, 52-55 zur römischen Allianz mit den Ghassaniden. 
Roms und Persiens und ihre reiche Infrastruktur. Die ersten Einfälle in römische Provinzen hatten den Charakter von Plünderungszügen mit dem Ziel der Beutegewinnung. ${ }^{233}$ Es zeigte sich allerdings schnell, dass das römische Heer, welches sich von den Strapazen des langwierigen Krieges gegen Persien noch nicht angemessen regeneriert hatte, den Aggressoren kaum standhalten konnte. Nachdem die Truppen des Statthalters von Palästina, Sergios, nahe Gaza im Februar 634 von den zahlenmäßig überlegenen arabischen Einheiten dezimiert worden waren, ${ }^{234}$ schickte Herakleios seinen Bruder Theodor mit rasch zusammengestellten Einheiten, um sich des Problems anzunehmen. Doch auch dieser wurde im Sommer 634 östlich des Jordans geschlagen. ${ }^{235}$ Damit war Palästina von römischer Verteidigung abgeschnitten und sah sich - zwanzig Jahre nach den traumatischen Erfahrungen der persischen Eroberung - schutzlos den feindlichen Plünderungen ausgesetzt. Allein befestigte Städte konnten noch gegen die Araber aushalten. Ein Erdbeben und das Auftauchen eines Kometen, der über mehrere Monate am Himmel sichtbar war, lösten zusätzlich Angst und Schrecken in der Bevölkerung aus. ${ }^{236}$ Im Winter 634 hatte sich die Situation bereits derart verschlechtert, dass die christliche Gemeinde anlässlich der Weihnachtsfeierlichkeiten den Weg zwischen Jerusalem und Bethlehem nicht mehr sicher zurücklegen konnte. ${ }^{237}$ Spätestens vor diesem Hintergrund wurde die Reliquie des Heiligen Kreuzes, die Herakleios im Jahr 630 nach Jerusalem rückerstattet hatte, nach Konstantinopel in Sicherheit gebracht. ${ }^{238}$

233 Lilie 1976, 34-41; zu der Entwicklung auf der arabischen Halbinsel siehe Howard-Johnston 2010, 445-465. Wiederholt wird in der Forschung darauf verwiesen, dass die frühen arabischen Eroberungen keinen religiösen Hintergrund hatten, etwa Stratos 1972, 43f., 119-122; für Howard-Johnston 2010, 470 - 473 ist der religiöse Faktor allerdings mit verantwortlich für den Erfolg der arabischen Expansion. Mischa Meier (2019, 1035-1088; 2020) hat zuletzt dafür argumentiert, das Ausgreifen der Araber sei eine Reaktion auf die allgemeinen Liturgisierungs-Tendenzen gewesen.

234 Theoph. Conf. AM 6121 (De Boor 336); Datum in Chron. 724 in Palmer 1993, 18; außerdem Chron. 1234, 108 (Chabot I, 189) und Mich. Syr. 11.4 (Chabot II, 413).

$235 \mathrm{Zu}$ dieser Schlacht siehe Theoph. Conf. AM 6125 (De Boor 337); Mich. Syr. 11.5 (Chabot II, 418); Chron. 1234, 110 (Chabot I, 190f.); Niederlage des Theodor auch bei Sebeos 42 (Thomson/HowardJohnston I, 96f.); zu dieser frühen Phase der Auseinandersetzungen siehe Kaegi 1992, 88-111; zur Schlacht von Gabitha/Adjnadayn und ihrer Abgrenzung zur späteren Schlacht am Yarmouk siehe auch Stratos 1972, 50-56

236 Ex eventu werden diese Phänomene in den Quellen als Vorzeichen der arabischen Eroberung interpretiert: Theoph. Conf. AM 6124 (De Boor 336); Mich. Syr. 11.4 (Chabot II, 414); Agapius (Vasiliev 454, 469); Chron. Seert (Scher 580); siehe mit weiteren Quellen Stratos 1972, $40 \mathrm{f}$.

237 Hoyland 1997, 70 f.; Booth 2013a, 20 f.

238 Laut Sebeos 41 (Thomson/Howard-Johnston I, 91), 42 (Thomson/Howard-Johnston I, 98) und Theoph. Conf AM 6125 (337) gelangte das Kreuz angesichts der arabischen Eroberung Palästinas nach Konstantinopel; laut Nik. Brev. 18 schickte Herakleios das Kreuz direkt nach seinem Besuch in Jerusalem in die Hauptstadt, wo es von dem Patriarchen Sergios in Blachernae empfangen und in der Hagia Sophia erhöht wurde. Nikephoros merkt an, dass dies in der zweiten Indiktion geschehen sei, die auf die Jahre 628/29 fällt, was der hier vorgeschlagenen Abfolge zuwiderlaufen würde. Zu dieser Problematik siehe Mango 1990, 185 und Zuckerman 2013, 204-206. Speck 2000 und Zuckerman 2013 gehen aufgrund einer alternativen Lesung des Chron. Pasch. davon aus, dass das Kreuz sich bereits im 
Während der letzten Jahre des Krieges zwischen Rom und Persien war Herakleios konstant als Oberbefehlshaber des römischen Heeres an den wichtigsten Kriegsschauplätzen präsent gewesen. Anfang der 630er Jahre hielt der Kaiser sich erneut im Osten des Reiches auf, wo er sich zuvor um die Einigung der christlichen Gemeinden bemüht hatte; doch anstatt die römischen Truppen persönlich anzuführen, delegierte er diese Aufgabe nun an Untergebene und koordinierte die Verteidigungsmaßnahmen von strategisch günstig gelegenen Zentren wie Emesa, Edessa bzw. Antiochia aus. ${ }^{239}$ Nachdem sein Bruder Theodor in Folge der verlorenen Schlacht des Sommers 634 offenbar in Ungnade gefallen war, bestimmte Herakleios einen seiner Schatzmeister, den Sakellarios Theodor, und den Armenier Baanes als Befehlshaber gegen die Araber. ${ }^{240}$ Doch auch dieses Gespann konnte trotz vereinzelter Erfolge das feindliche Vorrücken nicht aufhalten: Ab 635 musst sich Syrien dem Angriff stellen. Während die Araber zuvor nach den Plünderungen noch in die eigenen Gebiete zurückgekehrt waren, setzten sie sich nun auf römischem Territorium fest. Nach mehrmonatiger Blockade ergab sich Damaskus im Herbst 635 den Feinden; gegen die Entrichtung einer Steuer an die arabischen Besatzer wurden die Bewohner in Frieden gelassen. Weitere syrische Städte folgten diesem Beispiel. ${ }^{241}$

Von seinem Standort in Antiochia aus bemühte sich Herakleios, innerhalb kürzester Zeit eine Armee auszuheben, die zumindest zahlenmäßig den Arabern gewachsen war. Dieser heterogenen Truppe gelang es tatsächlich, die Feinde vorübergehend nach Süden zu drängen. Im Sommer 636 schließlich standen die beiden Heere sich östlich des Sees Genezareth gegenüber, in einer Gegend, die von den verzweigten Nebenflüssen des Jordan und tiefen Wadis geprägt ist. Nach vereinzelten Scharmützeln, die sich über Wochen hinzogen, kam es im August zur großen Feldschlacht am Fluss Yarmouk, bei der sich die Araber schnell als überlegen erwiesen. Ob aufgrund

September 629 in Konstantinopel befunden haben muss; ähnlich Klein 2001. Siehe Klein 2004, 34- 43 und ders. 2006, bes. 89-91 zum Fortleben der Kreuzreliquie in Konstantinopel. Teile des Kreuzes wurden bis zur Eroberung Konstantinopels durch die Kreuzfahrer 1204 in der Pharos-Kapelle im kaiserlichen Palast aufbewahrt.

239 Siehe Kaegi 2003, 23f.; für Emesa anstatt Edessa siehe Stratos 1972, 56.

240 Theoph. Conf. AM 6125 (De Boor 337); Chron. 1234, 110 (Chabot I, 191); laut Nik. Brev. 20 hatte Theodor die Ehe des Herakleios mit seiner Nichte Martina kritisiert und wurde deswegen unehrenhaft entlassen und in Konstantinopel festgesetzt; laut Mich. Syr. 11.6 (Chabot II, 420 f.) fungierte auch ein Sohn des Shahrbaraz als Befehlshaber für die Römer, der allerdings nach der Schlacht am Yarmouk versuchte, zu den Arabern überzulaufen; zum römischen Befehlshaber siehe Stratos 1972, 209. Manche Quellen erwähnen Theodor als Eunuch, siehe PLRE IIIB, Theodorus 164 qui et Trithyrius (1279f.); vgl. auch PLRE IIIA, Baanes (161).

241 Theoph. Conf. AM 6126 (De Boor 338); Chron. 1234, 111 (Chabot I, 191f.), 114f. (Chabot I, 194f.) und Mich. Syr. 11.6 (Chabot II, 421): Bei den syrischen Chronisten erfolgt die Einnahme der syrischen Städte nach der Schlacht am Yarmouk. Das erklärt sich dadurch, dass die arabischen Besatzer Teile Syriens zeitweise geräumt hatten und diese nach dem August 636 wieder einnahmen; siehe die Diskussion bei Stratos 1972, 59-62, 208f. Ob und inwiefern der fehlende Verteidigungswille einer Bevölkerung, die Konstantinopel bisweilen kritisch gegenüberstand, zu der raschen Invasion der Araber beigetragen hat, ist eine viel diskutierte Frage; siehe Stratos 1972, 66, 127-133 und Moorhead 1981. 
von schwierigen Wetterbedingungen, von Uneinigkeit innerhalb des römischen Heeres, der Desertation der ghassanidischen Föderaten oder schlichtweg aufgrund von militärischer Schwäche - das römische Heer erlitt eine vernichtende Niederlage. Nach der Schlacht am Yarmouk war die römische Verteidigung quasi handlungsunfähig. ${ }^{242}$ Herakleios verließ Antiochia und kehrte umgehend nach Konstantinopel zurück. ${ }^{243}$ Syrien, Palästina und Mesopotamien waren de facto verloren und wurden in den folgenden zwei Jahren sukzessive von den Arabern besetzt. ${ }^{244}$ Und diese waren gekommen, um zu bleiben; mit Umar, dem Nachfolger des 634 verstorbenen Abu Bakr, begab sich erstmals persönlich ein Kalif in die besetzten Gebiete. Nachdem Jerusalem sich 638 ergeben hatte, zog erneut ein Herrscher voller Ehrfurcht vor dem genius loci in die Heilige Stadt ein: Vom Ölberg kommend wurde Umar vom Patriarchen Sophronios in Empfang genommen. ${ }^{245}$

Nach der Sicherung Palästinas und Syriens wandten sich die Araber ab 639 auch nach Ägypten. Angesichts der unzureichenden Verteidigungslage schlug der Patriarch Kyros, ausgestattet mit umfassenden Vollmachten, gegenüber den Aggressoren den Weg der Diplomatie ein: Gegen jährliche Goldzahlungen sollte Ägypten von Plünderungen verschont bleiben. Kyros' Initiative stieß in Konstantinopel allerdings nicht auf Unterstützung. Im Gegenteil, Herakleios bezichtigte seinen einstmaligen Verbündeten des Hochverrats, zog ihn aus Alexandria ab und setzte stattdessen auf bewaffnete Konfrontation. ${ }^{246}$ Doch schnell zeigte sich, dass Kyros mit seinem Gespür richtig gelegen hatte. Trotz militärischer Verstärkung konnten die römischen Truppen Ägypten nicht halten; die vorwiegend miaphysitische Bevölkerung Ägyptens unter der Führung des exilierten Patriarchen Benjamin wiederum sah das Anrücken der Araber als Möglichkeit, sich von der Dominanz der Chalkedonenser zu befreien. ${ }^{247}$ In den folgenden drei Jahren sollte auch diese Provinz dem oströmischen Reich endgültig verloren gehen. ${ }^{248}$ Neben den römischen Süd-Ostprovinzen wurde auch Persien, das in-

242 Theoph. Conf. AM 6126 (De Boor 337f.) auch zur Revolte armenischer Kontingente, die den Baanes gar zum Kaiser ausriefen; Chron. 1234, 116 (Chabot I, 195f.) und Mich. Syr. 11.6 (Chabot II, 420 f.); siehe dazu Stratos 1972, 68-73; Donner 1981, 91-155; Kaegi 1992, 112-146 (auch zu der Frage nach dem zahlenmäßigen Umfang der Heere und der Verluste) und ders. 2003, 239-244.

243 Chron. 1234, 117 (Chabot I, 196f.) und Mich. Syr. 11.7; die syrischen Quellen zu Herakleios' Rückkehr sind auch in Hoyland 2011, 106-108 zusammengefasst. Vgl. Theoph. Conf. AM 6125 (De Boor 337), der die Rückkehr des Herakleios allerdings vor die Schlacht am Yarmouk ansetzt; siehe dazu Stratos 1972, 73 f.; Donner 1981, 145.

244 Stratos 1972, 74-86; Kaegi 1992, 147-180.

245 Zu Umar in Jerusalem siehe Theoph. Conf. AM 6127 (De Boor 339); Chron. 1234, 120 (Chabot I, 199f.) und Mich. Syr. 11.7 (Chabot II, 425f.); siehe Stratos 1972, 81f., 221 mit weiteren Quellen.

246 Theoph. Conf. AM 6126 (De Boor 338f.), Nik. Brev. 23; Chron. 1234, 118 (Chabot I, 197 f.) und Mich. Syr. 11.7 (Chabot II, 425); vgl. zu der Initiative des Kyros (auch aus Perspektive der arabischen Quellen) Kaegi 2003, 285-287 und Booth 2016.

247 So etwa Chron. 1234, 118 (Chabot I, 197f.).

248 Siehe Stratos 1972, 94-116 und zuletzt Booth 2013b, der dafür argumentiert, dass der arabische Vorstoß nicht nur über die Delta-Region erfolgte, sondern simultan auch von Mittelägypten her. Booth 
nenpolitisch seit der Ermordung Chosroes' II. nicht mehr zur Ruhe gekommen war, Opfer der arabischen Expansion. Während das oströmische Reich jedoch die Gebietsverluste verkraften und als politische Entität auf reduziertem Territorium fortbestehen konnte, versetzten die Niederlagen gegen die Araber dem sassanidischen Reich den Todesstoß; mit Yazdegerd III., einem Enkel des Chosroes II., starb 651 der letzte persische Großkönig. ${ }^{249}$

\subsubsection{Rückkehr nach Konstantinopel II}

Nachdem das römische Heer am Yarmouk vernichtend geschlagen worden war, kehrte Herakleios umgehend nach Konstantinopel zurück. Acht Jahre, nachdem er mit dem Triumph über die Perser im Rücken in die Stadt eingezogen war, waren die Voraussetzungen nun gänzlich andere. Dieses Unterkapitel befasst sich mit der Frage, wie der Kaiser mit militärischer Niederlage umging und welche direkten Auswirkungen das Debakel am Yarmouk auf seine Herrschaft zeitigte. Der Blick in die Forschungsliteratur offenbart eine recht einseitige Bewertung von Herakleios' späten Regierungsjahren: Führende Publikationen zeichnen - in Kontrast zum glorreichen Persersieger - ein Bild des Kaisers als gebrochener Mann, ein Bild von physischem und psychischem Niedergang, der spätestens dann einsetzte, als Herakleios' Restitutionswerk vor seinen Augen durch die Araber zunichte gemacht wurde. ${ }^{250}$ Dieser Stilisierung, die größtenteils auf der unkritischen Wiedergabe von tendenziösen Quellen basiert, soll im Folgenden eine alternative Bewertung entgegengehalten werden.

Die einzige Quelle, die Herakleios’ Rückkehr nach Konstantinopel in Folge der Schlacht am Yarmouk im Detail dokumentiert, ist das Breviarium des Nikephoros, verfasst um die Wende vom 8. zum 9. Jahrhundert. ${ }^{251}$ Der Text ist derart dicht an Informationen, dass sich eine vollständige Wiedergabe anbietet.

Zu dieser Zeit brach Herakleios nach Hause auf und richtete sich in dem Hiereia genannten Palast ein. Denn er hatte Angst davor, das Meer zu überqueren; und obwohl die Amtsträger und die Bürger der Stadt von ihm erwarteten, in die Stadt einzuziehen, überzeugten sie ihn nicht. Während der Festtage schicke er allein seine Söhne, und diese kehrten schnell wieder zu ihm zurück, nachdem sie in der Kirche die heilige Liturgie gefeiert hatten. Und wann immer sie den Pferderennen beiwohnten, kehrten sie ebenso zurück zu ihrem Vater. Aber während er dort weilte, wurde ihm verkündet, dass sein Sohn Atalarichos und Theodor - vom Rang eines Magisters, der Sohn des Theodor, des Bruders des Kaisers - mit einigen anderen dabei waren, sich gegen ihn zu verschwören. Überzeugt von den Informanten schnitt er deren Nasen und Hände ab; den Atalarichos verbannte er auf die Insel Prinkipos, den Theodor auf die Insel Gaudomelete, und befahl dem dortigen Kommandeur, diesem, wenn er bei ihm ankäme, einen der Füße zu entfernen. Und

diskutiert auch im Detail den zeitgenössischen Bericht des Johannes von Nikiu, der allerdings erst 639 wieder einsetzt (ab Joh. Nik. 111).

249 Zum Schicksal des sassanidischen Reiches siehe Bonner 2019, 318-340.

250 Siehe zum Beispiel Stratos 1972, 135f.; Treadgold 1997, 303-305 besonders Kaegi 2003, 265-299. $251 \mathrm{Zu}$ Nikephoros siehe oben Anm. $23 \mathrm{f}$. 
entsprechend rächte er sich auch an denjenigen, die gemeinsam mit diesen von dem Plan gewusst hatten.

Nachdem ausreichend Zeit vergangen war, brachten die Amtsträger des Kaisers den Eparchen dazu, viele Schiffe zusammenzubringen und diese aneinander zu befestigen, um die Stenon genannte Wasserstraße zu überbrücken, und beidseitig mit Zweigen von Bäumen und Laub eine Absperrung zu errichten, damit [der Kaiser], wenn er dort anwesend wäre, nicht das Meer sähe. Das Werk schritt schnell voran und der Kaiser überquerte als Reiter das Meer wie festes Land zu der Küste der sogenannten Bucht von Phidaleia; dort ließ er den Küstenstreifen auf der Seite und zog über die Brücke des Flusses Barbyssos nach Byzantion ein. Danach krönte er den Caesar Herakleios zum Kaiser. ${ }^{252}$

Nikephoros’ Bericht besteht, grob gesagt, aus zwei Elementen: erstens Herakleios' Niederlassung im kleinasiatischen Hiereia und seine Rückkehr nach Konstantinopel über eine Schiffsbrücke, die errichtet wurde, um dem Kaiser den Anblick des Wassers zu ersparen; zweitens die missglückte Verschwörung gegen ihn durch seinen unehelichen Sohn und seinen Neffen. Die Forschung tendiert dazu, beide Elemente inklusive der von Nikephoros vorgebrachten Bewertungen als faktisch zu übernehmen, was sich vor allem in Hinblick auf die Episode zur Schiffsbrücke als fatal erweist. Mit Verweis auf Nikephoros' Bericht hat sich in der Forschung gar der Allgemeinplatz verfestigt, Herakleios habe unter Hydrophobie, der Angst vor Wasser/Gewässern, gelitten: Sowohl sein Verweilen in Hiereia, auf der asiatischen Seite des Bosporus, als auch der Bau der Schiffsbrücke sei vor diesem Hintergrund zu verstehen. ${ }^{253}$ Kritische

252 Nik. Brev. 24f.: Toút

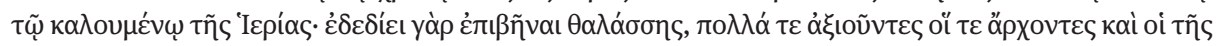

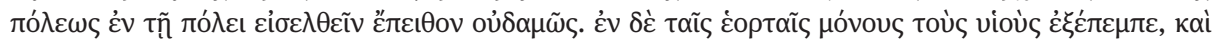

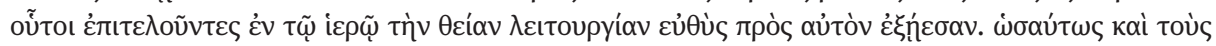

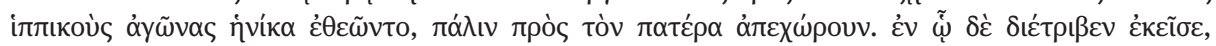

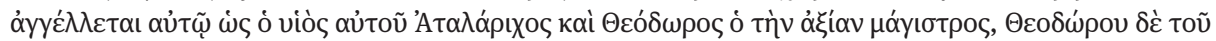

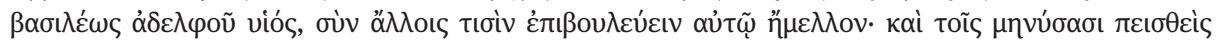

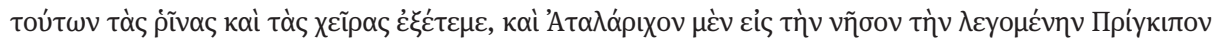

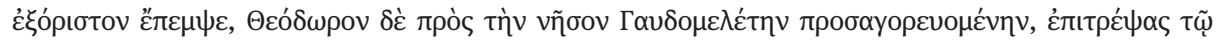

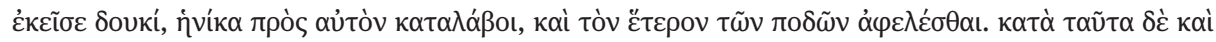

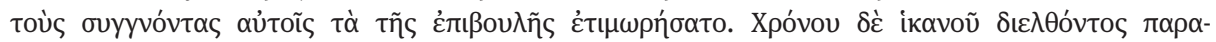

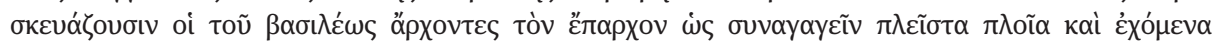

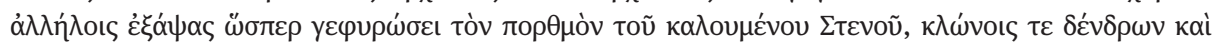

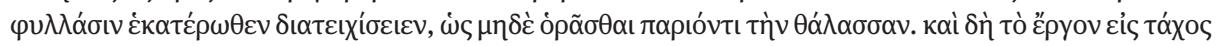

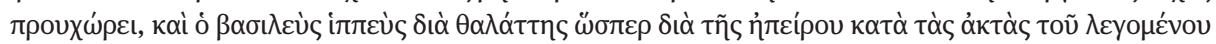

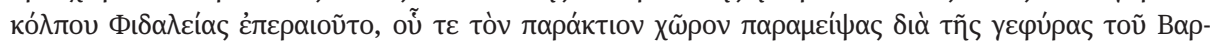

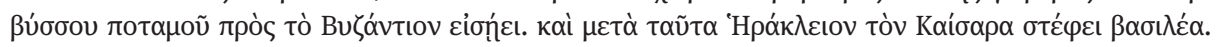
253 Siehe zum Beispiel Stratos 1972, 139; Treadgold 1997, 305: „Heraclius finally returned to his capital in 638, over a bridge of boats designed to allay his hydrophobia.“ Baynes 1952, 381: „[Heraclius] suffered so acutely from hydrophobia that he could return to Europe only over a bridge of boats closely shaded by boughs of trees so that the emperor might have no sight of water." Siehe auch Haldon 1990, 51 und Ma. Whitby 1998, 263; Mango 1990, 189 übergeht die Episode in seinem Kommentar zu Nikephoros schlichtweg. Es bleibt zu betonen, dass der Begriff hydrophobia weder in Nikephoros noch in

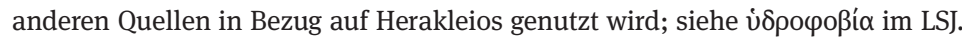


Stimmen dagegen gehen bisweilen so weit, die Episode zur Schiffsbrücke als Ganzes als Legende $\mathrm{zu}$ disqualifizieren. ${ }^{254} \mathrm{Um}$ den Gehalt von Nikephoros' Bericht angemessen zu erfassen, sollte indes ein Mittelweg eingeschlagen werden. Meiner Ansicht nach enthält die Episode einen authentischen Kern: Eine Schiffsbrücke, auf der Herakleios den Bosporus überqueren konnte, wurde tatsächlich gebaut; sie diente indes nicht dem Zweck, die vermeintliche Hydrophobie des Kaisers zu besänftigen, wie das Breviarium uns glauben machen will, sondern ist als triumphales Statement zu lesen.

$\mathrm{Zu}$ Beginn dieses Kapitels wurde bereits bemerkt, dass die Reintegration des Kaisers in die Hauptstadt nach längerer Abwesenheit prinzipiell mit spezifischen Anund Herausforderungen einherging und daher ein potentiell kritisches Moment darstellte. Im Jahr 636 hatte Herakleios allerdings - anders als ein knappes Jahrzehnt zuvor - keinen prestigereichen Sieg im Rücken, der seine Rückkehr nach Konstantinopel positiv konnotierte. Die Imago des glorreichen strategos, des kosmischen Siegers und Weltenerneuerers, die Georg von Pisidien nach 628 eindrucksvoll propagiert hatte, ${ }^{255}$ konnte den gewandelten Umständen kaum angepasst werden. Herakleios stand vor einem Dilemma: Einerseits musste die Stimmung in Konstantinopel nach dem Bekanntwerden der Niederlage unter Kontrolle gehalten werden - daher wohl seine rasche Rückkehr -, andererseits war er der praktischen und diskursiven Möglichkeiten beraubt, seinen Einzug in die Stadt gewinnbringend zu strukturieren. Anstatt Konstantinopel zu betreten und sich der direkten Konfrontation mit der hauptstädtischen Bevölkerung auszusetzen, saß Herakleios nun im kaiserlichen Palast von Hiereia fest. ${ }^{256}$ Das Verweilen in Hiereia erscheint in der Tat erratisch - vor allem vor dem Hintergrund eines wachsenden Unwillens gegenüber dem Kaiser. Doch lässt sich zumindest festhalten, dass Herakleios' Entscheidung kaum in einer vermeintlichen Angst vorm Wasser begründet lag, sondern eher in dem Umstand, dass die angespannte Gesamtsituation seine Handlungsmöglichkeiten massiv einschränkte. Dass Herakleios seine Söhne für öffentliche Auftritte bei religiösen Festen und Hippodromspielen an seiner Stelle in die Stadt schickte, war ein Notlösung, die von der

254 Kaegi 2003, 287f. (Zitat S. 288) kommentiert: „[Nicephorus'] unique story may be simply that: a story. [...] it may be an exaggerated elaboration of Heraclius' decision to remain in isolation during the crisis of the Muslim invasion [...]." Speck 1988, 406f. geht noch weiter und hält sowohl Herakleios' angebliche Hydrophobie als auch den Bau einer Schiffsbrücke für reine Legenden.

255 Dazu siehe oben S. 236-238.

256 Hiereia fungierte offenbar als Schwelle zwischen Provinz und Hauptstadt: 628 hatte die Bevölkerung Herakleios dort empfangen; 636 saß der Kaiser an eben diesem Ort fest; siehe McCormick 1986, $71 \mathrm{Anm} .130$ zu Hiereia als Treffpunkt. An einen Ort außerhalb der Stadt (eventuell auch Hiereia) hatte sich Herakleios gemäß Georg von Pisidien (Heracl. 2.108-121) bereits Anfang der 620er-Jahre zeitweise zurückgezogen, um sich auf den Feldzug gegen die Perser vorzubereiten; genauer gesagt, um Militärhandbücher zu studieren. Dass Georg darum bemüht ist, die Gründe für Herakleios' Verweilen außerhalb der Stadt zu betonen - nicht zum Vergnügen, sondern um sich in Ruhe den Staatsangelegenheiten widmen zu können - weist darauf hin, dass auch damals das hauptstädtische Umfeld das kaiserliche Verweilen auf der asiatischen Seite nicht gern sah; dies geht auch aus den darauffolgenden Versen (Heracl. 2. 122-132) deutlich hervor. 
hauptstädtischen Bevölkerung offenbar auch derart empfunden wurde. Konstantinopel forderte die Präsenz des Kaisers; das dauerhafte Ausharren in Hiereia war keine Option.

Tatsächlich dauerte es nicht lang, bis sich die Anspannung entlud: Eine Verschwörung, die Herakleios' Sturz zum Ziel hatte, wurde aufgedeckt, die Verschwörer hart bestraft. Nachdem Herakleios über beinahe drei Jahrzehnte weitgehend unangefochten geherrscht hatte, wurde er nun erstmals ernsthaft im hauptstädtischen Umfeld herausgefordert; dass dies in einem Moment kaiserlicher Schwäche geschah, als Herakleios' Akzeptanz in der Hauptstadt offenbar zu bröckeln begann, ist kaum verwunderlich. Die Maßnahmen, mit denen der Kaiser seine Herrschaft hatte stabilisieren können, allen voran die Betonung religiös konnotierter Sieghaftigkeit, verloren nach der katastrophalen Niederlage in Syrien an Wirkmächtigkeit. Abgesehen von dem Umstand, dass sich hiermit eine Usurpation im Zentrum der Macht, in Konstantinopel, zusammenbraute, ist auch die Identität der Herausforderer bemerkenswert: Die Verschwörung gruppierte sich um Herakleios' unehelichen Sohn Atalari$\operatorname{chos}^{257}$ und seinen Neffen Theodor; ${ }^{258}$ laut Sebeos hatten sich die beiden Männer mit einer Reihe armenischer Magnaten verbündet, die in Konstantinopel residierten. ${ }^{259}$

Obwohl die Details des Usurpationsversuches und seiner Aufdeckung im Dunkeln bleiben, treten die Mechanismen doch deutlich zu Tage: Eine Reihe einflussreicher Akteure formierte sich um Individuen mit dynastischem Prestige, um in das Machtvakuum in Konstantinopel, bedingt durch Herakleios' Verweilen in Hiereia, vorzustoßen und einen Regimewechsel einzuleiten. ${ }^{260}$ Seit dem Beginn seiner Regierung hatte Herakleios konsequent Mitglieder seiner Familie in hohe Ämter befördert, um sich gegen potentielle Herausforderer abzusichern; nun kam die Herausforderung aus den eigenen Reihen. Die Nachfolgeordnung, die Herakleios mit der Krönung seine Sohnes Herakleios Konstantin im Jahr 613 festgelegt hatte und seitdem öffentlich propagierte, stand erstmals zur Debatte. Ein besonders ernstzunehmendes Risiko scheint dabei Herakleios' Neffe Theodor dargestellt zu haben, der gleichnamige Sohn von Herakleios' Bruder Theodor, mit dem der Kaiser sich kurz zuvor angesichts der

257 PLRE IIIA, Ioannes qui et Atalarichus 260 (260). Atalarichos taucht erstmals in Nik. Brev. 17 auf, wo er im Jahr 622 als eine von mehreren Geiseln zu den Avaren geschickt wird; mehr Informationen finden sich zu ihm allerdings nicht. Der Name lässt auf einen nordafrikanischen Hintergrund schließen.

258 PLRE IIIB, Theodorus 171 (1284); Theodor war der Sohn des Theodor, Herakleios' Bruder.

259 Sebeos 41 (Thomson/Howard-Johnston I, 92-94) mit Kommentar in Thomson/Howard-Johnston 1999 II, $228-230$.

260 Dass Usurpationen sich um Verwandte eines regierenden oder bereits verstorbenen Kaisers gruppierten, ist im oströmischen Reich ein häufiges Phänomen; siehe zum Beispiel die Erhebung des Hypatios, Anastasios' Neffen, während des Nika-Aufstandes gegen Justinian 532; dazu Meier $2014 \mathrm{a}$. Auch die Nachfolger Justinians mussten sich gegen potentielle Herausforderer aus der Familie des Justin/Justinian erwehren; besonders die Familie des Germanos, ebenso wie Justinian ein Neffe des Justin I., stellte ein Risiko dar; dazu siehe oben S. 57 f., 59 f. 
katastrophalen Entwicklungen in Syrien überworfen hatte; ${ }^{261}$ der Neffe wurde nach dem Aufdecken der Verschwörung am härtesten bestraft. ${ }^{262}$ Während die Karriere des Atalarichos obskur bleibt, bekleidete Theodor laut Nikephoros das Amt des magistros - aller Wahrscheinlichkeit nach Magister militum. Er genoss damit also nicht nur dynastisches Prestige, sondern zählte auch zu den hohen militärischen Funktionsträgern - zu der Gruppe also, die den größten Druck auf den Kaiser ausüben konnte. ${ }^{263}$

Die Verschwörung wurde aufgedeckt, bevor konkrete Schritte hatten unternommen werden können; doch der vereitelte Usurpationsversuch hatte deutlich gemacht, dass es für Herakleios keine Option war, in Hiereia auszuharren und die Hauptstadt weitestgehend sich selbst zu überlassen. Nachdem seine Autorität herausgefordert worden war, musste der Kaiser ein deutliches Zeichen setzen. Was Nikephoros als eine Maßnahme der hauptstädtischen Funktionsträger beschreibt, Herakleios’ Angst vorm Wasser zu begegnen, offenbart in diesem Zusammenhang seine eigentliche Funktion: Die Schiffsbrücke über den Bosporus war von Herakleios als ein triumphales Statement intendiert, mit dem der Kaiser auf die nachlassende Akzeptanz in Konstantinopel reagierte; gerade im Moment außen- wie innenpolitischer Instabilität bedurfte es einer Inszenierung von größtmöglicher Öffentlichkeitswirkung.

Diese These wird unterstützt, wenn man den Blick weitet und auf den römischen Umgang mit militärischen Niederlagen im Allgemeinen lenkt. Für römische Kaiser stellten Niederlagen auf dem Schlachtfeld besonders prekäre Momente dar; das Sesshaftwerden der Kaiser ab dem späten 4. Jahrhundert hat Felix K. Maier überzeugend damit erklärt, dass die Monarchen sich den negativen Folgen militärischer Misserfolge zu entziehen suchten, welche sich in der Spätantike bekanntlich häuften. ${ }^{264}$ Dass militärische Niederlagen eine bedachte Reaktion von kaiserlicher Seite aus erforderten, zeigen die Jahren nach der verheerenden Schlacht von Adrianopel 378, bei der das römische Heer den auf Reichsboden siedelnden Goten unterlag. Nachdem der Kaiser Valens auf dem Schlachtfeld ums Leben gekommen war, bemühte sich sein Neffe Gratian, nun zum Senior Augustus aufgestiegen, um Schadensbegrenzung, indem er den erfahrenen Feldherren Theodosios zum Augustus erhob. ${ }^{265}$ Wie von Noel Lenski betont, zeichneten sich die darauffolgenden Jahre durch eine außerordentlich hohe Zahl an Siegesfeierlichkeiten aus, durchgeführt von Gratian und Theodosios, obwohl keine entscheidenden militärischen Siege hatten errungen werden können. Lenski schließt: „The emperors felt the need to glorify publicly their military achievements in order to counteract the ill effects of the Adrianople catas-

261 Nik. Brev. 20; Theodor hatte seinem Bruder Herakleios über Jahrzehnte als Befehlshaber zur Seite gestanden.

262 Er wurde verstümmelt und auf die Insel Gaudomelte nahe Malta verbannt; siehe Nik. Brev. 24. mit dem Kommentar bei Mango 1990, 190.

263 Dazu siehe oben S. 60 - 62.

264 Maier 2019, zusammenfassend 451-462; siehe dazu oben S. $31 \mathrm{f}$.

265 Zur Schlacht von Adrianopel siehe Lenski 1997. 
trophe.“266 Diese Beobachtung lässt sich direkt auf die Zeit nach der Schlacht am Yarmouk übertragen. Die Analyse von Herakleios' Rückkehr 628 hat gezeigt, dass triumphale Inszenierungen weiterhin einen zentralen Aspekt kaiserlicher Präsenz in Konstantinopel konstituierten; obwohl es nach der Niederlage in Syrien nichts zu feiern gab, bot der Kaiser der hauptstädtischen Öffentlichkeit ein knappes Jahrzehnt später mit der Schiffbrücke über den Bosporus ein triumphales Spektakel.

Ein Exkurs in die noch entferntere Vergangenheit kann die Deutung von Herakleios' Initiative weiter schärfen, war er doch nicht der erste römische Kaiser, der sich durch den Bau einer Schiffsbrücke hervortat. Ausgerechnet der als Tyrann verfemte Caligula (37-41 n. Chr.) ließ im Jahr 40 eine Schiffsbrücke im Golf von Neapel bauen, genauer gesagt zwischen Puteoli und Baiae, die der Kaiser zu Pferd mit einem ganzen Tross bewaffneter Reiter und Fußtruppen überquerte. Diese Inszenierung, die in vielerlei Hinsicht mit Versatzstücken eines traditionellen Triumphzuges spielte, löste Bewunderung ebenso wie Kritik aus, wie aus den Berichten von Sueton und Cassis Dio hervorgeht. ${ }^{267}$ Die Analogie gewinnt noch an Brisanz, wenn man bedenkt, dass Caligula zuvor bei einem Germanen- und Britannienfeldzug nicht die gewünschten Erfolge hatte erzielen können. Das Spektakel im Golf von Neapel ist nicht zuletzt vor dem Hintergrund des äußerst angespannten Verhältnisses zwischen dem Kaiser und dem römischen Senat zu verstehen. ${ }^{268}$ Als weiterer Verweis können die Schiffsbrücken angeführt werden, die der persische Großkönig Xerxes erbauen ließ, um seiner Armee 480 v. Chr. das Überqueren des Hellesponts zu ermöglichen. ${ }^{269}$ Dass Xerxes' Brücken auch im hauptstädtischen Umfeld des frühen 7. Jahrhunderts bekannt waren, zeigt eine Passage aus Georg von Pisidiens Expeditio Persica. ${ }^{270}$ Ich möchte an dieser Stelle nicht dafür plädieren, dass Herakleios sich mit seiner Schiffsbrücke direkt auf diejenige des Caligula oder des Xerxes bezog, zumal ein Vergleich mit dem Großkönig des Erzrivalen Persien nur dann eine positive Wirkung hätte entfalten können, wenn die Überlegenheit der herakleischen Konstruktion hätte herausgestellt werden können. ${ }^{271}$ Die angeführten Parallelen dienen an dieser Stelle schlichtweg als weiteres Indiz dafür, dass es sich bei einer derart aufwendigen und eindrucksvollen Konstruktion auch unter Herakleios um nichts anderes als um ein triumphales Statement gehandelt haben kann.

266 Lenski 1997, 140 - 141 (Zitat 140) mit Verweis auf McCormick 1986, 41-46; Lenski (ebd. 138-140) zeigt außerdem, dass sich die Panegyriken auf die Kaiser, die im Nachklang der Niederlage von Adrianopel verfasst wurden, durch einen dezidiert optimistischen Ton auszeichnen.

267 Suet. Cal. 19.1-3; Cass. Dio 59.19.3; dazu siehe Stein-Hölkeskamp 2015, 127-133, die die verschiedenen Elemente der Inszenierung aufschlüsselt.

268 Stein-Hölkeskamp 2015, 130 - 132.

269 Herod. 7.34 ff.; ebd. 4.83-88 zu einer Schiffsbrücke des Dareios I.

270 Georg. Pis. Exped. Pers. 2.304-326; das Gedicht wurde 622/623 komponiert, hat also nichts mit Herakleios' Rückkehr zu tun; zum Zeitpunkt von Herakleios' Rückkehr nach Konstantinopel in Folge der Schlacht am Yarmouk war Georg von Pisidien offenbar nicht mehr aktiv.

271 Sueton (Cal. 19.3) etwa betont, dass die Schiffsbrücke im Golf von Neapel länger als die des Xerxes gewesen sei. 
Trotz seiner irreführenden Bewertung bietet Nikephoros’ Bericht wertvolle Informationen zur Rekonstruktion der Schiffsbrücke über den Bosporus. Der westliche Brückenkopf saß an der Küste von Phidaleia, also der Gegend von Pera/Galata, nördlich der Mündung des Goldenen Horns in den Bosporus; das östliche Gegenstück ist wohl in Chrysopolis zu lokalisieren, womit die Brücke die Wasserstraße an einem engen Punkt überspannte. ${ }^{272}$ Bedenkt man die Topographie Konstantinopels, war die Schiffsbrücke sowohl von der aufsteigenden Küstenlinie der Stadt aus als auch von Pera weithin sichtbar, sodass die Bevölkerung Augenzeuge davon werden konnte, wie Herakleios den Bosporus zu Pferd überquerte. Was Nikephoros als beidseitige Absperrung aus Zweigen und Laub beschreibt, die dem Kaiser den Anblick des Meeres ersparen sollte, enthüllt seine eigentliche Funktion beim Blick auf Herodots Bericht: In Hist. 7.36 heißt es, dass an beiden Seiten von Xerxes' Brücke Schranken angebracht wurden, sodass die Pferde nicht angesichts des Wassers in Panik gerieten. In Herakleios’ Fall könnte die Absperrung darüber hinaus auch zum Schmuck der spektakulären Konstruktion gedient haben. Nachdem er den Bosporus überquert hatte, bewegte Herakleios sich in nordwestliche Richtung fort, um dann - so Nikephoros die Brücke über den Barbysses, den Fluss, der das Goldene Horn speist, zu überqueren. Sich Konstantinopel von Norden nähernd, erreichte der Kaiser die Stadtmauern aller Wahrscheinlichkeit nach auf der Höhe der Blachernenkirche, des zentralen Kultortes der Theotokos, die zuletzt zur wichtigsten Schutz- und Identifikationsfigur Konstantinopels aufgestiegen war. ${ }^{273}$ Obwohl Nikephoros hier keine weiteren Spezifika bietet, ist es durchaus vorstellbar, dass Herakleios der Kirche einen Besuch abstattete, damit seine Nähe zur Theotokos betonte und seinem triumphalen Einzug einen religiösen Anstrich verlieh. Wie sich die Inszenierung weiter innerhalb der Stadtmauern entfaltete, bleibt indes im Dunkeln.

Auf den triumphalen Einzug des nicht-siegreichen Kaisers folgte eine Phase erhöhter Aktivität. Nachdem Herakleios seinen erstgeborenen Sohn Herakleios Konstantin bereits 613 gekrönt hatte, erhob er nun - wie Nikephoros knapp vermerkt einen zweiten Sohn in den Rang des Augustus: Der Junge, in der Forschung in der Regel mit dem Namen Heraklonas bezeichnet, war als Sohn der Martina, Herakleios' zweiter Ehefrau, ca. 626 in Lazica geboren und bereits 632 zum Caesar ernannt worden; seine Krönung zum Augustus ist durch einen ausführlichen Bericht im Zeremonienbuch auf den 4. Juli 638 zu datieren. ${ }^{274}$ In der Stephanskirche im Palast wurde ihm in Anwesenheit seines Halbbruders, des Augustus Herakleios Konstantin, des Patriarchen Sergios und der Senatoren anstelle des Kamelaukions, der Kopfbedeckung der Caesaren, die kaiserliche Krone aufgesetzt. Sein im Jahr 630 geborener

272 Vgl. Mango 1990, 75. Herakleios' Schiffsbrücke war demnach etwas kürzer als die sieben Stadien (etwa 1,3 km, gemäß Herodot) der Brücke des Xerxes.

273 Dazu siehe oben S. $227 \mathrm{f}$.

274 Ausführliche Beschreibung des Rituals in De cerim. 2.27, außerdem Nik. Brev. 25; PMBZ Heraklonas (\#2565). 
Bruder David rückte bei dieser Gelegenheit in den Rang des Caesars nach. ${ }^{275} \mathrm{Im}$ Anschluss an die eigentliche Krönung traf Herakleios mit seinen Söhnen im prunkvollen Empfangssaal, dem Augusteus, auf die Spitze der hauptstädtischen Elite, die Patrikioi, um sich dann im offenen Hof des Palastes von den kaiserlichen Garden sowie Vertretern der städtischen Demen akklamieren zu lassen. Die Feierlichkeiten wurden mit einem gemeinsamen Gottesdienst in der Hagia Sophia abgeschlossen. ${ }^{276}$ Das Datum von Heraklonas' Krönung gibt schließlich auch Aufschluss zur Dauer von Herakleios' Verweilen im suburbanen Palast von Hiereia: Geht man davon aus, dass er kurz vor der Krönung, also im Frühjahr bzw. Frühsommer 638, über die Schiffsbrücke in Konstantinopel einzog, scheint er sich ein Jahr oder gar länger auf der asiatischen Seite niedergelassen $\mathrm{zu}$ haben. ${ }^{277}$

Die Krönung des Heraklonas verfolgte zwei Ziele: Nachdem der Usurpationsversuch Herakleios' Nachfolgeregelung in Frage gestellt hatte, setzte der Kaiser mit der Betonung seiner Kernfamilie ein klares dynastisches Zeichen gegen potentielle Herausforderer; die Krönungszeremonie gab ihm außerdem die Möglichkeit, mit einer weiteren öffentlichen Inszenierung die verschiedenen Gruppen der Hauptstadt anzusprechen - von der weltlichen und geistlichen Elite im Palast bis hin zur Gemeinde in der Hagia Sophia. Als die versammelte Menge dem frisch gekrönten Jungen akklamierte, drückte sie damit auch die Unterstützung des Vaters aus. Herakleios gewährte der hauptstädtischen Öffentlichkeit nun die Aufmerksamkeit, die sie während seines Aufenthaltes in Hiereia eingefordert hatte. Auch in den darauffolgenden Monaten zeigte Herakleios sich und die kaiserliche Familie wiederholt der Bevölkerung. Anlässlich der Feierlichkeiten von Heraklonas’ Konsulatsantritt begab der Kaiser sich am 1. Januar 639 mit seinen Söhnen und umgeben von den höchsten Würdenträgern in einer Prozession vom Palast in die Hagia Sophia. ${ }^{278}$ Vier Tage später versammelte die kaiserliche Familie sich erneut im Palast: Herakleios, seine Frau, die Augusta Martina, sowie seine Söhne und Töchter empfingen im Augusteus die städtische Elite, bevor Herakleios sich in die kaiserlichen Loge im Hippodrom begab, um von dort den Spielen beizuwohnen. ${ }^{279}$

Herakleios beschränkte sich indes nach seiner Rückkehr in die Hauptstadt nicht auf dynastische Statements, sondern wurde auch erneut in der Kirchenpolitik aktiv.

275 PLRE IIIA, David 8 (390)

276 Vgl. Dagron 2003, 75f.; Kaegi 2003, 265-268.

277 Die Schlacht am Yarmouk wird in der Regel auf den 20. August 636 datiert; siehe Kaegi 1992, 114; ob Herakleios noch im Jahr 636 oder erst 637 an den Bosporus zurückkehrte, ist allerdings unklar. 278 Zur Prozession siehe De cerim. 2.28, wo der Konsulats-Antritt des Heraklonas nicht explizit erwähnt wird (vgl. allerdings Nik. Brev. 27); eine Verbindung dieser beiden Ereignisse ist wahrscheinlich, siehe dazu Mango 1990, 191. An der Prozession nahmen auch der Patrikios Niketas, wahrscheinlich der Sohn des persischen Generals Shahrbaraz, teil sowie der Sohn des persischen Adligen Iesdem (dazu siehe Mango 1985, 105, 116f.).

279 De cerim. 2.29; zu diesem Zeitpunkt waren auch die Töchter des Herakleios und der Martina, Augustina und Anastasia, in den Rang einer Augusta erhoben worden; ihr Sohn Martin war Nobilissimus. 
Nachdem seine Einigungsbemühungen im Nachklang der Restitutio Crucis offenbar kurzzeitig einen gewissen Erfolg hatten verzeichnen können, erhob sich schnell vor allem von chalkedonensischer Seite erbitterter Widerstand gegen die Formel von der einen Energie. Die kaiserlichen Schlichtungsversuche stagnierten, als das Vorrücken der Araber die römische Aufmerksamkeit zunehmend beanspruchte. Doch nach Herakleios' triumphaler Rückkehr in die Hauptstadt nahm die Angelegenheit erneut Fahrt auf: Herakleios und Sergios unternahmen einen letzten Versuch, ihr Ziel der Kircheneinigung zu erreichen; vor allem die strikten Verfechter des Chalkedonense sollten damit wieder eingebunden werden. Im Herbst 638 unterzeichnete Herakleios eine leicht abgewandelte Kompromissformel in Form eines reichsweit bindenden Edikts, der sogenannten Ekthesis: Die Frage nach ein oder zwei Energien in Christus sollte nicht weiter diskutiert werden; ausgehend vom expliziten Festhalten an den zwei Naturen Christi, dem Kern des chalkedonensischen Glaubensbekenntnisses, sollte künftig stattdessen der eine Wille (hen thelema) in Christus die Grundlage der orthodoxen Christologie bilden. Das Edikt wurde nicht nur an alle vier Patriarchate versandt, sondern auch im Narthex der Hagia Sophia ausgestellt. ${ }^{280}$

$\mathrm{Zu}$ Beginn der 630er Jahre waren die Details der kaiserlichen Kirchenpolitik - soweit wir das aus dem Contra Severum des Georg von Pisidien schließen können nicht Teil des öffentlichen Diskurses der Hauptstadt; stattdessen wurde Herakleios, nach dem Sieg über die Perser auf dem Zenit seines Triumphes, in Konstantinopel primär als theologische Autorität und Verfechter der (chalkedonensischen) Orthodoxie stilisiert. Einige Jahre später, als dem Kaiser neben der außenpolitischen Sicherung des Reiches auch die innenpolitische Stabilität zu entgleiten drohte, sah sich Herakleios jedoch offenbar genötigt, auch auf dem Feld der Kirchenpolitik ein noch stärkeres Zeichen in Form eines kaiserlichen Ediktes zu setzen. Dass die Ekthesis ausgerechnet im Herbst 638 herausgegeben und öffentlichkeitswirksam in der Hagia Sophia ausgestellt wurde, wenige Monate nach Herakleios' Einzug in die Hauptstadt, ist kaum als Zufall zu werten. ${ }^{281} \mathrm{Zu}$ diesem Zeitpunkt waren die Gemeinden, auf die die Einigungspolitik ursprünglich abgezielt hatte, durch die Besatzung der Araber bereits erneut dem Zugriff der Zentralmacht entzogen. Es entsteht der Eindruck, dass die Ekthesis, die zuallererst die zwei Naturen Christi gemäß dem chalkedonensischen Glaubensbekenntnis betont, nicht zuletzt auf eine Rezeption in der hauptstädtischen Öffentlichkeit abzielte. ${ }^{282}$ Als die monoenergetische Lehre von chalkedonensischer

280 Theoph. Conf. AM 6121 (De Boor 330); der Text der Ekthesis bei Allen 2009, 209 - 217; vgl. Stratos 1972, 141-144; Alexakis 1995/1996, 93 f.; Kaegi 2003, 269-271; Hovorun 2008, 73; Lange 2012, 606 - 614 zu den theologischen Details der Ekthesis.

281 Meier 2019a 1041 weist darauf hin, dass die Ekthesis kurz nach dem Einzug des Kalifen Umar in Jerusalem proklamiert wurde.

282 Zur Frage, welches Ziel Herakleios und Sergios mit der Veröffentlichung der Ekthesis verfolgten, siehe Van Dieten 1972, 46 f., der meint, dass es weiterhin um die Reintegration der miaphysitischen Gemeinden im Osten ging. Für Winkelmann 2001, 38 ging es eher darum, die im Reichsverband verbliebenen, chalkedonensischen Denominationen zusammenzuhalten; zusammenfassend Lange 2012, 
Seite zunehmend auf Ablehnung stieß, musste sich Herakleios auch in Konstantinopel noch deutlicher positionieren.

Ich habe versucht zu zeigen, dass die kaiserliche Politik im Nachklang der römischen Niederlage am Yarmouk nicht etwa von Herakleios' physischem wie psychischem Niedergang bestimmt war, wie es die Forschungsliteratur in der Regel darstellt. Während die sesshaften Kaiser des 5. und 6. Jahrhunderts sich zu einem gewissen Grad gegen die Folgen militärischer Niederlagen hatten immunisieren können, brachte Herakleios’ persönliches Engagement als Befehlshaber den Umstand mit sich, dass die römische Performance auf dem Schlachtfeld erneut in wesentlich höherem Maße auf kaiserliche Verantwortlichkeit verwies. Nach der Niederlage in Syrien und der Verschwörung des Athalarich und Theodor war Herakleios' Aktivität von der Notwendigkeit bestimmt, die kaiserliche Autorität nach dem Prestigeverlust wiederherzustellen und Konstantinopel zu sichern; die Akzeptanz der hauptstädtischen Interessengruppen konstituierte weiterhin die Basis monarchischer Herrschaft. Herakleios' Interaktion mit der hauptstädtischen Öffentlichkeit lässt sich als Erweiterung von Mustern verstehen, die bereits für seine früheren Regierungsjahre beobachtet wurden - allen voran die Förderung der Kernfamilie, die Betonung dynastischer Kontinuität und imperialer Triumphalismus.

Herakleios' Maßnahmen zeitigten offenbar den erhofften Erfolg: Die Stimmung in Konstantinopel beruhigte sich und für die darauffolgenden Jahre sind keine weiteren Unruhen bzw. Herausforderungen der kaiserlichen Autorität verzeichnet; 641 starb Herakleios eines natürlichen Todes. Doch die öffentlichen Stellungsnahmen, zu denen der Kaiser sich angesichts seiner prekären Position genötigt gesehen hatte - die Erhebung eines zweiten Sohnes in den Rang des Augustus und eine deutliche religionspolitische Positionierung -, sollten sich nicht als nachhaltig erweisen; bereits kurz nach Herakleios' Tod offenbarten sich die Negativfolgen dieser Maßnahmen. Da mit der Krönung eines zweiten Augustus die klare Hierarchie der Nachfolgeregelung aufgehoben worden war, entbrannte zwischen den Halbbrüdern Herakleios Konstantin und Heraklonas (bzw. dessen Mutter Martina) nach dem Tod des Vaters ein erbitterter Machtkampf, dessen Dynamiken im folgenden Kapitel genauer betrachten werde. Angesichts des innerfamiliären Ringens konnten sich erneut militärische Funktionsträger - die Gruppe also, die Herakleios versucht hatte einzuhegen machtpolitisch positionieren. Die Ekthesis indes führte nicht etwa zu einem Abklingen des religiösen Konfliktes, sondern verschärfte den Widerstand von ultra-chalkedonensischer Seite gegen die Konstantinopolitaner Kompromisspolitik nur noch mehr. Als Hauptverantwortlicher stand nicht nur der 638 verstorbene Patriarch Ser-

611-614. In diesem Zusammenhang möchte ich darauf hinweisen, dass auch Herakleios’ Nachfolger Konstans II. ein kirchenpolitisches Edikt, den sog. Typos, genau dann erließ, als seine Herrschaft durch die Usurpation des Gregorios in Afrika herausgefordert worden war; siehe dazu Haldon 1990, 56f. und ders. 2016, 36-38. Derart öffentlichkeitswirksame Proklamationen scheinen also besonders in prekären Phasen für notwendig erachtet worden zu sein. 
gios im Kreuzfeuer der Kritik, sondern auch Herakleios selbst. ${ }^{283}$ Nach dem Tod des Papstes Honorius weigerten sich dessen Nachfolger, die Beschlüsse der Ekthesis anzuerkennen. ${ }^{284}$ Anstatt wie erhofft die Einigung der christlichen Gemeinden zu erwirken, trieb der Monotheletismus die Kirchen von Rom und Konstantinopel in ein Schisma, das sich noch weit über die Regierung des Herakleios hinauszog und erst beim sechsten ökumenischen Konzil in Konstantinopel (680/1) mit der endgültigen Verdammung der Lehre vom einen Willen beigelegt werden konnte. ${ }^{285}$ Dass Herakleios sich mit der Ekthesis offiziell zum Monotheletismus bekannt hatte, war nicht nur ein schweres Erbe für seine Nachfolger, sondern schädigte auch seinen Ruf massiv.

Es bleibt zum Ende dieses Kapitels die Frage, wie Nikephoros' irreführende Bewertung von der kaiserlichen Rückkehr nach Konstantinopel zu verstehen ist. Die Passage zur Schiffsbrücke ist nicht die einzige Stelle im Breviarium, in der sich eine kritische Haltung gegenüber Herakleios äußert. ${ }^{286}$ Anstatt davon auszugehen, dass diese Haltung auf Nikephoros selbst zurückgeht, ist jedoch auch denkbar, dass der Autor um die Wende vom 8. zum 9. Jahrhundert damit die Position seiner Quelle übernahm. ${ }^{287}$ Die Beurteilungen, mit der die Nachwelt auf Herakleios als Kaiser zurückblickte, sind prinzipiell gespalten; sie schwanken zwischen der Bewunderung für seinen grandiosen Sieg über die Perser einerseits und einem bisweilen gar polemischen Standpunkt andererseits, der vor allem aus der Verurteilung der kaiserlichen Kirchenpolitik resultierte. ${ }^{288}$ Doch selbst angesichts der Fülle an negativen Bewertungen scheint die Geschichte von der Schiffsbrücke, die gebaut wurde, um Herakleios’ Angst vorm Wasser zu besänftigen, derart absurd, dass nur eine Erklärung bleibt: Es handelt sich dabei um politische Satire.

Kritik am regierenden oder häufiger am verstorbenen Kaiser ist für die römische Monarchie ein gut belegtes Phänomen. ${ }^{289}$ Als eine spezifische Form der Kaiserkritik

$283 \mathrm{Zu}$ Tod und Beerdigung des Sergios siehe Nik. Brev. 26; De cerim. 2.30; vgl. Stratos 1972, 145 und Hovorun 2008, 73-76. Sergios Nachfolger Pyrrhos erwies sich als loyal gegenüber der kaiserlichen Linie; siehe siehe Van Dieten 1972, 57-75. Nach Sergios' Tod scheint Herakleios die Verantwortung für die Ekthesis zu einem gewissen Grad von sich gewiesen zu haben; dies legt zumindest ein Brief an den Papst Johannes IV. nahe; siehe Meyendorff 1989, 354 Anm. 56. Sollte der Kaiser sich tatsächlich darum bemüht haben, sich von der Ekthesis zu distanzieren, so änderte dies die öffentliche Wahrnehmung allerdings auch nicht mehr.

284 Zum Widerstand aus Rom siehe etwa Theoph. Conf. AM 6121 (De Boor 330 -332); vgl. Alexakis 1996/1996 (hier auch zu der Frage, ob Herakleios bis zu seinem Tod am Monotheletismus festhielt) und Booth 2014, 259-269.

285 Überblick über die Entwicklungen bei Haldon 1990, 304-317; Ekonomou 2007, 79-112; Hovorun 2008, 76-91; Meyendorff 1989, 362-373.

286 Vgl. Nik. Brev. 27.

287 Zu Nikephoros' Quellen siehe Mango 1990, 12-14 und Howard-Johnston 2010, 244-250, der davon ausgeht, dass Nikephoros eine hauptstädtische Chronik, genauer gesagt eine Erweiterung des Johannes von Antiochia, nutzte; siehe oben $23 \mathrm{f}$.

288 Zur Herakleios-Rezeption siehe Sirotenko 2017, 2018.

289 Zu römischer Kaiserkritik siehe zum Beispiel Tinnefeld 1971; Av. Cameron 1977 und einen Sammelband zu 'antimonarchic discourse' (Börm 2015b). 
zieht politische Satire ihre Wirkung daraus, dass sie mit Übertreibung, Verzerrung und Polemik Elemente kaiserlicher Repräsentation oder enkomiastischer Stilisierung ins Gegenteil verkehrt; sie fungiert als „parody of panegyrics“. ${ }^{290}$ Auch im spätantiken Konstantinopel war Satire eine mögliche politische Ausdrucksform, wie Prokops Geheimgeschichte in Bezug auf Justinian besonders eindrücklich zeigt. ${ }^{291}$ Was Herakleios als triumphales Statement intendiert und vollzogen hatte - die Schiffsbrücke über den Bosporus -, wurde in der satirischen Betrachtung ins Gegenteil verkehrt: in eine Initiative der hauptstädtischen Funktionsträger, den mental inkompetenten Kaiser nach Konstantinopel zu überführen. ${ }^{292}$

Von welcher Person bzw. Gruppe die Satire auf Herakleios ursprünglich ausging, ist schließlich kaum mehr festzustellen. Die Quelle, die Nikephorors für Herakleios’ späte Regierungsjahre nutze, scheint nicht lang nach dessen Tod 641 verfasst worden zu sein, da der Bericht recht abrupt inmitten der Nachfolgestreitigkeiten abbricht; den Sturz von Heraklonas und Martina 642 übergeht Nikephoros und setzt erst mit der Ermordung des Konstans II. im Jahr 665 mit seiner Erzählung wieder ein. ${ }^{293}$ Geht man davon aus, dass Nikephoros die Bewertung von Herakleios' Schiffbrücke aus seiner Quelle übernahm, so liegt es nahe, dass die Satire noch zu Lebzeiten des Kaisers oder kurz nach dessen Tod entstand - in einer Zeit also, als klar wurde, dass sein grandioses Restitutionswerk der Expansion der Araber zum Opfer gefallen und eine religionspolitische Einigung in weite Ferne gerückt war. Angesichts dieser Entwicklungen konnte imperialer Triumphalismus, wie ihn die Schiffsbrücke über den Bosporus zu

290 Halsall 2002, 102. Als ein Beispiel aus dem Prinzipat wäre Senecas Apocolocyntosis auf den verstorbenen Kaiser Claudius zu nennen.

291 Av. Cameron 1996a, bes. 58 betont, dass man dem Charakter der Geheimgeschichte nicht gerecht werden würde, wenn man sie im Ganzen als Satire qualifiziert (vgl. Halsall 2002, 102f. mit Anm. 55); dennoch enthält der Text sicherlich satirische Elemente. Das Bild des frommen, asketischen und geradezu heiligmäßigen Kaisers, als der Justinian in der Regel stilisiert wurde, verkehrt Prokop in der Geheimgeschichte ins Gegenteil: Justinian erscheint als dämonischer Herrscher, als der Antichrist höchstpersönlich, der schlaflos mit seinem Kopf unterm Arm durch den nächtlichen Kaiserpalast streift (siehe Prok. Hist. arc. 12 und dazu Börm 2015b, 334f.). Ebenso wie Panegyrik lässt sich auch satirischer Inhalt in verschiedenen literarischen Genres nachvollziehen: Die Beschreibung von Justins II. Krankheit in Johannes von Ephesos’ Kirchengeschichte (Hist. eccl. 3.2) könnte unter Umständen auch als eine Form der politischen Satire verstanden werden; zum Schicksal des Justin II. siehe oben S. $69 \mathrm{f}$;; vgl. Börm 2013, $81 \mathrm{f}$.

292 Die Idee, der Kaiser leide an Angst vorm Wasser, ist indes nicht vollkommen willkürlich; sie könnte daher rühren, dass Herakleios offenbar in seinen späten Jahren an Wassersucht litt - wenn wir die Berichte in Theoph. Conf. AM 6132 (De Boor 341) und Nic. Brev. 27 in ihren Grundzügen ernst nehmen. Was Satire besonders wirkungsvoll macht, ist, dass sie mit authentischen Versatzstücken arbeitet (wie etwa dem Umstand, dass eine Schiffbrücke konstruiert wurde oder dass der Kaiser unter physischen Beschwerden litt) und diese neu arrangiert, um das Objekt der Satire ins Lächerliche zu ziehen.

293 Siehe den Zeitsprung zwischen Nik. Brev. 32 und 33; in der Regel wird davon ausgegangen, dass dieser Bruch den Quellen geschuldet ist, die Nikephoros bei der Verschriftlichung des Breviariums zur Verfügung standen; siehe Mango 1990, 14f.; Howard-Johnston 2010, 248. 
transportieren gedacht hatte, nicht mehr überzeugen. Die Satire könnte in Form eines Gerüchtes, als urbaner Mythos zirkuliert und schließlich verschriftlicht worden sein. In der kollektiven Erinnerung der Hauptstadt blieb Herakleios' spektakuläre Inszenierung also nicht als solche haften; stattdessen nahm man den Bau der Schiffsbrücke zum Anlass, um den Kaiser ins Lächerliche zu ziehen. Mit der Zeit entwickelte die Geschichte von Herakleios' Angst vorm Wasser ein Eigenleben; das Verständnis der satirischen Ebene ging verloren, sodass auch die moderne Forschung die in Nikephoros' Bericht erhaltene Bewertung unkritisch als historische Gegebenheit übernahm. 


\section{Herakleios' Nachfolge}

Nach über dreißigjähriger Regierung und zuletzt schwerer Krankheit verstarb Herakleios Anfang des Jahres 641 in Konstantinopel eines natürlichen Todes. Seine Leiche wurde im kaiserlichen Mausoleum der Apostelkirche beigesetzt. ${ }^{1}$ Dies ist insofern bemerkenswert, als dass er sich damit von seinen beiden Vorgängern, Maurikios und Phokas, abhebt, deren Leben und Herrschaft 602 bzw. 610 ein gewaltsames Ende gefunden hatten. Die zwei Herrscherwechsel, die das hauptstädtische Sozialgefüge im ersten Jahrzehnt des 7. Jahrhunderts erschütterten, zeitigten einen profunden Effekt auf Möglichkeiten und Grenzen monarchischer Herrschaft: Spätestens mit Herakleios’ Usurpation 610 wurde deutlich, dass das hauptstädtische Umfeld - im Gegensatz zum 5. und 6. Jahrhundert - den sesshaften Kaisern keinen ausreichenden Schutz mehr bot; militärische Aggression von außen konnte die Stimmung in Konstantinopel zum Kippen bringen und einen Regimewechsel herbeiführen. Nachdem Herakleios sich selbst von Karthago aus an die Macht geputscht hatte, bestand seine zentrale Herausforderung darin, die hauptstädtische Akzeptanzbasis zu festigen und einer erneuten Usurpation aus dem militärischen Sektor vorzubeugen.

Die Maßnahmen, die Herakleios ergriff, um sich dieser Herausforderung zu stellen, zeitigten in der Tat die erhoffte Wirkung: Indem er von Beginn seiner Herrschaft an seine Kernfamilie förderte, indem er durch die Erhebung seines Sohnes Herakleios Konstantin die Nachfolge klar indizierte und in der Wahrnehmung der hauptstädtischen Öffentlichkeit verankerte, nahm er ambitionierten Militärs den Raum, sich machtpolitisch zu positionieren; den militärischen Sektor indes band er wieder stärker an die kaiserliche Autorität, indem er als erster römischer Kaiser seit über zweihundert Jahren die Truppen persönlich in den Krieg führte. Der Entscheidung, die im hauptstädtischen Umfeld als transgressiv empfunden wurde - die plötzliche Abwesenheit des Kaisers -, wurde durch Sinnangebote begegnet, die Herakleios' persönliches Engagement auf dem Schlachtfeld nicht nur rechtfertigten, sondern auch dezidiert positiv konnotierten. Neben einer Stabilisierung von Herakleios' Position lässt sich in diesem Zusammenhang auch eine Integration und Festigung der hauptstädtischen Identitätsgemeinschaft nachvollziehen. Der Sieg gegen die Perser schließlich sanktionierte die kaiserlichen Entscheidungen. Selbst die Expansion der Araber, die das herakleische Restitutionswerk innerhalb weniger Jahre zunichte machte, konnte das Prestige des Kaisers zwar ankratzen, seine Stellung jedoch nicht grundsätzlich gefährden.

\footnotetext{
1 Nik. Brev. 27, auch zur Krankheit Wassersucht, an der Herakleios gelitten haben soll; allerdings ist hier daran zu erinnern, dass Nik. eine Herakleios-kritische Quelle nutzt, die seine Krankheit als gerechte Strafe für seine Verfehlungen - die Ehe mit seiner Nichte Martina - interpretiert. Ob man den Bericht für bare Münze nehmen kann, ist daher fraglich. Vgl. Joh. Nik. 116. f., wo sein Tod mit den Münzbildern in Verbindung gebracht wird; Theoph. Conf. AM 6132 (De Boor 341); vgl. Woods 2006. 
Auf die Verwerfungen im ersten Jahrzehnt des 7. Jahrhundert folgte also eine über dreißigjährige Phase der relativen innenpolitischen Stabilität. Nach Herakleios’ Tod ging die Herrschaft unangefochten an seine Söhne über; als erste Dynastie seit der Einrichtung römischer Alleinherrschaft unter Augustus regierte die herakleische Familie über fünf Generationen hinweg, bis Justinian II. Dass Herakleios den dynastischen Aspekt seiner Herrschaft derart konsequent propagiert hatte, verfehlte die intendierte Wirkung nicht; an seiner Familie führte zunächst kein Weg vorbei. Doch was auf den ersten Blick nach einer Erfolgsgeschichte aussieht, offenbart bei genauerem Hinsehen eine tiefgreifende Problematik. Ausgehend von den Nachfolgestreitigkeiten, die nach dem Tod des Dynastiegründers innerhalb der Familie ausbrachen, zeigt dieses Kapitel die strukturellen Folgen von Herakleios' Politik für die oströmische Monarchie auf: Dynastische Kontinuität ging mit innenpolitischer Instabilität Hand in Hand. Die Bedeutungssteigerung des militärischen Sektors und die Remilitarisierung des Kaisertums, die unter Herakleios im politischen System Ostroms verankert worden waren, bestimmten - nicht zuletzt in Verbindung mit der arabischen Expansion auch den weiteren Verlauf des 7. Jahrhunderts.

\subsection{Sollbruchstellen der herakleischen Politik}

Nach Herakleios' Tod offenbarten sich rasch die Sollbruchstellen seiner Politik: Als die Autorität und ordnende Hand des Dynastiegründers wegfiel, kam es zu einem erbitterten Machtkampf zwischen den beiden Familienlinien, den Nachkommen seiner ersten Ehe mit Eudokia und denen seiner zweiten Ehe mit Martina. Zum Verhängnis wurde nicht zuletzt der Umstand, dass der Kaiser sich 638 angesichts eines Usurpationsversuches - sein unehelicher Sohn Atalarichos und sein Neffe Theodor hatten sich gegen ihn verschworen - dazu genötigt gesehen hatte, mit Heraklonas, seinem Sohn aus zweiter Ehe mit Martina, einen weiteren Sohn in den Rang des Augustus zu erheben. ${ }^{2}$ Während Herakleios Konstantin, der bereits im Jahr 613, gerade einmal einjährig, von seinem Vater zum Augustus gekrönt worden war, in der Nachfolgeregelung zuvor unumstritten an erster Stelle gestanden hatte, hob Heraklonas' Beförderung vom Caesar zum Augustus die klare Rangordnung auf. Laut Nikephoros setzte Herakleios ein Testament auf, gemäß dem seine beiden zu Augusti gekrönten Söhne nach seinem Tod als Kaiser von gleichem Rang regieren sollten; seine Witwe Martina sei als Kaiserin zu ehren. ${ }^{3}$ Doch diese Regelung konnte sich nicht durchsetzen.

Gleichrangige Kondominate, wie sie bis zur Absetzung des letzten weströmischen Augustus im Jahr 476 bestanden hatten, basierten auf der räumlichen Trennung der regierenden Kaiser und dem Vorhandensein mehrerer politisch-administrativer Zen-

2 Dazu siehe oben S. $310 \mathrm{f}$.

3 Nik. Brev. 27. 
tren. ${ }^{4}$ Als sich Konstantinopel im 5. und 6. Jahrhundert als unumstrittene Hauptstadt des römischen Reiches festigte, war eine derartige Entzerrung - nicht zuletzt auch angesichts der labilen Sicherheitslage in den von Justinian rückgewonnenen Territorien - kaum mehr möglich. ${ }^{5}$ Zwar hatten zeitweise durchaus mehrere Augusti am Bosporus residiert; bei diesen handelte es sich jedoch stets um einen Junior Augustus und einen Senior Augustus als dessen Auctor imperii: Die Rangfolge war dadurch immer zweifelsfrei indiziert. Ob Herakleios tatsächlich ein Testament verfasst hatte oder nicht, eine gleichrangige Herrschaft seiner beiden Söhne in Konstantinopel erwies sich als nicht praktikabel.

Entgegen dem Willen des verstorbenen Herakleios pochte im Jahr 641 offenbar die hauptstädtische Öffentlichkeit darauf, dem älteren Herakleios Konstantin gegenüber dem Halbbruder Heraklonas den Vorrang einzuräumen, da er den Rang des Augustus bereits wesentlich länger bekleidet hatte. ${ }^{6}$ Obwohl das politische System Ostroms nicht über eine institutionalisierte Nachfolgeregelung verfügte, konnten sich Akteure bzw. Akteursgruppen bei Entscheidungsfindungen also auf Konventionen wie Seniorität berufen. Den Ausschlag dafür, dass Herakleios Konstantin seinem Halbbruder übergeordnet wurde, gab die Unterstützung, die diesem in der Öffentlichkeit zuteilwurde; gegen derartigen Druck konnten sich Heraklonas und dessen Mutter Martina, die offenbar eigene Ambitionen verfolgte, nicht durchsetzen. Doch obwohl sich Herakleios Konstantin der öffentlichen Unterstützung hatte versichern können, standen offenbar auch hinter Heraklonas und Martina gewichtige Einflussnehmer, nicht zuletzt der Patriarch Pyrrhos, der Nachfolger des 638 verstorbenen Sergios; ${ }^{7}$ die Situation war keinesfalls abschließend geklärt. Ähnlich wie sein Vater nach dem Debakel der militärischen Niederlage in Syrien, residierte auch Herakleios Konstantin auf der

4 Dabei ist jedoch festzuhalten, dass es selbst zwischen Augusti, die nicht in der gleichen Stadt regierten, immer wieder zu Kompetenzstreitigkeiten - auch innerfamiliären Streitigkeiten - kam; die Beziehungen zwischen west- und oströmischem Kaiser werden etwa in Börm 2018 behandelt.

5 Laut Theoph. Sim. Hist. 8.11.7-10 tauchte unter Herakleios ein Dokument auf, das sich als Testament des Kaiser Maurikios ausgab: Demgemäß sollte nach Maurikios’ Tod dessen ältester Sohn Theodosios, den Maurikios 590 bereits zum Augustus erhoben hatte, in Konstantinopel regieren, sein zweitältester Sohn als Augustus im alten Rom; der Rest des Reiches sollte unter den anderen Söhnen aufgeteilt werden, die aufgrund ihres jungen Alters unter die Aufsicht des Bischofs Dometianos von Melitene gestellt würden. Nimmt man das Dokument für bare Münze, so plante Maurikios offenbar, eine Art Tetrarchie einzuführen, wie sie bereits aus dem vierten Jahrhundert bekannt war. Ob sich dies tatsächlich als eine praktikable Lösung herausgestellt hätte - wenn Maurikios und seine Familie nicht eines gewaltsamen Todes gestorben wären -, bleibt dahingestellt.

6 Siehe Nik. Brev. 28, laut dem sich an der Versammlung, die die Nachfolgefrage regeln sollte, neben dem Patriarchen Pyrrhos auch die Amtsträger und Vertreter des Volkes teilnahmen (Пúppov tòv

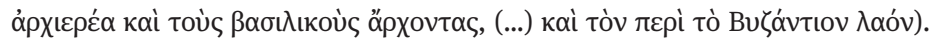

7 Laut Nik. Brev. 29 hatte Herakleios vor seinem Tod dem Pyrrhos Geldmittel zur Verfügung gestellt, mit denen dieser Martina und Heraklonas unterstützen sollte. Laut Joh. Nik. 119.19f. kam es vor diesem Hintergrund zu einer ersten Exilierung des Patriarchen Pyrrhos; siehe PMBZ Pyrrhos I. (\#6386); dazu auch Van Dieten 1972, 67 und Mango 1990, 193; Speck 1988, 469 - 471 dagegen bezweifelt, dass es zu einer Exilierung des Pyrrhos im Frühjahr 641 kam. 
asiatischen Seite des Bosporus, in Hiereia. ${ }^{8}$ Dass sich Herakleios Konstantin in Kleinasien aufhielt, mag man als Reaktion auf die angespannte Stimmung in der Hauptstadt lesen; es könnte allerdings auch dem Umstand geschuldet gewesen sein, dass er gezielt die Nähe der dort stationierten Truppen suchte. Aufgrund seines schlechten Gesundheitszustandes und des Risikos, das für seine Position von der schieren Präsenz des Augustus Heraklonas ausging, wandte sich Herakleios Konstantin mit Unterstützung seines Schatzmeisters Philagrios ${ }^{9}$ an das Heer: Eine großzügige Geldzahlung sollte die Soldaten an ihn und seinen Sohn Konstans ${ }^{10}$ binden. ${ }^{11}$ Seine Entscheidung, in der instabilen Situation das Militär einzubeziehen, erwies sich als folgenschwer.

Tatsächlich starb Herakleios Konstantin im Mai 641 nur wenige Monate nach seinem Vater. ${ }^{12}$ Der letzte verbleibende Augustus, der inzwischen etwa 15-jährige Heraklonas, konnte vorerst unter der Vormundschaft Martinas seine Machtbasis in Konstantinopel sichern. Philagrios und weitere Vertraute des verstorbenen Halbbruders wurden exiliert. Doch die Stimmung blieb angespannt. Von verschiedenen Seiten regte sich Widerstand: Innerhalb der hauptstädtischen Bevölkerung stießen die Maßnahmen gegen Philagrios auf Missfallen; erneut wurde das Thema der illegitimen Verbindung zwischen Herakleios und Martina virulent und die Legitimität des aktuellen Regimes in Frage gestellt. ${ }^{13}$ Die Verwerfungen blieben nicht auf den zivilen Bereich beschränkt. Während Martina zur Durchsetzung ihrer Interessen thrakische Kontingente in die Hauptstadt geholt hatte, sammelten sich in Chalkedon römische Soldaten, die dem verstorbenen Herakleios Konstantin die Treue hielten und auf das Recht von dessen Sohn Konstans als Thronfolger pochten. ${ }^{14}$ Angeführt wurden die Soldaten von Valentinos, einem Gefolgsmann des Philagrios, der sich mithilfe der kaiserlichen Gelder der Unterstützung der im Osten stationierten Truppen hatte versichern können. ${ }^{15}$ Im Herbst 641 standen also wieder einmal römische Soldaten, die

8 Nik. Brev. 29 gibt als Grund für das Residieren des Herakleios Konstantin in Chalkedon dessen labilen Gesundheitszustand an.

9 PLRE IIIB, Philagrius 3 (1018).

$10 \mathrm{Zu}$ dem 630 geborenen Konstans siehe PMBZ, Konstans II. (\#3691/corr.). Der Name des Jungen war ursprünglich der des Großvaters, Herakleios; bei seiner Krönung in der Hagia Sophia (Nik. Brev. 31) akklamierte ihm die versammelte Menge als Konstantin. Der Name Konstans bürgerte sich wohl auch in Abgrenzung zu seinem Vater ein; in der Forschung firmiert er als Konstans II. Konstans' Mutter war Gregoria, die Tochter von Herakleios' Cousin Niketas.

11 Nik. Brev. 29.

12 Zum Tod des Herakleios Konstantin siehe Mango 1990, 192; laut Theoph. Conf. AM 6132 (De Boor 341) wurde Herakleios Konstantin von seiner Stiefmutter Martina vergiftet; diese Version verbreitete auch dessen Sohn, der spätere Konstans II., siehe ebd. AM 6133 (342).

13 Joh. Nik. 119.20 - 24, 120.2; zur Verbannung des Philagrios siehe auch Nik. Brev. 30.

$14 \mathrm{Zu}$ den thrakischen Kontingenten Joh. Nik. 119.23; Armee in Chalkedon: Nik. Brev. 30; Joh. Nik. $120.39 \mathrm{f}$.

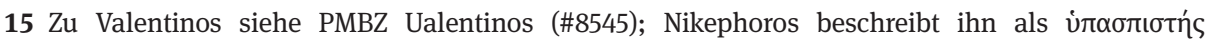
(„Schildträger“) des Sakellarios Philagrios; laut Sebeos 44 (Thomson/Howard-Johnston I, 104) war Valentinos Arsakide, also armenischer Abstammung, und wurde bereits von Herakleios Konstantin 
sich der Befehlsgewalt der Zentrale entzogen hatten, kurz vor Konstantinopel; allein der Bosporus trennte sie von der Stadt. ${ }^{16}$

Die Parteiung um Martina und Heraklonas bemühte sich, die Lage mit friedlichen Mitteln in den Griff zu bekommen; vor aller Öffentlichkeit wurde Konstans’ Unversehrtheit bezeugt, doch das römische Heer um Valentinos ließ sich nicht beschwichtigen. Als die Soldaten im Herbst 641 begannen, die hauptstädtische Bevölkerung unter Druck zu setzen, indem sie die Ernte auf den Feldern um Chalkedon zerstörten, geriet die Stimmung auch innerhalb der Stadtmauern zusehends außer Kontrolle. Obwohl die Heraklonas-treue Partei nicht müde wurden, die unlauteren Absichten des Valentinos zu betonen, blieb ihr nichts anderes übrig, als dessen Forderungen nachzukommen. ${ }^{17}$ Vor der versammelten Gemeinde bestieg Heraklonas mit dem Patriarchen Pyrrhos den Ambo der Hagia Sophia und krönte dort seinen etwa elfjährigen Neffen Konstans zum Augustus. ${ }^{18}$ Dass die Krönungszeremonie nicht etwa in der Stephanskirche im Palast stattfand, wo noch Heraklonas selbst gekrönt worden war, sondern vor versammelter Gemeinde in der Hagia Sophia, verwundert kaum: Wie im Kapitel zu den Krönungen des Phokas und Herakleios bereits herausgearbeitet wurde, bedurfte es bei Krönungsritualen in prekären Situationen einer breiten öffentlichen Teilhabe. Der Verlauf der Krönung ist schließlich ein eindringliches Beispiel dafür, wie intolerant die hauptstädtische Öffentlichkeit auf Abweichungen vom normativ gefestigten Ritualvollzug reagieren konnte: Als der Patriarch Pyrrhos sich anschickte, Konstans auf dem Ambo der Kirche zu krönen, bestand die Menge darauf, dass Heraklonas gemäß der Konvention als Senior Augustus diesen Akt persönlich vollzog; Heraklonas musste sich dem fügen. ${ }^{19}$ Um der Bedrohung durch das Heer zu begegnen, wurde außerdem deren Anführer Valentinos in das einflussreiche Amt des Comes excubitorum, des Kommandeurs der kaiserlichen Leibgarde, befördert. Damit war zwar der Meuterei der Truppen in Chalkedon vorerst ein Ende gesetzt, allerdings hatte man dem widerspenstigen Heermeister die Tore nicht nur Konstantinopels,

zum Befehlshaber erhoben. Haldon 1984, 174 vermutet, er sei Magister militum praesentalis bzw. Comes obsequii (siehe ebd. zu diesem Amt) gewesen, vgl. auch Kaegi 1981,155 und Mango 1990, 192. 16 Vgl. Stratos 1972, 189-192 und Kaegi 1981, $155 \mathrm{f}$.

17 Siehe Joh. Nik. 120.41-43 und Nik. Brev. 30f. gemäß denen dem Valentinos bereits zu diesem Zeitpunkt vorgeworfen wurde, nach der Kaiserwürde zu streben; dabei könnte es sich allerdings um die Projektion eines späteren Sachverhaltes handeln.

18 Nik. Brev. 31.

19 Siehe den Ablauf bei Nik. Brev. 31, den ich für plausibel halte. Konfligierende Angaben finden sich bei Joh. Nik. 120.44 und Sebeos 44 (Thomson/Howard-Johnston I, 104), wo ohne genauere Ortsangabe vermerkt wird, Valentinos habe Konstans’ Krönung übernommen. Dass ein militärischer Funktionsträger den Kaiser krönte, ist zu diesem Zeitpunkt jedoch völlig undenkbar; was Johannes von Nikiu und Sebeos mit diesem Vermerk indes ausdrücken, ist die faktische Abhängigkeit des Konstans von Valentinos: Formal war Heraklonas Konstans' Auctor imperii, faktisch aber Valentinos, der das römische Heer weitestgehend unter seine Kontrolle hatte. Diese Version ist also eher ein Spiegelbild der Machtverhältnisse und nicht des eigentlichen Ritualverlaufes. Siehe zur Krönung Stratos 1972, 192194. 
sondern auch des Palastes öffnen müssen. Zumindest so viel Verhandlungshoheit scheint Martina zu diesem Zeitpunkt noch besessen zu haben, dass im Gegenzug auch ihr zweitältester Sohn, der Caesar David, zum Augustus erhoben wurde. ${ }^{20}$ Doch selbst nach dieser Einigung kam Konstantinopel nicht zur Ruhe: Unmut in Teilen der hauptstädtischen Bevölkerung entlud sich gegen den Patriarchen Pyrrhos, den Vertrauten und Mitstreiter der Martina. Ob selbstbestimmt oder unter Zwang, Pyrrhus verließ Konstantinopel, um sich in Afrika niederzulassen; an seiner Stelle wurde Paulos II. zum Patriarchen ernannt. ${ }^{21}$

Während sich in Ägypten die letzten römischen Stützpunkte sukzessive der arabischen Übermacht ergeben mussten - der Patriarch Kyros, der zuvor von Herakleios abgezogen worden war, kehrte unter Heraklonas nach Alexandria zurück und trat erneut mit den Arabern in Verhandlungen -, verschärfte sich der in Konstantinopel schwelende Konflikt. ${ }^{22}$ Valentinos' Eindringen in den hauptstädtischen Raum führte zu einem militärischen Aufrüsten bei beiden Konfliktparteien; ein Bericht des Johannes von Nikiu, der in der Forschung bisweilen als verworren und unglaubwürdig disqualifiziert wird, ${ }^{23}$ erscheint vor diesem Hintergrund durchaus plausibel: Nachdem Martina zuvor bereits thrakische Kontingente als Gegengewicht zu den in Chalkedon stationierten Truppen des Valentinos nach Konstantinopel überführt hatte, ${ }^{24}$ soll sie nun eine Allianz mit einem gewissen Logotheten David geschlossen haben, den sie gar zu heiraten versprach. ${ }^{25}$ Ohne militärische Rückendeckung schien Machterhalt in Konstantinopel kaum mehr möglich. Doch selbst mit derartiger Unterstützung konnten sich Martina und Heraklonas nicht gegen Valentinos erwehren: Im Winter 641/642 wurden Mutter und Sohn abgesetzt, verstümmelt und exiliert; der minder-

20 Nik. Brev. 32; gemäß Joh. Nik. 120.43 wurde auch Philagrios aus dem Exil zurückgeholt. Unabhängig von Nikephoros bestätigt auch ein Siegel, dass Valentinos das Amt des Comes excubitorum innehatte; siehe Zagros/Veglery 1972, no. 1087.

21 Bei Nik. Brev. 31f. ist es selbstgewähltes Exil; laut Theoph. Conf. AM 6132 (De Boor 341f.) wurde Pyrrhos aus seiner Position vertrieben; auch bei Joh. Nik. 120.53 wird Pyrrhos abgesetzt - nach bzw. im Zuge des Coups gegen Martina und ihre Söhne.

22 Zur Rückkehr des Kyros und der Situation in Ägypten siehe Joh. Nik. 120.5-38, außerdem Theoph. Conf. AM 6126 (De Boor 338f.), laut dem Kyros noch durch Herakleios Senior zurückgeschickt wurde; vgl. dazu Booth 2016. Ähnlich wie über dreißig Jahre zuvor der Bürgerkrieg, welcher von der Revolte der Herakleioi in Afrika angefacht worden war, die römische Verteidigung gegen die persischen Aggressoren geschwächt hatte, scheinen auch die Nachfolgestreitigkeiten von 641 Auswirkungen auf die Verteidigungssituation gegen die Araber gehabt zu haben, siehe Joh. Nik. 120.4.

23 Siehe Stratos 1972, $219 \mathrm{f}$.

24 Joh. Nik. 119.23.

25 Joh. Nik. 120.46-49. Dass sich weibliche Mitglieder des Kaiserhauses an einflussreiche Militärs wandten, um ihre Position zu stärken, gar mit der Aussicht auf eine Hochzeit, lässt sich auch im weströmischen Reich des 5. Jahrhunderts verfolgen; siehe dazu Börm 2018, 109f. Laut Mal. 14.26 soll etwa Licinia Eudoxia, die nach der Ermordung ihres Mannes, dem Augustus Valentinian III., unter Druck stand, den Vandalenkönig Geiserich um Hilfe gebeten haben, was den darauffolgenden Einmarsch der Vandalen in Italien mit bedingte. 
jährige Konstans II. blieb als alleiniger Augustus zurück und Valentinos wurde als Oberkommandant des Heeres bestätigt.

Hinsichtlich der Verantwortlichen für den Putsch sind sich die Quellen uneins: Während Theophanes Confessor den Senat als Hauptakteuer bei der Entmachtung beschreibt, ${ }^{26}$ stimmen Johannes von Nikiu und Sebeos dahingehend überein, dass der Putsch vom Heer und dem hauptstädtischen Volk ausging. ${ }^{27}$ Eine eingehendere Betrachtung von Theophanes' Chronographie zeigt, dass der Autor - bzw. die von ihm genutzte Quelle - die Bedeutung des Senates derart konsequent betont, ${ }^{28}$ dass man kaum umhin kommt, darin eine gewisse Überinterpretation $\mathrm{zu}$ vermuten. Bewertet man die Entwicklung indes hinsichtlich der ihr innewohnenden Logik, so scheint mir die Verantwortung von hauptstädtischem Volk und Heer tatsächlich wesentlich plausibler; welche Machtmittel diesen beiden Akteursgruppen zur Verfügung standen, sollte sich auch in den kommenden Monaten noch zeigen.

Die politischen Dynamiken nach Herakleios' Tod erinnern stark an eine Phase im Konstantinopel des 5. Jahrhunderts: Oströmische Kaiser waren auf (teilweise nichtrömische) Heermeister angewiesen, um ihre Position zu sichern; diese untereinander konkurrierenden Heermeister nutzten wiederum die Schwäche der Kaiser, um sich selbst und ihre Familie - etwa durch Einheiraten ins Kaiserhaus - in der monarchischen Sukzession zu positionieren. Dass es im Osten nicht $\mathrm{zu}$ einer dauerhaften Überwältigung unmündiger Kaiser durch militärische Funktionsträger kam, wie es zeitgleich im Westen des Reiches zu beobachten war, lag nicht zuletzt an der hauptstädtischen Konfiguration von Monarchie, im Rahmen derer sich die Kaiser vor allem im 6. Jahrhundert eine gewisse Autonomie gegenüber dem militärischen Sektor er-

26 Theoph. Conf. AM 6133 (De Boor 341).

27 Bei Joh. Nik. 120.50 - 55 rebellieren Volk und Heer unter dem Kommando eines enigmatischen „Jutalijus, son of Constantine, named Theodor“ (zu diesem Stratos 1972, 199-205, 220 und PMBZ Iutalius [\#3568], eventuell ist er identisch mit dem Theodor, der nach dem Sturz des Valentinos das Oberkommando über die römischen Truppen übernahm). Laut Sebeos 44 (Thomson/Howard-Johnston I, 104) attackierte Valentinos mit seiner Armee Konstantinopel; zu dem Putsch siehe Stratos 1972, 199-205, 219f. und Kaegi 1981, 154-157. Der Bericht des Nikephoros deckt den Sturz von Martina und Heraklonas nicht mehr ab, sondern setzt erst mit Konstans’ Ermordung 668 (Brev. 33) wieder sein. Auch wenn nicht alle Details geklärt werden können, sind die verschiedenen Berichte doch durchaus vereinbar, nehmen nur jeweils eine andere Perspektive hinsichtlich der breiten Opposition gegen Martina und Heraklonas ein.

28 Theoph. Conf. AM 6134 (De Boor 342) gibt eine (fiktive) Rede des Konstans II. an den Senat wieder, in welcher der Kaiser die Leistung des Gremiums würdigt und dessen Mitglieder dazu aufruft, als seine Berater zum Wohle der Untertanen zu fungieren. In dieser Rede heißt es auch, dass Martina für den Tod ihres Stiefsohnes Herakleios Konstantin, Konstans’ Vater, verantwortlich gewesen sei. Oben S. 37-39 wurde bereits betont, dass der Konstantinopolitaner Senat als Gremium kaum institutionelle Macht hatte, sondern dass vielmehr die Männer mit illustrem Rang, aus denen sich der Senat zusammensetzte, politische Prozesse beeinflussen konnten. In der Forschung liest man indes oft, dass der Senat unter Konstans II. wieder an Bedeutung gewonnen habe; siehe etwa Haldon 1990, 53 und ders. 2016, 32; ebd. 159-192 ausführlich zu den Eliten in der 2. Hälfte des 7. Jahrhunderts. 
kämpfen konnten. ${ }^{29}$ Als Herakleios’ Tod 641 in der Hauptstadt ein Machtvakuum hinterließ, das seine Familie aufgrund der gerade umrissenen Zerrüttung nicht füllen konnte, gelang es Valentinos, die politischen Prozesse der Hauptstadt durch militärischen Druck nach seinem Gutdünken zu lenken. Valentinos' Position gemahnt dabei an militärische Funktionsträger des 5. Jahrhunderts wie den Alanen Aspar und den Isaurier Zenon, die um die Kontrolle über den Kaiser Leon I. konkurrierten. Die strukturellen Voraussetzungen für eine Überwältigung der Kaiser durch den militärischen Sektor waren also auch im 7. Jahrhundert - gerade angesichts außen- wie innenpolitischer Instabilität - weiterhin gegeben.

In den 640er Jahren war die Situation mit Valentinos' Erhebung zum Comes excubitorum indes noch lange nicht geklärt. Die Gerüchte, er selbst wolle die Kaiserwürde ergreifen, schienen sich wenige Jahre nach der Beseitigung von Martina und Heraklonas zu bestätigen. An der herakleischen Dynastie führte zwar kein Weg vorbei, Herakleios' Enkel verfügte in der Hauptstadt über breite Unterstützung; doch spätestens nach der Beseitigung von Martina und Heraklonas hatte Valentinos den minderjährigen Konstans in der Hand. Um seine Machtbasis zu erweitern, verlegte Valentinos sich auf Maßnahmen, die in Kapitel 2 als typisch für Ermächtigungsversuche militärischer Funktionsträger herausgestellt wurden: die Sicherung militärischer Kommandos einerseits und die Verbindung mit der kaiserlichen Familie andererseits. Nachdem seine Kampagnen gegen die Araber im östlichen Kleinasien keinen Erfolg gebracht hatten, ${ }^{30}$ griff Valentinos zum Äußersten. Wie versprengte Notizen in den Quellen nahelegen, versuchte er mehrmals, sich selbst den Purpur anzueignen und damit neben Konstans II. in kaiserliche Würden aufzusteigen. ${ }^{31}$ Laut Johannes von Nikiu rechtfertigte Valentinos seinen Griff nach dem Purpur mit dem Argument, dass er als Kaiser besser gegen die Araber kämpfen könne. ${ }^{32}$ Seit dem Paradigmenwechsel unter Herakleios war die Kombination von Kaiserwürde und Feldherrentum also nicht nur wieder in den Möglichkeitshorizont gerückt, sondern konnte gar als machtpolitisches Argument genutzt werden. Valentinos' Versuch, sich selbst den Purpur anzulegen, stieß zwar bei der hauptstädtischen Bevölkerung auf Empörung; doch selbst nach einer derartigen Anmaßung hatte der junge Kaiser bzw. dessen Umfeld nichts gegen den General in der Hand. Den kaiserlichen Beratern blieb nichts anderes übrig, als Valentinos in seinem Oberkommando über die römischen Truppen zu bestätigen; darüber hinaus heiratete Konstans dessen Tochter, die in diesem Zuge in den Rang der Augusta erhoben wurde. ${ }^{33}$ Valentinos, zum Schwiegervater des Kaisers aufgestiegen, hatte somit seine Position in Konstantinopel zementiert.

29 Diese Entwicklungen wurde eingehend in Kap. 2 thematisiert.

$30 \mathrm{Zu}$ seinen Kampagnen 432/3 siehe Stratos 1975, 31-35 und PMBZ Ualentinos (\#8545).

31 Sebeos 44 (Thomson/Howard-Johnston I, 106); Joh. Nik. 120.61.

32 Joh. Nik. 120.62.

33 Sebeos 44 (Thomson/Howard-Johnston I, 106); die Hochzeit wird allein bei Joh. Nik. 120.61-63 überliefert; entgegen Stratos 1975, 12 Anm. 45 ist die Nachricht meiner Ansicht nach plausibel. 
Wie weit Valentinos' Streben nach Macht ging, ob er zwischenzeitlich tatsächlich zum Caesar erhoben wurde, bleibt angesichts der fragmentierten Quellenlage unklar; ${ }^{34}$ seine Ressourcen scheint er in jedem Fall genutzt $\mathrm{zu}$ haben, um ein regelrechtes Militärregime in Konstantinopel einzurichten. ${ }^{35}$ Doch mit diesem Schritt überstrapazierte Valentinos schließlich - wenige Jahre nach der Beseitigung von Martina und Heraklonas - seinen Handlungsspielraum im hauptstädtischen Sozialgefüge. Während der minderjährige Konstans seinem Schwiegervater nichts entgegenzusetzen hatte, erhob sich schließlich die hauptstädtische Bevölkerung, unterstützt vom Patriarchen Paulos, gegen den Heermeister und dessen Truppen. Angesichts der Kompromisslosigkeit des Valentinos, der versuchte, den Aufruhr mit seinen Truppen niederzuschlagen, eskaliert die Situation: Er wurde gemeinsam mit seinen Handlangern überwältigt und ermordet. ${ }^{36}$ Damit war das kurze Kapitel der Überwältigung des Kaisers durch einen militärischen Befehlshaber vorerst abgeschlossen. Konstans II. blieb unangefochtener Repräsentant kaiserlicher Würde; an Valentinos' Stelle übernahm ein gewisser Armenier Theodor das Oberkommando über die Truppen. ${ }^{37}$ Dieser Aufstand des zivilen/urbanen Raumes gegen ein als unzumutbar empfundenes Ausgreifen des militärischen Sektors erinnert wiederum stark an das frühe 5. Jahrhundert, als der Gothe Gainas versucht hatte, in Konstantinopel ein Militärregime einzurichten, und an dem Widerstand der hauptstädtischen Bevölkerung gescheitert war. ${ }^{38}$ Es wird deutlich, dass die Bevölkerung Konstantinopels auch im 7. Jahrhundert weiterhin einen maßgeblichen Machtfaktor konstituierte; dem Repräsentanten monarchischer Macht, dem minderjährigen Konstans II., bzw. dessen senatorischen Beratern waren gegen den übermächtigen Militär dagegen die Hände gebunden gewesen.

Bereits die beiden gewaltsamen Machtwechseln von 602 und 610 hatten eine gesteigerte Wirkmächtigkeit des militärischen Sektors als Faktor für politische Prozesse in der Hauptstadt verdeutlicht; in den darauffolgenden Jahrzehnten verstärkte sich diese Tendenz. Indem Herakleios die römischen Truppen persönlich ins Feld führte, gelang es ihm, das Risikopotential, das aus dem militärischen Sektor für die Stabilität monarchischer Herrschaft erwachsen konnte, weitestgehend unter Kontrolle

\footnotetext{
34 Die Commemoratio, ein Bericht über den Prozess gegen Papst Martin (PL 129, 594C), kritisiert, dass Valentinos „auf Geheiß des Kaisers in Purpur gekleidet wurde und neben dem Kaiser saß“; siehe dazu PMBZ 1.5, Ualentinos (\#8545).

35 Sebeos 44 (Thomson/Howard-Johnston I, 106).

36 Bei Sebeos 44 (Thomson/Howard-Johnston I, 106f.) bleibt unklar, wer genau den Aufruhr gegen Valentinos anzettelte; zumindest wird deutlich, dass es sich dabei nicht um eine Intrige in Palastkreisen handelte, vielmehr sollte von einer breiten öffentlichen Beteiligung ausgegangen werden. Theoph. Conf. AM 6136 (De Boor 343) bestätigt die Usurpation des Valentinos sowie sein gewaltsames Ende und notiert, dass Konstans den Befehl zu dessen Exekution gegeben habe, was zumindest formal plausibel erscheint; dazu siehe Kaegi 1981, 157 f. und Stratos 1975, 10 - 13, 266 - auch zur Frage der Datierung; sehr knapp Haldon 1990, $305 \mathrm{f}$.
}

37 Sebeos 44 (Thomson/Howard-Johnston I, 107).

38 Zu Gainas siehe Faber 2011; Börm 2013, 76; Pfeilschifter 2013, 497-507. 
zu bringen; gleichzeitig betonte und untermauerte die kaiserliche Präsenz beim Heer dessen Bedeutungszuwachs. Während Herakleios das Militär kaiserlicher Autorität hatte unterwerfen können, begann diese fragile Hoheit seinen Nachfolgern rasch zu entgleiten: Es entbrannte nicht nur ein innerfamiliärer Machtkampf um die Nachfolge des Dynastiegründers, sondern auch ein Konflikt zwischen dem Militär und hauptstädtischen Akteuren. Dynamiken, die im Bezug auf die hauptstädtische Monarchie des 5. und 6. Jahrhunderts als typisch herausgestellt wurden und die Herakleios durch proaktive Maßnahmen vorübergehend hatte einhegen können, traten nun erneut zu Tage: Während arabische Truppen das römische Reich weiter dezimierten und ein Abflauen der Kampfhandlungen an den Grenzen nicht in Sicht war, versuchten militärische Funktionsträger, ihre Kontrolle über das Heer und die Schwäche des Kaiserhauses auszunutzen, um politische Entscheidungen in der Hauptstadt bis hin zu monarchischer Sukzession zu beeinflussen.

\subsection{Ausblick}

Die Überwältigung des oströmischen Kaisers Konstans II. durch einen ambitionierten Militär hatte durch einen Aufstand der hauptstädtischen Bevölkerung vorerst abgewandt werden können, der zivile Raum hatte sich gegenüber dem militärischen Sektor behauptet; doch zur Ruhe kam das römische Reich auch in den folgenden Jahrzehnten nicht. Wie der nun folgende kursorische Ausblick verdeutlicht, traten Krisenphänomene, die sich bereits zu Beginn des Jahrhunderts angedeutet hatten, nach Herakleios' Tod mit gesteigerter Vehemenz hervor. Unruhen aus dem militärischen Sektor einerseits sowie dynastische Grabenkämpfe andererseits prägten den weiteren Verlauf des 7. Jahrhunderts, begleitet und befeuert von dem Vorrücken der Araber und einer fortschreitenden Fragmentierung der noch zum Reich gehörigen Gebiete.

Aus einem provinzialen Kontext erwuchs die Revolte des Gregorios, des Exarchen von Karthago, der sich 646/647 gegen Konstans II. erhob. Sein Aufbegehren stand in Zusammenhang mit dem Vorrücken der Araber, die nach der Eroberung Ägyptens nun auch Afrika bedrohten, bezog sich indes gleichzeitig auch auf den kirchenpolitischen Streit, der durch Herakleios’ Förderung des Monoenergismus/Monotheletismus losgetreten worden war. In Afrika hatte sich unter der Führung des Maximos Confessor eine ultra-chalkedonensische Opposition gegen die Konstantinopolitaner Politik herausgebildet, die inzwischen auch die Unterstützung des Papstes gewonnen hatte; Gregorios positionierte sich - ob aus politischem Kalkül oder persönlicher Überzeugung - auf Seiten dieser chalkedonensischen Opposition. ${ }^{39}$ Bemerkenswert ist bei der Revolte nicht zuletzt der Umstand, dass Gregorios offenbar aus Herakleios’ Familie

39 Theoph. Conf. AM 6138 (De Boor 343) und Mich. Syr. 11.10 (Chabot II, 440) begnügen sich mit einer kurzen Notiz; weitere Quellen bei PMBZ, Gregorios (\#2345); siehe dazu Stratos 1975, 62-67 und Haldon 1990, 56f., 306-308. 
stammte, dass es sich bei dem Herausforderer also um Konstans' Verwandten handelte $^{40}$ - ein Umstand, der erneut zeigt, dass dynastische Verbindungen als machtpolitischer Faktor im 7. Jahrhundert weiterhin schwer wogen. Während in der Literatur bisweilen nahegelegt wird, dass Gregorios sich zum Kaiser habe erheben lassen, ${ }^{41}$ ist die Evidenz dafür bei genauerem Hinsehen spärlich. Ob Gregorios plante, wie einst Herakleios von Karthago aus die Herrschaft in Konstantinopel an sich zu reißen, muss offen bleiben, da die Revolte durch dessen Niederlage gegen die Araber ein vorzeitiges Ende fand..$^{42}$ Es könnte sich bei der Erhebung - anders als bei der der Herakleioi ab 607/8 - jedoch durchaus auch um eine lokale Abspaltungsbewegung gehandelt haben in Reaktion darauf, dass die Zentralmacht nicht mehr in der Lage war, die Verteidigung der Provinzen zu gewährleisten. ${ }^{43}$

Als lokale Abspaltungsbewegung vor dem Hintergrund kirchenpolitischer Verwerfungen und externer Bedrohung, in diesem Fall durch die Langobarden, ist auch die Revolte des Olympios, Exarch von Ravenna, einige Jahre später (650/651) zu interpretieren. Olympios war von Konstans nach Italien geschickt worden, um den Typos durchzusetzen, ein vom Kaiser 648 erlassenes Dokument, das besagte, dass die Ekthesis aus dem Narthex der Hagia Sophia entfernt werden solle, und jede weitere Diskussion des Monotheletismus unterband. Doch anstatt gemäß kaiserlichem Befehl den Papst Martin festzunehmen, der auf der Lateran-Synode 649 sowohl Ekthesis als auch Typos verurteilt hatte, schlug sich Olympios auf dessen Seite. Nachdem der Herausforderer bis nach Sizilien vorgedrungen war, erlag er 652 einer Krankheit. ${ }^{44}$

Während die Aufstände des Gregorios und Olympios Konstantinopel nicht direkt tangiert hatten, kam es kurz darauf zu einem massiven Umbruch in der Hauptstadt, dessen Details nur schwerlich nachzuvollziehen sind. In der thrakischen und präsentalen, also um die Hauptstadt stationierten Armee braute sich offenbar eine Ver-

40 PLRE IIIA, Fl. Gregorius 19 (554): Gregorios war aller Wahrscheinlichkeit nach der Sohn des Niketas, Herakleios' Cousin.

41 So etwa Kaegi 1981, 159; laut arabischen Quellen soll Gregorios Münzen geprägt haben, was aber aus dem Münzbefund nicht bestätigt werden kann; dazu siehe Stratos 1975, 66; PMBZ, Gregorios (\#2345) mit genaueren Angaben. Doch selbst wenn Gregorios Münzen prägte, heißt das noch nicht, dass er sich in Karthago hatte zum Kaiser erheben lassen; beim Blick auf die Revolte der Herakleioi wurde deutlich, dass Vater und Sohn durchaus Münzen prägten, aber von einer Krönung in der Provinz absahen und sich stattdessen als Konsuln auf den Münzen darstellen ließen; dazu siehe oben Kap. 3.2. 42 Theoph. Conf. AM 6139 (De Boor 343); laut Mich. Syr. 11.10 (Chabot II, 441) und anderen Quellen unterwarf sich Gregorios daraufhin wieder dem Konstans; wahrscheinlicher ist allerdings, dass auch er das Ende der Revolte nicht überlebte. Kurz nach dem Ende der Revolte veröffentlichte Konstans II. den sogenannten Typos, ein Edikt, das den Monotheletismus-Streit beizulegen gedachte; die Veröffentlichung ist nicht anders zu lesen denn als Reaktion auf den wachsenden chalkedonensischen Widerstand, der sich mit der Revolte des Gregorios auch erstmals konkret auf politischer Ebene Bahn gebrochen hatte. Nach Gregorios scheint noch ein weiterer Exarch von Karthago rebelliert zu haben, Gennadios, dessen Revolte aber nur in arabischen Quellen erwähnt wird; siehe PMBZ, Gennadios (\#1956).

43 Stratos 1975, 63 beschreibt Gregor als „king of Africa“.

44 Zur Revolte des Olympios siehe Stratos 1975, 104-111; Kaegi 1981, 163 f; Ravegnani 2011, 76f.; Haldon 2016, 38 f.; PMBZ, Olympios (\#5650/add.). 
schwörung gegen Konstans zusammen. ${ }^{45}$ Angesichts des Risikos, das eine derartige Konstellation für den Kaiser darstellte, erfolgten besonders harsche Restriktionen gegen die verantwortlichen Befehlshaber. Denn welch fatale Auswirkungen ein aufständisches Heer vor den Toren der Stadt auf die innenpolitische Stabilität haben konnte, hatte sich in den vorigen Jahrzehnten wiederholt gezeigt. Konstans, inzwischen in mündigem Alter, setzte offenbar alles daran, sich gegenüber den Militärs, die ihre Macht aus dem Rückhalt der Truppen zogen, zu emanzipieren. ${ }^{46}$

652/653 verließ Konstans erstmals für längere Zeit die Hauptstadt und begab sich zu den römischen Truppen in der Provinz. Wie bereits sein Großvater Herakleios scheint auch er versucht $\mathrm{zu}$ haben, sich durch persönliche Anwesenheit an den Kriegsschauplätzen einer Überwältigung aus dem militärischen Sektor zu erwehren und die Loyalität der Soldaten zu stärken. Der konkrete Anlass für Konstans’ Vorstoß war eine Rebellion der armenischen Kontingente, die von den Römern zu den Arabern übergelaufen waren; gemäß der armenischen Geschichte des Sebeos forderten die griechischen Soldaten die Präsenz des Kaisers, der sich der Forderung fügte. ${ }^{47}$ Konstans nutzte den Aufenthalt in Armenien außerdem, um mit dem miaphysitischen Katholikos von Dvin in Kontakt zu treten und eine religiöse Einigung zu erwirken; ${ }^{48}$ auch in diesem Sinne trat er in die Fußstapfen des Großvaters Herakleios, der sich seinerzeit persönlich um einen Kompromiss mit den miaphysitischen und nestorianischen Gemeinden des Ostens bemüht hatte. Gleichzeitig bereiteten die Araber eine erste Attacke auf Konstantinopel zu See vor: Im Jahr 654 wurde Rhodos und weitere Inseln in der Ägäis geplündert; eine von Konstans persönlich angeführte Expedition erlitt im Jahr darauf vor der lykischen Küste eine verheerende Niederlage. Erst nachdem ein Sturm die arabische Flotte entscheidend geschwächt hatte, konnten die Römer die Attacke abwenden. ${ }^{49}$

45 Sebeos 47 (Thomson/Howard-Johnston I, 133f.); siehe dazu Stratos 1975, 190 f.; Kaegi 1981, 160f.; Thomson/Howard-Johnston 1999 II, 263f. Die Chronologie dieser Jahre ist schwierig zu rekonstruieren. Während Stratos 1975, 190 und Kaegi 1981, 161 davon ausgehen, dass Konstans sich zu dem Zeitpunkt des Putsches in Armenien aufhielt, legt der Bericht des Sebeos meiner Ansicht nach nahe, dass er in Konstantinopel war und erst daraufhin aufbrach; vgl. auch Haldon 2016, 33 f.

46 Wie sehr Konstans auf seine Generäle angewiesen war, zeigen auch die Friedensverhandlungen mit dem arabischen General Mu’awiya, dem späteren Kaliphen, 650/651. Sebeos 45 (Thomson/HowardJohnston I, 112) beschreibt die Konstellation folgendermaßen: „But the Greek king Constans, because he was young, did not have the authority to carry this out without the agreement of the army." Vgl. Theoph. Conf. AM 6142 (De Boor 344). Während derartige Gesandtschaften noch unter Herakleios aus zivilen Würdenträgern zusammengesetzt worden waren, oblag die Verhandlung mit den Feinden nun hohen Militärs; Konstans musste sich - obwohl er mit zwanzig ein durchaus regierungsfähiges Alter erreicht hatte - deren Vorstellungen fügen. $\mathrm{Zu}$ dem Kontext der Friedensverhandlungen siehe Thomson/Howard-Johnston 1999 II, 259-262; außerdem Stratos 1975, 38 - 43; Kaegi 1981, 160.

47 Sebeos 48 (Thomson/Howard-Johnston I, 135-139); vgl. Theoph. Conf. AM 6143 (De Boor 344). Siehe dazu Kaegi 1981, 162; Haldon 1990, 312; Thomson/Howard-Johnston 1999 II, 270 f.

48 Sebeos 49 (Thomson/Howard-Johnston I, 141f.); siehe Thomson/Howard-Johnston 1999 II, $270 \mathrm{f}$. 49 Haldon 2016, 34. 
Bevor Konstans auf die Expedition gegen die Araber aufgebrochen war, hatte er 654 in Konstantinopel seinen ältesten Sohn Konstantin zum Augustus gekrönt. ${ }^{50}$ Dass die Krönung kurz vor Konstans' Expedition erfolgte, verwundert kaum; ähnlich war Herakleios im Jahr 613 mit Herakleios Konstantin verfahren, um seine Position in Konstantinopel zu sichern, bevor er zu seinem ersten Vorstoß gegen die Perser nach Nordsyrien aufbrach. Doch wie bereits in Bezug auf die Nachfolgestreitigkeiten nach Herakleios' Tod festgestellt, brachte die Kombination aus der konsequenten Stärkung der Dynastie einerseits und dem Nichtvorhandensein einer institutionalisierten Nachfolgeregelung andererseits ein gewisses Konfliktpotential mit sich: Um den Vorrang der eigenen Söhne zu gewährleisten, sah Konstans sich 659 gezwungen, seinen jüngeren Bruder Theodosios, der als Befehlshaber offenbar über Rückhalt bei den Truppen verfügte, als Kandidat für die monarchische Sukzession aus dem Weg zu räumen. ${ }^{51}$ Die Ermordung des Bruders ging mit der Erhebung von Konstans' jüngeren Söhnen, Herakleios und Tiberios, einher. ${ }^{52}$

Während inner-arabische Auseinandersetzungen um die Person des Kaliphen, die erste Fitna, den Vormarsch der Feinde vorrübergehend Einhalt gebot, verließ Konstans im Jahr 662 erneut die Hauptstadt, diesmal gen Westen; über Griechenland gelangte er nach Italien. ${ }^{53}$ Nach Konfrontationen mit den Langobarden, die weite Teile Italiens kontrollierten, und einem Abstecher in Rom ${ }^{54}$ ließ er sich im sizilischen Syrakus nieder. ${ }^{55}$ Die Gründe für Konstans' Ausgreifen in den Westen sind in der Forschung umstritten; es scheint durchaus plausibel, dass der Kaiser darauf abzielte, die dortigen römischen Gebiete - nicht zuletzt die reichen sizilianischen Getreidevorkommen - zu sichern und langfristig von Syrakus aus eine starke Präsenz im westlichen Mittelmeer zu etablieren; eine Region, die sowohl durch interne Konkurrenz (die Erhebungen des Gregorios und Olympios) als auch durch die Expansion der Araber bedroht war. ${ }^{56}$ Darüber hinaus mag diese Entscheidung allerdings auch durch den Umstand bedingt gewesen sein, dass Konstans’ Rückhalt beim Heer und in der hauptstädtischen Be-

50 PMBZ, Konstantinos IV (\#3702/corr.).

51 Theoph. Conf. AM 6151 (De Boor 347); Mich. Syr. 11.11 (Chabot II, 445f.); laut Letzterem erfolgte die Ermordung des Theodosios in Folge der römischen Niederlage gegen die Araber zu See; siehe auch PMBZ, Theodosios (\#7797/add.); vgl. Stratos 1975, 191-196. Auch Konstans’ ältester Sohn, Konstantin IV., entledigte sich Jahrzehnte später seiner jüngeren Brüder Herakleios und Tiberios: Nachdem die drei nach der Ermordung des Vaters 668 über ein Jahrzehnt zusammen regiert hatten, ließ Konstantin seine Brüder 681/682 absetzen und verstümmeln (Theoph. Conf. AM 6173 [De Boor 360]), um den Vorrang seines Sohnes Justinian II. zu sichern; siehe dazu PMBZ, Herakleios (\#2556/corr.).

52 Siehe PMBZ, Konstans II. (\#3691/corr.); Haldon 1990, 59 und ders. 2016, 40.

$53 \mathrm{Zu}$ Konstans in Griechenland und Italien siehe Stratos 1975, 197-217; Theoph. Conf. AM 6153 (De Boor 348).

54 In Rom blieb Konstans keine zwei Wochen und ließ seine Soldaten die Stadt plündern; siehe Lib. Pont. 78.2f.; dazu Corsi 1975, 357-359; Stratos 1975, 213-215; Antonopoulos 2012, 29 f.

55 Die Details von Konstans' Aufenthalt in Italien lassen sich aus lateinischen Quellen rekonstruieren, siehe dazu Corsi 1975; zu Konstans in Sizilien siehe Prigent 2010; außerdem Stratos 1975, $215-217$. 56 Siehe Stratos 1975, 198 -202; Antonopoulos 2012; Jankowiak 2013, 305; Haldon 2016, 40 f. 
völkerung schwand, nicht zuletzt aufgrund des Umgangs mit seinem Bruder. ${ }^{57}$ Mit der Kampagne nach Italien und Sizilien entzog der Kaiser sich der direkten Konfrontation mit der hauptstädtischen Öffentlichkeit und stärkte gleichzeitig die Bindung zum Heer. ${ }^{58}$ Doch während Herakleios seine Abwesenheit positiv hatte konnotieren können, wurde Konstans' dauerhaftes Verweilen im Westen in der hauptstädtischen Öffentlichkeit äußerst kritisch gesehen. Der Umstand, dass der Kaiser nach dem gescheiterten Langobardenfeldzug ab ca. 664 eine Residenz in Syrakus etablierte und sich damit ein alternatives politisch-administratives Zentrum herauskristallisierte, stieß auf Missfallen; einen derartigen Schritt, der den Vorrang Konstantinopels in Frage stellte, hatte Herakleios nie zu tun gewagt. Dass Konstans plante, seine Frau und seine Söhne nach Syrakus zu überführen, wie es eine Reihe von Quellen nahelegen, ${ }^{59}$ sollte allerdings nicht unkritisch für bare Münze genommen werden. ${ }^{60}$ Diese Maßnahme hätte die Aufgabe der Hauptstadt durch den Kaiser impliziert und machtpolitisch aller Wahrscheinlichkeit nach fatale Auswirkungen gehabt; ohne Konstantinopel zumindest durch einen designierten Nachfolger zu sichern, hätte Konstans kaum die Oberhoheit über das Reich halten können. Dass in Konstantinopel Nachrichten von der bevorstehenden Überführung der kaiserlichen Familie grassierten, zeigt eher das Maß an Irritation, das Konstans' Verweilen in Syrakus auslöste. Die hauptstädtische Öffentlichkeit - sowohl die dortige Funktionselite als auch die Bevölkerung - setzte sich vehement gegen eine mögliche Marginalisierung zur Wehr. ${ }^{61}$

Im Juli 668 wurde Konstans in Syrakus ermordet. ${ }^{62} \mathrm{Zu}$ den Hintergründen der Tat finden sich in der Forschung verschiedene Hypothesen; ${ }^{63}$ am plausibelsten erscheint

57 So Mich. Syr. 11.11 (Chabot II, 446); dazu Kaegi 1981, 163; Haldon 1990, 59 f. Auch Theoph. Conf. AM 6160 (De Boor 351) zählt eine Reihe an Gründen für Konstans' Unbeliebtheit auf (die Ermordung des Bruders, den Umgang mit dem Papst Martin und Maximos Confessor im Zusammenhang mit der monotheletischen Kontroverse und schließlich seinen angeblichen Versuch, die Hauptstadt nach Rom zu verlegen), allerdings erst im Zusammenhang mit dessen Ermordung. Dabei muss indes festgehalten werden, dass Theophanes Konstans aufgrund von dessen Kirchenpolitik dezidiert kritisch gegenübersteht.

58 Mich. Syr. 11.11 (Chabot II, 446) legt außerdem nahe, dass das Heer nicht nur die Präsenz des Kaisers, sondern auch dessen Engagement am Kriegsschauplatz forderte: „When he saw that he was detested, he became afraid and left for Rome. As he delayed there, the troops rebelled against him saying, 'It is not appropriate for the Emperor to reside at Rome, for that city is remote from the Taiyaye (Arabs).” Daraufhin sei Konstans nach Syrakus aufgebrochen „because he feared very much that his troops would massacre him just as he himself had massacred his brother without justification." Übersetzung nach Kaegi 1981, 163.

59 Theoph. Conf. AM 6153 (De Boor 348), AM 6160 (352); Mich. Syr. 11.11 (Chabot II, 446).

60 Vgl. Haldon 1990, 60.

61 Dass derartige Nachrichten mit Vorsicht zu handhaben sind, habe ich bereits in Bezug auf das Gerücht betont, Herakleios wolle die Hauptstadt nach Karthago verlegen, das offenbar Anfang der 620er Jahre in Konstantinopel grassierte; siehe oben

62 Lib. Pont. 78; Paul Diac. Hist. Lang. 5.11; Nik. Brev. 33; Theoph. Conf. AM 6160 (De Boor 351f.); Mich. Syr. 11.12 (Chabot II, 450 f.); Chron. 1234, 139 (Chabot I, 223). Konstans wurde von einem gewissen Cubicularius Andreas im Bad erschlagen. 
eine Verbindung mit einer zeitgleichen Belagerung bzw. See-Blockade Konstantinopels durch eine arabische Flotte. ${ }^{64}$ Während sich der abwesende Herakleios Jahrzehnte zuvor an der Macht hatte halten können, während Konstantinopel von Avaren und Persern belagerte wurde, verspielte Konstans seinen letzten Rückhalt, als er angesichts der Bedrohung der Hauptstadt vermeintlich untätig in Syrakus verweilte. ${ }^{65}$ In Folge des Mordes brachte der armenische General Mizizes Teile der Armee unter seine Kontrolle und beanspruchte auf Sizilien die Kaiserwürde für sich; ${ }^{66}$ in Konstantinopel indes stand außer Frage, dass der Augustus Konstantin IV. an die Stelle seines Vaters treten würde. ${ }^{67}$ Trotz Konstans' offenkundiger Unbeliebtheit, die sich nicht zuletzt angesichts seiner Vernachlässigung der Hauptstadt angestaut hatte, war dynastische Legitimität weiterhin das ausschlaggebende Argument bei der Aushandlung monarchischer Sukzession. Mizizes konnte schließlich von kaisertreuen Truppen überwältigt werden. Dass Konstantin IV. die Kampagne gegen den Herausforderer trotz seines jungen Alters persönlich leitete, wie es eine Reihe von Quellen nahelegen, halte ich - entgegen mancher Stimmen in der Forschung - für durchaus plausibel: ${ }^{68}$ Die Bindung des militärischen Sektors an den neuen Senior Augustus hatte angesichts der instabilen Situation nach dem Tod seines Vaters hohe Priorität.

Während Mizizes sich nicht hatte durchsetzen können, gelang es im frühen 8. Jahrhunderts mehreren Prätendenten aus dem militärischen Sektor, wie einst Herakleios die Macht in Konstantinopel an sich zu reißen. Im Jahr 695 wurde Justinian II., Sohn des Konstantin IV. und letzter Vertreter der herakleischen Dynastie, gestürzt. Zum neuen Kaiser erhob man den General Leontios, der zuletzt die Truppen in Grie-

63 Kaegi 1981, 165f. geht davon aus, dass der General Mizizes, der nach Konstans Tod selbst Anspruch auf die Nachfolge anmeldete (siehe unten), für den Mord verantwortlich war. Howard-Johnston 2010, 225, 490 f. stellt die gewagte These auf, dass der Kaliph Mu'awiya an einem Mordkomplott beteiligt war, was ich nicht für plausibel halte; vgl. Jankowiak 2013, 306f. mit Anm. 318. Konstans war offenbar auch in Sizilien nicht sonderlich populär, da die Stationierung der Armee finanzielle Spannungen mit sich brachte, siehe Haldon 1990, 60. Zum Mord an Konstans auch Stratos 1975, 253-260.

$64 \mathrm{Zu}$ der Blockade Konstantinopels siehe Jankowiak 2013, bes. 305-309; außerdem Prigent 2010, $175-177$.

65 Jankowiak 2013, 309: „What seems to have prompted the Byzantine elites to withdraw their support from Constans II was his inactivity in the face of the supreme danger threatening the Byzantine capital.” Ähnlich Haldon 2016, 42.

66 PMBZ, Mizizios (\#5163); ausführlich zur Revolte des Mizizes Jankowiak 2013, 309-314 und Prigent 2010, 178-185, der dafür plädiert, dass sich nach Mizizes auch dessen Sohn Johannes erhob. Laut Haldon 1990, 61 hatte Mizizes das Amt des Comes obsequii inne, war also der Befehlshaber der um Konstantinopel stationierten, praesentalen Armeen, die Konstans mit sich nach Italien geführt habe; vgl. Haldon 1984, 359 und ders. 2016, 42. Mizizes ließ Münzen prägen, auf denen er als Augustus auftrat, wenn man die Stücke denn als authentisch und nicht als Fälschung wertet; dazu siehe Grierson 1986.

67 PMBZ, Konstantinos IV (3702/corr.).

68 Theoph. Conf. AM 6160 (De Boor 352); gemäß Lib. Pont. 79.2 wurde Mizizes von der in Italien stationierten Armee überwältigt; zu den unterschiedlichen Meinungen siehe Kaegi 1981, 166; Jankowiak 2013, 309-314, bes. 310. 
chenland kommandiert hatte; Justinian wurde verstümmelt und auf die Chersones exiliert. Unter Leontios' Herrschaft fiel mit Karthago der letzte römische Posten in Afrika an die Araber. Die unterlegene römische Flotte rebellierte und brachte ihren Befehlshaber Apsimar als Gegenkaiser in Stellung. Über sechs Monate hinweg belagerten die aufständischen Truppen Konstantinopel zu See, bis ihnen schließlich die Übernahme der Stadt gelang. Leontios wurde ebenfalls verstümmelt und in einem Kloster kaltgestellt; Apsimar folgte ihm unter dem Namen Tiberios auf dem Thron nach. Doch auch die Herrschaft des Tiberios Apsimar währte nur kurz: Im Jahr 705 konnte der gestürzte Justinian II. mit militärischer Unterstützung durch den BulgarenKahn Tervel nach Konstantinopel zurückzukehren; seinen Sohn Tiberios krönte er zum Augustus. Erneut an der Macht begann Justinian, sich noch strikter als zuvor gegen seine politischen Gegner zur Wehr zu setzen, blieb damit jedoch letztendlich ohne Erfolg. Im Jahr 711 wurde er durch den General Bardanes gestürzt und ermordet, der seinerseits als Philippikos zum Kaiser gekrönt wurde. ${ }^{69}$ „What followed” - so fasst es John Haldon zusammen - „was further political confusion and, as the deacon Agathon - a contemporary of the events in question - described it, a period in which the emperor's authority counted for nothing, in which the empire had been reduced and humbled, and tyranny - that is usurpation and violent changes of power - was the order of the day. “70 Herakleios’ Maßnahmen, die auf die Stabilisierung kaiserlicher Herrschaft abzielt hatten, erwiesen sich nicht als nachhaltig. Erst nachdem die oströmische Monarchie mit dem Ikonoklasmus eine weitere Krise durchlaufen hatte, steuerte das Gemeinwesen ab dem späten 8. Jahrhundert langsam wieder in ruhigere Fahrwasser. ${ }^{71}$

69 Einen Überblick über die Ereignisgeschichte bietet Haldon 2016, 42-51.

70 Haldon 1990, 78.

71 Für einen Überblick über diese Entwicklungen siehe Treadgold 1997, 323-370. 


\section{Fazit}

Die Forschung der letzten Jahrzehnte hat das frühe siebte Jahrhundert wiederholt als eine neuralgische Phase in der Entwicklung des östlichen Mittelmeerraums und des Nahen Ostens beschrieben. Vor diesem Hintergrund hat die vorliegende Arbeit den Blick auf die oströmische Monarchie gelenkt, auf die Möglichkeiten und Grenzen monarchischer Herrschaft. Die Regierungszeit des Herakleios - durch eine Vielfalt von Quellen dokumentiert - zeichnet sich in diesem Zusammenhang durch eine besondere Dynamik aus. Um die Funktionsweisen der oströmischen Monarchie in der Spätantike nachzuvollziehen, hat die Untersuchung sich auf zwei zentrale Faktoren konzentriert: das Verhältnis des Kaisers zur Hauptstadt und - damit in enger Verbindung stehend - das Verhältnis des Kaisers zum militärischen Sektor.

Grundlage dieser Arbeit war die Überzeugung, dass sich die Herrschaft des Herakleios nur dann in ihrer Entwicklungslogik beleuchten lässt, wenn man sie vor dem Hintergrund der hauptstädtischen Monarchie des 5. und 6. Jahrhundert interpretiert. In der Forschung wurde zuletzt wiederholt betont, dass die enge physische wie ideelle Bindung der oströmischen Monarchen an Konstantinopel ab dem frühen 5. Jahrhundert maßgeblich zur Sicherung von deren Position beitrug und damit - im Gegensatz zum Westteil des Reiches - das Fortbestehen des Kaisertums als Institution ermöglichte. In diesem Zusammenhang hat sich das Kapitel 2 zum Ziel gesetzt, die Beziehung zwischen den sesshaften Kaiser und dem Militär einer Revision zu unterziehen. Dabei wende ich mich gegen die These, dass der Rückzug des Kaisers aus dem aktiven Kriegsgeschäft eine Marginalisierung des militärischen Sektors zur Folge hatte. Im Gegensatz zu den vorigen Jahrhunderten scheint das Gros der in den Provinzen stationierten Soldaten bei der Aushandlung und Sicherung monarchischer Herrschaft tatsächlich keine zentrale Rolle mehr gespielt zu habe; obwohl ihnen das Privileg der Kaisernähe entzogen wurde, blieben sie auf den sesshaften Kaiser bezogen und ihm loyal, solange dieser ihre angemessene Versorgung sicherstellte. Anders verhielt es sich allerdings mit hohen militärischen Funktionsträgern - den Magistri militum, die qua Amt in den Rang der Illustres erhoben wurden und damit dem aktiven Konstantinopolitaner Senat angehörten - und auch mit den kaiserlichen Garden bzw. deren Kommandeuren. Ein Überblick über monarchische Sukzession ebenso wie Usurpation im 5. und 6. Jahrhundert hat gezeigt, dass in der Regel militärische Funktionsträger die ausschlaggebenden Impulse gaben. Die sesshaften Kaiser sahen sich den ständigen Versuchen der Einflussnahme hoher Militärs ausgesetzt. Dass die Jahrhunderte der hauptstädtischen Monarchie innenpolitisch verhältnismäßig stabil waren, lag darin begründet, dass die Kaiser ihrerseits Strategien entwickelten, mit denen sie die militärischen Funktionsträger zu einem gewissen Grad einzuhegen konnten: Zwischen Kaiser und hauptstädtischer Bevölkerung bildeten sich Interaktionsformen heraus, die auf der Sakralisierung des Kaisers einerseits und auf ostentativ zur Schau gestelltem Triumphalismus andererseits aufbauten - auf dem Umstand 
also, dass es den Kaisern als ewige Sieger gelang, die Erfolge der römischen Generäle, sofern es denn überhaupt Erfolge gab, auf sich zu beziehen.

Im frühen 7. Jahrhundert lässt sich eine Verschiebung des Verhältnisses zwischen Kaiser, Hauptstadt und militärischem Sektor nachvollziehen, die an zwei Phänomenen festzumachen ist: (1) 602 und 610 kam es zu gewaltsamen Machtwechseln in Konstantinopel, die dadurch ausgelöst wurden, dass römische Truppen bzw. Befehlshaber von außen Druck auf die Hauptstadt ausüben. (2) Herakleios, der sich 610 von Karthago aus an die Macht putschte, verließ als erster Kaiser nach über zweihundert Jahren Konstantinopel für mehrere Jahre am Stück, um die römischen Truppen persönlich in den Krieg zu führen. Die vorliegende Arbeit hat versucht herauszuarbeiten, warum es zu dieser Verschiebung kam. Anstatt von einer strukturellen Krise der hauptstädtischen Monarchie auszugehen, legt die Analyse in Kapitel 3 nahe, dass die Ereignisdynamiken zu einem gewissen Grad durch persönliches Versagen des Kaisers Maurikios bedingt waren; Maurikios schien sich der potentiellen Gefahr aus dem militärischen Sektor bewusst, war allerdings nicht in der Lage, angemessen darauf zu reagieren. Als entscheidender Einschnitt wurde der Moment identifiziert, in dem eine Revolte der Balkanarmee angesichts der unpopulären Direktiven des Kaisers derart eskalierte, dass auch in Konstantinopel Unruhen ausbrachen; anstatt sich der hauptstädtischen Bevölkerung zu stellen, floh Maurikios des Nachts nach Kleinasien. Aus diesem Machtvakuum heraus wurde Phokas, der Anführer der rebellierenden Truppen, zum Kaiser gekrönt. Dieses Ereignis, weder geplant noch vorhersehbar, eröffnete neue Handlungsspielräume, die sich dann nur wenige Jahre später die Herakleioi zu Nutze machten, deren Machtbasis in der militärischen Kontrolle Afrikas lag; sie lieferten die Probe aufs Exempel, dass militärischer Druck von außen die Machtverhältnisse in Konstantinopel wieder maßgeblich beeinflussen konnte. Ihr erklärtes Ziel, den regierenden Kaiser zu stürzen und Herakleios Junior an seiner Stelle zu installieren, konnte allerdings nur deswegen erreicht werden, da die hauptstädtische Bevölkerung sich gegen Phokas stellte, der die Akzeptanz, die ihm bei seiner Erhebung 602 entgegengebracht worden war, durch grobes Fehlverhalten systematisch verspielt hatte. Angesichts des Thronprätendenten, der mit einer Flotte im Hafen von Konstantinopel geankert hatte, entledigte die hauptstädtische Bevölkerung sich des Phokas und erhob stattdessen Herakleios zum Kaiser. Zum Ende des Kapitels wird anhand der Analyse der Krönungen von 602 und 610 nachvollzogen, wie externe Kandidaten zum Kaiser in Konstantinopel aufsteigen konnten: Durch ein auf die spezifischen Umstände angepasstes Ritual wurden Phokas und Herakleios in den hauptstädtischen Raum überführt und damit die Phase der akuten Desintegration performativ überwunden. Dass die Krönungen erstmals in Kirchen stattfanden - die des Phokas in der Johanneskirche am Hebdomon und die des Herakleios in der Hagia Sophie im Stadtzentrum - zeigt die wachsende Bedeutung des christlichen Referenzrahmens. Im Falle des Machtwechsels von 610 wird deutlich, dass bereits die Krönung des Herakleios mit der systematischen und äußerst wirkmächtigen Diffamierung des Phokas als Tyrann einherging, aus der heraus der neue Kaiser als gotterwählter Herrscher stilisiert werden konnte. Die Dynamiken der Jahre 602 und 610 
offenbaren, dass der Rückhalt der Hauptstadt weiterhin der ausschlaggebende Faktor für die Stabilität von Herrschaft war; das sollte sich auch in den Jahrzehnten darauf nicht ändern: Nur wer Konstantinopel hinter sich hatte, war Kaiser. Die spezielle Konfiguration von Monarchie blieb auf die Hauptstadt bezogen, mit dem Unterschied jedoch, dass nun der Kaiser nicht mehr in der Hauptstadt blieb.

Warum verließ Herakleios Konstantinopel über Jahre hinweg? Die Antwort auf diese Frage ist komplex und nur unter Berücksichtigung des Umstandes zu beantworten, dass die Perser sukzessive die Ostprovinzen des römischen Reiches besetzten. In Kapitel 4 habe ich allerdings dafür plädiert, dass auch interne Faktoren in Betracht gezogen werden müssen, um diesen Prozess zu erklären. Herakleios war darum bemüht, die kaiserliche Autorität über den militärischen Sektor wiederherstellen, zu deren Erosion er durch seine Usurpation selbst beigetragen hatte; es galt, dem Prozedere vorzubeugen, mit dem er selbst an die Macht gekommen war. Während Phokas noch an den Praktiken der sesshaften Monarchen festgehalten hatte - trotz seines militärischen Hintergrundes und des erneut entflammten Krieges gegen die Perser blieb er nach seiner Krönung in Konstantinopel - ging Herakleios neue Wege, indem er sich an die Spitze der römischen Truppen setzte. Die Entscheidung zur persönlichen Kriegsführung indes brachte eine Reihe schwerwiegender Risiken mit sich: nicht nur die Gefahr der Niederlage und eines damit einhergehenden Gesichtsverlustes, sondern auch den Umstand, dass der Kaiser damit die Verhaltenserwartungen des hauptstädtischen Umfeldes enttäuschte. Trotzdem brach Herakleios 624 auf eine wahre Himmelfahrtsmission auf, die ihn mehrfach bis ins persische Kernland brachte; zu diesem Zeitpunkt blieb ihm offenbar nur noch die Flucht nach vorne.

Herakleios' Versuch, den militärischen Sektor wieder enger an den Kaiser zu binden, ging mit Anstrengungen zur Sicherung seiner Position in Konstantinopel einher, die er vor allem in dem Bereich der Familienpolitik verfolgte. Durch die gezielte Förderung seiner Kernfamilie knüpfte der Kaiser ein engmaschiges dynastisches Netzwerk. 613, kurz bevor Herakleios erstmals als Oberbefehlshaber des Heeres nach Syrien aufbrach, krönte er seinen einjährigen Sohn Herakleios Konstantin zum Augustus. Trotz Herakleios' zeitweiliger Abwesenheit befand sich also immer ein Augustus in Konstantinopel, der, wenn auch minderjährig, zumindest die zeremonielle Funktion des Kaisers zu einem gewissen Grad ausfüllen konnte. Eine derart klare Designation beugte gleichzeitig auch Ambitionen militärischer Funktionsträger vor, die in der Vergangenheit regelmäßig versucht hatten, sich durch strategische Heiratsallianzen mit dem Kaiserhaus zu verbinden und so für die Nachfolge in Stellung zu bringen. Auch Herakleios' Entscheidung, sich in zweiter Ehe mit seiner Nichte Martina zu vermählen - eine nach römischem Recht illegitime Verbindung -, kann vor diesem Hintergrund als Maßnahme einer endogamen Familienpolitik interpretiert werden.

Was das frühe 7. Jahrhundert ausmacht, war - wie bereits gesagt - die Verschiebung im Verhältnis zwischen Kaiser, Hauptstadt und militärischem Sektor: Nach Jahrhunderten der sesshaften Monarchen stellte Herakleios' Abwesenheit von der Hauptstadt einen massiven Bruch mit etablierten Verhaltenserwartungen dar; das urbane Umfeld war die Präsenz des Kaisers gewohnt und forderte diese auch ein. Für 
diese Verschiebung musste nun eine Sprache gefunden werden; es musste ein Narrativ entwickelt werden, das Herakleios' Transgression gegenüber dem hauptstädtischen Umfeld vermitteln konnte. In Form der Gedichte des Georg von Pisidien sind uns Quellen erhalten, anhand derer sich dieser kommunikative Prozess im Detail nachvollziehen lässt: Mit seinen panegyrischen Epen, die als Gelegenheitsschriften auf rezente politische Entwicklungen reagierten, bildete Georg eine kommunikative Scharnierstelle zwischen (abwesendem) Kaiser, der Amtselite Konstantinopels und dem klerikalen Sektor - versammelt im zeremoniellen Interaktionsraum des Palastes. Das Kapitel 5 arbeitet heraus, dass die Sprache, die für den neuerlich kriegführenden Kaiser gefunden wurde, eine christliche war - eine Sprache, die sich von früheren Modellierungen des kriegführenden bzw. triumphierenden Kaisers abhob. Georg von Pisidien zeichnet Herakleios als strategos, als obersten Befehlshaber und betont damit die kaiserliche Autorität über das Militär; Herakleios’ persönliches Engagement auf dem Schlachtfeld indes, sein Feldherrentum, modelliert der Dichter entlang des Vorbilds Heiliger Männer und erschafft damit das Bild des titelgebenden schwitzenden Kaisers, der sich als Vorkämpfer des Christentums den zoroastrischen Persern entgegenstellt. Während Georg von Pisidien Herakleios nach dessen Sieg über die Perser vorm hauptstädtischen Publikum zum transzendenten Lichtwesen und Weltenerneuerer erhob, florierten in den rückgewonnenen Ostprovinzen akut eschatologische Interpretationen der rezenten Ereignisse.

Dass die Deutung des kriegführenden Kaisers christlich geprägt war, ist nicht per se verwunderlich, sondern reagierte auf gesamtgesellschaftliche Trends. Im frühen 7. Jahrhunderte lassen sich kaum mehr Ausdrucksformen finden, die nicht aus einem christlichen Referenzrahmen hervorgingen, bzw. in diesen eingepasst wurden. Es gab keine traditionelle, säkulare Geschichtsschreibung mehr, auch Theophylakt Simokattes schrieb seine Historien vor einem christlichen Deutungshorizont. Die Gesetzgebung, die noch unter Justinian ein zentrales, traditionsorientiertes Herrschaftsinstrument gewesen war und zugleich auch eine kaiserliche Repräsentationsform, lief beinahe vollkommen aus. In seiner gesamten Herrschaftszeit erließ Herakleios nur eine Hand voll Novellen, die sich noch dazu allesamt klerikalen Belangen widmeten. Vor diesem Hintergrund ist auch die viel diskutierte Änderung der kaiserlichen Titulatur unter Herakleios zu verstehen: aus dem Imperator Caesar Augustus wurde der - wohlgemerkt griechische - pistos en Christo basileus. Mischa Meier plädiert dafür, dass es unter Justinian zu eine Hypersakralisierung des Kaisers kam; er beobachtet eine hypertrophe Entrückung des Monarchen, der sich indes nicht mehr ausreichend von seinen Untertanen abheben konnte, die als Resultat einer gesamtgesellschaftlichen Liturgisierung als Volk von Heiligen auftrat. Davon ausgehend stellt Meier die These auf, dass kaiserliche Frömmigkeit als Maßnahme zur Herrschaftssicherung ab dem späten 6. Jahrhundert an Funktionalität einbüßte. Die intensive Analyse der Quellen des frühen 7. Jahrhundert legt dagegen nahe, dass sich Sakralisierung des Kaisers keineswegs totlief, dass Frömmigkeit stattdessen weiterhin als zentrale Kaisertugend angesehen und eingefordert wurde. Die Art und Weise jedoch, wie diese Frömmigkeit ausgedrückt und verhandelt wurde, passte sich an die neuen Gegeben- 
heiten an, nämlich daran, dass der Kaiser nun zumindest zeitweise aus dem hauptstädtischen Interaktionsnetz heraustrat. Dies fand schließlich auch in Herakleios' spektakulärer Restitutio Crucis im Jahr 630 einen Ausdruck - diskutiert in Kapitel 6 -, als Herakleios als erster christlicher Kaiser Jerusalem einen Besuch abstattete, um das Heilige Kreuz in die Anastasis-Kirche rückzuführen. Während die Forschung von der Annahme bestimmt wird, Herakleios habe sich mit der Rückführung des zentralen Kultobjektes explizit in Beziehung zum jüdischen König David gesetzt, zeigt die umsichtige Analyse der Evidenz, dass stattdessen andere Bezüge und Diskurse weit bedeutender waren. Die Hauptstadt etwa sah den Kaiser in seiner Sorge um das Heilige Kreuz als neuen Konstantin. Herakleios' persönliches Engagement für eine Einigung der christlichen Gemeinden im östlichen Mittelmeerraum, welches die Jahre nach der Restitutio Crucis bestimmte, diente konkret einer Konsolidierung der rückgewonnenen Ostprovinzen; gleichzeitig sind seine Bemühungen auf dem religionspolitischen Feld aber auch aus der Notwendigkeit heraus zu verstehen, sein kaiserliches Profil weiter zu schärfen: Während Herakleios sich in Syrien um eine Kompromissfindung bemühte, konnte Georg von Pisidien ihn in Konstantinopel als vom Heiligen Geist inspirierten Streiter für die Orthodoxie feiern, der nicht nur die Perser, sondern auch die Häresien in die Knie zwang.

Bemerkenswert sind in diesem Zusammenhang die Wechselwirkungen zwischen Kaiserbild und dem Selbstverständnis des hauptstädtischen Umfeldes: Die spezifische Deutung des kriegführenden Kaisers reagierte auf allgemeine gesellschaftliche Trends; aber gleichzeitig zeitigte monarchische Praxis ihrerseits Auswirkungen auf breitere gesellschaftliche Diskurse. Besonders gut lässt sich das in dem Moment nachvollziehen, als Konstantinopel 626 von Avaren und Persern belagert wurde und Herakleios weiterhin bei den Truppen in Ostanatolien weilte. Dass der Kaiser in diesem Moment seiner Fürsorgefunktion nicht nachkam, hätte politischen Konkurrenten eine Steilvorlage liefern können; zu einer Usurpation kam es jedoch gerade nicht. Stattdessen lässt sich an den Quellen nachvollziehen, wie die Kompetenz und Rolle des Kaisers auf alternative Akteure übertragen wurde, die nicht in politische Konkurrenz zum Monarchen standen, sondern dessen Position ergänzten, nämlich auf den Patriarchen Sergios und die Theotokos, deren Kult in Konstantinopel bereits hoch im Kurs stand. Diese Beobachtung legt folgenden Schluss nahe: Dass die Marienverehrung in Konstantinopel im frühen 7. Jahrhundert einen vorläufigen Höhepunkt erlebte, war eine Folge und Kompensation der langfristigen Abwesenheit des Kaisers von seiner Hauptstadt. Im frühen 7. Jahrhundert durchlief Konstantinopel eine Phase der städtischen Integration; die vorrangig religiös geprägten Sinnstrukturen, die sich unter Herakleios verfestigten und in denen auch dem Kaiser weiterhin eine zentrale Rolle zukam, förderten die Resilienz und Stabilität des hauptstädtischen Sozialgefüges. Dass das oströmische Reich an dem äußeren wie inneren Druck im 7. und 8. Jahrhundert nicht zugrunde ging, ist unter anderem eben diesem Umstand - dem Vorhandensein eines starken politischen und ideellen Zentrums - geschuldet, der einer endgültigen Fragmentierung des Reiches entgegenwirkte. 
Nach Jahren der politischen Instabilität gelang des Herakleios tatsächlich, seine Herrschaft vorübergehend zu sichern, die getroffenen Maßnahmen zeitigten den gewünschten Erfolg. Die arabische Expansion, die sein Restitutionswerk wieder zunichte machte, führte allerdings zu einer weiteren Dynamisierung seiner Herrschaft. Das Kapitel 6 blickt zuletzt auch auf die innenpolitischen Maßnahmen, mit denen Herakleios auf die vernichtende Niederlage der Römer am Yarmouk und den erneuten Verlust der Ostprovinzen reagierte. Nachdem sich in Konstantinopel eine Verschwörung gegen ihn aus der eigenen Familie zusammengebraut hatte, sah der Kaiser sich gezwungen, deutliche Zeichen zu setzen. Mit einer hyperthrophen Inszenierung einer Schiffsbrücke über den Bosporus, über die der Kaiser zu Pferd nach Konstantinopel einzog - versuchte er, den erlittenen Prestigeverlust zu kompensieren. Dass dieses spektakuläre Ereignis im Nachhinein einer satirischen Deutung unterworfen und als Maßnahme erinnert wurde, um die Wasserangst des Kaisers zu beschwichtigen, zeigt, dass triumphale Statements vor dem Hintergrund der katastrophalen Entwicklung im Osten nicht mehr wertgeschätzt wurden. Auch die öffentlichkeitswirksamen Maßnahmen, die Herakleios nach seiner Rückkehr in die Hauptstadt traf die Krönung eines weiteren Sohnes zum Augustus und die Promulgation der Ekthesis zur Schlichtung der monoenegetischen Kontroverse - konnten langfristig gesehen nicht die erhoffte Wirkung erzielen.

Als Herakleios im Jahr 641 eines natürlichen Todes starb, stand in Konstantinopel die Fortführung seiner Dynastie außer Frage; gleichzeitig offenbarten sich jedoch die Sollbruchstellen seiner Politik, wie das Kapitel 7 verdeutlicht. Die Förderung der Kernfamilie hatte zwar Herakleios' Position ebenso wie die seiner Söhne in Konstantinopel stärken können; der Umstand jedoch, dass es beim Tod des Dynastiegründers zwei Augusti in Konstantinopel gab (Herakleios Konstantin, Sohn aus erster Ehe mit Eudokia, und Heraklonas, Sohn aus zweiter Ehe mit Martina), führte zu unüberbrückbaren Spannungen und machte friedliche monarchische Sukzession geradezu unmöglich. Zwischen den beiden Familienlinien entbrannte ein erbitterter Machtkampf. Angesichts erneuter Instabilität in Konstantinopel geschah genau das, was Herakleios mit seiner Politik über Jahrzehnte recht erfolgreich zu verhindern gewusst hatte: Militärischen Funktionsträgern, die sich des Rückhaltes der Truppen in den Provinzen sicher waren, gelang es, Einfluss auf die Entscheidungsprozesse der Hauptstadt zu nehmen. Die innere Stabilität, die das oströmische Reich zwischen 610 und 641 ausgezeichnet hatte, war primär an Herakleios' Person gebunden gewesen; Krisenphänomene, die bereits im frühen 7. Jahrhundert zu beobachten gewesen waren, traten nach seinem Tod mit gesteigerter Vehemenz hervor: Unruhen von Seiten des Heeres und Usurpationsversuche von Militärs nahmen zu. Herakleios' Remilitarisierung des Kaisertums hatte neue Standards gesetzt: Dass der Kaiser sich wieder persönlich als Oberbefehlshaber engagierte, verlor recht schnell den transgressiven Charakter; der kollektive Erwartungshorizont in Hinblick auf kaiserliches Verhalten passte sich an. Die Augusti balancierten dabei jedoch auf einem schmalen Grat: Wie der Blick auf den Akzeptanzverlust und die Ermordung des Konstans II. im sizilischen Syrakus zeigt, musste die Abwesenheit des Kaisers von der Hauptstadt wohl be- 
gründet sein. Sowohl das hauptstädtische Umfeld als auch das Heer erwarteten ein militärisches Engagement im Sinne der Sicherung des Reiches, welches dem Druck der arabischen Expansion kaum standhalten konnte. Das dauerhafte Verweilen in einer alternativen Residenz, die Konstantinopels Monopolstellung Konkurrenz machte, dagegen wurde nicht toleriert.

Das frühe 7. Jahrhundert kann zurecht als eine neuralgische Phase in der Entwicklung der oströmischen Monarchie identifiziert werden - als Phase, während derer die politischen Strukturen, die die oströmische Monarchie des 5. und 6. Jahrhunderts geprägt hatten, zur Disposition standen, eine graduelle Umformung durchliefen und damit schließlich die Richtung für die weitere Entwicklung vorgaben. In den ersten Jahrzehnten des 7. Jahrhunderts erwiesen sich etablierte Handlungsoptionen in ihrer Verfügbarkeit bzw. Wirkmächtigkeit als unsicher, Normen und Routinen wurden in Frage gestellt, es kam zu Anpassungen von individuellen und kollektiven Erwartungshaltungen. Dabei ist allerdings zu betonen, dass die Monarchie des 7. Jahrhunderts sich weiterhin durch die grundlegenden Funktionsmechanismen auszeichnete, die sich - angelegt in der Einrichtung einer spezifisch römischen Form von Monarchie unter Augustus - über das 5. und 6. Jahrhundert hinweg im östlichen Mediterraneaum etabliert hatten: Der Mann auf dem Thron rang nach wie vor um Akzeptanz, seine Position war weiterhin prekär; das Zentrum des Reiches wie auch der Bezugspunkt kaiserlichen Handeln war und blieb Konstantinopel. Es ist also durchaus gerechtfertigt, diese Monarchie im 7. Jahrhundert weiterhin als eine römische, bzw. oströmische, zu qualifizieren und zu analysieren. Allein das Gewand dieses Herrschaftssystems - die Äußerungen und Sinnstrukturen, im Rahmen derer die Zeitgenossen ihre Umwelt wahrnahmen - hatte sich gegenüber dem Vergangenen grundlegend gewandelt; die Andersartigkeit dieses Gewandes ist es, was sich mit dem Begriff ,byzantinisch` bezeichnen lässt. 


\section{English Summary}

In the spring of the year $622 \mathrm{CE}$, the emperor Heraclius (610 - 641), after having celebrated Easter in Constantinople, left the capital and crossed over to Anatolia; his aim was to prepare the Roman troops for a counter offensive against the Persians who had occupied the provinces of Syria, Mesopotamia, Palestine and Egypt. During the following years, Heraclius spent more time on the battlefield than in his imperial palace, at times advancing far into the Persian heartlands. In 628 his bold strategy paid off: unable to respond to the military pressure exerted by the Romans, the Sasanian King of Kings Chosroes II was overthrown and replaced by his son Kavadh Seiroe. The new ruler immediately proposed a truce, promising to vacate the occupied Roman territories. After years in the theatre of war, Heraclius returned to Constantinople in triumph.

Recent research has revealed the early seventh century to have been an exceptionally dynamic period, during which the Mediterranean and the Near East underwent a fundamental transformation. After the ephemeral Persian occupation, the Roman eastern provinces were granted only a few years of peace; from the early 630s onwards, Syria and Mesopotamia were confronted with the onsets of the Arab expansion. Weakened by decades of constant warfare, the Roman defence was not equipped to halt the new aggression. In 636, the Roman army suffered a crushing defeat by the Arab troops at the banks of the river Yarmouk; Heraclius' troops had no choice but to withdraw behind the natural border of the Taurus mountains. In the following years, the eastern provinces as well as Egypt and Africa fell to the new enemy; Heraclius' previous successes were obliterated: by the middle of the century, the Roman Empire was left with nothing but a core territory in Anatolia and Thrace as well as enclaves in Greece and Italy.

Against the backdrop of these large-scale processes, this book focuses on the development of the Eastern Roman monarchy in the early seventh century and discusses the opportunities and constraints of imperial rule. In this context, the fact that Heraclius personally acted as supreme commander against the Persians is of utmost importance. During the fifth and sixth centuries, the political system of the Eastern Roman Empire was characterized by a close physical and ideological bond between the emperor and Constantinople. Instead of travelling the provinces and leading the armies as their predecessors had done, the Eastern Roman monarchs virtually ceased to leave the new capital. In research, this specific configuration is often seen as a major reason for why the Eastern Empire survived the tumultuous period of Late Antiquity, whereas its western counterpart eventually succumbed to the pressure of mainly non-Roman military elites. After more than two hundred years of sedentary monarchy, Heraclius was the first emperor to leave Constantinople for an extended period of time in order to personally lead the Roman troops into battle. This book asks for the reasons for this shift of paradigm, it looks at the ways in which contemporaries coped with the sudden change in imperial behaviour and addresses the con- 
sequences of Heraclius' policies for the further development of the Eastern Roman monarchy. My aim is to not only recount Heraclius' reign but to highlight the structural mechanisms and causal foundations of political decision making as well as the impact of political communication.

The analysis centres around the relationship between the emperor, the capital and the military sector. As has been frequently emphasized in research, the sedentary type of monarchy of the fifth and sixth centuries effected a rise in the importance of the Constantinopolitan environment: the metropolitan people and elites played a major role in the process of negotiating imperial rule; their acceptance and support was paramount for the stability of an emperor's position. In turn, it has been argued that the military, which up until the late fourth century had made and unmade emperors, was gradually marginalized, losing its relevance for political processes once the emperors stayed in Constantinople. In contrast to this assessment, a revision of the relationship between the sedentary monarchs and the military sector during the fifth and sixth centuries, conducted in chapter 2, argues that certain groups within the military continued to make their influence felt. Whereas the mass of the soldiers did not pose a genuine threat as long as the emperors catered to their needs, high military officeholders - the magistri militum who by default rose to the rank of illustris and thus became members of the senate - had means at their disposal to transfer their prestige to the capital, put pressure on the emperor and influence political processes up to imperial succession. The same applies to the imperial guards, the scholae and excubitores, and especially to their commanders, whose control over the imperial palace was a major asset. The sedentary emperors, in turn, developed strategies to emancipate themselves from the military and curb the threat that was posed by high officeholders: within Constantinople, the emperors could draw on new forms of communication and representation structured by an increasing sacralization of the imperial office on the one hand and triumphalism on the other hand. As eternal victors, the sedentary and non-warring emperors succeeded in appropriating for themselves the triumphs won by their generals. Chapter 2 ends with a closer look at the reign of the emperor Maurice (581-602) who struggled to establish new ways of interacting with the military. His often insensitive measures, however, did not show the desired effect but sparked a backlash from both the metropolitan environment and the military, eventually contributing to his overthrow.

Chapter 3 traces a gradual shift in the relationship between emperor, the capital and the military sector in the early seventh century, which is closely related to a chain of events that unfolded in the fall of 602. After Maurice had ordered the Balkan army to winter beyond the Danube, the soldiers rebelled, chased away the magister militum Petrus, Maurice's brother, and acclaimed the centurion Phocas as their leader instead. As the army drew closer to Constantinople to enforce their claims, tension within the city walls also erupted. Given that the people had turned against him and parts of the city centre had been set ablaze, Maurice saw no other option but to flee the city at night and cross over to the Asian side of the Marmara See. In this power vacuum the green circus faction stepped forward and greeted Phocas as the new em- 
peror. Several days later, Maurice was seized and killed together with his family. In this book, the events of 602 are read as a contingent chain reaction. When the army first revolted against the imperial order, it had neither been planned nor foreseeable that Maurice would be overthrown and succeeded by Phocas. The result of this chain of events - the coronation of an external candidate -, however, broadened the space for manoeuvre: it had become clear that, as opposed to the centuries prior, military pressure could once again directly affect the metropolitan environment up to imperial succession. Only a few years later, Heraclius, the exarch of Carthage, made use of this option and rose up against Phocas. Numismatic evidence shows that, in this case, it was the aim from the start to overthrow the emperor and install Heraclius' son of the same name in his stead. Having secured Egypt and parts of the Levant by military force, a fleet led by Heraclius Junior sailed towards Constantinople. When faced with the contender anchoring in the harbours south of the city in October 610, the metropolitan people and elites deserted Phocas and acclaimed Heraclius emperor instead. The analysis of the coronation rituals of Phocas and Heraclius shows the unbroken impact of the metropolitan environment: involving the major Constantinopolitan interest groups, a cautiously staged ritual succeeded in transferring two external candidates into the city as new emperors and overcoming a period of internal strife and disintegration. Before Heraclius was crowned emperor in the Hagia Sophia, his predecessor Phocas, who had been frantically acclaimed by the metropolitan people eight years prior, was publicly humiliated and executed: having failed to establish functioning forms of communication and to sustain the necessary support as emperor, Phocas suffered the symbolic treatment of a failed usurper. As the last subchapter shows, the vilification of Phocas as tyrant formed a core aspect of Heraclius' self-representation and became so deeply ingrained in collective memory that it shapes historiography until today.

Chapter 4 looks at the remilitarization of the imperial office under Heraclius. After his coronation, Heraclius' main challenge was to prevent the scenario that had brought himself to power from happening again: he had to forestall another usurpation from the military sector. Whereas his predecessor Phocas had remained in Constantinople despite his military background and the reignited war with the Persians, Heraclius broke new ground. As Sasanian troops raided Syria and Anatolia, he left Constantinople in 613 to face the enemy in battle; the Roman army under his lead, however, suffered a crushing defeat. This situation showcases the risk Heraclius took by personally leading the troops: whereas his sedentary predecessors had been able to immunize themselves from the consequences of military defeat, the warring emperor could be held accountable; his prestige and standing could potentially suffer a severe blow. After this first unsuccessful advance, Heraclius withdrew to Constantinople. Only after the Persians had occupied vast parts of the Roman Empire, he seems to have seen no other choice but to prepare for another personal counter offensive: in 622 the emperor led a campaign in Asia Minor; in 624 he left the capital for several years to fight the Persians on their own territory. By leading the Roman army in person, Heraclius reacted to a Persian aggression that was far 
more severe than what the empire had experienced in the previous centuries; however, he simultaneously tried to curb an internal threat from the military sector: acting as supreme commander, Heraclius aimed at strengthening imperial authority over the military so as to prevent military officeholders from becoming too powerful and having designs on another usurpation. Heraclius' policies, however, were not only directed at the military; he also showed innovative approaches in the realm of family politics. In 613, shortly before he left for his first campaign against the Persians, he crowned his baby son Heraclius Constantine Augustus and systematically propagated this step on the obverses of gold, silver and copper coins. Despite Heraclius' temporary absence, there was always an Augustus present in the capital, who, despite his young age, could substitute for his father as the ceremonial centre of the imperial palace. By elevating his son as imperial colleague, Heraclius not only strengthened his family but made a clear statement as to imperial succession. In this context, a much-debated aspect of Heraclius' reign reveals its substance: after the early death of his first wife Eudocia, he married his niece Martina - a connection that defied Roman law and sparked controversy. In the fifth and sixth centuries, military officeholders had frequently tried to assert their influence and even position themselves for imperial succession by marrying into the imperial family. With his endogamous family policy and by systematically promoting family members like his cousin Nicetas to the highest positions, Heraclius tried to pre-empt potential contenders from entering into the highest echelons of power.

Chapter 5 turns towards the contemporary discourse. As the coups of 602 and 610 had shown, an emperor had to secure the support of the metropolitan groups in order to stay in power. By leaving the capital, however, Heraclius broke with established patterns of imperial behaviour; as the sources show, his attempt to act as supreme commander was heavily debated in Constantinople and at times faced a serious backlash. To not jeopardize his authority, Heraclius' transgression had to be framed with an acceptable narrative. In the panegyric poems of George of Pisidia, of which many can be read as a direct comment on current events, we can trace a process of negotiating the imperial position throughout Heraclius' reign. When presenting his elaborate verses in the imperial palace, George, himself a cleric in the staff of the patriarch Sergius, formed a communicative link between the emperor, the metropolitan elite and the church. In these poems, the war against the Persians is put into an explicitly religious framework as a conflict between Christians and Zoroastrian idolaters. Against this backdrop, Heraclius' engagement as supreme commander also gained religious implications. Leaving behind the aloof figurations of earlier emperors, George presented the warring Heraclius as a supreme commander fighting like one of his soldiers, struggling and sweating on the battlefield. The images evoked by George strengthened Heraclius' authority over the military sector; simultaneously, however, his verses drew on a religious frame of reference: by using vocabulary reminiscent of hagiography, the poet modelled the emperor's generalship according to the ascetic practice of Holy Men. The impact of communication becomes even more clear when, in 626, Constantinople had to face a double siege by the Avars 
and Persians while Heraclius remained with his army in eastern Anatolia. As the emperor, due to his absence, was unable to fulfil his traditional role as protector of the metropolitan people, George established two alternative figures of identification, the patriarch Sergius and the Virgin Mary, who filled the vacuum left by Heraclius without challenging his authority, thus leaving no room for potential political contenders. Marian devotion, which had already played a crucial role in Constantinople in the sixth century, reached a preliminary peak. In retrospect, the precarious situation was not only overcome but turned into a moment of civic pride which strengthened political and religious hierarchies and contributed to the city's resilience. After the victory over the Persians and his triumphal return to the capital, the sweating emperor, in George's laudatory words, was turned into a transcendental saviour figure, whereas Heraclius himself acted as a humble and God-fearing ruler. In Constantinople the Roman triumph was seen as the key to a new and better future; meanwhile, in the Eastern provinces which had suffered from several reversals of fortune during the past decades, recent developments in general and Heraclius' engagement in particular were interpreted in explicitly apocalyptic terms.

Chapter 6 turns the focus towards the last one and a half decades of Heraclius' reign and starts by assessing how Heraclius was practically reintegrated into Constantinople after years of absence. On the back of his spectacular victory, Heraclius could celebrate a triumphal return that connected liturgical elements with traditional forms of Roman victory festivities like hippodrome games. However, instead of remaining in the capital, Heraclius left for the eastern provinces again, intent on reintegrating the areas he had just regained for the Roman Empire. Having formed an alliance with the Persian general Shahrbaraz, Heraclius demanded the return of the relic of the True Cross which the Persians had taken from the Anastasis Church in Jerusalem in 614. In 630, Heraclius celebrated another triumph in a setting that was much less structured by norms and expectations than the imperial capital: he entered Jerusalem and returned the True Cross to its accustomed place, becoming the first Christian emperor to ever visit the holy city. Unsurprisingly, the Restitutio Crucis has received much scholarly attention: what remains undisputed is that contemporaries perceived it as an event of cosmic significance and that the ceremony seems to have played with parallels to Jesus' entry into Jerusalem. In my analysis of Heraclius' entry, however, I argue against the common notion that the emperor aimed at presenting himself as a new David and that he intended to put his visit to Jerusalem into an eschatological context. The evidence for this claim is too scarce, fragmented or removed from the actual event in space and time. In Constantinople, as another poem of George of Pisidia makes clear, Heraclius was not portrayed in relation to David but in explicit analogy to the emperor Constantine. After his Restitutio Crucis, Heraclius devoted himself to solving the religious strife between the different Christian denominations of the Near East. He personally met with representatives of the miaphysite Syrian and Armenian Churches, as well as with Nestorian Christians, to promote a new formula (monoenergism or later monotheletism) that was meant to appeal to all denominations. In the contemporary discourse of the cap- 
ital, however, these politics of reconciliation found no expression; instead, Heraclius was portrayed as a divinely inspired fighter for orthodoxy, crushing the Persians and the heresies alike. Yet, like so many of his predecessors, Heraclius did not succeed in his efforts to unify Christianity. While opposition against monoenergism rose from both the miaphysite and the chalcedonian side, Palestine and Syria had to face the first Arab attacks. When the Roman army suffered a crushing defeat at the banks of the river Yarmouk in 636, Heraclius returned to Constantinople. The last subchapter explores the consequences of this military disaster. After no one had dared to directly challenge Heraclius over several decades, a conspiracy against him, led by members of his own family, was hatched in Constantinople. As the conspiracy was revealed and those responsible punished, Heraclius felt the need to reclaim his position in the capital. Even though there was nothing to celebrate, he ordered a bridge of boats to be constructed over the Bosporus; having crossed the waters on horseback, he entered Constantinople. The emperor's spectacular and triumphal statement, however, was not remembered as such; as the Romans were unable to halt the Arab advance and the religious policy failed, the bridge of boats was ridiculed as a symbol of Heraclius' alleged fear of water.

In 641, Heraclius died a natural death. He had succeeded in securing his own position as emperor; his measures, however, quickly revealed substantial issues as chapter 7 shows. After the conspiracy in the wake of the battle of Yarmouk had challenged his authority, Heraclius had elevated a second son (Heraclonas, son of his second wife Martina), to the rank of Augustus. Given that there was no clear order of succession, a feud broke out between the two lines of the imperial family after Heraclius' death: his oldest son Heraclius Constantine, son of Eudocia and Augustus since 613 on the one side, and Martina and Heraclonas on the other fought for supremacy in Constantinople. In this unstable constellation, the group that Heraclius had been able to curb re-emerged as a major political factor: high military officeholders with the mass of soldiers behind them started putting pressure on Constantinople. After Heraclius Constantine's premature death, a rebellious army under the lead of the general Valentinus insisted on securing the position of Heraclius Constantine's infant son, who was crowned Augustus as Constans II in late 641. In what seems to be a military coup, Martina and Heraclonas were overthrown shortly afterwards. Valentinus, who by then had made his way into the palace, continuously tightened his grip on Constans II and tried to position himself and his family for imperial succession. By instituting a veritable military regime, however, he went one step too far: the metropolitan people, supported by the patriarch, rose against Valentinus and confirmed Constans as emperor. The Heraclian dynasty proved remarkably persistent, reigning over five generations; imperial succession, however, was regularly accompanied by family strife and infighting. With his remilitarization of the imperial office, Heraclius had set a precedent; his successors left the capital to lead the armies in person. Constans' attempt, however, to establish a new residency in Syracuse, Sicily, was heavily contested and eventually cost the emperor's life; Constantinople remained the Empire's undisputed centre. In the course of the seventh century, how- 
ever, crisis phenomena increased: while the Arabs established their rule on formerly Roman territories, rebellions from the military became more and more frequent; Justinian II, the last representative of the Heraclian dynasty, had to face several usurpations by powerful generals until he was eventually executed in 711 and succeeded by Philippikos Bardanes.

Identifying the reign of Heraclius as a crucial period in the development of the Eastern Roman monarchy, this book contributes to the discussion of the transition between Antiquity and the Middle Ages in the Eastern Mediterranean. As to the opportunities and constraints of imperial rule, Heraclius, in his attempts to secure his position and curb the threats from the military sector, set new standards by which his successors had to abide. What remained, however, was the structural setting established during the fifth and sixth centuries in which the emperor had to secure Constantinople and gain the acceptance of the relevant groups in order to stay in power. In the early seventh century, Constantinople underwent a process of civic integration by strengthening a common frame of reference - a process that substantially contributed to the city's unbroken importance and its resilience in the face of the Arab expansion. This frame of reference in which also the emperors negotiated their position was, by now, a comprehensively Christian one and can be qualified as distinctively byzantine. The ways in which imperial warfare in general and the engagement of the emperor in particular had been communicated under Heraclius - as a religious war with an almost sacred leader - showed its full impact in the centuries to come. 


\section{Anhang}

\subsection{Abkürzungen}

ACO Acta Concilorum Oecumenicorum, ed. E. Schwarz / J. Straub u. a, Berlin u. a., seit 1914.

DOC A. R. Bellinger / Ph. Grierson / M. F. Hendy, Catalogue of the Byzantine Coins in the Dumbarton Oaks Collection and in the Whittemore Collection, 5 Bde., Washington 1966-1999.

LSJ H. G. Liddell / R. Scott / H. S. Jones, A Greek-English Lexicon. With a Revised Supplement 1996, Oford 1996

MIB J. Hahn, Moneta Imperii Byzantini, 3 Bde., Wien 1973-1981.

PG Patrologia Cursus Completus, Series Graeca, ed. J.-P. Minge, 162 Bde., Paris 1857-1912.

PL Patrologia Cursus Completus, Series Latina, ed. J.-P. Minge, 221 Bde., Paris 1844-1865.

PLRE A. H. M. Jones / J. R. Martindale / J. Morris, The Prosopography of the Later Roman Empire, 3 Bde., Cambridge u.a. 1992.

PMBZ Prosopographie der mittelbyzantinischen Zeit, nach Vorarbeiten von F. Winkelmann erstellt von R.-J. Lilie / C. Ludwig / Th. Pratsch / I. Rochow / B. Zielke; online verfügbar: https:// www.degruyter.com/view/db/pmbz

\subsection{Quellenverzeichnis}

Alexanderlegende:

- E. A. W. Budge (Ed., Übers.), The History of Alexander the Great. Being the Syriac Version of the Pseudo-Callisthenes. Edited from Five Manuscripts with an English Translation and Notes, Cambridge $1889,255-275$.

Alexanderlied:

- G. J. Reinink (Ed., Übers.), Das syrische Alexanderlied, 2 Bde., CSCO 454 f., SS 195 f., Leuven 1983. Anastasios der Perser, Vita et translatio reliquiarum:

- B. Flusin (Ed., Übers.), Saint Anastase le Perse et l'histoire de la Palestine au début du VIle siècle, Bd. 1, Paris 1992.

Anthologia Graeca:

- H. Beckby (Ed., Übers.), Anthologia Graeca, griechisch-deutsch, 2. Aufl., Berlin/Boston 1957-1958. Antiochos Strategos (Strategios):

- G. Garitte (Ed., Übers.), La prise de Jérusalem par les Perses en 614, 2 Bde., CSCO 202f., SI 11f., Leuven 1960.

- G. Garitte (Ed., Übers.), Expugnationis Hierosolymae, A.D. 614, Recensiones Arabicae, 4 Bde., CSCO 340 f., 347 f., SA 26-29, Leuven 1973/1974.

- F.C. Conybeare (Übers.), in: English Historical Review 25 (1910), 502 - 517.

Chronicon ad annum 724:

- J.-B. Chabot (Ed., Übers.), Chronicon miscellaneum ad annum Domini 724 pertinens, Chronica Minora 2, CSCO 4, SS 4, Leuven 1955, 63-119.

- A. Palmer (Übers.), The Seventh Century in the West-Syrian Chronicles, Liverpool 1993, 13-23, 49-50.

Chronicon ad annum 1234:

- J.-B. Chabot (Ed., Übers.), Chronicon anonymi auctorus ad annum Christi 1234 pertinens, 3 Bde., CSCO 81f., 109, SS 36 f., 56, Paris 1916 -1937; A. Abouna (Übers.), CSCO 345, SS 154, Leuven 1974.

- A. Palmer (Übers.), The Seventh Century in the West Syrian Chronicles, Palmer 1993, 111-221. 


\section{Chronicon Paschale:}

- L. Dindorf (Ed.), Chronicon Paschale, 2 Bde., Bonn 1832.

- Mi. Whitby / Ma. Whitby (Übers.), Chronicon Paschale 284-628 AD, Liverpool 1989.

Chronik von Seert:

- A. Scher (Ed., Übers.), Histoire nestorienne inédite: Chronique de Séert, 4 Bde., Patrologia Orientalis 4.3, 5.2, 7.2, 13.4, Paris $1908-1919$.

Doctrina Jacobi nuper baptizati:

- G. Dagron / V. Déroche (Ed., Übers.), Juifs et chrétiens dans l'Orient du VIl' siècle, Paris 1991, 47 229.

Ekthesis:

- P. Allen (Ed., Übers.), Sophronius of Jerusalem and Seventh-Century Heresy. The Synodical Letter and Other Documents, Oxford 2009, 208-217.

Eutychios:

- M. Bredy (Ed., Übers.), Das Annalenwerk des Eutychios von Alexandrien: Ausgewählte Geschichten und Legenden kompiliert von Sa'id ibn Batriq um 934 AD, 2 Bde., CSCO 471f., SA 44 f., Leuven 1985.

Evagrios Scholastikos:

- A. Hübner (Ed., Übers.), Evagrius Scholasticus. Historia ecclesiastica - Kirchengeschichte, 2 Bde., Turnhout 2007.

- Mi. Whitby (Übers.), The Ecclesiastical History of Evagrius Scholasticus, Liverpool 2000.

Fredegar:

- J. M. Wallace-Hadrill (Ed., Übers.), The Forth Book of the Chronicle of Fredegar with its Continuations, London 1960.

Georg von Pisidien:

- A. Pertusi (Ed., Übers.), Giorgio di Pisidia, Poemi, Bd. I: Panegirici epici, Ettal 1959.

- L. Tartaglia (Ed., Übers.), Carmi di Giorgio di Pisidia, Turin 1998.

Geschichte der Patriarchen von Alexandria:

- B. Evetts (Ed., Übers.), History of the Patriarchs of the Coptic Church of Alexandria, 3 Bde., PO 1.2, 1.4, 5.1, Paris 1907-1910.

Goripp:

- Av. Cameron (Ed., Übers.), Corippus. In laudem Iustini Augusti minoris libri IV, London 1976.

Johannes von Antiochia:

- U. Roberto (Ed., Übers.), Ioannis Antiocheni fragementa ex historia chronica, Berlin u. a. 2005.

- S. Mariev (Ed.), Ioannis Antiocheni fragment aquae supersunt omnia, Berlin/Boston 2008.

Johannes von Nikiu:

- R. H. Charles (Übers.), The Chronicle of John, Bishop of Nikiu, translated from Zotenberg's Ethiopic Text, Oxford 1916.

Khuzistan Chronik (Anonymus Guidi):

- Th. Nöldeke (Übers.), „Die von Guidi herausgegebene syrische Chronik“, Sitzungsberichte der kaiserlichen Akademie der Wissenschaften, phil.-hist. Klasse 128 (1893), 1-48.

Leontios von Neapolis:

- A. J. Festugière (Ed., Übers.), Vie de Symeon le Fou et Jean de Cypre, Paris 1974, 255-637.

Liber Pontificalis:

- L. Duchesne (Ed.), Le Liber Pontificalis: texte, introduction et commentaire, Paris 1955.

- R. Davis (Übers.), The Book of Pontiffs: The Ancient Biographies of the First Ninety Bishops to AD 715, Liverpool 1989.

Michael Syrus:

- J. B. Chabot (Ed., Übers.), Chronique de Michael le Syrien, 4 Bde, Paris 1899-1910.

Movses Dasxuranci:

- C. J. F. Dowsett (Übers.), The History of the Caucasian Albanians by Movses Dasxuranci, London 1961. 
Nikephoros Patriarcha:

- C. Mango (Ed., Übers.), Nikephoros, Patriarch of Constantinople: Short History, Washington, DC 1990.

Prokop von Caesarea:

- J. Haury / G. Wirth (Ed.), Procopii Caesariensis Opera omnia, 4 Bde, Leipzig 1905-1913.

- H. B. Dewing / G. Downey (Ed. / Übers.), Procopius. Buildings, History of the Wars, and Secret History, 7 Bde., Cambridge, MA, 1914-1940.

- 0. Veh. (Ed. / Übers.), Anekdota. Geheimgeschichte am Kaiserhof von Byzanz. Mit Erläuterungen, einer Einführung und Literaturhinweisen von M. Meier und H. Leppin, 4. Aufl., Düsseldorf u. a. 2005.

Ps.-Methodios, Apokalypse:

- G. J. Reinink (Ed., Übers.), Die syrische Apokalypse des Pseudo-Methodius, 2Bde., CSCO 540 f., Scriptores Syri 220 f., Leuven 1993.

Reversio S. Crucis, Sermo de Exaltatione S. Crucis:

- S. Borgehammar (Ed., Übers.), „Heraclius Learns Humility: Two Early Latin Accounts Composed for the Celebration of 'Exaltatio Crucis'“, Millenium-Jahrbuch 6 (2009), 145-202.

Sebeos:

- G. V. Abgaryan (Ed.), Patmut'iwn Sebeosi, Erevan 1979.

- R. W. Thomson / J. Howard-Johnston (Übers.), The Armenian History Attributed to Sebeos, Liverpool 1999.

Sophronios Patriarcha:

- M. Gigante (Ed., Übers.), Sophronii Anacreontica, Rom 1957.

- A. Gallico (Übers.), Sofronio di Gerusalemme: Le omelie, Rom 1991.

- J. de La Ferrière (Übers.), Sophrone de Jérusalem: Fetes chrétiennes à Jérusalem, Paris 1999.

Theodor von Sykeon, Vita:

- A. J. Festugière (Ed., Übers.), Vie de Théodore de Sykéôn, 2 Bde., Brüssel 1970.

Theodor Synkellos:

- F. Combefis (Ed.), „Narratio in depositionem pretiosae vestis Deiparae in Blachernis“, in: Historia haeresis Monothelitarum, Paris 1648, Bd. II, 751-788.

- Av. Cameron (Übers.), „The Virgin's Robe: An Episode in the Hisotry of the Early Seventh-Century Constantinople“, Byzantion 49 (1979), $42-56$.

- L. Sternbach (Ed.), „De obsidione Constantinopolis“, in: Analecta Avarica, Krakau 1900, 298-342.

- F. Makk (Übers.), Traduction et Commentaire de l'homélie écrite probablement par Théodore le Syncelle sur le siège de Constantinople en 626, Szeged 1975.

Theophanes Confessor:

- C. de Boor (Ed.), Theophanis Chronographia, Leipzig 1883.

- C. Mango / R. Scott (Übers.), The Chronicle of Theophanes Confessor. Byzantine and Near Eastern History AD 284-813, Oxford 1997.

Theophilos von Edessa:

- R. G. Hoyland (Übers.), Theophilus of Edessa's Chronicle and the Circulation of Historical Knowlegde in Late Antiquity and Early Islam, Liverpool 2014.

Theophylakt Simokattes:

- C. de Boor (Ed.), Theophylacti Simocattae, Historiae, Leipzig 1887.

- P. Schneider (Übers.), Theophylaktos Simokates, Geschichte, Stuttgart 1985.

- Mi. Whitby / Ma. Whitby (Übers.), The History of Theophylact Simocatta, Oxford 1986.

Zeremonienbuch:

- J. J. Reiske (Ed.), De cerimoniis aulae Byzantinae, 2 Bde., CSHB 7 f., Bonn 1829-30.

- A. Moffat / M. Tall (Übers.), Constantine Porphyrogennetos, the Book of Ceremonies. With the Greek edition of the Corpus Scriptorum Historiae Byzantinae (Bonn, 1892), 2 Bde., Canberra 2012. 


\subsection{Literaturverzeichnis}

Akopjan, A. A. (1978), Albanija-Aluak, Erevan.

Alexakis, A. (1995/1996), „Before the Lateran Council of 649: The Last Days of Herakleios the

Emperor and Monotheletism“, Annuarium Historiae Conciliorum 27/28, 93-102.

Alexander, P. J. (1985), The Byzantine Apocalyptic Tradition, Berkeley, CA u.a.

Alföldi, A. (1970), Die monarchische Repräsentation im römischen Kaiserreiche, Darmstadt.

Allen, P. (1981), Evagrius Scholasticus, the Church Historian, Leuven.

Allen, P. (2002), Maximus the Confessor and His Companions. Documents from Exile, Oxford.

Allen, P. (2009), Sophronius of Jerusalem and Seventh-Century Heresy. The Synodical Letter and Other Documents, Oxford.

Antonopoulos, P. T. (2012), „Constans II's Intervention in Italy and its Ideological Significance“, in: J. Koder / I. Stouraitis (Hgg.), Byzantine War Ideology between Roman Imperial Concept and Christian Religion, Wien, 27-32.

Avni, G. (2010), „The Persian Conquest of Jerusalem (614 C.E.) - an Archaeological Assessment“, Bulletin of the American Schools of Oriental Research 357, 35- 48.

Ayaita, J. (2015), Justinian und das Volk im Nikaaufstand, online publ.: https://archiv.ub.uniheidelberg.de/volltextserver/20002/

Baldovin, J. F. (1989), The Urban Character of Christian Worship: The Origins, Development and Meaning of Stational Liturgy, Rom.

Bardill, J. (2006), „A New Temple for Byzantium. Anicia Juliana, King Solomon, and the Gilded Ceiling of the Church of St. Polyeuktos in Constantinople“, in: W. Bowden / A. Gutteridge /

C. Machado (Hgg.), Social and Political Life in Late Antiquity, Leiden, 339-370.

Barišic, F. (1955), „Le siège de Constantinople par les Avares et les Slaves en 626“, Byzantion 24, 371-395.

Barkhuizen, J. H. (1995), „Romanos Melodos: On Earthquakes and Fires“, Jahrbuch der österreichischen Byzantinistik 45, 1-18.

Bayliss, R. I. / Crow, J. G. (2002), „The Water Supply of Constantinople“, Anatolian Archaeology 8, 21-23.

Baynes, N. H. (1904), „The First Campaign of Heraclius against Persia“, The English Historical Review 19, 694-702.

Baynes, N. H. (1912a), „The Restoration of the Cross at Jerusalem“, The English Historical Review 27, 287-299.

Baynes, N. H. (1912b), „The Date of the Avar Surprise“, Byzantinische Zeitschrift 21, 110-128.

Baynes, N. H. (1949), „The Supernatural Defenders of Constantinople“, Analecta Bollandiana 67, $165-77$.

Baynes, N. H. (1952), „The Emperor Heraclius and the Military Theme System“, The English Historical Review 67, 380-381.

Beaucamp, J. (1979), „Temps et Histoire I: Le prologue de la 'Chronique pascale’“, Travaux et Mémoires 7, 223-302.

Begass, C. (2018), Die Senatsaristokratie des Oströmischen Reiches, ca. 457-518, München.

Begass, C. (2021), Senat II (Konstantinopel), Reallexikon für Antike und Christentum, Bd. 30, $294-311$.

Bell, P. N. (2009), Three Political Voices from the Age of Justinian. Agapetus: Advice to the emperor, Dialogue on political science, Paul the Silentiary: Description of Hagia Sophia, Liverpool.

Bellinger, A. R. (1966), „Byzantine Notes 10: Solidi of Heraclius and Heraclius Constantine“, American Numismatic Society. Museum Notes 12, $109 \mathrm{f}$.

Bijovski, G. (2010), „A Single Die Solidi Hoard of Heraclius from Jerusalem“, in: Mélanges Céciles Morrisson, Travaux et Memoirs 16, Paris, 55-92. 
Blockley, R. C. (1985), „Subsidies and Diplomacy: Rome and Persia in Late Antiquity“, Phoenix 39, $62-74$.

Boak, A. E. R. (1919), „Imperial Coronation Ceremonies of the Fifth and Sixth Centuries“, Harvard Studies in Classical Philology, 37-47.

Bonner, M. R. J. (2020), The Last Empire of Iran, Piscataway.

Booth, P. (2013a), „Sophronius of Jerusalem and the End of Roman History“, in: P. Wood. (Hg.), History and Identity in the Late Antique Near East, Oxford, 1-27.

Booth, P. (2013b), „The Muslim Conquest of Egypt Reconsidered“, in: C. Zuckerman (Hg.), Constructing the Seventh Century, Travaux et Mémoires 17, Paris, 639-669.

Booth, P. (2014), Crisis of Empire. Doctrine and Dissent at the End of Late Antiquity, Berkeley, CA. Booth, P. (2016), „The Last Years of Cyrus, Patriarch of Alexandria“, in: J.-L. Fournet, / A. Papaconstantinou (Hgg.), Mélanges Jean Gascou, Textes et études papyrologiques, Paris, $509-558$.

Booth, P. (2019), „The Ghost of Maurice at the Court of Heraclius“, Byzantinische Zeitschrift 112.3, 781-826.

Borgehammar, S. (1991), How the Holy Cross was Found. From Event to Medieval Legend, Stockholm.

Borgehammar, S. (2009), „Heraclius Learns Humility: Two Early Latin Accounts Composed for the Celebration of 'Exaltatio Crucis'“, Millennium-Jahrbuch 6, 145-202.

Börm, H. (2010), „Herrscher und Eliten in der Spätantike“, in: H. Börm (Hg.), Commutatio et Contentio. Studies in the Late Roman, Sasanian and Early Islamic Near East. In memory of Zeev Rubin, Düsseldorf, 159-198.

Börm, H. (2013), „Justinians Triumph und Belisars Erniedrigung. Überlegungen zum Verhältnis zwischen Kaiser und Militär im späten Römischen Reich“, Chiron 43, 63-91.

Börm, H. (2015a), „Born to be Emperor. The Principle of Succession and the Roman Monarchy“, in: J. Wienand (Hg.), Contested Monarchy: Integrating the Roman Empire in the 4th Century AD, Oxford, 239-264.

Börm, H. (2015b), „Procopius, His Predecessors, and the Genesis of the Anecdota. Antimonarchic Discourse in Late Antique Historiography“, in: H. Börm (Hg.), Antimonarchic Discourse in Antiquity, Stuttgart, 305-346.

Börm, H. (2016), „A Threat or a Blessing? The Sasanians and the Roman Empire“, in: ders. / C. Binder / A. Luther (Hgg.), Diwan. Studies in the History and Culture of the Ancient Near East and the Eastern Mediterranean, Duisburg, 615-646.

Börm, H. (2018), Westrom von Honorius bis Justinian, 2. Aufl., Stuttgart.

Brandes, W. (1989), Die Städte Kleinasiens im 7. und 8. Jahrhundert, Amsterdam.

Brandes, W. (1990), „Die apokalyptische Literatur“, in: ders. / F. Winkelmann (Hgg.), Quellen zur Geschichte des frühen Byzanz (4.-9. Jahrhundert), Berlin, 305-322.

Brandes, W. (1993), „Familienbande? Odoaker, Basiliskos und Harmatios“, Klio 75, 407-437.

Brandes, W. (1997), „Anastasios ,0 dikoros‘: Endzeiterwartung und Kaiserkritik in Byzanz um 500 n. Chr.“, Byzantinische Zeitschrift 90, 24-63.

Brandes, W. (2002a), „Heraclius between Restoration and Reform. Some Remarks on Recent Research“, in: G. J. Reinink / B. H. Stolte (Hgg.), The Reign of Heraclius (610-641). Crisis and Confrontation, Leuven, 17-40.

Brandes, W. (2002b), Finanzverwaltung in Krisenzeiten: Untersuchungen zur byzantinischen Administration im 6. -9. Jahrhundert, Frankfurt a. M.

Brandes, W. (2014), „Der Nika-Aufstand, Senatorenfamilien und Justinians Bauprogramm“, in: M. Meier / S. Patzold (Hgg.), Chlodwigs Welt. Organisation von Herrschaft um 500, Stuttgart, $239-268$.

Bredy, M. (1985), Das Annalenwerk des Eutychios von Alexandrian. Ausgewählte Geschichten und Legenden kompiliert von Sa'id ibn Batriq um 935 A.D., Leuven. 
Brodka, D. (2004), Die Geschichtsphilosophie in der spätantiken Historiographie: Studien zu Prokopios von Kaisareia, Agathias von Myrina und Theophylaktos Simokattes, Frankfurt a.M.

Brubaker, L. (2001), „Topography and the Creation of Public Space in Early Medieval

Constantinople“, in: M. de Jong (Hg.), Topographies of Power in the Early Middle Ages, Leiden u. a., 31- 43.

Budge, E. A. W. (1889), The History of Alexander the Great. Being the Syriac Version of the Pseudo-Callisthenes. Edited from Five Manuscripts with an English Translation and Notes, Cambridge.

Burgess, R. W. (1993/94), „The Accession of Marcian in the Light of Chalcedonian Apologetic and Monophysite Polemic“, Byzantinische Zeitschrift 86/87, 47-68.

Bury, J. B. (1930), The Constitution of the Later Roman Empire, Cambridge.

Cameron, Al. (1976), Circus Factions: Blues and Greens at Rome and Byzantium, Oxford.

Cameron, Av. (1967), „Notes on the Sophiae, the Sophianae, and the Harbour of Sophia“, Byzantion 37, $11-20$.

Cameron, Av. (1975), „The Empress Sophia“, Byzantion 45, 5- 21.

Cameron, Av. (1976a), Corippus. In laudem Iustini Augusti minoris libri IV, London.

Cameron, Av. (1976b), „An Emperor’s Abdication“, Byzantinoslavica 37, 161-167.

Cameron, Av. (1976c), „The Early Religious Policies of Justin II“, in: D. Baker (Hg.), The Orthodox Churches and the West, Oxford, 51-67.

Cameron, Av. (1977), „Early Byzantine Kaiserkritik: Two Case Histories“, Byzantine and Modern Greek Studies 3, 1-17.

Cameron, Av. (1978), „The Theotokos in Sixth-Century Constantinople: A City Finds Its Symbol“, The Journal of Theological Studies 29, 79-108.

Cameron, Av. (1979a), „The Virgin's Robe: An Episode in the History of Early Seventh-Century Constantinople“, Byzantion 49, 42-56.

Cameron, Av. (1979b), „Images of Authority: Elites and Icons in Late Sixth-Century Byzantium“, Past and Present 84, 3-35.

Cameron, Av. (1980), „The Artistic Patronage of Justin II“, Byzantion 50, 62-84.

Cameron, Av. (1981), Continuity and Change in Sixth-Century Byzantium, London.

Cameron, Av. (1994), „The Jews in Seventh-Century Palestine“, Scripta classica Israelica 13, 75-93.

Cameron, Av. (1996a), Procopius and the Sixth Century, London/New York.

Cameron, Av. (1996b), Changing Cultures in Early Byzantium, Aldershot.

Cameron, Av. (2002), „The 'Long' Late Antiquity: a Late Twentieth Century Model“, in: T. P. Wiseman (Hg.), Classics in Progress, Oxford, 165-192.

Cameron, Av. (2004), „Democratization Revisited - Culture and Late Antique and Early Byzantine Elites“, in: J. Haldon (Hg.), Elites Old and New in the Byzantine and Early Islamic Near East, Studies in Late Antiquity and Early Islam, Princeton, NJ, 91-107.

Cameron, Av. (2012), The Mediterranean World in Late Antiquity 395-700 AD, 2. Aufl., London u. a.

Cameron, Av. (2017), „Late Antique Apocalyptic: A Context for the Quran?“, in: H. Amirav /

E. Grypeou / G. G. Stroumsa (Hgg.), Apocalypticism and Eschatology in Late Antiquity, Leuven u. a., 1-20.

Canepa, M. P. (2009), The Two Eyes of the Earth: Art and Ritual of Kingship between Rome and Sasanian Iran, Berkeley, CA u. a.

Charles, R. H. (1916), The Chronicle of John, Bishop of Nikiu. Translated from Zotenberg's Ethiopic Text, London u.a.

Chrysos, E. K. (1978), „The Title Basileus in Early Byzantine International Relations“, Dumbarton Oaks Papers 32, 29-75.

Collins, R. (2007), Die Fredegar-Chroniken, Hannover.

Conybeare, F. C. (1910), „Antiochus Strategos' Account of the Sack of Jerusalem in A. D. 614“, The English Historical Review 25, 502-517. 
Corsi, P. (1975), „La spedizione in Italia di Costante II: fonti e problemi“, Nicolaus. Rivista di teologia ecumenico-patristica 3, 343-392.

Croke, B. (2003), „The Imperial Reigns of Leo II“, Byzantinische Zeitschrift 96, 559-576.

Croke, B. (2005a), „Dynasty and Ethnicity: Emperor Leo I and the Eclipse of Aspar“, Chiron 35, $147-204$.

Croke, B. (2005b), „Leo I and the Palace Guard“, Byzantion 75, 117-151.

Croke, B. (2007), „Justinian under Justin: Reconfiguring a Reign“, Byzantinische Zeitschrift 100, $13-56$.

Croke, B. (2008), „Poetry and Propaganda: Anastasius I as Pompey“, Greek, Roman and Byzantine Studies 48, 447- 466.

Crow, J. G. (2006), „Der Anastasische Wall: ,Die letzte Grenze““, in: G. Klose (Hg.), Grenzen des Römischen Imperiums, Mainz, 181-187.

Dagron, G. (1974), Naissance d'une capitale. Constantinople et ses institutions de 330 à 451, Paris.

Dagron, G. (2003), Emperor and Priest. The Imperial Office in Byzantium, Cambridge.

Dagron, G. / Déroche, V. (2010), Juifs et chrétiens en Orient byzantin, Paris.

Dawes, E. H. S. / Baynes, N. H. (1948), Three Byzantine Saints: Contemporary Biographies of St. Daniel the Stylite, St. Theodore of Sykeon, and St. John the Almsgiver, Crestwood, N.Y.

Delehaye, H. (1902), Synaxarium Ecclesiae Constantinopolitanae, Brüssel.

Demandt, A. (1970), „Magister militum“, in: Paulys Realencyclopädie, Suppl. 12, Sp. 553-790.

Demandt, A. (1980), „Der Spätrömische Militäradel“, Chiron 10, 609-636.

Demandt, A. (2007), Handbuch der Altertumswissenschaft: Die Spätantike, 2. Aufl., München.

De Vleeschouwer, A. (2019), „The Foreign Policy of Phocas (602-610): A Neorealist Reassessment“, Byzantion 89, $415-462$.

Diefenbach, S. (1996), „Frömmigkeit und Kaiserakzeptanz im frühen Byzanz“, Saeculum 47, 35-66.

Diefenbach, S. (2002), „Zwischen Liturgie und civilitas. Konstantinopel im 5. Jahrhundert und die Etablierung eines städtischen Kaisertums“, in: R. Warland (Hg.), Bildlichkeit und Bildorte von Liturgie. Schauplätze in Spätantike, Byzanz und Mittelalter, Wiesbaden, 21-49.

Diefenbach, S. (2012), „Constantius II. und die ,Reichskirche‘: Ein Beitrag zum Verhältnis von kaiserlicher Kirchenpolitik und politischer Integration im 4. Jh.“, Millennium Jahrbuch 9 , 59-121.

Diefenbach, S. (2019), „Zur Dynamik kaiserlicher Siegesrituale in der Spätantike. Konstantinopel und Rom im Vergleich“, in: R. Conrad / V. H. Drecoll / S. Hirbodian (Hgg.), Säkulare Prozessionen. Zur religiösen Grundierung von Umzügen, Einzügen und Aufmärschen, Tübingen, 63-110.

Dölger, F. (1976), Regesten der Kaiserurkunden des Oströmischen Reiches von 565-1453. Drei Teile in einem Band, Hildesheim.

Donner, F. M. (1981), The Early Islamic Conquests, Princeton, NJ.

Dowsett, C. J. F. (1961), Movses Dasxuranci. The History of the Caucasian Albanians, London.

Drijvers, J. W. (1992), Helena Augusta: the Mother of Constantine the Great and the Legend of her Finding of the True Cross, Leiden u. a.

Drijvers, J. W. (2002), „Heraclius and the Restitutio Crucis. Notes on Symbolism and Ideology“, in: G. J. Reinink / B. Stolte (Hg.), The Reign of Heraclius (610-641). Crisis and Confrontation, Leuven, 175-190.

Efthymiadis, S. (2010), „A Historian and His Tragic Hero: A Literary Reading of Theophylact Simokatta's Ecumenical History“, in: R. Macrides (Hg.), History as Literature in Byzantium, Farnham, 169-186.

Ekonomou, A. J. (2007), Byzantine Rome and the Greek Popes: Eastern Influences on Rome and the Papacy from Gregory the Great to Zacharias, A.D. 590-752, Lanham, Md. u. a.

Elm, E. (2012), „Memoriae damnatio“, Reallexikon für Antike und Christentum 24, Sp. 657-682. 
Ensslin, W. (1943/49), „Zur Frage der ersten Kaiserkönungen in Byzanz durch den Patriarchen und zur Bedeutung dieses Aktes im Zeremoniell“, Byzantinische Zeitschrift 42, 101-115, 369-372.

Ericsson, K. (1968), „Revising a Date in the Chronicon Paschale“, Jahrbuch der österreichischen byzantinischen Gesellschaft 17, 17-28.

Errington, R. M. (1983), „Malchos von Philadelphia, Kaiser Zenon und die zwei Theoderiche“, Museum Helveticum 40, 82-110.

Esders, S. (2009), „Herakleios, Dagobert und die ,beschnittenen Völker““, in: A. Goltz / H. Leppin / H. Schlange-Schöningen (Hgg.), Jenseits der Grenzen. Beiträge zur spätantiken und frühmittelalterlichen Geschichtsschreibung, Berlin/Boston, 239-312.

Esders, S. (2018), „The Prophesied Rule of a 'Circumcised People': A Travelling Tradition from the Seventh-Century Mediterranean“, in: Y. Hen / T. F. X. Noble (Hgg.), Barbarians and Jews. Jews and Judaism in the Early Medieval West, Turnhout, 119-154.

Evetts, B. (1907-1910), History of the Patriarchs of the Coptic Church of Alexandria, Paris.

Faber, E. (2011), „Anti-Germanism in Constantinople or the Revolt of Gainas?“, in: D. Hernández de la Fuente (Hg.), New Perspectives on Late Antiquity, Newcastle upon Tyne, 124-135.

Ferrière, J. de la (1999), Sophrone de Jérusalem. Fêtes chrétiennes à Jérsualem, Paris.

Festugière, A. J. (1970), Vie de Théodore de Sykéon, Brüssel.

Festugière, A. J. (1974), Vie de Symeon le Fou et Jean de Cypre, Paris.

Fischer-Lichte, E. (2003), „Performance, Inszenirung, Ritual: zur Klärung kulturwissenschaftlicher Schlüsselbegriffe“, in: J. Martschukat, / S. Patzold (Hgg.), Geschichtswissenschaft und „performative turn“. Ritual, Inszenierung und Performanz vom Mittelalter bis zur Neuzeit, Köln u. a., 33-54.

Flaig, E. (1992), Den Kaiser herausfordern: Die Usurpation im Römischen Reich, Frankfurt a. M.

Flaig, E. (1997), „Für eine Konzeptionalisierung der Usurpation im Spätrömischen Reich“, in: F. Paschoud / J. Szidat (Hgg.), Usurpationen in der Spätantike, Stuttgart, 15-34.

Flaig, E. (2007), „,Heiliger Krieg‘. Auf der Suche nach einer Typologie“, Historische Zeitschrift 285, $265-302$.

Flusin, B. (1992), Saint Anastase le Perse et l'histoire de la Palestine au début du VIle siècle, 2 Bde., Paris.

Fowden, G. (1993), Empire to Commonwealth: Consequences of Monotheism in Late Antiquity, Princeton, NJ.

Fowden, G. (2014), Before and after Muhammad: The First Millennium Refocused, Princeton, NJ.

Frank, R. (1969), Scholae palatinae: The Palace Guards of the Later Roman Empire, Rom.

Frend, W. H. C. (1972), The Rise of the Monophysite Movement: Chapters in the History of the Church in the Fifth and Sixth Centuries, Cambridge.

Frendo, J. D. C. (1984) „The Poetic Achievement of George of Pisidia: A Literary and Historical Study“, in: A. Moffatt (Hg.), Studies Robert Browning, Canberra, 159-187.

Frendo, J. D. C. (1988a), „History and Panegyric in the Age of Heraclius: the Literary Background to the Composition of the Histories of Theophylact Simocatta“, Dumbarton Oaks Papers 42, $143-156$.

Frendo, J. D. C. (1988b), „Religion and Politics in Byzantium on the Eve of the Arab Conquest“, Florilegium 10, 1-23.

Frendo, J. D. C. (2001), „Three Authors in Search of a Reader: An Approach to the Analysis of Direct Discourse in Procopius, Agathias and Theophylact Simocatta“, in: C. Sode / S. Takács (Hgg.), Novum Millennium: Studies on Byzantine History and Culture Dedicated to Paul Speck, Aldershot, 123-136.

Frolow, A. (1944), „La dédicace de Constantinople dans la tradition byzantine“, Revue de l'histoire des religions 127, 61-127.

Frolow, A. (1953), „La Vraie Croix et les expéditions d’Héraclius en Perse“, Revue des études byzantines 11, 89-105. 
Gallico, A. (1991), Sofronio di Gerusalemme. Le omelie, Rom.

Garland, L. (1999), Byzantine Empresses: Women and Power in Byzantium, AD 527-1204, London. Gehrke, H.-J. (1982), „Der siegreiche König. Überlegungen zur hellenistischen Monarchie“, Archiv für Kulturgeschichte 64, 247-277.

Gigante, M. (1957), Sophronii Anacreontica, Roma.

Girardet, C. M. (1980), „Das christliche Priestertum Konstantins d. Gr. Ein Aspekt der Herrscheridee des Eusebius von Caesarea“, Chiron 10, 569-592.

Gluschanin, E. P. (1991), Der Militäradel des frühen Byzanz, Barnaul.

Gräbner, M. (1982), „Maurikie Markianista“, Byzantina 11, 181-188.

Greatrex, G. (1997), „The Nika Riot: A Reappraisal“, The Journal of Hellenic Studies 117, 60-86.

Greatrex, G. / Lieu, S. N. C. (2002), The Roman Eastern Frontier and the Persian Wars. A Narrative Sourcebook, Bd. 2: AD 363-630, London.

Greisiger, L. (2013), „The Last Roman-Persian War of 602-28: Near Eastern and Constantinopolitan Fears and Hopes“, in: R. Alciati / F. Fatti (Hgg.), La controversia origenista: un affare mediterraneo. L'esperienza religiosa della crisi nel mondo mediterraneo, IV-VII sec., Brescia, $359-370$.

Greisiger, L. (2014), Messias - Endkaiser - Antichrist: politische Apokalyptik unter Juden und Christen des Nahen Ostens am Vorabend der arabischen Eroberung, Wiesbaden.

Greisiger, L. (im Druck), „From 'King Heraclius, faithful in Christ' to ‘Allenby of Armageddon': Christian Reconquistadores Enter the Holy City“, in: K. Klein / J. Wienand (Hgg.), City of Caesar, City of God: Constantinople and Jerusalem in Late Antiquity.

Grierson, P. (1950a), „Dated Solidi of Maurice, Phocas, and Heraclius“, in: The Numismatic Chronicle 10, 49-70.

Grierson, P. (1950b), „The Consular Coinage of Heraclius and the Revolt against Phocas of 608-610“, The Numismatic Chronicle 10, 71-93.

Grierson, P. (1959), „Solidi of Phocas and Heraclius: The Chronological Framework“, The Numismatic Chronicle 19, 131-154.

Grumel, V. (1966), „La Reposition de la vraie Croix à Jérusalem par Héraclius. Le Jour et l’Année“, Byzantinische Forschungen 1, 139-149.

Guran, P. (2009), „The Constantinople - New Jerusalem at the Crossing of Sacred Space and Political Theology“, in: A. M. Lidov (Hgg.), The Constantinople - New Jerusalem at the Crossing of Sacred Space and Political Theology, Moskau, 35-57.

Haldon, J. F. (1984), Byzantine Praetorians: An Administrative, Institutional and Social Survey of the Opsikion and Tagmata, c. 580-900, Bonn.

Haldon, J. F. (1990), Byzantium in the Seventh Century: The Transformation of a Culture, Cambridge / New York.

Haldon, J. F. (1994), „Constantine or Justinian? Crisis and Identity in Imperial Propaganda in the Seventh Century“, in: P. Magdalino (Hg.), New Constantines. The Rhythm of Imperial Renewal in Byzantium, $4^{\text {th }}-13^{\text {th }}$ Centuries, Aldershot, 95-107.

Haldon, J. F. (2002), „The Reign of Heraclius. A Context for Change?“, in: G. J. Reinink / B. Stolte (Hgg.), The Reign of Heraclius (610-641). Crisis and Confrontation, Leuven, 1-16.

Haldon, J. F. (2004), „The Fate of the Late Roman Senatorial Elite: Extinction or Transformation“, in: ders. / L. I. Conrad (Hgg.), Elites Old and New in the Byzantine and Early Islamic Near East, Princeton, NJ.

Haldon, J. F. (2016), The Empire that Would not Die. Eastern Roman Survival, 640-740, Cambridge, Mass. u.a.

Halsall, G. (2002), Humour, History and Politics in Late Antiquity and the Early Middle Ages, Cambridge.

Hammond, N. G. L. (1996), „The Construction of Xerxes’ Bridge over the Hellespont“, The Journal of Hellenic Studies 116, 88-107. 
Havener, W. (2016), Imperator Augustus. Die diskursive Konstituierung der militärischen „persona“ des ersten römischen „princeps“, Stuttgart.

Hebblewhite, M. (2017), The Emperor and the Army in the Later Roman Empire, AD 235-395, London.

Hendy, M. F. (1985), Studies in the Byzantine Monetary Economy c. 300-1450, Cambridge u.a. Henning, D. (1999), Periclitans res publica: Kaisertum und Eliten in der Krise des weströmischen Reiches 454/5-493 n. Chr., Stuttgart.

Herrin, J. (1987), The Formation of Christendom, Princeton, NJ.

Höfert, A. (2015), Kaisertum und Kalifat: der imperiale Monotheismus im Früh- und Hochmittelalter, Frankfurt a.M. u.a.

Hölkeskamp, K.-J. (2015), „,Performative turn“ meets ,spatial turn‘. Prozessionen und andere Rituale in der neueren Forschung“, in: D. Boschung, K.-J. Hölkeskamp, C. Sode (Hgg.), Raum und Performanz. Rituale in Residenzen von der Antike bis 1815, Stuttgart, 15-74.

Hovorun, C. (2008), Will, Action, and Freedom: Christological Controversies in the Seventh Century, Leiden.

Howard-Johnston, J. (1992), „The Official History of Heraclius’ Persian Campaigns“, in: E. Dąbrowa (Hg.), The Roman and Byzantine Army in the East, Krakau, 57-87.

Howard-Johnston, J. (1999), „Heraclius' Persian Campaigns and the Revival of the Eastern Roman Empire, 622-630“, War in History 6/1, 1-44.

Howard-Johnston, J. (2010), Witnesses to a World Crisis: Historians and Histories of the Middle East in the Seventh Century, Oxford.

Howard-Johnston, J. (2002), „Armenian Historians of Heraclius. An Examination of the Aims, Sources and Working-Methods of Sebeos and Movses Daskhurantsi“, in: G. J. Reinink / B. Stolte (Hgg.), The Reign of Heraclius (610-641). Crisis and Confrontation, Leuven, 41-62. Howard-Johnston, J. (2006), East Rome, Sasanian Persia and the End of Antiquity: Historiographical and Historical Studies, Ashgate.

Howard-Johnston, J. (im Druck), „Jerusalem in 630“, in: K. Klein / J. Wienand (Hgg.), City of Caesar, City of God: Constantinople and Jerusalem in Late Antiquity.

Hoyland, R. (1997), Seeing Islam as Others Saw it: A Survey and Evaluation of Christian, Jewish, and Zoroastrian Writings on Early Islam, Princeton, NJ.

Hoyland, R. (2011), Theophilus of Edessa's Chronicle and the Circulation of Historical Knowledge in Late Antiquity and Early Islam, Liverpool.

Hübner, A. (2007), Evagrius Scholasticus, Historia ecclesiastica, Turnhout.

Hunger, H. (1978), Die hochsprachliche profane Literatur der Byzantiner, Bd. 1: Philosophie, Rhetorik, Epistolographie, Geschichtsschreibung, Geographie, München.

Hurbanic, M. (2011), „The Eastern Roman Empire and the Avar Khaganate in the Years 622-624

AD“, Acta antiqua Academiae Scientiarum Hungaricae 51, 315-328.

Hurbanic, M. (2016), „Adversus ludaeos in the Sermon Written by Theodore Syncellus on the Avar Siege of AD 626“, Studia Ceranea 6, 271-293.

Hurbanic, M. (2019), The Avar Siege of Constantinople in 626. History and Legend, Cham. Huttner, U. (2004), Recusatio Imperii: ein politisches Ritual zwischen Ethik und Taktik, Hildesheim. Janin, R. (1969), Le géographie ecclésiastique de l'empire Byzantin, Bd. 1: Le siège de Constantinople et le patriarcat Oecuménique, Bd. 3: Les églises et les monastère, Paris. Jankowiak, F. (2013), „The First Arab Siege of Constantinople“, in: C. Zuckermann (Hgg.), Constructing the Seventh Century, Travaux et Mémoirs 17, Paris, 237-322.

Jones A. H. M. (1956), „Numismatics and History“, in: R. A. G. Carson / C. H. V. Sutherland (Hgg.), Essays in Roman Coinage Presented to Harold Mattingly, Oxford, 13-33.

Jones A. H. M. (1964), The Later Roman Empire 284-602, 2 Bde., Oxford.

Kaegi, W. E. (1968), Byzantium and the Decline of Rome, Princeton, NJ. 
Kaegi, W. E. (1973), „New Evidence for the Early Reign of Heraclius“, Byzantinische Zeitschrift 66, $308-330$.

Kaegi, W. E. (1981), Byzantine Military Unrest, 471-843: An Interpretation, Amsterdam.

Kaegi, W. E. (1992), Byzantium and the Early Islamic Conquests, Cambridge.

Kaegi, W. E. (2000), „A Misunderstood Place-Name in a Poem of George of Pisidia“, Byzantinische Forschungen 26, $229 \mathrm{f}$.

Kaegi, W. E. (2003), Heraclius, Emperor of Byzantium, Cambridge/New York.

Kalavrezou, I. (2003), Byzantine Women and Their World, Cambridge, Mass.

Kaldellis, A. (2004), Procopius of Caesarea. Tyranny, History, and Philosophy at the End of Antiquity, Philadelphia, PA.

Kaldellis, A. (2019), Romanland. Ethnicity and Empire in Byzantium, Cambridge, MA u. a.

Karayannopulos, J. E. (1959), Die Entstehung der byzantinischen Themenordnung, München.

Kelly, C. (2004), Ruling the Later Roman Empire, Cambridge, Mass. u. a.

Kelly, C. (2013), „Stooping to Conquer: The Power of Imperial Humility“, in: C. Kelly (Hg.), Theodosius II: Rethinking the Roman Empire in Late Antiquity, Cambridge, 221-243.

Kiel-Freytag, A. (2010), „Betrachtungen zur Usurpation des Illus und des Leontius (484-488 n. Chr.)“, Zeitschrift für Papyrologie und Epigraphik 174, 291-301.

Kirch, C. (1901), „Nicephori sceuophylacis encomium in S. Theodorum Siceotam“, Analecta Bollandiana 20, 249-272.

Klein, H. A. (2001), „Niketas und das wahre Kreuz“, Byzantinische Zeitschrift 94, 580-587.

Klein, H. A. (2004), Byzanz, der Westen und das „wahre“ Kreuz: die Geschichte einer Reliquie und ihrer künstlerischen Fassung in Byzanz und im Abendland, Wiesbaden.

Klein, H. A. (2006), „Sacred Relics and Imperial Ceremonies at the Great Palace of Constantinople“, in: F. A. Bauer (Hg.), Visualisierungen von Herrschaft. Frühmittelalterliche Residenzen, Gestalt und Zeremoniell, Istanbul, 79-100.

Koder, J. (1999), „Romanos Melodos und sein Publikum. Zur Einbeziehung und Beeinflussung der Zuhörer durch das Kontakion“, Österreichische Akademie der Wissenschaften. Anzeiger phil.-hist. Klasse 134, 63-94.

Koder, J. (2005), Romanos Melodos. Die Hymnen, 2 Bde., Stuttgart 2005.

Koehn, C. (2018), Justinian und die Armee des frühen Byzanz, Berlin u. a.

Kolb, F. (2001), Herrscherideologie in der Spätantike, 2001.

Kolbaba, T. M., (1998), „Fighting for Christianity. Holy War in the Byzantine Empire“, Byzantion 68, $194-221$.

Kolditz, S. (2013), „Ein umstrittener Kaiser und patriarchale Kirchen im späteren fünften Jahrhundert: Weltliche und geistliche Macht unter Basiliskos“, in: M. Grünbart / L. Rickelt (Hg.), Zwei Sonnen am Goldenen Horn?, Bd. 2, Berlin u.a., 19-54.

Konidaris, I. M. (1982), „Die Novellen des Kaisers Herakleios“, Fontes Minores 5, Forschungen zur byzantinischen Rechtsgeschichte 8, 33-106.

Köpstein, H. (1978), „Das 7. Jahrhundert (565-711) im Prozess der Herausbildung des Feu- dalismus in Byzanz", in: dies. / F. Winkelmann / H. Ditten / I. Rochow (Hgg.), Byzanz im 7. Jahrhundert. Untersuchungen zur Herausbildung des Feudalismus, Berlin, 289-301.

Koschorke, A. (2012), Wahrheit und Erfindung: Grundzüge einer allgemeinen Erzähltheorie, 2. Aufl., Frankfurt.

Koselleck, R. (1973), „Ereignis und Struktur“, in: ders. / W.-D. Stempel (Hgg.), Geschichte - Ereignis und Erzählung, München, 581-599.

Kosinski, R. (2010), The Emperor Zeno: Religion and Politics, Krakau.

Kosinski, R. (2016), Holiness and Power: Constantinopolitan Holy Men and Authority in the $5^{\text {th }}$ Century, Berlin u.a.

Krause, J.-U. (2013), „Die Spätantike (284-565 n. Chr.)“, in: H.-J. Gehrke / H. Schneider (Hgg.), Geschichte der Antike. Ein Studienbuch, 4. Aufl., Stuttgart/Weimar, 429-499. 
Kresten, O. (2000), „Herakleios und der Titel basileus“, Varia 7, $178 \mathrm{f}$.

Kuhoff, W. (2012), „Die Versuchung der Macht. Spätrömische Heermeister und ihr potentieller Griff nach dem Kaisertum“, in: S. S. Tschopp / W. E. J. Weber (Hgg.), Macht und Kommunikation, Berlin, 39-80.

Külzer, A. (2000), „Konstantinopel in der apokalyptischen Literatur der Byzantiner“, Jahrbuch der österreichischen Byzantinistik 50, 51-76.

Lange, C. (2012), Mia Energeia: Untersuchungen zur Einigungspolitik des Kaisers Heraclius und des Patriarchen Sergius von Constantinopel, Tübingen.

Larison, D. (2019), „George of Pisdia and Contra Severum: Panegyric and Polemic as Source for Interpreting Religious Policy“, in: Ch. Raffensperger / D. M. Olster (Hgg.), Radical Traditionalism. The Influence of Walter Kaegi in Late Antique, Byzantine, and Medieval Studies, London, 163-180.

Lauxtermann, M. D. (2003), Byzantine Poetry from Pisides to Geometres: Texts and Contexts, Bd. 1, Wien.

Lauxtermann, M. D. (2019), Byzantine Poetry from Pisides to Geometres: Texts and Contexts, Bd. 2, Wien.

Leader, R. E. (2000), „The David Plates Revisited: Transforming the Secular in Early Byzantium“, The Art Bulletin 82, 407-427.

Lee, A. D. (2007), War in Late Antiquity: A Social History, Oxford.

Lee, A. D. (2015), „Emperors and Generals in the Fourth Century“, in: J. Wienand (Hg.), Contested Monarchy: Integrating the Roman Empire in the $4^{\text {th }}$ Century AD, Oxford, 100-118.

Lemerle, P. (1979/81), Les plus anciens recueils des miracles de Saint Démétrius et la pénétration des Slaves dans les Balkans, 2 Bde., Paris.

Lenski, N. (1997), „Initium mali Romano imperio. Contemporary Reactions to the Battle of Adrianople“, Transactions of the American Philological Association 127, 129-168

Leppin, H. (2003), Theodosius der Große, Darmstadt.

Leppin, H. (2007), „Das Alte Testament und der Erfahrungsraum der Christen. Davids Buße in den Apologien des Ambrosius“, in: A. Peçar / K. Trampedach (Hgg.), Die Bibel als politisches Argument. Voraussetzungen und Folgen, München, 119-134.

Leppin, H. (2011), Justinian: Das christliche Experiment, Stuttgart.

Leppin, H. (2013), „Kaisertum und Christentum in der Spätantike: Überlegungen zu einer unwahrscheinlichen Sythese“, in: A. Fahrmeir / A. Irmhausen (Hgg.), Die Vielfalt normativer Ordnungen. Konflikte und Dynamik in historischer und ethnologischer Perspektive, Frankfurt a. M., 197-223.

Leppin, H. (2015), „Coping with the Tyrant’s Faction“, in: J. Wienand (Hg.), Contested Monarchy. Integrating the Roman Empire in the Fourth Century AD, Oxford, 198-214.

Leppin, H. (2017), „Das 4. Jahrhundert - Die christlichen Kaiser suchen ihren Ort“, in: S. Rebenich (Hg.), Monarchische Herrschaft im Altertum, Berlin/Boston, 485-508.

Leppin, H. (2020), „George Pisides' Expeditio Persica and Discourses on Warfare in Late Antiquity“, in: A. Lefteratou / F. Hadjittofi (Hgg.), The Genres of Late Antique Christian Poetry: Between Modulations and Transpositions, Berlin/Boston, 293-310.

Lilie, R.-J. (1976), Die byzantinische Reaktion auf die Ausbreitung der Araber: Studien zur Strukturwandlung des byzantinischen Staates im 7. und 8. Jhd., München.

Lilie, R.-J. (1989), „Die Krönungsprotokolle des Zeremonienbuches und die Krönung Kaiser Leons I.“, in: Ch.-F. Collatz (Hg.), Dissertatiunculae criticae. Festschrift für Günther Christian Hansen, Würzburg, 395-408.

Ludwig, C. (1991), „Kaiser Herakleios, Georgios Pisides und die Perserkreige“, Poikilia Byzantina 11, Varia 3, Bonn, 73-128. 
Ludwig, C. (2003), „David - Christus - Basileus. Erwartungen an eine Herrschergestalt“, in: W. Dietrich / H. Herkommer (Hgg.), König David - biblische Schlüsselfigur und europäische Leitgestalt, Fribourg, 367-382.

MacCormack, S. (1972), „Change and Continuity in Late Antiquity: The Ceremony of Adventus“, Historia 21/4, 721-752.

MacCormack, S. (1981), Art and Ceremony in Late Antiquity, Berkeley u. a.

MacCoull, L. S. B. (1998), „George of Pisidia, Against Severus: in Praise of Heraclius“, in: R. Dahood (Hg.), The Future of the Middle Ages and the Renaissance, Turnhout, 69-79.

Macrides, R. / Magdalino, P. (1988), „The Architecture of Ekphrasis: Construction and Context of Paul the Silentiary's Poem on Hagia Sophia“, Byzantine and Modern Greek Studies 12, 47-82.

Magdalino, P. (1994), New Constantines. The Rhythm of Imperial Renewal in Byzantium, $4^{\text {th }}-13^{\text {th }}$ Centuries, Aldershot.

Magdalino, P. (2007), „The History of the Future and its Uses: Prophecy, Policy, and Propaganda“, in: J. Shepard (Hg.), The Expansion of Orthodox Europe. Byzantium, the Balkans and Russia, Aldershot, 29-64,

Magdalino, P. / Nelson, R. S. (2010), The Old Testament in Byzantium, Washington DC.

Maier, F. K. (2019), Palastrevolution. Der Weg zum hauptstädtischen Kaisertum im Römischen Reich des vierten Jahrhunderts, Paderborn.

Makk, F. (1975), Traduction et commentaire de l'homélie écrite probablement par Théodore le Syncelle sur le siège de Constantinople en 626, Szeged.

Malone, Ch. (2009), „Violence on Roman Imperial Coinage“, in: Journal of the Numismatic Association of Australia 20, 58-72.

Mango, C. (1980), Byzantium: The Empire of New Rome, London.

Mango, C. (1984), „A Byzantine Hagiographer at Work: Leontios of Neapolis“, in: I. Hutter (Hg.), Byzanz und der Westen - Studien zur Kunst des europäischen Mittelalters, Wien, 25-41.

Mango, C. (1985), „Deux études sur Byzance et la Perse sassanide“, Travaux et Mémoires du Centre de recherche d'Histoire et Civilisation de Byzance 9, 105-118.

Mango, C. (1990), Nikephoros Patriarch of Constantinople. Short History, Washington DC.

Mango, C. (1992), „The Temple Mount AD 614-638“, in: J. Raby / J. Johns (Hgg.), Bayt Al-Maqdis: Jerusalem and Early Islam, Oxford, 1-16.

Mango, C. (1998), „The Origins of the Blachernae Shrine at Constantinople“, in: Acta XIII Congressus Internationalis Archaeologiae Christianae II, Studi di antichità cristiana 54, Vatican/Split, 61-76.

Mango, C. (2000), „Constantinople as Theotokoupolis“, in: M. Vassilaki (Hg.), The Mother of God: Representations of the Virgin in Byzantine Art, Mailand, 17-25.

Mango, C. / Scott, R. (1997), The Chronicle of Theophanes Confessor: Byzantine and Near Eastern History $A D$ 284-813, Oxford.

Maranci, C. (2008/2009), „The Humble Heraclius. Revisiting the North Portal at Mren“, in: Revue des études arméniennes 31, 167-180.

Mariev, S. (2008), Ioannis Antiocheni fragment aquae supersunt omnia, Berlin/Boston 2008.

Martin, J. (1984), „Zum Selbstverständnis, zur Repräsentation und Macht des Kaisers in der Spätantike“, Saeculum 35, 115-131.

Martin, J. (1997), „Das Kaisertum in der Spätantike“, in: F. Paschoud / J. Szidat (Hgg.), Usurpationen in der Spätantike, Stuttgart, 47-62.

Martschukat, J. / Patzold, S. (2003), Geschichtswissenschaft und „performative turn“. Ritual, Inszenierung und Performanz vom Mittelalter bis zur Neuzeit, Köln u. a.

Mateos, J. (1962), Le Typicon de la grande église, Bd. 1, Rom.

McCormick, M. (1986), Eternal Victory: Triumphal Rulership in Late Antiquity, Byzantium, and the Early Medieval West, Cambridge.

McEvoy, M. (2013), Child Emperor Rule in the Late Roman West, AD 367-455, Oxford. 
McKelvey, R. J. (1969), The New Temple. The Church in the New Testament, Oxford.

Meier, M. (1998), „Exarchat“, Der Neue Pauly 4, $331 \mathrm{f}$.

Meier, M. (2002), „Das Ende des Konsulats im Jahr 541/42 und seine Gründe. Kritische Anmerkungen zur Vorstellung eines ,Zeitalters Justinians'“, Zeitschrift für Papyrologie und Epigraphik 138, 277-299.

Meier, M. (2003a), Das andere Zeitalter Justinians. Kontingenzerfahrung und Kontingenzbewältigung im 6. Jahrhundert n. Chr., Göttingen.

Meier, M. (2003b), „Die Inszenierung einer Katastrophe: Justinian und der Nika-Aufstand“, Zeitschrift für Papyrologie und Epigraphik 142, 273-300.

Meier, M. (2003c), „Göttlicher Kaiser und christlicher Herrscher? Die christlichen Kaiser der Spätantike und ihre Stellung zu Gott“, Das Altertum 48, 129-160.

Meier, M. (2007a), „Staurotheis di’ hemas. Der Aufstand gegen Anastasios im Jahr 512“, Millennium-Jahrbuch 4, 157-238.

Meier, M. (2007b), „Die Demut des Kaisers. Aspekte der religiösen Selbstinszenierung bei Theodosius II. (408-450 n. Chr.)“, in: A. Peçar / K. Trampedach (Hrgg.), Die Bibel als politisches Argument. Voraussetzungen und Folgen, München, 135-158.

Meier, M. (2008), „Aristokratie(n) in Byzanz. Ein Überblick“, in: H. Beck (Hg.), Die Macht der Wenigen. Aristokratische Herrschaftspraxis, Kommunikation und ein „edler“ Lebensstil in Antike und früher Neuzeit, München, 277-300.

Meier, M. (2009a), „Der Christliche Kaiser zieht (nicht) in den Krieg: ,Religionskriege“ in der Spätantike?“, in: A. Holzem (Hg.), Krieg und Christentum. Religiöse Gewalttheorie in der Kriegserfahrung des Westens, Paderborn, 254-278.

Meier, M. (2009b), Anastasios I.: Die Entstehung des Byzantinischen Reiches, Stuttgart.

Meier, M. (2010), „Ariadne - Der ,Rote Faden“ des Kaisertums“, in: A. Kolb (Hg.), Augustae. Machtbewusste Frauen am römischen Kaiserhof?, Berlin, 277-292.

Meier, M. (2012), „Ostrom-Byzanz, Spätantike-Mittelalter. Überlegungen zum ,Ende‘ der Antike im Osten des Römischen Reiches“, Millennium 9, 187-254.

Meier, M. (2014a), „Flavios Hypatios: Der Mann, der Kaiser sein wollte“, in: S. Patzold / K. Ubl (Hgg.), Verwandtschaft, Name und soziale Ordnung (300-1000), Berlin, 73-96.

Meier, M. (2014b), „Kaiser Phokas (602-610) als Erinnerungsproblem“, Byzantinische Zeitschrift $107 / 1,139-174$.

Meier, M. (2015), „Herakles - Herakleios - Christus. Georgios Pisides und der kosmorhýstes“, in: H. Leppin (Hg.), Antike Mythologie in christlichen Kontexten der Spätantike, Berlin, 297-340.

Meier, M. (2016), „Liturgisierung und Hypersakralisierung. Zum Bedeutungsverlust kaiserlicher Frömmigkeit in Konstantinopel zwischen dem 6. und 7. Jahrhundert n. Chr.", in: N. Schmidt / A. Neuwirth / N. K. Schmid (Hgg.), Denkraum Spätantike. Reflexionen von Antiken im Umfeld des Koran, Wiesbaden, 75-106.

Meier, M. (2017), „Der Monarch auf der Suche nach seinem Platz. Kaiserherrschaft im frühen Byzanz (5. bis 7. Jahrhundendert n. Chr.)“, in: S. Rebenich (Hg.), Monarchische Herrschaft im Altertum, Berlin/Boston, 509-544.

Meier, M. (2019a), Geschiche der Völkerwanderung. Europa, Asien und Afrika vom 3. bis zum 8. Jahrhundert $n$. Chr., München.

Meier, M. (2019b), „Der ,Triumph Belisars‘ 534 n. Chr.“, in: R. Conrad / V. H. Drecoll / S. Hirbodian (Hgg.), Säkulare Prozessionen. Zur religiösen Grundierung von Umzügen, Einzügen und Aufmärschen, Tübingen, 43-61.

Meier, M. (2020), „The Roman Context of Early Islam“, Millennium-Jahrbuch 17.1, 265-302.

Menze, v. (2008), Justinian and the Making of the Syrian Orthodox Church, Oxford u.a.

Meyendorff, J. (1989), Imperial Unity and Christian Divisions: The Church 450-680 A.D., Crestwood, NY.

Mitterauer, M. (1991), „Christianity and Endogamy“, Continuity and Change 6/3, 295-333. 
Moffat, A. / Tall, M. (2012), Constantine Porphyrogennetos, the Book of Ceremonies. With the Greek edition of the Corpus Scriptorum Historiae Byzantinae (Bonn, 1892), 2 Bde., Canberra.

Moorhead, J. (1981), „The Monophysite Response to the Arab Invasions“, Byzantion 51, 579-591.

Morrisson, C. (2001), „Du consul a l'empereur: Les sceaux d'Heraclius“, in: C. Sode / S. Takács

(Hgg.), Novum Millennium: Studies on Byzantine History and Culture Dedicated to Paul Speck, Aldershot, 257-266.

Müller-Wiener, W. (1994), Die Häfen von Byzantion, Konstantinupolis, Istanbul, Tübingen.

Mundell-Mango, M. (1994), Imperial Art in the Seventh Century, Aldershot.

Nöldeke, Th. (1893), „Die von Guide herausgegebene syrische Chronik“, Sitzungsberichte der philosophisch-historischen Classe der kaiserlichen Akademie der Wissenschaften 128, 1- 48.

O’Flynn, J. M. (1983), Generalissimos of the Western Roman Empire, Edmonton, Alb.

Oikonomides, N. (1971), „Correspondence between Heraclius and Kavadh-Široe in the Paschale Chronicle (628)“, Byzantion 41, 269-281.

Oikonomides, N. (1975), „A Chronological Note on the First Persian Campaign of Heraclius (622)“, Byzantine and Modern Greek Studies 1, 1-9.

Olajos, T. (1981), „Contributions à une analyse de la genèse de l'Histoire Universelle de Théophylacte Simocatta“, Acta antiqua Academiae Scientiarum Hungaricae 29, 417-424.

Olster, D. M. (1982), „The Dynastic Iconography of Heraclius’ Early Coinage“, Jahrbuch der österreichischen Byzantinistik 32, 399-408.

Olster, D. M. (1985), „Chalcedonian and Monophysite: The Union of 616“, Bulletin de la Société d'Archeologie Copte 27, 93-108.

Olster, D. M. (1991), „The Date of George of Pisidia's 'Hexaemeron'“, Dumbarton Oaks Papers 45, $159-172$.

Olster, D. M. (1993), The Politics of Usurpation in the Seventh Century: Rhetoric and Revolution in Byzantium, Amsterdam.

Olster, D. M. (1994), Roman Defeat, Christian Response, and the Literary Construction of the Jew, Philadelphia.

Omissi, A. (2018), Emperors and Usurpers in the Later Roman Empire: Civil War, Panegyric, and the Construction of Legitimacy, Oxford.

O’Roark, D. A. (1996), „Close-kin Marriage in Late Antiquity: The Evidence of Chrysostom“, Greek, Roman and Byzantine Studies 37, 399-411.

Ortenberg West-Harling, V. (2016), „The Church of Ravenna, Constantinople and Rome in the Seventh Century“, in: J. Herrin / J. L. Nelson (Hgg.), Ravenna: Its Role in Earlier Medieval Change and Exchange, London, 199-210.

Ostrogorsky, G. (1963), Byzantinisches Handbuch, Bd. Teil 1, Bd. 2: Geschichte des byzantinischen Staates, 3. Aufl., München.

Ousterhout, R. (1990), „The Temple, the Sepulchre, and the Martyrion of the Savior“, Gesta 29/1, $44-53$.

Palmer, A. (1993), The Seventh Century in the West-Syrian Chronicles, Liverpool.

Parnell, D. A. (2012), „The Careers of Justinian's Generals“, The Journal of Medieval Military History 10, 1-16.

Parnell, D. A. (2017), Justinian's Men: Careers and Relationships of Byzantine Army Officers, 518-610, London.

Paul, N. L. (2012), To Follow in Their Footsteps: The Crusades and Family Memory in the High Middle Ages, Ithaka, NY u. a.

Payne, R. (2015), A State of Mixture. Christians, Zoroastrians, and Iranian Political Culture in Late Antiquity, Oakland.

Peltomaa, L. M. (2001), The Image of the Virgin Mary in the Akathistos Hymn, Leiden.

Peltomaa, L. M. (2009), „The Role of the Virgin Mary at the Siege of Constantinople in 626“, Scrinium. Journal of Patrology and Critical Hagiography 5/1, 284-299. 
Peltomaa, L. M. (2011), „Epithets of the Theotokos in the Akathistos Hymn“, in: L. Brubaker / M. B. Cunningham (Hgg.), The Cult of the Mother of God in Byzantium. Texts and Images, Farnham u. a., 109-116.

Penna, V. / Morrisson C. (2013), „Usurpers and Rebels in Byzantium: Image and Message Through Coins“, in: D. G. Angelov (Hg.), Power and Subversion in Byzantium, Farnham u. a., 21-42.

Pentcheva, B. V. (2002), „The Supernatural Protector of Constantinople: The Virgin and her Icons in the Tradition of the Avar Siege“, Byzantine and Modern Greek Studies 26, 2- 41.

Pentcheva, B. V. (2006), Icons and Power: The Mother of God in Byzantium, University Park, PA.

Pernice, A. (1905), L'Imperatore Eraclio, Florenz.

Pertusi, G. (1959), Georgius Pisida, Poemi, Bd. 1: Panegirici epici, Ettal.

Peters, F. E. (1983), „Who Built the Dome of the Rock?“, Graeco-Arabica 2, 119-138.

Petit, L. (1904), „Office inédit en l'honneur de Nicéphore Phocas“, Byzantinische Zeitschrift 13/2, $398-420$.

Pfeilschifter, R. (2012), „Die Unmöglichkeit des Machtverlusts. Kontinuität und Ohnmacht der spätantiken Hofeliten“, in: M. Meißner / K. Nebelin / M. Nebelin (Hgg.), Eliten nach dem Machtverlust? Fallstudien zur Transformation von Eliten in Krisenzeiten, Berlin, 133-146.

Pfeilschifter, R. (2013), Der Kaiser und Konstantinopel. Kommunikation und Konfliktaustrag in einer spätantiken Metropole, Berlin.

Pfeilschifter, R. (2014), „Drinnen und Draußen. Die Herrschaft des Kaisers über Konstantinopel und das Reich“, in: M. Meier (Hg.), Chlodwigs Welt. Organisation von Herrschaft um 500, Stuttgart, $111-142$.

Pfeilschifter, R. (2016), „Der Römische Triumph und das Christentum. Überlegungen zur Eigenart eines öffentlichen Rituals“, in: J. Wienand / F. Goldbeck (Hgg.), Der Römische Triumph in Prinzipat und Spätantike, Berlin/Boston, 1-32.

Podskalsky, G. (1972), Byzantinische Reichseschatologie: die Periodisierung der Weltgeschichte in den vier Grossreichen (Daniel 2 und 7) und dem Tausendjährigen Friedensreiche (Apok. 20); eine motivgeschichtliche Untersuchung, München.

Poguntke, A. (2014), „Handlungsspielräume (ost-)römischer Heermeister um 500“, in: M. Meier (Hg.), Chlodwigs Welt. Organisation von Herrschaft um 500, Stuttgart, 397-422.

Poguntke, A. (2016), „Das römische Heermeisteramt im 5. Jahrhundert. Überlegungen zum Verhältnis zwischen Kaiser und Heermeister in Ost und West“, in: C. Föller / F. Schulz (Hr.), Osten und Westen 400-600 n. Chr. Kommunikation, Kooperation und Konflikt, Stuttgart, $239-263$.

Pohl, W. (2002), Die Awaren: ein Steppenvolk in Mitteleuropa 567-822 n. Chr., 2. Aufl., München.

Prigent, V. (2010), „La Sicile de Constant II: l'apport des sources sigillographiques“, in: A. Nef /

V. Prigent (Hgg.), La Sicile de Byzance à l'Islam, 2010, 157-188.

Prinzig, G. (1988), „Beobachtungen zu ,integrierten“ Fürstenspiegeln der Byzantiner“, Jahrbuch der österreichischen Byzantinistik 38, 1-32.

Raby, J. / Johns, J. (1992), Bayt Al-Maqdis: Jerusalem and Early Islam, Oxford.

Rapp, C. (2004), „All in the Family: John the Almsgiver, Nicetas and Heraclius“, Nea Rhome 11, 21-134.

Rapp, C. (2010), „Old Testament Models for Emperors in Early Byzantium“, in: P. Magdalino /

R. Nelson (Hgg.), The Old Testament in Byzantium, Washington, DC, 175-197.

Raum, Th. (2019), „The Reinvention of the Soldier Emperor under Heraclius“, in: M. Kinloch /

A. MacFarlane (Hgg.), Trends and Turning Points. Constructing the Late Antique and Byzantine

World, Leiden/Boston 2019, 133-147.

Ravegnani, G. (2011), Gli esarchi d'Italia, Rom.

Reckwitz, A. (1997) Struktur. Zur sozialwissenschaftlichen Analyse von Regeln und Regelmäßigkeiten, Opladen. 
Redies, M. (1997), „Die Usurpation des Basiliskos (475-476) im Kontext der aufsteigenden monophysitischen Kirche“, Antiquité tardive 5, 211-221.

Reeves, J. C. (2006), Trajectories in Near Eastern Apocalyptic: A Postrabbinic Jewish Apocalypse Reader, Atlanta.

Regan, G. (2003), First Crusader: Byzantiums Holy Wars, New York u.a.

Reich, R. (1993), „The Cemetery in the Mamilla Area of Jerusalem“, Qadmoniot 26, 103-109.

Reinink, G. J. (1983), Das Syrische Alexanderlied, Leuven.

Reinink, G. J. (1985), „Die Entstehung der syrischen Alexanderlegende als politisch-religiöser Propagandaschrift für Herakleios' Kirchenpolitik“, in: C. Laga (Hg.), After Chalcedon. Studies in Theology and Church History Offered to Professor Albert van Roey, Leuven, 263-281.

Reinink, G. J. (1988), „Pseudo-Methodius und die Legende vom römischen Endkaiser“, in: W. Verbeke / D. Verhelst / A. Welkenhuysen (Hgg.), The Use and Abuse of Eschatology in the Middle Ages, Leuven, 82-111.

Reinink, G. J. (1993), Die Syrische Apokalypse des Pseudo-Methodius, Leuven.

Reinink, G. J. (2002), „Heraclius, the New Alexander. Apocalyptic Prophecies during the Reign of Heraclius“, in: ders. / B. Stolte (Hgg.), The Reign of Heraclius (610-641). Crisis and Confrontation, Leuven, 81-94.

Reinink, G. J. / Stolte, B. (2002), The Reign of Heraclius (610-641). Crisis and Confrontation, Leuven.

Roberto, U. (2005), Ioannis Antiocheni fragementa ex historia chronica, Berlin.

Roberto, U. (2010), „The Circus Factions and the Death of the Tyrant: John of Antioch on the Fate of the Emperor Phocas“, in: F. Daim / J. Drauschke (Hgg.), Byzanz - Das Römerreich im Mittelalter, Bd. 1: Welt der Ideen, Welt der Dinge, Mainz, 55-77.

Rösch, G. (1978), Onoma Basileias: Studien zum offiziellen Gebrauch der Kaisertitel in spätantiker und frühbyzantinischer Zeit, Wien.

Rösch, G. (1979), „Der Aufstand der Herakleioi gegen Phokas (608-610) im Spiegel numismatischer Quellen“, Jahrbuch der österreichischen Byzantinistik 2, 851-862.

Rubin, Z. (2004), „Nobility, Monarchy and Legitimation under the Later Sasanians“, in: J. F. Haldon / L. I. Conrad (Hgg.), The Byzantine and Early Islamic Near East, Princeton NJ., $235-274$.

Sarris, P. (2011), Empires of Faith. The Fall of Rome to the Rise of Islam, 500-700, Oxford.

Scher, A. (1908-1919), Histoire nestorienne inédite: Chronique de Séert, Paris.

Schilling, A. M. (2008), Die Anbetung der Magier und die Taufe der Sāsāniden: zur Geistesgeschichte des iranischen Christentums in der Spätantike, Leuven.

Schmitt, O. J. (1994), „Die Buccellarii. Eine Studie zum militärischen Gefolgschaftswesen in der Spätantike“, Tyche 9, 147-174.

Schneider, P. (1985), Theophylaktos Simokates, Geschichte, Stuttgart.

Schneider, P. (1989), „Eine chinesische Beschreibung Konstantinopels aus dem 7. Jahrhundert“, Istanbuler Mitteilungen 39, 493-505.

Schönborn, C. (1972), Sophrone de Jérusalem: vie monastique et confession dogmatique, Paris.

Schwarcz, D. (2003), „Marriage and Power Politics in the Fifth Century“, Medieval Prosopography $24,36-45$.

Scott, R. D. (1985), „Malalas, the Secret History, and Justinian’s Propaganda“, Dumbarton Oaks Papers 39, 99-109.

Scott, R. D. (2012), „Justinian's New Age and the Second Coming“, in: ders. (Hg.), Byzantine Chronicles and the Sixth Century, XVIII, 1-22.

Sguaitamatti, L. (2012), Der spätantike Konsulat, Fribourg.

Shahid, I. (1972), „The Iranian Factor in Byzantium during the Reign of Heraclius“, Dumbarton Oaks Papers 26, 293-320. 
Shahid, I. (1980/81), „Heraclius 'pistos en Christo basileus'“, Dumbarton Oaks Papers 34/35, $225-237$.

Shoemaker, S. J. (2008), „The Cult of Fashion: The Earliest 'Life of the Virgin' and Constantinople's Marian Relics“, Dumbarton Oaks Papers 62, 53-74.

Shoemaker, S. J. (2018), The Apocalypse of Empire: Imperial Eschatology in Late Antiquity and Early Islam, Philadelphia.

Siebigs, G. (2010), Kaiser Leo I.: Das oströmische Reich in den ersten drei Jahren seiner Regierung (457-460 n. Chr.), 2 Bde., Berlin u.a.

Simeonov, G. (2016), „Der Hafen und die Anlegestelle des Hebdomon“, in: F. Daim (Hg.), Die byzantinischen Häfen Konstantinopels, Mainz, 121-138.

Sirotenko, A. (2017), „Forgetting the Heretic: The Emperor Heraclius in the Byzantine Liturgical Tradition“, Jahrbuch der österreichischen Byzantinistik 67, 239-248.

Sirotenko, A. (2018), „Constructing Memory the Chronicle of Theophanes on the Reign of Heraclius“, in: Ch. Messis / M. Mullett / I. Nilsson (Hgg.), Storytelling in Byzantium. Narratological Approaches to Byzantine Texts and Images, Uppsala, 223-242.

Sivan, H. S. (2000), „From Byzantine to Persian Jerusalem: Jewish Perspectives and Jewish/Christian Polemics“, Greek, Roman and Byzantine Studies 41, 277-306.

Sivan, H. S. (2008), Palestine in Late Antiquity, Oxford u. a.

Sode, C. (2009), „Die Krönung des Kaisers Justin I. im Zeremonienbuch Konstantins VII. Porphyrogennetos“, Mediterraneo antico 12, 429-448.

Sommerlechner, A. (2003), „Kaiser Herakleios und die Rückkehr des Heiligen Kreuzes nach Jerusalem. Überlegungen zu Stoff- und Motivgeschichte“, in: Römische Historische Mitteilungen 45, 319-360.

Spain Alexander, S. (1977), „Heraclius, Byzantine Imperial Ideology, and the David Plates“, Speculum 52/2, 217-237.

Spanos A. Ph. / Zarras N. (2009), „Representations of Emperors as Saints in Byzantine Textual and Visual Sources“, in: M. Borgolte / B. Schneidmüller (Hgg.), Hybride Kulturen im mittelalterlichen Europa, Berlin, 63-78.

Speck, P. (1980), Zufälliges zum Bellum Avaricum des Georgios Pisides, München.

Speck, P. (1981), Artabasdos, der rechtgläubige Vorkämpfer der göttlichen Lehren: Untersuchungen zur Revolte des Artabasdos und ihrer Darstellung in der byzantinischen Historiographie, Bonn.

Speck, P. (1988), Das geteilte Dossier: Beobachtungen zu den Nachrichten über die Regierung des Kaisers Herakleios und der seiner Söhne bei Theophanes und Nikephoros, Bonn.

Speck, P. (1993), „Eine Gedächtnisfeier am Grabe des Maurikios. Die Historiae des Theophylaktos Simokates: der Auftrag; die Fertigstellung; der Grundgedanke“, Varia 4, Poikila byzantina 12, $175-254$

Speck, P. (1997a), „Epiphania et Martine sur les monnaies d'Héraclius“, Revue numismatique 152, 457-465.

Speck, P. (1997b), „Beiträge zum Thema byzantinische Feindseligkeit gegen die Juden im frühen siebten Jahrhundert nebst einer Untersuchung zu Anastasios dem Perser“, Varia 6, Poikila byzantina 15, Bonn.

Speck, P. (1998), „Ohne Anfang und Ende: Das ,Hexaemeron“ des Georgios Pisides“, in:

I. Ševcenko / I. Hutter (Hgg.), Aetos. Studies in honour of Cyril Mango, Stuttgart u.a., $314-328$.

Speck, P. (2000), „Zum Datum der Translation der Kreuzreliquien nach Konstantinopel“, Varia 7, Poikila Byzantina 18, 167-177.

Speck, P. (2003), „The Virgin’s Help for Constantinople“, Byzantine and Modern Greek Studies 27, $266-271$.

Speigl, J. (1995), „Formula lustiniani. Kircheneinigung mit kaiserlichen Glaubensbekenntnissen (Codex lustinianus I, 1, 5-8)“, Ostkirchliche Studien 44, 105-134. 
Stäcker, J. (2003), Princeps und miles: Studien zum Bindungs- und Nahverhältnis von Kaiser und Soldat im 1. und 2. Jahrhundert n. Chr., Hildesheim u. a.

Stein-Hölkeskamp, E., „Zwischen Parodie und Perversion. Verkehrungen des Triumphs in der frühen Kaiserzeit“, in: D. Boschung / K.-J. Hölkeskamp / C. Sode (Hgg.), Raum und Performanz. Rituale in Residenzen von der Antike bis 1815, Stuttgart, 127-142.

Steinicke, M. (2005), „Politische und artistische Zeichensetzung. Zur Dynamik von Krönungs- und Investiturritualen“, in: dies. / S. Weinfurter (Hgg.), Investitur- und Krönungsrituale. Herrschaftseinsetzungen im kulturellen Vergleich, Köln u.a., 1-26.

Sternbach, L. (1891), „Georgii Pisidae carmina inedita“, Wiener Studien. Zeitschrift für classische Philologie 13, 1-62.

Sternbach, L. (1892), „Georgii Pisidae Carmina inedita, pars II“, Wiener Studien. Zeitschrift für classische Philologie 14 (1892) 51-68.

Stewart, M. E. (2016), The Soldiers's Life: Martial Virtues and Manly Romanitas in the Early Byzantine Empire, Leeds.

Stoll, O. (2016), „Vae Victis? Das kaiserzeitliche Rom und sein Umgang mit Niederlage“, in: ders. / L. Meier (Hgg.), Niederlagen und Kriegsfolgen - Vae Victis oder Vae Victoribus?, Berlin, 1-10.

Stouraitis, I. (2012), ,Just War and Holy War in the Middle Ages. Rethinking Theory through the Byzantine Case-Study“, Jahrbuch der Österreichischen Byzantinistik 62, 227-264.

Stoyanov J. P. (2011a), Defenders and Enemies of the True Cross: the Sasanian Conquest of Jerusalem in 614 and Byzantine Ideology of Anti-Persian Warfare, Wien.

Stoyanov J. P. (2011b), „Archaeology versus Written Sources: The Case of the Persian Conquest of Jerusalem in 614", Terra antiqua Balcanica et mediterranea 1, 351-358.

Stratos, A. N. (1968), Byzantium in the Seventh Century, Bd. 1: 602-634, Amsterdam.

Stratos, A. N. (1972), Byzantium in the Seventh Century, Bd. 2: 634-641, Amsterdam.

Stratos, A. N. (1975), Byzantium in the Seventh Century, Bd. 3: 642-668, Amsterdam.

Stratos, A. N. (1978), Byzantium in the Seventh Century, Bd. 4: 668-685, Amsterdam.

Stratos, A. N. (1980), Byzantium in the Seventh Century, Bd. 5: Justinian II., Leontius and Tiberius 685-711, Amsterdam.

Stratos, A. N. (1979), „La première campagne de l'Empereur Héraclius contre les Perses“, Jahrbuch der Österreichischen Byzantinistik 28, 63-74.

Suter, A. / Hettling, M. (2001), „Struktur und Ereignis - Wege zu einer Sozialgeschichte des Ereignis“, in: dies. (Hgg.), Struktur und Ereignis, Göttingen, 7-32.

Szidat, J. (1979), „Die Usurpation des Eugenius“, Historia 28, 487-508.

Szidat, J. (1981), „Zur Wirkung und Aufnahme der Münzpropaganda (Iul. Misop. 355 d)“, Museum Helveticum 38/1, 22-33.

Szidat, J. (2010), Usurpator tanti nominis: Kaiser und Usurpator in der Spätantike (337-476 n. Chr.), Stuttgart.

Tambiah, S. (2008), „Eine performative Theorie des Rituals“, in: A. Belliger (Hg.), Ritualtheorien. Ein einführendes Handbuch, 4. Aufl., Wiesbaden, 223-246.

Tannous, J. (2014), „In Search of Monotheletism“, Dumbarton Oaks Papers 68, $29-67$.

Tartaglia, L. (1998), Carmi di Giorgio di Pisidia, Torino.

Thierry, M. / Thierry, N. (1971), „La cathédrale de Mrèn et sa decoration“, Cahiers archéologiques. Fin de l'antiquité et moyen-âge 21, 43-77.

Thierry, N. (1997), „Héraclius et la Vraie Croix en Arménie“, in: J.-P. Mahé / R. W. Thomson (Hgg.), From Byzantium to Iran. In Honour of Nina Garsoïan, Atlanta, 165-186.

Thomson, R. W. / Howard-Johnston, J. (1999), The Armenian History attributed to Sebeos, 2 Bde., Liverpool.

Tinnefeld, F. H. (1971), Kategorien der Kaiserkritik in der byzantinischen Historiographie: von Prokop bis Niketas Choniates, München. 
Trampedach, K. (2001), „Die Konstruktion des Heiligen Landes. Kaiser und Kirche in Palaestina von Constantin bis Justinian“, in: M. Sommer / I. Geiss / M. Heinz (Hgg.), Die Levante: Beiträge zur Historisierung des Nahostkonflikts, Freiburg i. Br., 83-110.

Trampedach, K. (2005), „Kaiserwechsel und Krönungsritual im Konstantinopel des 5. -6. Jahrhunderts“, in: M. Steinicke / S. Weinfurter (Hgg.), Investitur- und Krönungsrituale. Herrschaftseinsetzungen im kulturellen Vergleich, Köln u. a., 275-290.

Trampedach, K. (2015), „Ein neuer Tempel Salomons in Jerusalem? Der Bau der Nea-Kirche (531-543) durch Kaiser Justinian“, Millenium-Jahrbuch 12, 155-178.

Trampedach, K. (im Druck), „The Making of the Holy Land in Late Antiquity“, in: K. Klein / J. Wienand (Hgg.), City of Caesar, City of God: Constantinople and Jerusalem in Late Antiquity. Trampedach, K. (im Druck), „A New Temple of Solomon in Jerusalem? The Construction of the Nea Church (531-543) by Emperor Justinian“, in: K. Klein / J. Wienand (Hgg.), City of Caesar, City of God: Constantinople and Jerusalem in Late Antiquity.

Treadgold, W. T. (1997), A History of the Byzantine State and Society, Stanford, CA.

Treadgold, W. T. (2007), The Early Byzantine Historians, Basingstoke u. a.

Treitinger, O. (1938), Die oströmische Kaiser- und Reichsidee nach ihrer Gestaltung im höfischen Zeremoniell, Jena.

Trilling, J. (1978), „Myth and Metaphor at the Byzantine Court. A Literary Approach to the David Plates“, Byzantion 48, 249-263.

Trypanis, C. A. (1968), Fourteen Early Byzantine Cantica, Wien.

Tsamakda, V. (2010), „König David als Typos des byzantinischen Kaisers“, in: F. Daim / J. Drauschke (Hgg.), Byzanz - Das Römerreich im Mittelalter, Bd. 1: Welt der Ideen, Welt der Dinge, Mainz, $23-54$.

Turtledove, H. N. (1983), „Justin Il’s Observance of Justinian’s Persian Treaty of 562“, Byzantinische Zeitschrift 76, 292-301.

Uthemann, K.-H. (1999), „Kaiser Justinian als Kirchenpolitiker und Theologe“, Augustinianum 39, $5-84$.

Van Bekkum, W. J. (2002), „Jewish Messianic Expectations in the Age of Heraclius“, in: G. J. Reinink / B. Stolte (Hgg.), The Reign of Heraclius (610-641). Crisis and Confrontation, Leuven, 95-112.

Van Dieten, J. L. (1972), Geschichte der Patriarchen von Sergios I. bis Johannes VI. (610-715), Amsterdam.

Van Dieten, J. L. (1985), „Zum ,Bellum Avaricum‘ des Georgios Pisides. Bemerkungen zu einer Studie von Paul Speck“, Byzantinische Forschungen 9, 149-178.

Van Donzel, E. J. / Schmidt, A. (2010), Gog and Magog in Early Eastern Christian and Islamic Sources: Sallams Quest for Alexanders Wall, Leiden u. a.

Van Esbroeck, M. (1976), „Une chronique de Maurice à Héraclius dans un récit des sièges de Constantinople“, Bedi Kartlisa 34, 74-96.

Van Ginkel, J. J. (2002), „Heraclius and the Saints. The 'Popular' Image of an Emperor“, in: G. J. Reinink / B. Stolte (Hgg.), The Reign of Heraclius (610-641). Crisis and Confrontation, Leuven, 226-240.

Viermann, N. (im Druck), „Surpassing Solomon. Church-building and Political Communication in Constantinople“, in: K. Klein / J. Wienand (Hgg.), City of Caesar, City of God: Constantinople and Jerusalem in Late Antiquity.

Vivian, T. / Athanassakis, A. N. (1994), The Life of St. George of Choziba and the Miracles of the Most Holy Mother of God at Choziba, San Francisco.

Wallace-Hadrill, J. M. (1960), The Fourth Book of the Chronicle of Fredegar with its Continuations, London.

Wander, S. H. (1973), „The Cyprus Plates: The Story of David and Goliath“, Metropolitan Museum Journal 8, 89-104. 
Wander, S. H. (1975), „The Cyprus Plates and the 'Chronicle’ of Fredegar“, Dumbarton Oaks Papers $29,345 \mathrm{f}$.

Wassiliou-Seibt, A.-K. (2017), „From magister militum to strategos: the Evolution of the Highest Military Commands in Early Byzantium $\left(5^{\text {th }}-7^{\text {th }} \text { c.) }\right)^{\text {c }}$, in: B. Caseau / V. Prigent / A. Sopracasa

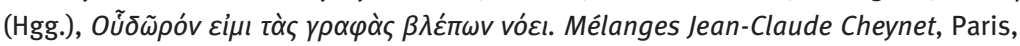
$789-802$.

Watt, J. W. (2002), „The Portrayal of Heraclius in Syriac Historical Sources“, in: G. J. Reinink / B. Stolte (Hgg.), The Reign of Heraclius (610-641). Crisis and Confrontation, Leuven, 63-80.

Wellesz, E. (1956), „The 'Akathistos.' A Study in Byzantine Hymnography“, Dumbarton Oaks Papers 9/10, $141-174$.

Welskopp, Th. (2001), „Die Dualität von Struktur und Handeln. Anthony Giddens' Strukturierungstheorie als ,praxeologischer" Ansatz in der Geschichtswissenschaft“, in: A. Suter / M. Hettling (Hgg.), Struktur und Ereignis, Göttingen, 99-119.

Wenger, A. (1955), L'assomption de la T. S. vierge dans la tradition byzantine du Vle au Xe siècle: études et documents, Paris.

Whately, C. (2013), „Militarization, or the Rise of a Distinct Military Culture? The East Roman Ruling Elite in the $6^{\text {th }}$ Century AD“, in: S. O'Brien / D. Boatright (Hgg.), Warfare and Society in the Ancient Eastern Mediterranean, Oxford, 49-57.

Wheeler, B. M. (1991), „Imagining the Sasanian Capture of Jerusalem. The 'Prophecy and Dream of Zerubbabel' and Antiochus Strategos' 'Capture of Jerusalem'“, Orientalia christiana periodica $57,69-85$.

Whitby, Ma. (1985), „The occasion of Paul the Silentiary’s Ekphrasis of S. Sophia“, The Classical Quarterly 35, 215-228.

Whitby, Ma. (1987), „On the Omission of a Ceremony in Mid-Sixth Century Constantinople: Candidati, Curopalatus, Silentiarii, Excubitores and Others“, Historia 36, 462-488.

Whitby, Ma. (1994), „A New Image for a New Age: George of Pisidia on the Emperor Heraclius“, in: E. Dąbrowa (Hg.), The Roman and Byzantine Army in the East, Krakau, 197-225.

Whitby, Ma. (1995), „The Devil in Disguise: The End of George of Pisidia's Hexaemeron Reconsidered“, The Journal of Hellenic Studies 115, 115-129.

Whitby, Ma. (1998), „Defender of the Cross: George of Pisidia on the Emperor Heraclius and his Deputies“, in: dies. (Hg.), The Propaganda of Power. The Role of Panegyric in Late Antiquity, Leiden u.a., 247-273.

Whitby, Ma. (2002), „George of Pisidias Presentation of the Emperor Heraclius and his Campaigns: Variety and Development“, in: G. J. Reinink / B. Stolte (Hgg.), The Reign of Heraclius (610-641). Crisis and Confrontation, Leuven, 157-174.

Whitby, Ma. (2003), „George of Pisidia and the Persuasive Word: Words, Words, Words...“, in: E. Jeffreys (Hg.), Rhetoric in Byzantium, Ashgate, 173-186.

Whitby, Ma. (2020), „The Patriarch Sergius and the Theotokos“, Jahrbuch der österreichischen Byzantinistik 70.

Whitby, Ma. / Whitby, Mi. (1986), The History of Theophylact Simocatta. An Englisch Translation with Introduction and Notes, Oxford.

Whitby, Ma. / Whitby, Mi. (1989), Chronicon Paschale 284-628 AD, Liverpool.

Whitby, Mi. (1988), The Emperor Maurice and His Historian: Theophylact Simocatta on Persian and Balkan Warfare, Oxford.

Whitby, Mi. (2000a), „The Successors of Justinian“, in: ders. / Av. Cameron / B. Ward-Perkins (Hgg.), The Cambridge Ancient History, Bd. 14: Late Antiquity. Empire and Successors, Cambridge, 86-111.

Whitby, Mi. (2000b), „The Army, c. 420-602“, in: ders. / Av. Cameron / B. Ward-Perkins (Hgg.), The Cambridge Ancient History, Bd. 14: Late Antiquity. Empire and Successors, Cambridge, $288-314$. 
Whitby, Mi. (2000c), The Ecclesiastical History of Evagrius Scholasticus, Liverpool.

Whitby, Mi. (2004), „Emperors and Armies, AD 235-395“, in: S. Swain (Hg.), Approaching Late Antiquity. The Transformation from Early to Late Empire, Oxford, 156-186.

Wickham, Ch. (2005), Framing the Early Middle Ages: Europe and the Mediterranean 400-800, Oxford u.a.

Wienand, J. (2011), „Der blutbefleckte Kaiser. Constantin und die martialische Inszenierung eines prekären Sieges“, in: M. Fahlenbock (Hg.), Inszenierung des Sieges - Sieg der Inszenierung, Innsbruck u. a., 237-254.

Wienand, J. (2012), Der Kaiser als Sieger: Metamorphosen triumphaler Herrschaft unter Constantin I., Berlin.

Wienand, J. (2015a), „The Cloak of Power: Dressing and Undressing the King“, in: ders. (Hg.), Contested Monarchy. Integrating the Roman Empire in the Fourth Century AD, Oxford, 3-14.

Wienand, J. (2015b), „O tandem felix civili, Roma, victoria! Civil-War Triumphs from Honorius to Constantine and back“, in: ders. (Hg.), Contested Monarchy. Integrating the Roman Empire in the Fourth Century AD, Oxford, 169-197.

Wienand, J. (2016a), „The Impaled King: A Head and its Context“, in: ders. / H. Börm / M. Mattheis (Hgg.), Civil War in Ancient Greece and Rome: Contexts of Disintegration and Reintegration, Stuttgart, 417-432.

Wienand, J. (2016b), „Religiöse Toleranz als politisches Argument: Konzeptionelle Überlegungen zur konstantinischen Wende“, in: M. Wallraff (Hg.), Religiöse Toleranz. 1700 Jahre nach dem Edikt von Mailand, Berlin u.a., 67-100.

Wienand J. / Klein, K. (im Druck), City of Caesar, City of God: Constantinople and Jerusalem in Late Antiquity.

Wijnendaele, J. (im Druck), „Irregularly Recruited Soldiers“, in: Ph. Rance (Hg.), Brill Compagnion to Military Culture in Late Antiquity.

Wilken, R. L. (1992), The Land Called Holy: Palestine in Christian History and Thought, New Haven u.a.

Winkelmann, F. / Ditten, H. / Rochow, I. (1978), Byzanz im 7. Jahrhundert. Untersuchungen zur Herausbildung des Feudalismus, Berlin.

Winkelmann, F. (1978), „Zur Rolle der Patriarchen von Konstantinopel bei den Kaiserwechseln in frühbyzantinischer Zeit“, Klio 60, 467-482.

Winkelmann, F. (1987), „Die Quellen zur Erforschung des monoenergetisch-monotheletischen Streites“, Klio 69, 515-559.

Winkelmann, F. (2001), Der monenergetisch-monotheletische Streit, Frankfurt a. M. u. a.

Winterling, A. (2011), „Zu Theorie und Methode einer neuen Römischen Kaisergeschichte“, in: ders. (Hg.), Zwischen Strukturgeschichte und Biographie, Oldenburg, 1-11.

Wood, Ph. (2011), „We Have no King but Christ“: Christian Political Thougth in Greater Syria on the Eve of the Arab Conquest (c. 400-585), Oxford.

Wood, Ph. (2013), The Chronicle of Seert: Christian Historical Imagination in Late Antique Iraq, Oxford.

Woods, D. (2006), „On the Health of the Emperor Heraclius c. 638-641“, Byzantinoslavica 64, 99-110.

Yannopoulos, P. A. (1978), L'hexagramme: un monnayage byzantin en argent du VIle siècle, Louvain-la-Neuve.

Zagros, G. / Veglery, A. (1972), Byzantine Lead Seals, Bd. 1.1, Basel.

Zahnd, U. (2008), „Novus David - Neos David: zur Frage nach byzantinischen Vorläufern eines abendländischen Topos“, Frühmittelalterliche Studien 42, 71-87.

Zocca, E. (1992), „Onorio e Martino: due papi di fronte al monotelismo“, in: Martino I papa (649-653) e il suo tempo, Spoleto, 103-147. 
Zuckerman, C. (1988), „The Reign of Constantine V in the Miracles of St. Theodore the Recruit (BHG 1764)“, Revue des études byzantines 46/1, 191-210.

Zuckerman, C. (1995), „La petite Augusta et le Turc. Epiphania-Eudocie sur les monnaies d'Héraclius“, Revue numismatique 6 (150), 113-126.

Zuckerman, C. (2002), „Heraclius in 625“, Revue des études byzantines 60/1, 189-197.

Zuckerman, C. (2007), „The Khazars and Byzantium - The First Encounter“, in: P. B. Golden / H. Ben-Shammai / A. Róna-Tas (Hgg.), The World of the Khazars. New Perspectives, Leiden u. a., 399-432.

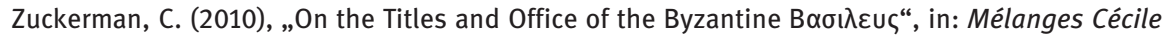
Morrisson, Travaux et Mémoires 16, 865-890.

Zuckerman, C. (2013), „Heraclius and the Return of the Holy Cross“, in: ders. (Hg.), Constructing the Seventh Century, Travaux et Mémoirs 17, Paris, 197-218. 


\subsection{Register}

\subsubsection{Personenregister}

Abu Bakr 300, 303

Agapios 22, 25

Agathias 9,

Alexander der Große 18, 139, 236, 242-248

Alexander (Prätorianerpräfekt) 209

Alkestis 135, 239, 297 Anm. 216

Al-Tabari 25

Anastasia (Tiberios' Ehefrau) 168

Anastasia (Herakleios' Tochter) 311 Anm. 279

Anastasios I. 48f., 51, 54-58, 60-63, 65, $88,92,109,116$,

Anastasios der Perser 13 Anm. 4, 16 f., 201 Anm. 69

Anicia Juliana 54

Anicius Olybrius 54, 63

Anthemios 53, 63

Antiochos Strategos 16, 269, 271

Antonina 99

Ardabur 51

Ardashir 261, 263 Anm. 40, 283

Areobindos 54, 61

Ariadne $\quad 51-55,61$

Arkadios 27, 29, 31, 50 f., $162 \mathrm{f}$., 168

Armatos 52 Anm. 111, 53, 89

Artabanes 57, 61

Aspar 44, 48, 51f., 54f., 60f., 63, 109, 324

Atalarich 207 Anm. 94, 304, 307 f., 318

Athanasios der Kameltreiber 286

Augustina 311 Anm. 279

Baanes 302

Baram Chobin 71-74, 89, 233, 283

Basiliskos 51-53, 78f., 89f., 114, 118, 167

Benjamin 26, 286, 303

Belisar 42-44, 47, 57, 64f., 89, 99, 197, 199

Bonifaz 143

Bonos 184, 189-191, 210-212, 214, 218, 224 ,

Bonosos 95, 102

Boran 283, 286

Caligula 309

Callinicus 134

Charito 59

Chosroes I. 67f., 71

Chosroes II. 10, 12, 17, 19, 71-73, 89 f., 134, 140 f., 147 f., 151, 157, 164, 179-181, $206-$

209, 230-233, 237-239, 248, 252-254, 260, 263, 280, 283, 291, 294, 296, 299, 304,340

Constantius II. 37

Constantius Chlorus 50

David (Herakleios' Sohn) 175, 235, 311, 322

David (König) 223f., 274-279, 281, 298f., 337, 344

David (General) 263

David (Logothet) 322

David Saharuni 269 Anm. 66

Dionysios von Tel-Mare 22

Domentzia 99, 148

Domentziolos (Phokas' Bruder) 101, 140

Domentziolos (Phokas' Neffe) 140 f., 144

Eleutherios 179

Epiphania 177 Anm. 188, 155 Anm. 75, 162 f., 184, 207, 229 Anm. 207

Eudokia 102 Anm. 120, 113, 119, 162, 171f., 318, 338

Eugenius 163

Euseb von Caesarea 133, 191 Anm. 26, 246, 297

Eutychios (Patriarch) $292 \mathrm{f}$.

Eutychios (Sa'id ibn Batriq) 25

Evagrios Scholastikos 78 f., 128

Ezr 286

Flavios 174 f., Anm. 169

Fredegar 22, 245 Anm. 270, 269, Anm. 67, 278, 287, Anm. 163

Gainas 91, 325

Gelimer 125 Anm. 213, 255 Anm. 10

Georg von Antiochia 81

Georg von Pisidien 12-15, 24, 100 f., 131 136, 181, 181-197, 200-205, 213-228, 236, 238-242, 249f., 253, 256, 259 f., 270 f., $274-282,293-297,306,309,312$, $336 \mathrm{f} ., 343 \mathrm{f}$.

Georg Synkellos 24

Germanos Senior 57-59

Germanos Junior 59f., 71, 84 f., 87 f., $91 \mathrm{f}$., 99, 110, 120 f., 146 f., 150

Germanos (Kommandeur von Edessa) 83 
Goliath $275,277 \mathrm{f}$.
Goripp $\quad 66 \mathrm{f}$.
Gratian $\quad 308$
Gregor der Große $142 \mathrm{f}$.
Gregoria $\quad 161,174$
Gregorios $\quad 313 \mathrm{Anm} .282,326 \mathrm{f} ., 329$

Helena $264 \mathrm{f}$.

Herakleios Konstantin 117 Anm. 187f., 119, 155f., 161-166, 172, 174, 178, 184, 187, 190 f., 207 f., 215 f., 220, $224-226,234$ f., 256, 258, 282, 307, 310, 317-320, 329, 338

Herakleios Senior 71, 79, 94-99

Herakles 135f., 200 Anm. 67, 213, 239, 294, 297 Anm. 216

Heraklonas 117 Anm. 186, 188, 166 f., 172

Anm. 156, 175 Anm. 169, 236, 259

Anm. 26, 310-313, 315, 318-325, 338

Honorius 50, 73 Anm. 200

Honorius (Papst) 287, 314

Hormizdas 71

Hypatios $47,55-57,61,90$

Illous $53 \mathrm{f}$.

Ishoyahb 283-286

Jesaja $223 \mathrm{f}$.

Johannes der Almosengeber 19, $161 \mathrm{f}$.

Johannes von Antiochia 11, $148 \mathrm{f}$.

Johannes Lydos 31

Johannes Malalas 11

Johannes von Nikiu 19f., 98, 112, $323 \mathrm{f}$.

Johannes Seismos $209 \mathrm{f}$.

Johannes (Mizizes’ Sohn) 331 Anm. 66

Jovian 50

Julian 54, 68, 78, 107 Anm. 142, 120 Anm. 194, 169

Justin I. $\quad 51,55 \mathrm{f} ., 60,118$

Justin II. $58 \mathrm{f.,} 62 \mathrm{f.}, 66-70,96,145,168$, 173f., 189, 290

Justin (General) 63

Justinian I. $38,40,42-44,47-49,51$, $55-58,61,65-68,89-90,94,96,108 f .$, $118,123,168,198-200,215,241,258$, 260, 265, 273, 289, 292f., 307 Anm. 260, 315,336

Justinian II. $\quad 70,318,331 \mathrm{f}$.

Justinian (General) 70, 307 Anm. 260
Kallinikos 58

Kalliopas 102 Anm. 120

Kavadh Seiroe 12, 181, 203, 231-233, 252254, 257, 260 f., 340

Kedrenos 149

Keler 55

Komentiolos (General) 81, 140

Komentiolos (Phokas' Bruder), 151-153

Komitas 21

Konstans II. 23, 313 Anm. 282, 315, 320331, 338

Konstantin der Große $39,45,50,78 f ., 126$, 167, 170, 190, 191 Anm. 126, 197, Anm. 149, 255, 281-283, 289, 297 Anm. 217

Konstantin IV. 23, 329, 331

Konstantin Lardys 88,140

Konstantin Porphyrogennetos 25

Konstantin (Herakleios' Sohn) $174 \mathrm{f}$., Anm. 169

Konstantina 59, 143 Anm. 23, 146 f., 168

Kosmas 144

Kyriakos $88,110,143$ Anm. 23

Kyros 286-288, 303, 322

Leon I. $\quad 31$, Anm. 16, 44, 46, 48, 51-53, 60 f., $63,107-109,114,116,221,324$

Leon II. 51, 108, 114

Leontia (Tochter des Leon I.) 53

Leontia (Phokas' Ehefrau) 111, 142, 148, 168

Leontios (Usurpator unter Zenon) 35 Anm. 29, 53 f., 83, 127

Leontios (Kaiser) $331 \mathrm{f}$.

Leontios von Neapolis 19

Leontios (Sakkelarios) 126

Longinos $48,54,65$

Markian I. $\quad 38,48,51$ f., 61, 109 Anm. $150-$ 152, 164 Anm. 112, 289, 297

Markian 53

Markos 51, 167

Martin (Papst) 327

Martina $166,171-175,184,207,266,276$, 278 Anm. 117, 310f., 313, 315, $318-325$, $335,338,343,345$

Maurikios $5,10,23,51,59-61,70-77$, 79-94, 97, 99, 101, 103f., 110-112, 114, $116,118,120,122-125,134,139-144$, 146-148, 151f., 154, 156, 162-164, 168, 
181f., 202, 233, 240, 252, 284, 298, 317,

319 Anm. 5, 334

Maxentius 45, 126, 200 Anm. 66

Maximos Confessor 288, 298 Anm. 224, 326, 330 Anm. 57

Melchisedek $298 \mathrm{f}$.

Menander Protektor 10

Menas 144

Michael Syrus 22

Mizizes 331

Modestos 16, 20, 266, 268 Anm. 64

Mohammed 300

Moses 132, 219 Anm. 155, 224

Movses Dasxuranci 21

Mundos 47

Narses (Eunuch) 64, 74

Narses 140-142, $151 \mathrm{f}$.

Nikephoros 23f., 120,154f., 171-173, $180 \mathrm{f}$., 233f., 257-259, 304-306, 308, 310, $314 \mathrm{f.}, 318$

Nikephoros Phokas 203 Anm. 83, 204 Anm. 87

Niketas (Herakleios' Cousin) 95, 98, 155 Anm. 75, 156, 160-162, 174, 182, 291

Niketas (Shahrbaraz' Sohn) 262, 311 Anm. 278

Odoaker 27

Olympios 327,329

Patrikios 52

Paulos Silentiarios 189, 199

Paulos II. (Patriarch) 322, 325

Petros (Maurikios' Bruder) $81-83,111,140$

Philagrios 320

Philippikos 81, 161

Philippikos Bardanes 332, 346

Phineas $132 \mathrm{f}$.

Phokas 5, $10 \mathrm{f} ., 20,44,47,79,83-85,99-$ $105,107,110-116,118,120-153,156 \mathrm{f} .$, $161,164,166,168,182-185,202,238$, 240, 284, 296, 317, 321, $334 \mathrm{f}$.

Pompeios 55-57

Praeiecta 57

Priscian 65

Priskos 44, 47, 81-83, 98-102, 122, $120 \mathrm{f}$., 140, 148, 153-156, $160 \mathrm{f.,} 174$

Probos 55
Prokop von Caesarea 9, 42, 44, 65, 98, $199 \mathrm{f.}, 315$

Pseudo-Methodios 269

Pulcheria 52, 61 Anm. 154

Pyrrhos 23 Anm. 103, 319, $321 \mathrm{f}$.

Razadh 230, 278 Anm. 119

Romanus 143

Romulus Augustulus 27

Saul 275

Sebeos 20f., 147, 157, 164, 265, 307, 323, 328

Sergios (Patriarch) 11-14, 112f., 143 Anm. 23, 172, 184 f., 189-191, 209, 211, $218-220,223-228,236,241,256,258$, 284 f., 287f., 292f., 295-297, 310, 312, 314 Anm. 283, 319, 337

Sergios (Statthalter) 301

Severos 293-295

Shahin 152f., $178 \mathrm{f}$., $208 \mathrm{f}$.

Shahraplakan 208, 230

Shahrbaraz 177, 192, 208-210, 253f., 261 264, 277, 283, 299, 244

Smaragdus $142 \mathrm{f}$.

Sophia $58-70,168$

Sophronios 17, 19, 144, 288, 303

Stephan von Kyzikos 100

Stilicho 40, 61 Anm. 154

Tervel 332

Theoderich Strabo 53

Theoderich 76

Theodor (Herakleios' Bruder) 156f., 161, 212, 253, $301 \mathrm{f}$.

Theodor (Herakleios' Neffe) 304, 307f., 313, 318

Theodor (Comes von Abydos) 100

Theodor (Sakellarios) 302

Theodor Synkellos 14, 221-227, 248

Theodor von Sykeon 15, 144, 151, $157 \mathrm{f}$., 277

Theodora $57 \mathrm{f}$.

Theodosios I. $\quad 30 \mathrm{f} .$, 38, 50, 74, 159, $162 \mathrm{f}$., 256, 308

Theodosios II. 28, 31, 50-52, 60 f., 162, 215, 297

Theodosios (Bruder des Konstans II.) 329

Theodosios (Sohn des Herakleios) $174 \mathrm{f}$. Anm. 169, 262 
Theodosios (Sohn des Maurikios) 51, 73, 76, 84 f., 87 f., 92, 111 Anm. 163, 125

Anm. 208, 140 f., 146-148, 151, 162, 164, 168, 170, 319 Anm. 5

Theophanes Confessor $22-24,70,98,100$, 113, 119, 145, 147, 149, 171-174, 202 f., 239 f., $248 f$., 256 f., 259, 276 f., 323

Theophilos von Edessa 22-25

Theophylakt Simokattes $9-11,24,75 \mathrm{f}$., $83-85,89,91,118,134-136,248,296-$ 299, 336

Theotokos 14, 100 f., 136, 218-228, 233, 236, 238, 251, 250, 310, 337

Tiberios (Sohn des Justinian II.) 332

Tiberios II. 58-61, 69-73, 75, 108 Anm. 147, 116, 168

Tiberios Apsimar 332

Turbalak 243

\subsubsection{Ortsregister}

Abydos 100

Antiochia am Orontes 94 Anm. 94, 152, 161, 176, $302 \mathrm{f}$.

Alexandria 19, 95, 165, 179, 253 Anm. 4, 287, 291, 303, 322

Alexandretta 95

Anastasis-Kirche (Jerusalem) 177, 262, 264 266., 272f., 337, 344

Anchialos 75

Apamea 152

Apostelkirche (Konstantinopel) 317

Arabissos 262

Autonomos-Kirche 90, 111

Bethlehem 273 Anm. 91, 301

Blachernen (-Viertel, -Kirche) 8 Anm. 24, 14 f., 206 Anm. 93, 212, 221, 226f., 310

Caesarea Cappadociae $\quad 152-158,208,256$ Anm. 13

Caesarea Maritima 16, 177,

Chalkedon 21 Anm. 89, 111, 125, 178, 210, 284-293, 296-299, 312, 320-322

Chrysopolis 210-310

Cotyaeum 54

Ctesiphon 16, 71, 89, 177, 179, 203, 230 f., 253, 262-263, 283, 291
Umar 269, 303, 312 Anm. 281

Urbikios 54

Valens 78, 159 Anm. 91, 308

Valentinian III. 63 Anm. 159, 125 Anm. 213, 322 Anm. 25

Valentinos $320-325$

Verina 35 Anm. 29, 52f., 127

Vitalian $55,62 \mathrm{f} ., 86,92$

Xerxes $309 \mathrm{f}$.

Yazdegerd III. 21, 304

Zacharias 16, 177, 266

Zenon 33 Anm. 22, 48, 51-54, 60 f., 70 f., 89 f., 114, 183 Anm. 206, 199 Anm. 60, 324

Zosimos 78

Zuzos 52 Anm. 111

Damaskus 176, 302

Dara $\quad 58,68,73,141,159,198$ Anm. 55

Dastagert 16,230

Dvin 20, 208, 328

Edessa $\quad 83 \mathrm{f} ., 140 \mathrm{f} ., 151 \mathrm{f} ., 253,284,286,302$

Emesa 152, 302

Felsendom (Jerusalem) $272 \mathrm{f}$.

Forum Romanum 143

Ganzak 208, $230 \mathrm{f}$.

Gaza 301

Goldenes Tor (Konstantinopel) 103, 111, 115, 126, 272

Goldenes Tor (Jerusalem) 8 Anm. 24, $272 \mathrm{f}$.

Grabeskirche $\rightarrow$ Anastasis-Kirche

Hafen (Konstantinopel) 101, 103, 111-113, 115-117, 119, 125f., 153, 334

Hagia Sophia (Konstantinopel) 13, 15, 87, 110 Anm. 155, 112, 116 f., 119, 136 Anm. 263, 139, 163, 178, 180, 189, 207, 209, 231, 233, 240, 263, Anm. 41, 301 Anm. 238, $311 \mathrm{f} ., 321,327,334,342$

Hebdomon 34, 53, 55, 90 f., 101, 107 f., 110, $114-116,118,122,124 \mathrm{f} ., 134,215,334$

Herakleia Perinthos 100, 114, $206 \mathrm{f}$. 
Hierapolis 72, 263, 285

Hiereia 256, 258f., 304-308, 311, 320

Hippodrom 47, 52, $56 \mathrm{f}$., 65, 69, 71, 86, 88, 90, 99, 108, 111, 113f., 117f., 122f., 126, 146, 148 f., 163, 171, 255-260, 311

Jerusalem 8 Anm. 24, 9, 16-19, 21, 177180, 203f., 208, 222f., 225, 234, 244, $248-250,257,261-275,279-283,288$, 291, $300 \mathrm{f} ., 303,337,344$

Johannes-Prodromos-Kirche (Hebdomon) 110, 116 Anm. 182

Kalonimon 100

Karthago 119 f., 39, 79, 93-96, 98 Anm. 92, 165, 317, 326f., 332, 334

Mardin 18

Martyropolis 73, 277 Anm. 115, 298

Mauer (Lange) 8 Anm. 23, 74, 101, 206, 210, 215,258

Mauer (Theodosianische) $8 \mathrm{Anm} .24,28,34$, $44,80,86-89,91-93,111,114$ f., $210-$ $212,219,221,224,259,310$

Monokarton 81, 83

Mren 8 Anm. 24, $268 \mathrm{f}$.

Nikaia 289

Nikomedia 191, 207

Niniveh 230, 252

\subsubsection{Stellenregister}

Acta Anastasii Persae

$\begin{array}{ll}-8 & 179\end{array}$

$-43 \quad 232,254$

Agapius

- Vasiliev 454301

- Vasiliev 465232

- Vasiliev 469301

Akathistos Hymnos

- 2. proem. 15, 225, 227

Alexanderlegende

- Budge 144-158 242

- Budge 154f. 243

- Budge $158243 \mathrm{f}$.
Ölberg $\quad 267,270,303$

Pantheon 143

Partaw 208, 229

Pera 210, 310

Pylai 191

Ravenna $\quad 39,78,94,179,327$

Rom 107, 215 Anm. 213, 126, 142 f., 144, 179 Anm. 186, 254 f., 288, 329

Sebasteia 209

Stephans-Kirche (im Palast) 113, 116 f., 119, 162f., 310, 321

Sycae $\rightarrow$ Pera

Sykeon 15, 151, $157 \mathrm{f}$.

Syrakus 5, 329-331, 338

Takht-i-Sulaiman 208

Tarsos 53, 83, 127, 157

Tempelberg (Jerusalem) 8 Anm. 24, 178

Anm. 179, 265, 272-274, 279

Theodosiopolis 208, 286

Theodosius-Forum (Konstantinopel) $112 \mathrm{f}$.

Thessaloniki 15 Anm. 60, 211

Thomas-Kirche (Konstantinopel) 112f., $116 \mathrm{f}$.

Tiberias 264 Anm. 42, 270 Anm. 78

Tiflis $229 \mathrm{f}$.

Yarmouk (Schlacht am) 302-304, 309, 313, 338,340

Ammianus Marcellinus

$-20.4 .15-17 \quad 120$

Anonymus Guidi

- Nöldeke $15 \mathrm{f}$. 140, 147

- Nöldeke $28 \quad 230$

- Nöldeke 29291

- Nöldeke 31f. 263

- Nöldeke 32f. 283

Anonymus Valesianus

- 41 53, 90

Anthologia Graeca

-1.120 f. 226, 275

$-9.6558$ 
Anthologia Palatina

- 16.46f. 161

$-16.63 \mathrm{f} . \quad 198$

Antiochos Strategos

- Conybeare 504-508 177

- Conybeare $510 \quad 266$

- Conybeare 514-516 177

- Conybeare 516 171, 263f., 266, 268, 271, 282

Bibel

- Gen 14.18-20 298

- 2 Sam $6.5 \quad 274$

- 2 Sam 6.14-15 274

- 2 Sam 16-18 $276 \mathrm{f}$.

- Ps 110298

- Ez 38f. 224

- Mt 1.1-17 274

- Mt 21.1-12 270

- Mt 24.2273

- Mt $24.14 \quad 299$

- Mk 11.1-19 270

- Mk 13.2273

- Mk 13.10299

- Lk 3.23-38 274

- Lk 19.37-48 270

- Lk 21.6273

- Hebr 7.1298

- 1 Petr $5.4 \quad 204$

- Apk 20.7f. 224

Candidus, fragmenta

$\begin{array}{ll}-1 & 109\end{array}$

Cassius Dio

$-59.19 .3 \quad 309$

\section{Chronicon Paschale}

- AD 402 51, 162

- AD 53290

- AD 590 73, 76, 168

- AD $60280,85,110 \mathrm{f}$.

- AD 603 146, 148

- AD 605146

- AD 609 95, 129

- AD 610 47, 94, 101-103, 112f., 125f., 129, 132

- AD 61197,162

- AD 612 117, 129, 153, 155f., 160, 162,
- AD 613 117, 162f., 165, 169, 234

- AD 614 177f., 180

- AD $615 \quad 120,134,164,178-181$

- AD $618 \quad 180$

- AD $623 \quad 206$

- AD 624 172, 184, 208

- AD 626 209-212,

- AD 627 184, 213, 221, 228

- AD 628 12, 134, 189f., 192, 230-233, 254

Chronicon 724

- Palmer 18 262, 301

Chronicon 1234

$-91164$

$-92152 \mathrm{f}$.

-98 171f., 253

$-102253$

$-103 \quad 261,263$

$-108301$

$-110301 \mathrm{f}$.

$-111302$

- 114f. 302

$-116303$

$-117303$

$-118 \quad 287,303$

$-120 \quad 269,303$

$-139330$

Chronik von Seert

- Scher 500 f. 140 f., 148

- Scher 544544

- Scher 556263

- Scher 557f. 283

- Scher 557-560 286

- Scher 580301

Codex lustinianus

$-9.12 .1046$

Codex Theodosianus

- 3.12.1 171, 175

Collectio Avellana

- 141120

Consularia Constantinopolitana

- ad a. 386256 
Doctrina Jacobi

- Dagron/Déroche 128148

- Dagron/Déroche 31f. 287

De cerimoniis aulae Byzantinae

$-1.91108 \mathrm{f}$.

-1.92 108f., 120, 199

-1.93 55f., 109, 120

$-1.94108$

$-1.95108$

- 1 App. 75, 258

$-2.27117,167,175,276,310$

$-2.28 \quad 311$

$-2.29311$

$-2.30 \quad 314$

Evagrius, Historia ecclesistica

- $3.353,90$

$-3.4178 \mathrm{f}$.

$-5.1369$

$-6.4-6 \quad 81$

$-6.584$

$-6.9-18 \quad 81$

$-6.1772$

Eusebius, Laus Constantini

- 200.20 297

De Vita Constantini

- 1.44297

$-3.33 .1265$

$-4.22 \quad 297$

$-4.24 \quad 297$

Eutychios

- Breydy 108f. 264, 270

Exaltatio Sanctae Crucis

- 4266

$-9278$

$-17-21 \quad 267$

Reversio Sanctae Crucis

$-5266$

$-14-17 \quad 267$

Fredegar

- 4.6464

$-4.65 \quad 269,287$

$-4.66245$
Georg von Pisidien, Bellum Avaricum

$-1-15 \quad 218$

- 49f. 136

$-49-57 \quad 217$

$-58-66 \quad 210$

$-87 \quad 216$

$-96216$

$-108-124206$

$-125-129191,218$

$-130-140 \quad 219$

$-136-143218 \mathrm{f}$.

$-141-144218$

- 165-168 213, 216

$-214-225 \quad 211$

$-223-225 \quad 218$

- 226-245 211

$-237 \quad 218 \mathrm{f}$.

- 246-260 217

$-257 \mathrm{f} . \quad 215$

$-266-279 \quad 218$

$-278-283 \quad 209,218$

$-288-292 \quad 218$

-290 f. 217

$-302-306 \quad 217$

$-311-347 \quad 211$

$-313218$

- 366-373 211, 219

- 381-389 219

- 396-501 212

$-405219$

$-445 \quad 219$

$-451-456 \quad 219,222$

$-457 \quad 219$

$-493-497 \quad 219$

$-535-541 \quad 220$

Contra Severum

- 2f. 294

$-7 \quad 294$

$-9-55 \quad 294$

$-24-33293$

$-58-61 \quad 294$

$-65 \quad 294$

- 69294

$-73-75 \quad 294$

$-77 \quad 295$

$-79-84 \quad 295$

- 156f. 295

$-450-457 \quad 294$ 
$-706-712 \quad 294$

-717 f. 295

\section{Epigrammata}

- $95 \mathrm{f} . \quad 226$

Expeditio Persica

-1.17-19 193

$-1.35-50 \quad 189,193$

$-1.49201$

-1. 104-111 187

$-1.112-125$ 181, 186f., 191, 193

$-1.126193$

$-1.129193$

-1.132-138 191

$-1.139-151 \quad 192,203$

$-2.8-11192$

$-2.19193$

$-2.39-65192$

$-2.85 \mathrm{f} . \quad 203$

- 2. 88-97 203

$-2.103-106203$

$-2.105-115 \quad 203$

$-2.113-115 \quad 277$

$-2.116-148 \quad 192$

$-2.122-126 \quad 192$

$-2.163-169192$

$-2.163-174203$

$-2.206-3.304192$

$-2.235 \mathrm{f} . \quad 194$

-2.239 f. 194

$-2.244 \quad 194$

$-2.252 \quad 194,203$

$-2.304-326309$

$-3.48-53194$

-3.87 f. 195

$-3.92194$

- 3.93-124 $195 \mathrm{f}$.

$-3.305-321192$

$-3.112-115 \quad 280$

$-3.333238$

$-3.385194$

$-3.401194$

$-3.407-410 \quad 201$

\section{Heraclias}

$-1.65-70239$

-1.71-73 135, 239

$\begin{array}{ll}-1.82-84 & 239\end{array}$

$-1.84-92 \quad 239$

$$
\begin{aligned}
& \text { - } 1.93-98 \quad 236 \\
& -1.98-102 \quad 207 \\
& -1.110-121236 \\
& -1.131-139236 \\
& -1.143-147 \quad 238 \\
& -1.148 \quad 136 \\
& -1.151 \quad 136 \\
& \text { - } 1.172-218 \quad 237 \mathrm{f} \text {. } \\
& -1.201 \quad 236,250 \\
& -1.202 \quad 201 \\
& -1.212-218 \quad 236,256 \\
& -1.215 \quad 239,250 \\
& -1.216216 \\
& \begin{array}{ll}
-1.217 \quad 239 \\
-1.218
\end{array} \\
& -1.218 \quad 239 \\
& -2.5-11 \quad 136 \\
& \text { - 2.13-16 101, } 239 \\
& -2.14-23136 \\
& -2.29-33 \quad 249 \\
& -2.63-65 \quad 239 \\
& -2.83 \quad 238 \\
& -2.108-121306 \\
& -2.118-121 \quad 182 \\
& -2.122-132 \quad 181,306 \\
& -2.138 \quad 238 \\
& -2.153-230208 \\
& \text { - fragm. } 54
\end{aligned}
$$

Hexaemeron

-51-56 277

- 90 f. 277

$-1826250$

$-1829250$

$-1834 \mathrm{f} . \quad 250$

$-1836 \mathrm{f} . \quad 249 \mathrm{f}$.

In Alypium

$-117 \mathrm{f} . \quad 277$

In Bonum

-14-45 214

$-46-48 \quad 214$

$-51-55 \quad 214$

$-56-110 \quad 214$

$-58 \quad 136$

-91-101 214

- $96 \quad 136$

- 111-113 215

- 116-127 215

-160 f. 201, 214 
In Heraclium ex Africa redeuntem

$-2-14130$

$-14-38131$

$-47-60 \quad 132$

$-63-83133$

$-86-89133$

In Restitutionem S. Crucis

$-1-8 \quad 270,280$

$\begin{array}{ll}-8 & 296\end{array}$

$-16280$

$-19-26 \quad 280$

$-27-29 \quad 266$

$-27-38 \quad 280$

-30 f. 280

-41 f. 280

$-43-46280$

$-50 \mathrm{f.} \quad 281$

$-56-63281$

$-65-68 \quad 280$

$-71-77 \quad 274$

$-82-84 \quad 281$

-103 f. 190

$-104-116 \quad 264,270,280 f$.

In Resurrectionem Christi

- 106-110 215

$-112-118 \quad 215$

Laudatio Anastasii

$-15 \quad 201$

Geschichte der Patriarchen von Alexandria

- Evetts 489 f. 287

- Evetts $492 \quad 287$

Gorippus, In Laudem lustini Augusti minoris

$-1.275-287 \quad 125$

$-2.84-360109$

$-2.249-274 \quad 67$

$-2.399-406 \quad 67$

$-3.151-407 \quad 67$

$-4 \quad 67$

Gregor der Große, Epistulae

- 13.1 (Hartmann) 142

- $13.34($ Hartmann $)=13.32($ Norberg $) \quad 142$

- $13.41($ Hartmann $)=13.39($ Norberg $) \quad 142$

$-13.42($ Hartmann $)=13.40($ Norberg $) \quad 142$
Gregor von Tours, Historia Francorum

$-5.30 \quad 59$

Herodot

$-4.83-88 \quad 309$
$-7.34 f$.

$-7.34 \mathrm{ff} . \quad 309$

Johannes von Antiochia, fragmenta

$-303 \quad 44,53$

$-31681$

$-317 \quad 87$

- 318 80, 83, 90 f., 110

- 319 98, 100, 135, $148 \mathrm{f}$.

- $32144,47,100-102,112,124,126$

Johannes von Ephesus, Historia ecclesiastica

$-3.2-5 \quad 69,315$

$-5.20 \quad 80$

$-6.179$

$-6.24 \quad 67$

Johannes Lydos, De magistratibus

$-2.131$

$-3.4131$

Johannes von Nikiu

$-94.2660$

$-95.1,21 \mathrm{f} . \quad 80$

$-102.9-12 \quad 80,83$

$-103.4-8 \quad 80,110$

$-10494$

$-105 \quad 94$

$-107.1-8 \quad 95$

$-107.1695$

$-107.19-109.1795$

$-109.298$

$-109.2598$

$-109.26 \quad 100$

- 109.27-110.3 102f.

$-110.1112$

$-110.4180$

$-110.5-7 \quad 103,126$

$-110.9112 \mathrm{f}$.

$-116.3170,317$

$-119.20-24 \quad 320,322$

$-120.2320$

$-120.4322$

$-120.5-38322$

$-120.39 \mathrm{f} . \quad 320$

$-120.41-43 \quad 321 f$. 


$$
\begin{aligned}
& -120.44 \quad 321 \\
& -120.46-49 \quad 322 \\
& -120.50-55 \quad 323 \\
& -120.53 \quad 322 \\
& -120.61-63 \quad 324
\end{aligned}
$$

Justinian, Novellae

- 78.4.1 202

- 148 pr. 67

Kedrenos

- 1.685202

$-1.709149$

\section{Liber Pontificalis}

- 68143

$-69 \quad 144$

$\begin{array}{ll}-71 & 179\end{array}$

$-78329 \mathrm{f}$.

- 79331

Malalas

- 14.26322

$-14.40 \quad 44,47$

- 15.2f. 53, 90

$-15.553$

$-18.7190$

Malchos, fragmenta

- 18.3 33, 184

Marcellinus Comes, Chronicon

- ad a. 386256

- ad a. 374 53, 90

Menander Protector, fragmenta

$-14 \quad 67$

Michael Syrus

$-10.25140$

- 11.1152 f., 164

- 11.3a $171 \mathrm{f}$.

- $11.3 \quad 232,253,286$

$-11.4 \quad 287,300$

$-11.5300$

$-11.6302 \mathrm{f}$.

$-11.7 \quad 263,269,303$

$-11.10326 f$.

$-11.11329 \mathrm{f}$.

$-11.12330$
Movses Dasxuranci

$-2.9245$

$-2.10 \quad 208$

- 2.11f. 229

$-2.12 \quad 208,230$ f., 245

Nikephoros, Breviarum

- 1 98, 100-103, 112, 125f., 148

- 2 44, 112, 120, 153-156, 161, 164, 187

$-5156,161,174$

$-6-7 \quad 179$

$-8180$

$-10206$

- 11 171f., $174 \mathrm{f}$.

- 12 172, $174 \mathrm{f} ., 229$

$-13 \quad 207,210,212 \mathrm{f}$.

$-14 \quad 230,278$

- 15 231f., 234, 263

$-17 \quad 161,174,262$

- $18 \quad 257$

- 19 167, 257, 259

- $20171,278,300,308$

$-23 \quad 303$

- $24 \mathrm{f} . \quad 304 \mathrm{f} ., 308$

$-25167,174$ f., 310

$-26314$

-27 311, $314 \mathrm{f}$., $317 \mathrm{f}$.

$-28 \quad 319$

$-29319 \mathrm{f}$

$-30320 \mathrm{f}$.

- $31 \quad 320-22$

- 32 f. $\quad 315,322$

$-33 \quad 323,330$

Nikephoros Kallistos, Historia ecclesiastica $-8.32129$

Notitia dignitatum

$-1145$

Panegirici Latini

- 12[9].9.3-10.3 200

Parastaseis syntomoi chronicai

- 42.7- $10 \quad 180$

Paulus Diaconus, Historia Langobardorum

- 4.34179

$-5.11330$ 
Paulos Silentiarios, Ekphrasis

- 39199

Petros Patrikios, fragmenta

$-1372$

Prokop, De Aedificiis

- 1.2.7-12 198

- 1,7,7-11 199

$-1.10 .17-19 \quad 200$

Bellum Vandalicum

- 1.7.18 53, 90

- 1.10.18-21 202

-1.11.1- 2144

$-1.20 .21 \quad 43$

$-2.8 .1-543$

Bellum Gothicum

- 3.1.20 44

$-6.29 .17-41 \quad 43$

Bellum Persicum

$-1.24 .32-38 \quad 89$

$-1.24 .39-51 \quad 47$

$-1.25 .1799$

Historia arcana

- $12 \quad 315$

$-13.23-30199$

$-24.15 \quad 45$

Sebeos

- 31 111, 140, 147

- $33111,140,147$

$-33-34152$

- 34154 f., 157, 164f., 169, 177, 291

- 38 179, 203, 207-209, 230

-39 231f., 253, 257

$-40 \quad 261-163$

$-41 \quad 265 f ., 284,286,300,307$

$-42300$

-44 320f., $324 \mathrm{f}$.

$-47-49 \quad 328$

Sokrates, Historia ecclesiatica

- 7.18.15-18 30

$-7.23 .11 \mathrm{f} . \quad 256$
Sophronios, Anacreontica

- 14.69-102 177

$-21144 \mathrm{f}$.

Sozomenos

$-9.1 .361$

Suetonius, Caligula

-19.1-3 309

Theodor Lector, epitome

$-40153,90,114$

Theodor Synkellos, De obsidione Constantinopolis

$-2 \quad 222$

$-3223 \mathrm{f}$.

$-5 \quad 222$

$-7223 \mathrm{f}$.

$-11 \mathrm{f} . \quad 223 \mathrm{f}$.

$-13222 \mathrm{f}$.

$-14223 \mathrm{f}$.

- $15 \quad 224$

- 17 211, 219, 224

- $19 \quad 222$

- 20 f. 211, 224

$-22 \quad 212$

$-24 \quad 219$

- 32f. 212

$-33222$

- $34 \mathrm{f} ., 212$

$-37 \quad 212,277$

$-38 \mathrm{f} . \quad 222 \mathrm{f}$.

$-40-44 \quad 222$

$-46 \quad 222$

- 51f. $\quad 223-225,277$

In depositionem pretiosae vestis

- 14, 206

Theodoret, Historia religiosa

$-21.1200 \mathrm{f}$.

Theophanes Confessor, Chronographia

- AM 5967 53, 90

- AM 596953

- AM $5971 \quad 44,53$

- AM $6051 \quad 74,215$

- AM 6074 59, 70

- AM $6076 \quad 74$ 


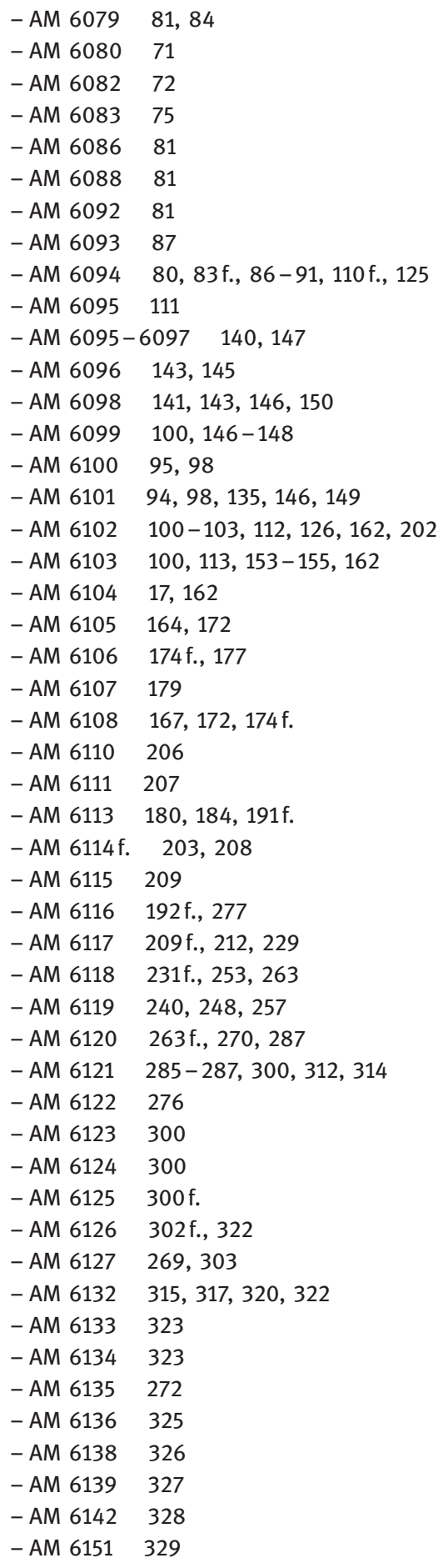

- AM $6153329 \mathrm{f}$.

- AM $6160330 \mathrm{f}$.

Theophylakt Simokattes, Dialogos

- $135,297 \mathrm{f}$.

Historiae

- 1.1.2 108

$-1.7 .274$

$-3.1-4 \quad 81$

$-3.2 .5 \quad 84$

$-3.2 .8 \quad 80$

$-3.6 .571$

$-3.11 .5-3.12 .169$

$-4.6 .1-371$

- 4.9.10.-4.10.10 72

- 4.11.1-11 72, 233

$-4.16 \quad 278$

$-4.16 .3298$

$-4.16 .23 \quad 232$

$-5.15 .5-7 \quad 248$

$-5.16 .2-4 \quad 33,181,187$

$-5.16-6.3 .875 f$.

$-5.16 .11202$

$-6.7 .6-16 \quad 81$

$-6.10 .1-3 \quad 81$

$-7.181$

$-7.13 .8-14.12 \quad 81$

$-7.15 .7 \quad 74$

$-8.1 .9-1181$

$-8.4 .10 \quad 85$

$-8.4 .11-5.4 \quad 87$

$-8.6-8.13 \quad 80$

$-8.6 .2-8.7 .6 \quad 82$

$-8.7 .7-10 \quad 83,87$

-8.7 .8 f. $\quad 86$

-8.8 .1 f. $\quad 86$

$-8.8 .3-5 \quad 84$

$-8.8 .6 \quad 86$

$-8.8 .11-8.9 .6 \quad 87 \mathrm{f}$.

$-8.9 .7 \quad 88,90,124$

$-8.9 .1090$

$-8.9 .1189 \mathrm{f}$.

$-8.9 .13-8.10 .191$

- 8.10.2-4 110, 118 f., 135

$-8.10 .6110 \mathrm{f}$.

$-8.10 .6-8.11 .6125$

-8.10 .8 f. 111

$-8.10 .13111$

-8.11 .1 f. 90 
$-8.11 .1-6 \quad 111$

$-8.11 .7-10 \quad 319$

$-8.12 .1-9 \quad 111$

$-8.12 .14 \quad 134$

- 8.13.3-6 111, 147, 164

$-8.15 .8-9 \quad 111,147,164$

Translatio corporis Sancti Anastasii Persae

$-1264 \mathrm{f}$.

Victor von Tunnuna

- s.a. 475 53, 90

- s.a. 52556

Vita S. Danielis Stylitae

- 6953,90
Vita Theodori Syceotae

- $54 \quad 144$

$-82144$

$-97 \quad 144$

$-133144$

- 140144

- 152 144, 161

- 153 151-154

- 154 153-156, 256

$-155157$

$-166157$

Zosimus

$-4.33 .1256$ 